

\section{DISCLAIMER}

This report was prepared as an account of work sponsored by an agency of the United States Government. Neither the United States Government nor any agency Thereof, nor any of their employees, makes any warranty, express or implied, or assumes any legal liability or responsibility for the accuracy, completeness, or usefulness of any information, apparatus, product, or process disclosed, or represents that its use would not infringe privately owned rights. Reference herein to any specific commercial product, process, or service by trade name, trademark, manufacturer, or otherwise does not necessarily constitute or imply its endorsement, recommendation, or favoring by the United States Government or any agency thereof. The views and opinions of authors expressed herein do not necessarily state or reflect those of the United States Government or any agency thereof. 


\section{DISCLAIMER}

Portions of this document may be illegible in electronic image products. Images are produced from the best available original document. 


\section{NOTICE}

This report was prepared as an account of work sponsored by the United States Government. Neither the United States nor the United States Department of Energy, nor any of their employees, nor any of their contractors, subcontractors, or their employees, makes any warranty, express or implied, or assumes any legal liability or responsibility for the accuracy, completeness or usefulness of any information, apparatus, product or process disclosed, or represents that its use would not infringe privately owned rights.

This report has been reproduced directly from the best available copy.

Available from the National Technical Information Service, U. S. Department of Commerce, Springfield, Virginia 22161.

Price: Paper Copy $\$ 15.00$

Microfiche $\$ 3.00$ 
OCEAN THERMAL ENERGY CONVERSION (OTEC). POWER SYSTEM DEVELOPMENT

\author{
Preliminary Design Report, Final
}

December 4,1978

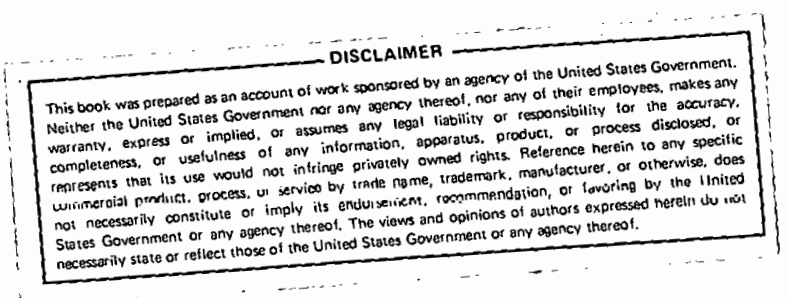

Contract No. EG-77-C-03-1570

TRW

Systems and Energy

Redondo Beach, California

DISTRUTHOA 


\section{ACKNOWLEDGEMENTS}

The Preliminary Design Phase of the PSD-I Project was conducted by a team consisting of:

- TRW Defense and Space Systems Group, the prime contractor, responsible for power systems design and analysis including: availability, materials technology, design integration, and project management.

- C F Braun and Company, subcontractor to TRW, responsible for mechanical design and fabricability of heat exchangers and design of ammonia support subsystems. They provided technical support in the areas of rotating machinery, thermal-fluid design of heat exchangers, system safety, and installation

- The following were consultants to TRW:

- Dr. A.J. Impink, Jr., Dr. J.F. Osterle and Dr. K.P. White, Jr., Carnegie-Mellon University. This team of consultants made major contributions in the areas of off-design and dynamic modeling of the ammonia power loop

- Dr. R.R. Rothfus, Carnegie-Mellon University, provided basic design data and analyses in support of heat exchanger thermal design

- Dr. L.L. Ambs, University of Massachusetts, provided turbine design and optimization support

- Dr. R.T. McLaughlin (ENWATS), provided design and analysis support in the areas of seawater subsystem design including dynamic modeling.

Under a separate contract with TRW, Elliott Company performed an ammonia turbine/generator design and optimization study for OTEC. 


\section{CONTENTS}

1. INTRODUCTION AND SUMMARY

$1-1$

1.1 Project Objectives

$1-1$

1.2 Redefined Project Objectives $1-2$

1.3 Design Requirements and Guidelines $1-3$

1.3.1 Applicable Documents 1-3

1.3.2 Design Life Goals · 1-6

1.3.3 Startup/Shutdown $1-6$

1.3.4 Control and Instrumentation (C\&I) $\quad 1-6$

$\begin{array}{ll}\text { 1.3.5 Electric Power System Utilization } & 1-6\end{array}$

$\begin{array}{ll}\text { 1.3.6 Biofouling } & 1-6\end{array}$

1.3.7 Physical Characteristics 1-6

$\begin{array}{lll}\text { 1.3.8 Plant Availability } & 1-7\end{array}$

$\begin{array}{ll}\text { 1.3.9 Maintenance } & 1-7\end{array}$

$\begin{array}{ll}\text { 1.3.10 Design Temperatures } & 1-7\end{array}$

1.3.11 Sizing $1-7$

1.3.12 Containment Vessel and Sea Dynamics 1-8

$\begin{array}{ll}\text { 1.3.13 Handling and Installation } & \text { 1-10 }\end{array}$

1.3.14 Material, Processes, and Parts 1-10

$\begin{array}{ll}\text { 1.3.15. Safety } & 1-10\end{array}$

1.4 Conformance to Deliverables and Evaluation Criteria 1-10

1.5 Report Outline 1-16

1.5.1 Preliminary Design Report, Volume I 1-16

1.5.2 Preliminary Design Report, Volume II 1.19

2. PRELIMINARY DESIGN OF THE.10 MWe POWER MODULE AND THE $200 \mathrm{kWe}$ TEST ARTICLES 2-1

$2.1 \quad 10 \mathrm{MWe}$ Power Module Design $2.1-1$

2.1.1 Design and Performance Summary 2.1-1

2.1.2 Process Flow Diagrams and Discussion 2.1-14

2.1.3 Piping and Instrumentation Diagram and Discussion 2.1-21

2.1.4 General Arrangement Drawings 2.1-28

2.1.5 Critical Interfaces 2.1-34

$\begin{array}{ll}2.1 .6 & \text { Materials and Processes } \\ 2.1-47\end{array}$

2.1.7 System Design, Optimization Update 2.1-49

2.1.8 System Design Characteristics and Sensitivities $\quad 2.1-52$

iii 


\section{CONTENTS (CONTINUED)}

\subsubsection{References}

Page

2.1-71

2.2 System Operation and Performance 2.2-1

2.2.1 Instrumentation and Control Requirements 2.2-2

2.2.2 Control

2.2-11

$\begin{array}{ll}\text { 2.2.3 Trips and Alarms } & \text { 2.2-17 }\end{array}$

$\begin{array}{ll}2.2 .4 & \text { Steady State Performance } \\ 2.2 .5 & \text { Startup and Shutdown }\end{array}$

$\begin{array}{ll}2.2 .5 & \text { Startup and Shutdown } 2.2-30\end{array}$

\begin{tabular}{l} 
2.2.6 Transient Performance 2.2.-38 \\
\hline
\end{tabular}

2.3 Power System Cost Estimates 2.3-1

2.3.1 Approach and Assumptions 2.3-1

2.3.2 Cost Tables 2.3-2

2.410 MWe Heat Exchangers $2.4-1$

2.4.1 Design Requirements and Approach 2.4-2

2.4.2 Design Description $2.4-3$

2.4.3 Thermal/Hydraulic Design and Performance 2.4-11

2.4.4 Materials and Corrosion Control 2.4-33

2.4.5 Biofouling and Cleaning Considerations 2.4-41

2.4.6 Mechanical Design and Producibility $2.4-45$

2.4.7 Adequacy of Design 2.4-59

2.4.8 References 2.4-ţo

$2.5200 \mathrm{kWe}$ Heal Excliangen 'l'esl Arlicles $2.5-1$

2.5.1 Cost Effectiveness of the $200 \mathrm{kWe}$ Test Articles 2.5-1

2.5.2 Design Objectives $2.5-2$

2.5.3 Scaling Criteria and Implementation 2.5-2

2.5.4 Design Description 2. 2.5-6

2.5.5 Instrumentation and Data Plans 2.5-6

2.5.6 Interface Definitions $2.5-6$

2.5.7 Mechanical Design and Producibility $2.5-24$

2.6 Biofouling Control, Ammonia Leak Detection, and Leak Repair 2.6-1

2.6.1 Approaches and Objectives 2.6-1

2.6.2 Chlorination Subsystem 2.6-1

2.6.3 Tube Cleaner Subsystem 2.6-3

2.6.4 Ammonia Leak Detection 2. 2.6-17

2.6.5 Ammonia to Seawater Leak Repair 2.6-26 


\section{CONTENTS (CONTINUED)}

Page

2.7 Rotating Machinery ‘ - 2.7-1

2.7.1 Turbine Generator 2.7-1

2.7.2 Ammonia Feed and Recirculation Pumps 2.7-32

2.7.3 Seawater Pumps 2.7-41

$\begin{array}{lll}2.7 .4 & \text { References } & 2.7-50\end{array}$

2.8 Support Subsystem $\quad \cdot 2.8-1$

2.8.1 Subsystem Requirements 2.8-1

2.8.2 Ammonia Storage Conditioning and Recovery Subsystem $\quad 2.8-1$

2.8.3 Nitrogen Support Subsystem 2.8-11

2.9 Instrumentation and Control 2.9-1

2.9.1 Instrumentation and Control System Design 2.9-1

2.9.2 Sensors 2.9-1

2.9.3 Control 2.9-4

2.9.4 Control Center $\quad 2.9-6$

2.9.5 Diagnostic Instrumentation 2.9-10

2.9.6 Plant Computer ' $2.9-12$

2.9.7 Instrumentation Wiring 2.9-15

$\begin{array}{lll}2.9 .8 & \text { References } & 2.9-17\end{array}$

2:10 Electrical Subsystem $\quad 2.10-1$

2.10.1 Requirements $2.10-1$

2.10.2 Design Approach 2.10-1

$\begin{array}{ll}2.10 .3 \text { References } & 2.10-13\end{array}$

2.11 Installation Approach $2.11-1$

2.11.1 Introduction 2.11-1

2.11.2 Assembly at the Outfitting Dock $2.11-4$

2.11.3 Installation at Sea $2.11-5$

2.11.4 Heat Exchanger Attachment 2.11-13

2.11.5 References 2.11-16

2.12 Net Energy and Resource Analysis 2.12-1 


\section{CONTENTS (CONTINUED)}

2.13 Operability, Maintainability and Safety

Page

2.13.1 Availability Analysis

2.13-1

2.13.2 Operability/Maintenance Plan

2.13-2

2.13.3 Safety Issues

2.13-27

2.13.4 References

2.13-34

2.13-47

3. 40 MWe COMMERCIAL POWER SYSTEM (CONCEPTUAL DESIGN)

3-1

3.1 Design Approach

3-1

3.2 General Arrangement Drawing

3-5

3.3 Performance and Cost Estimates

3-6

3.4 Critical Interfaces

3-6 


\section{ILLUSTRATIONS}

1.3-1 Ship Type Platform 1-9

$\begin{array}{ll}\text { 1.3-2 Hull Motion Limits, Velocity vs. Frequency } & 1-10\end{array}$

2.1 Perspective of 10 MWe Power Module 2-4

2.2 Perspective of the $200 \mathrm{kWe}$ Test Articles 2-5

2.1-1 10 MWe Power Module Process Flow Diagram Nominal Flow $\begin{array}{ll}\text { Condition } & \text { 2.1-18 }\end{array}$

2.1-2 10 MWe Power Module Process Flow Diagram Maximum Flow Condition

2.1-3 10 MWe Power Module Process Flow Diagram Minimum Flow Condition

2.1-4 $10 \mathrm{MWe}$ Power Module Piping and Instrumentation Diagram 2.1-22

2.1-5 10 MWe Power Module System Elevation Criteria 2.1-29

2.1-6 10 MWe Power Module Turbine Deck Plan and Elevation 2.1-31

2.1-7 10 MWe Power Module Pump Deck Plan 2.1-32

2.1-8 10 MWe Power Module Sections 2.1-33

2.1-9 $10 \mathrm{MWc}$ Power Module Power/Ship System Interfaces Plan and
Section

2.1-10 10 MWe Power Module Power/Ship System Interface Sections 2.1-38

2.1-11 10 MWe Power Module Power/Ship System Interfaces Plan and Sections

2.1-39

2.1-12 10 MWe Power Module Power/Ship System Interfaces Sections $\begin{array}{ll}\text { and Notes } & \mathbf{2} .1-40\end{array}$

2.1-13 10 MWe Module, Critical System Functional Interfaces $2.1-42$

2.1-14 OTEC Design Model - System Optimization - 2.1-51

2.1-15 Mollier Chart 2.1-53

2.1-16 Static Pressure Profile 2.1-56

2.1-17 Piezometric Head Distribution Warm Water Subsystem (Nominal) 2.1-58

2.1-18 Piezometric Head Distribution Cold Water Subsystem (Nominal) 2.1-58

2.1-19 Loss Coefficients 2.1-61

2.1-20 Energy Transfer Rates in Ammonia Power Loop 2.1-63

2.1-21 Sensitivity of Net Power and Energy Cost to Turbine Efficiency . 2.1-66

2.1-22 Sensitivity to Heat Exchanger Performance 2.1-67

2.1-23 Off-Design Analysis Variability of Ammonia Loop Parameters 2-1-70 


\section{ILLUSTRATIONS (CONTINUED)}

2.2-1 PSD-1 Instrumentation Interfaces 2.2-3

2.2-2 Function Performed by Instrumentation and Control 2.2-8

2.2-3 Ammonia Control Loops (Redundent Pumps and Tanks Not Shown) 2.2-12

2.2-4 Flow Diagram of Steady-State Model 2.2-20

2.2-5 Power Output vs. Evaporator Recirculation Rate (Above 800 LB/SEC) 2.2-23

2.2-6 Power Output vs. Evaporator Recirculation Rate 2.2-25

2.2-7 Power Output vs. Warm Water Inlet Temperatures (Cold Water $=$ $40^{\circ} \mathrm{F}$ ) $2.2-25$

2.2-8 Efficiency and Quality vs. Warm Water Inlet Temperature (Cold Water $=40^{\circ} \mathrm{F}$ )

2.2-9 Power Output vs. Cold Water Inlet Temperature $($ Warm Water $=$ $80^{\circ} \mathrm{F}$ )

2.2-10 Efficiency and Quality vs. Cold Water Inlet Temperature (Warm Water $\left.=80^{\circ} \mathrm{F}\right) \quad 2.2-26$

2.2-11 Heast Exchanger Discharge Temperature vs. Inlet Temperature 2.2-28

2.2-12 Net Power vs. Warm Water Fouling Factor (Cold Water $=$ $40^{\circ} \mathrm{F}, \mathrm{f}_{\mathrm{c}}=0.0001$ )

2.2-13 Net Power vs. Warm and Cold Water Fouling Factor 2.2-29

2.2-14 Overall Heat Transfer Coefficient vs. Fouling Factor 2.2-29

2.2-15 Power Output vs. Water Flow Rate 2.2-31

2.2-16 Kadiations Among Plant Uperating Procedures 2.2-32

2.2-17 Startup Power with Variable-Speed Seawater Pumps 2.2-39

2.2-18 Water Level In Headers and Troughs Caused by Heave in Sea $\begin{array}{ll}\text { State } 6.2 .42 & \end{array}$

2.2-19 Water Velocity Relative to the Pipes Caused by Heave in Sea $\begin{array}{ll}\text { State } 6 & 2.2-43\end{array}$

2.2-20 Output Power Variations Caused by Heave in Sea State $6 \quad 2.2-45$

2.4-1 10 MWe Evaporator Features $\quad 2.4-4$

2.4-2 $10 \mathrm{MWe}$ Condenser Features $\quad 2.4-5$

2.4-3 10 MWe Power Module Evaporator $\quad$ 2.4-7

2.4-4 $10 \mathrm{MWe}$ Power Module Condenser $\quad$ 2.4-8

2.4-5 Performance Effectiveness of Flutes 2.4-15

2.4-6 Tube Cost/Performance Effectiveness 2.4-16

2.4-7 Evaporator Tube $\quad$ 2.4-17 


\section{ILLUSTRATIONS (CONTINUED)}

2.4-9 Tube Description 2.4-19

2.4-10 Seawater Side Heat Transfer and Pressure Drop (Internal Axial $\begin{array}{ll}\text { Fluted Tubes) } & 2.4-20\end{array}$

2.4-11 Evaporation Heat Transfer - Freon 11 (External Axial Fluted Tubes) 2.4-22

2.4-12 Composite Condensing Heat Transfer Coefficients for Ammonia 2.4-23

2.4-13 Finite Difference Model for Fluted Tube 2.4-24

2.4-14 Effect of Fouling on Overall Heat Transfer Coefficient 2.4-26

2.4-15 Temperature Distribution in Evaporator 2.4-27

2.4-16 Temperature Distribution in Condenser 2.4-27

2.4-17 Pressure Distribution Evaporator and Condenser 2.4-30

2.4-18 Access Lanes Evaporator 2.4-32

2.4-19 Ammonia Metering Insert 2.4-38

2.4-20 Polyethylene Inserts 2.4-39

2.4-21 Evaporator Distribution Inserts $\quad$ 2.4-40

2.4-22 Annulized Cost of OTEC Heat Exchangers $\quad$ - * $\quad$ 2.4-42

2.4-23 Heat Exchanger Cost 2.4-43

2.4-24 Thermal Resistance vs. Time 2.4-44

2.4-25 Tube Bundle Skeleton Detail . 2.4-47

2.4-26 Tubesheet Support 2.4-51

2.4-27 Evaporator Feedlanes 2.4-53

2.4-28 Tubular Area Enhancement Processes 2.4-54

2.4-29 Sample Tube Made by the Roll-Upset Process (22 Flutes on a
1-Inch O.D. Titanium Tube)

2.4-30 Sample Enhanced Area Tubes Made by the Roll-Upset Process
Starting With Round (1-Inch O.D.) Titanium Tubes .

2.4-31 Sample Made by Roll-Forming Pitch of 0.100 Inch (Equivalent to
31 Flutes on a 1-Inch O.D. Tube)

2.4-32 Tube-to-Tubesheet Joint 2.4-58

2.5-1 Relation of Test Segment to Total Tube Bundle 2.5-4

2.5-2 Normalized Pressure Drop vs. Radius 2.5-5

2.5-3 Evaporator Test Article $\quad$ 2.5-7

2.5-4 Condenser Test Article $2.5-7$ 


\section{ILLUSTRATIONS (CONTINUED)}

Page

2.5-5 $200 \mathrm{kWe}$ Test Article Evaporator 2.5-8

2.5-6 $200 \mathrm{kWe}$ Test Article Condenser : 2.5-9

2.5-7 $200 \mathrm{kWe}$ Test Loop - 2.5-18

2.5-8 $200 \mathrm{kWe}$ Process Flow Diagram (Nominal Condition) 2.5-20

2.5-9 $200 \mathrm{kWe}$ Test Article Evaporator Test Loop Piping and Instrumentation Diagram

2.5-10 Evaporator Recirculation Loop Pressure Profile 2.5-22

2.6-1 Chlorinator Block Diagram $\quad 2.6-2$

2.6-2 10 MWe Heat Exchanger Tube Cleaner $\quad 2.6-4$

2.6-3 OTEC Heat Exchanger Tube Cleaner 2.6-5

2.6-4 Schematic Showing Relationship Between Controller, Positioner and Head $2.6-6$

2.6-5 PSD-1 Biofouling Control Subsystem Tube Cleaner Functional Flow 2.6-8

2.6-6 OTEC 10 MWe Evaporator Cleaning Sequence 2.6-9

2.6-7 Controller/Recorder Block Diagram 2.6-13

2.6-8 OTEC Heat Exchanger Hydraulic Tube Cleaner - Concept 2.6-14

2.6-9 Schematic of Submerged and Primed Pump 2.6-15

2.6-10 OTEC 0.2 MWe Heat Exchanger - Tube Cleaner Concept 2.6-18

2.6-11 Bulk Outlet Sampling - Schematic 2.6-20

2.6-12 Composite Sampling Mode - Schematic (One Tube Sample Shown) 2.6-22

2.6-13 Individual Sampling Mode - Schematic 2.6-23

2.6-14 Reservoir Location and Brush Assembly - 2.6-25

2.6-15 Heat Exchanger Tube Sealing Plug Concept 2.6-27

2.6-16 Heat Exchanger Tube Sealing Plug Concept - Operation 2.6-28

2.7-1 Optimization STudy, Four-Flow, Radial Inflow Designs 2.7-9

2.7-2 Optimization Study, Single-Stage, Single-Flow Designs Idealized Blades, Base Diameter $=31$ In. $\quad 2.7-10$

2.7-3 Optimization Study, Four-State, $10 \mathrm{MWe}$ Net Designs Real Blades $\quad$ 2.7-10 2.7-4 Optimization Study, Double-Flow Designs, Real Blades, Base
Diameter $=31 \mathrm{In}$.

2.7-5 Variable Stator Control Linkage 2.7-13

2.7-6 Turbine Cross Section 2.7-15

2.7-7 Turbine Generator/String Arrangement $\quad$ 2.7-16 


\section{ILLUSTRATIONS (CONTINUED)}

Page

2.7-8 Proposed Control Schematic

2.7-19

2.7-9 . Thrust Bearing (Typical)

2.7-27

2.7-10 Face Seal With Shutdown Features 2.7-29

2.7-11 Pump Configuration 2.7-34

2.7-12 Evaporator Pump Head-Flow Curve (Typical) 2.7-35

2.7-13 Evaporator Recirculation Pump Section 2.7-35

2.7-14 Recirculation Pump Outline Drawing 2.7-36

2.7-15 Fixed and Variable Speed Pump Head-Flow Characteristics and System Head-Flow Curve

2.7-37

2.7-16 Seawater Pump Concept 2.7-43

2.7-17 OTEC Seawater Pump Arrangement 2.7-44

2.7-18 Pleuger Pump 400,000 GPM Head-Flow Curve 2.7-45

2.7-19 Pleuger Pump 400,000 GPM Requirements ' 2.7-46

2.7-20 Pleuger Pump 800,000 GPM Head-Flow Curve 2.7-47

2.7-21 Pleuger Pump 800,000 GPM Power Requirements 2.7-48

2.8-1 Ammonia Support System Schematic $2.8-2$

2.8-2 Ammonia Storage System 2.8-3

2.8-3 10 MWe Power Module Ammonia Support System Piping and Instrumentation Diagram

2.8-4 10 MWe Power Module Ammonia and Nitrogen Support System Plan and Elevation

2.8-5 Ammonia Support Subsystems 2.8-12

2.8-6 10 MWe Power Module Nitrogen Support System Piping and Instrumentation Diagram

2.9-1 OTEC Instrumentation and Control System Block Diagram 2.9-2

2.9-2 Floor Plan of Control Room 2.9-7

2.9-3 Control Room Wall and Console Displays 2.9-11

2.10-1 10 MWe Power Module - Distribution and Control of Primary Power 2.10-2

2.10-2 $15 \mathrm{kV}$ Switchgear General Arrangement 2.10-3

, 2.10-3 10 MWe Power Module - Electrical Subsystem Auxiliary and Control $\quad 2.10-4$

2.10-4 10 MWe Power Module - Electrical Equipment Room Plan and Elevation 
2.11-1 Pert Chart for Manufacturing and Installation of 10 MWe Power System Module

2.11-3

2.11-2 Installation of Equipment Within the PSM-1 Barge

2.11-6

2.11-3 A Major Lift

2.11-7.

2.11-4 Moving a Large Vessel Overland for a Short Distance

2.11-9

2.11-5 Large Cylindrical Vessels Loaded on a Transport Ship

2.11-10

2.11-6 Lifting an Exchanger from the Transport Barge

2.11-11

2.11-7 Rotating an Exchanger to the Vertical Orientation by Loosening the Jib Crane

$2.11-11$

2.11-8 Final Positioning of an Exchanger to the Side of the PSM-1 Barge

2.11-14

2.13-1 Flow Diagram OTECSOS Program

2.13-2 Operability Simulation Input Data Block Diagram for Failure Repair Expectations

2.13-10

3.1-1 Surface Interacting Hull

3-3

3.1-2 Surface Decoupled Hulls

3-4

3.1-3 40 MWe Platform Plan, Elevation and Sections 


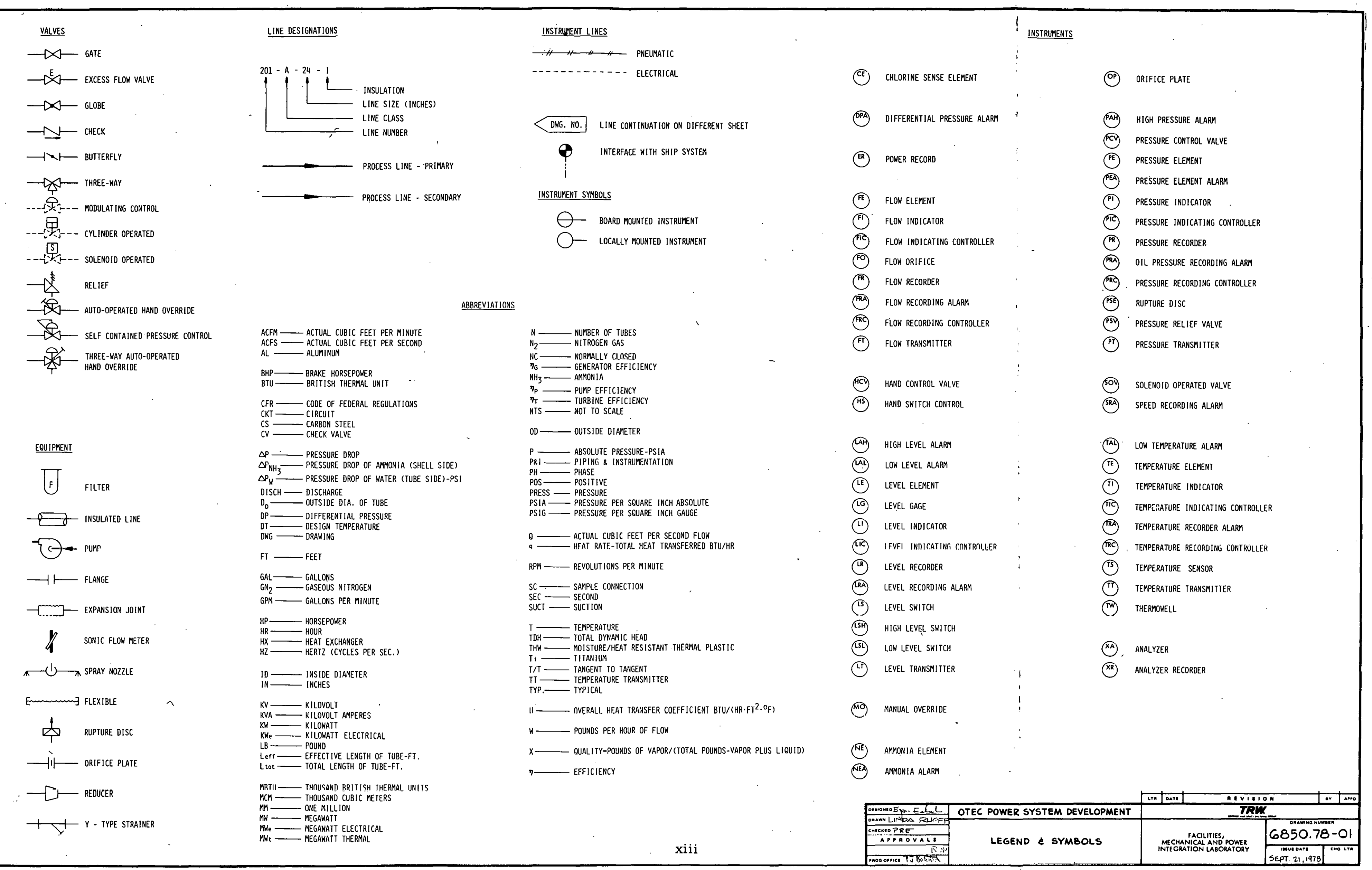




\section{DEPARTMENT OF ENERGYY. \\ OCEAN THERMAL ENERGY CONVERSION POWER SYSTEM DEVELOPMENT - 1}

PRELIMINARY DESIGN
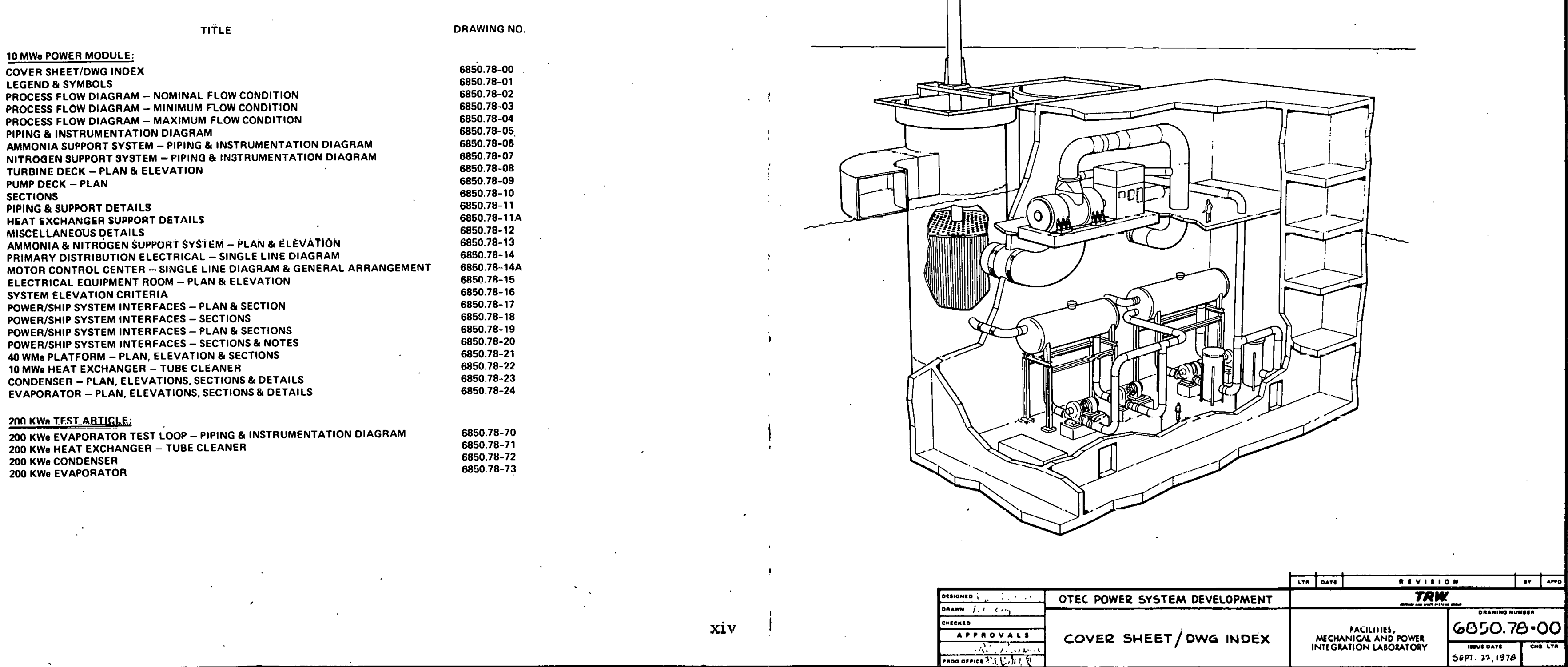


\section{RESPONSE TO PDR COMMENTS}

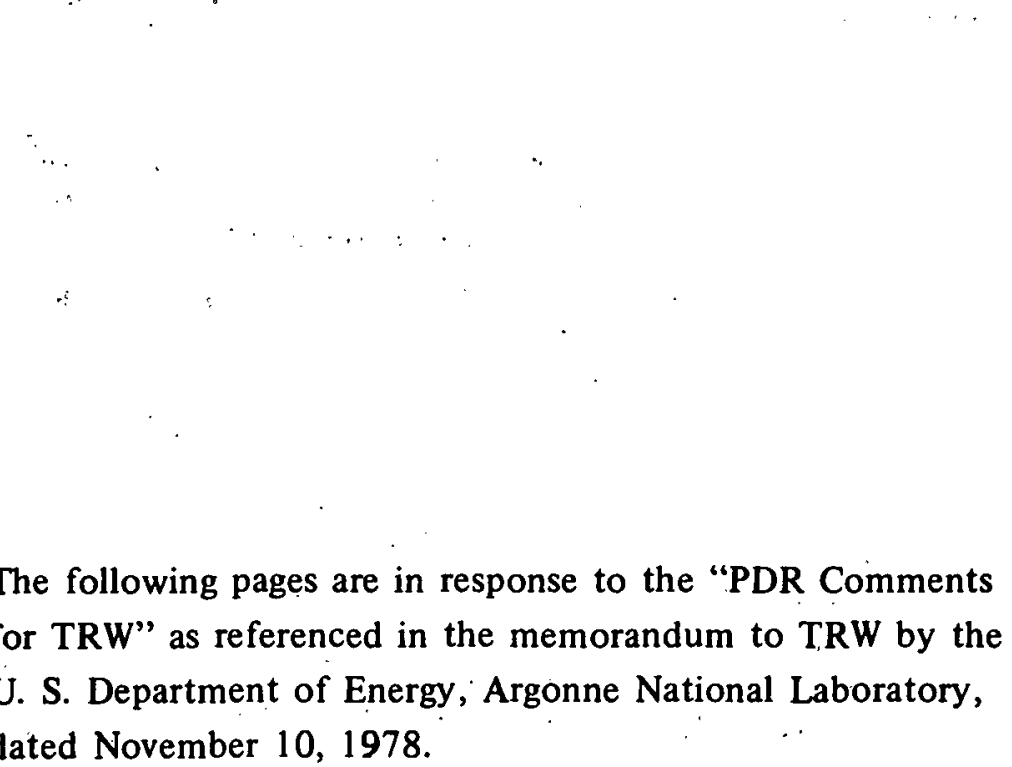

dated November 10, 1978. 
THIS PAGE

\section{WAS INTENTIONALLY \\ LEFT BLANK}


1. What will be the plan to qualify materials for ammonia service? Also indicate which materials must be qualified.

It is planned to qualify the materials for ammonia service in two ways.

1. Most materials used on this project will be qualified by virtue of their extensive, longterm use in commercial ammonia service. The C. F. Braun Company, which has designed many ammonia plants, will provide the choice of materials from their applications data bank. Their materials engineering is widely recognized in this field of metallurgy and, together with. TRW's Materials Engineering Department, they will be cognizant over materials selection during the detailed design phase.

2. Those materials that have not been used or tested in equivalent service (i.e., those used for the turbine's rotating parts) will be tested to prove they are not susceptible to stress corrosion cracking. This is required because of the susceptibility of high-strength, lowalloy steels that are exposed to anhydrous ammonia containing oxygen or air. An example of the type of testing to be performed is the following four-point stress test:

The ends of the test specimen are retained in grooves of a test jig as illustrated in the figure below. The test specimen is loaded at mid-span by a load screw mechanism to stress the material. Insulation is used between the test specimen and jig to avoid electrical currents. The entire assembly is placed in fluid or vapor. An accelerated test, performed at elevated temperatures, will be conducted to obtain early results for initiation of material selection/procurement. Operational temperature testing will continue to confirm results of the accelerated tests.

Candidate materials for the turbine rotor will be tested in three liquids: pure ammonia, ammonia saturated with air, and ammonia saturated with carbon dioxide.

(A) SPECIMEN

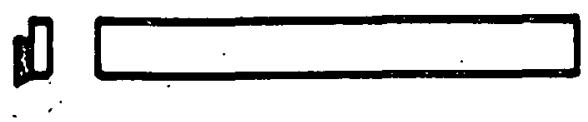

(B) FIXTURE
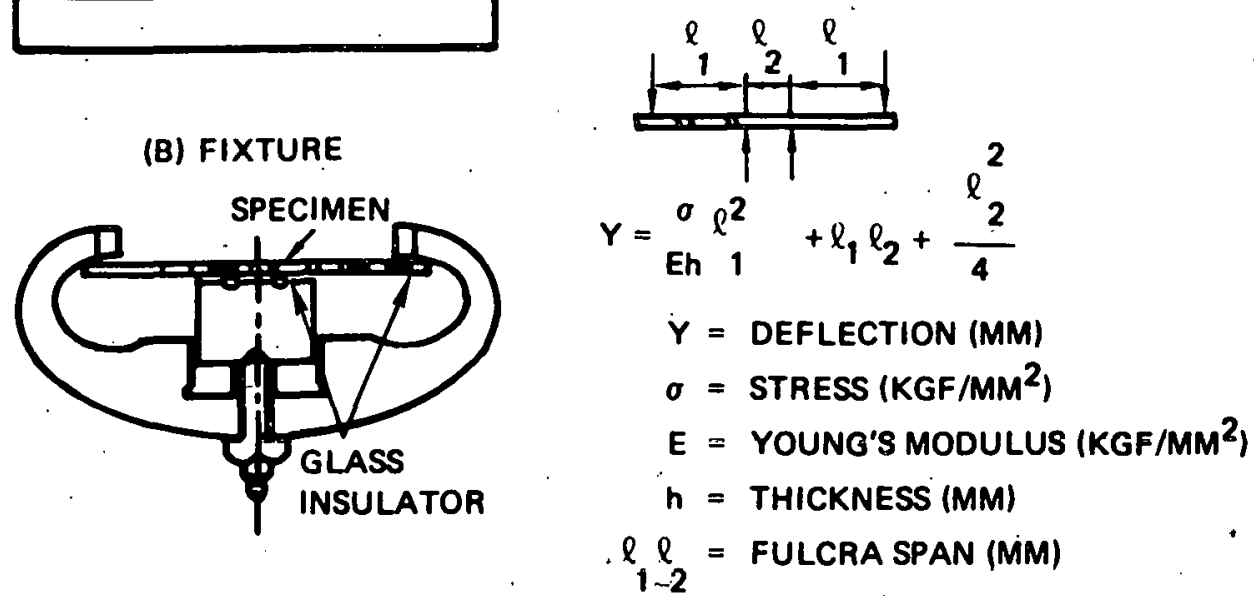

4-POINTS FULCRA BENDING SPECIMEN AND FIXTURE 
The materials which must be qualified are given in the following table. These materials have been selected over materials normally used for the various parts because they (materials in the table) are less susceptible to stress corrosion in an ammonia atmosphere.

For the rotating components, the materials proposed are of the same composition as those usually employed for steam turbines. The conditions of heat treatment, however, are different. In conventional steam turbines, these materials would be heat treated to a yield strength in the range of 80,000 to $100,000 \mathrm{psi}$. In this case, in order to improve resistance to stress corrosion cracking, the annealed condition will be used. In this condition, the yield strength will be approximately 30,000 to $50,000 \mathrm{psi}$, which is sufficient for the application.

Materials of Construction for Major Components of Ammọnia Expander

\begin{tabular}{|c|c|c|c|}
\hline Part & Material & Form & Min. Yield - psi \\
\hline Outer Casing Barrel & $\begin{array}{l}S A-516 \\
\text { GR } 60\end{array}$ & Plate & 32,000 \\
\hline Endwalls & $\begin{array}{l}\text { SA-226 Class } 1 \\
\text { SA-516 GR } 60\end{array}$ & $\begin{array}{l}\text { Forged } \\
\text { Plate }\end{array}$ & $\begin{array}{l}30,000 \\
32,000\end{array}$ \\
\hline Stator Housing & SA-216 GR WCB & Cast & 36,000 \\
\hline Diaphragms & SA-516 GR 60 & Plate & 32,000 \\
\hline Stator Blades & AISI Type 405 & Bar & 25,000 \\
\hline Rotor Blades & $\begin{array}{l}\text { AISI Type } 403 \\
\text { Annealed }\end{array}$ & Bar & 35,000 \\
\hline Discs & $\begin{array}{l}\text { AISI } 4140 \\
\text { Annealed }\end{array}$ & Forged & 50,000 \\
\hline Shaft & $\begin{array}{l}\text { AISI } 4140 \\
\text { Annealed }\end{array}$ & Forged & 50,000 \\
\hline
\end{tabular}


2. Describe the procedure for qualifying fluted tube heat exchangers per ASME code. Also include the inspection plans for the fluted tubes.

The procedure for qualifying fluted tube heat exchangers per USCG/ASME code requirements shall be as follows:

1. Only ASME code materials will be used. These materials will be in accordance with Section VIII, Division 1, Subsection C.

2. Fluted tubes will be designed according to the requirements of ASME code Section VIII, Division 1, Paragraph 28. Because this design procedure is for round tubes, the reduction in collapse strength and increased stress concentrations resulting from fluting will be analyzed using a finite element computer program. The increase in tube wall thickness to account for fluting effects will be determined and incorporated into the design.

3. Hydrostatic testing of the fluted tube will be accomplished to verify the design collapse strength.

4. All pressure-containing elements of the heat exchanger, including the shell, nozzles, joints, supports, etc., will be designed to the ASME code Section VIII, Division 1.

5. The completed heat exchangers, with tubes installed, will be tested hydrostatically in accordance with the ASME code Section VIII, Division 1, Paragraph UG-99.

Production inspection procedures will be developed for corrugated tubes based on results of initial qualification tests. These initial tests. will include, but not be limited to, the following:

- Flaw detection by X-ray and dye-penetrant methods

- Sectioning for contour/geometry measurements

- Analysis of grain structure and mechanical properties

- Collapse pressure tests on tube samples

- Internal hydrostatic tests on țube samples

- Therinal-hydraulic performance tests.

Based on results of these initial qualification tests and analysis of the production process, TRW will work with the tube manufacturer to develop a tube manufacturing specification that will be the basis for the detailed inspection procedure. Existing specifications for smooth titanium tubing will be used as applicable. 
Specific steps in the production inspection process include the following:

- As-Received Material (if formed from welded round tubing)

Sample size: $5 \%$ of lot

Inspection: Dye-penetrant of welded seam and seam heat affected zone. Method: Per MIL-I-6866B, Amendment 2, Type 2

Acceptance criteria: No cracks allowed

Inspection: Radiographic of weld seam and seam heat affected zone

Method: Per MIL-I-453

Acceptance criteria: No cracks allowed

- Qualification (first article inspection)

Sample size: First six tubes of production run

Inspection: Optical comparator measurement for conformance to specified cunfiguratiun (sliape, thinning, dimensions)

Method: Section one tube's middle and each end

Acceptance criteria: TRW specification

Inspection: Dye-penetrant of outside surface

Method: Per MIL-I-6866B, Amendment 2, Type 2

Acceptance critcria: No oracks allowed

Inspection: Kadiographic of weld seam and seam heat aftected zone

Mcthod: Mì $\bar{L}-\bar{I}-453$

Acceptance criteria: No cracks. allowed

Inspection: Metalographic examination of grain

Method: Procedure TBS

Acceptance criteria: TRW specification

Test: Tensile strength

Method: Procedure TBS

Acceptance criteria: TRW specification

Test: Hydrostatic pressure (internal)

Method: Procedure TBS

Acceptance criteria: No deformation or leakage

Test: Collapse pressure (external)

Method: Procedure TBS

Acceptance criteria: 1.5 times design pressure, minimum 
In addition to the above, a thermal hydraulic performance test will be conducted in simulated OTEC operation conditions. This test will evaluate the capability of the as-built tubes to provide the predicted performance.

- Manufacturing

The production tests will repeat most of the qualification tests on a sampling basis. Typically, the first, last, and middle tubes of each lot (1 percent) will be checked. MIL-Q-9858A will be used for setting the acceptable quality level (AWL), i.e., sampling frequency and parameters to be measured. 


\section{THIS PAGE WAS INTENTIONALLY LEFT BLANK}


3. Clarify the method of supporting the fluted tubes at the support plates. Does your design meet TEMA requirements for hole tolerances in view of the fact that the fluted tubes are necked down?

The tube support design takes the following into account:

- The tubes are 1 -inch outer diameter at the ends (smooth tube portion)

- Code tolerance on tube outer diameter is \pm 0.005 inch

- The nominal diameter over the flutes is 0.990 inch

- Nominal TEMA $R$ tube sheet hole diameter tolerance is $+0.010,-0.000$ inch.

The support plates are $1 \frac{1}{2}$ inches thick to maximize the bearing area which in turn, minimizes bearing unit pressure.

For the condenser, support contact is between the tube flute's outer diameter and the drilled hole in the support plate; the tube will bear on either one or two flute crests. Clearance between the tube and tubehole will be determined during detail design.

For the evaporator, process requirements necessitate a different approach: adequate clearance between the tube and tubehole must be provided so the falling film of liquid ammonia is not impeded. To achieve this, a three-point support will be provided, two points of which will normally contact the tube. These support points will be spaced 120 degrees apart, and each will be two flutes wide to minimize bearing stress.

This three-point support is provided by an insert similar to the liquid distribution orifice inserts in the distributor plate, except that a maximum opening between the support points is maintained. (See figure on the following page.) This insert material is the same as that used for the liquid distribution orifice inserts. 

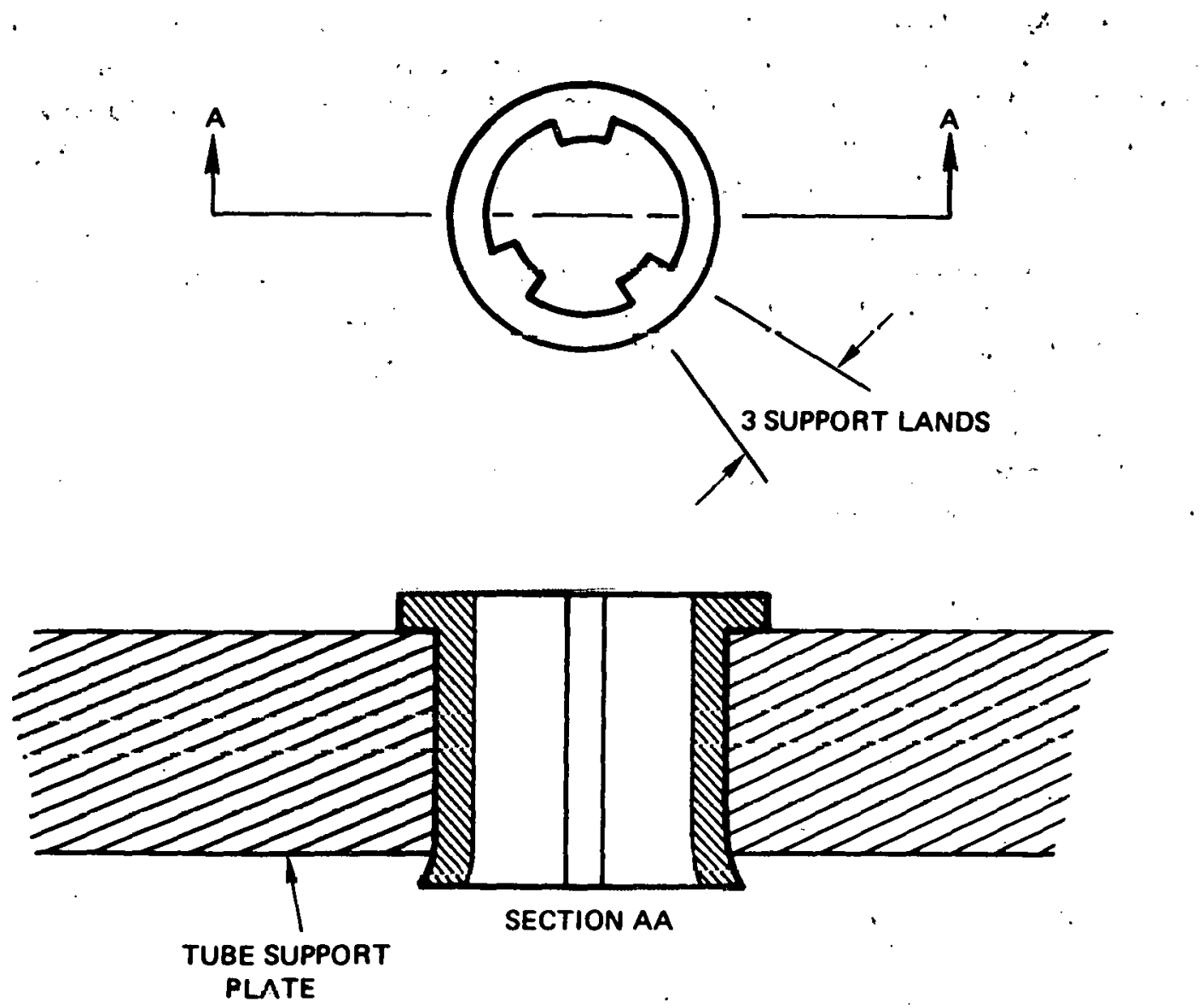

EVAPORATOR TUBE SUPPORT INSERT 
4. Describe the tube-to-tube sheet joint in more detail; namely, weld design, expansion method, rationale for joint selection, etc.

The tube-to-tubesheet joining method proposed is similar to that developed by Nooter Corp. and is shown on the following page. The tubes are hydraulically expanded almost the full thickness of the tubesheet, including cladding. The last $1 / 8$ inch at each end is not expanded. Hydraulic expansion is employed. because the expansion loads are applied evenly across the tube surface in the tube sheet area. This reduces the amount of work hardening at the inner surface of the thin wall tube relative to that which occurs if rolling were used. The tubesheet grooves are of the TEMA configuration.

Hydraulic expansion is available in two general forms: the original German development which uses hydraulic fluid (or water) to apply internal pressure confined to the tubesheet area to expand the tube, and a Japanese variation that uses mechanically-induced expansion of a rubber sleeve to achieve the same result: Both methods are widely used in Europe and Japan, and the tooling is now available in this country.

Many methods have been developed for seal welding tubes to tubesheets. Each heat exchanger manufacturer has a method for manufacturing these joints; their manufacturing is set up to their design and they offer this known skill when quoting equipment.

The over-the-flute tolerance has been established at \pm 0.005 inch. Both the evaporator and condenser support plate hole tolerances will meet the requirements of TEMA (Paragraph R-4.2, Sixth Edition) as shown below:

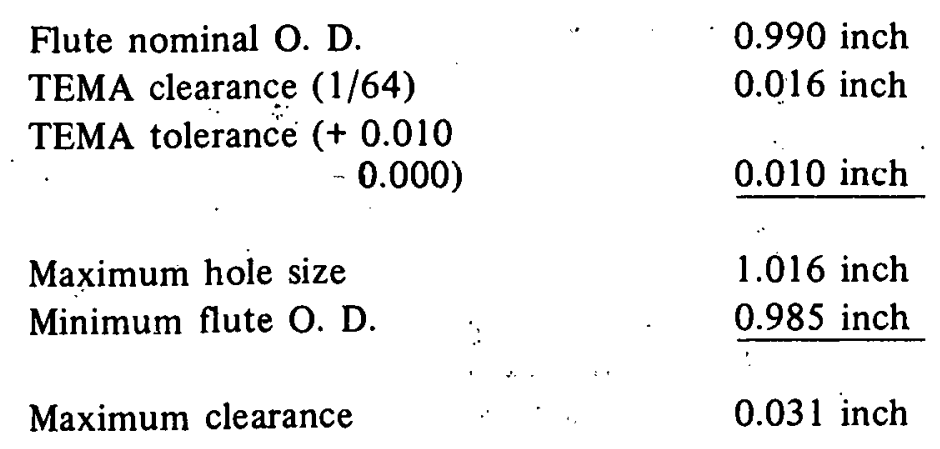

This satisfies the TEMA requirements.

Since the TEMA tolerances allow 0.010 inch variation in support plate hole diameter, the minimum hole size could be 1.006 inch. With the maximum possible tube $O$. D. (at smooth ends) of 1.005 inch, the clearance is inadequate for tube assembly. Therefore, we will maintain support plate hole size between 1.010 inch and 1.016 inch. This tolerance limit will allow us to drill the support plates and stay within TEMA tolerances for the condenser. The evaporator support plates will also meet TEMA tolerances because the support lands of the baffle inserts will be designed to the tolerances of the TEMA standard. However, the tube holes in the support plates will be larger than normal to allow space for the baffle inserts. The inserts will act as part of the support plate and support the tube within the TEMA tolerance. 


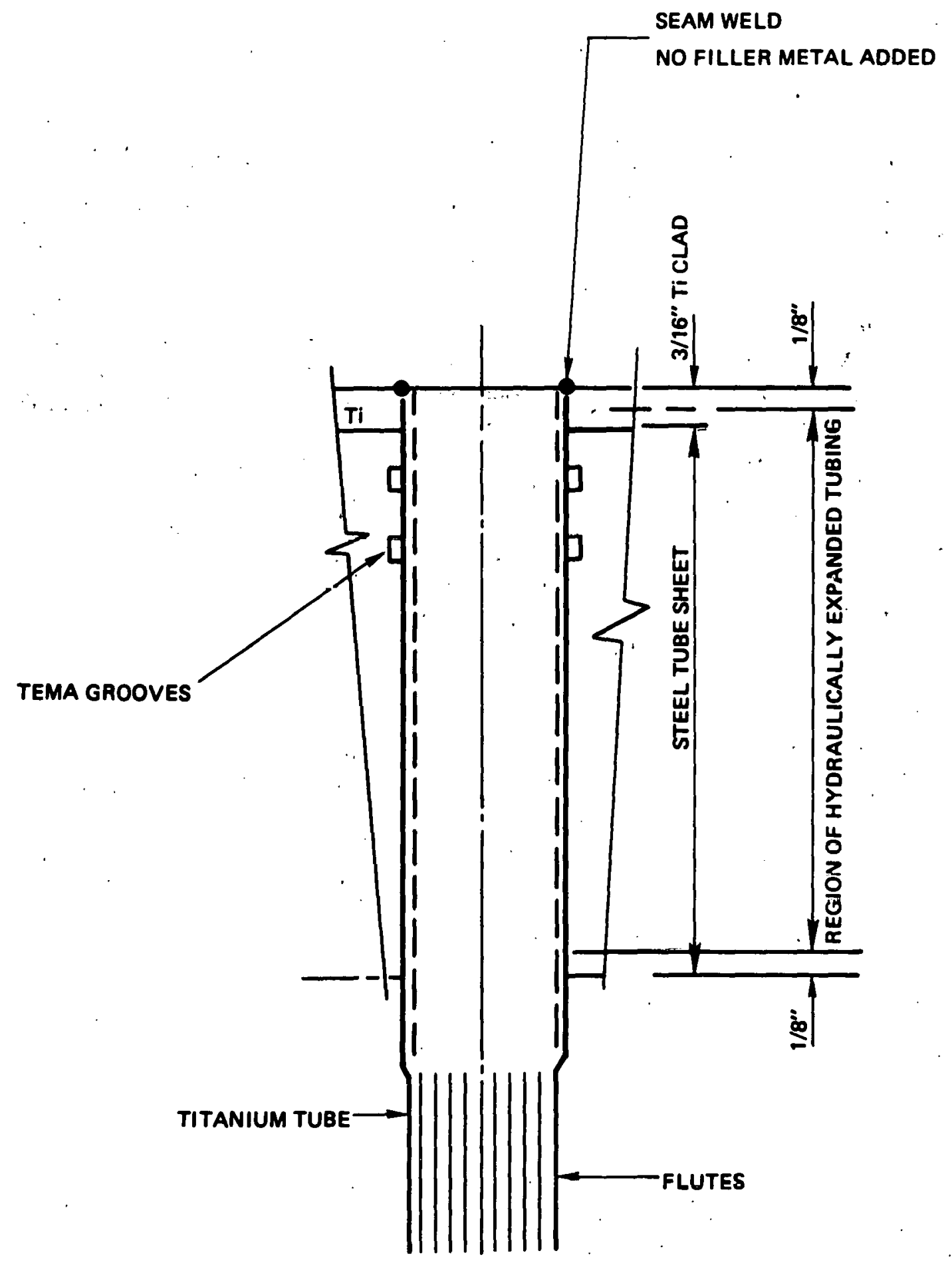

TYPICAL HYDRAUICALLY EXPANDED AND WELDED TUBE-TO-TUBE SHEET JOINT 
5. Address the question of non-condensible venting of $10 \mathrm{MWe}$ and $0.2 \mathrm{MWe}$ condensers.

The $10 \mathrm{MWe}$ condenser has a non-condensible removal pipe located at the center of the tube field. This is the best location in vertical exchangers for efficient performance. Incoming ammonia vapor will have non-condensibles present, particularly at startup. As the incoming non-condensibles, mixed with ammonia vapor, flow radically inward across layers of the tube bundle, only the ammonia vapor condenses. The non-condensibles are swept radically inward by the ammonia vapors and non-condensible concentration reaches a maximum at the center of the bundle where it is removed.

The $200 \mathrm{kWe}$ condenser design was selected to duplicate the flow in the larger exchanger as closely as practical. Here the non-condensible removal pipe is located near the apex of a pie-shaped segment of the bundle. The bundle was designed as a segment of the larger, fullscale unit. As in the larger unit, the ammonia/non-condensible mixture flows across the tubes in the tube bundle with ammonia condensing as it crosses the tube layers. The non-condensibles concentrate at a position near the segment apex, where they are removed.

During operations, non-condensibles venting will be accomplished intermittently on an asrequired basis. The performance of the condenser (e.g., condenser pressure) will be monitored to signal the need for non-condensible venting. It is to be noted that exclusion of ammonia vapor from the non-condensible stream is not possible or practical. However, by locating the vent pipe at the point of maximum non-condensible concentration, the loss of ammonia is minimized.

If necessary, baffle plates or similar barriers will be situated at the inner extremity of the vapor lanes. This will mitigate short circuiting of ammonia vapor through the vapor lanes directly to the vent pipe. It presently appears that such baffles will not be necessary. This is because the effect of a sink is generally localized. Short range effects plus intermittent short-duration venting indicate that loss of ammonia by short circuiting through the vapor lanes is not a.problem. 
THIS PAGE WAS INTENTIONALLY LEFT BLANK 
6. Comment on the anticipated flatness to be achieved by welded tubesheet segments (in the 10. MWe heat exchanger) together to form one large tubesheet.

It is recognized that our approach to tubesheet fabrication is not apt to yield "flat" tubesheets primarily because of warpage during welding; however, tubesheet flatness is not critical. to the design and performance of the heat exchanger. Satisfactory tubesheet flatness (to within one-half inch of flat) is achievable, if necessary, with post welding flattening.

From a fabrication standpoint, "flat" tubesheets are not necessary. Furthermore, our tubing and seal welding approach accommodates non-flat tubesheet as follows:

- Tubesheets will be drilled parallel to the heat exchanger centerline. Drilling will not be referenced from the tubesheet surface.

- During tubing, the tubes will be installed flush with the outer surface of one tubesheet and expanded in place. The opposite tube ends will then be trimmed flush with that tubesheet face and the tube expanded. Seal welding will then be performed.

From a thermal-hydraulic standpoint; non-flat tubesheets are expected to have virtually no effect on the overall performance. 


\section{THIS PAGE}

\section{WAS INTENTIONALLY \\ LEFT BLANK}




\section{Elaborate on the expected corrosion rates of the tube sheet at the sacrificial anodes.}

This question is not clear and may not be appropriate to our heat exchangers since our design does not employ sacrificial anodes. However, if the concern is the protection of the tubesheet to shell weld, please note the following.

During fabrication, the titanium cladding on the tubesheet is stripped from the weld zone. The carbon steel shell is welded to the carbon steel tubesheet. To prevent the titanium cladding/carbon steel boundry from being wetted with seawater, thus forming a voltaic cell, a neoprene. seal is applied.

This neoprene seal has been shown to be effective in English installations. For example, a neoprene seal coating called Limpetite, made by Protective Rubber Coatings, Ltd., was applied to the tube plates, water boxes, valves, etc. at the saltwater-cooled Portishead power generating station. No degradation to the coating, other than mechanical damage from maintenance (the coating is repairable), has occurred during the 32 years it has been in service.

A Dupont elastomer of formula and performance comparable to Limpetite will be used on the shell and tubesheet weld. Thus, it is expected that corrosion will not be a problem at the tubesheet-to- shell weld. 


\section{THIS PAGE WAS INTENTIONALLY LEFT BLANK}


8. Describe in further detail (perhaps a sketch) the proposed brush design.

The proposed brush design is as shown on the following page. It is anticipated that each brush will consist of hard and soft bristles. The hard bristles will clean the flute area at the largest inside diameter and the softer bristles will clean the flutes where the $I$. $D$. is a minimum. 
NYLON BAISTLES

(TWO STIFFNESSES/BRUSH)

ATTACAMENT ALLOWING BRUSH
TO ROTATE SLIGHTLY IN SERVICE

MWO STIFFNESSESARUSH

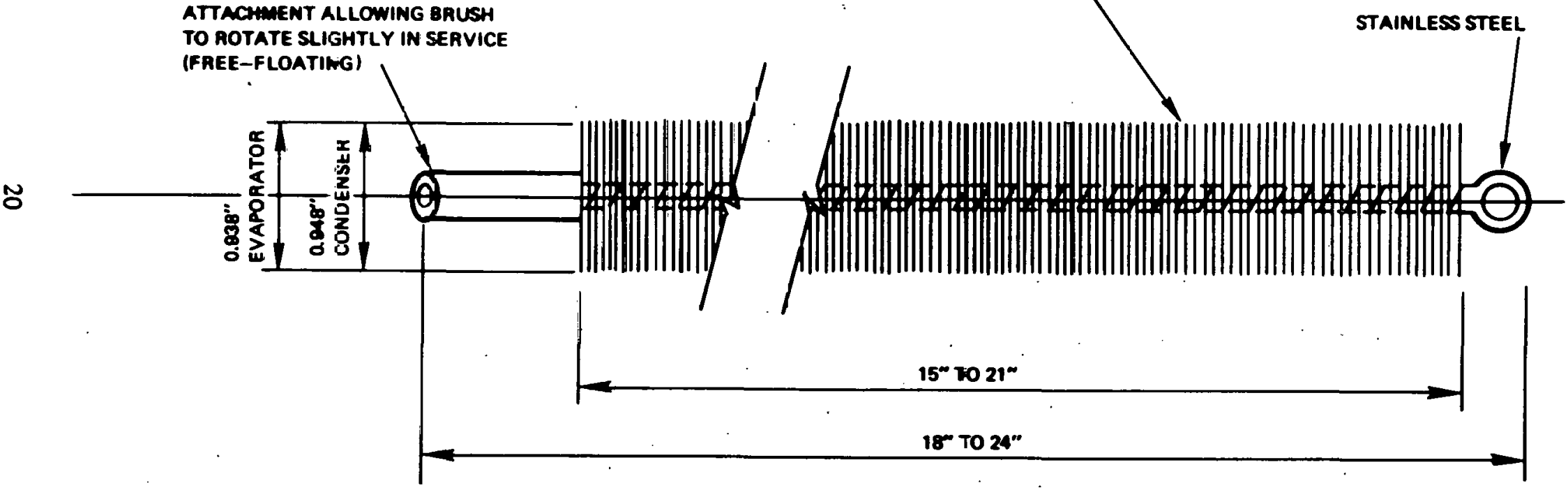

PROPOSED BRUSH FOR TUBE CLEANING MACHINE 
9. Expand upon your method of calculating evaporating and condensing heat transfer coefficients from single tube data of ORNL and CMU. Note specifically the rationale for the prediction of ammonia coefficient from the Freon data.

\section{Evaporator Heat Transfer Coefficient}

The basic data were obtained at the CMU thermal-hydraulic laboratories. The experimental results gave a composite heat transfer coefficient for Freon-11. A composite heat transfer coefficient includes the combined effects of evaporation and the metal wall.

A heat transfer coefficient for ammonia was obtained by scaling the coefficient for Freon-11. The scale factor is the ratio of the 0 factors for ammonia and Freon-11. The 0 factor is defined as follows:

$$
\text { where } \quad \begin{aligned}
0 & =\left(\mathrm{k}^{3} \rho^{2} \mathrm{~g} / \mu^{2}\right)^{1 / 3} \\
\mathrm{k} & =\text { thermal conductivity } \\
\rho & =\text { density } \\
\mathrm{g} & =\text { gravitational constant } \\
\mu & =\text { viscosity }
\end{aligned}
$$

The ratio of 0 factors is 6.27 . Thus, the ammonia side heat transfer coefficient is 6.2 : times the composite coefficient for Freon-11. (See page 1.1-3:) The resulting ammonia-side heat transfer coefficient was corrected by incorporating the wall effect of the PSD-1 tube to obtain a composite coefficient.

The use of 0 factor ratio in this manner is correct for obtaining evaporation heat transfer coefficients, but is theoretically imprecise for composite coefficients. However, for practical purposes, the computation yields usable results because the tubes in the experiment were aluminum and had a conductance of the order of 21,500, whereas the composite Freor coefficients varied from about 230 to 1800 . It is apparent that, in the case of Freon, the ccm posite resistance (reciprocal of the conductance) is essentially all due to the evaporation resistance.*

Experiments on falling film composite heat transfer coefficients in condensers using both Freon data and ammonia data validated the use of the 0 correction factor.

Condenser Heat Transfer Coefficient

The condensing heat transfer coefficient was determined from ORNL data on condensin. ammonia as given in Section I.1.3 of this report.

\footnotetext{
*Actually, the scatter of the data on Freon was greater than the inf'?ence of the metal conductance on the composite heat transfer coefficient.
} 
Single Versus Multiple Tubes

While single vertical fluted tube performance data are available, unfortunately no similarly comprehensive data on vertical tube bundles of significant size are available. $:$

The design and performance projections of our heat exchanger are predicated on the assumption that any one tube performs identically to any of the other 43,000 tubes in the bundle.

The underlying rationale and basis for this are discussed in detail on page 2.4-6 of this report. 
10. In Section 2.3.1 remove the parenthetical EES, 326, C-205 as the phrase is not a file number.

This correction is incorporated in the report. 


\section{THIS PAGE WAS INTENTIONALLY LEFT BLANK}


11. Furnish in document or separately to GTR the description and listing of the system performance program, Page $\mathbf{A}-85$.

The program description and listing are being forwarded separately to GTR, Jeffrey S.

Horowitz, of Argonne National Laboratory. 


\section{THIS PAGE WAS INTENTIONALLY LEFT BLANK}


12. Provide additional information such as catalogues, etc., about Technicon Monitor IV ammonia detector.

The requested information is enclosed (see following pages). 


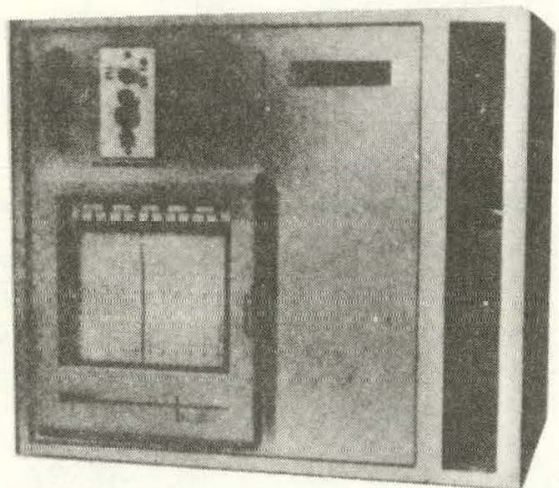

Figure 1-1 MONITOR IV OVERALL DIMENSIONS
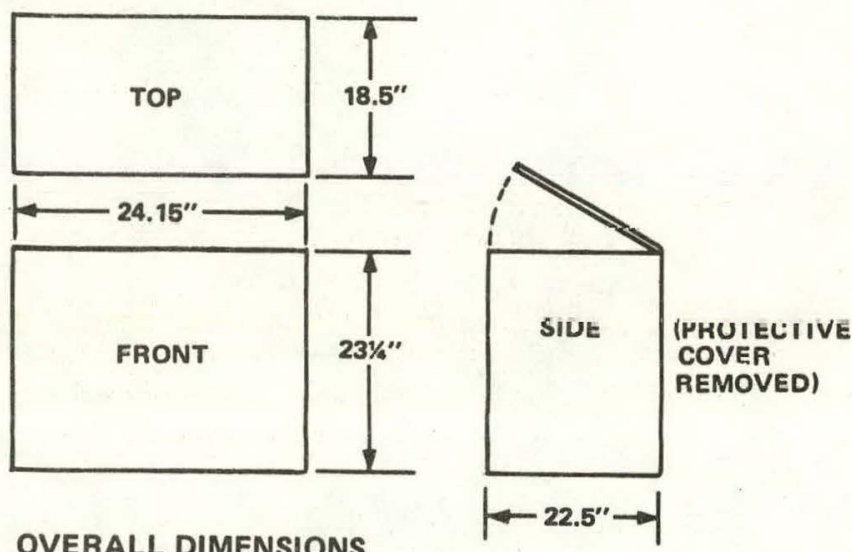

1.0

General

The Monitor IV system shall be a continuous, on-line system for wet chemical analysis of water for a variety of parameters. The system shall enable concentration levels of the parameter being monitored to be presented continuously on a moving strip of Recorder chart paper.

Each step of the analysis shall be completely automated, from collection of the sample to printout of results on the Recorder. Output of the system shall be available for interfacing with computers or for process control (Figure 1-2).

The basic system shall consist of an Overflow Sampler, Solenoid Valve, Proportioning Pump, Manifold Assembly, Colorimeter, and Recorder. All components shall conform to accepted electrical and plumbing codes and requirements when properly installed.

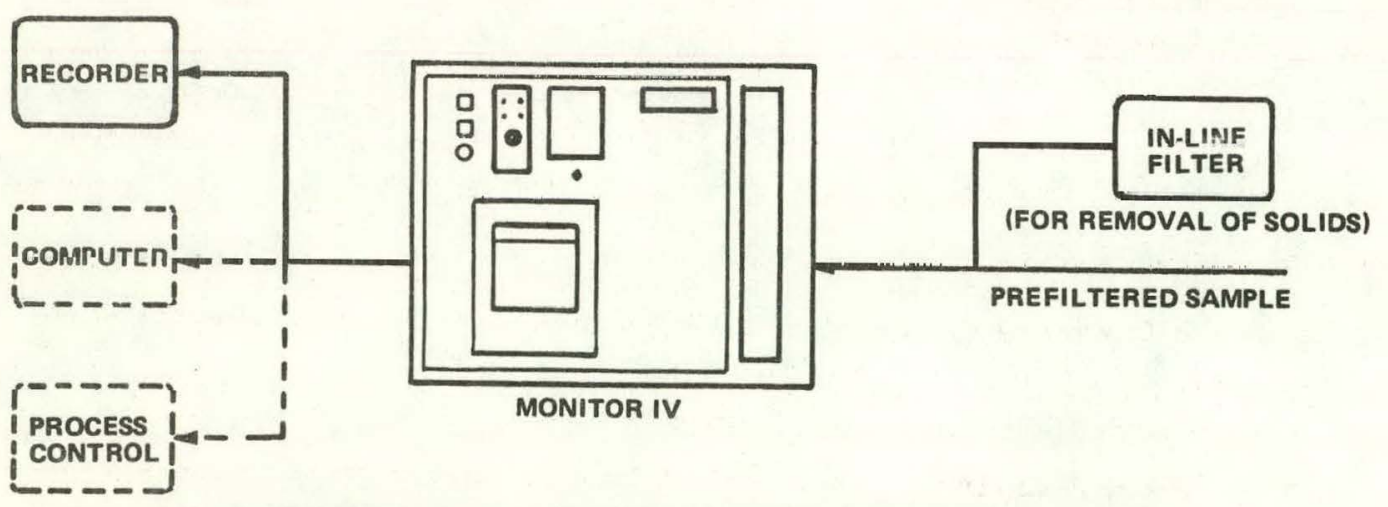

Figure 1-2 SCHEMATIC OF THE MONITOR IV SYSTEM AND OPTIONS. OTHER EQUIPMENT WHICH CAN BE USED WITH THE SYSTEM IS SHOWN BY DOTTED LINE. 


\title{
SPECIFICATIONS AND ENGINEERING STANDARDS
}

\author{
BASIC INSTRUMENTATION SPECIFICATIONS \\ FOR TECHNICOÑ MONITOR IV SYSTEM \\ FOR CONTINUOUS, ON-LINE ANALYSIS
}

2.0 Principle of Operation

The system shall operate on the principle of continuous-flow analysis, where airsegmented streams of sample and reagent(s) are brought together and reacted under carefully controlled conditions. The resulting color, or color reduction, shall be measured by absorbance of a beam of light, as the analytical stream passes through a Colorimeter : flowcell.

3.0 Automațic Correction

This shall be provided by means of a Solenoid Valve automatically programmed to introduce a standard solution or baseline solution into the analyzer sample stream. The resultant recorder signal shall be automatically corrected whenever it does not agree with a preset value. The frequency of this correction shall be adjustable by a programmer. The automatic correction can also be used for checking reagent baseline if a baseline solution is introduced instead of a standard solution.

4.0 Overall Specifications

Size: . . . . . . . . 25 inches wide $\times 23 \frac{1}{4}$ inches high $\times 22 \frac{1}{2}$ inches deep

Shipping Weight: . . . . Approximately 150 pounds

Electrical Requirements: $115 \pm 11.5$ volts, $60 \mathrm{~Hz}$, single phase, 5 amperes. (A system is also available for $50 \mathrm{~Hz}$ ) A third wire grounding type receptacle is required.

The Monitor IV shall have a separate chassis ground with dual switching of both sides of the electrical power input. The system shall be capable of maintaining stable operation during conditions where line voltage may drop as low as 103.5 volts for extended periods of time. In addition, the system shall be designed so that it shall not be damaged if line voltage drops to 90 volts for short periods of time.

Analysis Rate: . . . ..... Continuous

Environmental

Requirements: . . . . Operating Temp. Range: $50^{\circ} \mathrm{F}$ to $90^{\circ} \mathrm{F}$

Temperature Coefficient: $0 \pm 0.0001$ Absorbance Units per degree Fahrenheit change in temperature from the standardization temperature.

Relative Humidity: Between 10 and $80 \%$

Electrical Zero Stability

Drift with Time: ..... $0 \pm 0.00005$ Absorbance Units per hour (applicable after 24 hours of continuous operation)

Electrical Noise: . . . $0 \pm 0.25 \%$ of full scale

Electrical Span Drift: . . $0 \pm 0.1 \%$ of full scale per degree Fahrenheit change in temperature from standardization temperature. 


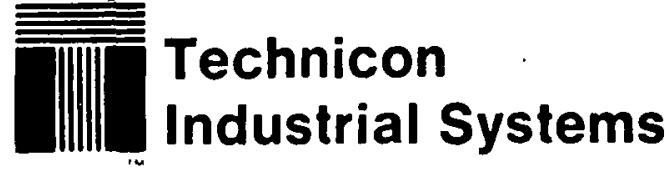

A Division of Technicon Instruments Corporation

\section{BASIC INSTRUMENTATION SPECIFICATIONS FOR TECHNICOÑ MONITOR IV SYSTEM FOR CONTINUOUS, ON-LINE ANALYSIS}

+ Drain Requirements: .. Dependent upon parameter being measured.

Reagents: . . . . . . . Dependent upon parameter being measured.

Sample Flow: . . . . . . Dependent upon parameter being measured.

\section{Materials of Construction:}

Pump Tubing: TYGON, Silicone or Acidflex

Manifold Connective Tubing: Glass, polyethylene, KEL-F, or TYGON

Fittings: Glass or polyethylene

Cabinet: Wood and FORMICA, with a steel front panel

Electronics: All electronics, except for the Recorder, shall be solid state.

\subsection{Overflow Sampler}

The Overflow Sampler shall allow an aliquot of liquid sample to be introduced into the system by the Proportioning Pump, while excess sample flows to waste.

\subsection{Solenoid Valve}

The Solenoid Valve, energized by a 24-hour timer, shall be capable of introducing either liquid sample, reference solution or baseline solution into the system.

\subsection{Proportioning Pump}

A peristaltic-action Proportioning Pump shall be used to move sample and reagent(s) through the system. The pump shall be capable of containing up to 15 flexible pump tubes having the same wall thickness but differing in internal diameter, enabling flow rates to be accurately and reproducibly proportioned for different chemical tests. The pump shall also be used to segment the analytical stream with air bubbles, optimizing system reponse time and preventing cross-contamination of samples.

Basically, the Proportioning Pump shall consist of two parallel stainless steel roller chains connected by five equally spaced stainless steel rollers, a constant-speed motor which drives the chain assembly, and a spring-supported platen. Resilient pump tubes, held taut by two end blocks, shall be positioned between the rollers and the platen. As the rollers move over the pump tubes. pressure shall occlude the tubes at points of contact, pushing fluids forward through the tubes. and drawing fluids into the tuhes from behind.

Electrical Requirements: ..... $115_{-15}^{+12}$ volts, $60 \mathrm{~Hz}, 1.25$ amperes (I.Init also available for $50 \mathrm{~Hz}$ )

Flow Rate: . . . . . . . . . Proportional to the inside diameter of the pump tubes

Type:.............. Two speed

\subsection{Manifold Assembly}

The Manifold Assembly shall be appropriately designed for the specific analysis to be performed. The Monitor IV unit shall be designed to facilitate changing Manifold Assemblies for different analyses. 


\section{SPECIFICATIONS AND ENGINEERING STANDARDS \\ BASIC INSTRUMENTATION SPECIFICATIONS \\ FOR TECHNICON MONITOR IV SYSTEM \\ FOR CONTINUOUS, ON-LINE ANALYSIS}

The Manifold Assembly shall be capable of containing, if required, one or two separate, adjustable-temperature heating baths. The heating baths shall be equipped with solid state proportional control regulators using the latest zero-crossing techniques to eliminate electrical switching transients.

Each Manifold Assembly shall be equipped with the necessary glassware, tubing, heating baths, dialyzers and fittings for a particular analysis and range. All manifold components (with the exception of special auxiliary distilling and pumping units) shall be housed in a single modular unit with removable see-through cover.

9.0 Colorimeter

The Colorimeter shall be provided with sample and reference channels with a common excitation source and discrete phototube detectors for operation in the range of 340 to $880 \mathrm{~nm}$ with appropriate filters. Detector system gain shall be continuously variable from 0-2 Absorbance Units to 0-.05 Absorbance Units, full scale, and be switchable to read out either absorbance or negative absorbance.

The Colorimeter shall provide linear signal outputs of 0-60mv DC and 0-5 VDC simultaneously. It shall be capable of accomodating flow cells of either 15 or $50 \mathrm{~mm}$ pathlength.

The Colorimeter shall be supplied with a voltage stabilized transformer providing 6 VDC to the source lamp and with appropriate entry and exit fittings for air-segmented sample and reference streams.

Electrical Requirements (Voltage Stabilizer)

Input ....... $113 \pm 13.5$ volts, $60 \mathrm{~Hz}$ (unit also available for $50 \mathrm{~Hz}$ ) 0.5 amperes

Output ....... 6 volts (regulated; load current between 3.8 and 4.5 amperes will not vary more than \pm 1 percent when input changes between 100 and 127 volts $A C)$

\subsection{Recorder}

The Recorder shall be a single pen type, equipped for recording of $0-60 \mathrm{mv}$ DC signals with an indicating acrurary of $\pm 0.1 \%$ of signal input. The Recorder shall be a riull balance potentiometric type with an off-null signal impedance of less than 100,000 ohms.

A chart paper wldth of seven inches minimum shall be provided. The Recorder shall have a ground isolated slidewire with a minimum impedance of $1,500 \mathrm{ohms}( \pm 1 \%)$ and a total overhang of less than $\mathbf{5 0}$ ohms. The slide wire shall be equipped to accept an easily attached retransmitting potentiometer.

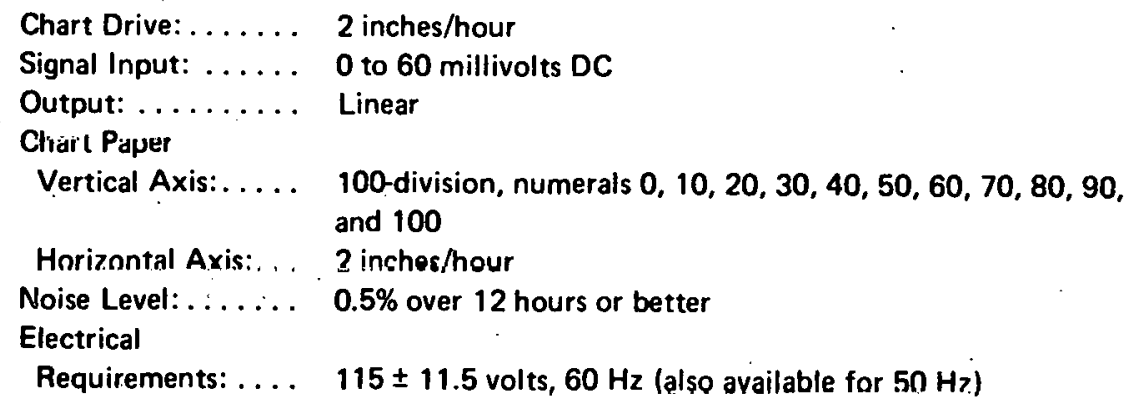




\begin{tabular}{|c|c|c|}
\hline & 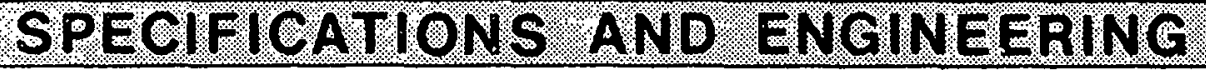 & 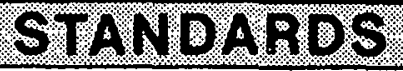 \\
\hline & $\begin{array}{l}\text { BASIC INSTRUMENTATION SPECIFICATIONS } \\
\text { FOR TECHNICON MONITOR IV SYSTEM } \\
\text { FOR CONTINUOUS, ON-LINE ANALYSIS }\end{array}$ & \\
\hline
\end{tabular}

11.0 Options

The following options shall be available from the supplier for use with the system.

11.1 Dual Analysis

This option shall permit the system to sample two separate streams by the addition of a second timer and a.second programmable valve.

11.2 Hi-Lo Alarms

Hi-Lo alarm signals, operated by the Recorder pen drive, shall be available as an option.

\subsection{In-Line Filter System}

An optional in-line filter system shall be available to provide preflltered samples for analysis, by removing particulate larger than 0.5 microns. The in-line filter shall have automatic solfs:leaning and reusable filter element.

Flow through the filter shall be provided by a positive displacement pump of the progressive cavity type. In operation, output from the pump shall pass through the inertial filter and on to waste. Clear filtrate shall flow to the Overflow Sampler.

Automatic backflushing shall be provided to periodically purge the fllter. The system shall include a timer and programmer to control the duration of, and intervals between, backflushing cycles.

A screened intake and check valve shall be available as an option for sampling from bodies of water such as lakes and streams.

Cabinet Slze: . . . . 22 iirches wide $\times 37$ inchos high $\times 19$ incher doep. (An additinnal 10 inches is required behind the cabinet for connections.)

Weight: ....... 175 pounds

Pump: ........ 1/4 HP; 4 gallons/minute (minimum) (The height of the pump above the water surface, plus equivalent friction head loss in the suction line, should not exceed 25 feet.)

Low-flow cut-off:. . . Turns off pump motor when flow is insufficient for proper pump operation.

Materials of

construction: ..... A Ail plplng and flttings up lu llie filter are stainless stcol, polyvinylchlorido, or polvpropylene.

\subsection{Operator Attendance Requirements}

The system shall be capable of operating unattended for a period of seven days minimum, under normal circumstances, provided that an appropriate environment and sample are available. Preventive maintenance should be performed at seven day intervals, and the system shall not require longer than one hour to perform this maintenance.

Tarrytown, New York 10591 / Telephone: 914-631-8000 / Cable Address: Techintlab New York / TWX: 710-567-1220 


\section{Automated Ion-Selechive Electrode Method for Deternuning Fluoride in Natural Waters}

David E. Erdmann, U.S. Geological Survey, Lakewood, Colo. 80225

An automated fluoride method which uses AutoAna. lyzer modules in conjunction with a fluoride ion-selective electrode was evaluated. The results obtained on 38 natural water samples are in excellent agreement with those determined by a similar manual method (average difference $=0.026 \mathrm{mg} / \mathrm{l}$ ). An average fluoride concentration of $0.496 \mathrm{mg} / \mathrm{l}$ was found when several natural water samples were spiked with $0.50 \mathrm{mg} / \mathrm{l}$ fluoride. Aluminum is the only significant interfering substance, and it can be easily tolerated if its concentration does not exceed $2 \mathrm{mg} / \mathrm{l}$. Thirty samples were analyzed per hour over a concentration range of $0-2 \mathrm{mg} / \mathrm{l}$.

Fluoride is one of the more commonly determined constituents in natural water; therefore, it is desirable to determine fluoride by a method which is not only accurate, simple, and relatively free from interference, but also zapid. Frant and Ross $(1,2)$ introduced a fluoride-ion-selective electrode which exhibited a Nernstian response over a wide concentration range. A total ionic strength adjustment buffer (TISAB) was used to regulate the $\mathrm{pH}$ of the samples and also to provide an ionic strength which remains very nearly constant for the samples analyzed. The chemical interference from aluminum was greatly reduced when Harwood (3) replaced titrate with cyclohexanediaminetetraacetic acid (CDTA) as a chelating agent.

This paper describes an automated fluoride method which utilizes an ion-selective electrode. Carryover, reproducibility, concentrations found for known additions, and interferences are considered.

\section{Experimental}

Apparatus. A Technicon sampler, proportioning pump, analytical cartridge, and recorder were used. The potentiometer incorporated into the above system was a prototype model supplied by Technicon Instruments Corp. It utilizes an Orion fluoride electrode (No. 94-09) and a Corning reference electrode (No. 476001). The small amount of sample required by the fluoride electrode assembly facilitates rapid response with a minimum of carrynver fmm the previous sample. The assembly for the reference electrode is similar although the liquid reservoir is larger.

Reagents. All chemicals were reagent grade unless ntherwise specified. A stock fluoride solution $(100 \mathrm{mg} / \mathrm{l})$ was prepared by dissolving 0.2210 gram of $\mathrm{NaF}$ in distilled deionized water and diluting to 1 liter. Working standards were prepared by appropriate dilution of this stock standard.

The 'IISAB solution was prepared by adding 58 grams of $\mathrm{NaCl}, 57 \mathrm{ml}$ of glacial $\mathrm{HC}_{2} \mathrm{H}_{3} \mathrm{O}_{2}$, and 4.5 grams of CDTA to approximately $500 \mathrm{ml}$ of distilled deionized water, and then slowly adding $5 \mathrm{M} \mathrm{NaOH}$ with stirring and cooling until the $\mathrm{pH}$ of the solution was 5.0-5.5. When the solution reached room temperature. it was diluted to 1 liter with distilled deionized water and $0.5 \mathrm{ml}$ of BRIJ ${ }^{\mathrm{H}}-35$ surfactant was added.

\section{Results and Discussions}

The water sample and the TISAB solution, both of which are carried in a 0.051 -in. pump tubing, are mixed, and the resulting solution stream is heated to $55^{\circ} \mathrm{C}$ before it enters the potentiometer. When this determination was considered, two approaches were taken. In the first, distilled water containing $0.2 \mathrm{mg} / \mathrm{l}$ of fluoride was used as the wash solution; consequently, $0.2 \mathrm{mg} / \mathrm{l}$ of fluoride was added through the sample tube during the rinse cycle. In the second approach the TISAB solution was spiked 0.2 $\mathrm{mg} / \mathrm{l}$ of fluoride and, as a result, fluoride was continuously introduced into the system. A concentration of $0.2 \mathrm{mg} / \mathrm{l}$ of fluoride was added in both of these approaches with the intention of avoiding the slow electrode response normally encountered for low-level concentrations of fluoride. The potentiometer was adjusted in both procedures to give a full-scale reading for a $2-\mathrm{mg} / \mathrm{l}$ standard. The potentiometer output is very nearly linear over the $0-2-\mathrm{mg} / \mathrm{l}$ range. If conditions dictate, this range can be either expanded or contracted somewhat by adjusting the calibration control on the potentiometer.

The spiked TISAB method proved to be superior, as shown in Tables I and II, when considering reproducibility, low-level fluoride samples, and results obtained when consecutive samples differed greatly in concentration. Six replicates of each of 0.50 - and $1.50-\mathrm{mg} / \mathrm{l}$ standards were analyzed with the first sample in each group preceded by a distilled water blank. As given in Table I, the results from the $0.50-\mathrm{mg} / \mathrm{l}$ standard were identical for both methods but they were considerably poorer for the unspikedTISAB method when the $1.5 \cdot \mathrm{mg} / \mathrm{l}$ standards were analyzed.

\begin{tabular}{|c|c|c|c|}
\hline \multicolumn{4}{|c|}{ (All concentrations are in $\mathrm{mg} / \mathrm{l}$ ) } \\
\hline $\begin{array}{l}\text { Standard } \\
\text { concen }\end{array}$ & Range & Moan & Std dev \\
\hline \multicolumn{4}{|c|}{ Spiked TISAB- } \\
\hline 0.5 & $0.49-0.50$ & 0.497 & 0.005 \\
\hline 1.5 & $1.47-1.50$ & 1.492 & 0.012 \\
\hline \multicolumn{4}{|c|}{ Unspiked TISAB } \\
\hline 0.5 & $0.49-0.50$ & 0.497 & 0.005 \\
\hline 1.5 & $1.44-1.52$ & 1.488 & 0.027 \\
\hline
\end{tabular}

Table II. Effect of Electrode Response and Carryover on Two Fluoride Methods

\begin{tabular}{ccc} 
Sample concn, mo/l & \multicolumn{2}{c}{ Spparent concn, mo/ } \\
\cline { 2 - 3 } 2.00 & 2.01 & Unsplked TiSAB \\
0.00 & 0.04 & 2.00 \\
0.00 & 0.01 & 0.09 \\
0.00 & 0.01 & 0.05 \\
1.00 & 0.98 & 0.04 \\
0.00 & 0.02 & 1.00 \\
2.00 & 1.98 & 0.06 \\
2.00 & 2.01 & 1.93 \\
0.20 & 0.22 & 2.00 \\
0.00 & 0.02 & 0.25 \\
2.00 & 1.98 & 0.06 \\
0.10 & 0.12 & 1.94 \\
& & 0.17
\end{tabular}




\begin{tabular}{|c|c|c|c|}
\hline $\begin{array}{l}\text { Manual } \\
\text { mothod. } \\
\text { mo/I }\end{array}$ & $\begin{array}{l}\text { Automoled } \\
\text { mothod, mg/lu }\end{array}$ & $\begin{array}{l}\text { Manual } \\
\text { mothod, } \\
\text { mg/i }\end{array}$ & $\begin{array}{l}\text { Aulomated } \\
\text { mothod, mo/l }\end{array}$ \\
\hline 0.24 & $0.26,0.26$ & 0.08 & $0.11,0.10$ \\
\hline 0.14 & $0.16,0.14$ & 0.14 & $0.16,0.14$ \\
\hline 0.25 & $0.28,0.28$ & 0.15 & $0.20,0.20$ \\
\hline 0.32 & $0.34,0.36$ & 1.20 & $1.20,1.20$ \\
\hline 0.31 & $0.30,0.27$ & 1.10 & $1.13,1.17$ \\
\hline 0.28 & $0.30,0.29$ & 1.01 & $0.98,0.98$ \\
\hline 0.44 & $0.44,0.44$ & & \\
\hline & \\
\hline
\end{tabular}

Table.IV. Recovery of Fluoride Added to Natural

\begin{tabular}{|c|c|c|}
\hline $\begin{array}{l}\text { Concn of samplo }+ \\
\text { known addition, mg/l }\end{array}$ & $\begin{array}{l}\text { Fluoride found } \\
\text { fluorlde orliginally } \\
\text { present, ma/fe }\end{array}$ & known कoddition, $\%$ \\
\hline $\begin{array}{l}0.75 \\
0.65\end{array}$ & $\begin{array}{l}0.50 \\
0.50\end{array}$ & $\begin{array}{l}100 \\
100\end{array}$ \\
\hline 0.77 & 0.51 & 102 \\
\hline 0.84 & 0.49 & 98 \\
\hline 0.78 & 0.49 & 98 \\
\hline 0.79 & 0.51 & 102 \\
\hline 0.94 & 0.51 & 102 \\
\hline 0.60 & 0.48 & 96 \\
\hline 0.64 & 0.50 & 100 \\
\hline 0.69 & 0.48 & 96 \\
\hline 1.68 & 0.49 & 98 \\
\hline 1.63 & 0.49 & 98 \\
\hline 1.46 & 0.50 & 100 \\
\hline Mean values & 0.496 & 99.2 \\
\hline Std dev & 0.0103 & \\
\hline orrected for dilutio & & \\
\hline
\end{tabular}

Part of the results of a study involving possible errors due to sample carryover and electrode response is given in Table II. The samples are listed in the same order as they were analyzed.

When using unspiked TISAB, it is apparent that devialiuns fium the actual coneentrutions ase largely dus in slow electrode response. This is especially true at low concentrations and when a sample of high concentration immediately follows one of low concentration or vice versa. The ability to overcome this problem by using spiked TISAB, basically a known addition method, was the reason that this automated procedure was adopted as the method of choice for determining fluoride. The carryover problem is not highly significant if fluoride concentrations are less than $2 \mathrm{mg} / \mathrm{l}$.

Thirty-eight natural water samples were provided by the U.S. Geological Survey Laboratory in Salt Lake City. The specific conductances of these samples ranged from $3145,000 \mu \mathrm{mho} / \mathrm{cm}$ at $25^{\circ} \mathrm{C}$. The flinnide results obtained on these samples by the above automated method were compared with those from a manual ion-selective electrode method. Harwood's (3) manual method was followed with the exception that the CDTA concentration in the TISAB was increased to $4.5 \mathrm{~g} / \mathrm{l}$. The fluoride concentrations ranged from $0.04-7.75 \mathrm{mg} / 1$. The average difference between the two methods was $0.026 \mathrm{mg} / \mathrm{l}$ fur these samples. The differences encountered between methods were comparable over the concentration range studied. The average difference between the duplicate runs for the auto. mated method was $0.011 \mathrm{mg} / \mathrm{l}$. A random sampling of these results is listed in Table III.

\begin{tabular}{|c|c|c|}
\hline Substence added & Concn, mg/l & $\begin{array}{l}\text { Apperent lluoride } \\
\text { concn, mg/fid }\end{array}$ \\
\hline $\mathrm{Fe}$ & 0.05 & 1.00 \\
\hline $\mathrm{Fe}$ & 1.0 & 1.00 \\
\hline $\mathrm{Fe}$ & 5.0 & 0.99 \\
\hline $\mathrm{Fe}$ & 10.0 & 0.99 \\
\hline Al & 0.5 & 0.98 \\
\hline Al & 1.0 & 0.99 \\
\hline Al & 2.0 & 0.98 \\
\hline Al & 5.0 & 0.94 \\
\hline Al & 10.0 & 0.89 \\
\hline$P O_{1} \cdot \mathrm{P}$ & 25 & 1.01 \\
\hline $\mathrm{SiO}_{2}$ & 100 & 1.01 \\
\hline
\end{tabular}

- Volues are average of 4 determinations.

These samo 13 samples wore slgo spiked with 0.51$)$ min $: 1$ of fluoride by adding two $\mathrm{ml}$ of $25 \mathrm{mg} / \mathrm{l}$ of standard $t i \mathrm{~s}$ $\mathrm{ml}$ of sample. The final concentration of fluoride in these solutions is therefore equal to $0.50 \mathrm{mg} / \mathrm{l}$ from the known addition plus $98 \%$ of the original sample concentrations Table IV lists the amount of fuoride found after corre:c:tion for the original sample concentration.

Silica, iron, and aluminum form complexes with flus ride and will interfere with this ion-selective method if CDTA is incapable of destroying these complexes Conse. quently, standards containing $1.00 \mathrm{mg} / \mathrm{l}$ of fluoride were spiked with varying concentrations of aluminum, irun. and silica to determine if any of these would intertere with this determination. A standard containing $25 \mathrm{mg} / \mathrm{l}$ al PO,-P was used to check for anionic interference. The results ure given in Table $V$. Aluminum is the nnly ion which interfered and its cffect is small if the aluminum cuncentration is leas than $2 \mathrm{mg} / \mathrm{l}$. A concentration of $i$ $\mathrm{mg} / \mathrm{l}$ of aluminum produces an error of approximately $6 \%$ at the $1-\mathrm{mg} / \mathrm{l}$ fluoride level. This will not usually be a fac: tor when analyzing natural waters because gluminum con. centrations of this magnitude are rarely found

A 30-(6/I) cam was used with the Technicun sampler thruguliuut mogt of this at.uny. Howover, 40 samples jer hour can be analyzed without substantial loss of accuracy if the concentration of fluoride does not - vary greatly frmm sample to sample. It is necessary to add continuously a constant concentration of fluoride to the system to achieve reproducible and accurale results. In this way. Inw inn centrations which produce much slower electrode response are avoided. The accuracy, reproducibility, and recovery of this method are excellent.

\section{Acknowledgment}

The author thanks Technicon Corp. for supplying the potentiometer protorype, and Martin Topf, Ralph Pirrita nn, Marvin Fishman, and Oliver Feist, Jr., for their heip and suggestions.

\section{Literalure Cited}

(1) Frant, 'M.S., Ross, J. W., Jr., Science, 154, 1553-5 (1968).

(2) Frant, M. S., Rose, .1. W., Jr., Anal. Chem., 40, 1169.71 (1968).

(3) Harwood, J. E., Water Res., 3, 273-80 (1969). . Received for review July 12, 1974. Accepted Nou. 21. 1974. Mrn-
tion of commercial products does not constitute endrrspment li.

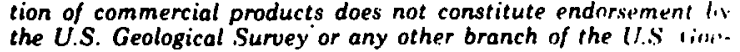
emment. 


\section{INTRODUCTION AND SUMMARY}

\subsection{PROJECT OBJECTIVES}

The objectives of the PSD-I project were stated in the DOE Request for Proposal No. EG-77-R-03-1400 dated, March 1977, as follows:

- "To develop a preliminary design for the full-sized (25 MWe nominal), closed-cycle ammonia power system module for the 100 MWe OTEC Demonstration Plant."

- "Included in this Phase I effort is the conceptual and preliminary design of (1) the 25 MWe power system module, (2) a scaled (5 MWe nominal) proof-of-concept power system, and (3) 1 MWe heat exchangers (evaporator and condenser), representative of the 25 MWe design, for early test and design verification.".

To accomplish these objectives, DOE divided the effort into two phases as follows:

$\because$ Phase I

- Conceptual design of the nominal 25 MWe power system module and development test articles

- Preliminary design of the nominal 25 MWe power system module and development test articles

- Phase II Plan (Proposal).

- Phase II

- Detailed design and development of the test articles

- Fabrication, checkout, delivery, installation support, and test operation support of the test articles.

The TRW team was chosen to perform Phase I design on the OTEC Power System Development Utilizing Advanced, High-Performance Heat Transfer Techniques. The heat exchanger design concept is characterized by:

- Shell and tube heat exchangers exploiting

- Vertical tube, falling ammonia film on the shell side

- Longitudinal flutes that entiances heat transfer.

The Conceptual Design Phase work (nugust 1977 - January 1978) was documented in TRW's Conceptual Design Report, SAN/1570-1, dated 12 May 1978 (draft report dated January 30, 1978) : : 
TRW concluded, during the Conceptual Design Phase, that a 12.5 MWe (net) power module consisting of dual 6.25 Mwe heat exchangers was a cost effective module size. The scaled proof-of-concept power system utilized the 6.25 MWe heat exchangers in a 6.25 MWe (net) arrangement. A concept of the scaled heat exchangers ( 1 MWe nominal) was also developed.

\subsection{REDEFINED PROJECT OBJECTIVES}

Subsequent to completing the Conceptual Design Phase, DOE redefined the project objectives (Amendment Modification M002 to Contract No. EG-77-C-03-1570 effective May 1, 1978):

- Development of a Preliminary Design for a 10 MWe Power System. Module for use in an operational modular application which projects economic viability

- Preliminary Design of proof-of-concept scaled heat exchangers (test articles)

- Conceptual Design of a Power System Module for use in a 40-50 MWe Commercial Power. System

- Phase II Hardware and Support Plan for the modular application power system module and the test article heat exchangers.

This Preliminary Design Report addresses all the objectives above except the last which is the subject of a separate Phase II proposal.

The following TRW interpretaliun of the technical pedfrection was presented at the Interim Design Review, June 5, 1978:

- 100 MWe Demonstration Plant is removed from consideration and is supplanted by a 40-50 MWe (net) commercial power system

- Perform conceptual design on power module for this power system including costing for prototype, first and eighth production units

- : 5 MWe (nominal) proof-of-concept, test article power system is supplanted by an operational modular application power system - using a 10 MWe (net) module

- The 10 MWe (net) module shall employ immersed heat exchangers and titanium tubes, with the top tube sheet between zero and 20 feet below sea level:

- Prepare a preliminary design for the modular application power module including costing for prototype, first and eighth production units 
- 1 MWe (nominal) pair of heat exchangers has been supplanted by a pair of $200 \mathrm{kWe}$ heat exchangers

- Prepare preliminary design for these test heat exchangers

- The reference containment vessel remains a surface ship hull.

The material presented in this design report conforms to the redirection as interpreted above.

\subsection{DESIGN REQUIREMENTS AND GUIDELINES}

The following requirements and guidel ines have been established through DOE directions. They are included here for reference. Table 1-1 identifies the paragraphs. of the report in which each requirement is discussied:.

\subsubsection{Applicable Documents}

Standards:

\begin{tabular}{|c|c|}
\hline NBS Circular 142 & $\begin{array}{l}\text { Tables of the Thermodynamic } \\
\text { Properties of Ammonia }\end{array}$ \\
\hline NBS Circular 564 & $\begin{array}{l}\text { Tables of the Thermal } \\
\text { Properties of Gases }\end{array}$ \\
\hline OSHA Standard 1910.111 & $\begin{array}{l}\text { Storage and Handling of } \\
\text { Anhydrous Ammonia }\end{array}$ \\
\hline
\end{tabular}

Specifications:

USCG Booklet 115

Marine Engineering Regulations and Materials Specifications

Other:

ANSI / ASME BPV-VIII - 1

ASME Boiler and Pressure Vessel

1 July 1977

Code, An American National Standard, Section VIII, Rules for. Construction of Pressure Vessels, Division 1

Contract EG-TI-C-03-1570

Ocean Therma 1. Energy Conversion

1 August 1977

(OTEC) Power System Development

Letter from J. Littlehales to Phase II Proposal Offerors, July 27, 1977

Answers to written questions on the Instructions for the Phase II Proposal Submittal 
Table 1-1. PSD-I Requirements versus Capabilities

\begin{tabular}{|c|c|c|}
\hline Destgn and Functional Requirements & Solution and/or Approach & $\begin{array}{l}\text { Where } \\
\text { Discussed }\end{array}$ \\
\hline 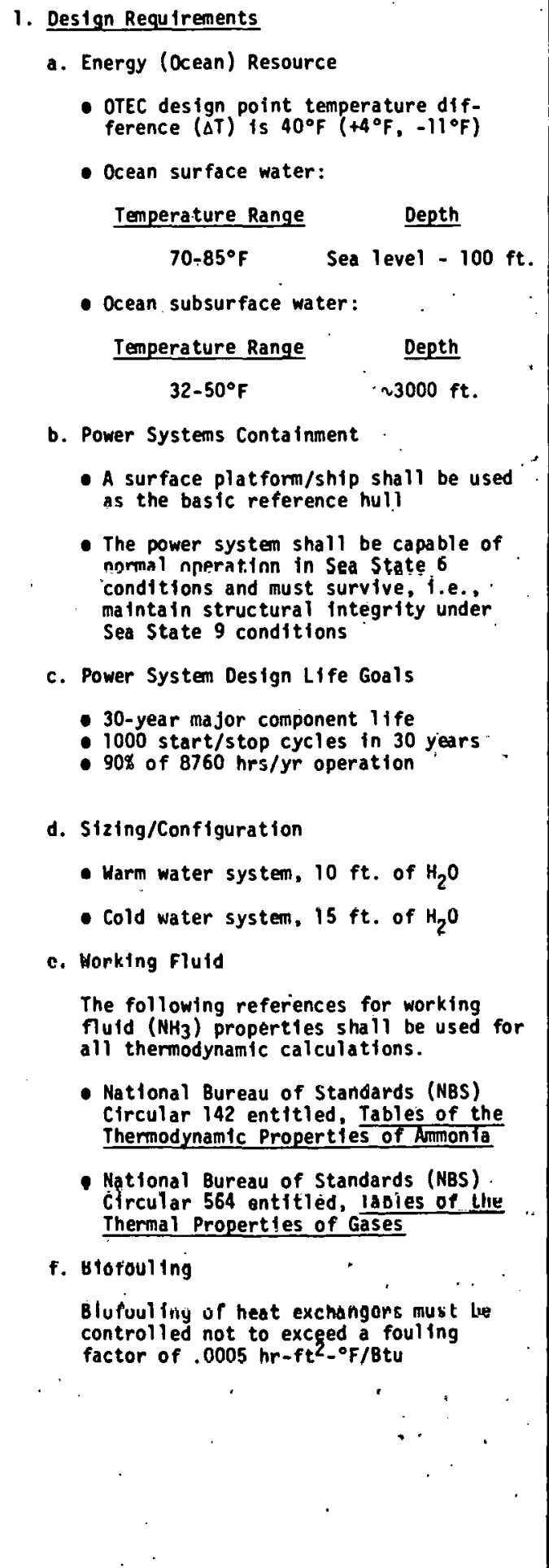 & $\begin{array}{l}\text { Used as basis for system design } \\
\text { and verified by simulation } \\
\text { System performance analyzed } \\
\text { over full range } \\
\text { - } \\
\text { System performance analyzed } \\
\text { over full range } \\
\text { Power module design considers } \\
\text { platform/ship hull } \\
\text { Power output fluctuations are } \\
\text { calculated at Sea State } 6 \\
\text { Prel ininary structural analysis } \\
\text { (based on out } 5 \text { pecirications). } \\
\text { Detail analysis wili occur } \\
\text { during Phase } 2 \\
\text { Allocation of avallability } \\
\text { requirements to subsystems and } \\
\text { components. Corrosion/erosion } \\
\text { allowances included for heat } \\
\text { exchangers and specified for } \\
\text { major components }\end{array}$ & $\begin{array}{l}\text { Section } 2.2 .4 \\
\text { Section } 2.1 .4, \\
2.1 .5 \\
\text { Section } 2.2 .6 \\
\text { Section } 2.1 .3 \text {, } \\
2.4 .6,2.4 .7\end{array}$ \\
\hline
\end{tabular}


Table 1-1. PSD-I Requirements versus Capabilities (Con't.)

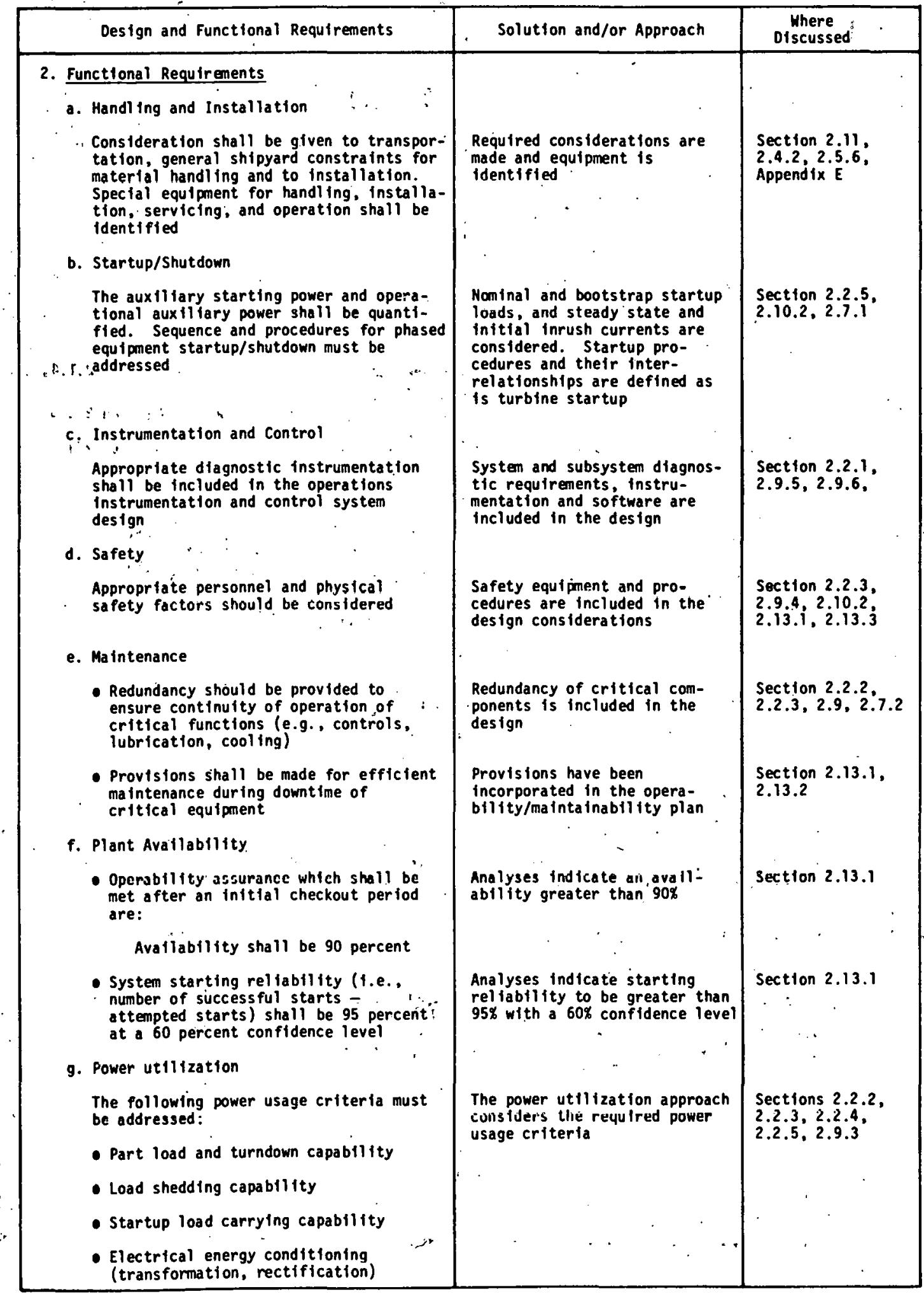




\subsubsection{Design Life Goals}

The power module shall be designed for the following:

a. 30-year major component 1 ife

b. 1000 start/stop cycles

c. $90 \%$ of $8760 \mathrm{hrs} / \mathrm{yr}$ operation.

\subsubsection{Startup/Shutdown}

The auxiliary starting power and operation auxiliary power shall include sequential logic and procedures for phased test equipment and prototype module(s) startup/shutdown. The staged application of torque on pump motors shall be a consideration in the design.

\subsubsection{Control and Instrumentation (C.8I) it .6}

Design of the OTEC power system shall include transient characteristics and component response.

\subsubsection{Electric Power System Utilization}

The power module shall initially be conditioned for use as utility power generation. The following power usage criteria shall be addressed:

a. Part load and turndown capab1lity

b. Load shedding capability

c. Startup load carrying capabtlity

d. Electrical energy conditioning (transformaliun, rectification).

The main requirements guiding the design of the electric power system are: operating flexibility, growth capability, high reliability, ease of maintenance equipment replacement, and low cost.

\subsubsection{Biofouling}

Biofouling of the heat exchanger shall be controlled such that a fouling factor not to exceed $0.0005 \mathrm{hr}-\mathrm{ft}^{2}-{ }^{\circ} \bar{F} / B$ Bu is maintained.

\subsubsection{Physical Characteristics}

Properties for the working fluid, ammonia $\left(\mathrm{NH}_{3}\right)$, shall be in accordance with NBS Circulars 142 and 564. 


\subsubsection{Plant Availability}

Operability assurance which shall be met after an initial checkout period are:

a. Operability' (actual operational time $\div$ required operation time shall be no less than 0.90 ).

b. System starting reliability (number of successful starts : attempted starts) shall be no 1 ess than 0.95 at a 60 percent confidence.

\subsubsection{Maintenance}

a. Redundancy shall be provided as required to ensure continuity of operation of critical functions (e.g., controls, lubrication, cooling).

b. Provisions shall be made for efficient maintenance during downtime of critical equipment.

\subsubsection{0 'Design Temperatures}

The system shall produce required power output with the following design temperatures:

a. OTEC design point nominal temperature difference $(\Delta T)$ is $40^{\circ} \mathrm{F}$

b. Ocean surface (warm) water temperature is $80^{\circ} \mathrm{F}$.

c. Ocean subsurface (cold) water temperature is $40^{\circ} \mathrm{F}$.

When exposed to alternate environments, the system shall operate with reduced power output with the following temperature variations:

a. Ocean surface water range from 70 to $85^{\circ} \mathrm{F}$

b. Ocean subsurface water range from 32 to $50^{\circ} \mathrm{F}$

c. OTEC design point temperature difference $(\Delta T)$ is $\left(+4^{n} F,-11^{n} F\right)$.

\section{3 .11 stztng}

Design for approximate total pressure drops for the heat source and sink as follows:

- Warm water system, 10 feet of seawater

- Cold water systeili, 15 reet of seawater 


\subsubsection{Containment Vessel and Sea Dynamics}

Because the specific containment vessel has not been chosen, a surface platform/ship shall be used as the reference hull during preliminary design (Figure 1.3-1).

The power system shall be capable of normal operation in a surface vessel under Sea State 6 conditions, and shall survive in a secured condition in a Sea State 9. A Sea State 6 condition has a significant wave height of 10 feet; a Sea State 9 has a significant wave height of 80 feet and is indicative of hurricane conditions.

Based on the attendant wave form forcing functions, nominal vertical and horizontal accelerations of the vessel are:

\begin{tabular}{|c|c|c|}
\hline Direction & \multicolumn{2}{|c|}{ Sea-State } \\
\hline & Six. & Nine \\
\hline Vertica! & $0,0.5 \mathrm{~g}$ & $0.15 \mathrm{~g}$ \\
\hline Horizontal & $0.01 \mathrm{~g}$ & $0.07 \mathrm{~g}$ \\
\hline
\end{tabular}

Hull motions associated with frequencies below $1 \mathrm{~Hz}$ have a maximum acceleration of $0.5 \mathrm{~g}$ in the vertical, fore and aft, and athwartships directions.

Maximum hull angular velocities of $0.5 \mathrm{radian} / \mathrm{sec}^{\mathrm{s}} \mathrm{roll}$, and 0.1 radians/sec in pitch and yaw shall be considered.

For components connected to the hull structure, the following limits shall be observed. (see Figure 1.3-2):

\begin{tabular}{|c|c|c|}
\hline \multirow[t]{2}{*}{ Frequency } & \multicolumn{2}{|c|}{ Limit (Vertical and Horizontal } \\
\hline & Hard Mounted & Soft Mounted \\
\hline $1-30 \mathrm{~Hz}$ & $1 \mathrm{in} / \mathrm{sec}$ & 2 in/sec \\
\hline $30-100 \mathrm{~Hz}$ & $0.5 \mathrm{~g}$ & $1.0 \mathrm{~g}$ \\
\hline
\end{tabular}

Hard mounted refers to equipment components which are mounted directly to the hull. Soft mounted refers to equipment that is mounted on structures that would tend to amplify the motion. 


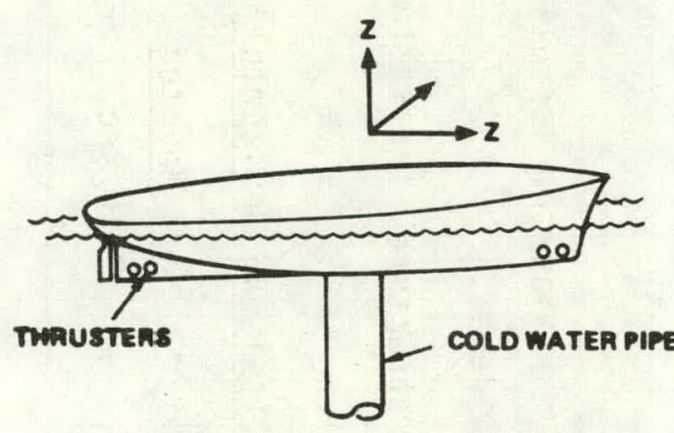

MOMINAL DIMENSIONS AND RESPONSE

$$
\begin{aligned}
& \text { LENGTH }=700 \mathrm{FT} \\
& \text { EEAM }=300 \mathrm{FT} \\
& \text { DRAFT }=100 \mathrm{FT}
\end{aligned}
$$

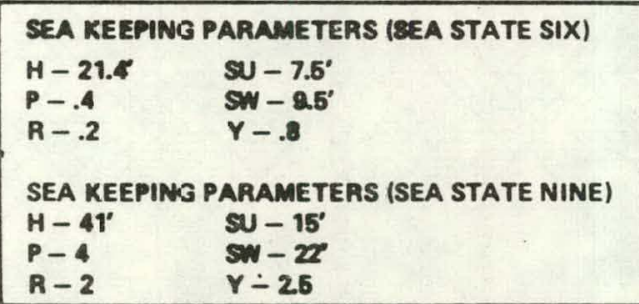

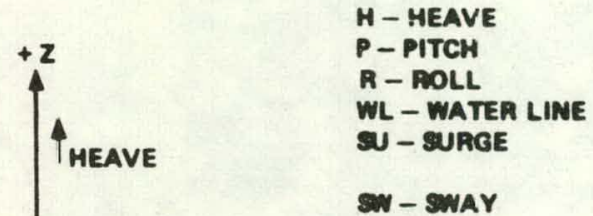

Y - YAW
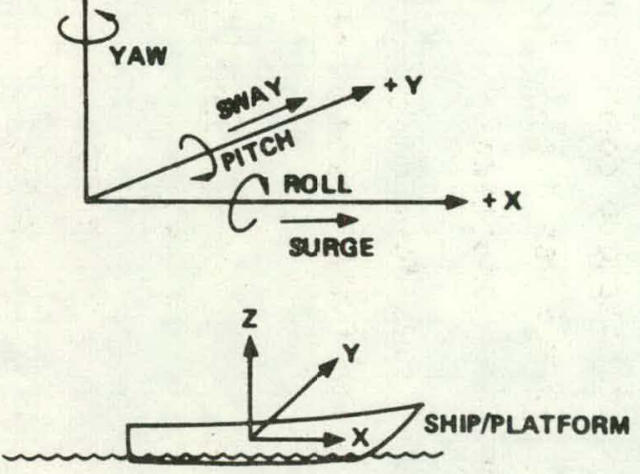

Figure 1.3-1. Ship Type Platform 
SHOCX SPECTRA $(X 10)$

$\overrightarrow{1}$

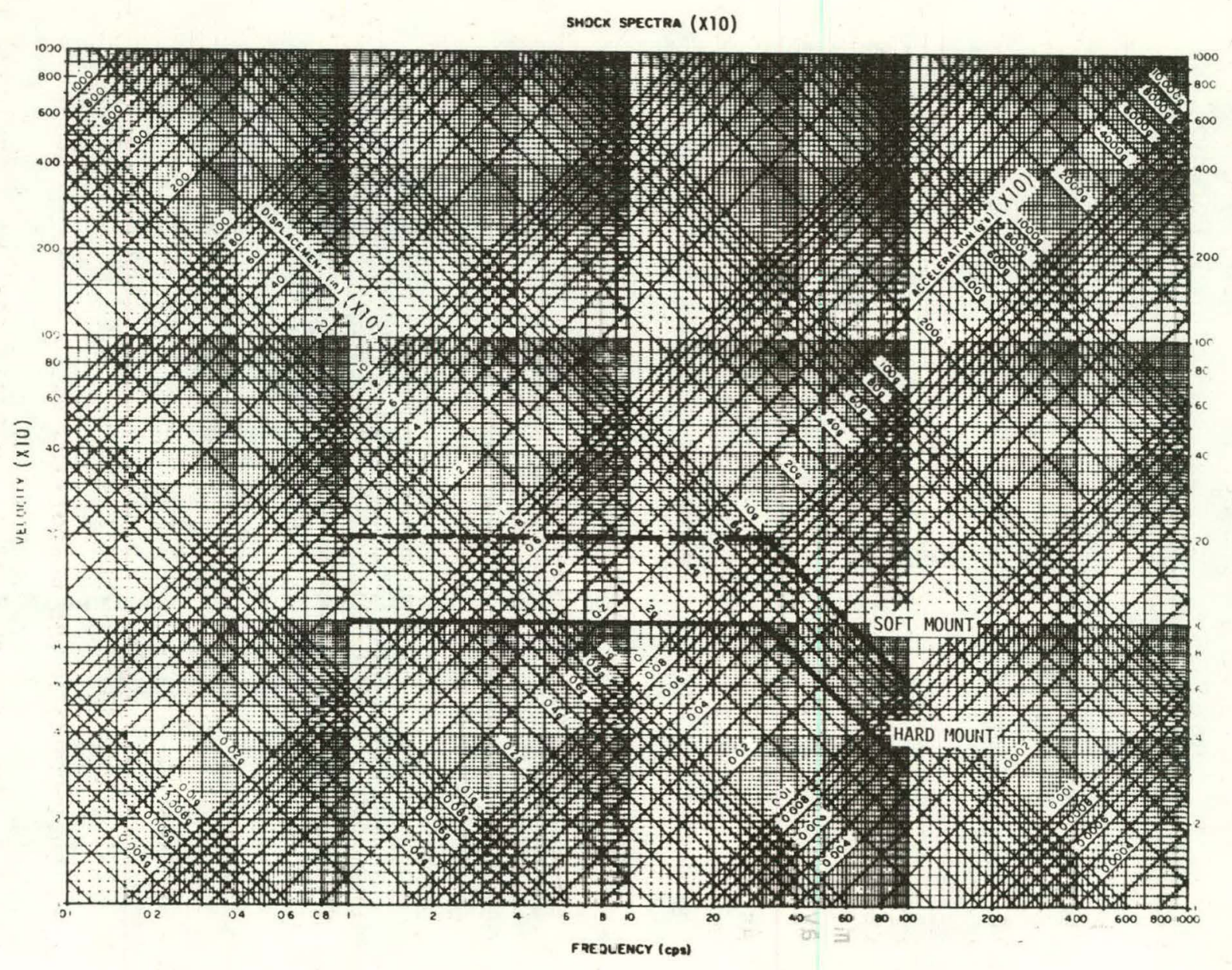

Figure 1.3-2. Hull Motion Limits, Velocity vs. Frequency 


\subsubsection{Handling and Installation}

Consideration shall be given to transportation, general shipyard constraints for material handling, and installation. Special equipment for handling, installation, servicing, and operation shall be identified.

\subsubsection{Material, Processes, and Parts}

a. The hardware shall have an operational life in an ocean environment (saltwater corrosion, blofouling) consistent with the design life noted in Section 1.3:2. Sealing problems associated with the various subsystems shall be addressed $\left(\mathrm{NH}_{3}, \mathrm{H}_{2} \mathrm{O}\right.$, lube, inert gas purge).

b. Equipment. which cannot be fabricated of materials resistant to an ocean environment shall be designed with sealed casings, compartments, or protective coatings to ensure that design life, availability, and reliability goals are met.

c. As materials are evaluated and selected for operation in these environments, they shall be clearly identified and the criterla for selection (design technique description) documented.

\subsubsection{Safety:}

The following safety factors shall be considered:

a. Human factors (heat, light, ventilation, adequate exits, working space, equipment, accessibility) shall be consistent with recognized standards ( $A B S$, USCG)

b. Other factors such as fire hazard, explosion hazard, development of toxic compounds, electrical hazards, shall be consistent with applicable OSHA and marine engineering regulations

c. Designs shall be fail safe.

\subsection{CONFORMANCE TO DELIVERABLES AND EVALUATION CRITERIA}

Table 1-2 shows the deliverables requested by DOE and paragraphs of this report that contain the supporting data.

Table 1-3 shows the evaluation criterla that were included as Enclosure II to DOE's undated letter, "Instructions/Guidance for PSD-I Task 3 (Phase II Proposa1) submittal." The paragraphs of this report that address each criterion are identified. 
Table 1-2, Preliminary Design Data Deliverables

(Contract No. EG-TI-C-03-1570)*

\begin{tabular}{|c|c|c|}
\hline Title of Deliverable & Sections Where Addressed & Contents \\
\hline $\begin{array}{l}\text { System Description } \\
\text { and Flow Dlagrams }\end{array}$ & $\begin{array}{l}\text { Section } 2.1 .1,2.1 .2 \\
2.5 .6, \text { Drawing Package }\end{array}$ & $\begin{array}{l}\text { Describes three cases of operating condttions } \\
\text { for the } 10 \text { MWe Power Module - maximum, minimum } \\
\text { and nominal flow. Includes integration of the } \\
\text { major power cycle components and parameters } \\
\text { required to define the cycle and efficiencies. } \\
\text { Provides thermodynamic flow diagrams and mass } \\
\text { flow, pressure and temperature diagrams. } \\
\text { Presents component power budget diagrams for } \\
\text { the } 10 \text { MWe system. Describes } 200 \text { kWe test } \\
\text { article operating conditions. }\end{array}$ \\
\hline $\begin{array}{l}10 \text { Me System } \\
\text { Specification } \\
200 \text { kWe System } \\
\text { Specification }\end{array}$ & Spectfication Package. & 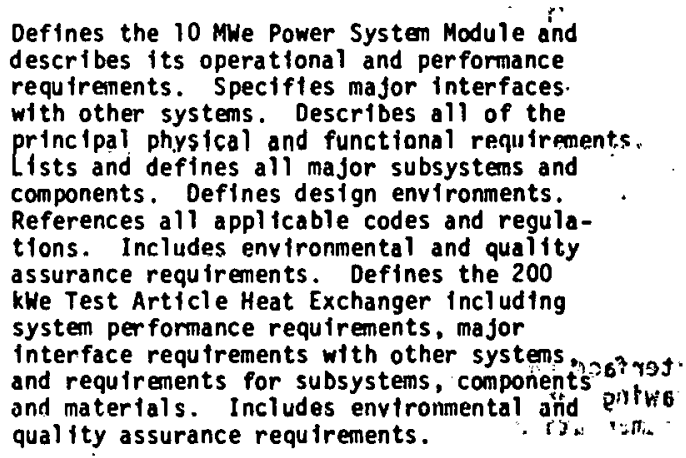 \\
\hline $\begin{array}{l}\text { Par formance } \\
\text { Calculat lons }\end{array}$ & $\begin{array}{l}\text { Eysten Performance } \\
\text { Sectlons } 2.1 .2,2.1 .8, \\
2.2 .4,2.2 .5,2.2 .6, \\
2.13 .1 \\
\text { Appendix A2, A3, C1 } \\
\text { Major subsystem } \\
\text { performance calcula- } \\
\text { tlons are in } \\
\text { approprlate sections } \\
\text { throughout the report } \\
\text { and appendices }\end{array}$ & $\begin{array}{l}\text { Descr fbes the perfuinlance of the lu mue } \\
\text { design. Includes detafled cycle analysis, } \\
\text { heat exchanger thermal destgn calculations, } \\
\text { turbogenerator performance calculations, } \\
\text { mass and energy balances and power budget; } \\
\text { analyses of dynamic stability and transient } \\
\text { response to major disturbances. Require- } \\
\text { ments for instrumentation, control and } \\
\text { operating procedures; and avallability. }\end{array}$ \\
\hline $\begin{array}{l}\text { Control } \\
\text { Instrumentation } \\
\text { Functions for } \\
\text { Operator and } \\
\text { ofagnostie } \\
\text { Evaluation }\end{array}$ & $\begin{array}{l}\text { Sections } 2.2 .1,2.2 .2 \\
2.9,2.5 .4 \\
\text { Appendix } k\end{array}$ & $\begin{array}{l}\text { Defines interfaces, requirements, startup/ } \\
\text { shutuuwn procedures, power budget, stéady- } \\
\text { state per fonmance analyses, power } \\
\text { fluctuations in response to ship heave, } \\
\text { aud requ Irements for diagnostic/operational } \\
\text { instrumentation, alarm, trip and control } \\
\text { room design. Describes the hardware } \\
\text { required for system operator, control and } \\
\text { monitoring. Lists spectfic sensors } \\
\text { required by type; specifies range, } \\
\text { accuracy, signal source and destribution, } \\
\text { electrical and mechanical interface, etc. } \\
\text { Identifies instrumentation and signals } \\
\text { for the } 200 \mathrm{kHe} \text {. }\end{array}$ \\
\hline $\begin{array}{l}\text { General Arrangement } \\
\text { Drawings }\end{array}$ & $\begin{array}{l}\text { Section } 2.1 .4,2.5 .4 \\
\text { Drawing Package }\end{array}$ & $\begin{array}{l}\text { Illustrates the configurations and spatial } \\
\text { relationships of all components and sub- } \\
\text { systems. Includes } 10 \text { MWe system elevation } \\
\text { criteria, turbine deck plan and el evation, } \\
\text { pump deck plan, and power modulo section, } \\
\text { Illustrates } 200 \text { kHe heat exchanger configura- } \\
\text { tlon and spatial relationships of components. }\end{array}$ \\
\hline $\begin{array}{l}\text { Subsystem and } \\
\text { Component Layout } \\
\text { Drawings. }\end{array}$ & $\begin{array}{l}\text { In appropriate } \\
\text { sectlons throughout } \\
\text { the report, Drawing } \\
\text { Package }\end{array}$ & $\begin{array}{l}\text { Illustrates major subsystems of the } 10 \text { MHe } \\
\text { power system and } 200 \text { kWe heat exchanger } \\
\text { wlth major component, plping and fnstalla- } \\
\text { tlon diagrams. Wirting diagrams are included } \\
\text { for each subsystem. }\end{array}$ \\
\hline
\end{tabular}

*The depth of specific deliverables reflects Contract Change Notice M002, TRW Letter \#1780.1-78-7064 dated June 2, 1978 and TRW Letter \#1780.1.78-7072, dated June 28,1978 
Table 1-2. Preliminary Design Data Deliverables (Con't)

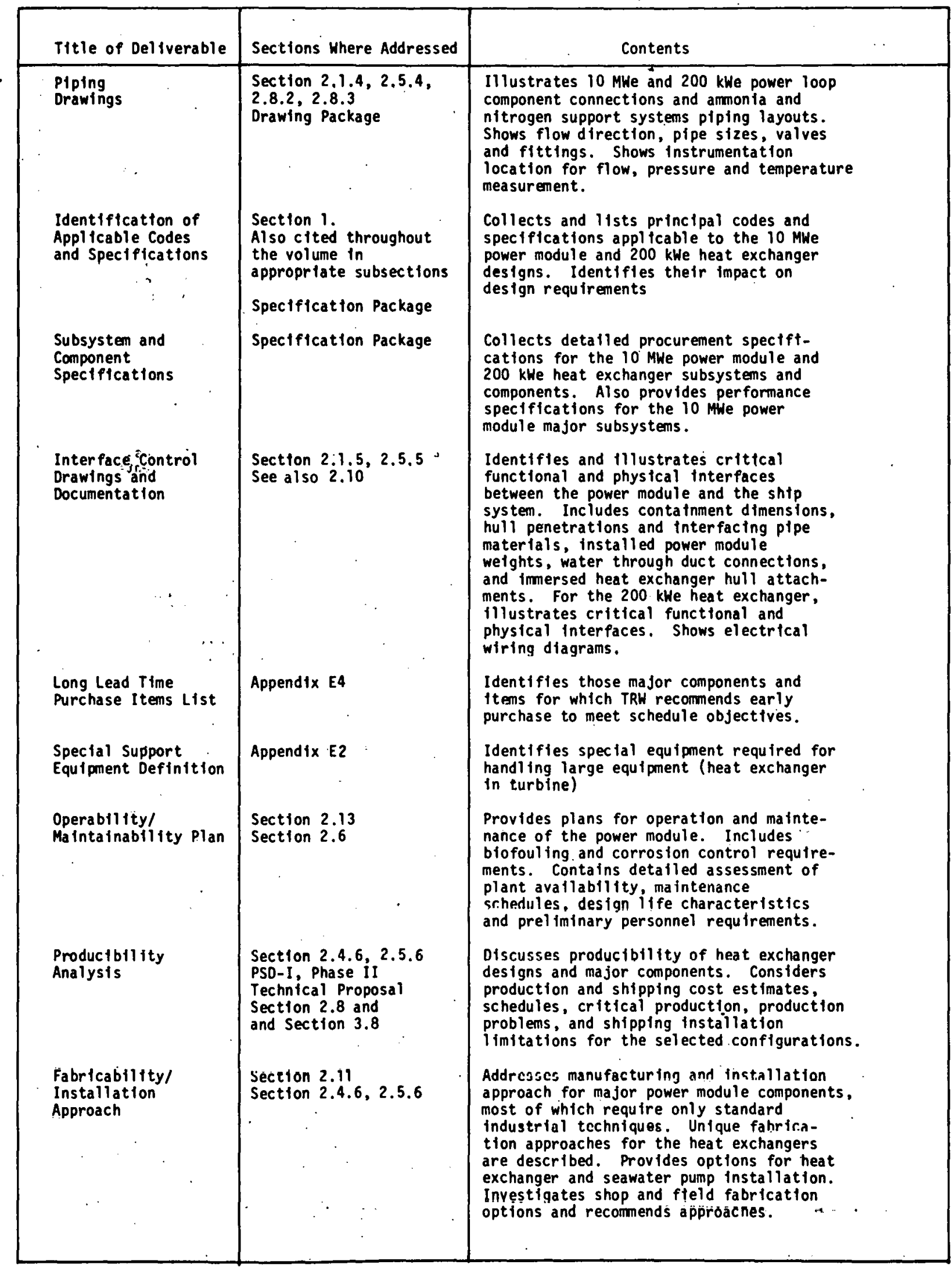


Table 1-2. Preliminary Design Data Deliverables (Con't.)

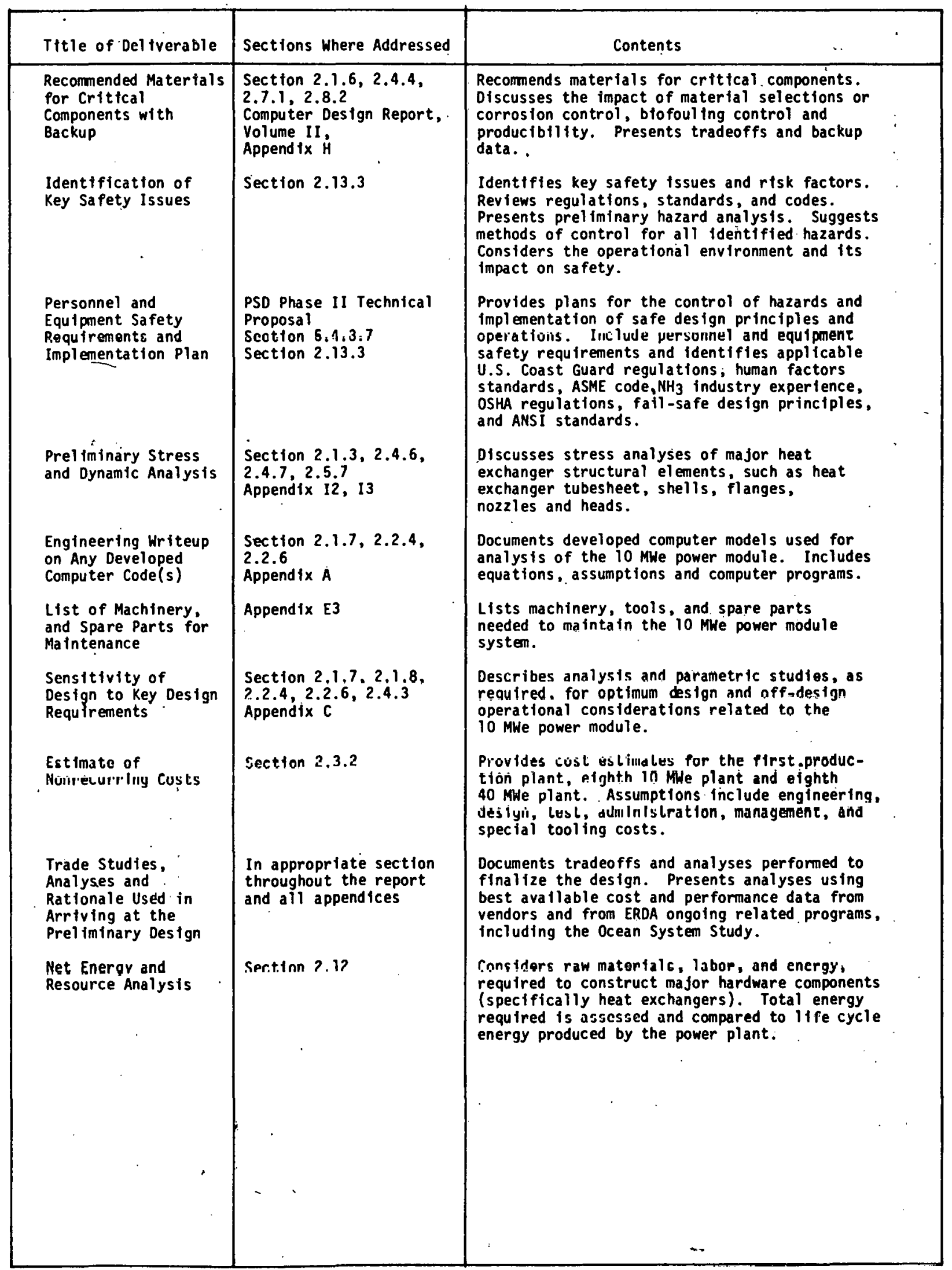




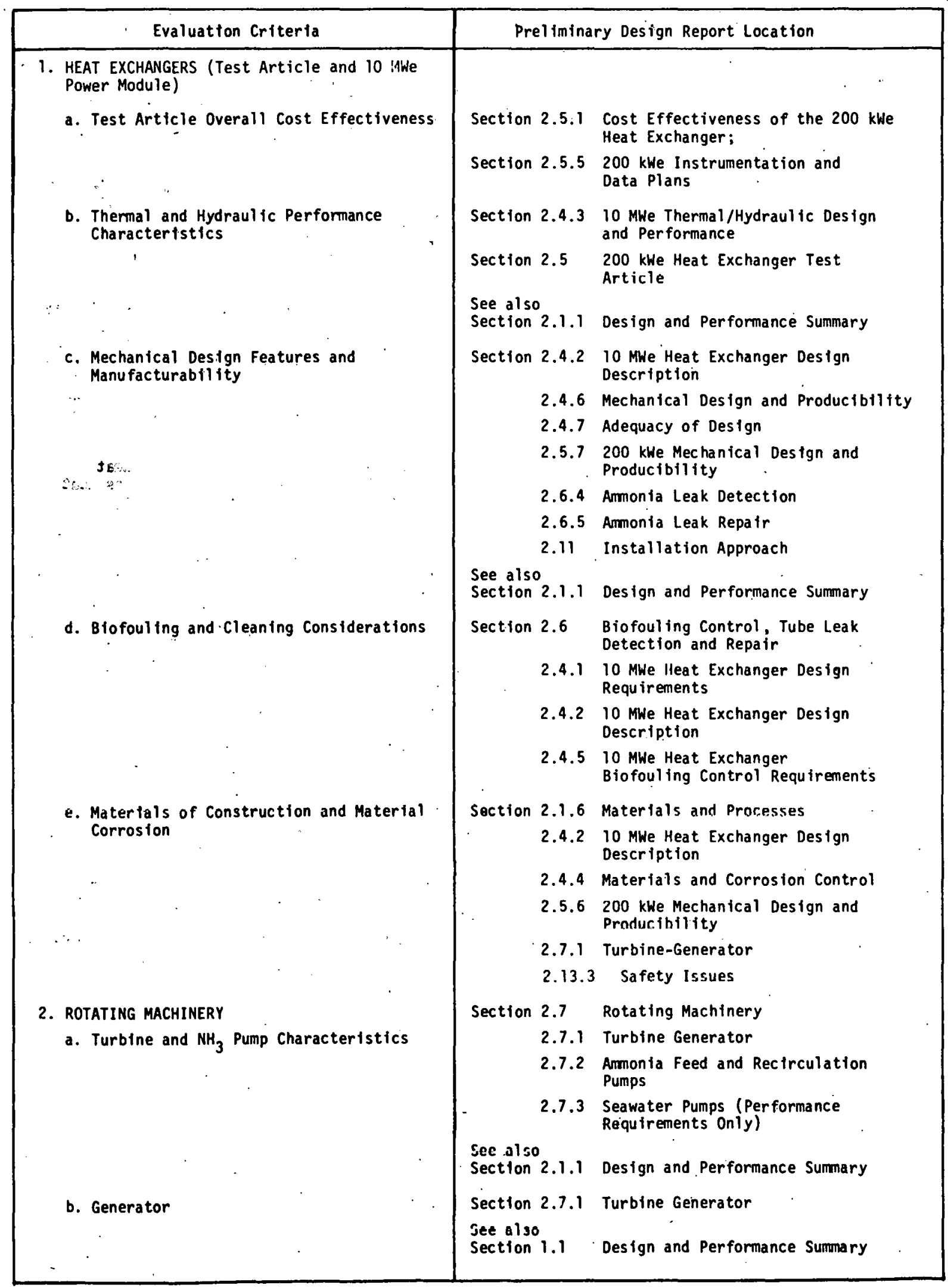


Table 1-3. Evaluation Criteria Cross Reference (Con't)

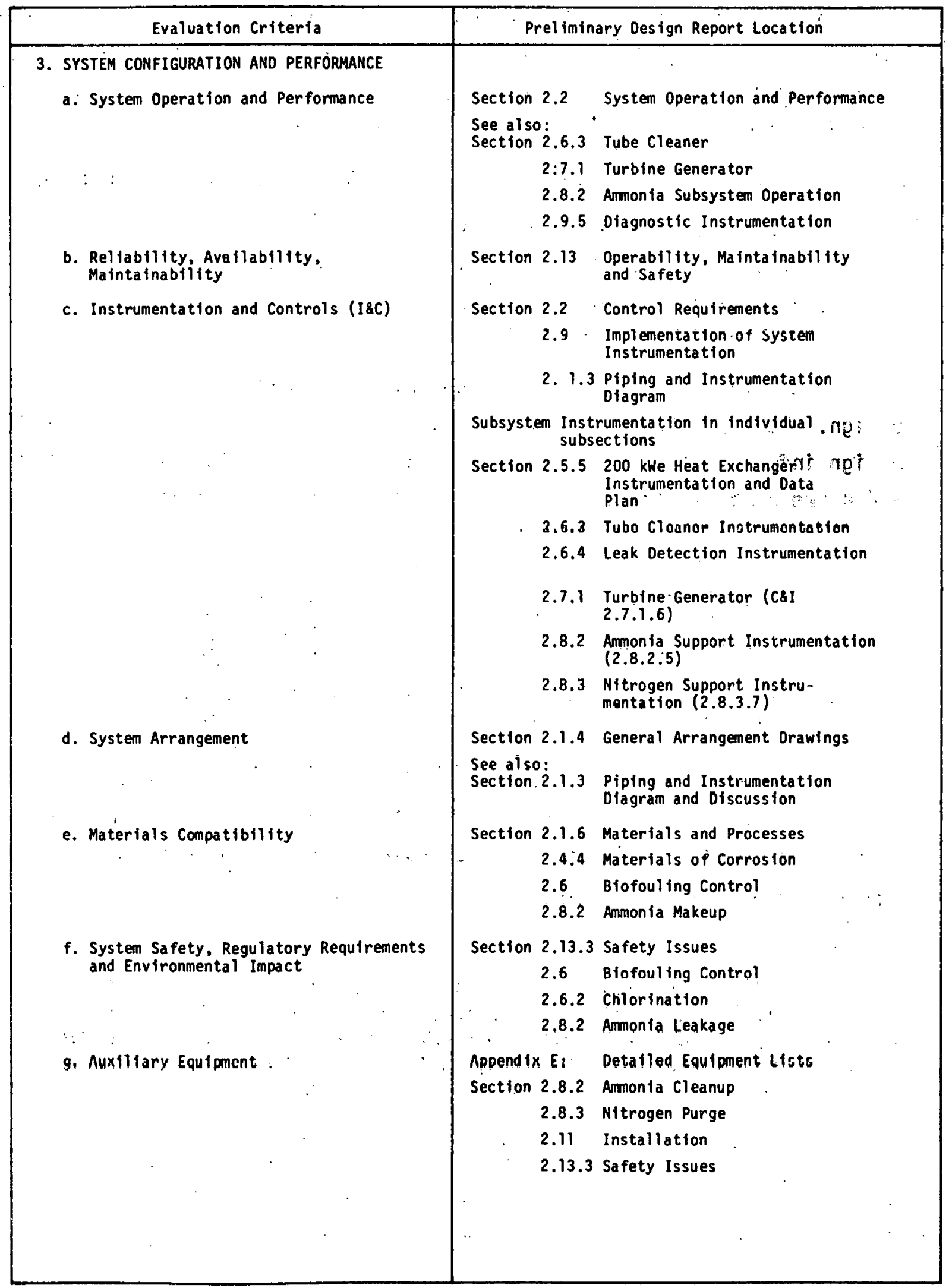




\subsection{REPORT OUTLINE}

This report documents the work accomplished during the Conceptual and Preliminary Design Phases. Preliminary designs are presented for the 10 MWe power module and the $200 \mathrm{kWe}$ test articles. A conceptual design of a 40 MWe commercial power system is also included.

The complete prel iminary design documentation consists of four parts:

1. Preliminary Design Report, Volume I

2. Prëliminary Design Report, Volume II, Appendices (Part 1 and 2)

3. Preliminary Design Specification Package

4. Preliminary Design Drawing Package

Part 1 (Volume I) presents a summary and overview of the preliminary design. Most of the supporting analyses, tradeoff studies and detailed design information is included in Part 2, (Volume II, Appendices). Parts 3 and 4 are compiled packages of relevant engineering documentation.

\subsubsection{Preliminary Design Report, Volume I}

The content of Part 1 is organized in three main sections:

1. Introduction and Summary

2. Preliminary Design of the 10 MWe Power Module and the $200 \mathrm{kWe}$ Test Articles

3. Conceptual Design of the 40 MWe Power System.

The principal portion, the preliminary design of the 10 MWe power module and the 200 kWe test heat exchangers, are described in Section 2 which is organized as follows:

\subsection{MWE POWER MODULE DESIGN}

Summarizes the major design characteristics of the 10 MWe including system description, process and instrumentation diagrams, general arrangements, critical physical and functional interfaces, materials, design optimization and design sensitivities. 


\subsection{OPERATION, PERFORMANCE AND CONTROL}

Addresses system operation and performance. Presents instrumentation and control (I\&C) requirements including ship and hydraulic (seawater pumps and pipes) interfaces. Control room and computer requirements are discussed, including trips and alarms. The control policy is derived, based on design simulations of steadystate and transient performance of the ammonia power loop and the hydraulic subsystem. The interrelationships of procedures for startup, shutdown, purge, trip, etc. are defined and examples of procedures are given. Steady-state startup power is analyzed and means for reducing are proposed.

\subsection{COST ESTIMATES}

Contains the detailed cost and design data sheets required by DOE.

\subsection{MWe HEAT EXCHANGER DESIGN}

- $\therefore$ : $\therefore$ वतT

Describes TRW's 10 MWe heat exchanger design approach and rèquirements defined by system tradeoffs. Provides details of thermal $\%$ hydraulic design, materials selection and mechanical design features. Requirements for the biofouling and leak detection subsystems and heat exchanger producibility are also addressed.

\section{$2.5200 \mathrm{kWe}$ HEAT EXCHANGER TEST ARTICLES}

Discusses design objectives and approach to design of the 200 .. kWe heat exchanger test articles including scaling criteria and implementation. Major design features and characteristics, test data parameters and requirements and major physical interfaces, similarities and differences in mechanical design and producibility rolative to the full scale exchangers are presented.

\subsection{BIOFOULING CONTROL, TUBE LEAK DETECTION AND REPAIR}

Addresses biofouling implementation approach to biofouling control through chlorination and mechanical tube cleaning. The proposed mechanical brush concept and an al ternate hydraulic brush cleaning concept are presented. Ammonia leak detection and tube leakage repair by plugging are described and proposed design solutions presented.

\subsection{ROTATING MACHINERY}

Discusses the turbine generator, ammonia feed and recirculation pumps and seawater pumps. Turbine design and tradeoffs leading to the recommended machine are discussed in detail. Performance at design conditions and off-design conditions, control and instrumentation and mechanical design features are presented together with scalability considerations. Performance and design features of candidate ammonia pumps are given, together with a summary of tradeoff studies of driver and control concepts. Seawater pump functional requirements (GFE equipment) and a candidate design for these pumps are given. 


\subsection{SUPPORT SUBSYSTEMS}

The design of two support subsystems is described: the ammonia support subsystem and the nitrogen support subsystem. The three functions of the ammonia system: storage, purification and recovery are discussed and a design solution presented. The nitrogen system is required for purging to avoid flammable mixtures of ammonia and air. A simple nitrogen system design is described.

\subsection{INSTRUMENTATION CONTROL} $\therefore$

Discusses instrumentation subsystem design, sensors, actuators, and remote versus local control, control room layout and displays. Identifies diagnostic instrumentation, sizes the functions performed by the control room computer and describes wiring.

\subsection{ELECTRICAL SUBSYSTEM}

The design approach and voltage selection for primary power disetribution and control of the power distribution are summarized. The 480 volt motor control center and the 4160 volt hydraulic pump supply are described. Generator short-circuit currents and parasitic power inrush current are addressed.

\subsection{INSTALLATION APPROACH}

Presents an approach to installation of major components on the platform. Three candidate methods for transportation and installation of the heat exchangers are described. It is shown by examples that similar transportation and installation jobs have been accomplished success fully.

\subsection{NET ENERGY ANALYSIS}

Presents a net energy analysis based on weight of all major power module components and the use of energy coefficients obtained from avaiable literature.

\subsection{OPERABILITY, MAINTAINABILITY AND SAFETY}

Addressès availability requirements and presents results of Monte Carlo simulations of operability, availability, and startup reliability. Allocates availability among subsystems and presents sensitivity analyses. Other topics covered are gross hazards analysis, operability/maintainability plan and safety issues. 


\subsubsection{Prel iminary Design Report, Volume II}

Volume II, Appendices, conta in supporting data and calculations and is bound in 2 parts (for handling). The contents are:
A. Developed Computer Models
B. Hydraulic System Studies
C. Miscellaneous Performance Analyses
D. Materials and Processes
E. Detailed Equipment Lists
F. Turbine Design Studies
G. Tube Cleaner Design
H. Ammonia Leak Detection
I. Heat Exchanger Design Supporting Data
J. Electrical Subsystem
K. Instrumentation and Monitoring
L. Ammonia Pumps Trade Study
M. Ammonia Support Subsystems
N. Piping and Support Design Calculations.
0. Operability Data 


\section{PRELIMINARY DESIGN OF THE 10 MWe P.OWER MODULE}

AND THE $200 \mathrm{kWe}$ TEST ARTICLES

A perspective of the 10 MWe power module is shown in Figure 2-1. It shows the arrangement of the main components including the externally mounted heat exchangers (immersed in seawater), the tube cleaning machine on top of the heat exchangers, the turbine/generator and ammonia piping and pumps. The arrangement is compact, yet provides for space and access for ma intenance and repair. Significant features of the design are discussed below.

\section{Heat Exchangers}

The heat exchangers incorporate a vertical fluted tube, falling film, evaporator concept and a vertical fluted tube condenser concept. In the system the evaporator achieves an overall heat transfer coefficient (U) of about $900 \mathrm{Btu} / \mathrm{hr}-\mathrm{ft}^{2}-{ }^{\circ} \mathrm{F}$ and the condenser a $U$ of about $800 \mathrm{Btu} / \mathrm{hr}-\mathrm{ft}^{2}-{ }^{\circ} \mathrm{F}$. The performance of these heat exchangers is based on experimental data taken at Carnegie-Mellon University and the Oak Ridge National Laboratory.

TRW. has selected titanium over other materials for the tubes based upon its expected long life in a seawater environment. This is a minimum risk approach. Fabrication of titanium into the desired flute configuration has been verified using an upsetting/rolling process. Available data on aluminum in seawater are not conclusive (study by Dr. F. LaQue*). However, aluminum tubes can easily be incorporated in the design if aluminum is qualified for this service.

The design includes a unique open top which simplifies the water box construction, reduces cost, and allows access to the waterside of the tubes for non-interruptive tube cleaning and repair. Incorporation of existing tube cleaning technology by designing a multiple spindle axial drive with brushes and using a low dosage rate of chlorination will result in economic control of fouling factors to approximately $0.0001^{\circ} \mathrm{F}-\mathrm{hr}_{-}-\mathrm{ft}^{2} / \mathrm{Btu}$ in the heat exchangers.

*Report prepared for DOE, paper to be presented at the Energy Technology Conference November 5-9, Houston, Texas. 
Per DOE direction, the heat exchangers are externally mounted, immersed in seawater. This results in a savings of containment hull volume at the expense of a more hostile environment as compared to internal mounting.

\section{System Arrangement}

The power module has been arranged in the ship type reference hull in an arrangement which minimizes containment volume while maintaining service accessibility. This design enables application of existing tools and procedures and precludes the necessity of developing undersea construction and maintenance operations except for the externaliy mounted heat exchangers.

An open trough cold and warm water distribution system has been incorporated to el iminate water hammer effects inherent in closed systems, decouple water side hydraulics, minimize cavitation potential, and eliminate the requirement for expensive water side valves and piping. These open water troughs, coupled with the vertical orientation of the heat exchangers, result in a compact power plant configuration with shirtsleeve environment of major power module components.

\section{Turbine Design}

Based on a study by Elliott Company, subcontractor to TRW, a four stage double flow axtal machine was selected. The turbine efficiency calculated for this design is 89.6 percent versus 85 percent assumed for system sizing. The proposed control system includes variable nozzles (variable stator vanes) for the first stage. This will provide for increased power developed at off-design conditions compared to fixed nozzles.

\section{Ammonia Storage, Conditioning and Recovery}

C. F. Braun \& Co., subcontractor to TRW, designed an ammonia subsystem which provides three functions: storage, conditioning, and recovery. A unique feature of this subsystem is that warm seawater is used in the rectification column reboiler which recovers dry ammonia from the wet heel. This saves energy as compared to using electrical power. Ammonia is recovered from all major components of the power loop whenever possible. An economic analysis shows that this is essential in order to project favorable plant economics. 
The 200 kWe test articles were configured in the OTEC -1 hull as shown conceptually in the perspective, Figure 2-2. The duty of the test article heat exchangers are nominally, $1 / 50$ of the full scale exchangers and the scaling was. performed to maintain the following characteristics of the full scale design:

- Thermal and hydraulic performance

- Materials and corrosion effects

- Biofouling and countermeasures effects

- Fabrication techniques

To achieve these requirements a pie shaped segment of the full size bundle in a cylindrical shell was selected. With this approach major features of the full scale design are maintained as follows:

- Fulli scale tube design

- Tube-to-tubesheet joints

- Tubesheet design

- Support baffle design

- Metering orifices

- Materials of construction

- Open water box design

- Non-condensables collection

- Sea-dynamic effects

Consequently, the TRW heat exchanger test articles satisfy DOE requirement for cost/effectiveness. 


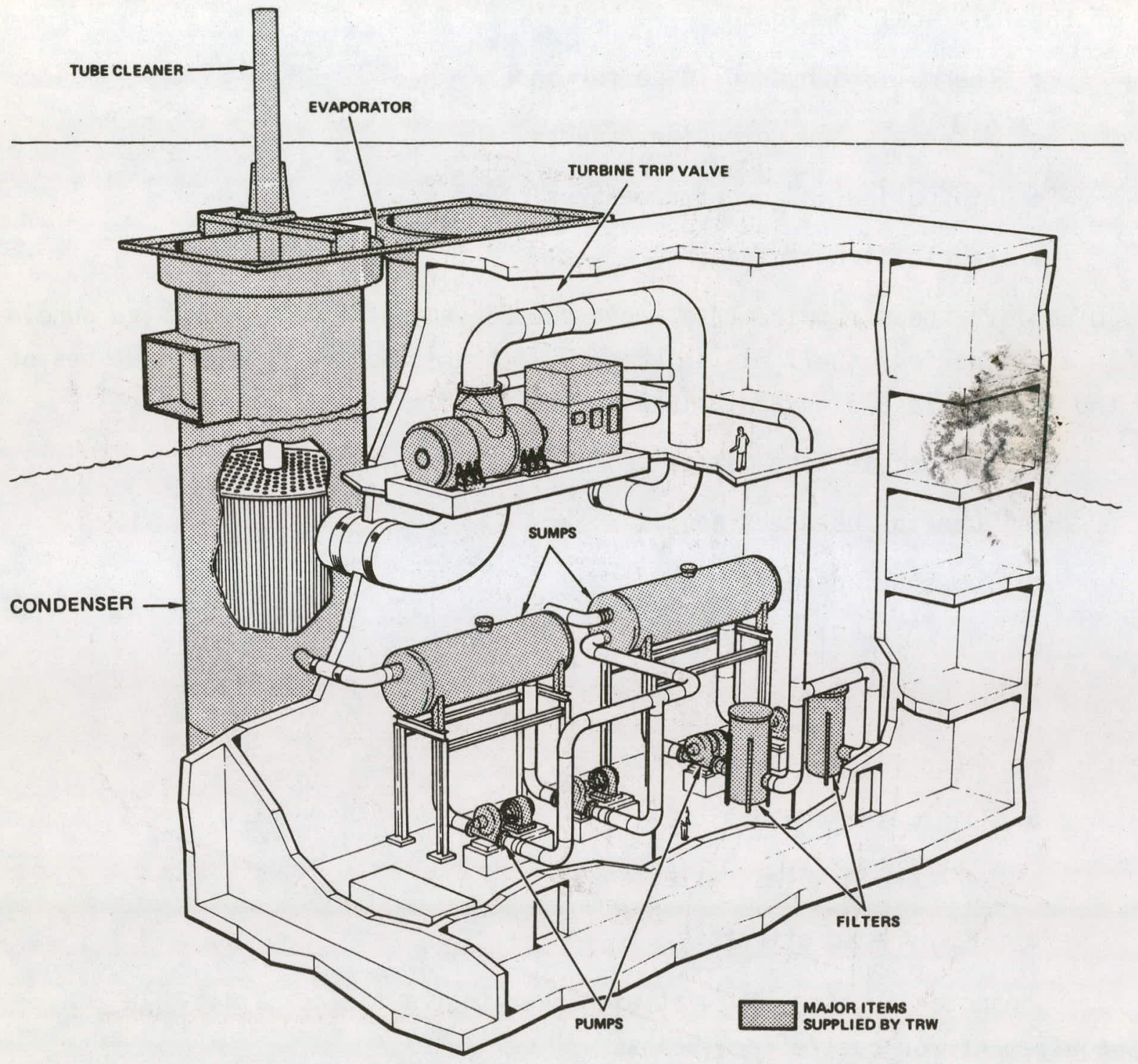

Figure 2-1. Perspective of 10 MWe Power Module 


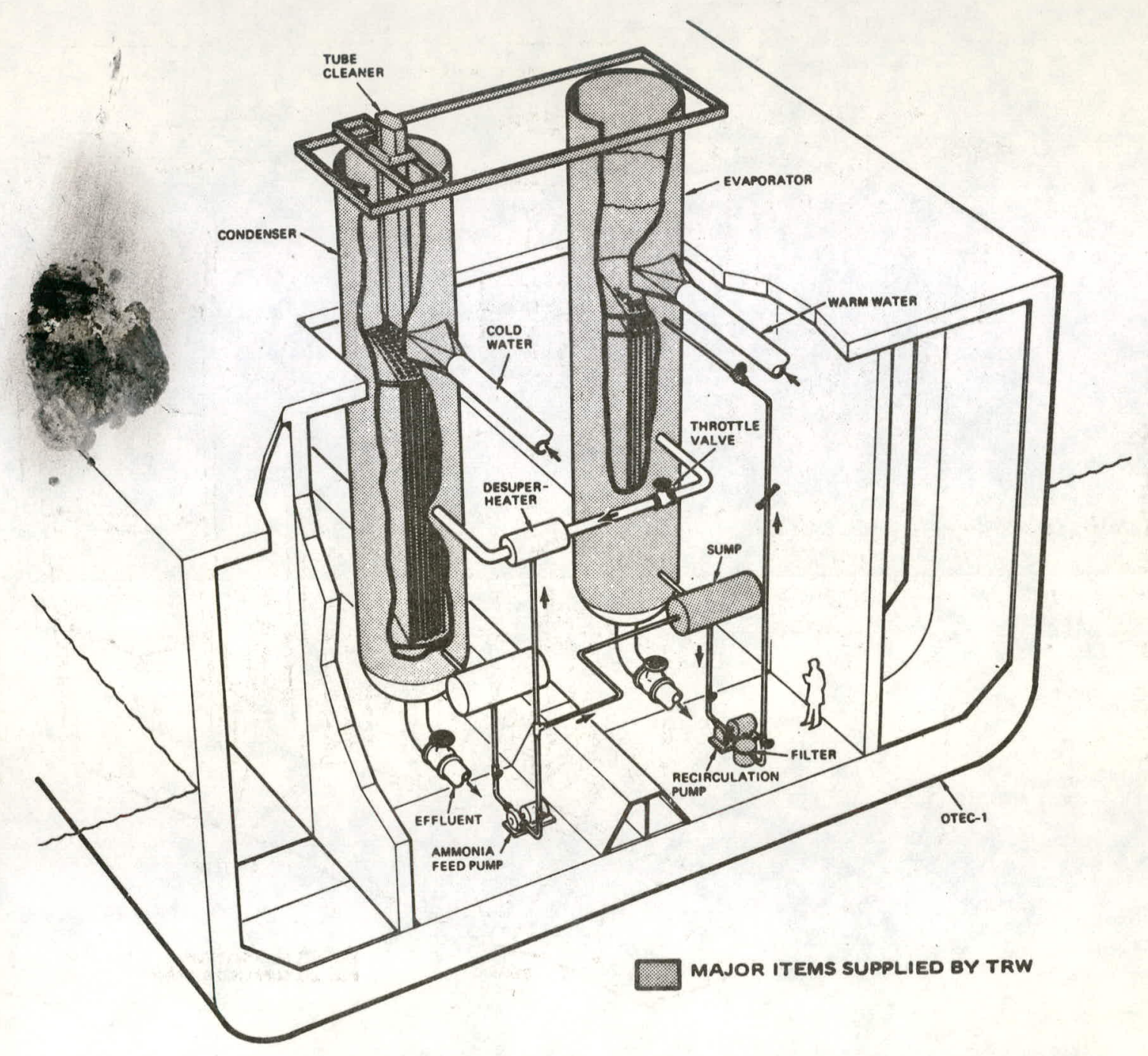

Figure 2-2. Perspective of the 200 kWe Test Articles 


\subsection{MWE POWER MODULE DESIGN}

\subsubsection{Design and Performance Summary}

Performance, design and cost characteristics of the selected baseline 10 MWe power module are described in the following tables with reference to applicable report sections for further descriptions:

\begin{tabular}{lll} 
Table & \multicolumn{1}{c}{ Title } & \multicolumn{1}{c}{ Report Section } \\
& Baseline Power Module & $2.1 .2,2.1 .7,2.1 .8$ \\
$2.1-2$ & Rotating Machinery & 2.7 \\
$2.1-3$ & $\begin{array}{l}\text { Turbine and Pump Condition at Design } \\
\text { Point Operation }\end{array}$ & $2.1 .7,2.1 .8,2.7$ \\
$2.1-4$ & Evaporator Design Data & $2.4 .1,2.4 .3,2.4 .6$ \\
$2.1-5$ & Condenser Design Data & $2.4 .1,2.4 .3,2.4 .6$ \\
$2.1-6$ & Evaporator Thermal Data & $2.1 .7,2.4 .2$ \\
$2.1-7$ & Condenser Thermal Data & $2.1 .7,2.4 .2$ \\
$2.1-8$ & Power Plant Cost Breakdown & 2.3 \\
$2.1-9$ & Evaporator Cost Breakdown & 2.3 \\
$2.1-10$ & Condenser Cost Breakdown & 2.3 \\
$2.1-11$ & Generator Design & $2.1 .8,2.7 .1$ \\
$2.1-12$ & Seawater Pumps Specifications & 2.7 .3
\end{tabular}


Table 2.1-1. Baseline Power Module (10.0 We Nominal)

Gross Power

Net Power

Gross Power/ Net Power

Warm Water Pumping Power

Cold Water Pumping Power

Ammonia Feed Pumping Power

Ammonia Recirculation Pumping Power

Chlorination Power

Mechanical Cleaning Power

Controls, Miscellaneous
$14.03 \mathrm{MWe}$

$10.00 \mathrm{MWe}$

1.40

1.35 MW

$1.78 \mathrm{MWe}$

0.24 MW

0.14 MW

0.05 AWe

$0.01 \mathrm{MWe}$

0.46 MW :

$2.1-2$ 
Table 2.1-2. Rotating Machinery (Per Basel ine Module of 10 MWe)

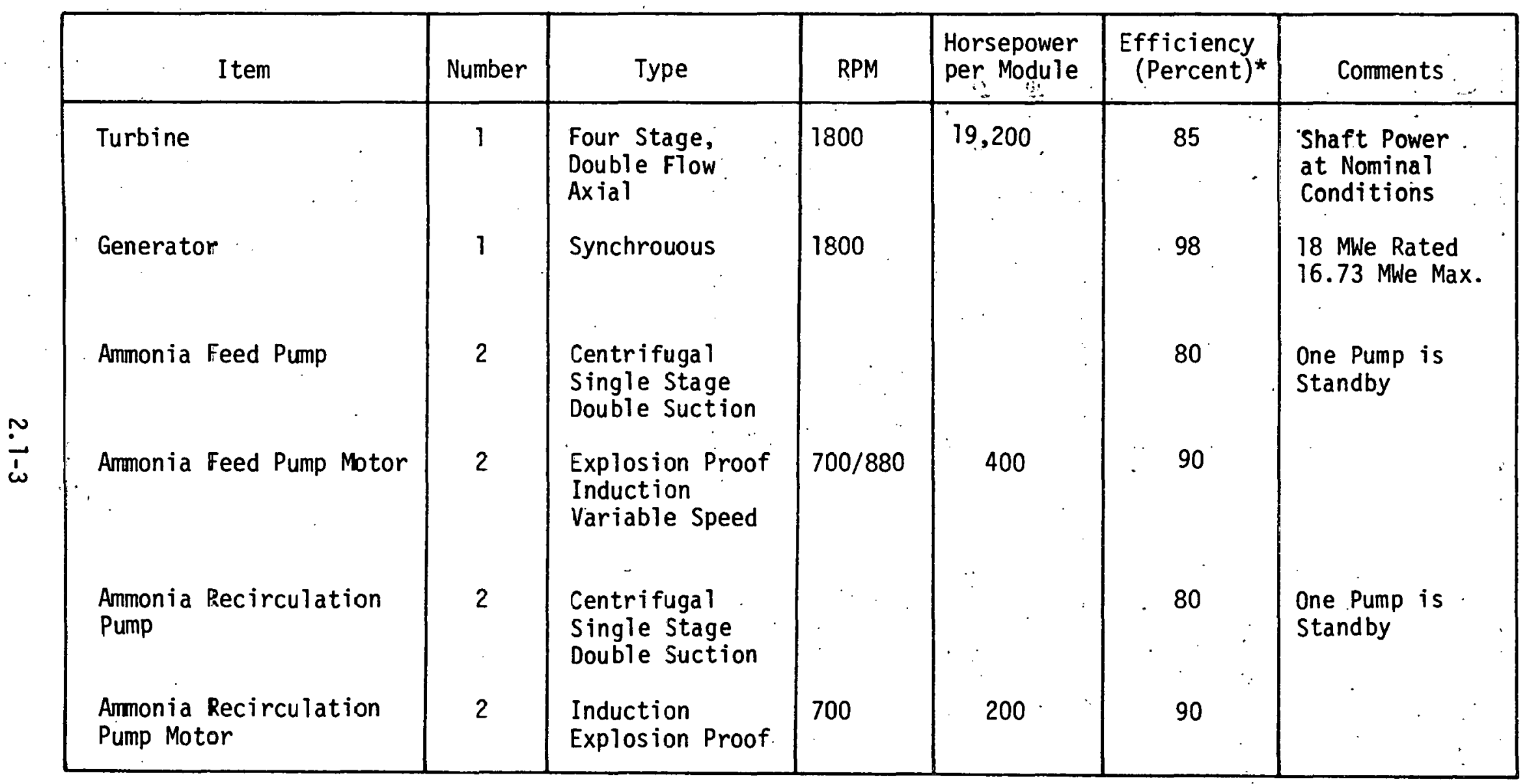

* Assumed for System sizing, actual machinery will be slightly different, see Table 2.1.11 for actual turbine data. 
Table 2.1-3. Turbine and Pump Conditions at Design Point Operation

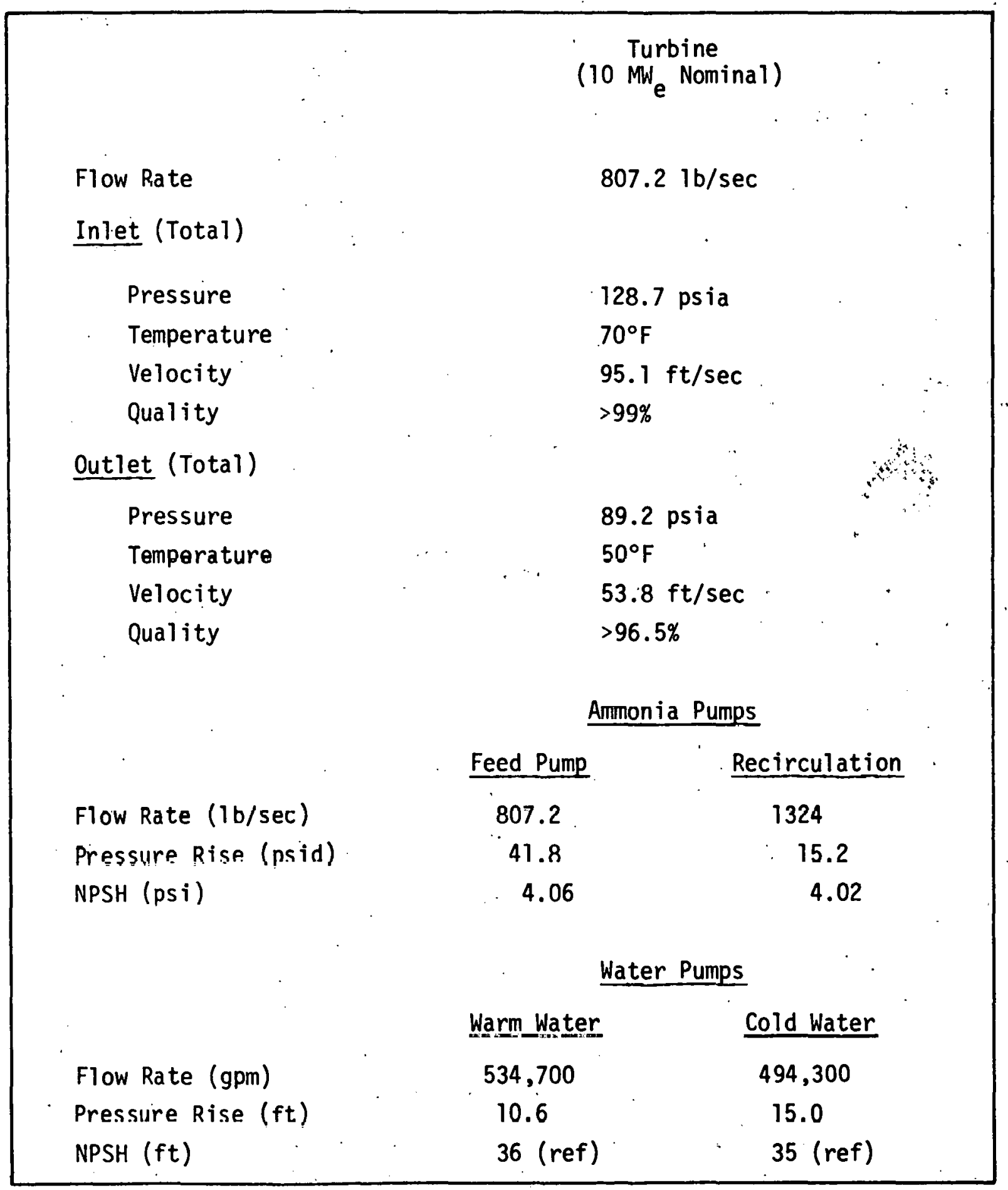


Table 2.1-4. Evaporator Design Data (10 MWe Nominal)

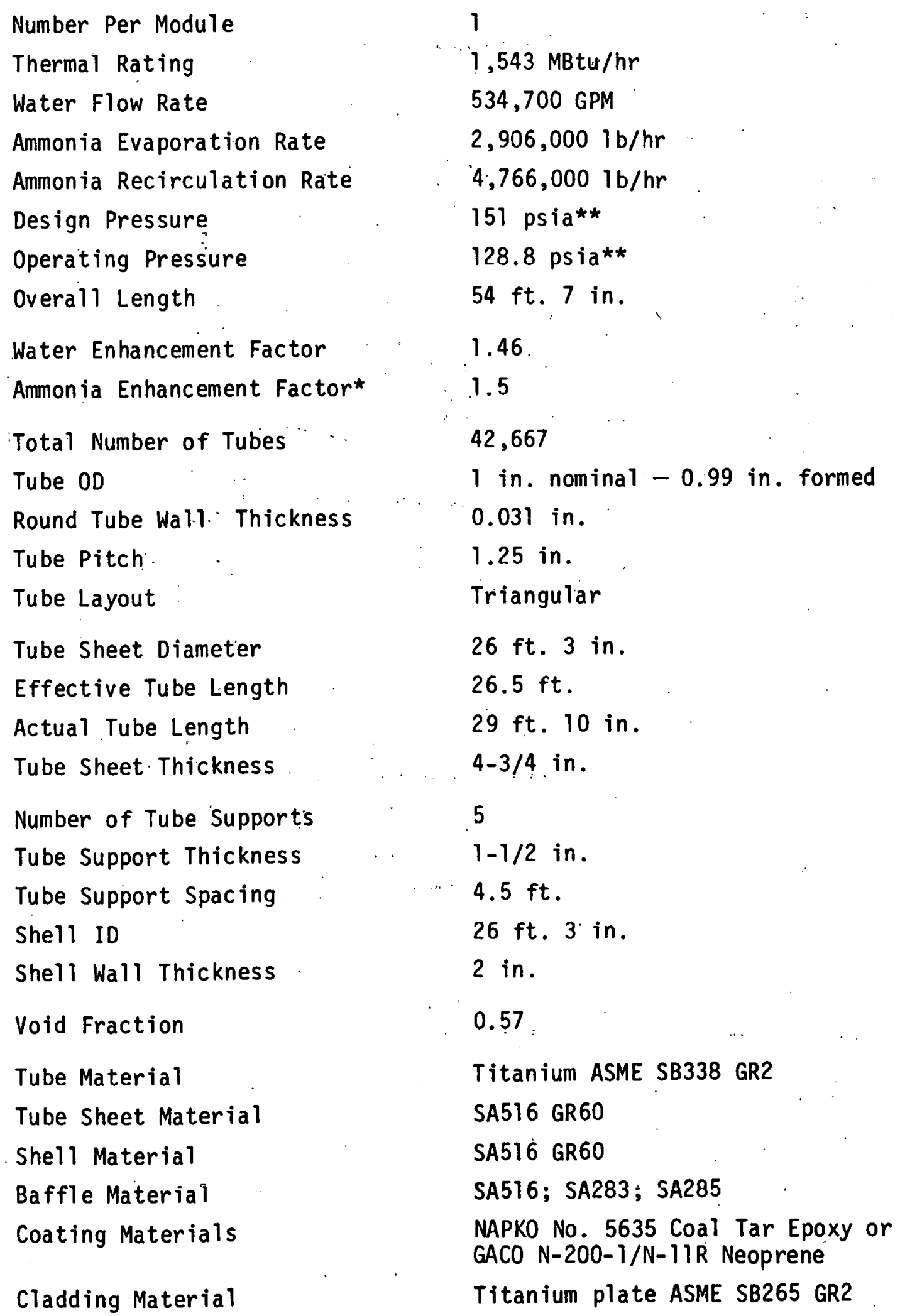

*Area ratios, fluid mechanic effect not included.

**Internal $2.1-5$ 
Table 2.1-5. Condenser Design Data (10 MWe Nominal)

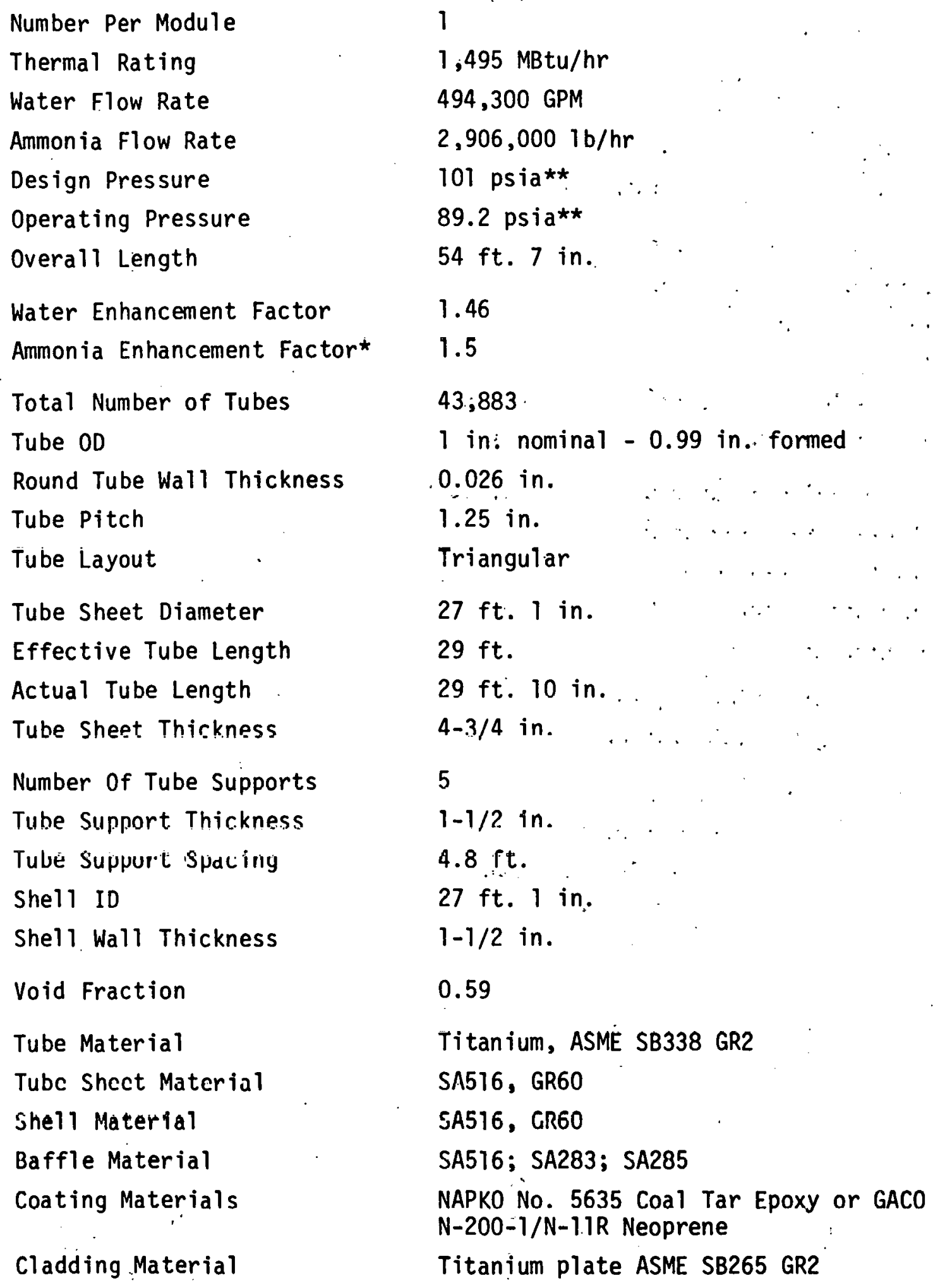

Titanium, ASME SB338 GR2

SA516, GR60

SA516, GR6O

SA516; SA283; SA285

NAPKO No. 5635 Coal Tar Epoxy or GACO $\mathrm{N}-200-1 / \mathrm{N}-1.1 \mathrm{R}$ Neoprene Titanium plate ASME SB265 GR2

*Area ratios, fluid mechanic effect not included **Internal 
Table 2.1-6. Evaporator Thermal Data (10 MWe Nominal)

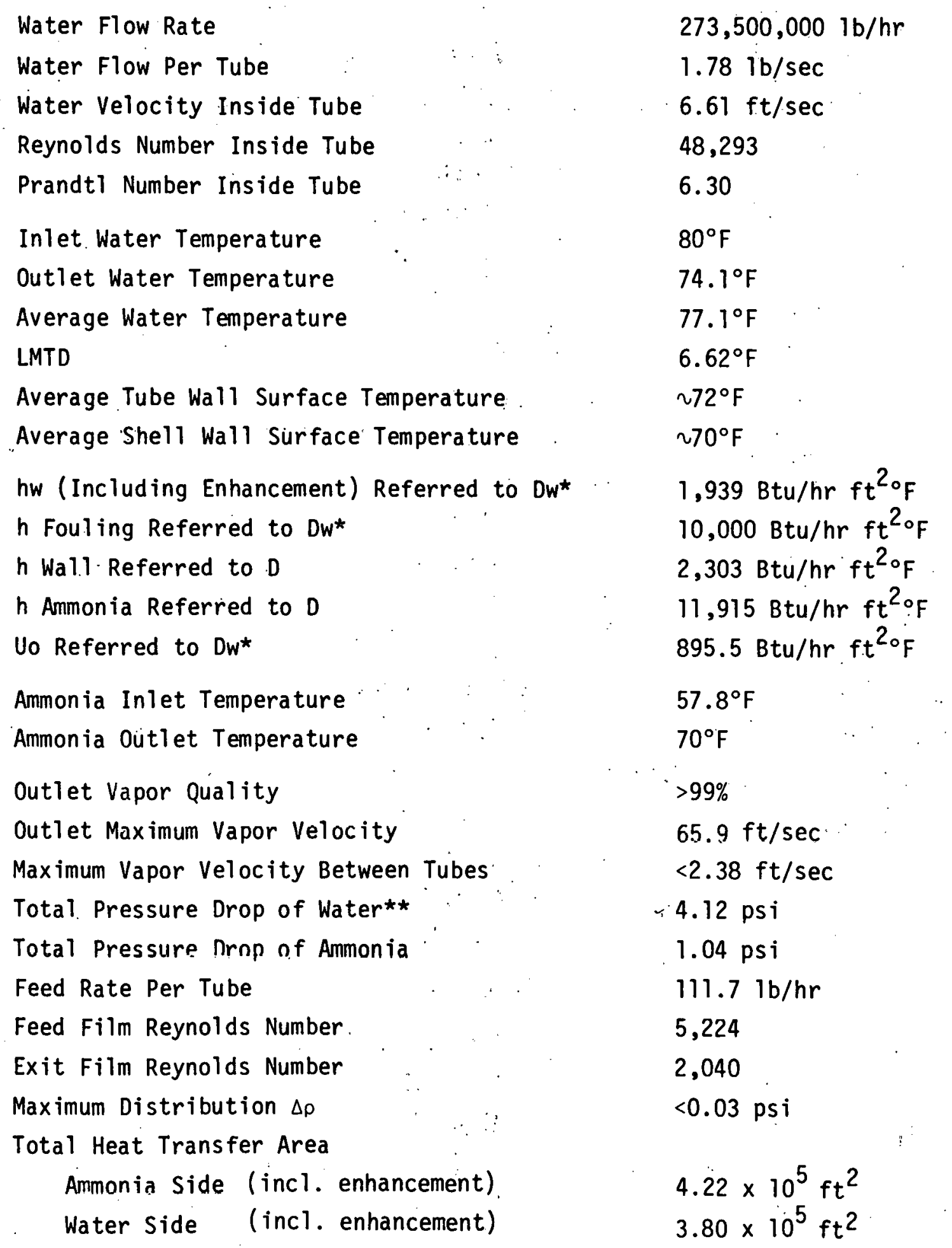

*Dw, water-side diameter corresponding to the cross section area of the water passage through the tube; $D$; the diameter of the external flutes (rill-to-rill diameter).

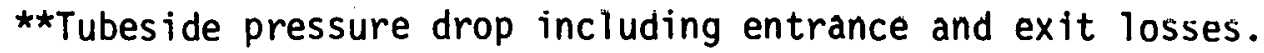


Table 2.1-7. Condenser Thermal Data (10 MWe Nomina1)

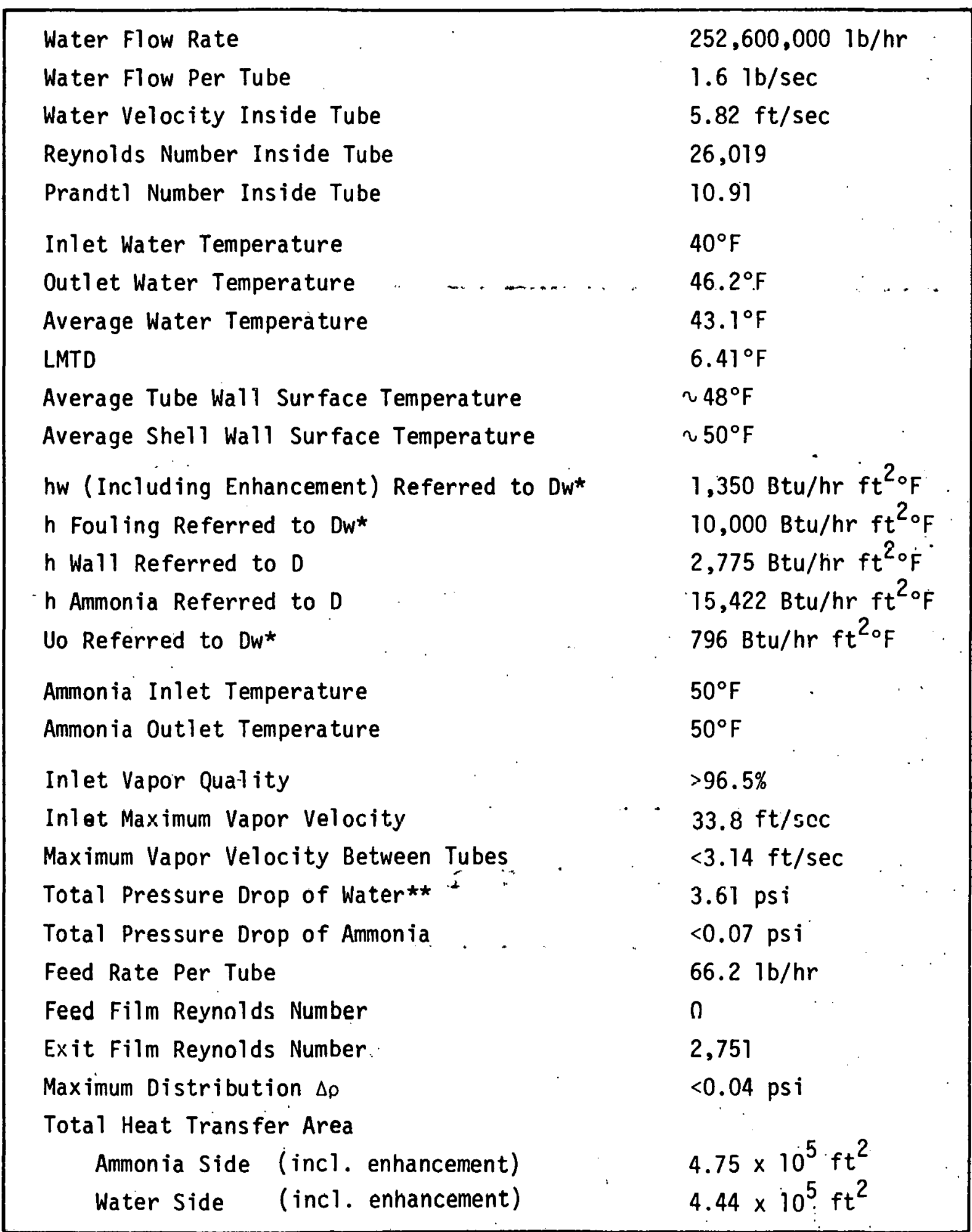

${ }^{*} \mathrm{DW}$, water-side diameter corresponding to the cross section area of the water passage through the tube; $D$, the diameter of the external flutes (rill-to-rill diameter).

**Tubeside pressure drop including entrance and exit losses.

$$
\text { 2.1-8 }
$$


Table 2.1-8. Power Plant Cost Breakdown Summary*

\begin{tabular}{|c|c|c|c|c|}
\hline Item & $\begin{array}{c}\text { Prototype } \\
(\$ / \mathrm{klle})^{\prime} \\
(10 \mathrm{MWe}) \\
\end{array}$ & $\begin{array}{c}\text { 1s.t Production } \\
\text { (\$/kWe }) \\
(10 \mathrm{MWe})\end{array}$ & $\begin{array}{l}8 \text { th } P l a n t-10 \mathrm{MWe} \\
(\$ / \mathrm{kWe})\end{array}$ & 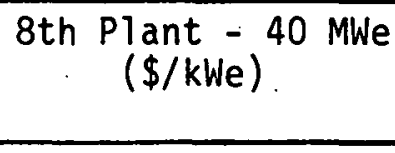 \\
\hline Evaporator & 890 & 763 & 565 & 505 \\
\hline Condenser & 871 & 744 & 546 & 483 \\
\hline Turbine/Generatcr & 307 & 226 & 168 & 153 \\
\hline Ammonia Feed Pumps & 25 & 23 & 13 & 13 \\
\hline Ammonia Recirculation Pumps & 28 & 26 & 15 & 15 \\
\hline Ammonia System Piping & 119 & 108 & 75 & 72 \\
\hline Ammonia System l'alves & 111 & 100 & 67 & 63 \\
\hline Control Systems & 64 & 59 & 46 & 44 \\
\hline Chlorination Systems & 21 & 19 & 12 & 11 \\
\hline Cleaning System,Leak Detector & 190 & 171 & 34 & 32 \\
\hline Ammoria Support Systems & 208 & 112 & 79 & 72 \\
\hline Electrical Equipment & 39 & 35 & 25 & 24 \\
\hline TOTALS & 2873 & 2386 & 1645 & 1487 \\
\hline
\end{tabular}

(1). Cost tables and details in Section 2.3.2

(2) July 1978 installed costs, New Orleans, La. 
Tatile 2.1 1-9. Evaporator Cost Breakdown

(July' 1978 costs FOB St. Louis, Mo.)

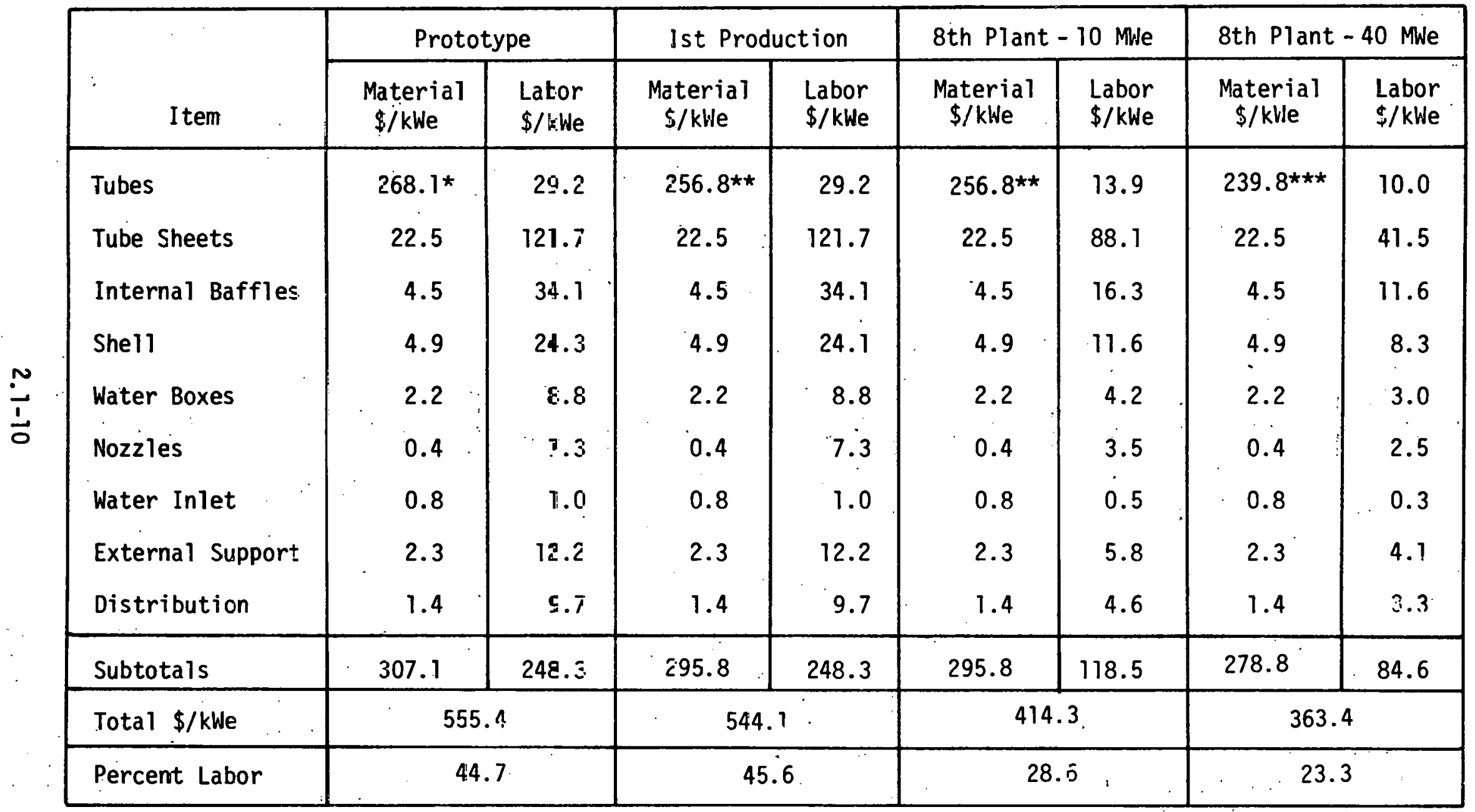

*Tubes at $\$ 1.44 / \mathrm{ft}$ basic plus $\$ 0.25 / \mathrm{ft}$ enhancement

**Tubes at $\$ 1.44 / \mathrm{ft}$ basic plus $\$ 0.65 \mathrm{jt}$ enhencement

$\star \star \star T u b e s$ at $\$ 1.44 / \mathrm{ft}$ basic plus $\$ 0.50$ ift enhencement 
Table 2.1-10. Condenser Cost Breakdown

(July 1978 Costs FOB St. Louis, Mo.)

\begin{tabular}{|c|c|c|c|c|c|c|c|c|}
\hline \multirow[b]{2}{*}{ Item } & \multicolumn{2}{|c|}{ Prototype } & \multicolumn{2}{|c|}{ Ist Production } & \multicolumn{2}{|c|}{ 8th Plant-10 MWe } & \multicolumn{2}{|c|}{ 8th Plane - 40 MWe } \\
\hline & $\begin{array}{l}\text { Material } \\
\$ / \mathrm{kWe}\end{array}$ & $\begin{array}{l}\text { Labor } \\
\$ / \mathrm{kWe}\end{array}$ & $\begin{array}{l}\text { Material } \\
\$ / \mathrm{kWe}\end{array}$ & $\begin{array}{l}\text { Labor } \\
\$ / \mathrm{kWe}\end{array}$ & $\begin{array}{l}\text { Material } \\
\$ / \mathrm{kWe}\end{array}$ & $\begin{array}{l}\text { Labor } \\
\$ / \mathrm{kWe}\end{array}$ & $\begin{array}{l}\text { Material } \\
\$ / \mathrm{kWe}\end{array}$ & $\begin{array}{l}\text { Labor } \\
\$ / \mathrm{kWe}\end{array}$ \\
\hline Tubes & $249.9 *$ & 29.2 & $237.1 * \star$ & 29.2 & $237.1 * \star$ & 13.9 & $218.0 \star \star \star$ & 10.0 \\
\hline Tube Sheets & 26.2 & 129.0 & 26.2 & $129.0^{\circ}$ & 26.2 & 61.6 & 26.2 & 44.0 \\
\hline Shell & 5.0 & 24.3 & 5.0 & 24.3 & 5.0 & 11.6 & 5.0 & 8.3 \\
\hline Water Boxes & 2.3 & 8.8 & 2.3 & 8.8 & 2.3 & 4.2 & 2.3 & 3.0 \\
\hline Nozzles & 0.4 & 7.3 & 0.4 & 7.3 & 0.4 & 3.5 & 0.4 & 2.5 \\
\hline Bustle & - & 4.9 & - & 4.9 & - & 2.4 & - & 1.6 \\
\hline Subtotals & 291.3 & 250.8 & 278.5 & 250.8 & 278.5 & 119.8 & 259.4 & 85.4 \\
\hline Total \$/kwie & \multicolumn{2}{|c|}{542.1} & \multicolumn{2}{|c|}{529.3} & \multicolumn{2}{|c|}{398.3} & \multicolumn{2}{|c|}{344.8} \\
\hline Percent Labor & \multicolumn{2}{|c|}{46.3} & \multicolumn{2}{|c|}{47.4} & \multicolumn{2}{|c|}{30.1} & \multicolumn{2}{|c|}{24.8} \\
\hline
\end{tabular}

*Tubes at $\$ 1.18 / \mathrm{ft}$ basic pius $\$ 0.75 / \mathrm{ft}$ enhancement

$\star \star$ Tubes at $\$ 1.18 / \mathrm{ft}$ basic plus $\$ 0.65 / \mathrm{ft}$ enhancement

$\star \star \star$ Tubes at $\$ 1.18 / \mathrm{ft}$ basic plus $\$ 0.50 / \mathrm{ft}$ enhancement 
Table 2.1-11. Generator Design for 10 MWe Nominal

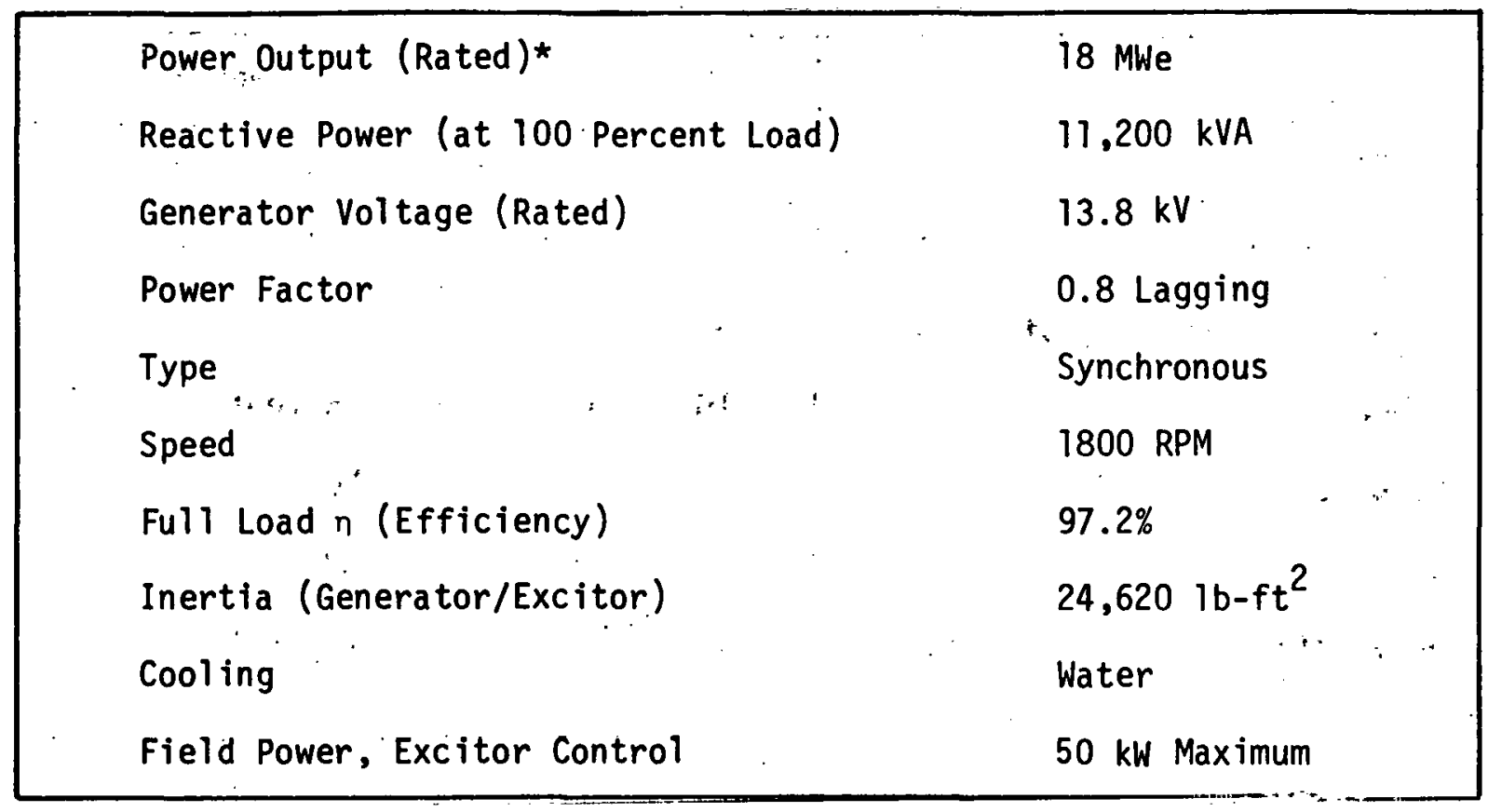

*Maximum Demand $=16.73$ MWe Gross Power at $84^{\circ} \mathrm{F}$ Warm Seawater Temperature. 
Table 2.1-12. Seawater Pumps Specification

(10 MWe Power Module)

\begin{tabular}{|l|l|l|}
\hline & Evaporator & \multicolumn{1}{c|}{ Condenser } \\
\hline Number per Module . & One & One \\
Flow Rate/Pump & $534,700 \mathrm{gpm}$ & $494,300 \mathrm{gpm}$ \\
Overall n Including Diffusers & $80.4 \%$ & $80.4 \%$ \\
Operating Head & $10.6 \mathrm{feet}$ & 15 feet \\
Flow Control & None & None \\
Shutoff Valves & No & No \\
Drive Motor & $1,680 \mathrm{BHP}$ & $2,210 \mathrm{BHP}$ \\
& $(1,350 \mathrm{~kW})$ & $(1,780 \mathrm{~kW})$ \\
Motor Voltage & $4,160 . \mathrm{V}$ & $4,160 \mathrm{~V}$ \\
$\quad$ & $3 \phi$ & $3 \phi$ \\
Motor $n$ & 60 hertz & 60 hertz \\
MTBF (Allocated) & 0.8 & 0.8 \\
MTTR (Allocated) & 720 days & 720 days \\
\hline
\end{tabular}

Note: Seawater pumps to be provided by ship systems. Tabular information was utilized in power loop system optimization. 


\subsubsection{Process Flow Diagrams and Discussion}

The preliminary design was initiated by developing process flow diagrams for the 10 MWe power module. These were developed for three cases of operating conditions:

- "Maximum Flow Conditions," warm water temperature $84^{\circ} \mathrm{F}$

- "Nominal Flow Conditions," warm water temperature $80^{\circ} \mathrm{F}$

- "Minimum Flow Conditionș," warm water temperature $76^{\circ} \mathrm{F}$

These conditions correspond to "summer," "average," and "winter" operating conditions assuming that the annual warm water temperature variation is $80 \pm 4^{\circ} \mathrm{F}$. For the purpose of design, TRW assumed a fixed cold water temperature of $40^{\circ} \mathrm{F}$. The sensitivities to these assumptions over ranges as specified by $D O E$ are investigated in Section 2.2.4.

The design optimization leading: to the design defined in the flow diagram for the nominal (design) case is described in Section 2.1.7. An updated version (see Appendix A1) of the OTEC design program was used. A printout of the final program results is shown in Table 2.1-13. The maximum and minimum flow conditions were derived by a modified version of the design program making certain assumptions about the evaporator and condenser state conditions. These assumptions are discussed in Section 2.1.8. Results are shown in Tables 2.1-14 and 2.1-15. The computer results represent the initial design sperification.

Several minor revisions are reflected in the flow diagrams, Figures $2.1-1,2.1-2$, and 2.1-3. These diagrams show state conditions and several important design characteristics or assumptions. The flow diagrams formed the basis for the system design.

TRW's detailed off-design computer program, which became operational towards the end of the preliminary design phase, is described in Appendix A2. Rosults obtaincd with this model (discussed in Section 2.2.4) confirm the results of the approximate analysis leading to the maximum and minimum flow conditions defined in Figures 2.1-2 and 2.1-3, althouqh the ammonia flow variations predicted by the off-design program is smaller, $\pm 8 \%$ versus $\pm 10 \%$. This can be explained on the basis of a more detailed turbine model, see Section 2.2.4. 
Table 2.1-13. OTEC Major Design Characteristics Program Outputs

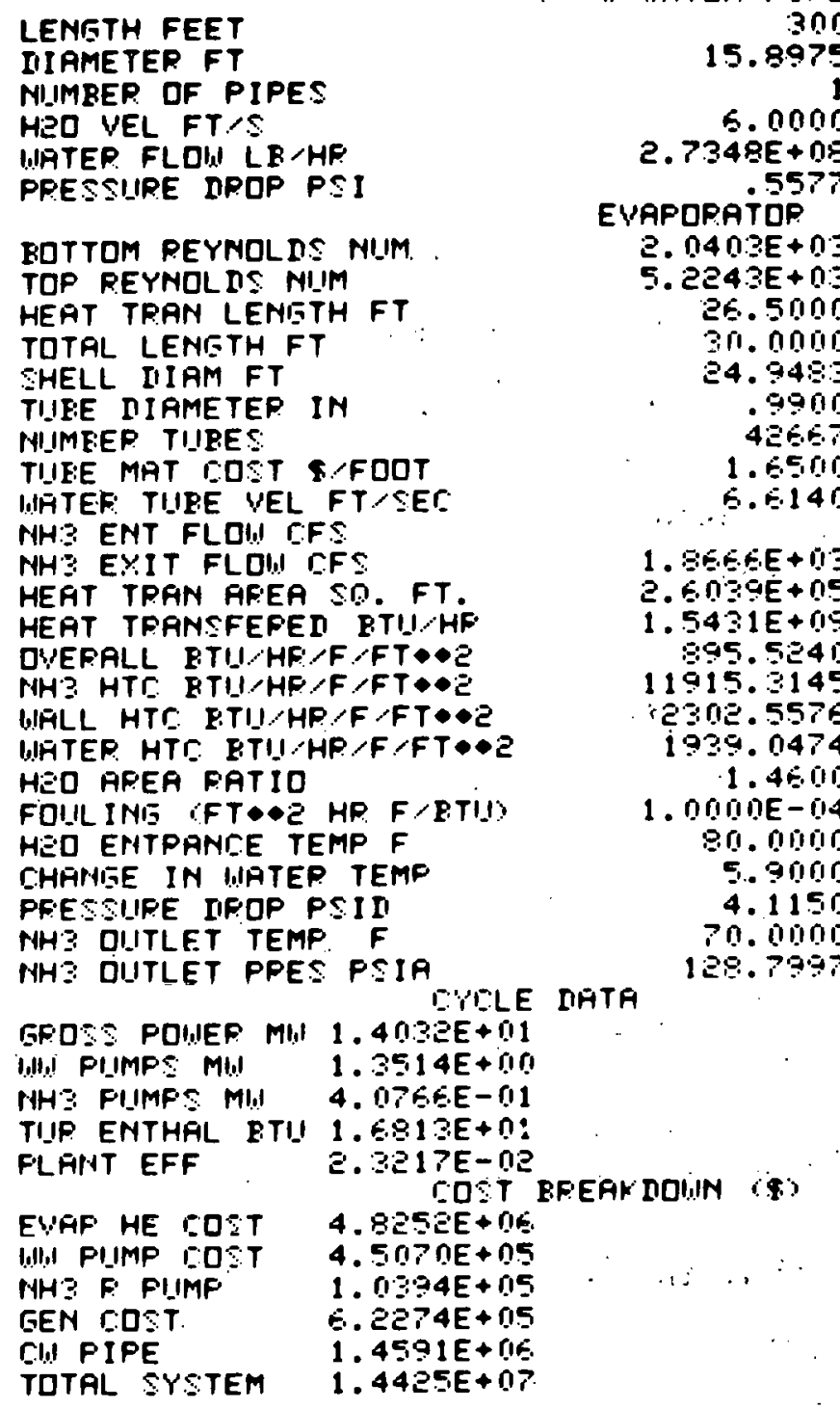

$$
\begin{aligned}
& \text { CASE NO } 17 \text { (NOMINAL FLOW) } \\
& \begin{array}{l}
\text { CONDENSEP } \\
2.7510 E+03
\end{array} \\
& \begin{array}{r}
2.7510 E+03 \\
0.00
\end{array} \\
& \text { 29. } 0000 \\
& \text { 30. nחत } \\
& \text { 25. } 2425 \\
& \text {. 9un } \\
& 43678 \\
& \text { 5. } 8225 \\
& \text { 2. } 5943 E+13 \\
& \text { 2. } 0591 E+n 1 \\
& \text { 2. } 9491 E+05 \\
& \text { 1. } 4950 E+119 \\
& 154 \sum i .6060 \\
& \text { 2774. } 56.93 \\
& 1349.8942 \\
& \text { 1. } 4600
\end{aligned}
$$

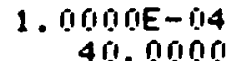

$$
\begin{aligned}
& \text { E. enn! } \\
& \text {. E. E. } \\
& 50.0000
\end{aligned}
$$

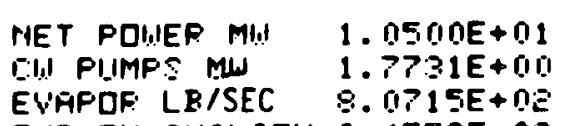
TIJP EX DIIALITY $2.4553 \mathrm{E}-0 \mathrm{C}$

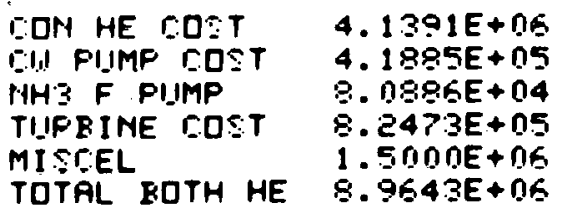


Table 2.1-14. Maximum Flow

$$
\begin{gathered}
\text { CASE ND } 17 \\
\text { DFF DESIGH WIATER TEMP } 84.0
\end{gathered}
$$

LENETH FEET
IIARETER FT

NUMEER DF FIPES

HED WEL FT

MIATER FLDU LB HF:

FRESSUIFE DFOF FSI

FOTTOM FEYNDL DS HIM

TOF REYNOLIS NIIM

HEAT TRAN LENETH FT

TOTAL LENETH FT

SHELL IIIAM FT

TUEE IIIAMETER IN

MIMEEF TUEES

WIATEF: TUEE YEL FT,SEL:

HHS EHT FLOW EFS

NHS EXIT FLDUN CFS

HEAT TRAIT RFEA SQ. FT. HEAT TRAIYSEFED BTU HR

DYERALL BTU HF: $\angle F$ FT $\bullet: 2$

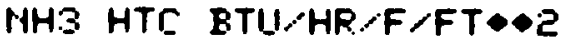

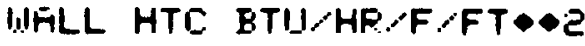

WHTER HTR ETII HR F FT PQE

HED RF:EA FETTID

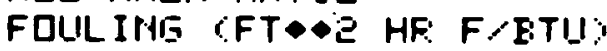

HED ENTRAHEE TEMF $F$.

EHANISE IH WATER TEMP

FRESSIJFE DRDP PSID

HHS DIITLET TEMP $F$

HHS DUTLET FRES PSIA

EYCLE DATA

GROSS PQLER MWI $1.6727 E+01$

1,11] PIJMPS MU $1.3513 E+00$

HHS FUIAFS MW $4.7576 E-111$

TUFEIME BTULLB $1.810 B E+01$

PLANT EFF. 2.625BE-02
I.) WATER PIPE

$$
\therefore 15.3975
$$

6.00100

$2.7334 \mathrm{E}+108$

$\therefore$. 2577

EVAFDEATOP.

$1.9701 E+0.3$

$5.495 .5 E+103$

26.5000

30.0100

24.9485

9900

42567

6.6138

$1.9636 \mathrm{E}+03$

$2.6039 \mathrm{EE}+10.5$

$1.7057 \mathrm{~F}+09$

902.7970

11630.3446

2302.5575

1981.2208

1.4600

1. OMUNE-014

84. 0nחत

6.5237

4.1149

73.0000

135.5971
C MATER FIFE

e900.0000

15.2524

6.0000

2.5อ61E+ 0

EDHIIENSER

3 . $0450.0 E+03$

$$
0.0
$$

29. nogng

30.9000

25.2421 .

.990!

43078

5 . Bละล

2. $8123 \mathrm{E}+0.3$

2. $2931 E+01$

2. $9480 E+0.5$

...1 . E.484E+ 99

795.8492

14897.1483

2774.5603

1353.4703

1.4600

1 . OIOUE-014

40.0000

6.8364

3.6098

$51.0 \mathrm{E} 4 \mathrm{C}$

90.9554

NET POUER MU $1.3127 E+11$

CW PIJMPS MW $1.7530 \mathrm{~B}+00$

EVRFUR LB $/ S E C$ \$. $9335 E+02$

TIIR EX QIIRLITY $9.7349 E-01$

TIIRBINE EFF 8.4 OIOE- 1 
Table 2.1-15. Minimum Flow

CASE HO
DFF DESIGH WATER TEMP 76.0

\begin{abstract}
LEHETH FEET
DIAMETER $F T$

NUMBER DF PIPES

HED VEL FT $/ S$

WATER FLDW LB/HR

PRESSURE DRDP PSI

BOTTOM REYNDLDS NLM

TOP REYNOLDS NUM

HEAT TRAN LENGTH FT

TOTAL LENGTH FT.

SHELL IIAM FT

TURE IIAMETER IN

NIJMBER TIIBES

WATER TUEE VEL FT/SEC

NH3 ENT FLDU CFS

NH3 EXIT FLDIN CES

HERT TRFN ARER SQ. FT.

HEAT TRANSFERED ETU/HR

QVERALL BTU/HR/F/FT $\bullet \bar{C}$

NH3 HTC BTU/HR/F/FT••?

WJALL HTC BTU/HR/F/FT••E

WATER HTC BTUI HR/F,FT $\bullet \odot$

HED AREA RATID

FOULINIS CFT••Z HR F/BTU)

HED ENTRAMLE TEMF $F$

CHANGE IN WATER TEMP

FRESSUPE DROP PSID

NH3 DIJTLET TEMP $F$

NH3 DLITLET PRES PSIA
\end{abstract}

CYCLE IATA

GROSS PDLER MWJ 1.1257E+01

WWJ PUMPS MW $1.3513 E+00$

NH3 PUMPS MUI $3.4492 E-01$

TURBINE BTU/LB $1.5089 E+01$

PLANT EFF $1.9240 E-02$
W WATER PIFE 300 15.8975

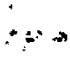

6.0000

$2.7360 E+018$ .5577

EVAFORATUR

ट. $1144 E+0: 3$

$4.961 .5 E+03$

26.5000

30.0000

24.9485

.9900

426.5

$\therefore 6.6138$

$1.7564 E+0.3$

$2.6039 E+0.5$

1. $3810 E+09$ 887.3747

12213.5285

2302.5576

1894.0868

1.4500

$1.0000 E-04$

76.0000

. 5.2791

4.1149

67.0000

$122 \cdot 16.50$ c. MIATER PIFE: 2900.0000

15.2524

$2.526 .3 E+0.9$

3.0504

CDNDENSER.

$2.459 .3 E+0.3$

29.0000

30.0000

25.2421

.900

43678

5 . $3 \mathrm{EZ2}$

$2.3595 E+03$

$1.8471 E+01$

$2.9480 E+0.5$

$1 \cdot 3424 E+09$

795.1661

15973.8148

2774.56013

1346.3273

1.4500

1. $0000 E-04$.

40.0000

5.5674

3.6098

48.9822

87.4650

NET PQUER MU $7.7876 E+00$

CU PLIMPS MUI 1.7730 D +00

EVAPOP LE/SEC $7.2151 E+02$

TIJR EX QIJALITY $9.7818 E-01$

TILRBINE EFF $8.4000 E-01$ 


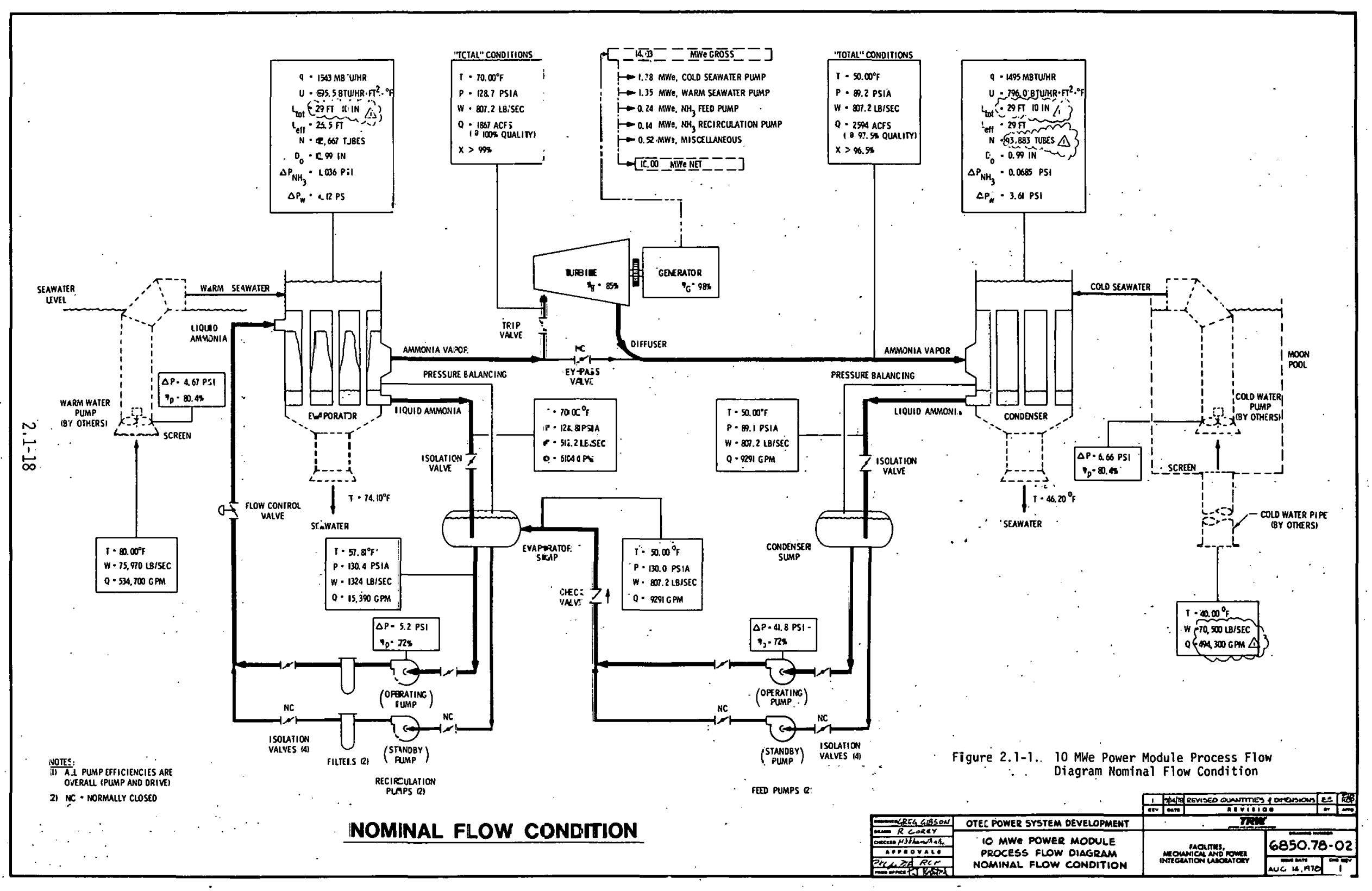




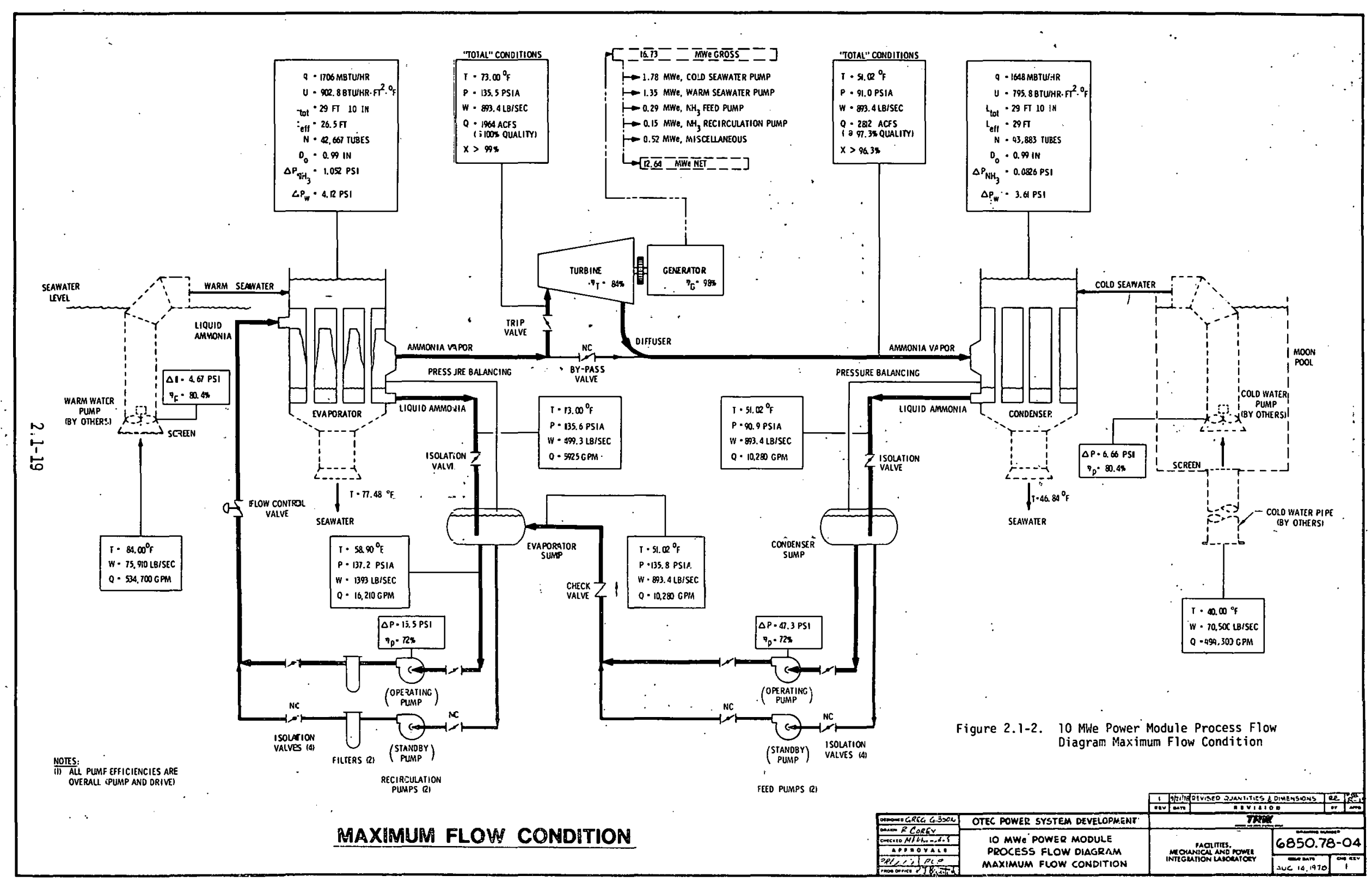




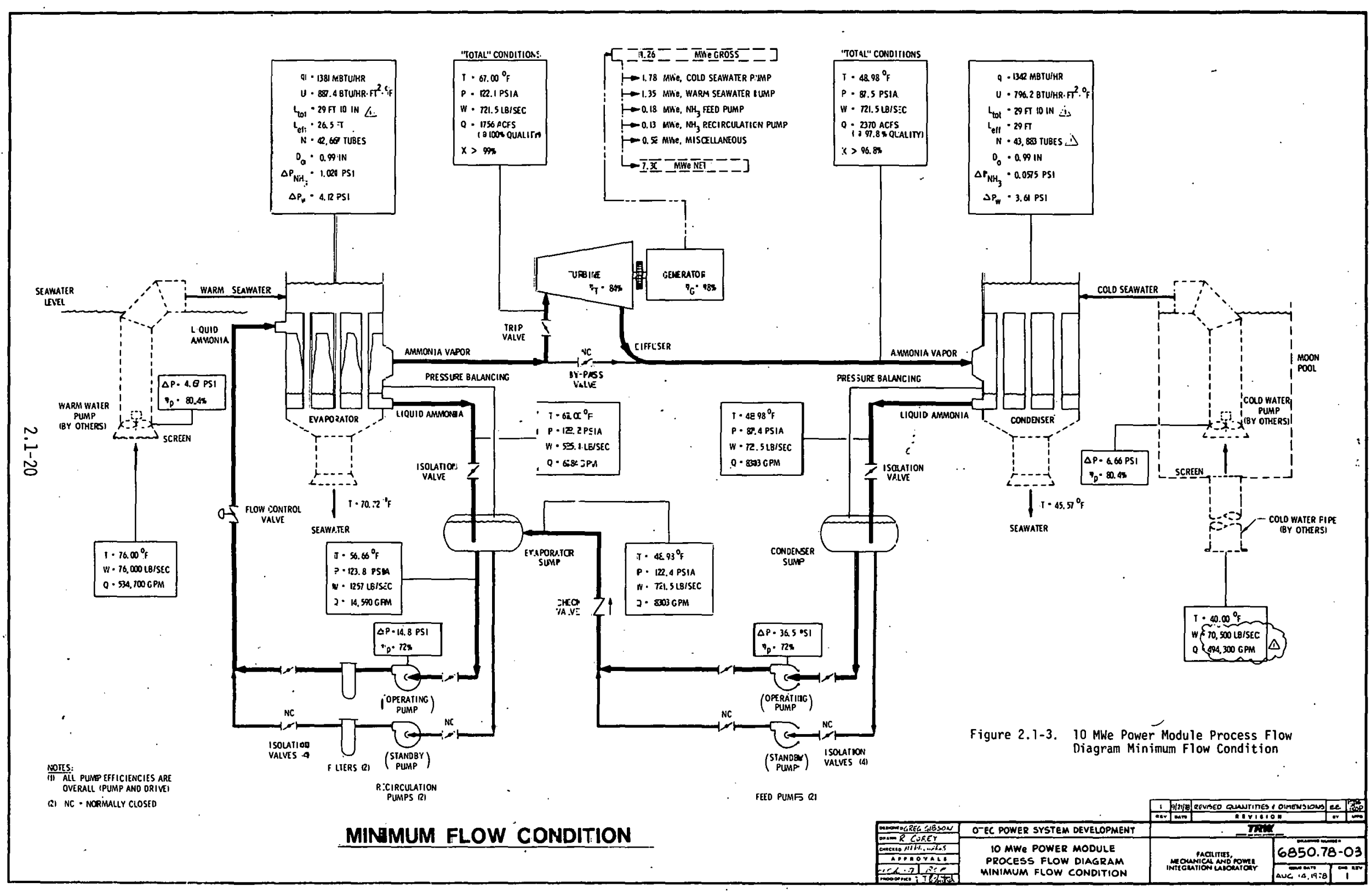


Note that the preliminary design presented in this report is based on estimates of performance characteristics of equipment for similar service. As design data become available from the Phase II bid evaluation, design drawings and specifications will be updated to reflect selected equipment.

A discussion of the power module equipment and functions is included in Section 2.1.3.

\subsubsection{Piping and Instrumentation Diagram and Discussion}

The piping and instrumentation drawing. (P\&ID), Figure 2.1-4, shows the necessary interconnections, piping, component items and instrumentation points for the Power Loop Ammonia System. The ammonia support system P\&ID and description are in Section 2.8.2 and the nitrogen support system P\&ID and description in Section 2.8.3. Figure 2.1-4 1ists the nominal ratings and capacities of the major system components including the turbine generator and the evaporator and condenser. The components are further described in the item list in Appendix E. Interfaces with the ship's hull, seawater pumps and other supporting subsystem such as, the ammonia supply, nitrogen supply, and vent and recovery systems are indicated on this drawing. The following power loop description is keyed to Figure 2.1-4, item list (Table 2.1-16) and a line list (Table 2.1-17). See Appendix $N$ for piping specifications, which convey additional information.

Ammonia Fill and Make-Up. Ammonia is admitted under pressure to the power loop through fill valves, $V-6, V-7$ and $V-8$ to a predetermined level in Sumps $T-1$ and $T-2$. The system is then purged of nitrogen and other residual inerts by'opening vent valves $V-17, V-18$, and $V-19$ under controlled venting procedures (see start-up procedure). Ammonia make-up during operation is through valve $V-6$, controlled by a liquid level instrument sensing level in the condenser sump, T-2.

Ammonia Feed and Recirculation Loops. Ammonia is pumped from the condenser sump $T-2$ to the evaporator sump $T=1$ by pump $P-5$ ( $P-6$ is an inplace standby and is controlled to come on automatically in the event of failure of $P-5) . P-5$ and $P-6$ are variable speed pumps and are controlled by a liquid level sensor in the evaporator sump, $T-1$. The recirculation pump, $P=3$, pumps ammonia from the evaporator condenser through a filter, 


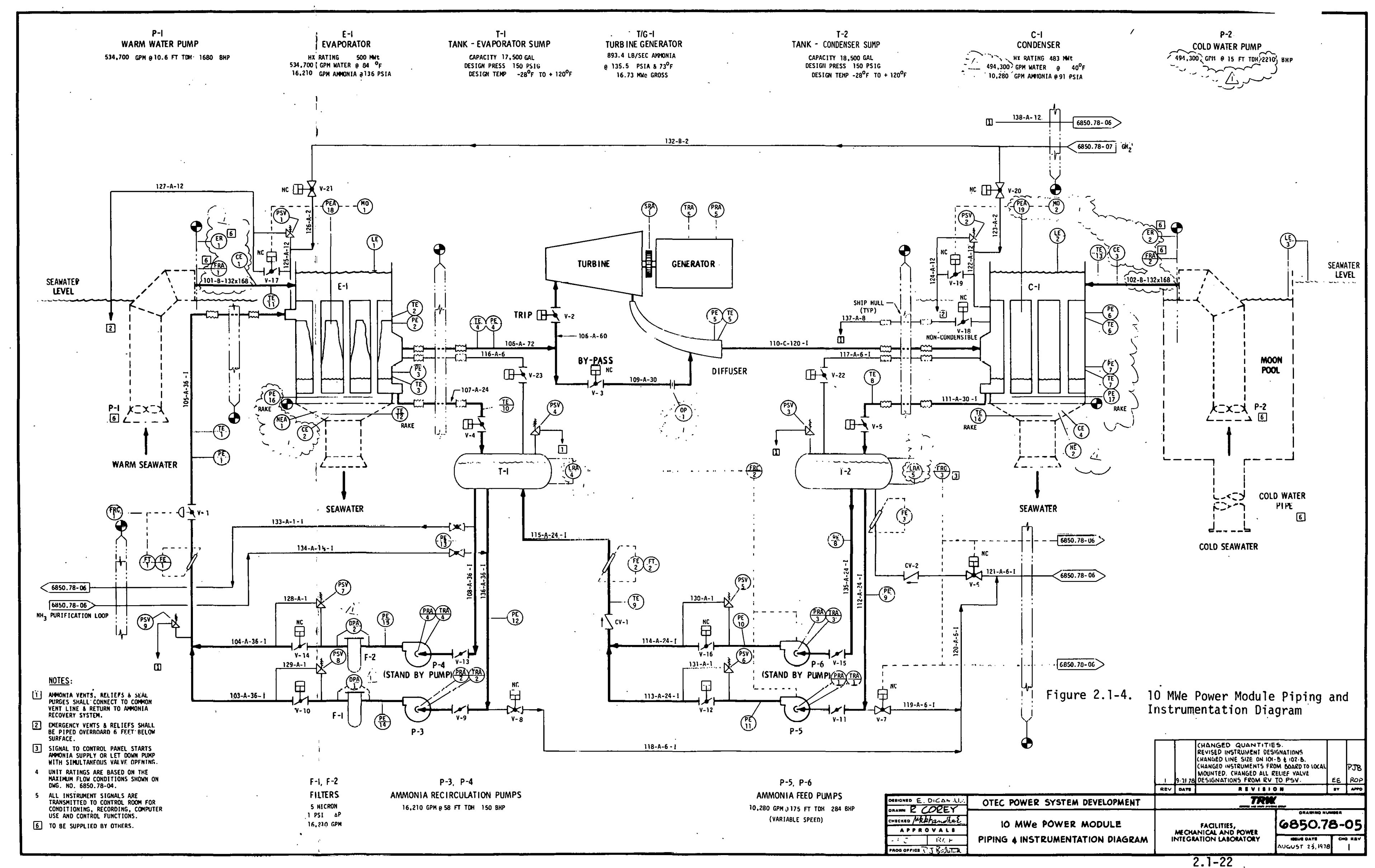


Table 2.1-16. 10 MWe Power Loop Ammonia Subsýstem Item List

\begin{tabular}{|c|c|c|c|c|c|c|}
\hline $\begin{array}{l}\text { Reference } \\
\text { Designator }\end{array}$ & Description & $\begin{array}{l}\text { Specification or } \\
\text { Drawing No. }\end{array}$ & $\begin{array}{l}\text { Manufacturing and } \\
\text { Part No. }\end{array}$ & $\begin{array}{c}\text { Est } \\
W t / L b\end{array}$ & Dimensions & $\begin{array}{l}\text { Supplementary } \\
\text { Information }\end{array}$ \\
\hline$V-1$ & Flow Control Valve & CP-EQ2-546 & \multirow{19}{*}{. } & 5,200 & 36" B.W. & Remote \\
\hline$v-2$ & Turbine Trip Valve & $C P-E Q 2-547$ & & 8,000 & $60^{\prime \prime}$ B.W. & Remote \\
\hline$v-3$ & Turbine By-Pass & CP-EQ2-547 & & 3,600 & $30 "$ B.W. & Remote \\
\hline$V-4$ & Evap. Drain Shut-aff & $6850.78-05$ & & 2,200 & $24 "$ B.W. & Remote \\
\hline$V-5$ & Cond. Drain Shut-Off & $6850.78-05$ & & 3,700 & 30" B.W. & Remote \\
\hline$v-6$ & Ammonia Supply & CP-EQ2-544 & & 125 & $6 "-300 \#$ ANSI & Remote \\
\hline$v-7$ & Ammonia Return & CP-EQ2-544 & & 125 & $6 "-300 \$$ ANSI & Remote \\
\hline$V-8$ & Ammonia Return & CP-EQ2-544 & & 125 & 6"-300\# ANSI & Remote \\
\hline$V-9$ & Recirc. Pump Shut-1)ff & $6850.78-05$ & & 4,500 & 36" B.W. & Manual \\
\hline$V-10$ & Recirc. Pump Shut-0ff & $6850.78-05$ & & 5,000 & $36 "$ B.W. & Remote \\
\hline$v-11$ & Feed Pump Shut-0ff & $6850.78-05$ & & 1,900 & 24" B.W. & Manual \\
\hline$v-12$ & Feed Pump Shut-0ff & $6850.78-05$ & & 2,200 & $24 "$ B.W. & Remote \\
\hline$V-13$ & Recirc. Pump Shut-0ff & $6850.78-05$ & & 4,500 & $36 "$ B.W. & Manual \\
\hline$V-14$ & Recirc. Pump Shut-off & $6850.78-05$ & & 5,000 & $36^{\prime \prime}$. B.W. & Remote \\
\hline$V-15$ & Feed Pump Shut-0ff & $6850.78-05$ & & 1,900 & $24 "$ B.W. & Manual \\
\hline$v-16$ & Feed Pump Shut-0ff & $6850.78-05$ & & 2,200 & 24" B.W. & Remote \\
\hline$v-17$ & Purge and $\mathrm{Blowdown}$ & $6850.78-05$ & & 440 & $12^{\prime \prime}-300 \#$ ANSI & Remote \\
\hline$V-18$ & Non-Cond. Purge & $6850.78-05$ & & 210 & $8^{\prime}-300 \#$ ANSI & Remote \\
\hline$V-19$ & Furge and Blowdown & $6850.78-05$ & & 440 & $12^{\prime \prime}-300 \#$ ANSI & Remote \\
\hline
\end{tabular}


Table 2.1-16. 10 MWe Power Loop Ammonia Subsystem Item List (Continued)

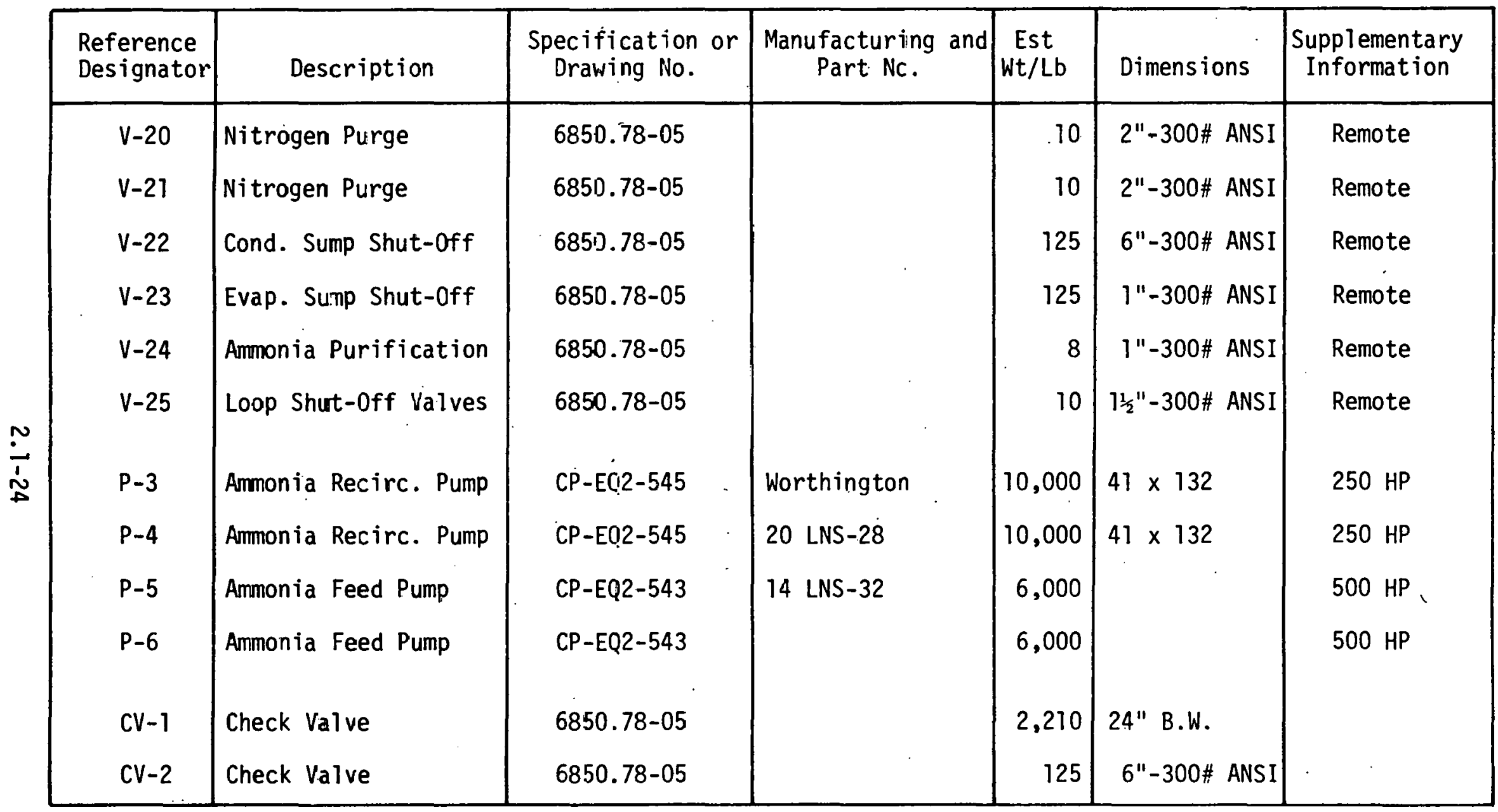


Table 2.1-16. 10 MWe Power Loop Ammonia Subsystem Item List (Continued)

\begin{tabular}{|c|c|c|c|c|c|c|}
\hline PSl-1 & Rel ief Valve & $6850.78-05$ & & 440 & $12^{\prime \prime}-300 \#$ ANSI & Set 86 PSIG \\
\hline PSV-2 & Relief Valve & $6850.78-05$ & & 440 & $12 "-300 \#$ ANSI & Set 136 PSIG \\
\hline PSV -3 & Relief Valve & $6850.78-05$ & & 200 & $6 "-300 \#$ ANSI & Set 150 PSIG \\
\hline PSI -4 & Relief Valve & $6850.78-05$ & & 200 & $6 "-300 \#$ ANSI & Set 150 PSIG \\
\hline PSL -6 & Relief Valve & $6850.78-05$ & & & $1 "-300 \#$ ANSI & Set 150 PSIG \\
\hline PSW-7 & Relief Valve & $6850.78-05$ & & & $1 "-300 \#$ ANSI & Set 150 PSIG \\
\hline PSL -8 & Relief Valve & $6850.78-05$ & & & $1 "-300 \#$ ANSI & Set 150 PSIG \\
\hline PSW-9 & Relief Valve & $6850.78-05$ & & & $1 "-300 \#$ ANSI & Set 150 PSIG \\
\hline$F-1$ & Ammonia Filter & $6850.78-05$ & & 5,000 & $36 "$ B.W. & W/FLG FOR \\
\hline$F-2$ & Ammonia Filter & $6850.78-05$ & & 5,000 & $36 "$ B.W. & SERVICING \\
\hline
\end{tabular}


Table 2.1-17. Line List

Page No. 1

$I$ = Insulated Line

Ref: Dwg. 6850.78-05

\begin{tabular}{|c|c|c|c|c|c|c|c|}
\hline $\begin{array}{l}\text { Line } \\
\text { No. }\end{array}$ & $\left|\begin{array}{l}\text { Line } \\
\text { Class }\end{array}\right|$ & $\begin{array}{l}\text { Line } \\
\text { Size } \\
\text { Inch }\end{array}$ & From & To & Media & $\begin{array}{l}\text { OF Oper. } \\
\text { Temp. }\end{array}$ & $\begin{array}{l}\text { PSIG } \\
\text { Oper. } \\
\text { Press. }\end{array}$ \\
\hline 101 & B & 180 & $P-1$ & $E-1$ & $\begin{array}{l}\text { Sea } \\
\text { Water }\end{array}$ & 80 & 4.6 \\
\hline 102 & B & 180 & $P-2$ & $C-1$ & $\begin{array}{l}\text { Sea } \\
\text { Water }\end{array}$ & 40 & 6.5 \\
\hline 103 & A & $36 \mathrm{I}$ & $P-3$ & Line 105 & $\mathrm{NH}_{3}$ & 60 & 132 \\
\hline 104 & A & $36 \mathrm{I}$ & $P-4$ & Line 105 & $\mathrm{NH}_{3}$ & 60 & 132 \\
\hline 105 & A & $36 I$ & Line $103 / 104$ & $E-1$ & $\mathrm{NH}_{3}$ & 60 & 132 \\
\hline 106 & A & $72 / 60$ & $E-1$ & $T / G-1$ & $\mathrm{NH}_{3}$ & 70 & 114 \\
\hline 107 & A & 24 & E-1 & $T-1$ & $\mathrm{NH}_{3}$ & 70 & 114 \\
\hline 108 & A & $36 \mathrm{I}$ & $T-1$ & $P-4$ & $\mathrm{NH}_{3}$ & 70 & 114 \\
\hline 109 & A & 30 & Line 106 & Line 110 & $\mathrm{NH}_{3}$ & 70 & 114 \\
\hline 110 & C & $\mid 120 \mathrm{I})$ & $T / G=1$ & $C-1$ & $\mathrm{NH}_{3}$ & 50 & 76 \\
\hline 111 & A & $30 \mathrm{I}$ & $c-1$ & $T-2$ & $\mathrm{NH}_{3}$ & 50 & 76 \\
\hline 112 & A & $24 \mathrm{I}$ & $T-2$ & $P-5$ & $\mathrm{NH}_{3}$ & 50 & 76 \\
\hline 113 & A & $24 \mathrm{I}$ & $P-5$ & Line 115 & $\mathrm{NH}_{3}$ & 50 & 114 \\
\hline 114 & A & $24 \mathrm{I}$ & $P-6$ & Line 115 & $\mathrm{NH}_{3}$ & 50 & 114 \\
\hline 115 & A & $24 \mathrm{I}$ & Line $113 / 114$ & $T-1$ & $\mathrm{NH}_{3}$ & 50 & 114 \\
\hline 116 & A & 6 & $T-1$ & $E-1$ & $\mathrm{NH}_{3}$ & 70 & 114 \\
\hline 117 & A & $6 \mathrm{I}$ & $T-2$ & $c-1$ & $\mathrm{NH}_{3}$ & 50 & 76 \\
\hline 118 & A & $6 \mathrm{I}$ & Line 136 & Line 120 & $\mathrm{NH}_{3}$ & 70 & 114 \\
\hline 119 & A & $6 I$ & Line 112 & Line 120 & $\mathrm{NH}_{3}$ & 70 & 114 \\
\hline 120 & A & $6 \mathrm{I}$ & Line 119 & $\mathrm{NH}_{3}$ Storage & $\mathrm{NH}_{3}$ & 70 & 114 \\
\hline 121 & A & $6 \mathrm{I}$ & $\mathrm{NH}_{3}$ Supply & $T-2$ & $\mathrm{NH}_{3}$ & 70 & 114 \\
\hline
\end{tabular}


Table 2.1-17. Line List (Continued)

Page No. 2

$I=$ Insulated Line

Ref: Dwg. 6850-78.05

\begin{tabular}{|c|c|c|c|c|c|c|c|}
\hline $\begin{array}{l}\text { Line } \\
\text { No. }\end{array}$ & $\begin{array}{l}\text { Line } \\
\text { Class }\end{array}$ & $\begin{array}{l}\text { Line } \\
\text { Size } \\
\text { Inch }\end{array}$ & From & To & Media & $\begin{array}{l}{ }^{\circ} \mathrm{F} . \text { Oper. } \\
\text { Temp. }\end{array}$ & $\begin{array}{l}\text { PSIG } \\
\text { Oper. } \\
\text { Press. }\end{array}$ \\
\hline 122 & $A$ & 12 & $c-1$ & RV -2 & $\mathrm{NH}_{3}$ & AMB & 76 \\
\hline 123 & $A$ & 2 & Line 122 & Line 122 & $\mathrm{NH}_{3}$ & AMB & 76 \\
\hline 124 & $A$ & 12 & RV -2 & Overboard & $\mathrm{NH}_{3}$ & AMB & AMB \\
\hline 125 & A & 12 & $E-1$ & RV-1 & $\mathrm{NH}_{3}$ & AMB & 114 \\
\hline 126 & A & 2 & Line 125 & Line 132 & $\mathrm{NH}_{3}$ & AMB & 114 \\
\hline 127 & A & 12 & Line $125 \&$ RV-1 & Overboard & $\mathrm{NH}_{3}$ & AMB & AMB \\
\hline 128 & A & 1 & Line 104 & Line 104 & $\mathrm{NH}_{3}$ & 70 & 132 \\
\hline 129 & A & 1 & Line 103 & Line 103 & $\mathrm{NH}_{3}$ & 70 . & 132 \\
\hline 130 & A & 1 & Line 114 & Line 114 & $\mathrm{NH}_{3}$ & 50 & 114 \\
\hline 131 & A & 1 & Line 113 & Line 113 & $\mathrm{NH}_{3}$ & 50 & 114 \\
\hline 132 & B & 2 & $\mathrm{GH}_{2}$ Supply & $V-20 \& \quad V-21$ & $\mathrm{GN}_{2}$ & 100 & 100 \\
\hline 133 & A & $7 \frac{1}{2} I$ & Line 108 & $\mathrm{NH}_{3}$ Purification & $\mathrm{NH}_{3}$ & 70 & 114 \\
\hline 134 & A & $1 I$ & $\mathrm{NH}_{3}$ Purification & Line 136 & $\mathrm{NH}_{3}$ & 70 & 114 \\
\hline 135 & A & $24 \mathrm{I}$ & $T-2$ & $P-6$ & $\mathrm{NH}_{3}$ & 70 & 114 \\
\hline 136 & A & $36 \mathrm{I}$ & $T-1$ & $P-3$ & $\mathrm{NH}_{3}$ & 60 & 114 \\
\hline 137 & A & 8 & $C-1$ & Vent Header & $\mathrm{NH}_{3}$ & AMB & AMB \\
\hline 138 & A & 12 & Vent Header & $\mathrm{NH}_{3}$ Recovery System & $\mathrm{NH}_{3}$ & AMB & AMB \\
\hline & & & & & & & \\
\hline & & & & & & & \\
\hline & & & & & & & \\
\hline & & & & & & & \\
\hline
\end{tabular}


$\mathrm{F}-1$ through a throttling valve, $\mathrm{V}-1$, and to the evaporator. Unevaporated ammonia returns to sump $T-1$ by gravity. $P-4$ is an inplace standby for $P-3$ and is controlled to come on automatically in the event of failure of $P-3$. $P-3$ and $P-4$ are fixed speed pumps.

Ammonia Turbine Loop. The evaporated ammonia leaves the evaporator $E-1$, and flows to the turbine. After expanding through the turbine it passes through an exit diffuser and to the condenser, $C-1$ where it condenses and flows by gravity to sump T-2.

Flow Measurements. Flow measurements are taken in the recirculation line to the evaporator and the feed line to $T-1$. These flow measurements will be time averaged and used to determine mass flows through each loop of the system. An additional flowmeter, installed in the ammonia make up line, will be used to monitor unusual changes in ammonia consumption.

Nitrogen Purge Capability. Gaseous nitrogen is piped to the upper vent line connections to the evaporator, $E-\bar{l}$, and condenser $C-1$. This permits a number of alternative purge sequences for inerting all or part of the power loop ammonia subsystem.

Supporting Data. Calculations and supporting data for line sizing, NPSH, relief valves, sump sizing etc., are included in Appendix $N$.

2.1.4 General Arrangement Drawings

The 10 MWe modular application power system module (PSM) has been configured for containment in the DOE directed reference surface platform/ ship hull described in Section 3.

The power system module general arrangement incorporates verticallyoriented open-top heat exchangers immersed in seawater by attachment on the exterior of a hull section containing the power plant and support systems in a shirt-sleeve environment. This arrangement approach was directed by DOE to obtain minimum containinent volume dnd lower hull costs. TRW has reduced the conceptual design hull draft from 75 feet to 60 feet by judicious design of horizontal ammonia sumps and liquid level control characteristics and by selection of ammonia pumps with low NPSH. The optimized system elevation design criteria are indicated in Figure 2.1-5. 


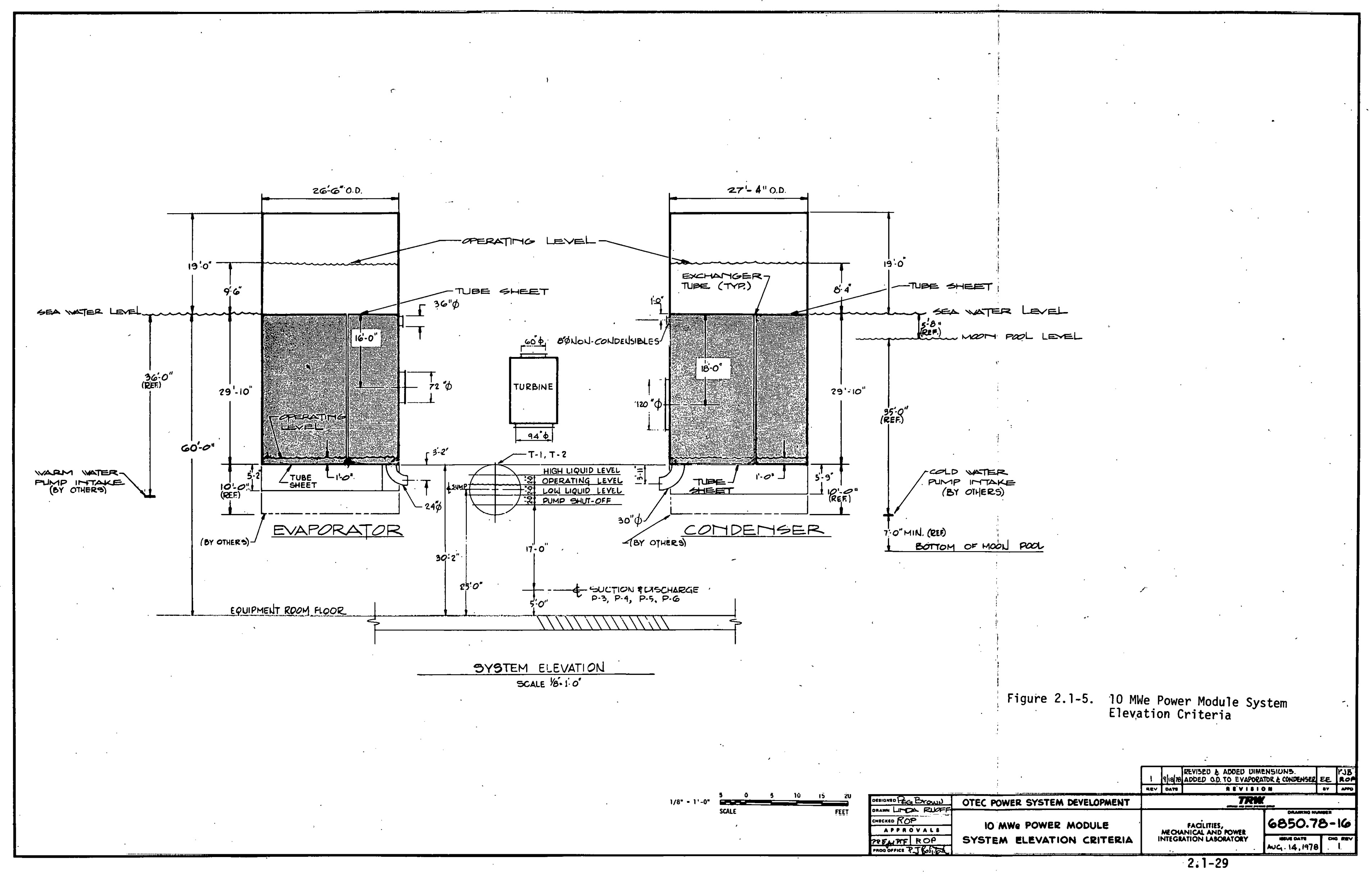


The minimized power system module containment configuration maintains service accessibility as indicated in Figures 2.1-6, 2.1-7 and 2.1-8. The power loop ammonia piping is shown with line codes. Subsystem component reference designators are keyed to the P\&ID drawing, Figure 2.1-4. Piping is configured with long radius ells to minimize pressure drops and parasitic power losses. All piping is made up with weld joints to minimize ammonia leaks. The small ammonia and nitrogen make-up, let-down and vent piping does not impact the system arrangement and has been omitted for clarity. The drawings and details of piping and tank supports on the platform are described in Appendix N. Space has been provided for turbine removal for maintenance.

The immersed heat exchangers are attached to the hull with coffer dams for at-sea make up of through hull piping fittings described in Section 2.11 with detailed design drawings and description in Appendix N. As shown, flexible couplings are provided on both sides of the through hull interfaces to provide for fabrication alignment and rellef of differential movements between the hull and power system components.

The warm and cold water pumps ( $P-1$ and $P-2)$, provided by ship systems, are shown in Figure 2.1-6 located with respect to the reference hull described in Section 3. The enclosed pump supply troughs interface with the heat exchanger transition sections as described in Section 2.1.5. The depth and velocity of water as it leaves lhe truagh fruil a seawater pump and enters the top water box of a heat. exchanger are cont.rnlled hy the depth in the top water box. When the depth in the box is $10 \mathrm{ft}$. or greater, the depth at the entrance is also $10 \mathrm{ft}$. or greater and the velocity is $8 \mathrm{ft}$. per second or less. If the depth in the box falls to 5 or $6 \mathrm{ft}$., however, the velocity of flow at the entrance to the water box will increase to 13 or $16 \mathrm{ft}$. per second. At these high velocities the water flowing across the tube sheet would tend to skip over the ends of the tubes near the entrance rather than cnter the tubcs. The rate of flow in those tubes would be less than in tubes further from the entrance of the water box. Although the results of the model for hydraulic transients (Section 2.2.6) indicates that the depths in the top water hox do not fall to 5 or $6 \mathrm{ft}$. during Sea State 6, it is wise to consider the possibility. 


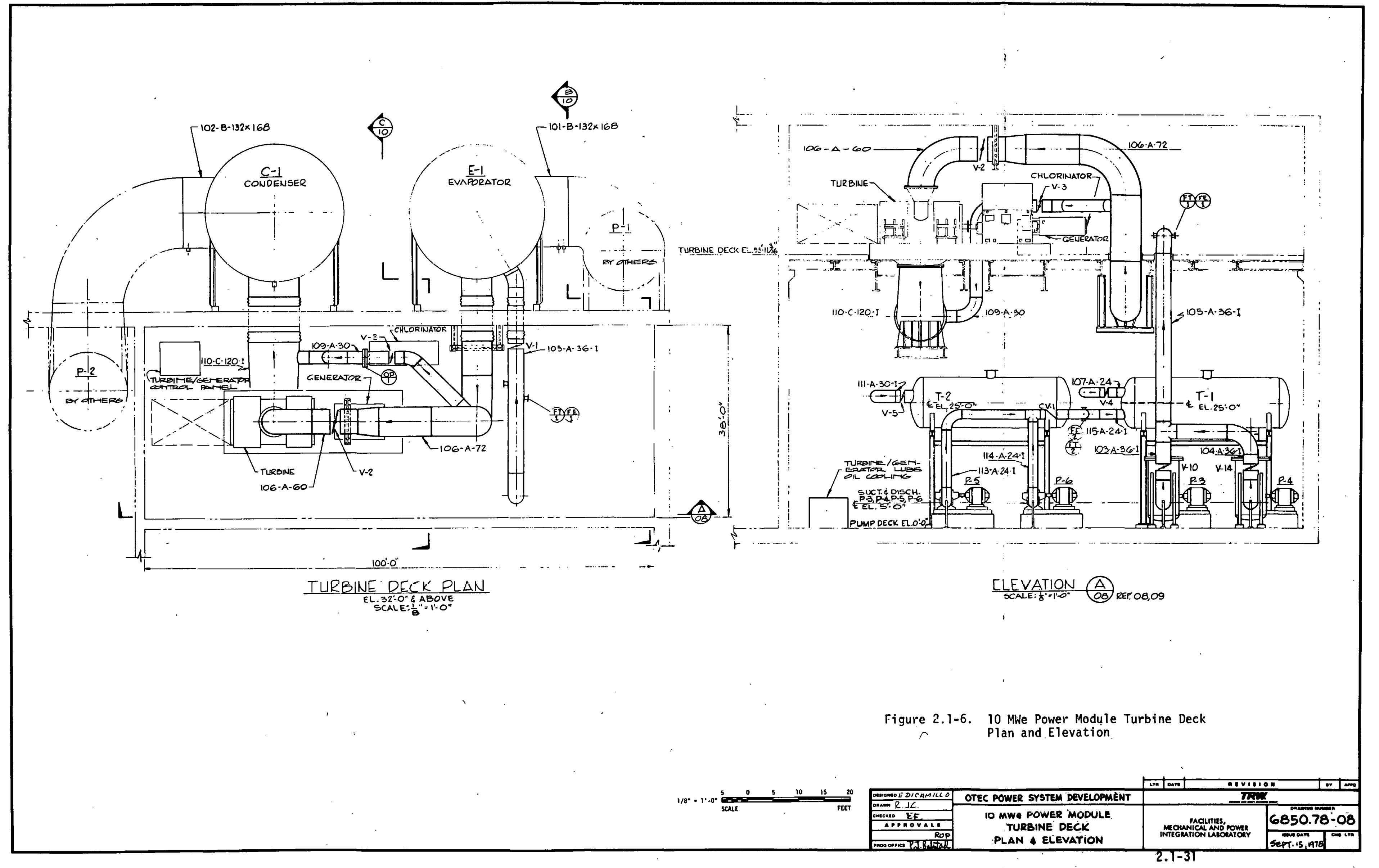




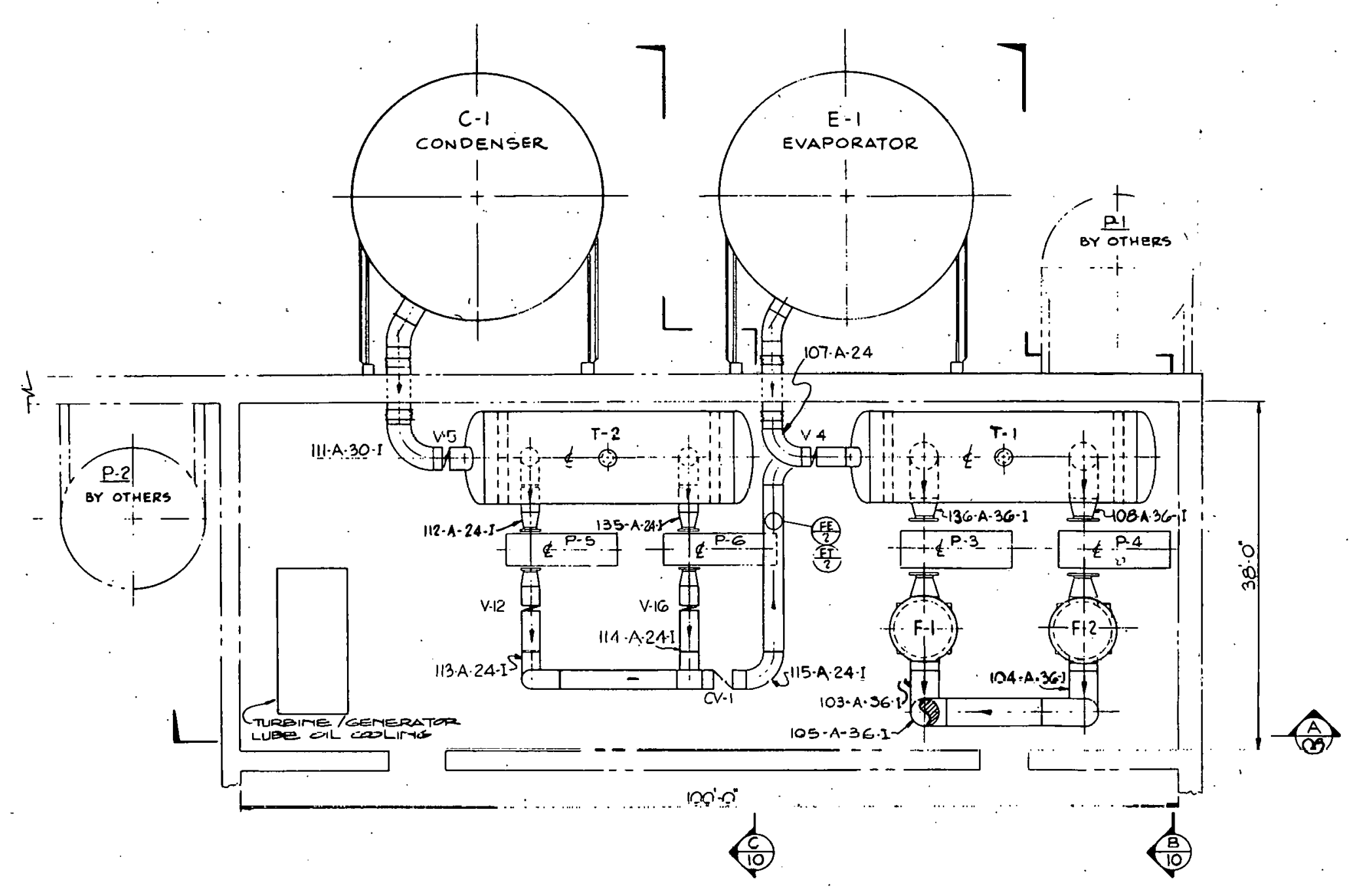

PUMP DECK PLAN

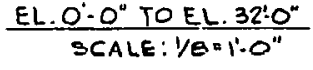

Figure 2:1-7. 10 MWe Power Module Pump Deck Plan

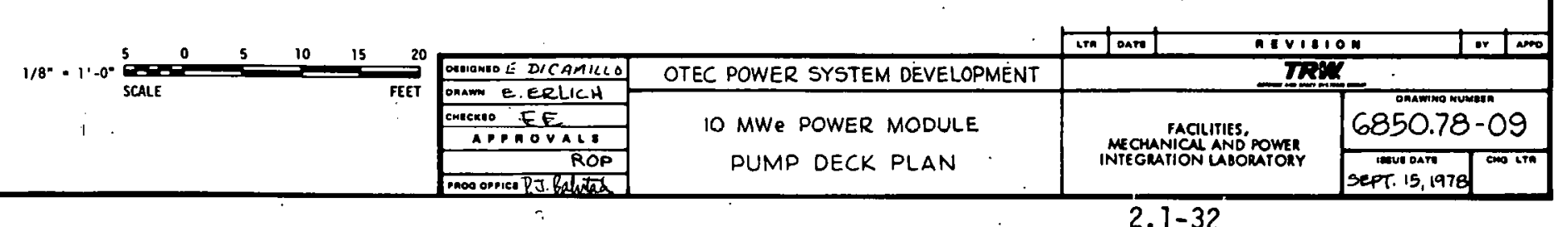




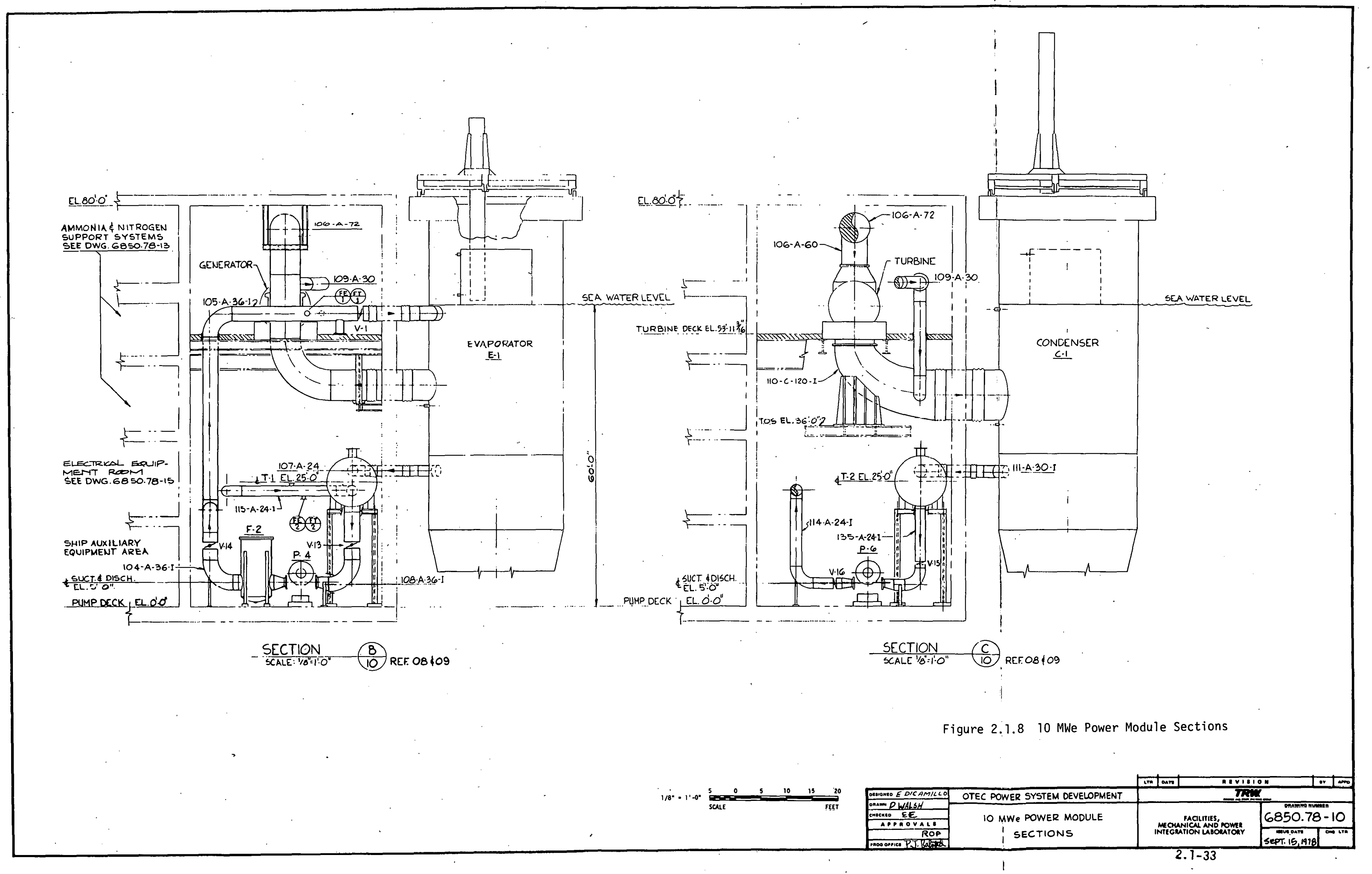


The basic approach to the problem is to prevent the water from entering the water box with high horizontal velocity. A simple method would be to place a low weir across the flow of the trough, normal to the direction of flow and just before the entrance to the water box. A depth of 3 feet might be sufficient. A more effective method is to use two or more rows of baffles. Each baffle is essentially a short section of weir about 4 feet long in the direction across the trough and spaced 4 feet in that direction to form a row across the trough. In a second row, the sections are located in line with the open spaces in the first row. Two or three rows across the trough would create a pattern of staggered baffles to slow the flow at the entrance to the water box. The height of the baffles might be 2 feet. These baffles are commonly used in stilling basins at the low ends of a chute or spillway from a dam, and they are called stilling basin blocks or hydraulic piers. The stilling basin blocks shown on figures 2.4-3 and 2.4-4, described in Section 2.4.2, are representative only and detailed design must be configured by study in a hydraulic model laboratory.

A complete set of preliminary design drawings describing the 10 MWe Power Module, 40 MWe Commercial Power System Platform and the $200 \mathrm{kWe}$ Test Articles is appended to this report as a drawing package as listed in Table $2.1-10$.

\section{1 .5 Critica] Interfaces}

The critical interfaces between the 10 MiWe modular application power system module and ship systems are described in this section.

\subsubsection{Physical Interfaces}

The physical interfaces shown in Figures 2.1-9, 2.1-10, 2.1-11 and 2.1-12, include:

- Containment dimensions

- Hull penetrations and interfacing pipe materials

- Installed power system module weights

- Water trough duct connections

- Immersed heat exchanger/hull attachments 
Table 2.1-18. OTEC PSD-1 Drawing List

\begin{tabular}{|c|c|}
\hline Title & Drawing No. \\
\hline \multicolumn{2}{|l|}{10 MWe POWER MODULE: } \\
\hline COVER SHEET/DWG INDEX & $6850.78-00$ \\
\hline LEGEND AND SYMBOLS & $6850.78-01$ \\
\hline PROCESS FLOW DIAGRAM - NOMINAL FLOW CONDITION & $6850.78-02$ \\
\hline PROCESS FLOW DIAGRAM - MINIMUM FLOW CONDITION & $6850.78-03$ \\
\hline PROCESS FLOW DIAGRAM - MAXIMUM FLOW CONDITION & $6850.78-04$ \\
\hline PIPING AND INSTRUMENTATION DIAGRAM & $6850.78-05$ \\
\hline *AMMONIA SUPPORT SYSTEM - PIPING AND INSTRUMENTATION DIAGRAM & $6850.78-06$ \\
\hline *NITROGEN SUPPORT SYSTEM - PIPING AND INSTRUMENTATION DIAGRAM & $6850.78-07$ \\
\hline TURBINE DECK - PLAN AND ELEVATION & $6850.78-08$ \\
\hline PUMP DECK - PLAN & $6850.78-09$ \\
\hline SECTIONS & $6850.78-10$ \\
\hline PIPING AND SUPPORT DETAILS & $6850.78-11$ \\
\hline HEAT EXCHANGER SUPPORT DETAILS & $6850.78-11 \mathrm{~A}$ \\
\hline MISCELLANEOUS DETAILS & $6850.78-12$ \\
\hline *AMMONIA \& NITROGEN SUPPORT SYSTEM - PLAN \& ELEVATION & $6850.78-13$ \\
\hline PRIMARY DISTRIBUTION ELECTRICAL - SINGLE LINE DIAGRAM & $6850.78-14$ \\
\hline $\begin{array}{l}\text { MOTOR CONTROL CENTER - SINGLE LINE DIAGRAM \& GENERAL } \\
\text { ARRANGEMENT }\end{array}$ & $6850.78-14 \mathrm{~A}$ \\
\hline ELECTRICAL EQUIPMENT ROOM - PLAN \& ELEVATION & $6850.78-15$ \\
\hline SYSTEM ELEVATION CRITERIA & $6850.78-16$ \\
\hline POWER/SHIP SYSTEM INTERFACES - PLAN \& SECTION & $6850.78-17$ \\
\hline POWER/SHIP SYSTEM INTERFACES - SECTIONS & $6850.78-18$ \\
\hline POOWER/SHIP SYSTEM INTERFACES - PLAN \& SECTIONS & $6850.78-19$ \\
\hline POWER/SHIP SYSTEM INTERFACES - SECTIONS \& NOTES & $6850.78-20$ \\
\hline 40 MWe PLATFORM - PLAN, ELEVATION \& SECTIONS & $6850.78-21$ \\
\hline 10 MWe HEAT EXCHANGER - TUBE CLEANER & $6850.78-22$ \\
\hline CONDENSER - PLAN, ELEVATIONS, SECTIONS \& DETAILS & $6850.78-23$ \\
\hline EVAPORATOR - PLAN, ELEVATIONS, SECTIONS \& DETAILS & $6850.78-24$ \\
\hline
\end{tabular}

*PREPARED BY C.F. BRAUN 
Table 2.1-18. OTEC PSD-1 Drawing List (Continued)

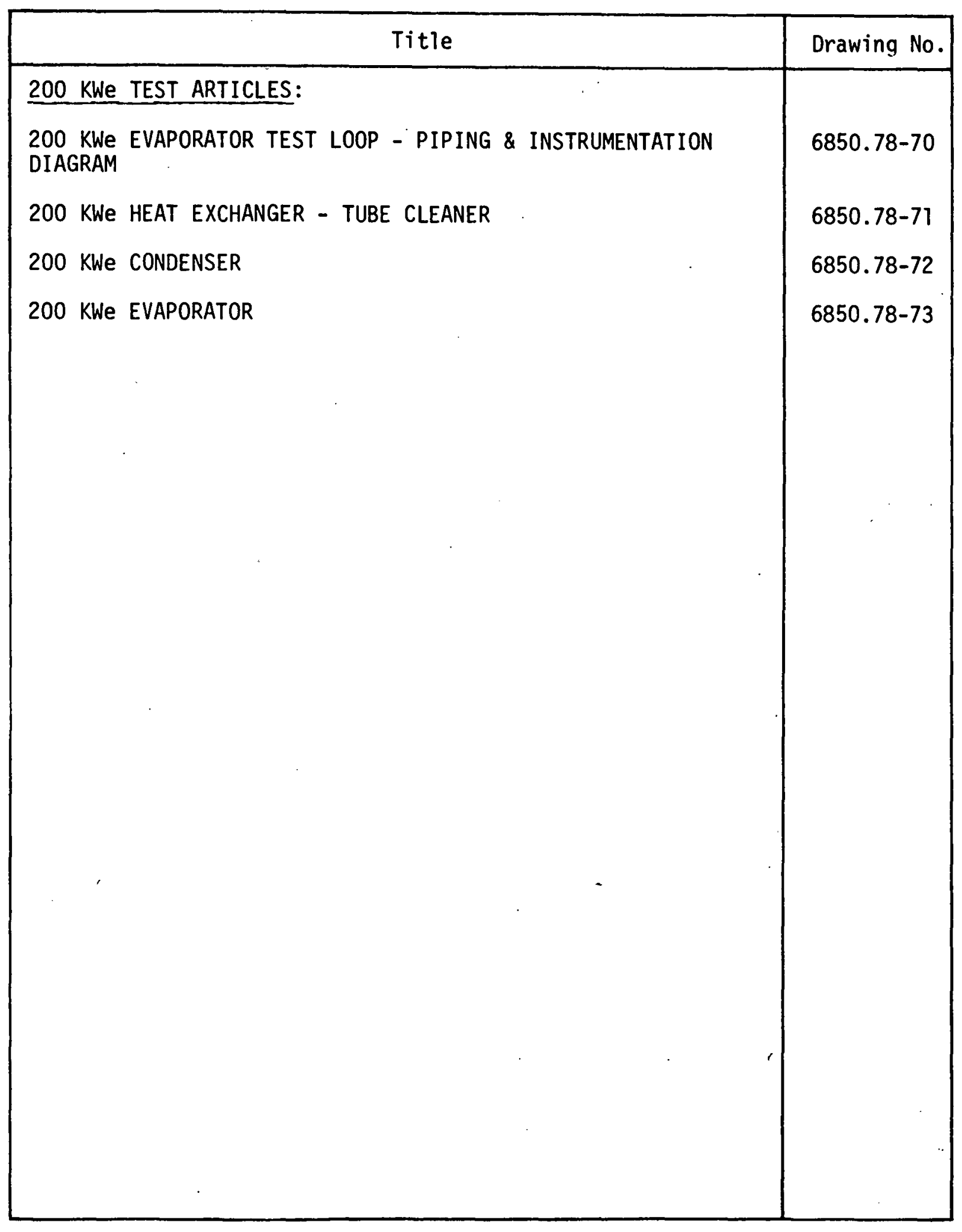

2.1-36 


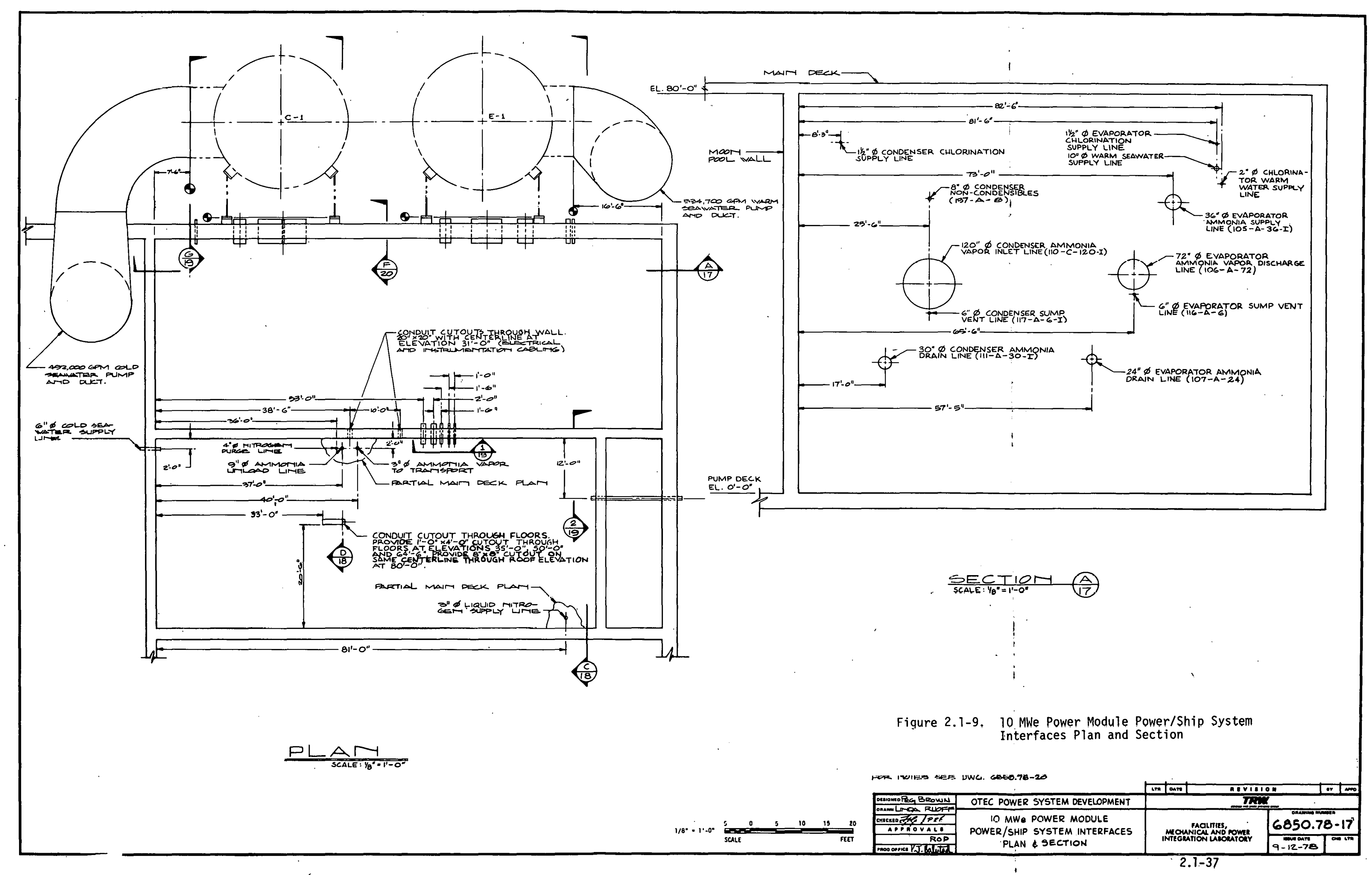




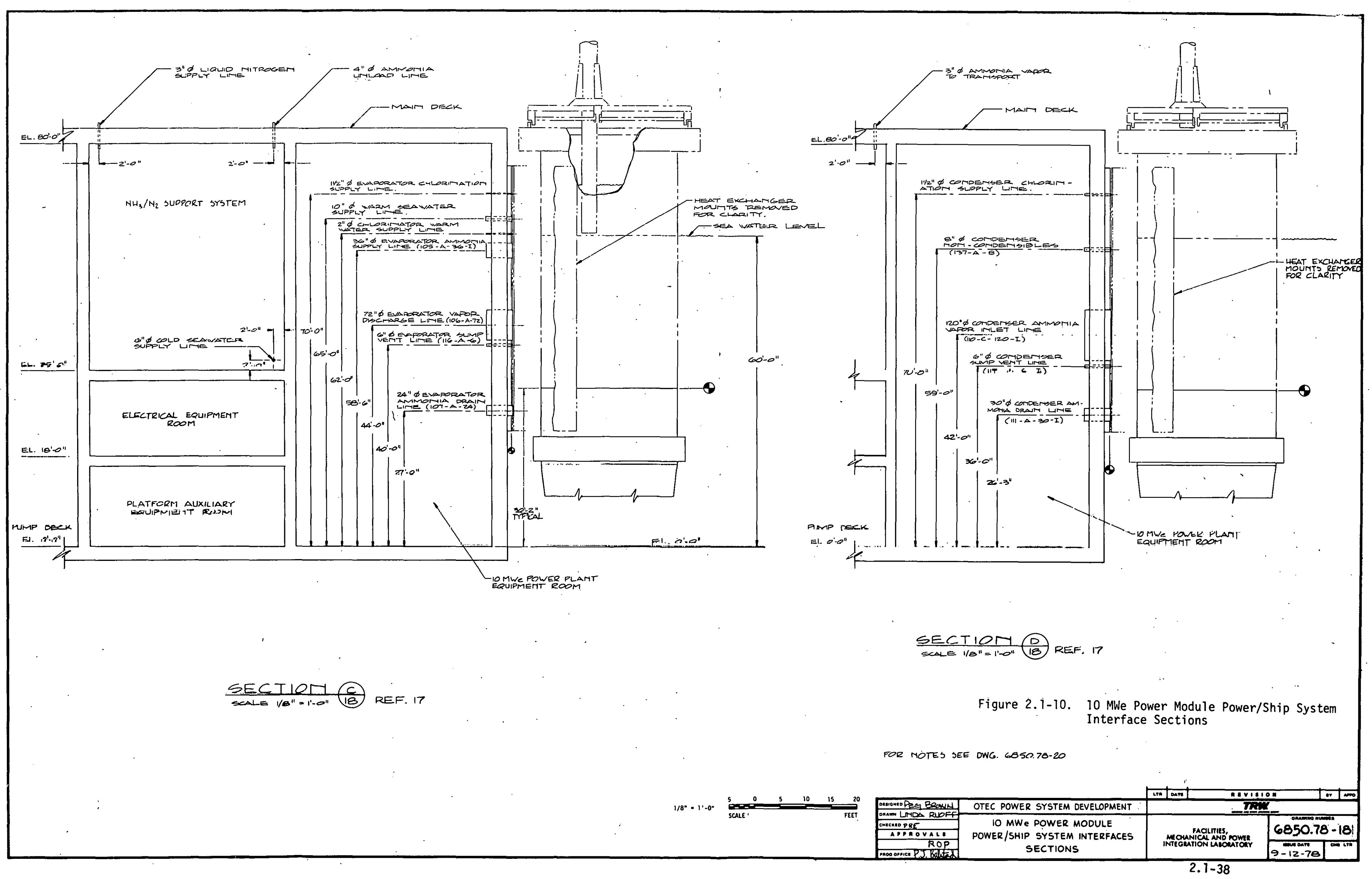




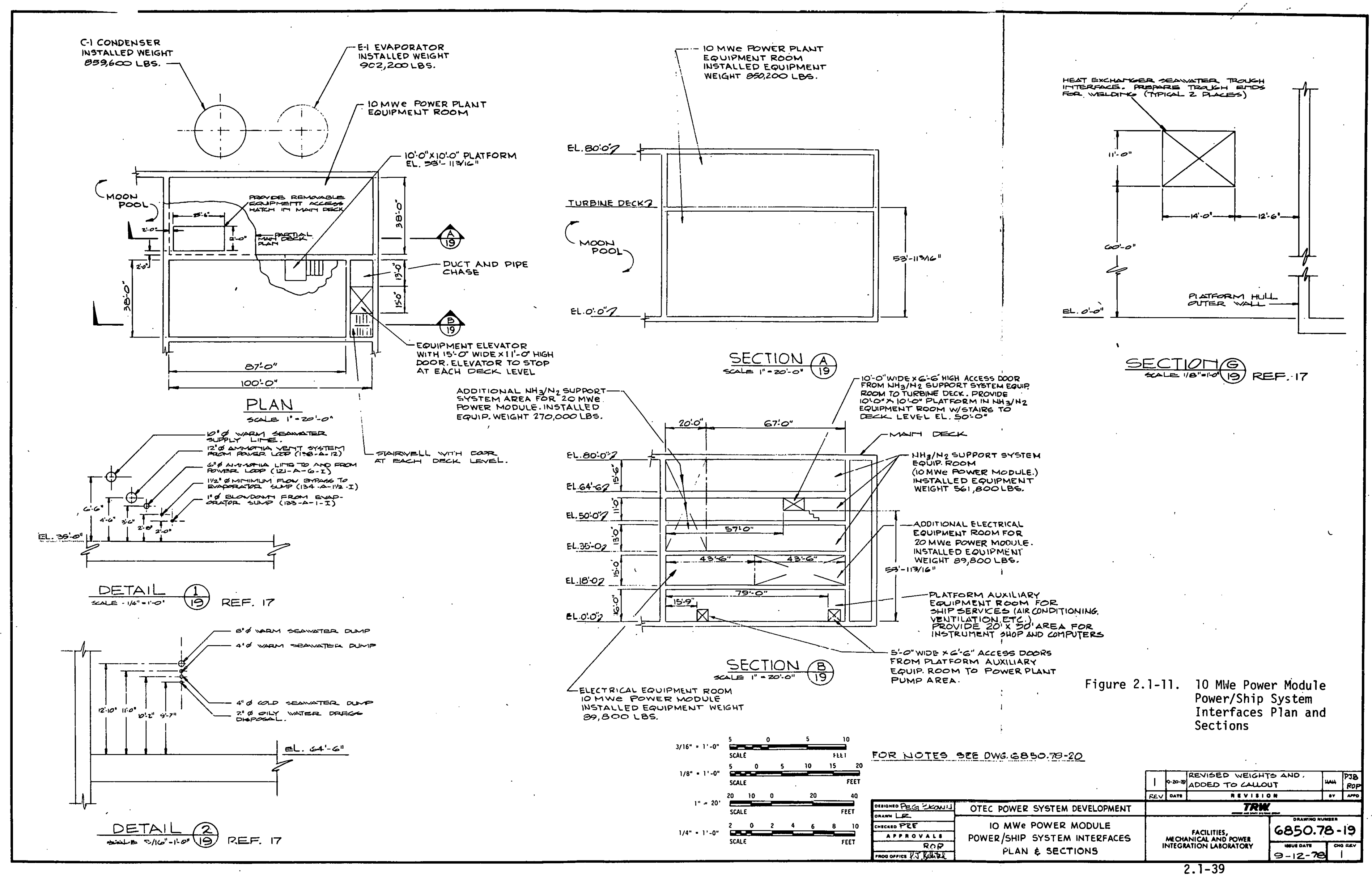




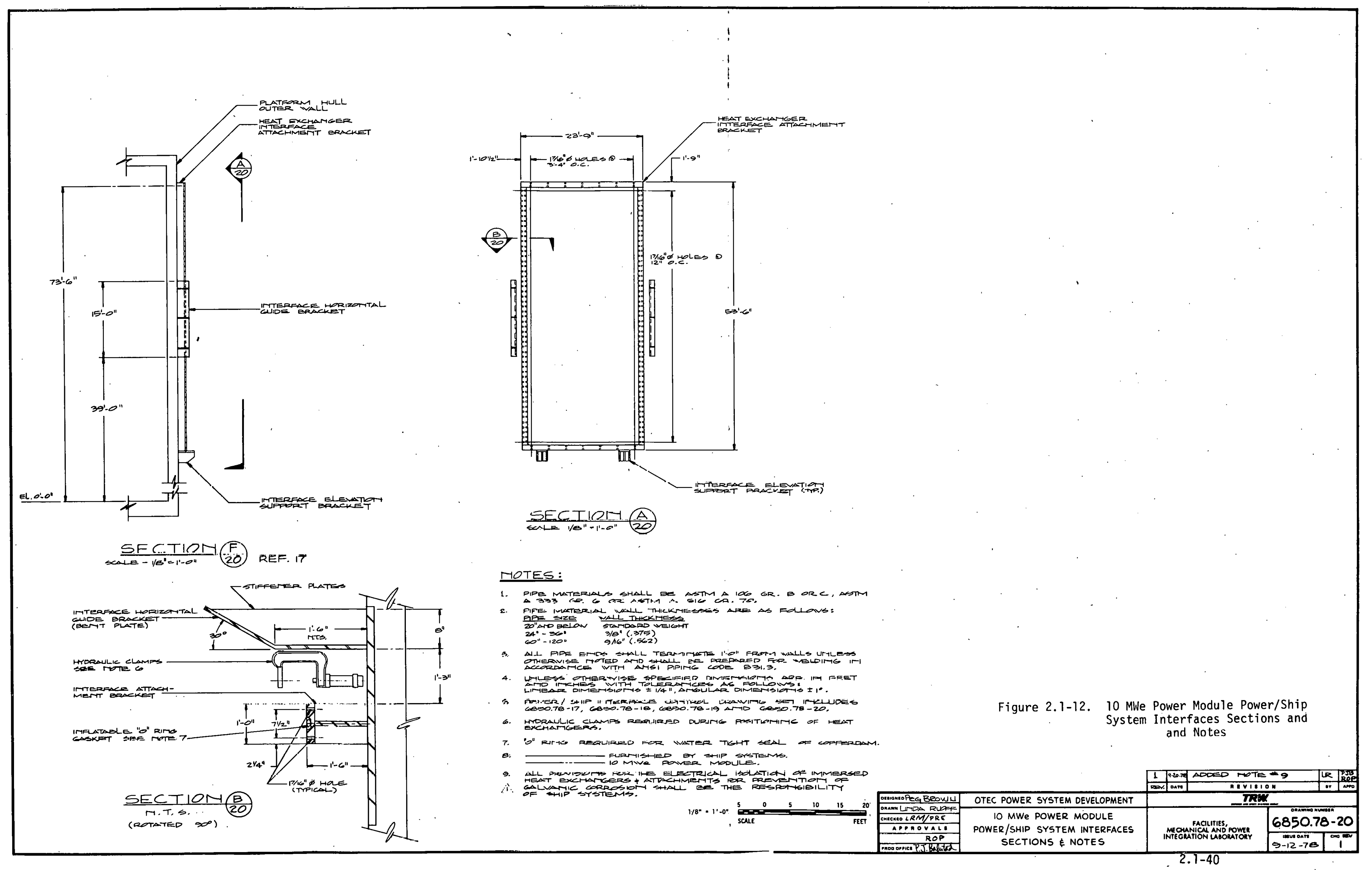


The physical interface relationship of the 10 MWe power system module and a 40 MWe commercial power system hull is described in Section 3.2.

\subsubsection{Functional Interfaces}

Functional interfaces with ship systems are shown in Figure 2.1-13, summarized in Table 2.1-19, and described as follows:

Interface 1: The warm seawater pump is part of the ship system. Thus at the interface with the power system module, there is an input warm water flow. The warm water enters the evaporator water box above the upper tube sheet of the evaporator, and below the water surface with a warm water temperature range of $70-85^{\circ} \mathrm{F}$. The module is designed to operate normally on $80 \pm 4^{\circ} \mathrm{F}$ warm water range. For warm water temperatures below $80^{\circ} \mathrm{F}$ the module operates at reduced output (see Section 2.2.4). The water flow variations caused by ship heave result in a fluctuating power output with a 16 second period. Section 2.2.6.4 explains that this is acceptable when delivering power to a large grid. It also shows how to attenuate the fluctuations when delivering power to an isolated grid, at the expense of reduced average power output.

Interface 2: DOE has defined this boundary as just below the bottom tube sheet of the evaporator where the warm seawater is discharged. The rest of the discharge ducting is government furnished equipment. The flow rate was assumed to be nominally the same as the rate at which water is pumped in.

The present design requires that the head loss through the lower portion of the heat exchanger (exit loss, transition to discharge pipe loss, discharge pipe friction, dumping loss) shall not exceed 0.78 feet.

Interface 3: The generator output is fed to an electric power, distribution and control subsystem. The $15 \mathrm{kV}$ switchgear (Interface 3a in Table 2.1-19) delivers the power to the external grid through governmentfurnished equipment. The nature of the external grid determines the method of turbine speed control, as explained in Sections 2.2.2.7 2.2.2:9. Parasitic power (e.g., station power) is supplied from 480 volt and 4160 volt transformers and switchgear. During startup, the parasitic inads are connected to the external grid. An automatic transfer swilch, 


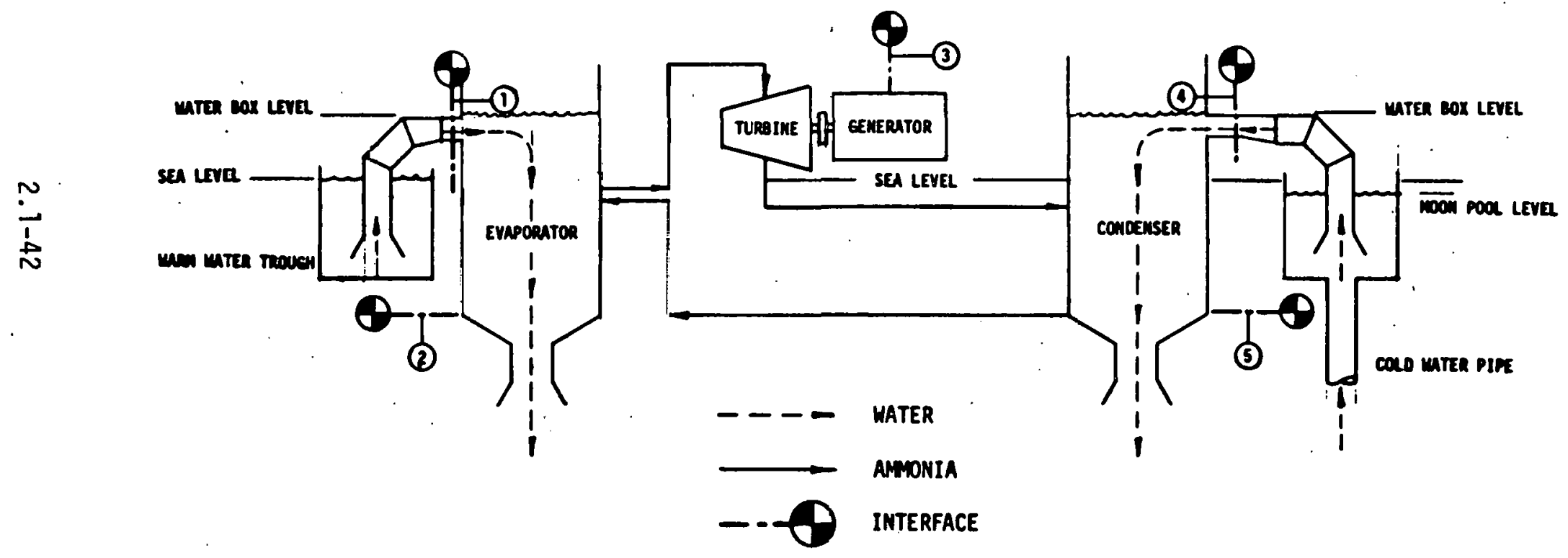

Figure 2.1-13. 10 Mtje Module, Critical System Functional Interfaces 
Table 2.1-19. Pertinent Interface Parameters and Variations

\begin{tabular}{|c|c|c|c|c|c|c|c|}
\hline \multirow{2}{*}{$\begin{array}{l}\text { Interface } \\
\text { Number }\end{array}$} & \multirow[b]{2}{*}{ Location } & \multicolumn{2}{|c|}{ Quantity } & \multicolumn{2}{|c|}{ Temperature $\left({ }^{\circ} \mathrm{F}\right)$} & \multicolumn{2}{|c|}{ Piezometric Head (Ft) } \\
\hline & & Nominal & Variation & Nominal & Variation & Nominal & Variation \\
\hline 1 & $\begin{array}{l}\text { Warm Water } \\
\text { Duct }\end{array}$ & $\begin{array}{c}\text { Water } \\
534,700 \mathrm{GPM}\end{array}$ & TBD & 80 & $70-85$ & 9.82 & TBD \\
\hline 2 & $\begin{array}{l}\text { Just Below } \\
\text { Evaporator } \\
\text { Bottom Tube } \\
\text { Sheet }\end{array}$ & $\begin{array}{c}\text { Water } \\
534,700 \text { GPM }\end{array}$ & TBD & $\begin{array}{l}\text { Inlet } \\
\text { Minus } \\
5.9^{\circ}\end{array}$ & $\begin{array}{l}\text { Temp. } \\
\text { Approx. }\end{array}$ & 0.37 & TBD \\
\hline $3 a$ & $\begin{array}{l}15 \mathrm{KV} \\
\text { Switch Gear }\end{array}$ & $\begin{array}{l}\text { Voltage } \\
13.8 \mathrm{KV} \\
(30,60 \mathrm{~Hz}) \\
\\
\text { Power } \\
\text { 14.03 MWe } \\
\text { gross } \\
\text { 10.00 MWe net }\end{array}$ & $\begin{array}{l}\text { Steady State } \\
\pm 0.75 \% \\
\quad(30 \mathrm{sec}) \\
\pm 7.5 \%(4 \mathrm{hr}) \\
\frac{\text { Transient }}{-70 \%} \\
\quad(\leqq 2.5 \mathrm{sec}) \\
+\mathrm{TBD} \\
(\leqq 2.5 \mathrm{sec}) \\
\pm 20 \%\end{array}$ & & & & \\
\hline
\end{tabular}


Table 2.1-19. Pertinent Interface Parameters and Variations (Continued)

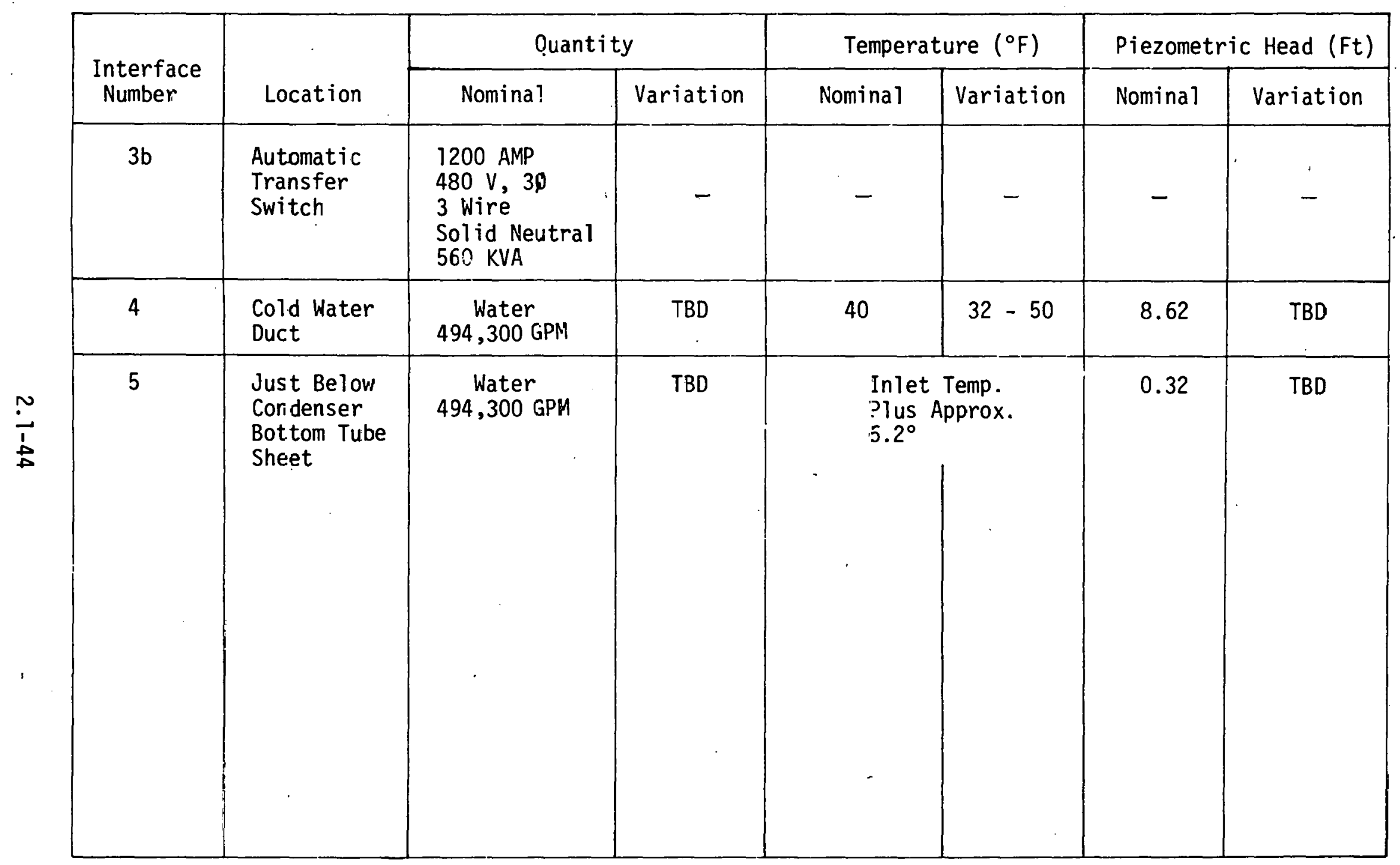


Interface $3 b$, transfers to module power when the appropriate operating level is reached. The steady-state startup power is $4 \mathrm{MW}$, with singlespeed water pumps or $600 \mathrm{kw}$ with 3-speed pumps, using the bootstrap startup procedure described in Section 2.2.5.8. The inrush current sizes the voltage drop at the external source, the cabling size, and the switchgear (see Section 2.10.2.5).

Interface 4: As with Interface 1, government furnished systems provide a supply of cold water. The interface with the power system module is at the input to the water box above the upper tube sheet of the condenser, and below the water surface. The module is designed to operate normally with $40^{\circ} \mathrm{F}$ cold water. Since water reaches its maximum density just above $39^{\circ} \mathrm{F}$, the temperature of cold water brought from 3,000 feet depth probably will not be appreciably less than $40^{\circ} \mathrm{F}$. At this depth, the temperature is almost insensitive to seasonal variation. Thus, the design is based on the assumption that the cold water supply at the condenser inlet is constant at $40^{\circ} \mathrm{F}$. Section 2.2.4.6 analyzes the reduction in power output if the cold water temperature exceeds $40^{\circ} \mathrm{F}$. Variations in cold-water trough level caused by ship heave result in output power fluctuations. Section 2.2.6.4 explains that these fluctuations are acceptable when delivering power to a large grid. It also explains how to attenuate the fluctuations when delivering power to an isolated grid.

Interface 5: As with Interface 2, DOE has defined this interface to be located just below the bottom of the lower tube sheet of the condenser. The rest of the discharge ducting is government furnished equipment. The flow rate was assumed to be nominally the same as the rate at which water is pumped in. The present design requires that the head loss through the lower portion of the heat exchanger (exit loss, transition to discharge pipe loss, discharge pipe friction, dumping loss) shall not exceed $0.69 \mathrm{ft}$.

\subsubsection{Ship Service Interfaces}

Ship services to be provided by ship system auxiliaries are:

- 50,000 CFM ventilation air to Power Module Equipment Room

- 50,000 CFM ventilation air to $\mathrm{NH}_{3} / \mathrm{N}_{2}$ Support Systems Room 
- 15,000 CFM ventilation air to Electrical Equipment Room

- Air conditioning (2 tons of refrigeration) for the Control Room

- Lighting - Control Room 100 foot candles; equipment areas 80 foot candles

- Fire protection system

- Shop air, TBD CFM at 100 psig dry, filtered to TBD microns, nominal.

\subsubsection{Power Plant/Ship Control}

Instrumentation and control interfaces with ship systems are introduced in Section 2.2.1 and identified as follows:

a. From Seawater Pumps

Pump status

Pump speed

Pump power

Water flow rates

Alarms

b. From Ship

Voice

TV monitor of hazardous areas

Air quality in machinery spaces

Wave motion Alarm

Ship's electric power states: generation consumption

c. To Ship

Trip status

Key subsystem status

Alarms

Gross and net power output

Voice 


\subsubsection{Seawater Pump Availabilities}

The condenser and evaporation seawater pumps have been allocated the following goals to achieve the required overall power system availability of 0.90 :

$$
\begin{aligned}
& \text { MTBF (each pump) }=720 \text { days } \\
& \text { MTTR (each pump) }=80 \text { hours }
\end{aligned}
$$

As discussed in Section 2.13 these values are estimates based on experience with related equipment.

\subsubsection{Materials and Processes}

The materials and processes for the power module. components and auxiliary equipment are selected with the objective of satisfying the 30 year design life through an optimum repair/replacement/maintenance program. In selecting specific materials, the following guidelines were used:

- All selected materials must have a reasonable delivery (availability) and be fabricable by methods currently available to the industry.

- Ammonia-side materials must conform to OSHA Standard 1910.111, "Storage and Handling of Anhydrous Ammonia," and the proposed amendments to the standard published in the Employment Safety and Health Guides, Number 259, 7 March 1976.

- The pressure containing portions of the heat exchangers must conform to the applicable portions of the ASME pressure vessel codes (Sections II, V, VIII Division 1, and $(X)$.

- The selected materials and processes must meet the applicable structural and thermal requirements of the power system.

In subsystem design and construction, the following guidelines have been established for parts, materials and processes:

- Dissimilar metals, as defined in MS33586, shall not be in direct contact.

- Fungus nutrient materials shall be avoided. When these materials are used and not hermetically. sealed, they shall be treated with a suitable fungicidal agent.

- Standard and commercial parts shall be used wherever practical. 
- The surface preparation, finish and curing of each component shall meet applicable requirements and be adequate to prevent deterioration from exposure to specified environments that might jeapordize required performance. Finishes shall meet applicable bonding requirements.

The materials for the heat exchangers, the principal materials concern, are detailed in Section 2.4.3. Materials for other components and equipment are selected during the detail design phase using the constraints discussed. Basically, steel or corrosion resistant steel (CRES) is used for ammonia system components and steel or CRES, a luminum bronze or glass fiber reinforced plastic are used for water system components.

Recommended design materials for the PSD-I power system are shown in Table 2.1-20. The basic tradeoffs were performed during the conceptual design and are presented in the Conceptual Design Report. A detailed description of additional work is presented in Sections 2.4.4 and 2.4.6.

As expected for any marine system, periodic maintenance and repair is planned for the PSD-I power module. For the heat exchanger life prime areas of concern are the coated surfaces of the water box and shell. If the coating is damaged or fails by some mechanism, then corrosion of the steel substrate can occur. Periodic inspection and repair of the coatings will prevent unacceptable corrosive attack. If the cathodic protection system provided by the hull designer is inadequate, galvanic attack at the cofferdam, supports, and connections and/or blistering of protective coatings can occur. Again, periodic inspection and repair will be rcquired to assure structural integrity. Any failure of the tubes will be detected by the ammonia leak detection system. Individual tubes will be plugged to prevent further leakage.

The ammonia and water system components will be maintained following standard shipboard practices. Replacement of seals, wear parts and maintenance at coatings are routine. Special attention will be given to erosion and impingement attack ol lines (espccially at elbows, tron, etc..). valves and pumps. Material specific problems, such as dezincification of brass will be identified for special inspection. A discussion of the maintenance plan and timetable is presented in Section 2.13.2. 
Table 2.1-20. Recommended Design Materials

\begin{tabular}{|c|c|}
\hline Heat Exchanger & \\
\hline Shell & SA516 GR60 Steel \\
\hline Tubesheets & SA516. GR60; SA283 or SA285 GR B Steel \\
\hline Tubesheet Cladding & SB254 GR1 or GR2 Titanium \\
\hline Tube & SB338 GR2 Titanium \\
\hline $\begin{array}{l}\text { Internal Structural } \\
\text { Members }\end{array}$ & SA516, SA283, SA285, ASTM A36 Stee1 \\
\hline Water Boxes & $\begin{array}{l}\text { SA516, SA283, SA285 Steel, G1ass Fiber- } \\
\text { Reinforced Plastic }\end{array}$ \\
\hline $\begin{array}{l}\text { Water Box, Shell } \\
\text { or Pipe Coating }\end{array}$ & $\begin{array}{l}\text { GACO N-200-1/N-11R Neoprene (or) NAPCO No. } 5635 \\
\text { Coa 1 Tar Epoxy }\end{array}$ \\
\hline \multicolumn{2}{|l|}{ System } \\
\hline $\begin{array}{l}\text { Ammonia System } \\
\text { Components }\end{array}$ & $\begin{array}{l}\text { Steel or CRES* (specific composition dependent } \\
\text { on availability) See also Appendix D3. }\end{array}$ \\
\hline $\begin{array}{l}\text { Water System } \\
\text { Components }\end{array}$ & $\begin{array}{l}\text { Steel or CRES (specific composition dependent } \\
\text { on availability), Aluminum Bronze, Glass Fiber } \\
\text { Reinforced Plastic, Copper Nickel }\end{array}$ \\
\hline
\end{tabular}

Designations are ASME except where noted *CRES = Corrosion Resistant Steel (Austenitic Stainless Steel)

\subsubsection{System Design Optimization Update}

At the conclusion of the Conceptual Design Phase, TRW recommended a 12.5 MWe Power Module consisting of two 6.25 MWe submodules driving a common generator (see Reference 1). The 6.25 MWe heat exchangers had 2 inch 0.D. fluted titanium tubes 45.5 feet long for the evaporator and 43 feet long for the condenser. Each evaporator and condenser had approximately 5,300 tubes and 7,200 tubes, respectively.

Subsequently, two events necessitated a complete update of the system design:

a. DOE's directive (discussed in Section 1) to change the rating uf lhe puwer mudule to 10 MWe and to 1minerse the heat exchangers in seawater. 
b. Technical information regarding the collapse strength of corrugated titanium tubes. It was demonstrated that the tube thickness of 0.028 inches assumed in the Conceptual Design Phase would not provide sufficient strength for 2 inch tubes.

Considering these events, TRW decided that a complete reoptimization of the system design was required. The system design model, OTEC-I, was updated to incorporate the latest available performance models. Appendix Al describes in detail the updating of the model and includes a listing of the OTEC-II computer program. Together with the description of the OTEC-I program contained in Appendix $E$ of the Conceptual Design Report, (Reference 2), this constitutes a complete description of the models and the computer program.

The major characteristics of the design which evolved as a result of the reoptimization (consistent with the DOE direction) were presented in Sections 2.1.1 through 2.1.6. The major design changes relative to the conceptual design are discussed here.

The increase in tube wall thickness with tube diameter forced the system cost optimum towards a tube diameter for both evaporator and condenser of about 1 inch 0.D. Figure 2.1-14 shows the direct cost of a prototype : power module versus tube diameter for three water side enhancement ratios. The required tube thickness is essentially proportional to tube diameter, however, for tube diameters less than 1 inch 0.D. the thickness was assumed constant dictated by forming constraints rather than strength.

Figure 2.1-14 demonstrates that approximately 1 inch 0.D. is the optimum tube diameter, and that a water side enhancement ratio of 1.5 is more cost effective than smooth tubes and the more extreme (and more difficult tube to clean) area ratio of 2.0. In all cases the ammonia side enhancement ratio was kept equal to 1.5 as recommended by $\mathrm{Dr}$. Rothfus.

The effect of tube diameter and enhancement ratio have a strong impact on the optimum tube length. Approximately, the tube length increases pro-. portionally with tube diameter and decreases with increasing enhascement ratio. For tube diameters around 1 inch, the optimum tube length ranges from 25 to 50 feet, depending on the area ratio. For tube diameters around 2 inches, the optimum length ranges from 40 to 80 feet. Considering, in 
addition to the cost impact on the power system, other factors such as arrangement, draft (the ammonia pumps must be lower than the lower tubesheet by the distance required to provide sufficient suction head) and heat exchanger performance risk (possible performance degradation due to ammonia side Reynolds number effects) TRW selected a nominally 1 inch 0.D. tube with 36 flutes. This tube design is discussed in Section 2.4. For this tube design, the OTEC-II program was exercised to determine the major design characteristics as shown in Table 2.1-13 which shows the program output. The model was run with a required net output of 10.5 MWe to account for miscellaneous loads not included in the model (model accounts for seawater

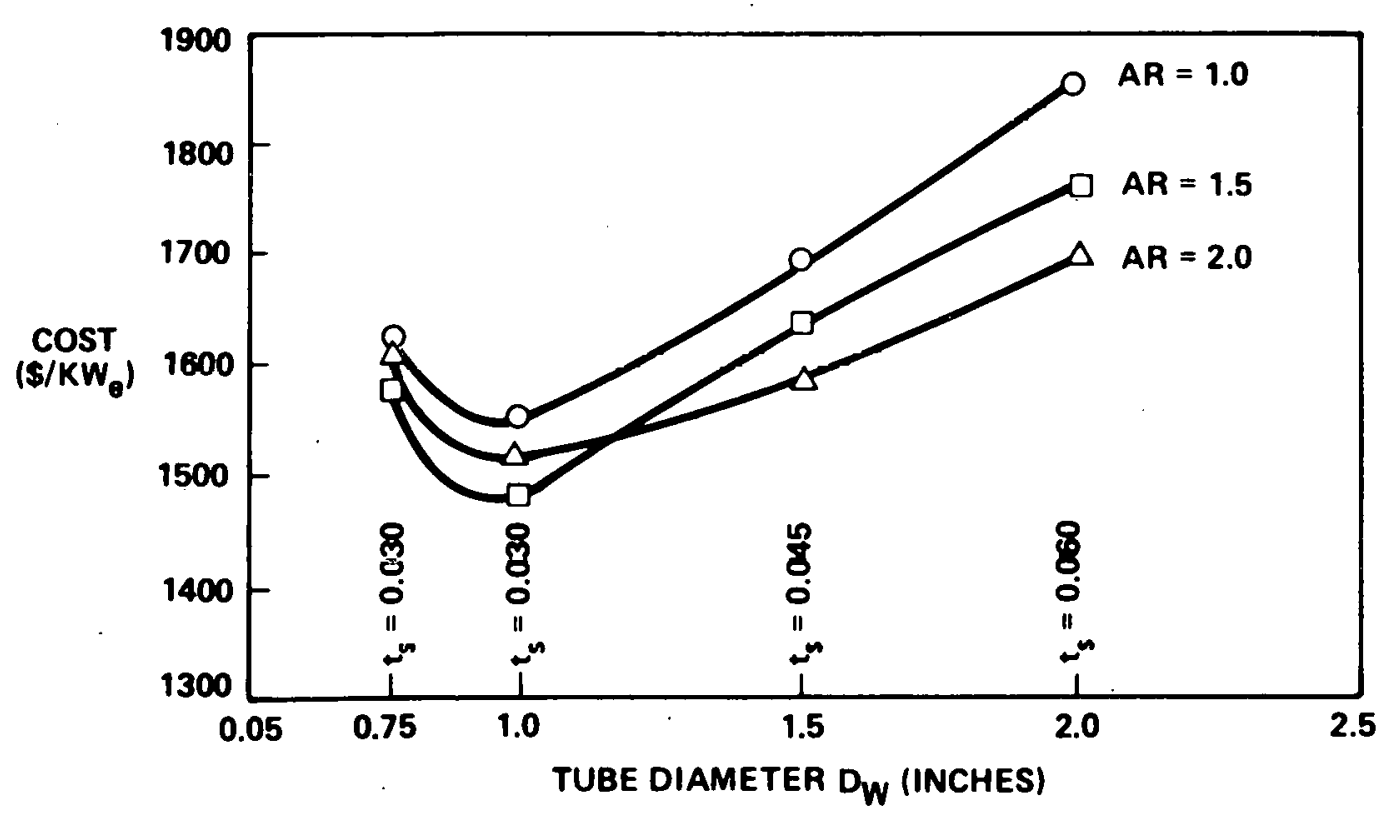

Figure 2.1-14. OTEC Design Model - System Optimization 
pumps and power loop ammonia pumps as parasitic losses). The plant efficiency listed is based on 10.5 MWe power "net."

It may be observed that the total length of the evaporator and condenser tubes are the same, 29 feet, 10 inches. This simplifies the topology of the design and does not penalize cost. Computer studies showed that for suboptimized design with tube length constrained were within 2.5 percent of the "mathematical" optimum for any combination of tube lengths in the 30 to 40 feet range (see Figure 2 of Appendix A1).

\subsubsection{System Design Characteristics and Sensitivities}

The functional characteristics of the system design were derived by the computer optimization studies discussed in the previous section. The validity and accuracy of the computer model were checked by extensive hand calculations which verified the modeling approach. This section ampliffes the computer results by independently deriving and discussing major functional characteristics.

\subsubsection{Ammonia Power Loop}

The closed ammonia power cycle is a simple Rankine cycle with none of the complications of modern steam power plants such as superheat, reheat and regeneration. The Mollier chart in Figure 2.1-15 shows the state points of the cycle at nominal design conditions ignoring minor pressure drops in the ammonia cycle and the small amount of energy added by the ammonia pumps. (These minor effects have been taken into account in the OTEC II model. See àiso Section 2.1.8.3.)

The following important observations can be made from the Mollier chart:

1. The cycle is very close to the ideal Carnot Cycle. Therefore, practically nothing can be gained by reheating and regenerative heating. The ideal Carnot Cycle efficiency is for $\mathrm{T}_{\text {evap }}=70^{\circ} \mathrm{F}$ $\mathrm{T}_{\text {cond }}=50^{\circ} \mathrm{F}$

$$
\varepsilon_{\text {Carnot }}=\frac{70-50^{\circ}}{459.7+70}=3.78 \%
$$




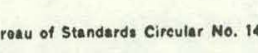

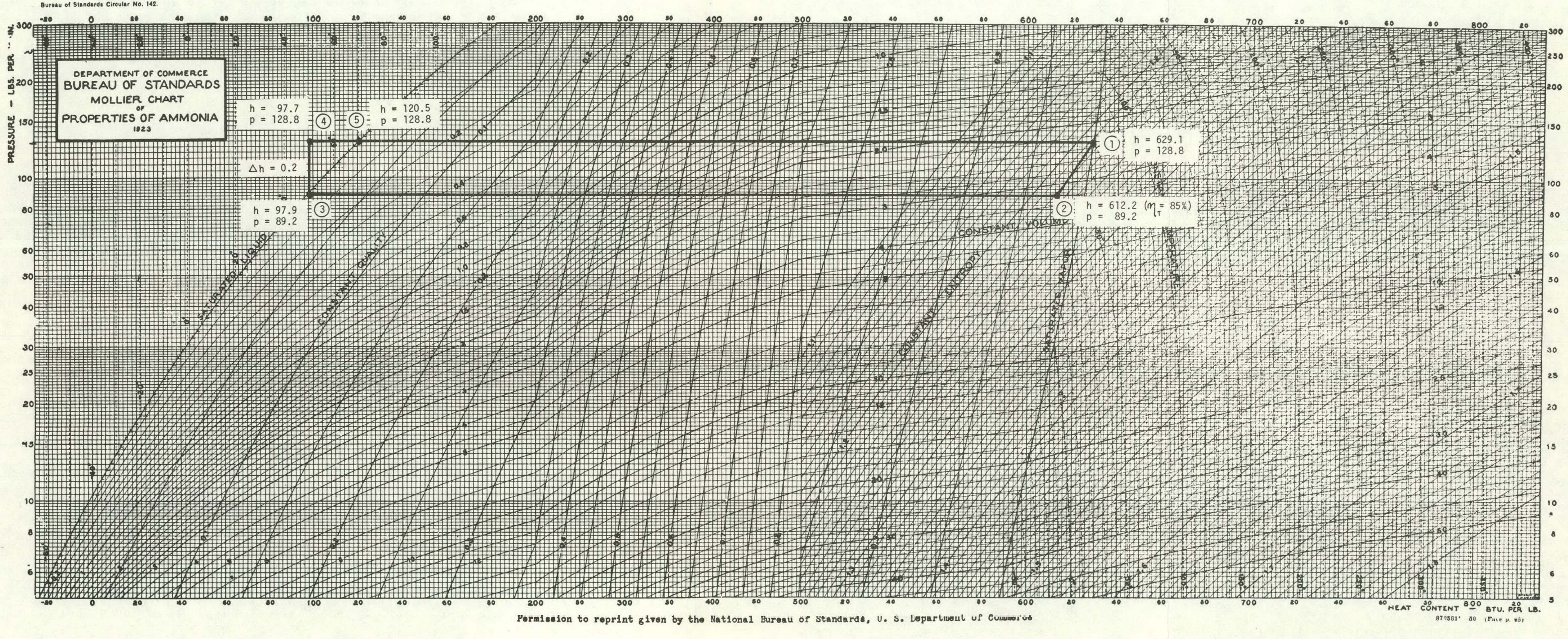

Pormiesion to reprint given by the National Bureau of Standarde, U. S. Leppartusul uf evumosivo 
The Rankine Cycle efficiency with 85 percent turbine efficiency is (ignoring pump work) from Figure 2.1-15:

$$
\varepsilon_{\text {Rankine }}=\frac{h_{1}-h_{2}}{h_{1}-h_{3}}=\left(\frac{629.1-612.2}{629.1-97.9}\right) \times 100=3.18 \%
$$

In other words, with an ideal turbine the ideal Rankine Cycle efficiency is $3.18 / 0.85=3.74 \%$, i.e., very close to Carnot. (Note that if the ideal pump work is included as is normally done when defining Rankine Cycle efficiency this last number is reduced to $3.70 \%$.) The plant efficiency of $2.32 \%$ shown in Table 2.1-13 accounts for parasitic losses due to ammonia and water pumps.

2. The preheating load is only a small fraction of the total evaporator load:

$$
\varepsilon_{\text {P.H }}=\frac{h_{5}-h_{4}}{h_{1}-h_{4}}=\left(\frac{120.5-97.7}{629.1-97.7}\right) \times 100=4.3 \%
$$

In other words, almost all of the heat is added at the highest temperature, a requirement for high efficiency. (Note that in the OTEC II model the effective tube length does not include the portion of the tube within the distribution plenum (see Section 2.4) which leads to a slightly conservative estimate of the heat transfer capability of the exchanger.)

3. The turbine exit quality is approximately 2.5 percent lower than the inlet. quality. With an inlet quality approaching 100 percent in our design, the exit quality is about 97.5 percent. Conventional steam power plants operate typically with 90 percent or lower quality in their low pressure stages without serious efficiency or materials erosion problems.

A detailed static pressure profile for the complete ammonia loop at nominal operating conditions was prepared to validate the design and support detailed mechanical design. Figure 2.1-16 shows the profile with station numbers delined in lhe insert to this figure. The computed values of absolute pressure are summarized in Table 2.1-21. The pressures shown are based on the actual plant layout as shown in Figure 2.1-6. 
- Table 2.1-21. Computed Values of Absolute Pressure

\begin{tabular}{|c|c|c|}
\hline Station No. & Location & Static Pressure (psia) \\
\hline 1 & Condenser Outlet & 89.12 \\
\hline$\cdot 2$ & Condenser Sump & 89.15 \\
\hline 3 & Feed Pump Inlet & 93.34 \\
\hline 4 & Feed Pump Outlet & 135.14 \\
\hline 5 & Evaporator Sump & 128.80 \\
\hline 6 & Recirculation Pump Inlet. & 131.82 \\
\hline 7 & Recirculation Pump Outlet & 146.97 \\
\hline 8 & Filter Outlet & 145.97 \\
\hline 9 & Control Valve Inlet & 137.74 \\
\hline 10 & Control Valve Outlet & $137.54^{\circ}$ \\
\hline 11 & Evaporator Inlet & 129.84 \\
\hline 12 & Evaporator Mean & 129.32 \\
\hline 13 & Evaporator Outlet & .128 .80 \\
\hline 14 & Turbine Intet & 128.70 \\
\hline 15 & Turbine Outlet & 89.19 \\
\hline 16 & Condenser Inlet & 89.19 \\
\hline 17 & Condenser Mean & 89.15 \\
\hline
\end{tabular}




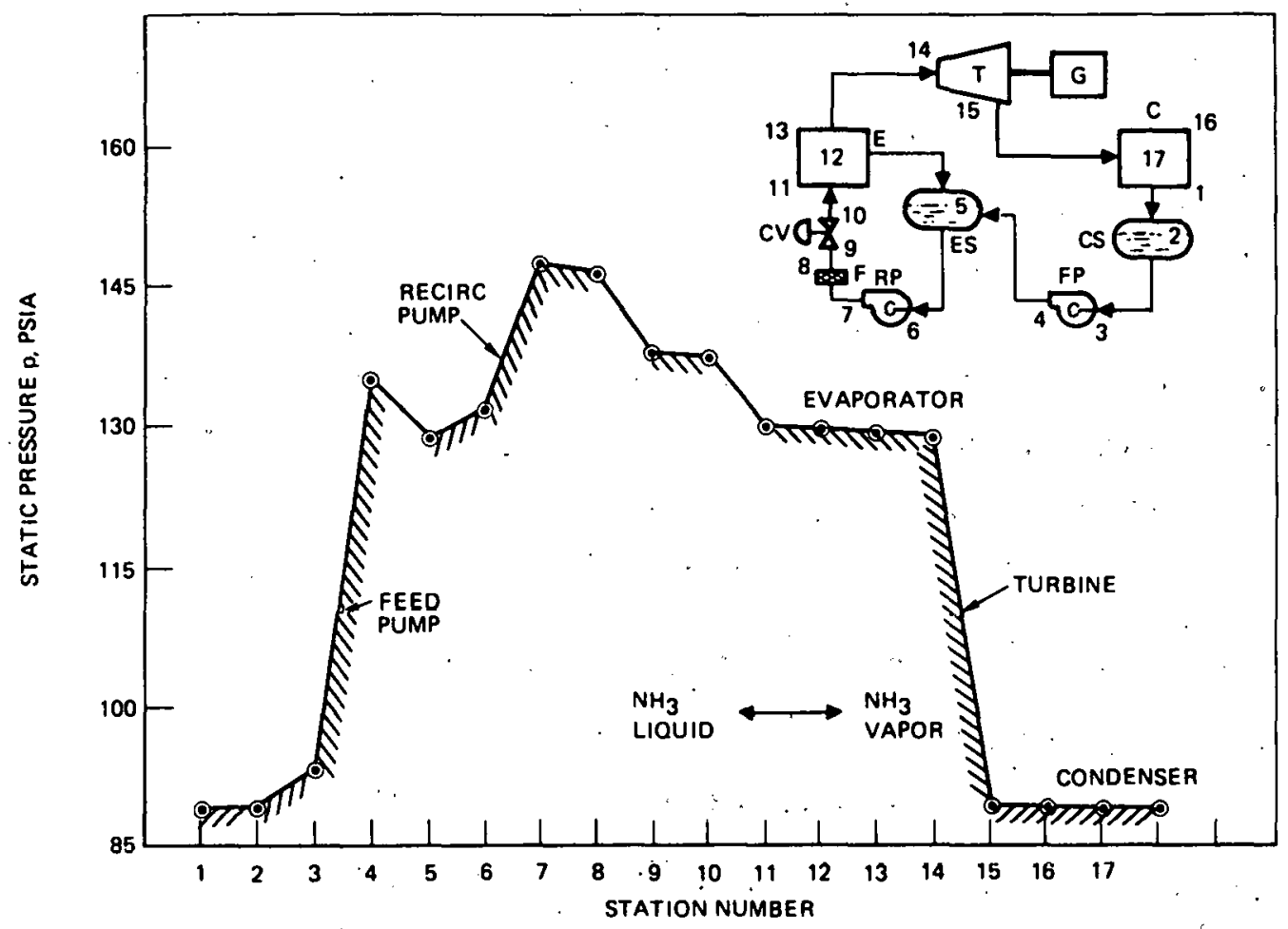

Figure 2.1-16. Static Pressure Profile

\subsubsection{Warm and Cold Water Loops}

To perform a system level optimization of the power module design, TRW conceptualized a design of the warm and cold seawater supply and discharge subsystems. This allowed verification of the total DOE pressure drop requirements of:

- Warm water subsystem, 10 feet of $\mathrm{H}_{2} \mathrm{O}$

- Cold water subsystem, 15 feet of $\mathrm{H}_{2} \mathrm{O}$

Without an allocation to the heat exchangers and to the components external to the heat exchangers, the above requirements are meaningless. On the other hand, it would be too restrictive on the overall system to define. al lowable pressure drops for the heat exchangers only.

TRW's approach was to postulate a design of the warm and cold seawater subsystems and then to optimize the design of the power module including the water systems. This optimization addressed the cost of the power module, cost of water pumps and drives, and cost of water ducting. The parasitic 
power of the seawater pumps was included in the power budget and the cost of net power $(\$ / \mathrm{KWe})$ was minimized. The linear velocity in the external ducting was constrained to 6 fps based on experience from total system optimization studies. (Prior studies for ERDA (Reference 3 ) indicated that the optimum velocity of flow in the cold water pipe is in the 6 to 7 fps range.)

The depth to the cold water intake was fixed at 3000 feet as specified by DOE and the length of the discharge ducts were selected to be 300 feet. The system optimization study; using the approach outlined above; resulted in overall pressure drops as follows:

\section{- Warm water subsystem 10.6 feet of warm seawater \\ - Cold water subsystem 15.0 feet of cold seawater}

It should be emphasized that it was somewhat fortuitous that the optimum total pressure drops came out so close to the requirement.

Figures 2.1-17 and 2.1-18 show the piezometric head distribution (or grade line) and Tables 2.1-22 and 2.1-23 give the actual head values at each station. From the tables it can be deduced that the pressure drops allocated to the evaporator and condenser (including allowance for entrance and exit losses to and from the tubesheets) are 9.30 and 8.14 feet respectively at design conditions. The ducting diameters at optimum flow rate are 15.9 feet I.D: and 15.3 feet I.D., respectively, for the warm and cold water ducts (including cold water pipe). Note that the cold water pipe I.D. of 15.3 feet is for one 10 MWe power module. For a 40 . MWe system the optimum diameter would be about twice as large.

These results are for a set of asșumed nominal conditions for friction factors and loss (K) factors. The basis for the analysis including results of a sensitivity study considering low (optimistic), nominal, and high (pessimistic) estimates for the loss coefficients and tube friction factors. of \pm 10 percent relative to nominal, are summarized in Figure 2.1-19. The impact on the power budget (fixed flow rate such that pumping power is proportional to head) is shown. in Table 2.1-24. The net power variation. . is +5 and -10 percent. 


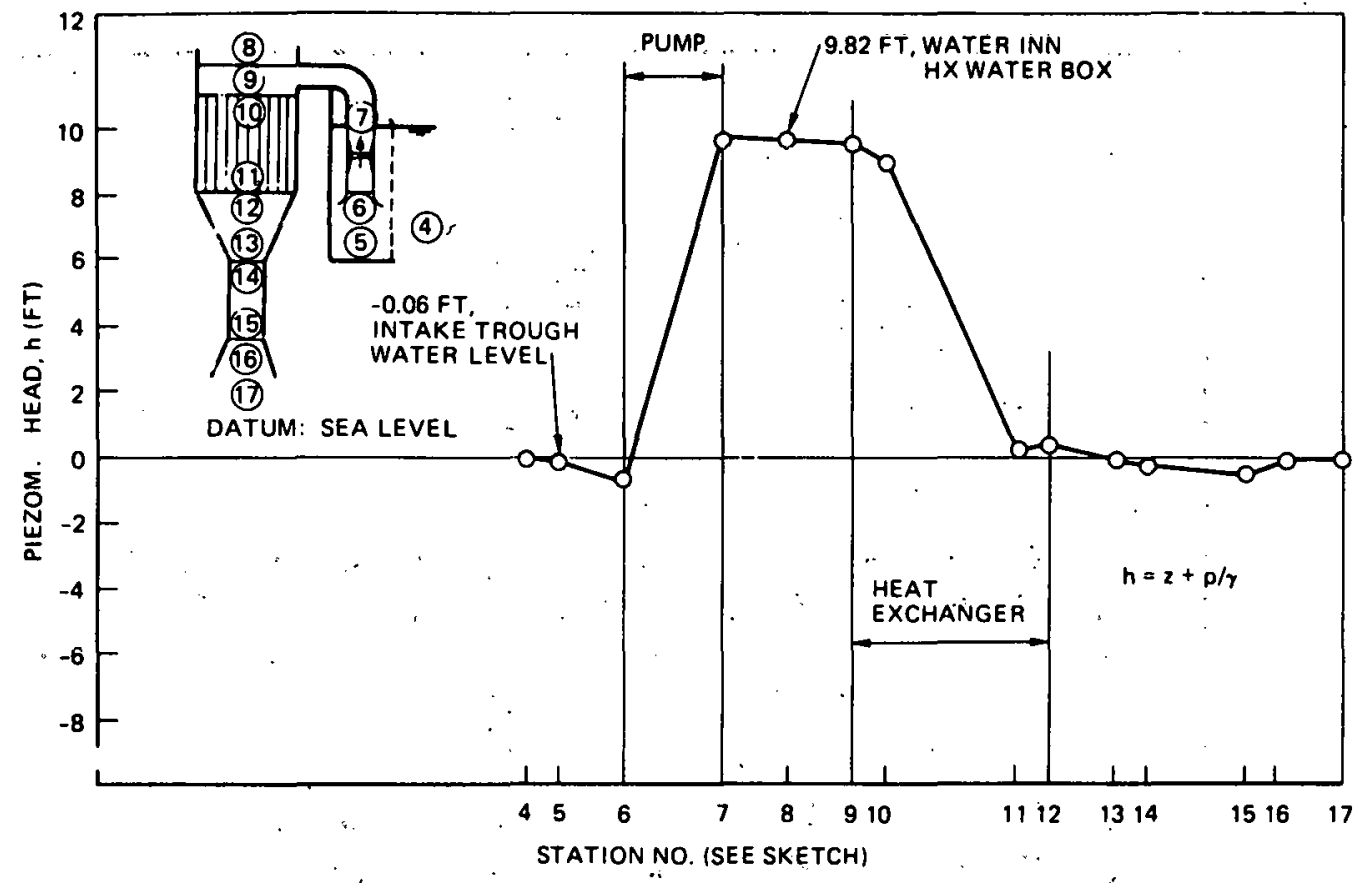

Figure 2.1-17. Piezometric Head Distribution Warm Water Subsystcm (Nominal)

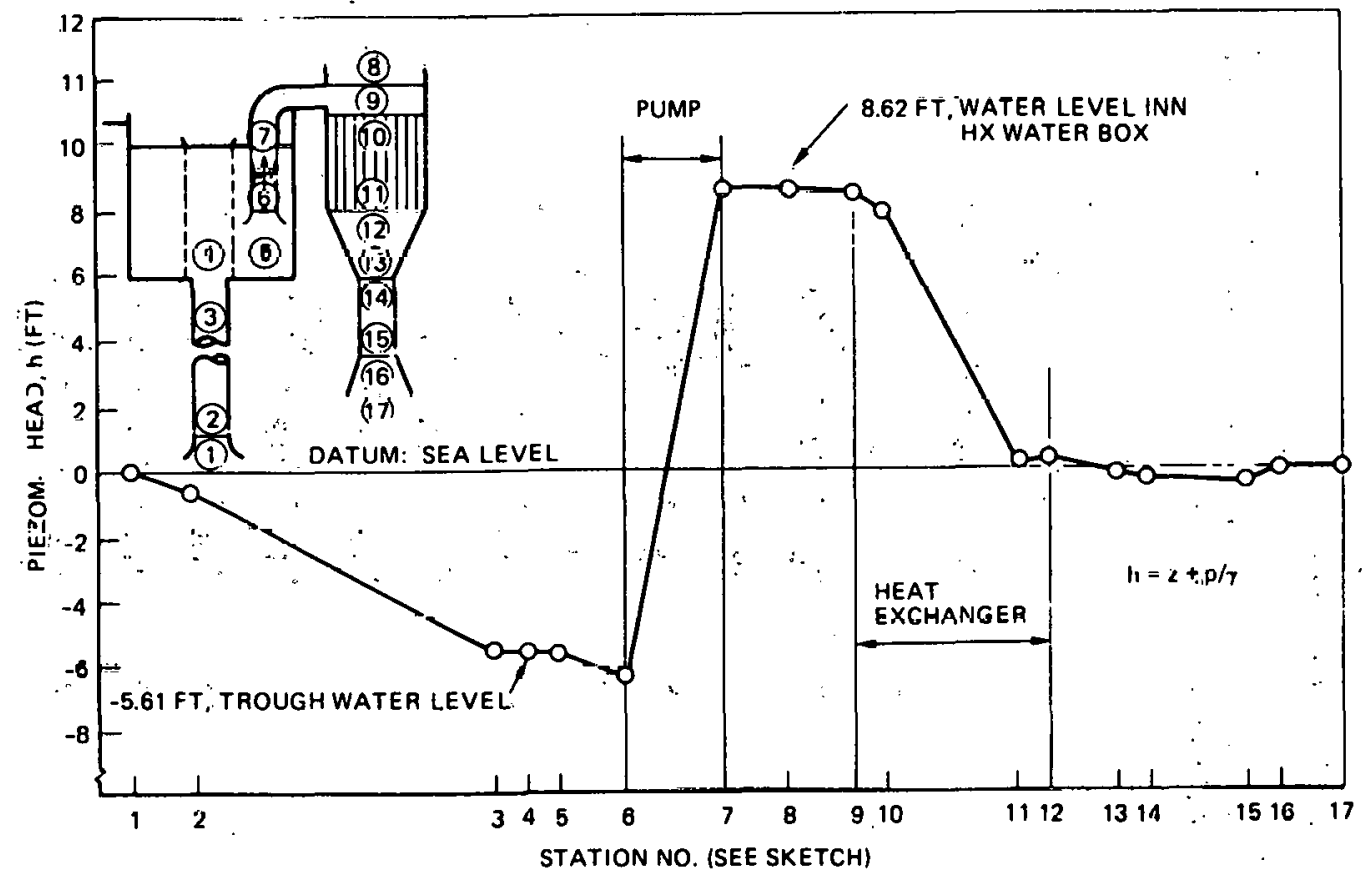

Figure 2.1-18. Piezometric Head" Distribution Cold Water Subsystem (Nominal) 
Table 2.1-22. Piezometric Head, Cold Water Side (Nominal) $z_{0}+\frac{P_{0}}{\gamma}+\frac{V_{0}{ }^{2}}{2 g}=z_{1}+\frac{P_{1}}{\gamma}+\frac{V_{1}{ }^{2}}{2 g}+H_{L}$ $h=z+P / \gamma(f t)$

\begin{tabular}{|c|c|c|c|c|}
\hline Station 1 & $\mathrm{~h}_{Y}=0$ & & & $\therefore$ \\
\hline 2 & $h_{2}=h_{1}-v^{2} / 2 g-H_{L}$ & $=0-0.56-0.14$ & $=-0.70$ & \\
\hline 3 & $h_{3}=h_{2}-H_{L}-H_{G}$ & $=-0.70-1.91-3.00$ & $=-5.61$ & \\
\hline 4 & $h_{4}=h_{3}-H_{L}+v^{2} / 2 g$ & $=-5.61-0.56+0.56$ & $=-5.61$ & \\
\hline 5 & $h_{5}=h_{4}-H_{L}$ & $=-5.61-0.06$ & $=-5.67$ & \\
\hline 6 & $h_{5}=h_{5}-v^{2} / 2 g-H_{L}$ & $=-5.67-0.56-0.14$ & $=-6.37$ & \\
\hline 7 & $h_{7}=h_{6}+H_{\text {pump }}$ & $=-6.37+14.99$ & $=+8.62$ & \\
\hline 8 & $h_{8}=h_{7}+v^{2} / 2 g-H_{L}$. & $=8.62+0.56-0.56$ & $=8.62$ & \\
\hline 9 & $h_{9}=h_{8}-v_{1}^{2} / 2 g$ & $=8.62-0.14$ & $=8.48$ & Based on $V_{1}=3 \mathrm{fps}$ \\
\hline 10 & $h_{10}=h_{g}+V_{1}^{2} / 2 g-V_{2}^{2} / 2 g-H_{L}$ & $=8.48+0.14-0.56-0.16$ & $=7.90$ & Based on $v_{2}=6 \mathrm{fps}$ \\
\hline 11 & $h_{11}=h_{10}-H_{L_{2}}$ & $=7.90-7.77$ & $=0.13$ & \\
\hline 12 & $h_{12}=h_{11}+V_{2}^{2} / 2 g-V_{1}^{2} / 2 g-H_{L}$ & $=0.13+0.56-0.14-0.21$ & $=0.34$ & \\
\hline 13 & $h_{13}=h_{12}+v_{1}^{2} / 2 g-v_{2}^{2} / 2 g$ & $=0.34+0.14-0.56$ & $=-0.08$ & \\
\hline 14 & $h_{14}=h_{13}-H_{L}$ & $=-0.08-0.14$ & $=-0.22$ & \\
\hline 15 & $h_{15}=h_{14}-H_{L_{2}}$ & $=-0.22-0.20$ & $=-0.42$. & \\
\hline 16 & $h_{16}=h_{15}+v_{2}^{2} / 2 g-v_{1 / 2 g}^{2}$ & $=-0.42+0.56-0.14$ & $=0.00$ & \\
\hline 17 & $h_{17}=h_{16}+V_{1}^{2} / 2 g-H_{L}$ & $=0.00+0.14-0.14$ & $=0.00$ & \\
\hline
\end{tabular}

See Figure 2.1-20 for head losses 
Table 2.1-23. Piezometric Head, Warm Water Side (Nominal)

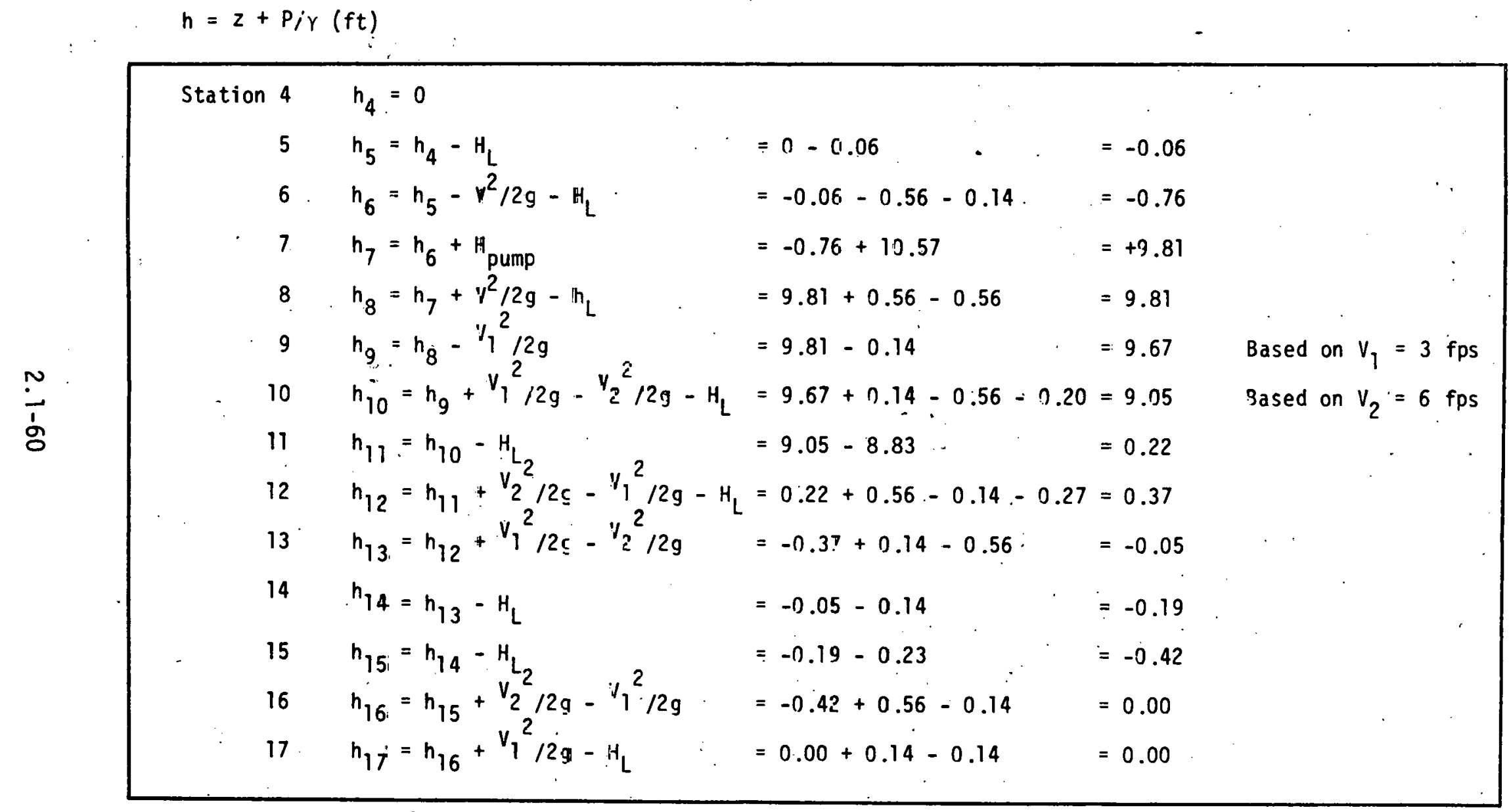

See Figure 2,1-20 for head lossès 


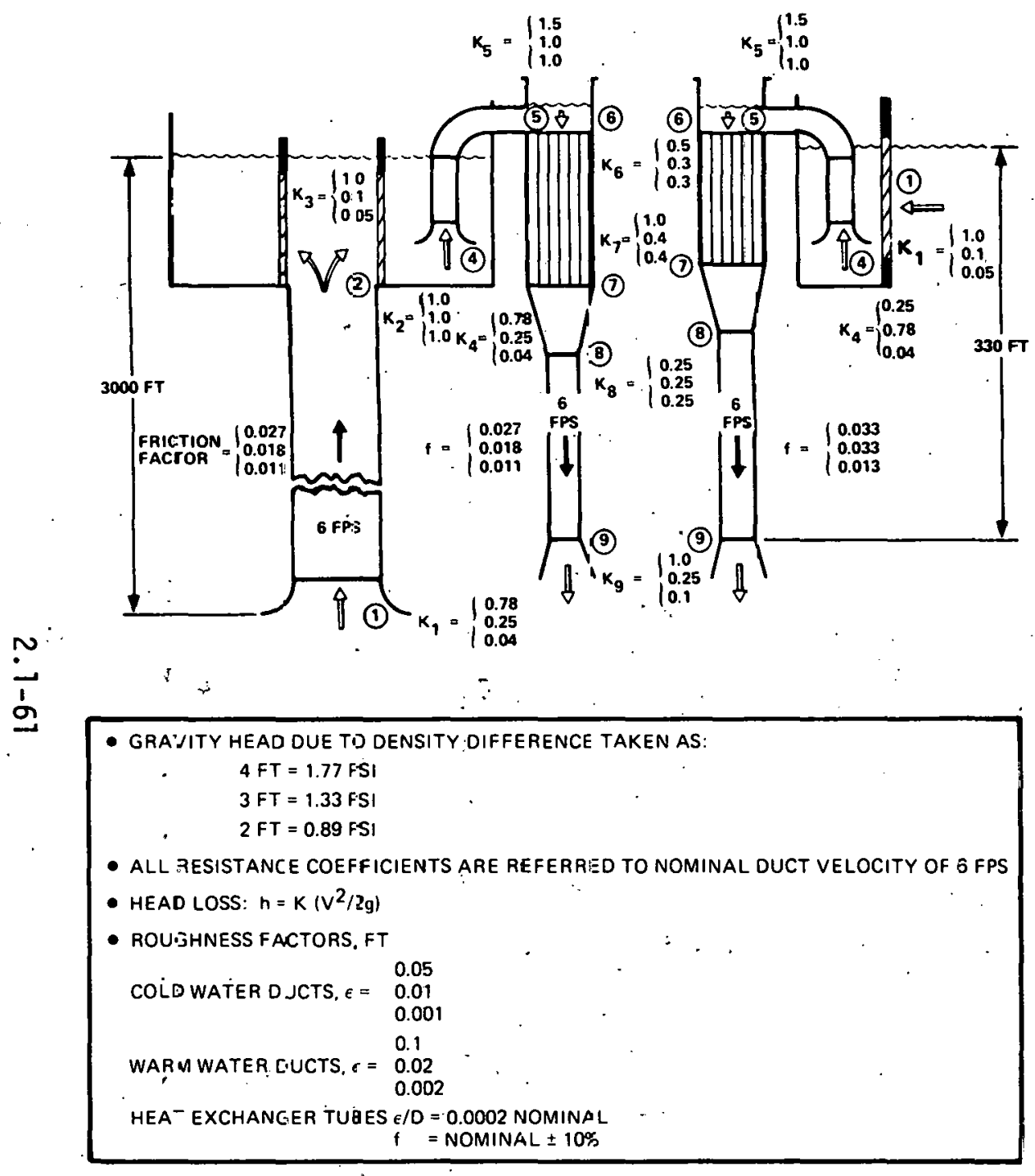

\begin{tabular}{|c|c|c|c|c|}
\hline & & & & \\
\hline \multirow{2}{*}{ KEY } & \multirow{2}{*}{ DESCRIPTION } & \multicolumn{3}{|c|}{$\begin{array}{c}\text { PRESSURE LOSS ESTIMATE, } \\
\mathrm{FT}\end{array}$} \\
\hline & & Low & NOMINAL & $\mathrm{HIGH}$ \\
\hline $1_{1}$ & WARM WATER TROUGH SCREEN & 0.03 & 0.06 & 0.56 \\
\hline 4 & WW PUMP ENTRANCE & 0.02 & 0.14 & 0.44 \\
\hline 5 & WW DUCT BEND AND DUMPING * & 0.56 & 0.56 & 0.84 \\
\hline 6 & EVAPORATOR ENTRANCE & 0.20 & 0.20 & 0.33 \\
\hline $6-7$ & EVAPORATOR TUBES FRICTION & 7.95 & 8.83 & 9.71 \\
\hline 7 & EVAPORATOR EXIT & 0.27 & 0.27 & 0.68 \\
\hline 8 & TRANSITION TO WW DISCHARGE PIPE & 0.14 & 0.14 & 0.14 \\
\hline 7.9 & WW DISCHARGE PIPE FRICTION & 0.14 & 0.24 & 0.37 \\
\hline 9 & WW DUMPING & 0.06 & 0.14 & 0.56 \\
\hline . & TOTAL & 9.37 & 10.58 & 13.63 \\
\hline
\end{tabular}

\begin{tabular}{|c|c|c|c|c|}
\hline \multicolumn{5}{|c|}{ COLD WATER SIDE } \\
\hline 1 & CWP ENTRANCE & 0.02 & 0.14 & 0.44 \\
\hline 1.2 & CWP FRICTION & 1.16 & 1.91 & 2.86 \\
\hline 1.2 & CWP GRAVITY DIFFERENCE & 2.00 & 3.00 & 4.00 \\
\hline 2 & CWP EXIT & 0.56 & 0.56 & 0.56 \\
\hline 3 & CW TROUGH SCREEN & 0.03 & 0.06 & 0.56 \\
\hline 4 & CW PUMMP ENTRANCE : & 0.02 & 0.14 & 0.44 \\
\hline 5 & CW DUCT BEND AND DUMPING & 0.56 & 0.56 & 0.84 \\
\hline 6 & CONDENSER ENTRANCE & 0.16 & 0.16 & 0.26 \\
\hline 6.7 & CONDENSER TUBES FRICTION & 6.99 & 7.77 & 8.55 \\
\hline 7 & CONDENSER EXIT & 0.21 & 0.21 & 0.53 \\
\hline 8 & TRANSITION TO CW DISCHARGE PIPE & 0.14 & 0.14 & 0.14 \\
\hline 7.9 & CW DISCHARGE PIFE FRICTION & 0.12 & 0.20 & 0.30 \\
\hline 9 & CW DUMPING & 0.06 & 0.14 & .0 .56 \\
\hline \multicolumn{2}{|r|}{ TOTAL } & 12.03 & 14.99 & 20.04 \\
\hline
\end{tabular}

Figure 2.1-19. Loss Coefficients 
Table 2.1-24. Parasitic Power Losses For Baseline Power Module (10 MWe Nominal)

\begin{tabular}{|l|c|c|c|}
\hline \multicolumn{1}{|c|}{ OTEC Power Budget } & Design Norm & Optimistic & Pessimistic \\
\hline Gross Power (MWe) & 14.03 & 14.03 & 14.03 \\
Net Power (MWe) & 10.00 & 10.50 & 9.01 \\
Gross Power/Net Power & 1.403 & 1.336 & 1.557 \\
Warm Water Pumping Power (MWe) & 1.35 & 1.20 & 1.74 \\
Cold Water Pumping Power (MWe) & 1.78 & 1.43 & 2.38 \\
Ammonia Feed Pumping Power (MWe) & 0.24 & 0.24 & 0.24 \\
$\begin{array}{l}\text { Ammonia Recirculation Pumping } \\
\text { Power (MWe) } \\
\text { Miscellaneous (MWe) }\end{array}$ & 0.14 & 0.14 & 0.14 \\
\hline
\end{tabular}

\subsubsection{Energy Balance and Power Budget}

The plant energy balance for the power module (actually an energy rate or power balance) is illustrated in Figure 2.1-20. All the important energy transfer rates in the ammonia power loop are shown making the assumption that all piping, except for the condenser, is thermally insulated. (Heat leaks into the condenser (at $50^{\circ} \mathrm{F}$ ) from warm seawater (at $80^{\circ} \mathrm{F}$ ).) The thermal leakage into the condenser is estimated to be approximately 7.0 MBtu/hr or about 0.5 percent of the condenser duty. In the present design, about 200 tubes will be added to compensate for this effect.

The energy balance diagram was based on the results of the OTEC=II computer program (see Table 2.1-13) except for a minor update of the ammonia pumip luads. Extensive hand colculations were carried out for additional checking. The energy balance and power budget displayed are based on the nominal conditions of $80^{\circ} \mathrm{F}$ warm water and $40^{\circ} \mathrm{F}$ cold water.

The energy balance includes effects of the ammonia pumps and the loads on the environmental control system (ECS) (ventilation, cooling, etc.) due to drive and pump inefficiencies and to generator inefficiency. 
In the power budget an allowance of 0.52 MWe was included for other parasitic losses. A gross estimate of power required to run the ammonia support subsystem is 50 to $300 \mathrm{~kW}$ (depending on whether the rectification column (see Section 2.8) is operating or not. This leaves about $200 \mathrm{kWe}$

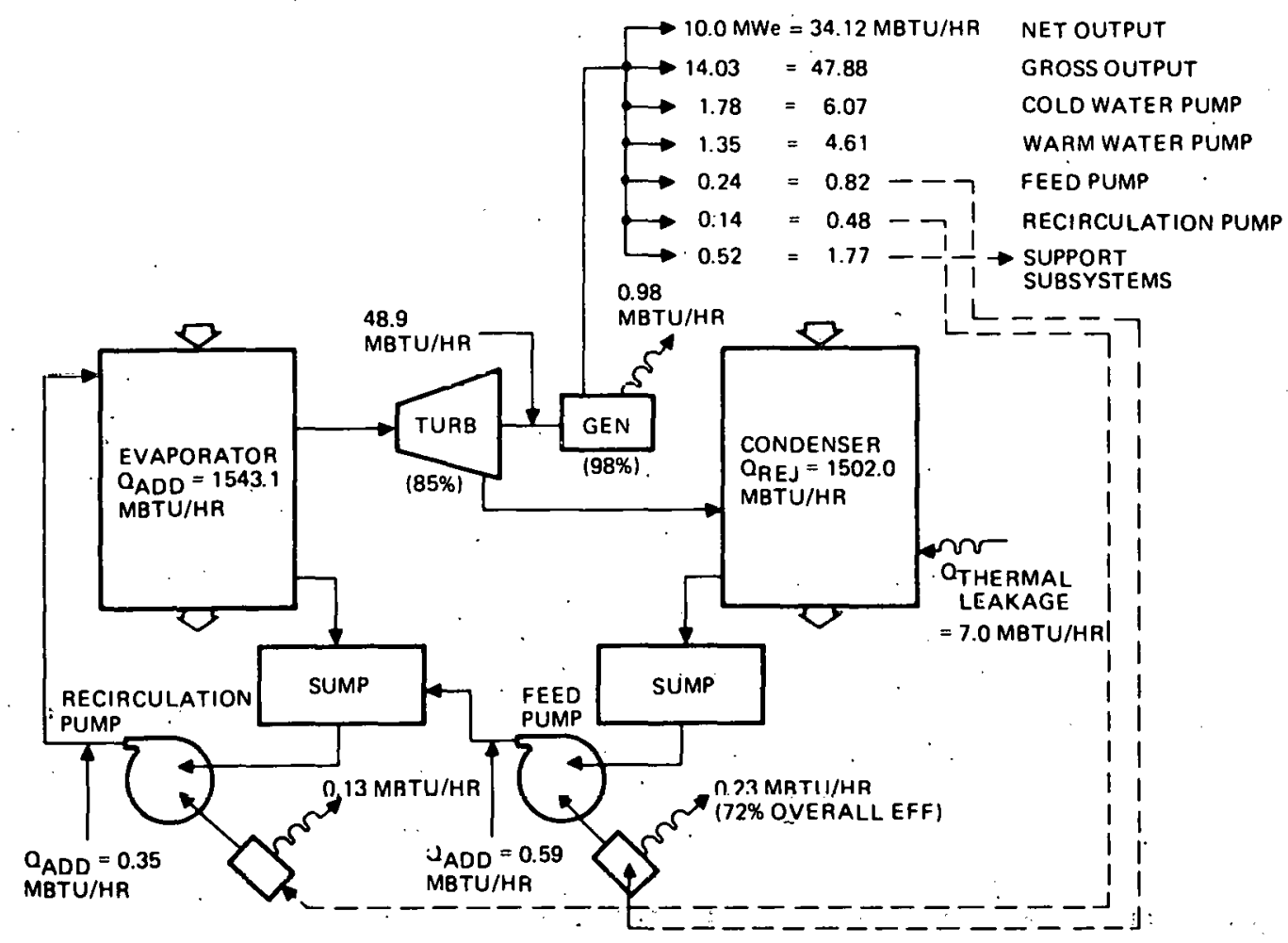

1) GROSS ENERGY BALANCE ON AMMONIA LOOP

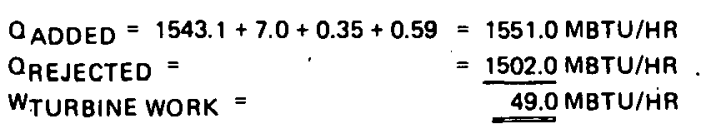

WTURBINE WORK $=\quad 49.0 \mathrm{MBTU} / \mathrm{HR}$

2) ENVIRONMENTAL CONTROL SYSTEM LOADS

$a_{E C S}=0.98+0.13+0.23+Q_{\text {SUPPORT SUBSYSTEMS MBTU/HR }}$

Figure 2.1-20. Energy Transfer Rates in Amonia Power Loop 
for other support subsystems. Variations of net and gross power with water flow rate, temperature, fouling, etc. are discussed in Section 2.2.4.

The power module efficiency can be'calculated from the data in the figure 2.1-20:

$$
\varepsilon=\frac{W_{\text {Net }}}{Q_{\text {Evap }}}=\left(\frac{34.12}{1543.7}\right) \times 100=2: 21 \%
$$

The seawater side energy balances can be verified using data from Table 2.1-13. The energy added to the seawater by the seawater pumps and. motors result in only $0.018^{\circ} \mathrm{F}$ and $0.025^{\circ} \mathrm{F}$ of heating of the warm and cold * water respectively and thus was neglected. (The effects also.tend to . : cancel each other.)

Adiabatic cooling of water from 3000 feet amounts to about a $0.14^{\circ} \mathrm{F}$ temperature decrease ( 1 :ference 4 ). This effect is partially or completely offset by thermal conduction through the cold water pipe wall in the upper warmer layers. A simple analysis shows that this last effect is small (less than $0.5^{\circ} \mathrm{F}$ ) even in bare steel pipes if the pipe diameter is larger than about 20 feet. For smaller pipes thermal insulation may be required above the thermocline.

\subsubsection{Design Sensitivity Analyses}

litis sectlon summarizes the result's of various design sensitivity studies. Sensitivity analyses addressing specifically off-design performance are discussed in Section 2.2.4.

Turbine Efficiency. The system design was completed assuming a turbine efficiency of 85 percent at design'conditions. Results from Elliott's turbine study (Appendix F), available near the end of the preliminary design phase, indicate that efficiencies of about 88 percent can be expected. Since gross output of a given plant is directly proportional to turbine 
efficiency, hand calculations are sufficient to determine the sensitivity of net power and cost of delivered energy to actually achieved turbine efficiency. Figure 2.1-21 shows the result and inherent assumptions. A change in turbine efficiency from 85 to 88 percent results in an increase in net power from 10 MWe to 10.5 MWe: a five percent increase in power resuits from a three percent increase in efficiency.

An alternate analysis, using the OTEC-II model to optimize designs for three different turbine efficiencies $(80,85$ and 90 percent), provides additional substantiation. The model was run with a fixed tube design (length, diameter, enhancement) equal to our baseline design. Optimization with respect to number of tubes and seawater flow rates produced the results of Table 2.1-25. Each percentage point is worth approximately $17 \$ / \mathrm{KW}$. It is cost effective to pay up to $\$ 170,000$ to increase turbine efficiency one percentage point. Table 2.1-25 also shows the obvious result that for a fixed net power the heat exchanger tube count (or heat exchanger area) decreases with increasing efficiency. Each percentage point results in a savings of approximately 720 tubes per exchanger or about 1.7 percent heat transfer area reduction per percent turbine efficiency increase.

Heat Exchanger Performance. The prediction of the performance of a given heat exchanger design is complicated by uncertainties in fouling, water and ammonia side heat transfer coefficients. A simplified analysis, assuming constant turbine efficiency at off-design conditions, was performed to estimate the sensitivity of net power and cost of delivered energy with heat exchanger performance. Figure 2.1-22 shows the result assuming the same relative variation of both evaporator and condenser performance. In our design, if the fouling factor increases from the design value of 0.0001 to $0.0005 \mathrm{~F}-\mathrm{hr}-\mathrm{ft}^{2} / \mathrm{Btu}$, the heat transfer coefficients decrease on the average by 25 percent such that $U$ to $U$ design $=0.75$. The net power thus will decrease from 10 MWe to approximately 7.4 MWe. More accurate analyses, using TRW's recently developed off-design model, are discussed in Section 2.2.4.

Distribution of Available $\Delta T$ Between Turbine and Heat Exchangers. Based on prior OTEC system analysis studies, the available $\triangle T$ was allocated between evaporator, turblne drid cundenser according to the $(1 / 4,1 / 2,1 / 4)$ rule at design conditions. All tradeoff analyses used this constraint. 


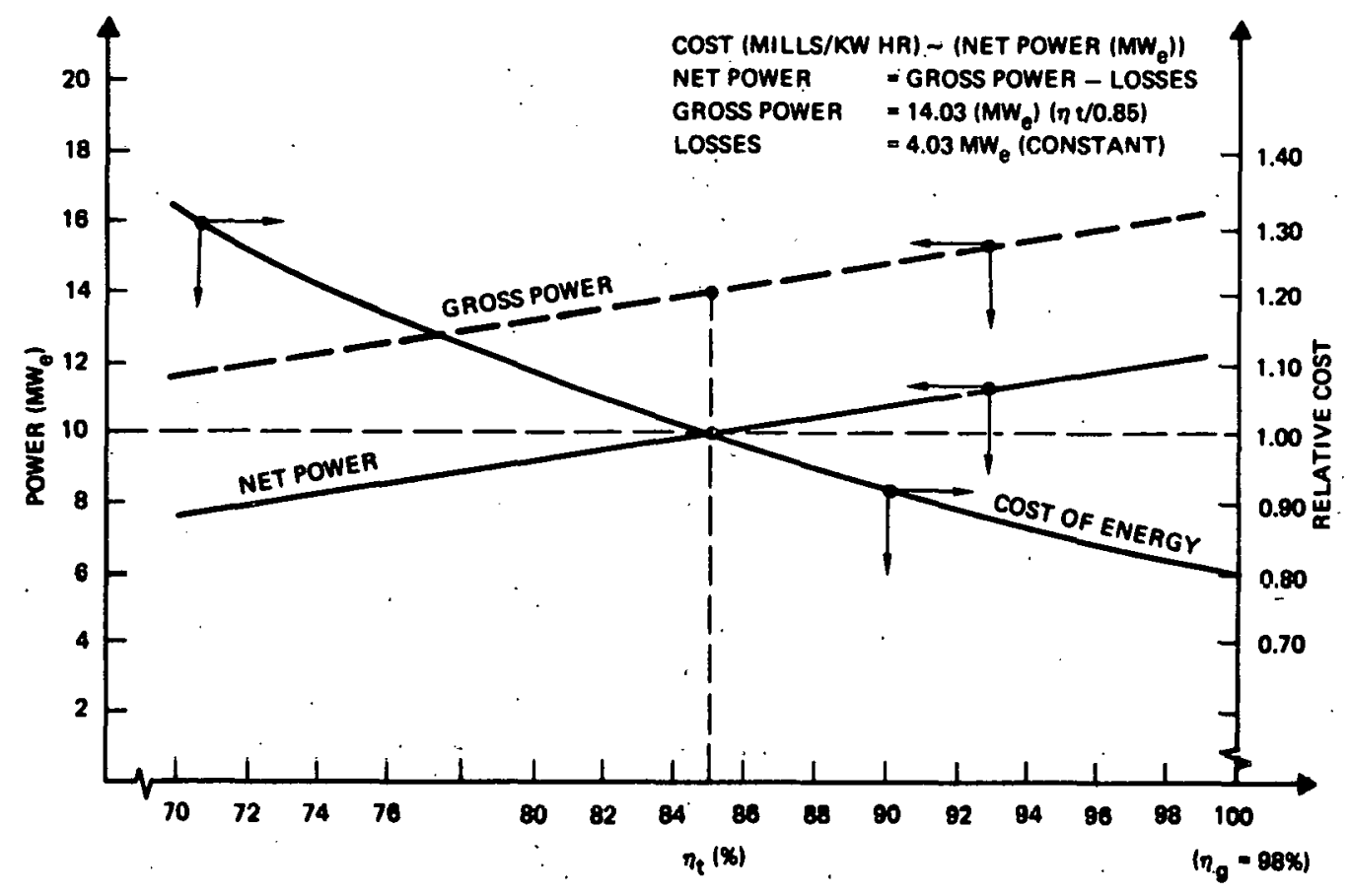

Figure 2.1-21. Sensitivity of Net Power and Energy Cost to Turbine Efficiency

Table 2.1-25. Design and Cost Versus Turbine Efficiency

\begin{tabular}{|c|c|c|c|c|c|}
\hline \multirow{2}{*}{$\begin{array}{c}\text { Turbine } \\
\text { Eff., Percent }\end{array}$} & \multirow{2}{*}{$\begin{array}{l}\text { Net } \\
\text { Power, } \\
\text { MWe }\end{array}$} & \multicolumn{2}{|c|}{ Number of Tubes } & \multirow{2}{*}{$\begin{array}{l}\text { Cost Mode1 } \\
\text { Prototype, } \\
\$ / \mathrm{kW}\end{array}$} & \multirow{2}{*}{$\begin{array}{l}\text { Cost Sens. } \\
\$ / \mathrm{kW}\end{array}$} \\
\hline & & Evaporator & Condenser & & \\
\hline 90 & 10 & 39995 & 39523 & 1362 & -81 \\
\hline $85 \ldots$ & 10 & 42667 & 43678 & 1443 & 0 \\
\hline 80 & 10 & 46984 & 46938 & 1536 & 93 \\
\hline & Slope at & $5 \% \frac{93-(-\varepsilon}{10}$ & $=17.4$ & $\$ / \mathrm{kW} / \%$ & $\therefore$ \\
\hline
\end{tabular}




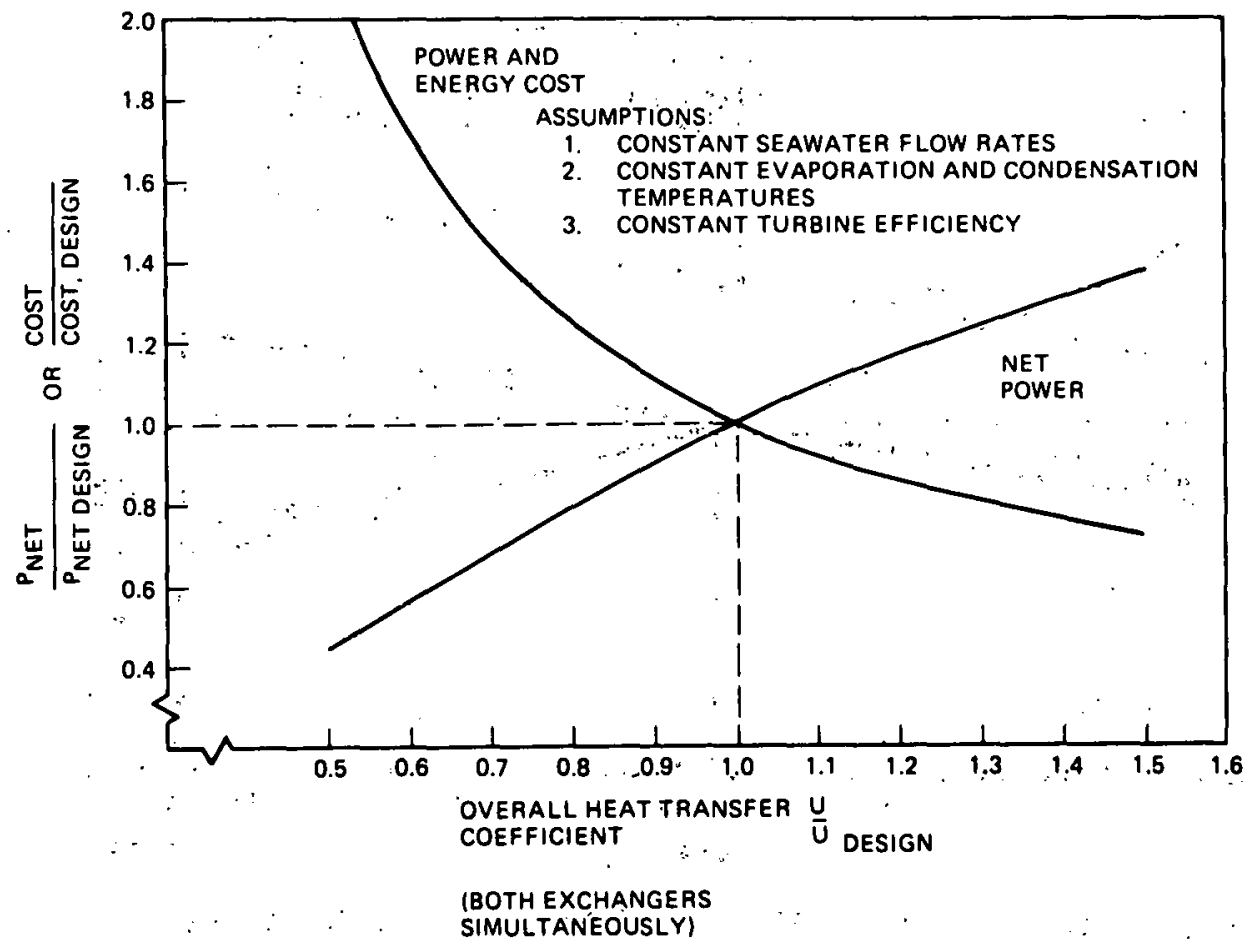

Figure 2.1-22. Sensitivity to Heat Exchanger Performance

[This rule has been derived independently by various OTEC investigators including Dr. A.L. London (Private Communication, August 1976). His simplified analysis also showed that the optimum split is insensitive to small variations.]

To validate the rule, the OTEC-II model was used to derive the results shown in Table 2.1-26: The results demonstrate that the approximation used indeed is valid. For 10 percent variations in the allocation of overall $\Delta T$, the system cost changes less than 1 percent. The table further indicates the variation of major plant characteristics with the allocation. An interesting result is that the plant efficiency is not a good measure of plant performance: a variation of about 20 percent at a fixed overall $\Delta T$. has no significant impact on system cost.

Optimum Design $\Delta T^{\star}$. Dr. A. Lavi (DOE's power plant project manager) has conjectured that the optimum design $\Delta T^{\star}$ should be lower than the annual average $\Delta T=40^{\circ} \mathrm{F}$. This conjecture was analyzed as described in Appendix C2. 
Table 2.7-26. Comparison Of System Sensitivity To Temperature Distribution of Available $\Delta T$ Nominally 10 Mle Net Power, $T_{H}=80^{\circ} \mathrm{F}, T_{C}=40^{\circ} \mathrm{F}$

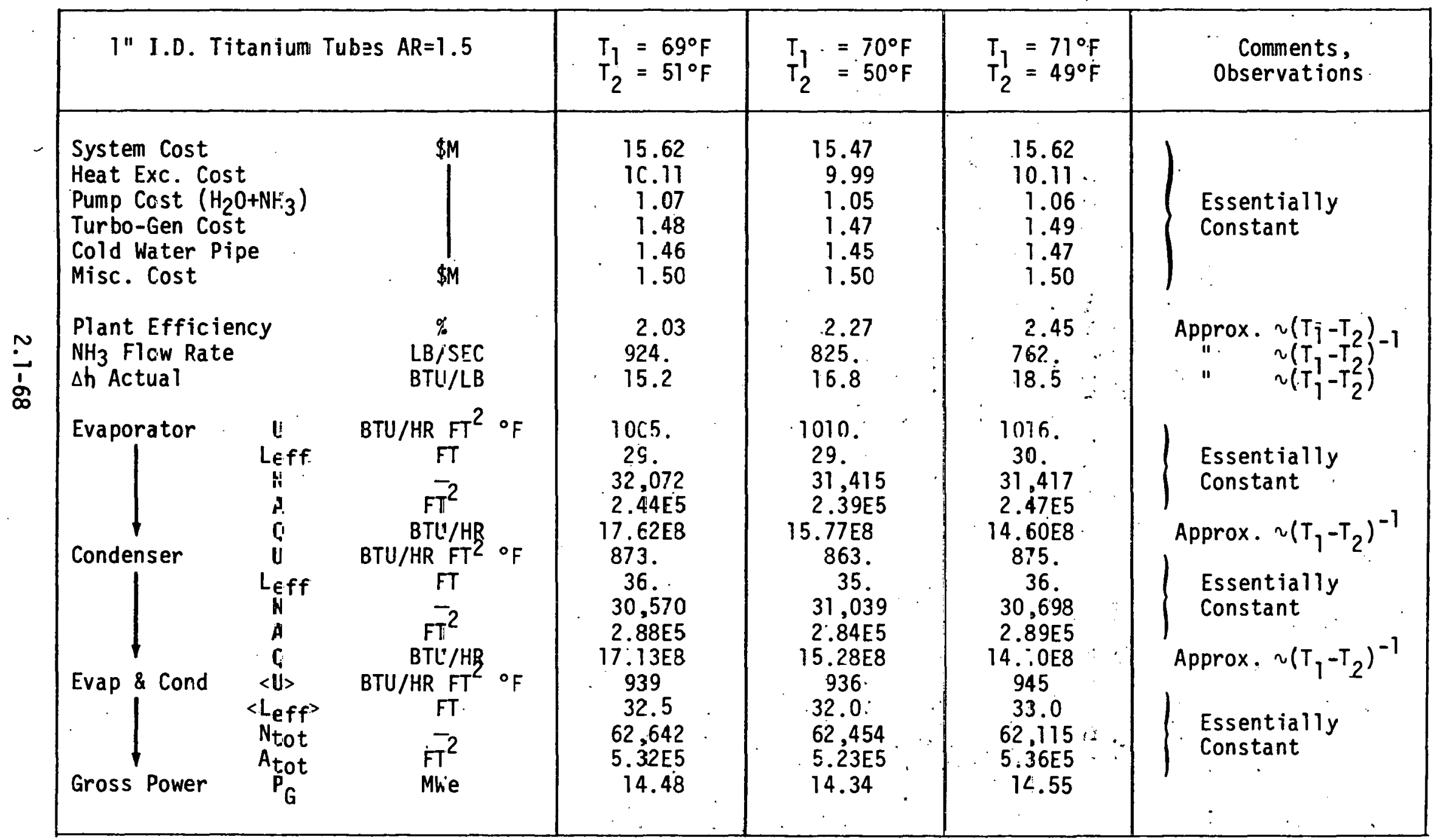

NOTE: These results are based on an early version of the OTEC A Model. 
Our design temperature is equal to the specified average available temperature. A model of plant cost versus design $\Delta T$, verified in the conceptual design phase, shows that a minimum energy cost occurs for a design $\Delta T$ of about $38^{\circ} \mathrm{F}$. However, the model is approximate, and does not account for off-design performance degradation. Considering also that the cost sensitivity is insignificant, it was decided to make the plant design point temperatures equal to the annual average temperatures.

Analytical Study of Off-Design.Performance. To support early preliminary design phase activities, turbine requirements at off-design performance of the ammonia loop were specified as described in Appendix $\mathrm{Cl}$. Results of this study, Figure 2.1-23, show steady state evaporator $\left(T_{1}\right)$ and condenser $\left(T_{2}\right)$ temperatures as a function of warm water temperature. Turbine flow versus pressure drop for two models, subsonic nozzle and sonic nozzle was assumed. The subsonic nozzle results yield temperature distributions very close to the $(1 / 4,1 / 2,1 / 4)$ rule. Note that the flow diagrams in Section 2.1.2 are based on the assumption that this rule applies at offdesign conditions, whereas the results in Section 2.2-4 are based on our recently completed detailed off-design model which incorporates a more sophisticated turbine representation. These latest results indicate that the actual turbine performance is approximated by the sonic nozzle. Finally, it should be pointed out that the turbine specifications given to Elliott (see Section 2.7.1) were based on early results of the simple model presented in Appendix $\mathrm{Cl}$. 
STEADY STATE RESPONSE OF $T_{1}$ AND $T_{2}$

TO VARIATIONS IN $T_{W}$

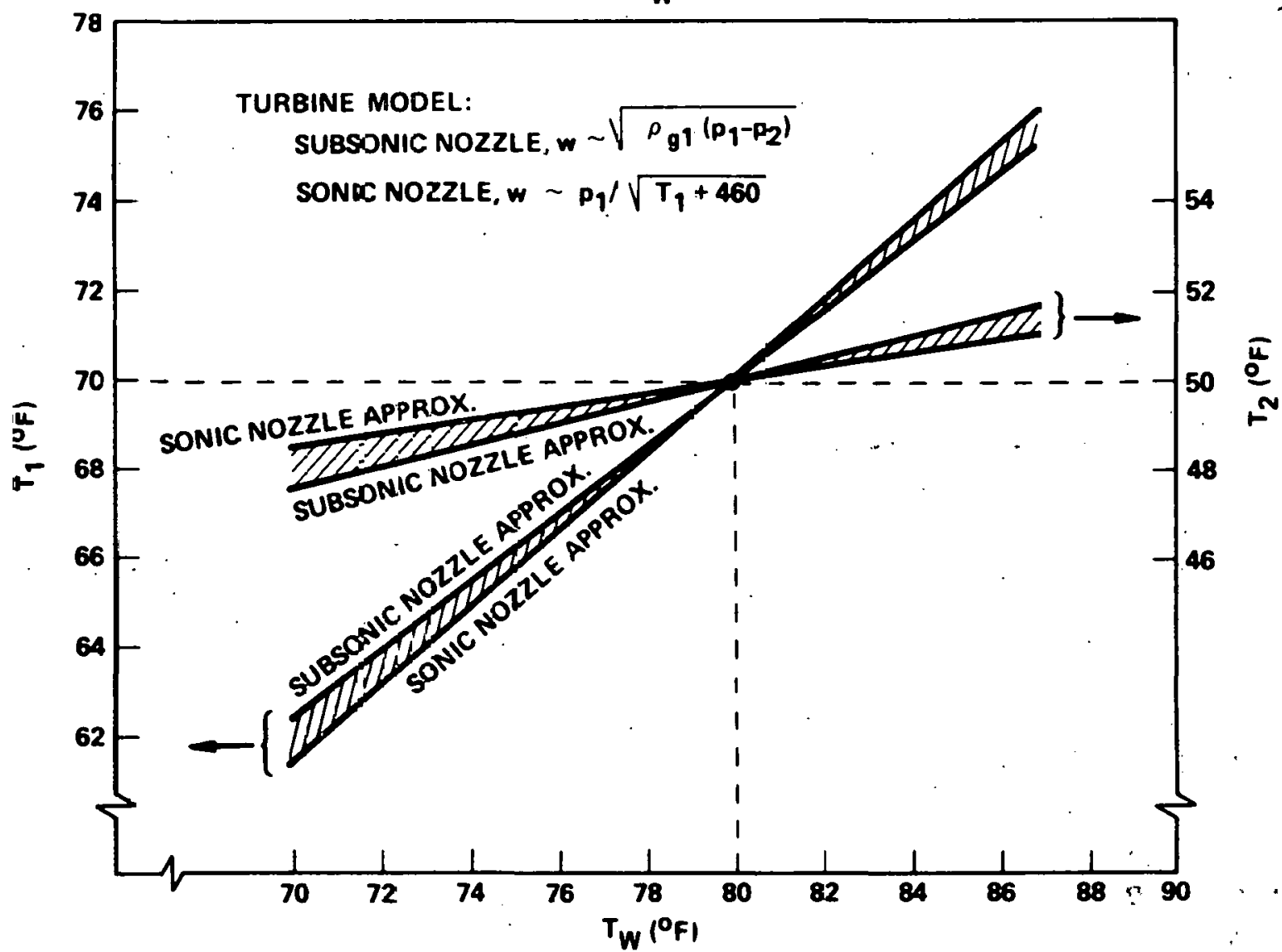

Figure 2.1-23. Off-Design Analysis Variability of Ammonia Loop Parcmeters 


\section{$2.1 .9 \cdot$ References}

1. TRW PSD-I Conceptual Design Report SAN/1570-1, Vol. I, 12 May 1978.

2. Vol. II of above reference.

3. OTEC Research on ari Engineering Evaluation and Test Program, TRW Report No. NSF-C958, June 1975.

4. Sverdrup, Johnson and Fleming, "The Oceans," Prentice-Hall, P.64, 1957. 


\subsection{SYSTEM OPERATION AND PERFORMANCE}

This section describes the operation of the OTEC plant, including TRW's assumptions about the ship's interfaces. Two mathematical models are described: one, the power cycle, predicts full-load and part-load performance; the other predicts fluctuations in power caused by ship heave. Based on these mathematical models, the control requirements are defined for full and part power. Procedures are described for startup, shutdown, purging, charging, and draining and their interrelationship is analyzed. Based on r those procedures, plant diagnostic requirements are established. Finally, requirements for instrumentation, control, alarms, trips, and the control room are established, that are implemented in Section 2.9. The steady level of startup power is analyzed in Section 2.2.5.8. 


\subsubsection{Instrumentation and Control Requirements}

\subsubsection{Power System Requirements}

At full-load, the PSD-I must deliver the maximum possible instantaneous power into an infinite grid (thousands of megawatts). At part-load, the system must deliver a reduced average output as requested by the system dispatcher. At present, no requirement exists for dynamic load following on an infinite grid (it is assumed that by the 1980s the utilityindustry will have learned how to accept dynamic load variations of 25 percent by small units in a large grid, due to the introduction of solar, wind, and OTEC units). As a result, the turbine-generator is sized to deliver the largest gross output expected for the site (i.e., the output generated under the most favorable water temperature difference expecled for the site). The turbine operating point for maximum efficiency is tentatively chosen at the nominal gross power level (1.e., corresponding to the average temperature difference at the site). During Phase II, the mathematical model discussed in Section 2.2.4 will be used to fine-tune the exact turbine operating point.

There is also a requirement to consider an "island option" in which the power module is the sole power producer on a grid or is one of several small units on an isolated grid. Active control of turbine speed would then be needed (typically $\pm 0.5 \mathrm{~Hz}$ ) in accordance with NAPSIC standards.: On an isolated grid, smoothing of dynamic variations in power output (e.g., produced by ship motion) would be necessary within a few tenths of a megawatt.

\subsubsection{Ship and Seawater Subsystem Interfaces}

Figure 2.2-1 shows the instrumentation interfaces among:

1. The power module's displays and controls

2. The GFE seawater subsystem displays and controls

3. The ship's subsystems (electrical power, television monitor, intercom, air quality measurements, alarms, etc.).

For purposes of the PSD-I study, it is assumed that the seawater subsystem control panels and power module coritrul panels are collocated in the same control room and that the ship's control center is separate, perhaps on 


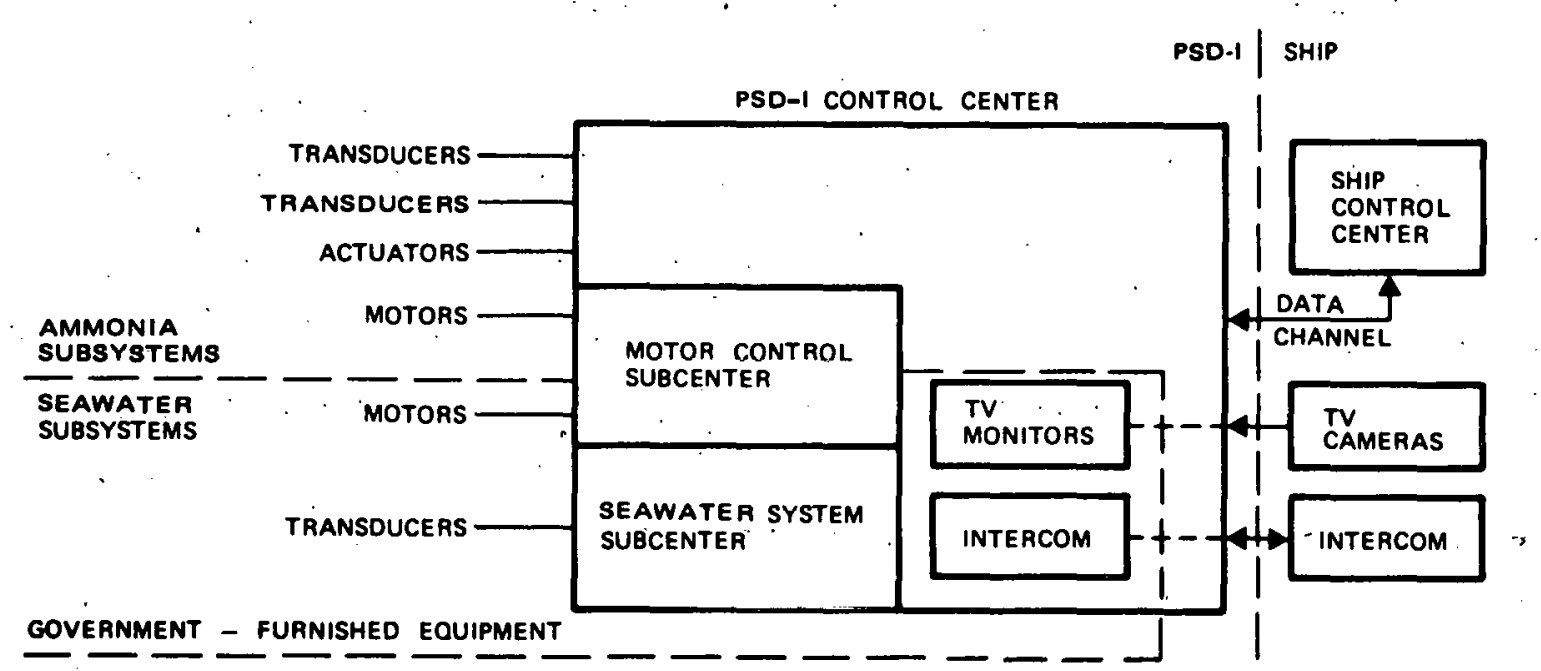

Figure 2.2-1. PSD-1 Instrumentation Interfaces

the bridge. Information exchange among these three elements is shown in Tables 2.2-1 and 2.2-2. The equipment that TRW assumes will be furnished by DOE to handle that information is listed on Table 2.2-3. Details of the interfaces to government-furnished equipment will be defined during Phase II in conjunction with DOE.

Voice and television monitoring are provided by the host ship; PSD-I provides panel space for the intercom and 4 television monitors. Because PSD-I may not operate within design limits above Sea State 6 , a wired sea state alarm is assumed to exist from the ship. Status of the ship's electric-power generators also is required, especially during startup and trip of PSD-I. It is desired that the ship's power display be compatible with the PSD-I power display and be adjacent to it." PSD-I furnishes some status and alarms to the ship as well as gross and net generated priver for display on the bridge. All data are assumed to be sent via a 2-way. computer-to-computer link whose details will be defined during Phase II.

\subsubsection{Diagnostics}

The purposes of the power module's diagnostics are:

1. To assess normal performance of the power module

a. Subsystem performance

b. System performance (efficiency, overshoots, etc.) 
2. To determine the cause of abnormal events, such as trips

3. To confirm mathematical models used in subsystem design and system performance prediction

4. To produce a historical record of plant operating states

5. To evaluate the results of experiments conducted on the plant.

Some of the diagnostic data are required in near-real-time on the ship.

These include:

1. Review of recent historical data

2. Evaluate enough results of experiments to determine the remaining course of action and change the test plan

3. Assess gross plant performance.

i

Table 2.2-1. Instrumentation Interfaces with Ship Subsystem

From Ship

Voice

Tèlevision monitor of hazardous areas

Air quality in machinery spaces and control room Wave motion alarm

Ship's electrical power status: generation consumption ',

To ship

Trip status

Key subsystem status

Alarms

Gross and net power output

Voice 
Table 2.2-2. Instrumentation Interfaces with Seawater Subsystem .. :

\begin{tabular}{|l|}
\hline From Seawater Subsystems \\
Pump status \\
Pump speed \\
Pump power \\
Uater flow rates \\
Trough level measurement \\
Alarms \\
Diagnostic instrumentation* \\
Water flow dynamics* \\
Display panel \\
To Seawater Subsystems \\
Motor trips
\end{tabular}

*For unit No. 1.

Table 2.2-3. Assumed Ship's Electrical. Interface Equipment Furnished by DOE

Control Panels for Power Module Control Center

4 Television Monitors

2 Intercoms

Air Quality Panel

Wave Motion Alarm

Ship's Electric Power Status

Ship's KW Generation

Ship's KW Consumption

Seawater Subsystem

Seawater Instrumentation Multiplexer

Ship's Instrumentation Multiplexer/Demultiplexer

Control Panels for Ship's Bridge

Key Power Module Alarms and Status

Power Module Electric Power Generation 
To produce the diagnostics, a requirement has been imposed to instrument all significant plant state variables and to identify which measurements are for operational use and which are needed only for Unit 1. Appendix $K$ contains the list of measurement points presently understood to conform to these requirements. Table 2.9.1 summarizes those point counts.

The sampling and recording rates are based on the following analysis of characteristic times of dynamic processes in the plant:

1. The daily generation of a typical grid shows two peaks and two valleys each day. If PSD-I operates in an island option, it will show similar fluctuations.

2. The time-constant of hydraulic flow is the 16 second period of the ship.

3. The time-constant of the heat exchangers is approximately 6 seconds.

4. The time-constant of the ammonia pumps is approximately 3 seconds.

5. The time-constant of the electrical switchgear is $1 / 60$ second but the fractional-second switching dynamics are not of interest.

Therefore a requirement is imposed on the instrumentation system to sample all data once per second. A 10 second burst of all data is recorded each hour, on operator command, and when an alarm is detected by the plant computer. A running record of the past 2 minutes of data is stored in the computer (120 samples of 550 measurements) for display or recording by the operator. Records are made on cartridges that are stored in the control room and transported to DOE data processing centers.

Some of the diagnostics remain on all units, some are removed on Unit 2.

\subsubsection{Operational Instrumentation and Actuators}

The operational instrumentation serves the following purposes:

1. Display plant status to the operators

2. Detect trip conditions

3. Control the automatic actuators

4. Collect data needed for diagnostics.

Figure 2.2-2 graphically illustrates the interfaces between instrumentation and actuators. The actual mechanization is described in Section 2.9.1. The power module sensors and transducers are located in the $2.2-6$ 
field. Critical sensors (those that can detect an impending costly accident) and control sensors (those used in the computation of actuator commands) are at least dually redundant. Where access to a sensor is expensive, added redundancy is required, as computed from the probable life-cycle cost of failures. All other sensors and transducers can be nonredundant. Both sets of redundant control transducers connect to the computer complex, as do all nonredundant transducers.

Actuators consist of motors and valves, All motors are started and stopped from the motor control center: Those that are automatically tripped or controlled also have remote actuations. All valves have integral electrical on-off provisions. The ten valves identified on Table 2.9-3 are required for sustained plant operation and are under the control of local computers. They have set-points established manually from the control room. The two valves needed for setting generated power must also be operated by the central computer complex, based on demanded power output. Those valves used intermittently for plant operation only require a local control board in the hull of the ship. Trip actuators are driven from "or" gates (one out of two logic elements) that trip the wired logic or computer trips. Table 2.2-4 shows the drivers for various functions performed by the instrumentation and control.

Redundant instrumentation wiring will be physically separated. Instrumentation wiring will be run in separate trays and conduits from power wiring to reduce electromagnetic interference.

\subsubsection{Control Room Requirements}

The power module control room contains all displays and controls needed to run and trip the power cycle and ammonia support plant, and to open and close electrical switchgear. It provides space for DOE-furnished ship's interface panels and seawater subsystem panels. It accommodates all electronics that require frequent or immediate access by the operators (such as cartridge records) and provides workstations for a supervisor, an operator, and an assistant operator. The supervisor and operator sit at the console whereas the assistant operator sits at a desk when he is not working unl llie wall panels or in the hull. 


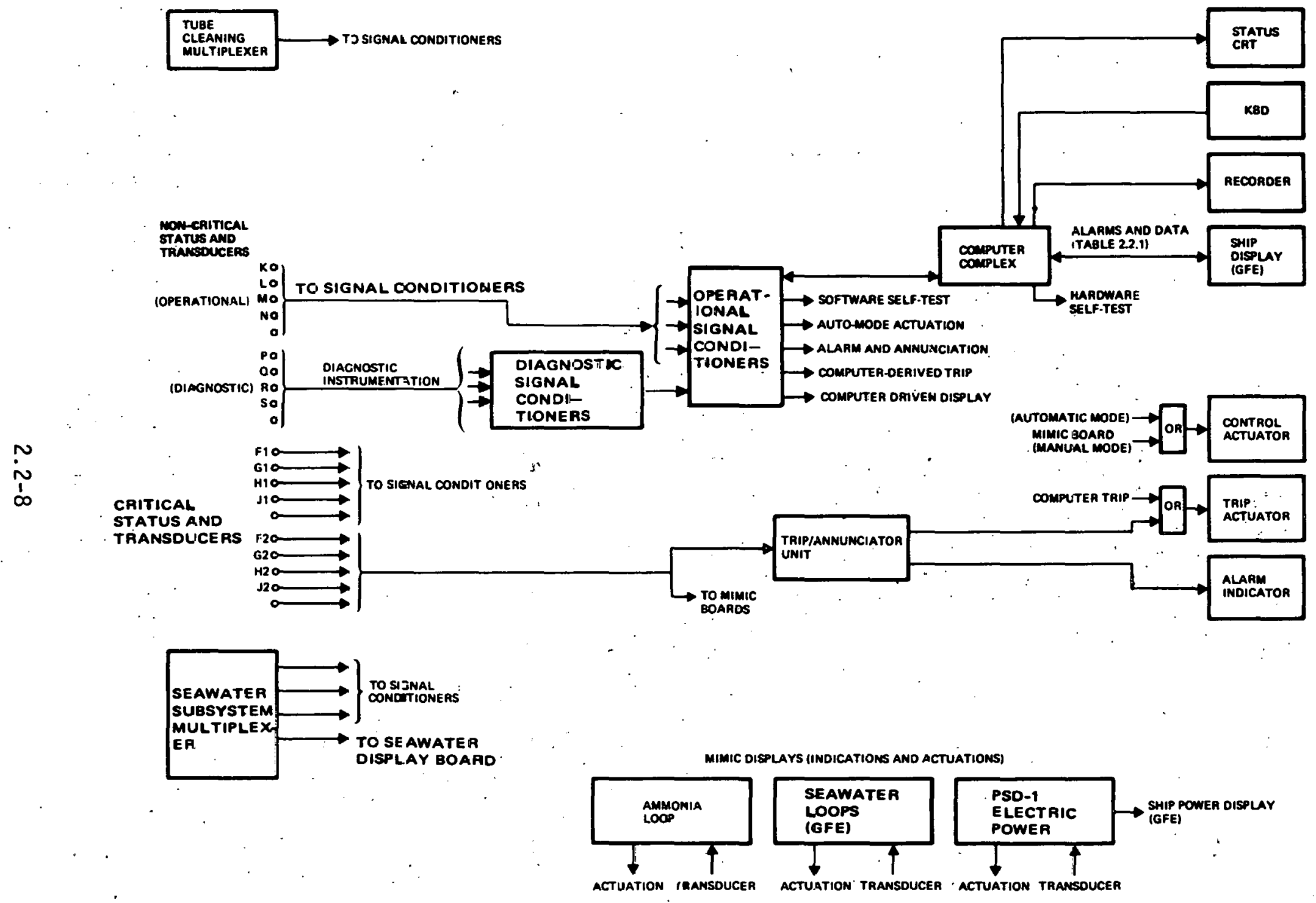

Figure 2.2-2. Function Performed by Instrumentation and Control 
Table 2.2-4. Activation Data Flow Requirements

\begin{tabular}{|c|c|}
\hline Function & Driver \\
\hline $\begin{array}{l}\text { Electrical mimic and } \\
\text { ammonia mimic board }\end{array}$ & $\begin{array}{l}\text { Directly from transducers } \\
\text { computer-driven digital displays }\end{array}$ \\
\hline Status CRT & Computer : \\
\hline Keyboard & Computer : \\
\hline Control Actuators & $\begin{array}{l}\text { Automatic } \\
\quad 2 \text { set-points }\end{array}$ \\
\hline & $\begin{array}{l}\text { From Control Room } \\
\text { Set-points from mimic board } \\
\text { Local } \\
\text { Set-points or direct actuator }\end{array}$ \\
\hline Trip actuators & $\begin{array}{l}\text { - Trip/annunciator unit drives Train } 1 \\
\text { - Computer drives Train } 2\end{array}$ \\
\hline $\begin{array}{l}\text { Al arms and } \\
\text { annunciators }\end{array}$ & $\begin{array}{l}\text { - Trip/annunciator unit drives lamps } \\
\text { - Computers preempt status CRTs }\end{array}$ \\
\hline Recorders & Computer \\
\hline Seawater subsystem & Computer multiplex !ine \\
\hline $\begin{array}{l}\text { Motor control } \\
\text { center trips }\end{array}$ & $\begin{array}{l}\text { Computer, trip/annunciator or, } \\
\text { mimic board }\end{array}$ \\
\hline
\end{tabular}

Figure 2.2-1 shows the control center interface requirements. Section 2.9.4 shows the implementation of the center including two drawings of the center. The control center is required to have a console and wallmounted displays. It is required to have mimic boards of the ammonia power loop, treatment plant, and electric power distribution, with dedicated control switches for those actuations that may be required within 5 minutes of an alarm or display.

Redundant alarms are required for all signals that can indicate a potentially hazardous condition or one that can have expensive consequences to the plant.

\subsubsection{Plant Computer Requirements}

The plant computer complex performs the tunctions shown in lable $2.2-b$. It monitors and calculates diagnostics, controls set points, and does extensive formatting and engineering unit conversion. There is no

$$
\text { 2.2-9. }
$$


Table 2.2-5. Plant Computer Functions

\begin{tabular}{|c|c|}
\hline Function & Example \\
\hline Executive & \\
\hline Software self-test & \\
\hline Input-output peripherals: & $\begin{array}{l}\text { Keyboard } \\
\text { CRT } \\
\text { Recorders }\end{array}$ \\
\hline Input/output to data devices: & $\begin{array}{l}\text { Mimic boards } \\
\text { Ship interface } \\
\text { Seawater interface } \\
\text { Trtp/annuriciatur units } \\
\text { Transducer IOUs }\end{array}$ \\
\hline Format generation: & $\begin{array}{l}\text { CRT tables } \\
\text { CRT mimic displays } \\
\text { Recorder }\end{array}$ \\
\hline $\begin{array}{l}\text { Alarm and trip computations } \\
\text { Control law: }\end{array}$ & $\begin{array}{l}\text { a. Evaporator flow as function } \\
\text { of water temperature, and } \\
\text { dcsircd power } \\
\text { b. Turbine variable nozzle control }\end{array}$ \\
\hline $\begin{array}{l}\text { Diagnostics: } \\
\text { (operational and } \\
\text { developmenta } 1 \text { ) }\end{array}$ & $\begin{array}{l}\text { System level } \\
\text { Electric power } \\
\text { Machinery } \\
\text { Heat exchanger } \\
\text { Turbo-generator } \\
\text { Chlorination } \\
\text { Tube cleaner (if complete } \\
\text { functions are combined) } \\
\text { Support system }\end{array}$ \\
\hline
\end{tabular}

requirement for computer redundancy, depending on the economics of the implementation. The implementation of Section 2.9 is nonredundant.

The development of computer programs is assumed to take place on a shore-based scientific computer where verification tests can be performed prior to delivery to the ship. Some of the software may be written in a high-order language and compiled on the scientific computer. It is assumed that a high-order language interpreter is not needed in the plant computer itself. The procedure for software development and the need for tools such as compilers, editors, emulators, and interpreters will be reevaluated during Phase III to match DOE's desires for operating the plant. 


\subsubsection{Control}

During Phase II, TRW designed and analyzed two control schemes for the plant:

Scheme 1. Control of the entire plant by a central direct-digitalcontrol computer complex. All circuit breakers are controlled by the central computers. This alternative permits fully automatic operation, startup, and shutdown. However, it is somewhat more expensive and less flexible in an experimental station than is. the second scheme.

Scheme 2. Dedicated decentralized controllers for all actuators. The PSD-I control room contains remote set-points for the ten actuators needed to operate the plant normally (Table 2.9.3). The central computer establishes set-points for the two power-demand actuators (ammonia recirculation rate and turbine variable nozzle). All circuit breakers are manually operated; trip breakers have an input from the computer. This scheme permits automatic operation in the steady-state and permits the operators to experiment with procedures without rewriting software. It permits the plant to operate without the central computer, thus increasing plant availability and reducing cost by permitting the use of a single computer. However, it requires manual intervention in the startup and shutdown.

TRW implemented the second scheme, as described in Section 2.9, for purposes of the Phase II sizing and cost estimates.

\subsubsection{Seawater Subsystems}

The cold water trough is filled passively from the sea, as water is pumped into the condenser. The cold water and warm water pumps run at constant speed, so motor-starters are satisfactory for control. No control is provided on. water flow because of the large surge power requirements (see Section 2.2.6.4). During Phase II, TRW will analyze the possibility of smoothing-out heave-induced ammonia flow fluctuations by varying pump speed (though the power consumption is expected to be excessive) and of reducing external startup power requirements by varying pump speed.

\section{2:2.2.2 Ammonia Treatment}

A fraction of the ammonia flow is continuously removed at the heel of the power loop and stored in a wet-ammonia tank, Figure 2.2-3. The ammonia is fed to a purification column from which dry ammonia is removed to a 


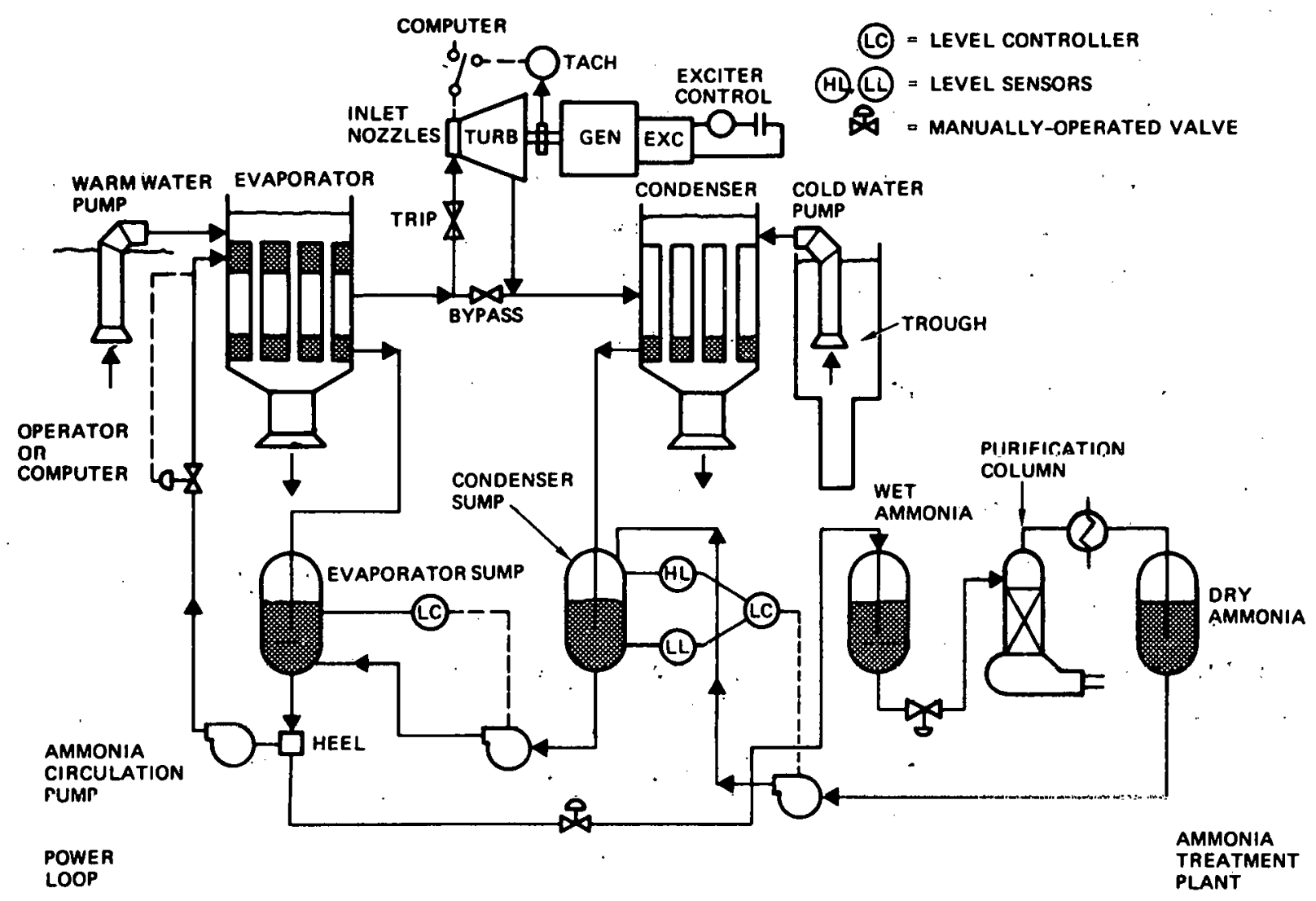

Figure 2.2-3. Ammonia Control Loops (Kedundant Pumps Ánd Tanks Nót Showin)

storage tank from which it is pumped into the condenser sump (see Section 2.8). All controllers are located on the local control panel near the ammonia treatment plant. Only four of them, required during normal plant operation, have remote set-points in the PSD-1 control room (see Table 2..9-3):

1: Feed rate of wet ammonia from the heel of the power loop

2. Feed rate of wet ammonia to the purification column

3. Reflux rate in the purification column

4. Pumping rate to the condensate sump.

The first and second set-points are manually selected by the operator, based on his choice of the fraction of ammonia to be treated. These set-points are decoupled, because the tank volumes are so large, and need to be set 
once per shift. The third set-point is manually selected based on an intermittent chemical analysis of the dry ammonia. None of these three setpoints requires automatic control provisions. The fourth set-point is normally controlled by an on-off controller, from the condenser sump level.

The ammonia treatment plant is monitored from the PSD-I control room and can be tripped by the operator, either from the local-control panel or from the PSD-I control room. An ammonia plant trip isolates each piece of equipment from the others, without immediately affecting the power cycle. of course, if the tripped state persists, the power cycle will eventually have to shut down.

\subsubsection{Ammonia Power Cycle}

The controls for the ammonia power cycle are shown on Figure 2.2-3 and in Table 2.9-3. The condensate feed pump's speed is controlled by the level in the evaporator sump, resulting in an average speed proportional to flow rate in the turbine. An on-off controller is not used because of the small volume of the tank relative to the flow rate and the consequent need for tight control. The ammonia recirculation pump operates at constant speed. Flow is controlled by a throttle valve that regulates coarse power output. It is operated either manually or from the digital computer, as described in Section 2.2.2.7. A fixed-speed recirculation pump with a throttle was chosen because the lifetime cost of lost electricity due to throttling does not exceed $\$ 30,000$, which is less than the cost of a variable-speed motor (furthermore, the constant speed motor is far more reliable than the variable-speed motor).

A second liquid-side design option was considered during Phase $I$, in which the condensate feed pump and the recirculation pump both feed the evaporator header in parallel. The evaporator sump level would be controlled by the recirculation valve and the condenser sump level would be controlled by the makeup valve. This second option may be somewhat less expensive than the chosen design because it requires a smaller evaporator sump and smaller recirculation pumps. However, it is subject to flow instabilities between the parallel pumps and requires a third valve to control gross power output. The chosen design is simpler from a rontrol viewpoint and has the added advantage that the recirculation pump handles subconoled ammonia such that the pump setting depth can be reduced significantly. 


\subsubsection{Turbine Generator}

The turbine-control actuator is a set of variable nozzles with a common controller, Section 2.7.1.6. During startup, it is used for speed control; after synchronization, it is controlied for maximum net power output, either manually or by a hunting program in the central computer. When the generator is connected to an infinite grid, its speed is locked at 1800 rpm and a "wide-open valves" policy produces maximum power. If the generator were connected to an isolated grid, the variable nozzles would provide speed control, using inputs of shaft speed to the digital computer. The central computer would then be necessary for normal plant operation and would probably have to be redundant. The baseline design is for an infinite grid, a nonredundant computer, and manual backup for the recirculation rate and nozzle set-points. In Phase III, TRW will compare a self-contained turbine controller with use of the central computer for high-frequency control of the nozzles.

\subsubsection{Power Distribution}

Control of the power-distribution circuit breakers is manual self-contained, as described in Section 2.10, except for remotely-operated trips. Generator-to- 1 ine phase angle and important voltages and currents are measured, displayed, recorded, and alarmed, see Section 2.9. Control of the seawater pumps (on-off) is from a panel dedicated to that subsystem.

\subsubsection{Tube Cleaning Machine}

The tube-cleaning machine is controlled and manually backed-up from a remote station located in the hull near the heat exchangers. Ten status monitoring alarms (nonredundant) are provided in the FSD-I control room.

\subsubsection{Full-Power Operation}

Startup and synchronization are done at zero power output, the auxiliary loads being taken from the power mains (see Section 2:2.5). The recirculation valve establishes a low steady-state evaporation rate and the turbine's variable speed nozzles control the speed. In the infinite grid option, the speed control disengages after synchronization and the nozzles are used to modulate power. In the island option, speed control is retained at the cost of approximately $20 \mathrm{~kW}$ of net power output in a calm sea. If 
power fluctuations due to ship.'s heave also are to be removed, an additional 0.7 MW average output power is lost, as described in Section 2.2.6.

Startup is described in detail in Section 2.2.5.

The control policy, when operating at steady-state into an infinite grid, is to generate as much instantaneous power as possible, allowing the rest of the grid to load-follow. 'At full power, the evaporator recirculation valve establishes the approximate power. level and the turbine's variable nozzles are fine-tuned for maximum power output, either manually or with the central computer.

Seasonal water temperature variations are sensed at the heat exchanger water inlets. The simulations discussed in Section 2.2.4 show that the evaporator recirculation rate does not have to be changed (within $10 \mathrm{~kW}$ ) as water temperatures change, thus simplifying the control, whether manual or automatic.

The dynamic response of power output to ship's motions at full-power and part-power is discussed in Section 2.2.6.

Ful1-power control in the island option will use the turbine nozzles. to regulate speed and the recirculation throttle to maintain power output. It will be studied in detail during Phase III.

The ammonia treatment plant operates unattended, using remote set points. The tube-cleaning machine operates remotely under control of its computer. If a problem should develop in either local control board, an alarm will appear in the PSD-I control center. If the problem is serious, an automatic trip may occur, from the local control board, or the operator may trip the treatment plant from the PSD-I control room. Plant alarms and trips are discussed in Section 2.2.3. Shutdowns from an operating state or after a trip are discussed in Section 2.2.5. All shutdowns are manually controlled, to save computer interfaces and software and to permit maximum flexibility for experiments.

\subsubsection{Part-Power Operation}

At part-power, the recirculation throttle is partly closed, reducing the recirculation rate and the output power (see-Section 2.2:4): Efficiency is of minor importance; the objective is to predict the set-points needed 
to generate any desired net power. Thus, the seasonal temperatures and desired average power are used to calculate the nominal recirculation rate, which is established either by the plant computer or by the operator. Fine-tuning to match a dispatch request is done manually by the operator or by the central computer using the nozzles. All other control loops operate at part-power exactly as they do at full-power.

The potential problem of steady-state control at very low recirculation rates will be examined during Phase III. If the recirculation rate cannot be reduced low enoughito permit a zero-power turbine start (because vapor forms in the lines downstream of the valve) a continuously-variable bypass control valve will be introduced.

\subsubsection{Dynamic Response}

The simulations of Section 2.2.6 show that the plant is stable without active high-frequency control at any steady power level. Section 2.2.6 also shows that the power output fluctuates substantially with ship heave in heavy seas. No dynamic compensation was provided in Phase II, so that the plant could develop maximum power output at all times as appropriate when connected to an infinite grid. During Phase III, TRW will analyze stability in more detail and will design methods for smoothing power fluctuations, as described in Section 2.2.6.4.

A dozen level, measurements are both displayed and fed to controllers. To obtain an accurate level measurement on a moving ship, several precautions are taken:

1. Baffles are installed in tanks to raise the frequency of oscillation and reduce the amplitude

2. Sensors are filtered over several slosh cycles where high frequency respones. is not necded

3. Two or four sensors are placed in. those tanks whose amplitude of oscillation is high and that require measurements several times during a ship oscillation period.

During Phase III, specific level sensor deșigns will be made, using data from vendors experienced in shipboard measurements. 


\subsubsection{Interlocks}

Interlocks are provided in the manual and automatic modes. As usual in process control system designs, interlocks are provided only to protect against damage; unnecessary interlocks are avoided since the plant designer cannot predict all actions that an operator may take, especially in abnormal conditions. Two typical interlocks are:

a. Verify turbine oil pressure before opening a closed turbine trip valve

b. Remove nonessential loads when transferring to ship's power (see Section 2.10).

Other potential interlocks will be examined in Phase III.

\subsubsection{Trips and Alarms}

The purposes of trips are:

1. To protect the plant against damage following a fault

2. To protect the operators against dangerous conditions such as a massive ammonia release

3. To initiate a shutdown procedure.

The purpose of alarms is to alert the operator that a potentially hazardous or costly event has occurred in the plant that requires his. immediate attention.

Sensor indications that foretell hazardous or potentially costly consequences within 5 minutes are connected to automatic trips and to alarms. Sensors that can foretell hazardous consequences in longer times are connected to alarms. All sensors are also connected to the computer complex, for, performance calculations, status monitoring, and recording.

Three kinds of trips are defined, as summarized in Table-2.2-6. A full trip stops the water pumps and the ammonia pumps, shuts the turbine inlet trip valve, opens the bypàs and does other actions in the sequence described in Section 2.2.5. Some typical sensors whose outputs cause a full trip if they are out of limits are shown in Table 2.2-6. The second kind of trip is to zero power, which stops the ammonia pumps, shuts the turbine valve, and lets the water pumps and ammonia treatment plant operate. The sequence of events is shown in Section 2.2.5. A zero-power trip is 
actuated by sensors such as those shown in Table 2.2-6. It allows a rapid restart. The third kind of trip places the ammonia treatment plant in a safe state without affecting the ability to generate power. It is initiated manually, from the P.SD-I control room or from the local panel, or is. initiated automatically. During Phase II, TRW will analyze the feasibility Table 2.2-6. PSD-I Trips and Their Causes

\begin{tabular}{|c|} 
Full Trip \\
Operator action \\
Ammonia overpressure in evaporator \\
Ammonia overpressure in condenser \\
Hydraulic system trip (GFE) \\
Wave action trip (GFE) \\
Trip to Zero Power \\
Operator action \\
Excessive ammonia pump power \\
Generator overload or underload (motoring) \\
Turbine overspeed \\
Loss of turbine oil pressure \\
Ammonia Plant Trip \\
Operator action \\
Automatic trip sensors to be defined
\end{tabular}

of tripping isolation valves that limit the volume of ammonia leakage following a pipe break. As it is now designed, the ammonia system contains flow restrictors, as required by the CFR-46 code.

- Redundancy requirements for the protective trips are based solely on economics. If any safety trips are identified, their design will be based, on one-out-of-two logic or on one-out-of-three logic, following nuclear power plant practices: Pending the results of the economic analysis, dual sensors and transducers are required for all trips. Sensors and transducers may be shared with the control systems. One channel of trip logic. must be wired, and independent of the control computer. The other can be wired-logic or can be performed in the computer; the latter is chosen for PSD-I. Each trip actuator has logic that initiates a trip if either the computer: channel or the wired channel indicates a trip. 
Though such logic may cause a few inadvertent trips, it has the great advantage of increasing the probability of protecting the costly experimental system from damage. The Phase III study will determine, from MTBF, MTTR, and the cost of OTEC. outages, whether dual redundancy is economically correct.

Approximately 90. alarms have already been defined, Table 2.9-1, for al1 PSD-I subsystems. The alarmed-sensors connect to a device that permits upper, lower, or upper and lower alarm levels to be set. The alarms operate lights on the mimic board, lights on an annunciator panel, and an audible annunciation. The second alarmed-sensor channel passes into the computer where an out-of-11mit condition trips the recorder (see section 2.2.1) and is displayed on the status CRTs.

\subsubsection{Steady State Performance}

\subsubsection{Introduction}

This section presents results of the steady-state performance analyses of the OTEC 10 MWe power module. The analyses covered both full-and partpower operation. Part power operation was evaluated primarily from the standpoint of control and how to achieve it with minimum effect on full power output.

The full power performance analyses investigated evaporator feed flow sensitivity, fixed and variable speed ammonia pumps, seasonal $\Delta T$ performance sensitivity, fouling factor effects, flow losses, and optimum water flow rates. Because plant performance (efficiency) is not an issue at less than full power, that part of the anaiysis was limited to investigating the alternatives to control: turbine throttle, bypass valve, and evaporator recirculation rate.

The simulation program developed for this analysis is described in Appendix A2. The scope of the model is indicated by the material and information flow diagram in Figure 2.2-4. The program was developed by TRW and by its Carnegie-Mellon University and University of Massachusetts consultants to simulate as closely as possible steady-state performance of the OTFC plant. The simulation models all major system elements: heat exchangers, turbine, pumps, pipes, bends and valves. The hea't exchanger models are based on the most recent data developed by CMU and Oak Ridge 


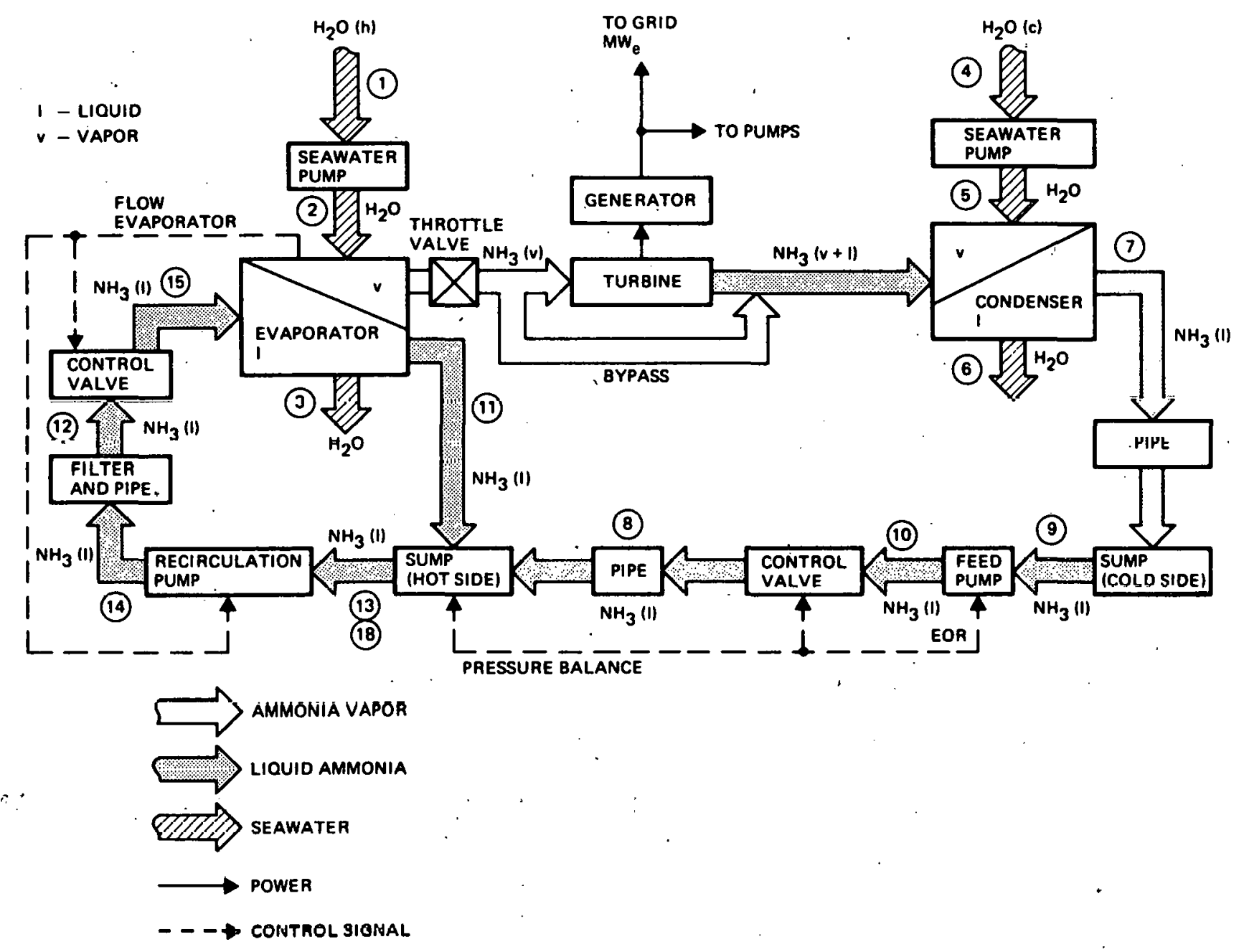

Figure 2.2-4. Flow Diagram of Steady-State Mode1

and the model integrates over the length of the tube to determine total heat transfer. The turbine model is based on the performance simulation results generated by Professor Lawrence Ambs of University of Massachussetts for a computer design of a single stage ammonia turbine optimized to our nominal operating parameters. Regression fits to the off-nominal performance of this design were used to define the turbine algorithms. A multistage model will be developed in Stage III.

An example of the program output is shown in Table 2.2-7 which shows the variation in performance with warm water temperature varying from 70 to $88^{\circ} \mathrm{F}$. 


\subsubsection{Steady State Full Power Performance}

In order to evaluate the steady-state performance mode 1 with respect to the design optimization model (Section 2.1.7), the steady-state model was run with the selected design and performance parameters (such as fouling factor and water flow rates) for the three values of warm water temperatures representing the initial design specification discussed in Section 2.1.2. The computer printout is shown in Table 2.2-7.

1. The net power is about 5 percent higher than nominal. This is for the most part due to the turbine model which predicts turbine efficiencies in the 88-89 percent range compared to the 84-85 percent range assumed in the flow diagrams, Figures 2.1-1, 2.1-2, and 2.1-3.

2. The evaporator and condenser temperatures and ammonia flow rates predicted at off-design conditions $\left(T_{\text {warm }}=84^{\circ} \mathrm{F}\right.$ and $76^{\circ} \mathrm{F}$ ) are slightly different from the preliminary estimates reflected in the process flow diagrams. The performance model predicts smaller variability of flow with changing seawater temperature and larger variability in the evaporator temperature than does the optimizing program.

\subsubsection{Evaporator Recirculation Flow}

It was necessary to establish the sensitivity of the plant performance to the ammonia flow rate into the evaporator to determine if an optimization about this parameter would be required for subsequent performance analyses. For this evaluation, the recirculation pump speed was allowed to vary. Figure 2.2-5 shows gross and net power and the evaporation rate as a function of the evaporator input flow rate near the nominal operating conditions. This figure shows that both gross and net power are insensitive to the ammonia recirculation flow near full power. Examination nf the data indicated that the nominal flow of $1324 \mathrm{lbs} / \mathrm{sec}$ was within 0.02 MW of optimum over the expected variation in warm water temperature of $80 \pm 4^{\circ} \mathrm{F}$. Using throttling of the recirculation pumps to control the flow to a more optimum level reduces this difference to about $0.01 \mathrm{MW}$. Since variable speed drive losses can approach these levels, the selection of a fixed speed recirculation pump is justified from the standpoint of plant efficiency.

With these results as a basis, it was decided to use the nominal value of evaporator recirculating flow in subsequent simulations near full power. 
Table 2.2-7. Sample Output of Steady-State Model

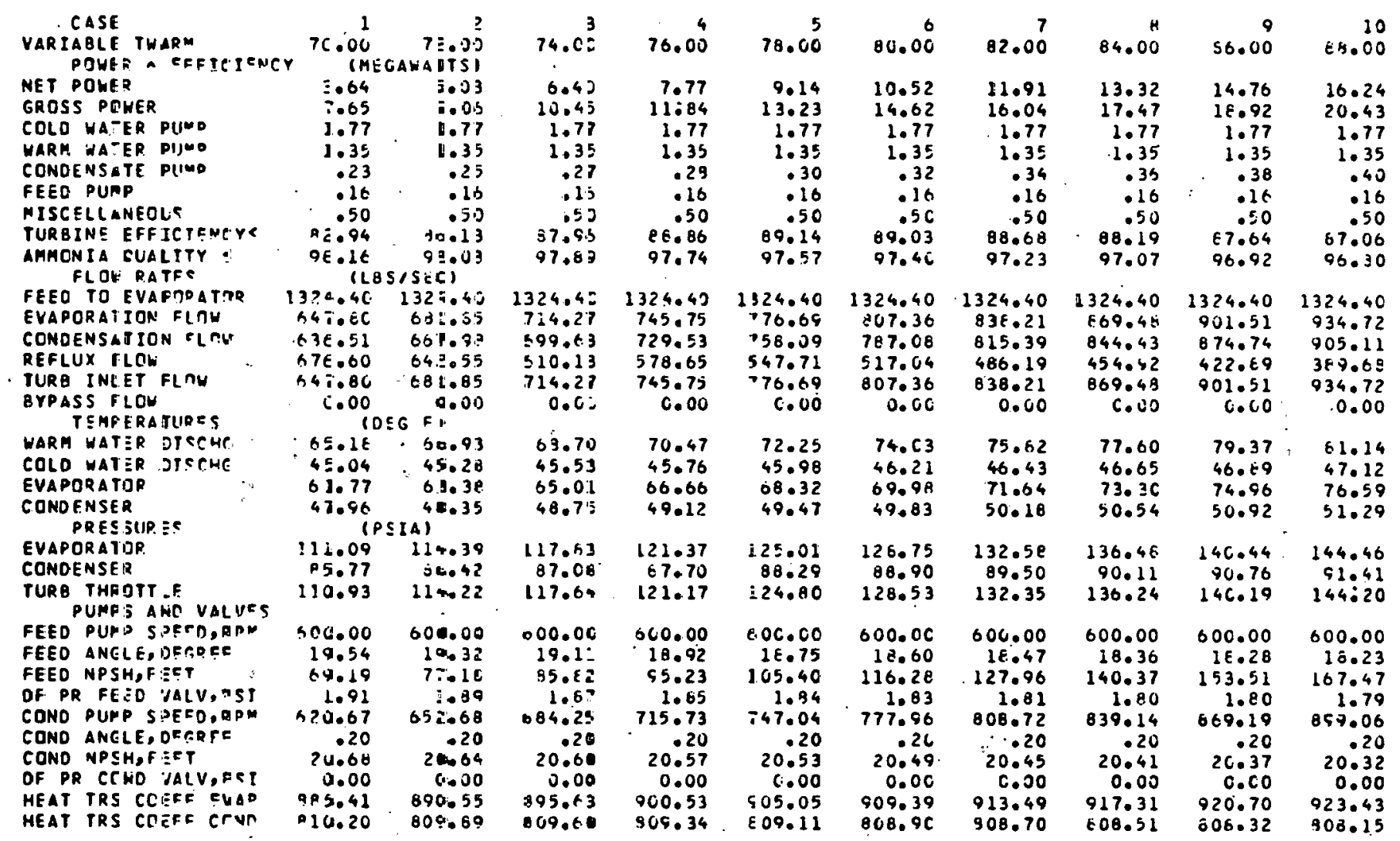




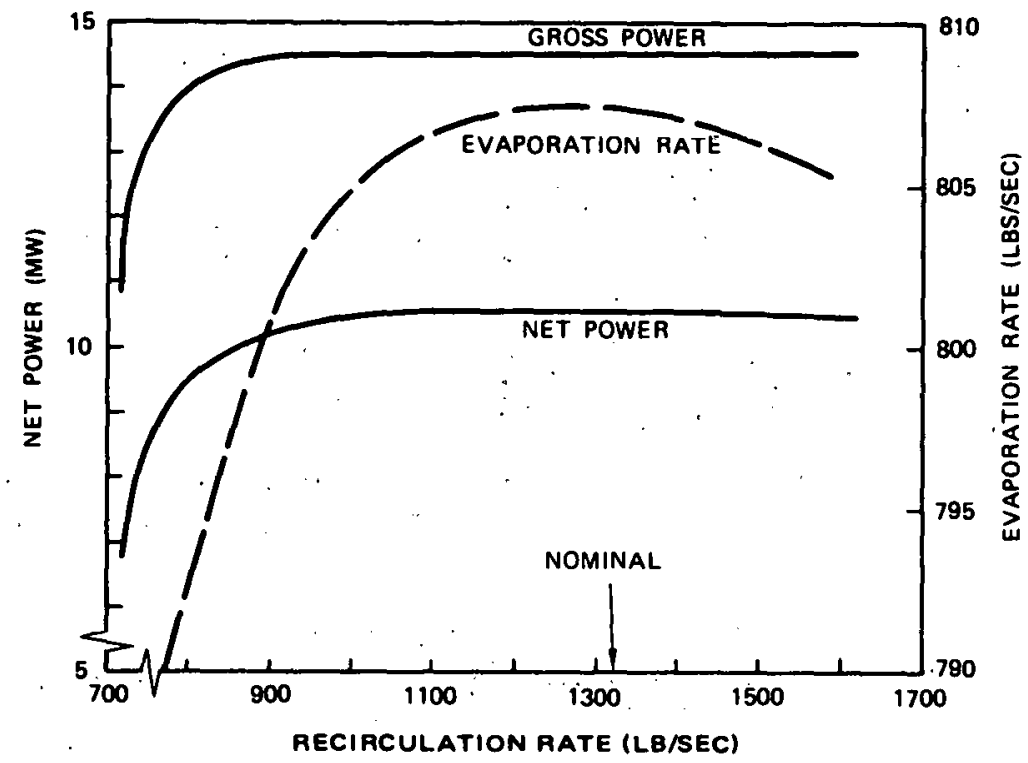

Figure 2.2-5. Power Output vs Evaporator Recirculation Rate (Above 800 LB/SEC)

\subsubsection{Part Power Performance}

The operation of an OTEC plant at reduced power does not result in a saving of consumable resources in contrast to conventional power plants. For this reason, the interest in part power operation is primarily that of control and how it may be obtained; efficiency at reduced output is not important.

There are three options available for reducing the power output of the plant: turbine throttle, bypass throttle, and evaporator recirculation rate control. All three of these methods were investigated with the simulation model to determine the sensitivity of power to valve actions. Use of the bypass valve for power control was considered least desirable due to the high sensitivity of power output to valve angle as the valve is initially opened (if used, it should be at near-zero power). Throttling with a turbine valve or variable nozzle was found to have an even characteristic and would be acceptable. The last alternative, throttling the ammonia recirculation rate to the evaporator, also provided an even characteristic. This would have the advantage of requiring a much smaller valve whose losses at full power would be less. Additionally, a recliculatiun throttle 
valve is desirable to help optimize full power performance. The disadvantage of throttling the recirculation flow would be the slow response time that could be expected due to the transmit time and thermal lag in the evaporator.

Since the baseline system, includes a turbine with variable inlet nozzles, which can be used both to modulate and optimize power and would have a high frequency capability, a control mechanization is suggested in which large changes in power are accomplished with the flow control whereas small perturbations would be controlled by the turbine inlet nozzles. Figure, 2.2-6 shows the variation of gross power output with the evaporator recirculation flow at reduced rate. This is the recommended approach to part-power operation.

\subsubsection{Fixed and Variable Speed Pumps}

As indicated on page 2.2-2.1, the net power gain associated with a variable speed recirculation pump is quite small (less than $0.01 \mathrm{MW}$ ) and is probably negligible when the losses of a variable-speed drive are included. However, since the condensate feed pump consumes significantly more power and its pumping rate is dictated by the evaporation rates, a variable speed pump would appear to be appropriate (see Appendix L, Ammonia Pump Trade Study). Simulation results with the feed pump sized for maximum difference temperature: (warm water $=84^{\circ} \mathrm{F}$ ) showed that condensate pumping power of $0.36 \mathrm{MW}$ was required at all temperatures when using a throttle to control flow. These results rompare with the variable speed pump power reyulrements of $0.32 \mathrm{MW}$ at $80^{\circ} \mathrm{F}$ and $0.28 \mathrm{MW}$ at $76^{\circ} \mathrm{F}$ or 0.04 and $0.08 \mathrm{MW}$ less at nominal and minimum $\Delta T$. Thus the variable-speed condensate pump would result in an average 11 percent savings. in pumping. power.

\subsubsection{Seassonal Variations}

The change in the warm water temperature is expected to be the primary varlable affecting steady-state plant performance: rigure 2.2-7 shows the net and gross power as a function of the warm water inlet temperature. The graph shows a virtually linear relationship between power and warm water temperature. Figure 2.2-8 shows the variation of turbine efficiency and ammonia quality with warm water temperature. Figures 2.2-9 and 2.2-10 show 


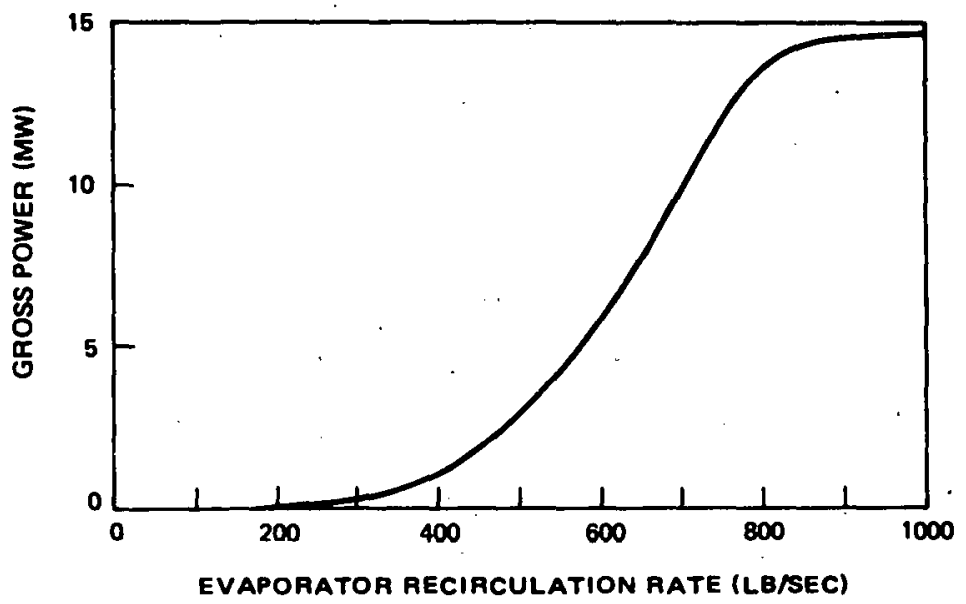

Figure 2.2-6. Power Output vs Evaporator Recirculation Rate

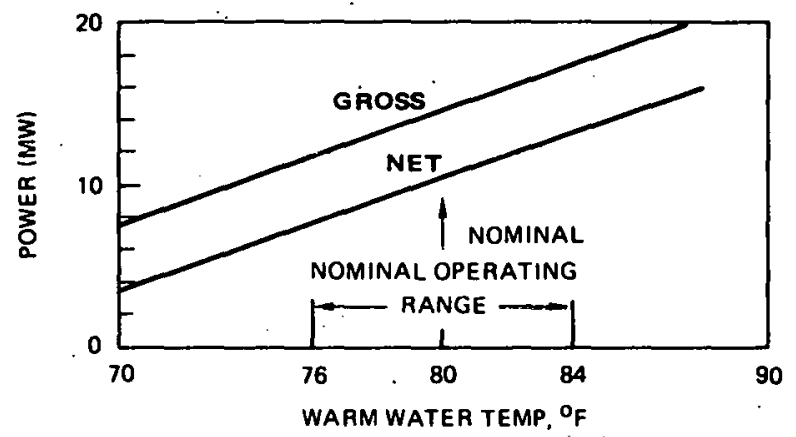

Figure 2.2-7. Power Output vs Warm Water Inlet Temperatures Cold Water $=400^{\circ} \mathrm{F}$ )

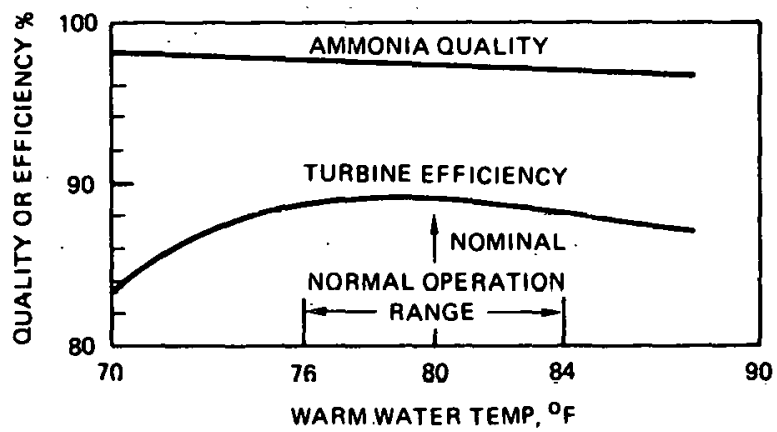

Figure 2.2-3. Efficiency and Quality vs Warm Water Inlet Temperature (Cold Water $=40^{\circ} \mathrm{F}$ ) 


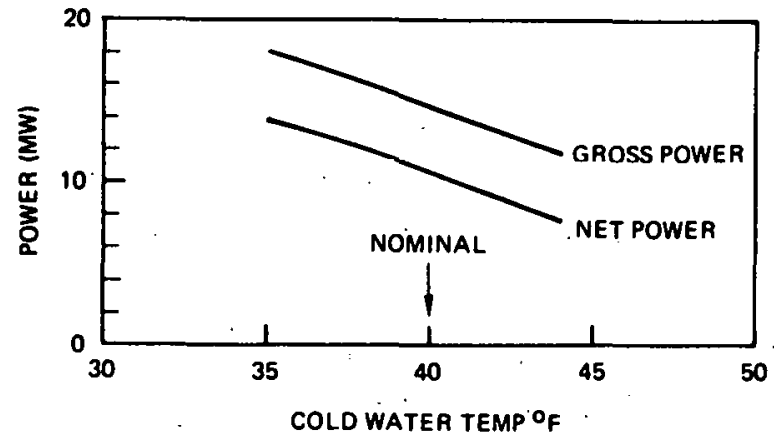

Figure 2.2-9. Power Output vs Cold Water Inlet Temperature (Warm Water $=80^{\circ} \mathrm{F}$ )

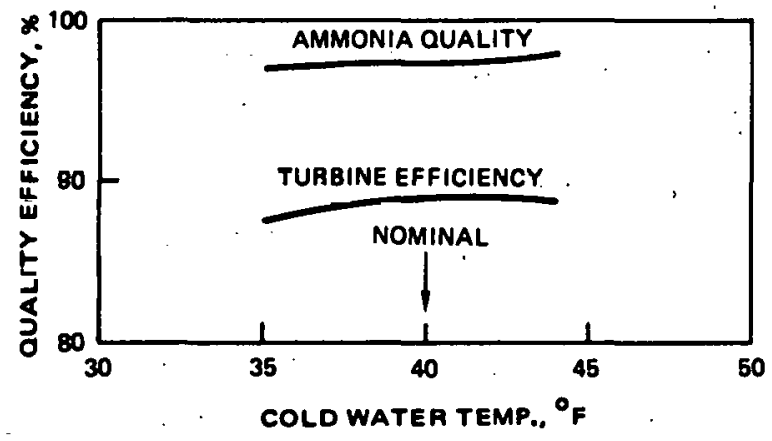

Figure 2.2-10. Efficiency and Quality vs Cold Water Inlet Temperature (Warm Water $=80^{\circ} \mathrm{F}$ )

the power, efficiency and quality variation with varyiriy cold water temperature. Again, power appears to be nearly a linear function of ater temperature.

The warm and cold water temperature effect on power were found to be essentially additfve. Therefore, it was posstble to develop the following expression for power as a function of these temperatures:

$$
\begin{aligned}
P_{T(\text { Gross })} & =14.62+0.70\left(T_{W}-80\right)-0.701\left(T_{C}-40\right) M W_{e} \\
P_{T(\text { Net })} & =10.52+0.694\left(T_{W}-80\right)-0.693\left(T_{C}-40\right) M_{e}
\end{aligned}
$$

where the water temperatures $\left(T_{w}\right.$ and $\left.T_{c}\right)$ are in degrees $F$. These expressions match the simulation results within 0.02 to $0.03 \mathrm{MW}_{\mathrm{e}}$ over the normal temperature range. 
The evaporator and condenser discharge temperatures and water discharge temperatures as a function of warm water temperature are shown in Figure 2.2-11.

\subsubsection{Fouling Factor}

Heat exchanger fouling affects net power and overall heat transfer coefficient significantly. Figure 2.2-12. shows the effect of warm water fouling factor at the nominal, maximum, and minimum warm water temperature using the nominal cold water fouling factor of $0.0001 \mathrm{ft}^{2}-\mathrm{hr}-{ }^{0} \mathrm{~F} / \mathrm{Btu}$.

Figure 2.2-13 shows the effect of warm water fouling at various levels of cold water fouling and of cold water fouling with the nominal warm water fouling factor $\left(0.0001 \mathrm{ft}^{2}-\mathrm{hr}-{ }^{0} \mathrm{~F} / \mathrm{Btu}\right)$. The fouling factors have a 1 inear, additive effect on net.power and can be represented as:

$$
\begin{aligned}
P_{\text {Net }}= & P_{T(\text { Net })}-\left(0.37+0.0088 \Delta T_{W}\right)\left(f_{W}-0.0001\right) \times 10^{4} \\
& -\left(0.33+0.0088 \Delta T_{W}\right)\left(f_{C}-0.0001\right) \times 10^{4} \mathrm{MW} e
\end{aligned}
$$

where $\Delta T_{W}$ is the amount by which the warm water inlet temperature exceeds $80^{\circ} \mathrm{F}$ and $f_{W}$ and $f_{C}$ are the warm and cold water fouling factors.

Figure 2.2-14 shows the effect on the overall heat transfer coefficients of the evaporator and condenser fouling factors.

\subsubsection{Flow Losses}

A series of simulation runs was made to determine power losses due to the friction associated with the vapor and fluid flows in the system piping. This was accomplished by selectively zeroing out the coefficients in the program associated with valives, bends, and friction losses. $\therefore$ The losses in the bends were found to have the greatest impact and amounted to 0.06 to $0.07 \mathrm{MW}_{\mathrm{e}}$ over the normal temperature range. The majority of this loss occurs on the vapor side. The friction in the pipes and the valve $K$ factors (a nominal $k$ value of 0.2 was assumed for all wide-open valves) 


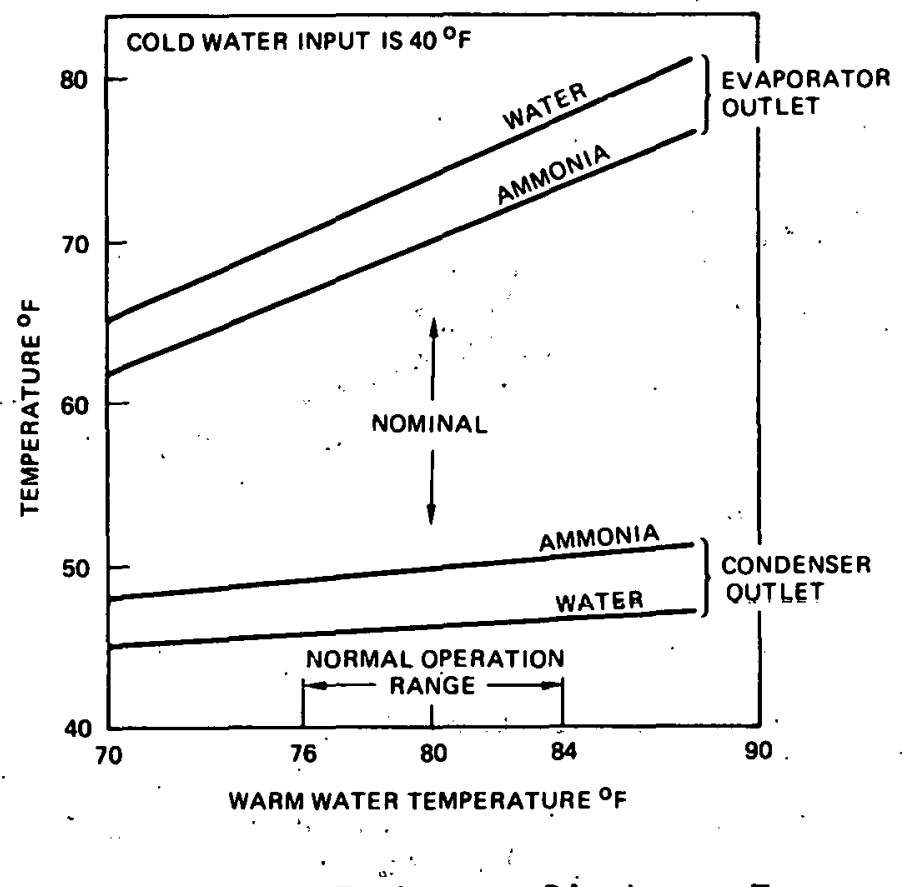
Figure 2.2-11. Heat Exchanger Discharge Temperature vs
Inlet Temperature

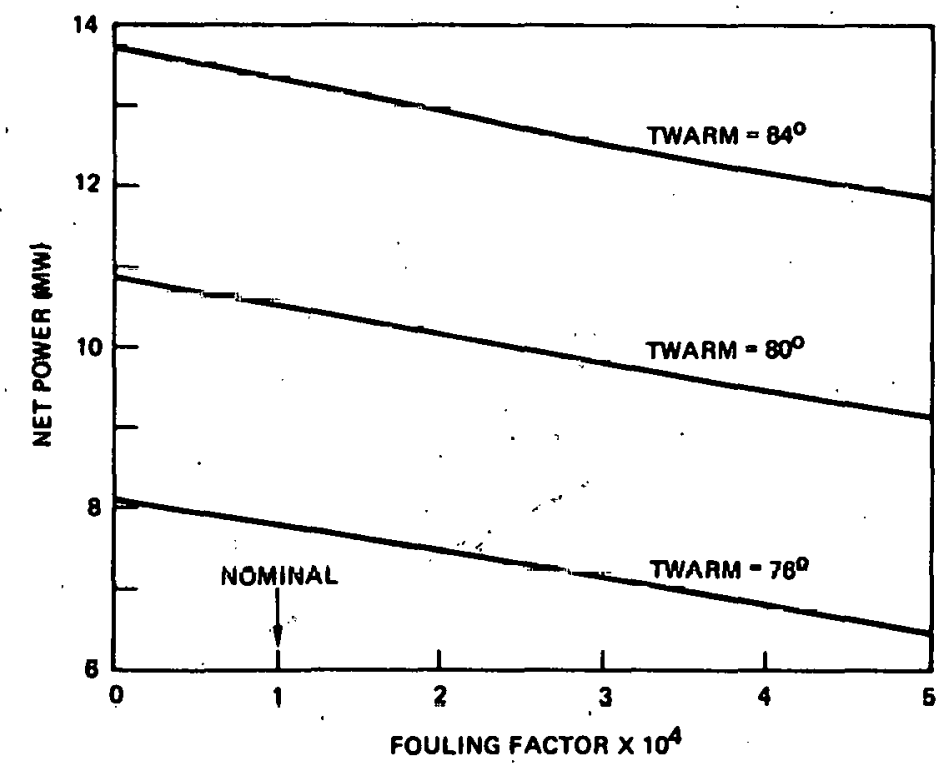

Figure 2,2-12. Net Power vs Warm Hater Fouling Factor (Cold Water. $=40^{\circ} \mathrm{F}, \mathrm{f}_{\mathrm{c}}=0.0001$ ) 


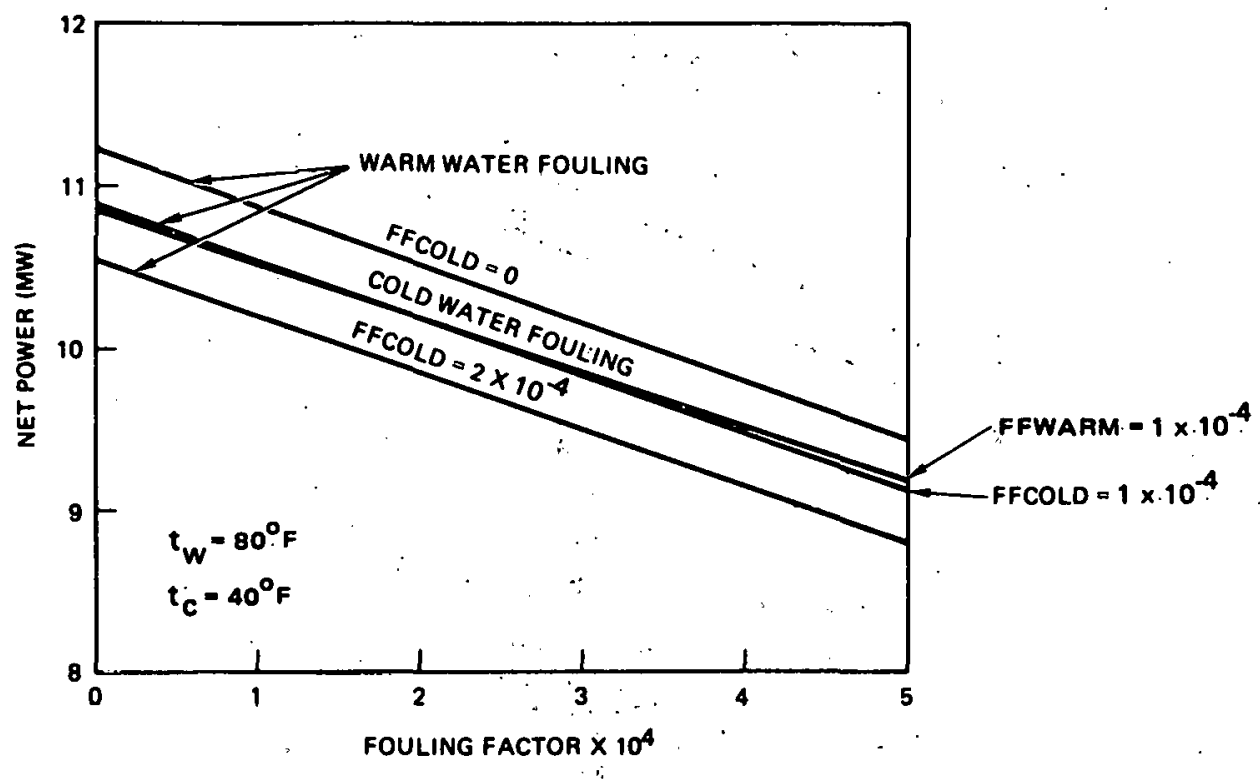

Figure 2.2-13. Net Power vs Warm and Cold Water Fouling Factor

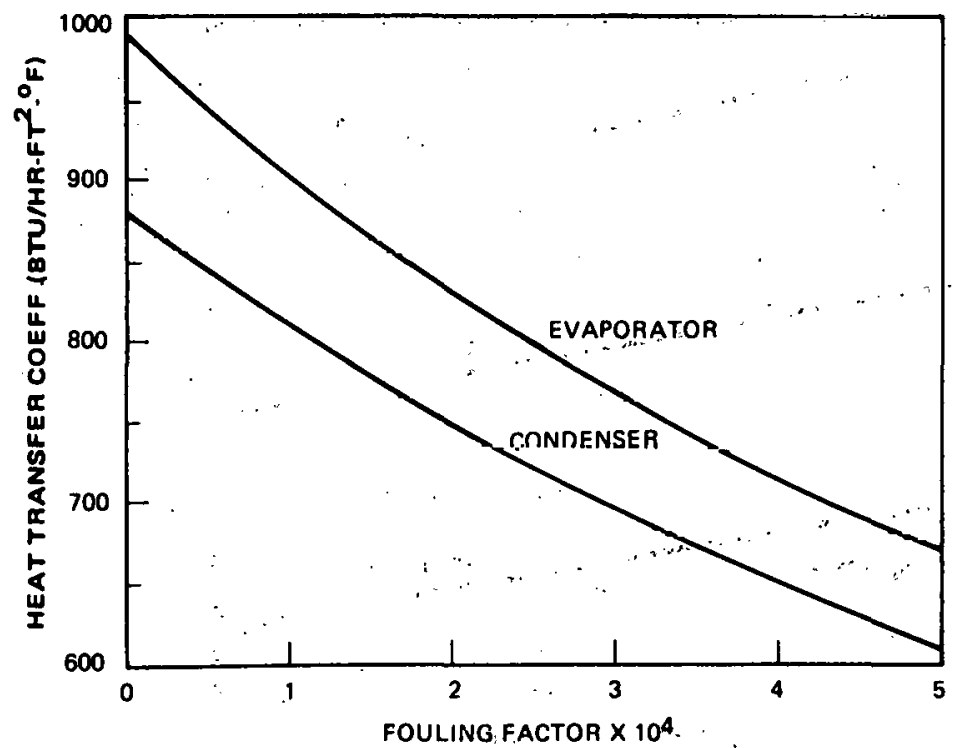

Figure 2.2-14. Overal1 Heat Transfer Coefficient vs Fouling Factor 
had roughly equal effects at $0.01 \mathrm{MW}$ each. The loss in the ammonia filter and evaporator header were found to be negligible at less than $0.005 \mathrm{MW}$ each.

\subsubsection{Water Flow Rates}

The effect of varying the warm and cold water flow rates in the evaporator and condenser was investigated to determine sensitivity. Figure 2.2-15 shows that the nominal water flow rates are very close to optimum. This verifies the design program optimization because, within about \pm 10 percent variation in flow, the change in net power is not significant. This is a desirable characteristic of the design since small variations in pump performance will occur.

\subsubsection{Startup and Shutdown}

Figure 2.2-16 shows the relationship among installation tests, purging, ammonia charging, startup, shutdown, and trip. The remainder of this section is a first estimate of operational procedures; it does not address installation and checkout procedures.

During Phase III, these lists of events will be expanded and the times between all events will be determined.

\subsubsection{Nitrogen Purging}

The air or ammonia in the piping and subsystems is replaced with dry .nitrogen stored at $225 \mathrm{psig}$ in five consecutive purges, Section 2.8,3,4, By closing valves $V-4, V-23, V-5 ; V-22$ and $V-1$ in Figure 2.1-4, the evaporator, the turbine and the condenser are isolated and purged. By closing valves $V-2$ and $V-3$, each heat exchanger is isolated and purged. Purging ceases when an Orsat analysis shows sufficiently low oxygen and $\mathrm{CO}_{2}$ content in the nitrogen (if the system was previously filled with air) or sufficiently low ammonia content (if the system was previously filled with ammonia). Purging ends with the power cycle pressurized at approximately 80 psta.

\subsubsection{Ammonia Charging}

The inert power cycle is charged with nitrogen. At the time of initial Installation and following any shutdown that requires removal of the ammonia, the system must be recharged with ammonia and flushed of nitrogen. Ammonia recharge consists of three ammonia flushes followed by loading of the desired amount of ammonia.

$$
\text { 2. } 2-30
$$




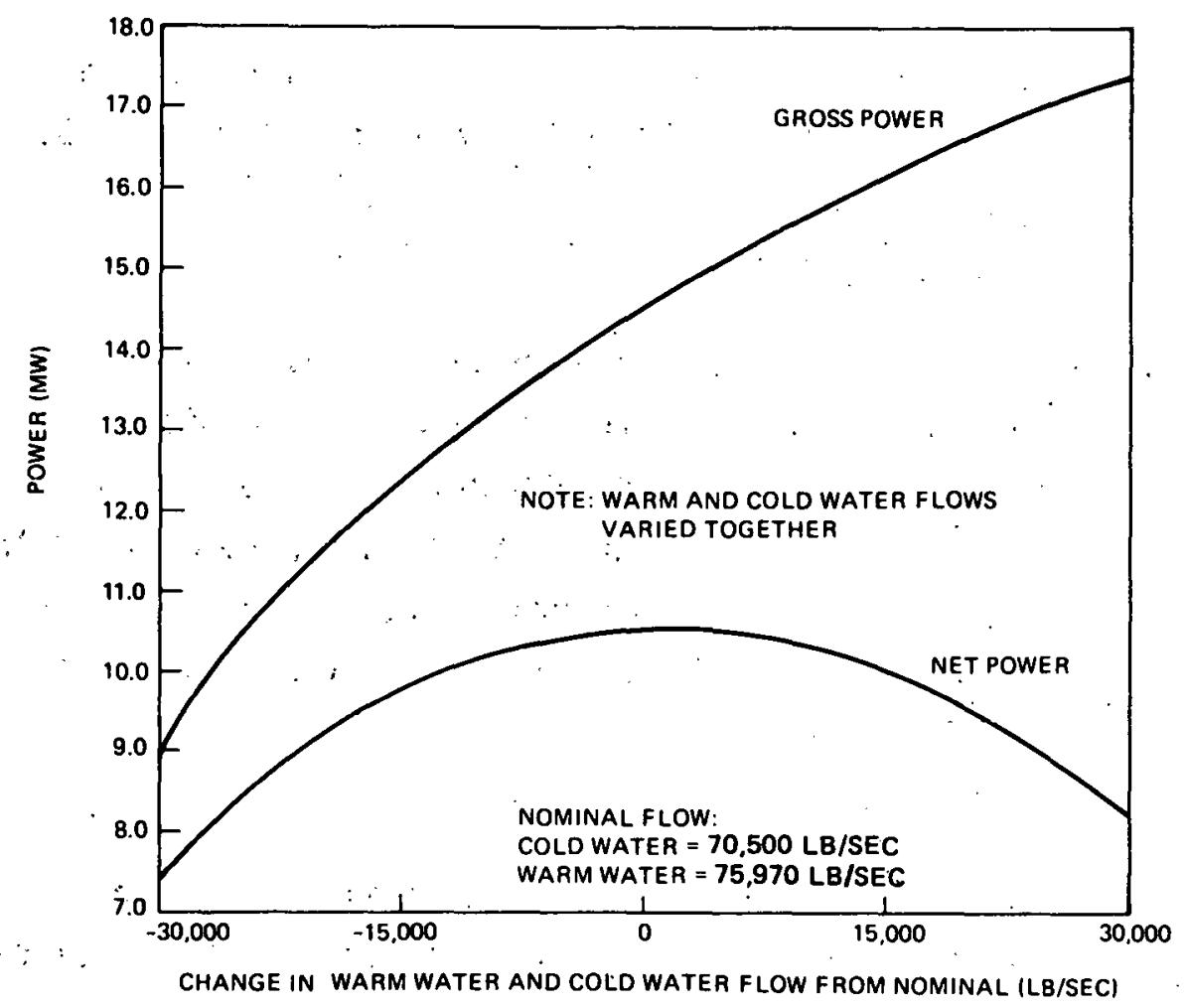

Figure 2.2-15. Power Output vs Water Flow Rate

A first estimate of the sequence of events is as follows, starting with an atr-filled piping system.

1. Purge, as in Section 2.2.5.1.

2. Bleed nitrogen overboard until the power cycle pressure drops to 65 psia by partially opening $V-17$ or $V-19$.

3. Open liquid $\mathrm{NH}_{3}$ supply valve $V-6$ to admit ammonia at 1.00 psia, 560F. The power cycle will fill with ammonia vapor. Liquid ammonia will begin to fill the evaporator sump and condenser sump.

4. Vent $\mathrm{N}_{2}$ overboard. To do so, close $V-6, V-4, V-23$. Open V-17 or $V-19$ until the pressure drops to 65 psia.

5. Repeat the ammonia flush (steps $2,3,4$ ) two more times. Vent the ammonia-nitrogen mixture to the treatment plant via $V-18$. Condense $\mathrm{NH}_{3}$ in the seawater condenser and release the $\mathrm{N}_{2}$ to the atmosphere. Flushing ceases when an Orsat analys is shows sufficiently low nitrogen content in the ammonia. 


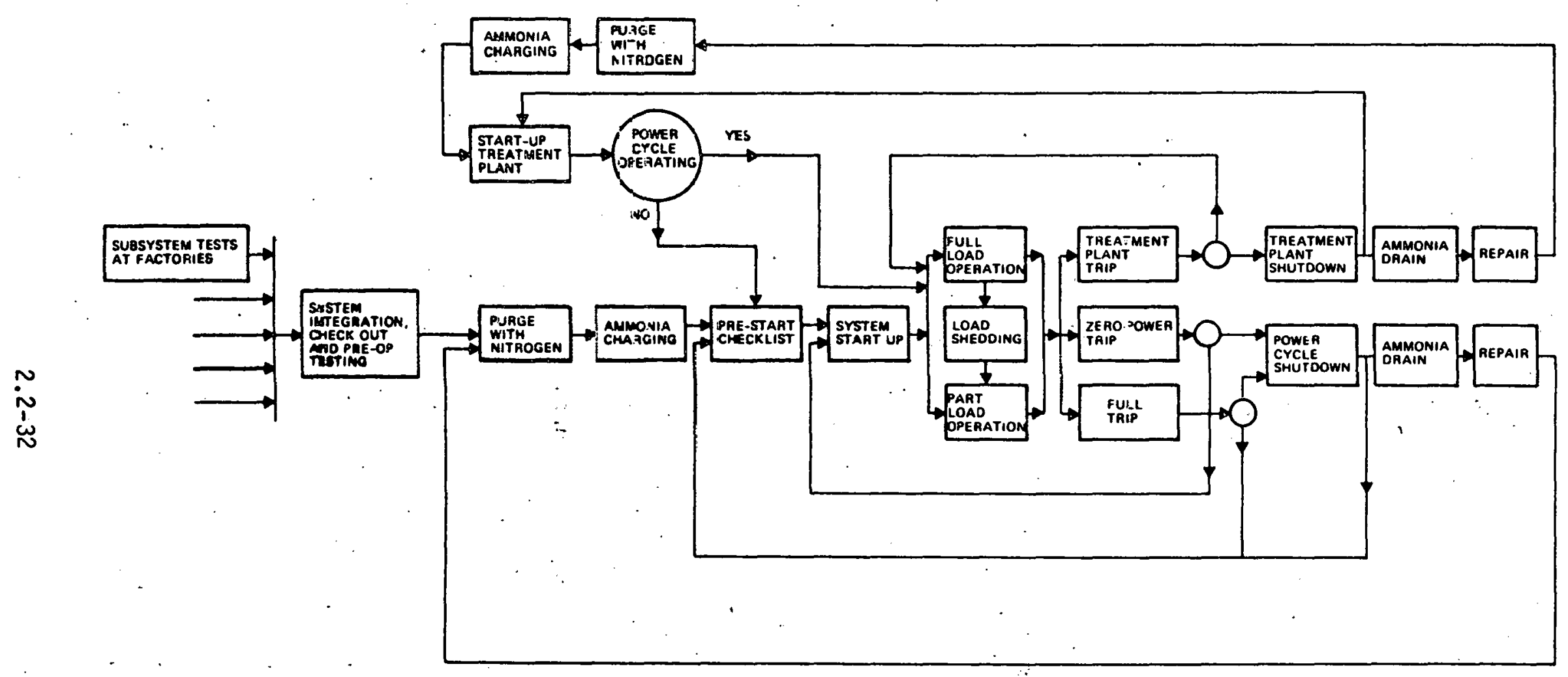

Figure 2.2-16. Radiations Among Plant Operating Procedures 
6. Charge the power cycle with the desired weight of ammonia, until the total system pressure reaches TBD psia (approximately 90 psia) through $V-6$. To charge the treatment plant, bottled ammonia is fed into the system until ful1, then the system is checked-out and started, a procedure estimated to take one full day.

\subsubsection{Prestart Checklist}

Prior to starting the hydraulic pumps and ammonia loops, the operators will review a checklist. During Phase. II, TRW prepared an example of such a checklist to be elaborated during Phase.III, when the time to complete each item on the checklist will be determined. The following items are verified:

1. Preoperational testing is succèsfully completed on all subsystems

2. The system is charged with ammonia and residual nitrogen content is satisfactory

3. Shiploads are connected to ship generator

4. Plant loads are connected to the external power grid

5. Turbine/generator is disconnected from the external power grid

6. Trip valve at turbine inlet is closed $(V-2)$

7. Turbine bypass valve is open $(v-3)$

8. Tube cleaning machines are off

9. Pressure-balancing valves are open $(V-22, V-23)$

10. Sump isolation valves are open $(V-4, V-5)$

11. All vent and drain valves are closed (e.g., V-6,V-7, V-8, V-17, $v-18, V-19, V-20, V-21$ )

12. Remaining ammonia process valves are open (e.g., $V-1, V-9, V-10$, $\mathrm{V}-11, \mathrm{~V}-12, \mathrm{~V}-13, \mathrm{~V}-14, \mathrm{~V}-15, \mathrm{~V}-16)$

13. Supply and return valves in ammonia purification loop are open (two values)

14. Instruments and analyzers are calibrated.

\subsubsection{Startup}

The normal operation of OTEC-10 is to sunnly electricity to an infinite grid. Thus, startup will occur on power drawn from the grid until the generator is synchronized at zero load. During the presynchronization 
period, ship loads are probably carried by the ship's diesel generators. Based on the Phase II work, TRW envisions the following startup sequence.

1. Verify that the prestart checklist (Section 2.2.5.3) has been completed.

2. Turn on instrument air supply. $\because$.

3. Turn on power to instrumentation: recorders, controllers, transmitters, solenoids, valve actuators, indicators, alarms, and annunciators.

4. Turn on power to process-control computers and self-test them.

5. Turn on turbine lube pumps and oll seals. Check o11 level and pressure. Check operation of redundant pumps and standby pumps.

6. Start ammonia support subsystem (Section 2.8).

7. Turn on cold seawater pump $(P-2)$. Check pump and motor instrumentation. Check seawater temperature (TE-13) and flow rate (FR-2). Check pump NPSH, moonpool level (LE-3) and condenser water box. level (LE-2).

8. Turn on warm seawater pump $(P-1)$. Check pump and motor instrumentation. Check seawater temperature (TE-11) and flow rate $(F R-1)$. Check pump NPSH and evaporator water box level (LE-1).

9. Allow TBD minutes for steps 6,7 , and 8 .

10. Isolate standby ammonia pumps, close $V-16$ for standby feed pump $(P-6)$, close $V-14$ for standby recirculation pump $(P-4)$.

11. Start backup ammonia recirculation pump (P-4). Check pump and motor instrumentation and flow rate $(1-E-1)$. Stop backup pump and restart primary pump. ( $P-3)$. Check instrumentation, and flow rate.

12. Start backup ammonia feed pump $(P-6)$. Check pump and motor instrumentation and flow rate $(F E-2)$. Stop backup pump and start primary pump $(P-5)$. Check pump motor workstation and flow rate. This is a variable speed pump, sn set. the pump speed tri in perrent flow. Check pump NPSH.

13. Allow TBD minutes and check sump levels (LE-4, LE-5).

14. When ammonia pressure at evaporator outlet (PE-4) is TBD psia, set the variable nozzles of the turbine stator to minimum setting and open the trip valve (V-2) to admit a small amount of vapor to the turbine. When enough torque is developed to overcome frictional forces, the turbine/generator will come up to some minimum speed ( 100 to 200 RPM). Monitor bearing temperature, noise, oil pressure, flow, etc., for turbine and generator. 
15. Set the ammonia recirculation valve $(V-1)$ to TBD percent flow.

16. Computer controls the variable nozzles to maintain nearsynchronous speed at zero power output. . Connect the line circuit breaker (PCB-2) when the phase-meters read zero. Check turbine speed.

17. Open the ammonia recirculation valve ( $V-1)$ gradually to approximately 30 percent flow.

18. Open the variable nozzles gradually to load turbine until TBD MWe (amount of plant and ship loads). Adjust exciter for power factor. Switch ship loads to turbine/generator when appropriate. Close turbine by-pass valve $(V-3)$.

19. Turn on tube-cleaning machine. Test and enter automatic cycle.

20. Start chlorination and leak detection subsystems.

21. Plant is now self-sustaining at zero net power and ready to be set as requested by dispatcher.

\subsubsection{5, Trip}

As described in Section 2.2.3, the power cycle, the hydraulic system or the ammonia treatment plant can be tripped. Each of the three trips can be initiated manually or can occur automatically if sensors go out of limits. Following a trip, the plant is either restarted or is shutdown, Figure 2.2-16.

\subsubsection{Shutdown}

Shutdown is operator-initlated after a trip, Figure 2.2-16. The power cycle shutdown procedure is as follows:

1. Start ship's generator and synchronize

2. Switch ship loads to ship generator

3. Switch plant loads to external power grid

4. Stop warm seawater pump if from partial trip $(P-1)$

5. Stop ammonia recirculation pump $(P-3)$

6. When pressure in evaporator $(P E-4)$ is equalized with pressure in condenser (PE-7), stop cold seawater pump if from partial trip $(P-2)$. 
7. Stop ammonia feed pump (P-5)

8. Turn off tube cleaning machine

9. Stop chlorination and leak detection subsystems.

\subsubsection{Ammonia Drain}

Following a shutdown, if the system is to be repaired, the ammonia must be removed and the system purged, Figure 2.2-16. Purging is necessary for safety so workmen do not encounter ammonia when opening components and for fire protection. Nitrogen purge also reduces the exposure of valve-isolated components to corrosive salt air.

The procedure for removing ammonia following a shutdown is as follows:

1. Close pump isolation valves $V-9$ and $V-11$. Open ammonia let-down valves, $V-7$ and $V-8$. Start let-down (drain) pumps to remove liquid ammonia from sumps.

2. When completely drained, stop let-down pumps. Close valves, $V-7$ and $V-8$. Open valves, $V-9$ and $V-11$.

3. Start nitrogen support subsystem and purge the system (see Section 2.2.5.1).

4. System is now accessible and ready for maintenance.

\subsubsection{Startup Power}

Parasitic power requirements during startup are summarized in Table 2.2-8, The full-pewer load of 4 MW ran only be reduced to 3.5 MW during startup with single-speed hydraulic motors. Section 2.10.2.5 shows the inrush currents required, with low-voltage and full-voltage starting.

An OTEC plant connected to an infinite grid starts with power drawn off the mains through a transformer and switchgear. The source of pnwer for an island-option plant or an isolated plant is to be analyzed during Phase II but could be a nearby OTEC plant, another generator on the island grid, or a barge.

During Phase III TRW will compare the full-pump-power startup with the following bootstrap procedure that uses variable speed hydraulic pumps. On lowest speed, they consume approximately $400 \mathrm{~kW}$ while vaporizing enough ammonia to generate the Startup parasitic power of $600 \mathrm{~kW}$,

\section{$2.2-36$}


Table 2.2-8. Startup Power Budget

\begin{tabular}{|c|c|c|c|c|}
\hline \multirow[b]{3}{*}{ Parasitic Load } & \multirow[b]{3}{*}{$\begin{array}{l}\text { Mechanical } \\
\text { Power }\end{array}$} & \multicolumn{3}{|c|}{ Power Consumption, KW } \\
\hline & & \multirow[b]{2}{*}{$\begin{array}{l}\text { Full } \\
\text { Power }\end{array}$} & \multicolumn{2}{|c|}{ Startup } \\
\hline & & & $\begin{array}{l}\text { 1-Speed } \\
\text { Seawater } \\
\text { Pumps }\end{array}$ & $\begin{array}{l}\text { 2-Speed } \\
\text { Seawater } \\
\text { Pumps }\end{array}$ \\
\hline Pumps $\quad \therefore$ & & & & \\
\hline Seawa ter & $3890 \mathrm{hp}$ & 3130 & 3130 & 984 \\
\hline Ammonia Loop & $434 \mathrm{hp}$ & 380 & 190 & 190 \\
\hline $0 i 1$ Pumps & $50 \mathrm{hp}$ & & & \\
\hline Ammonia Column Feed & $3 \mathrm{hp}$ & 110 & 110 & 110 \\
\hline Ammoniä Compressor & $75 \mathrm{hp}$ & & & \\
\hline Reflux & $20 \mathrm{hp}$ & & & \\
\hline Ammonia Transfer & $100 \mathrm{hp}$ & & & \\
\hline $\mathrm{N}_{2}$ Seawater Return & $15 \mathrm{hp}$ & 190 & 0 & 0 \\
\hline $\begin{array}{l}\mathrm{N}_{2} \text { Transfer } \\
\text { Blowdown }\end{array}$ & $\begin{array}{r}50 \mathrm{hp} \\
7.5 \mathrm{hp}\end{array}$ & & & \\
\hline Ammonia Blowdown & $20 \mathrm{hp}$ & & & \\
\hline Recovered Ammonia & $3 \mathrm{hp}$ & & & \\
\hline Total Pumps & $\therefore$ & $\overline{38.10}$ & $\overline{3430}$ & $\overline{1280}$ \\
\hline Cther Loads & & & & \\
\hline 011 Heater & $12.5 \mathrm{KW})$ & & & \\
\hline Degasification Heater & $3 \mathrm{KW}$ & 5 & . & A) \\
\hline Controls & $6 \mathrm{~kW}$ & $=41.5$ & 41.5 & .41 .5 \\
\hline $\begin{array}{l}\text { Turbine-Generator } \\
\text { Auxillaries }\end{array}$ & $20 \mathrm{~kW})$ & & & \\
\hline Tube Cleaner & $10 \mathrm{hp}$, & & & \\
\hline Chlorinator & $100 \mathrm{~kW}$ & 180 & 0 & 0 \\
\hline other & $73 \mathrm{kWl}$ & & & \\
\hline Total Other & & 220 & $\overline{42}$ & 42 \\
\hline Parasitic Load, MW & & 4.03 & 3.47 & 1.33 \\
\hline
\end{tabular}


Figure 2.2-17. When equilibrium is established at 600 kwe gross power output, the pumping power is raised gradually while closing the ammonia throttle, thereby generating enough electricity to sustain the plant. When the gross output power reaches $3.5 \mathrm{MWe}$, the non-essential auxiliaries are switched on until, at 4 MWe, the plant begins to produce a surplus of electricity and the ammonia recirculation throttle can be opened. During Phase III, when the external grid is defined, TRW will compare the cost of variable-speed seawater pumps to the cost of full-pump-power startup.

\subsubsection{Transient Performance}

\subsubsection{Dynamic Models}

The objectives of the transient performance analysis are to verify small perturbation stability, to determine if high-frequency control is needed to reduce power fluctuations due to ship motions, to determine the timing of events during startup, and to evaluate system overshoot following a trip. To achieve these objectives, four dynamic mathematical models are planned, one of which was constructed during Phase II using TRW funds. It was decided not to make a general-purpose, steady-state and dynamic model that would address all issues because of its high cost and long-term of development. That decision was corroborated by the fact that the steady state model and the first dynamic model have been completed and are operat-

ing. The four dynamic models are:

1. Net output power fluctuations in response to water oscillations. This mathematical model is intended to calculate the smallperturbation fluctuations in net power produced by ship heave (to be expanded to include ship roll and pitch in Phase III). It consists of two models that are run independently: the water model which calculates the variations in water flow rate caused by ship motion; and the ammonia model which calculates the net power output caused by changing water flow rates. Both models are working and are described below, as are the early results.

2. Smal1-perturbation stability model at full and part power to be constructed in Phase III. This model will simulate the dynamic variations in ammonia flow and net power caused by changes in actuator positions. It will be used to demonstrate open-loop stability of the plant at full and part power. Simplified models will represent the subsystem dynamic characteristics from 0.01 to $3 \mathrm{~Hz}$. If control loops are required, they will be modeled and run in a closed-loop manner to verify stability of the controlled plant. Control-system performance (attenuation and phase lag) will be calculated from the model. 


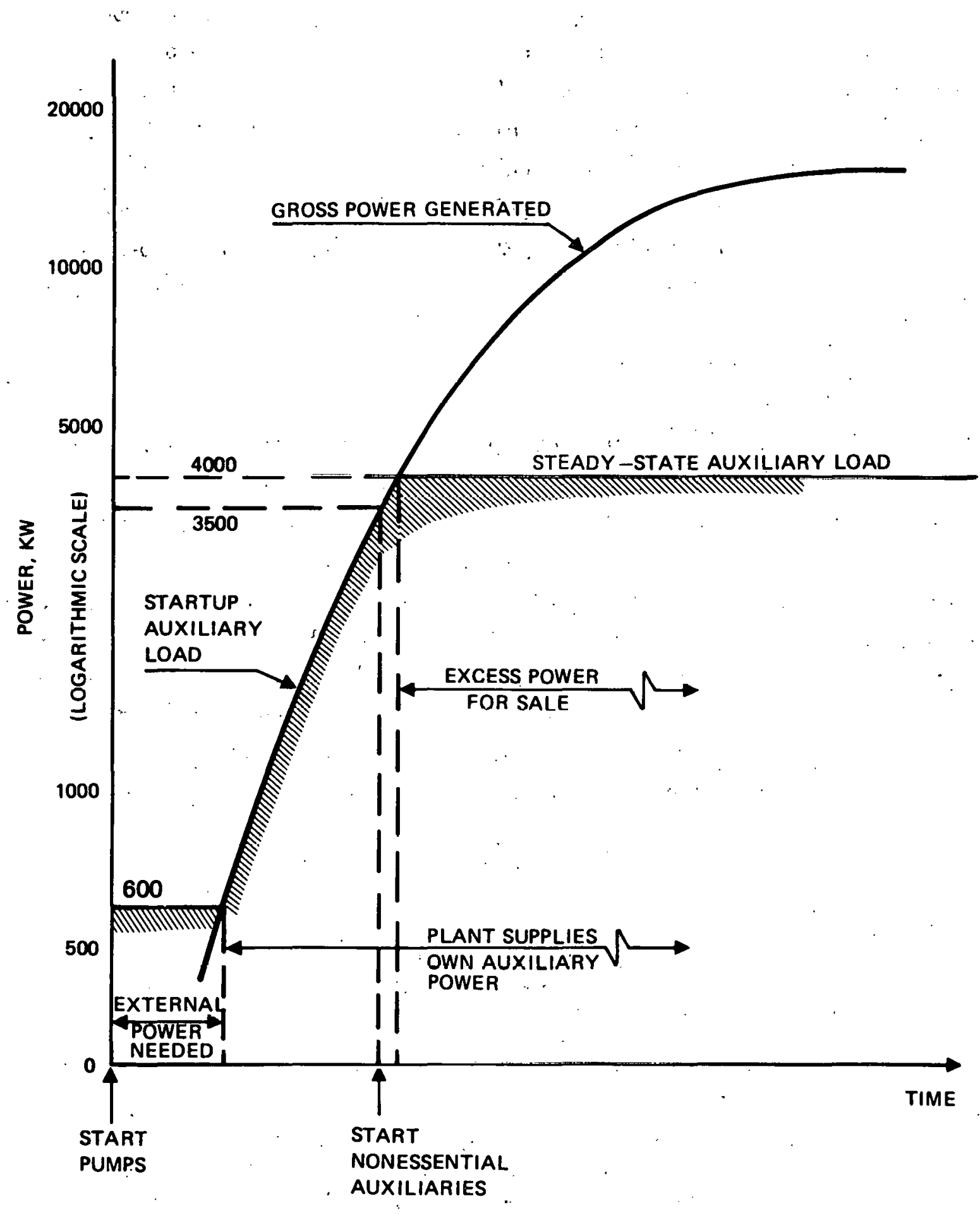

Figure 2.2-17. Startup Power with Variable-Speed Seawater Pumps 2.2-39 
3. Startup timing model. This model is a large-perturbation model designed to predict the times between events during a startup or power-level change. The model will be written in Phase III.

4. Trip overshoot analysis. This is a special-purpose model to analyze overshoots during a trip, to be written in Phase III. As of Phase II, the only critical overshoots are believed to be turbine speed, pressure in the evaporator header, and pressures in the shell spaces of the two heat exchangers. By modeling the inlet pipe, valve dynamics, and diffuser, we will verify that overspeed is within the turbine manufacturer's specifications. By modeling the recirculation valve dynamics, we will verify that the evaporator header pressure overshoot is within design limits.

\subsubsection{Power Loop Transient Model}

This model analyzes power output fluctuations in response to water flow variations induced by wave action and ship motion. The turbine was assumed to be synchronously locked to an infinite grid so its speed remained constant. The principal dynamics were in the heat exchangers: Each heat exchanger was modeled as thousands of thermodynamically identical tubes. Each tube is divided into 10 axial segments, in each of which the evaporation/condensation rate and film thickness are constant. A differential equation is written for each segment that includes: a) flow to and from other segments, and b) evaporation or condensation. The shell space of the heat exchanger is assumed to be at uniform pressure and temperature despite the transverse flow of vapor. The transit time of water flow in the tubes is also included. The heat exchanger model was reviewed and approved by Professor Rothfus at Carnegie-Mellon University, who is experimentally determining heat transfer coefficients of fallingfilm heat exchangers. On the liquid side, the model includes sump volumes and pump head-flow-rate curves (speed variations in the pumps will be added to the dynamic models in Phase III). The results of the modeling are described in Section 2.2.6.4.

\subsubsection{Hydraul ic Transient Model}

The vertical motion of the hull causes flow transients in the cold and warm water systems, which cause unsteady flow on the waterside of the heat exchangers. In order to examine the nature of the unsteady flow and 
to determine its effect, a dynamic mathematical model of the water flow was formulated and solved numerically by computer. In the model, the hydraulic features of a 40 MWe platform are represented by three subsystems. The cold water pipe and open trough are represented as a single subsystem.

The second subsystem consists of a condenser, an evaporator, and their common effluent discharge pipe. The third subsystem includes the two seawater pumps.

A detailed discussion of the model may be found in Appendix A3. Reference is also made to Appendix B which contains a general study of the various options for water supply and distribution subsystem design, as well as the expected response to various modes of ship motion.

Results of design studies with the hydraulic transient model are discussed in Section 2.2.6.4.

\subsubsection{Simulation Results}

DVE has specified-Sea State 6 dynamics of the platform equal to 21.4 feet (peak to peak) resulting in a vertical acceleration of $0.5 \mathrm{~g}$. A harmonic (sinusoidal) oscillation of the ship with period of 16.2 seconds and amplitude of $21.4 / 2=10.7$ feet meets these requirements and was used as input to the hydraulic transient model to describe ship heave. Figure 2.2-18 shows the transient behavior of water levels in the cold water trough and in the heat exchanger's headers relative to the platform. 'The level in the trough varies \pm 1.2 feet. Due to changing head on the pumps and to heave-induced velocity changes, the water levels in the headers or top water boxes fluctuate by about \pm 1.1 feet at Sea. State 6 .

The resulting changes in cold water pipe velocity and heat exchanger tube velocities relative to the platform are shown in Figure 2.2-19. The cold water pipe velocity is practically 180 degrees out of phase with the ship heave and of equal magnitude. In other words, the inertial velocity in the cold water pipe is practically constant due to the mass of water in the 3000-foot pipe. The relative water velocity in the pipe varies \pm 4 feet/second due to vertical oscillations of the ship. On the other hand, the water velocity in the 300-foot warm water pipe is influenced more strongly by the changing hydraulic head in the water box and therefore varies more in inertial space. Thus, as shown in Figure 2.2-19, the 


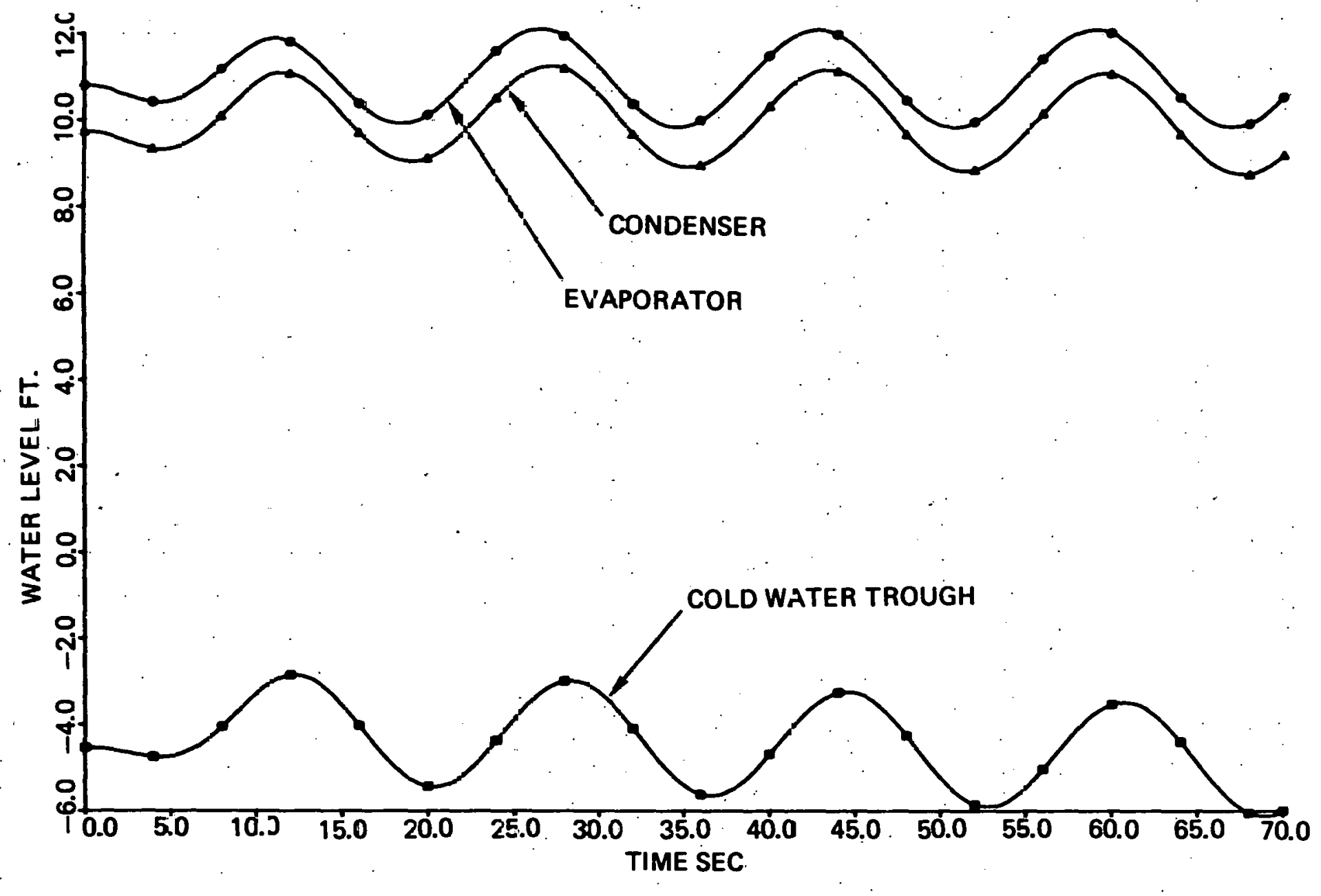

Figure 2.2-18. Water Level In Headers And Troughs Caused By Heave In Sea State 6 


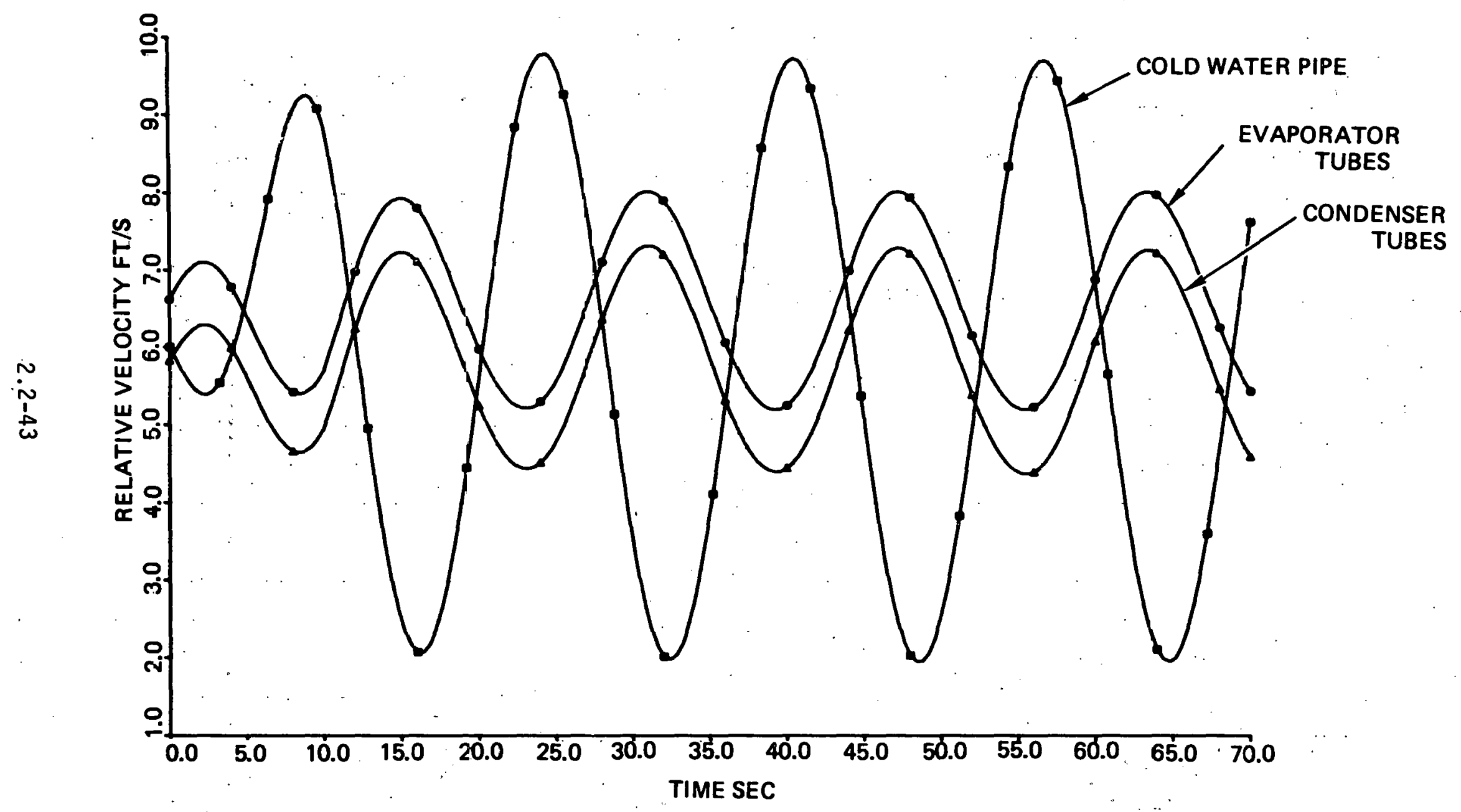

Figure 2.2-19. Water Velocity Relative to the Pipes Caused by Heave in Sea State 6 
relative water velocity in the evaporator tubes fluctuates only \pm 1.4 feet/ second due to heave and heave-induced changing head in Sea State 6 .

The computer model of the hydraulic system is ideally suited to investigate design options. For example, a run was made with the water box diameter increased to 38 -feet, equivalent to a doubling of the waterbox area. This reduced the level amplitude to about \pm 0.55 feet, but only reduced the velocity variations in the warm water pipe from \pm 1.4 feet/ second to \pm 1.3 feet/second.

The heat exchanger tube velocity variations were used as input to the power loop transient model to investigate the resulting fluctuations in gross power output of the uncontrolled plant. Preliminary results with the model indicate that the gross power oscillates with about a \pm 2 MWe amplitude in Sea state 6 and period equal to the input 16.2 second heave period (see Figure 2.2-20). This is nearly the steady state performance which is not unreasonable since the largest fluid and heat transfer time constants and delays are estimated to be about 6 seconds. The power oscil-' lations are asymmetric, causing a reduction in average output power in rough seas. A 0.7 MWe reduction results during Sea State 6 .

During Phase III, these preliminary dynamic models will be upgraded to include :

a. Speed changes in the hydraulic pumps and pump moment of inertia

b. Effect of ship's angular motion

c. Crossflow of vapor in the heat exchanger.

The upgraded simulations will be run to assess:

a. Power fluctuations at various sea states

b. Power fluctuations as the frequency of the heave oscillation changes.

OTEC-10 being a base-loaded plant delivering low incremental cost electricity into a large grid, the optimum strategy is to generate as much power as possible at each instant. However, if the large fluctuations predicted in Figure 2.2-20 are conflrmed and are considered excessive by the utility standards of the 1980s (perhaps because the plant is connected 


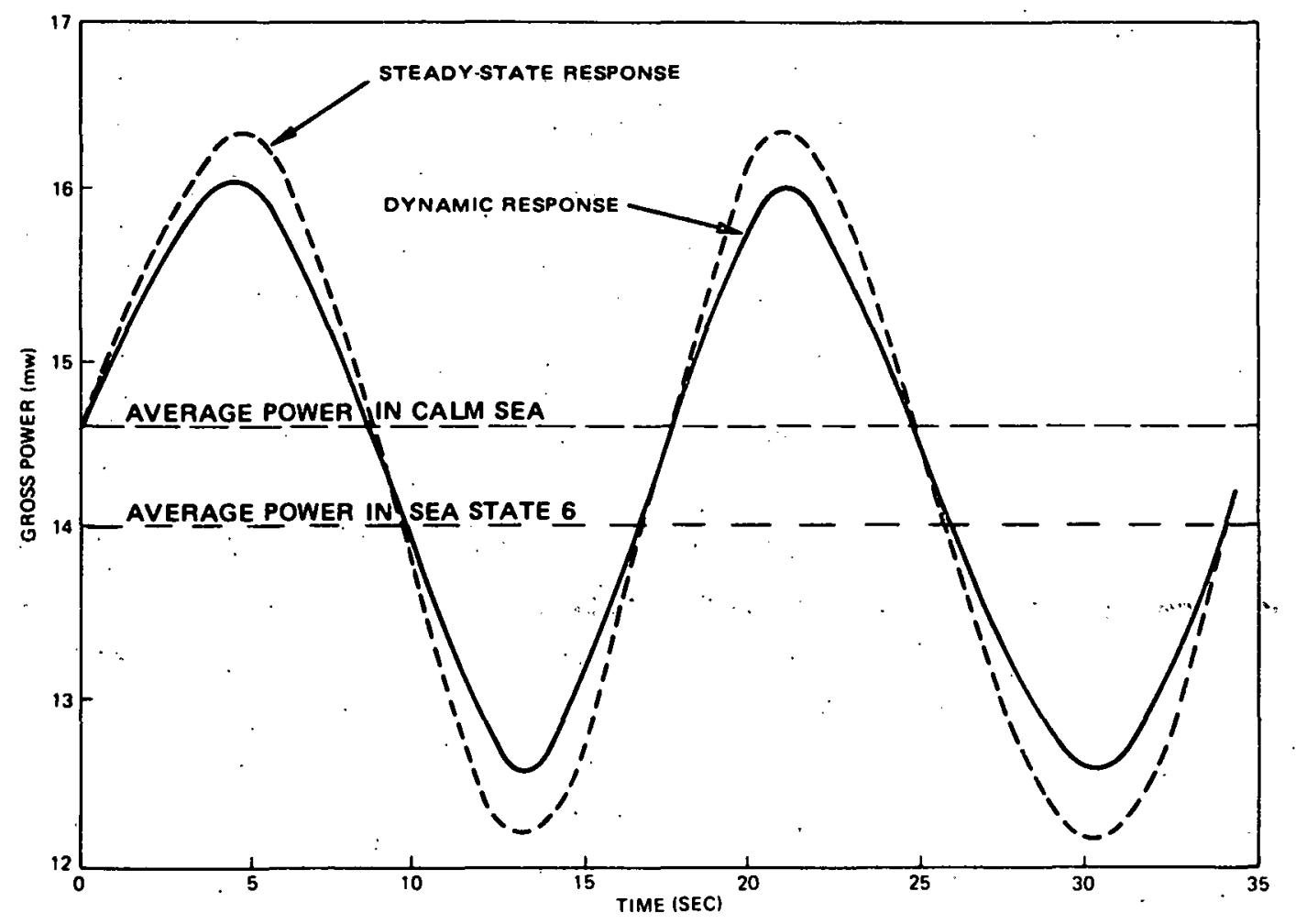

Figure 2-2-20. Output Power Variations Caused by Heave in Sea State 6

to a small island grid). TRW could reduce the fluctuations in any of these ways :

a. Vary the speed of the hydraulic pumps to change the hydraulic head on the heat exchangers in such a way as to keep the flow constant as the ship moves. The hydraulic transient model would verify the technical feasibility and TRW would request DOE to modify the government-furnished pump.

b. Increase the shell-space volume of the heat exchangers, thus smoothing the ammonia flow.

c. Control the ammonia flow to the turbine, either with a newly added turbine inlet valve, or with a continuously-variable bypass valve, or with the variable nozzles. Any of these would be controlled by water temperature or flow rate. Controlling the ammonia flow will cause a penalty in. net power output because of:

1). The presence of the partly open throttle value or partly closed bypass valve. This penalty will be 
large since on the average the plant would have to be throttled 20 percent.

2) Nonlinear characteristic of throttling that causes the average power to be'further depressed when the valve oscillates symmetrically. The average power reduction will probably be $0.5 \mathrm{MW}$.

The acceptability of power oscillations and methods of compensating them will be addressed in Phase II. TRW anticipates that utility companies will learn how to deal with fluctuating loads in the 1980s because of the growing usage of solar, wind-generating, and OTEC stations. 


\subsection{POWER SYSTEM COST ESTIMATES}

\subsubsection{Approach and Assumptions}

The overall approach to developing cost estimates is based on the D.0.E. guidelines received on August 4, 1978. As specified all costs are presented in July 1978 dollars.

Preliminary design drawings were developed in sufficient detail (see attached drawing package) to provide a basis for developing credible cost estimates. Specifications were developed based on the design and drawings (see attached specification package) and sent to vendors for prototype quote as described in the Phase II proposal. The selected vendors are designated in column (5) of the cost tables included in Section 2.3.2.

Cost estimates were then projected for first production plant, eighth 10 MWe plant and eighth 40 MWe plant based on the following assumptions:

a) Since vendor quotes were requested as fixed price bids it is assumed that the quote is high and therefore no other contingencies were considered. Contingencies of five to ten percent were considered on in-house estimates such as piping, electrical wiring and ammonia support systems.

b) Piping and electrical wiring cost estimates were based on preliminary drawing take-offs using "Building Construction Cost Data, 1978", R. S. Means as data source and New Orleans, La. as installation site.

c) No heat exchanger replacement is planned with titanium tubes. Heat exchangers were designed with corrosion allowances and provisions for in service leaking tube plugging.

d) Fees are included in all referenced procured equipments but are not included in indirect costs associated with design and integration.

e) Procured equipments include combined G\&A and procurement burden of 24 percent for items under $\$ 300,000$ and a reduced factor of 9.5 percent for procured items over $\$ 300,000$.

f) Indirect costs include engineering services and home office costs. Engineering includes preliminary engineering, optimization studies, specifications, detail engineering, vendor drawing review and resident engineering services during construction. The indirect costs for the prototype are based on developed detailed cost estimates. The sum of these two categories for production plants falls into historically consistent percentages in the range of 5 to 15 percent, depending on the complexity of the project. The apportionment of percentages by type is as follows: 


\begin{tabular}{llll} 
Plant Type & Engineering & Home Office & Total \\
\cline { 2 - 3 } & 17.7 percent & 10.5 percent & 28.2 percent \\
First Production & 12.5 percent & 3.0 percent & 15.5 percent \\
Eighth Production & 5.0 percent & 3.0 percent & 8.0 percent
\end{tabular}

g) Learning curve adjustments are based on the following assumptions: Labor and materials costs are listed separately if the information was developed or (in the case of vendor bids) provided in such a form. In these cases where a total dollar amount was provided, a best-engineering-judgment estimate was made for the portion that represented labor. These percent estimates are listed in the appropriate colums (e.g., 5,7,13) but no breakdown is given in the cost columns.

For learning curve computations, the Wright/Northrup curve is used. This curve is used by TRW manufacturing. It is defined as follows (Tavg) $2 n=L$ (Tavg) n

where $(\operatorname{Tavg}) 2 n=$ average cost or time, per unit, to produce $2 n$ units

$$
\begin{aligned}
(\text { Tavg })_{n}= & \text { average cost or time, per unit, to } \\
\text { produce } n \text { units } & \\
L= & \begin{array}{l}
\text { learning curve factor, usually } \\
\text { expressed as a percentage. }
\end{array}
\end{aligned}
$$

For this analysis the actual cost of the $n^{\text {th }}$ unit, rather than the average cost, is used. The choice of factor, $L$, is based on the amount of hand labor represented in a particular item. For items where there is a high level of hand labor, TRW has found that $L=85$ percent is a representative factor for scaling labor. For items where there is a high level of repetition, or where the labor is performed by machine, the curve defined by $L=90$ percent is more appropriate.

\subsubsection{Cost Tables}

Cost tables for components and subsystems are presented on the following six sheets in the format requested by DOE. The eighth 10 MWe plant and eighth 40 MWe plant are shown in the same spread sheets for comparative convenience. 
MoDULAR APPLICATION PONER SYSTEM - COST DATA

\begin{tabular}{|c|c|c|c|c|c|c|c|c|c|c|c|c|c|c|c|c|c|c|c|c|}
\hline \multirow{2}{*}{ 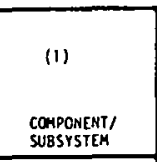 } & \multirow{2}{*}{$\begin{array}{c}\text { (2) } \\
\text { Descrpption } \\
\end{array}$} & \multirow{2}{*}{ 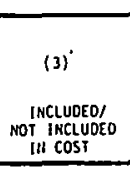 } & \multicolumn{2}{|c|}{ 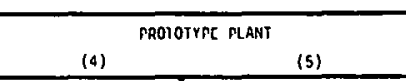 } & \multicolumn{3}{|c|}{ 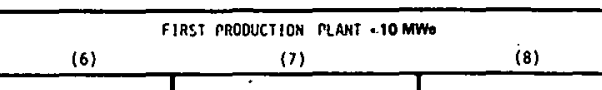 } & \multicolumn{6}{|c|}{ 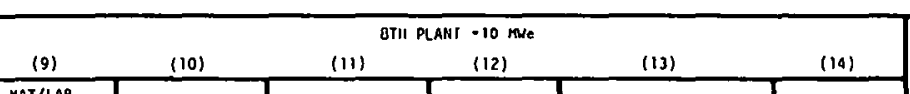 } & \multirow[t]{2}{*}{ (15) } & \multicolumn{6}{|c|}{ 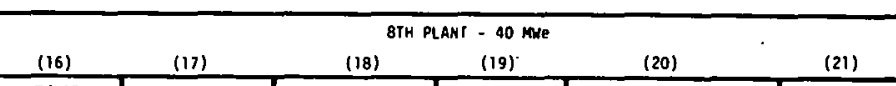 } \\
\hline & & & 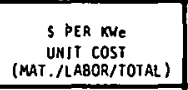 & 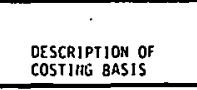 & 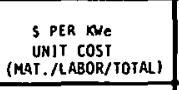 & 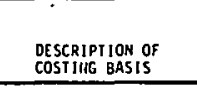 & 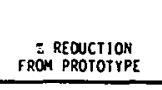 & 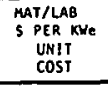 & 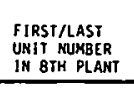 & 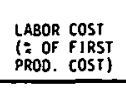 & 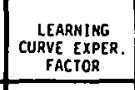 & 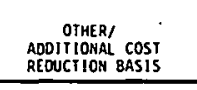 & 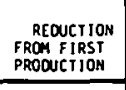 & & 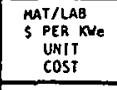 & 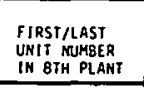 & 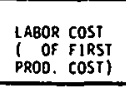 & 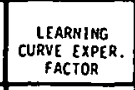 & 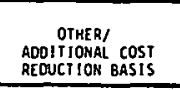 & 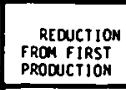 \\
\hline $\begin{array}{l}\text { conofenser } \\
\text { cinil }\end{array}$ & 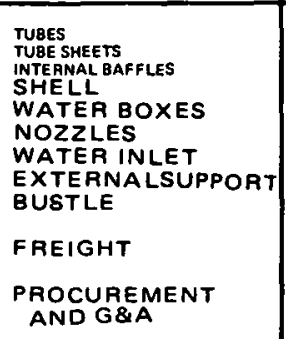 & & 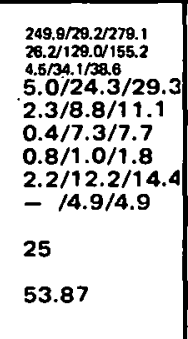 & 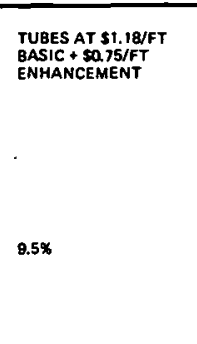 & 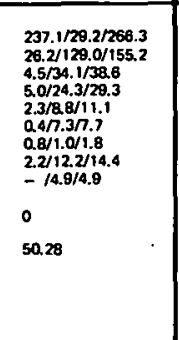 & 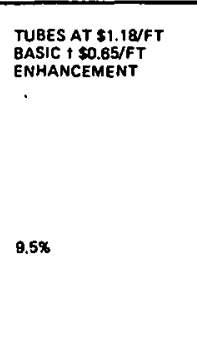 & $\begin{array}{c}1 \\
\vdots \\
+\infty \\
1\end{array}$ & 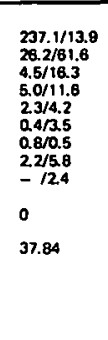 & 8 & $\begin{array}{l}{ }_{4} \\
\text { an. }\end{array}$ & $85 x$ & 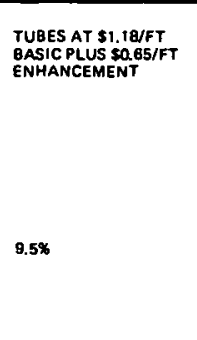 & 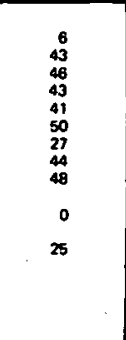 & JuLY II78 DOLLAAS & 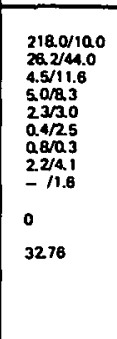 & $20 / 32$ & $i_{i}^{2, i}$ & osis & 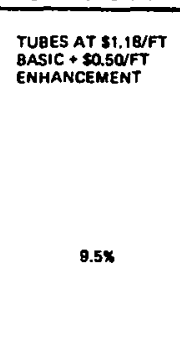 & 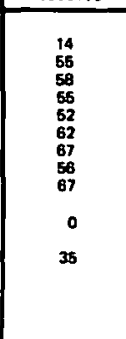 \\
\hline Sve-10rat & & & 621.0 & & 579.6 & & 1 & s3. & & & & & 25 & & $37 n .8$ & & & & & 35 \\
\hline 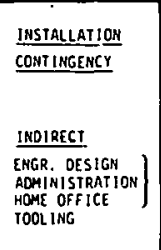 & S5S50 A A SEA & & 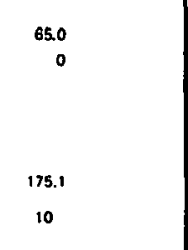 & $\begin{array}{l}\begin{array}{l}\text { FIXED PAREE } \\
\text { BID QY NOOOTER }\end{array} \\
28.2 \times \text { OF SUB-TOTAL }\end{array}$ & 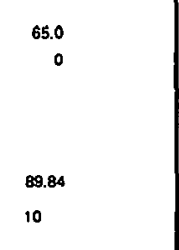 & 15.5x Of SUB-TOTAL & 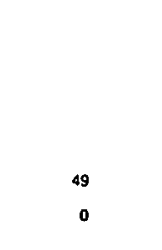 & $\begin{array}{l}3 ., 88 \\
10\end{array}$ & & & & | ox of suarototal & ${ }^{81}$ & $i$ & $\begin{array}{l}3021 \\
10\end{array}$ & & & & ax of suartotal & ${ }_{0}^{8 B}$ \\
\hline rorat & & & 87.1 & & 794.4 & & 15 & 545.0 & & & & & 27 & & 42.8 & & & & & 3 \\
\hline
\end{tabular}

\begin{tabular}{|c|c|c|c|c|c|c|c|c|c|c|c|c|c|c|c|c|c|c|c|}
\hline 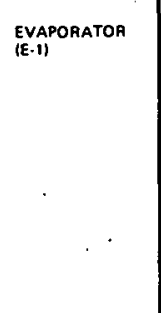 & 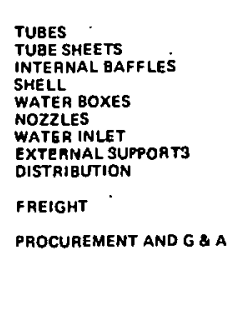 & 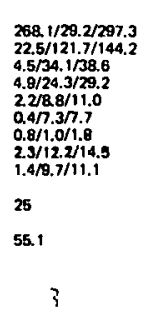 & 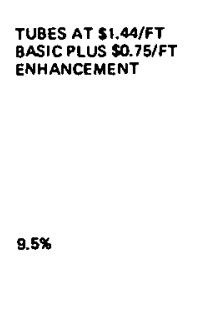 & 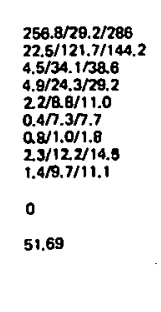 & 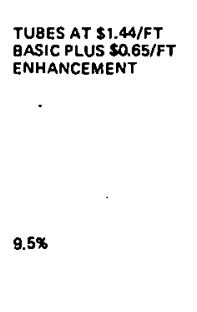 & $\AA_{0}^{4}$ & 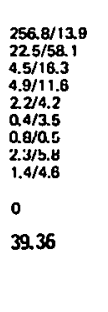 & 8 & 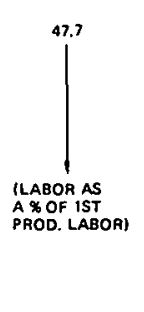 & ${ }^{85 x}$ & 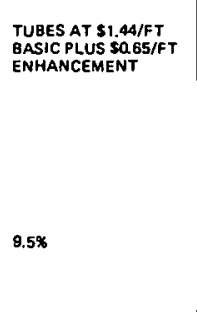 & 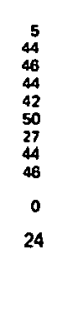 & JuLY 1978 DoLLAaAs & 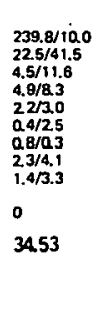 & 2032 & 1 & $85 x$ & 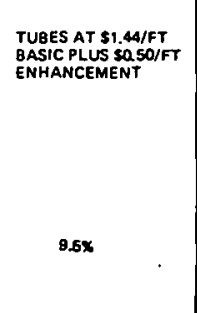 & 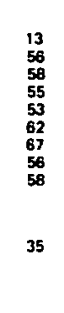 \\
\hline sub-rorat & & eas.5 & & 5968 & & 8 & 4537 & & & & & 24 & & 398.0 & & & & & 35 \\
\hline 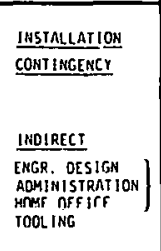 & Coso K A A EEA & $\begin{array}{l}\text { 65.0 } \\
0 \\
0.9 \\
179.2 \\
10\end{array}$ & 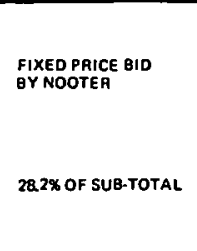 & 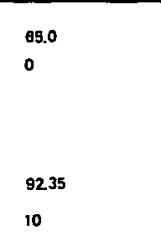 & 15.5x OF SUZ TOTAL & 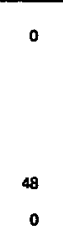 & $\begin{array}{l}65.0 \\
{ }^{\circ} \\
. \\
36.29 \\
10\end{array}$ & & & & | ox of subrototal & 61 & 1 & $\begin{array}{l}31.84 \\
10\end{array}$ & & & & ax of sub-total & 6 \\
\hline TOTAL & & $\$ 9.7$ & & 763.7 & & 14 & 565 & & & & & 26 & & 509.8 & & & & & $\infty$ \\
\hline
\end{tabular}


MOOULAR APPLICAT ION PCWER SYSTEM - COST DATA

\begin{tabular}{|c|c|c|c|c|c|c|c|c|c|c|c|c|c|c|c|c|c|c|c|c|}
\hline & & \multirow{3}{*}{ 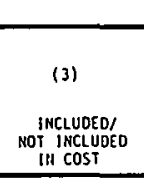 } & \multirow{2}{*}{\multicolumn{2}{|c|}{ 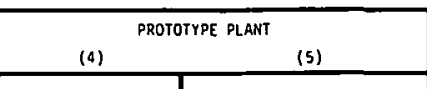 }} & MOOULAR & UICAT OON PCENER STSS & COST DATA & & & & & \multicolumn{3}{|c|}{ SHT 2 of $\underline{\theta}$} & & & & & & \\
\hline \multirow{2}{*}{ 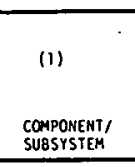 } & \multirow{2}{*}{$\begin{array}{c}\text { (2) } \\
\text { OescRiption }\end{array}$} & & & & \multicolumn{3}{|c|}{ 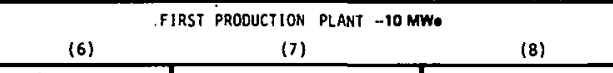 } & \multicolumn{2}{|l|}{ (9) } & \multicolumn{2}{|c|}{ 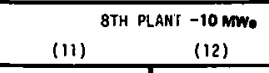 } & (13) & (14) & (15) & \multicolumn{4}{|c|}{ 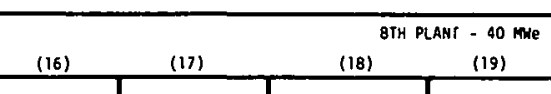 } & (20) & (21) \\
\hline & & & 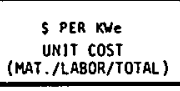 & 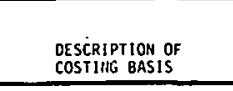 & 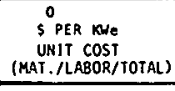 & 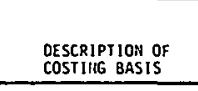 & 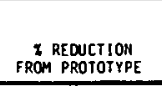 & $\begin{array}{c}s \text { per nere } \\
\text { ante } \\
\text { cost }\end{array}$ & 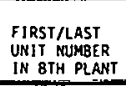 & 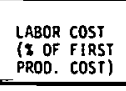 & 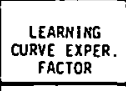 & 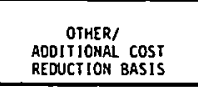 & 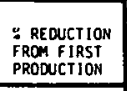 & canerers & 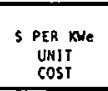 & 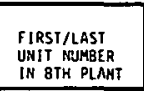 & 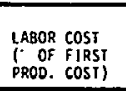 & 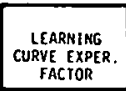 & 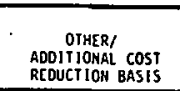 & 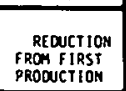 \\
\hline TURBIIIE - & 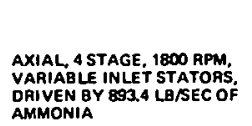 & 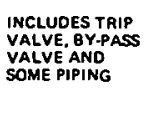 & 20,9 & 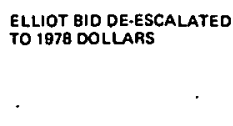 & 183.9 & 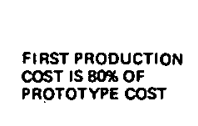 & ${ }^{20}$ & 127.0 & $8 / 8$ & 82.4 & $\mathbf{\infty}$ & 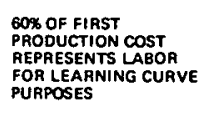 & 23 & JuLY 1978 DoLLAAS & 114.9 & 2092 & 50.2 & $\infty$ & & so \\
\hline $\begin{array}{l}\text { GEEERATOR } \\
\text { ITG-1) }\end{array}$ & 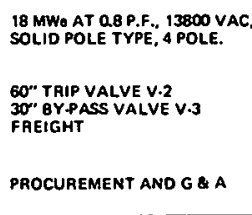 & & $\begin{array}{c}. \\
6.1 . \\
2.6 \\
2.57 \\
20.3\end{array}$ & $9.5 \times$ & $\begin{array}{c}6.1 \\
2.1 . \\
\text { a.6. } \\
16.5 \\
16.5\end{array}$ & . & $\begin{array}{l}: \\
\vdots \\
15 \\
15\end{array}$ & $\begin{array}{l}\frac{6.1}{2.1} \\
0.57 \\
13\end{array}$ & 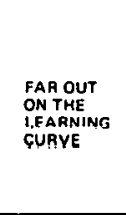 & & & $0.5 x$ & $\begin{array}{l}: \\
\vdots \\
18\end{array}$ & & $\begin{array}{l}6.1 \\
2.6 \\
0.57 \\
11.8\end{array}$ & & & & $0.5 x$ & $\vdots$ \\
\hline SUB-TOTAL & & & 234.5 & & 189.7 & & 15 & 149.3 & & & & & 18 & & 136 & & & & & 21 \\
\hline 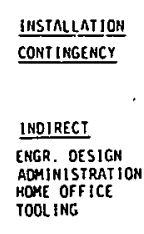 & SGGK AT DOCKSIDE & & 66.1 & $\left.\right|_{28.2 \times}$ OF SUB-TOTAL & $\begin{array}{c}6.5 \\
0\end{array}$ & | $15.6 \%$ of 5 SUBTOTAL & 53 & 11.9 & & & & ex & $\circ$ & & $\begin{array}{c}6.5 \\
0\end{array}$ & & & & ox & $\infty$ \\
\hline ninal. & & & 307.1 & & 2025.6 & & 23 & 16.7 & & & & & 21 & & 153.4 & & & & & 28 \\
\hline
\end{tabular}

\begin{tabular}{|c|c|c|c|c|c|c|c|c|c|c|c|c|c|c|c|c|c|c|c|c|}
\hline 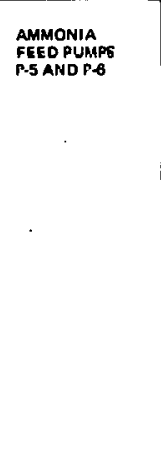 & 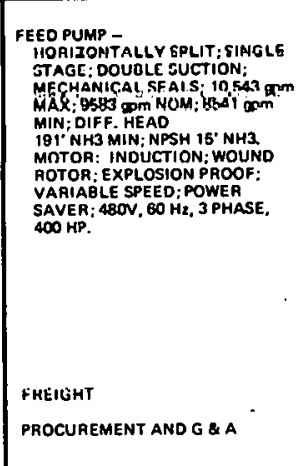 & $\begin{array}{l}\text { Mctuoks. } \\
\text { Motonss. }\end{array}$ & $\begin{array}{l} \\
0.32 \\
3.77\end{array}$ & 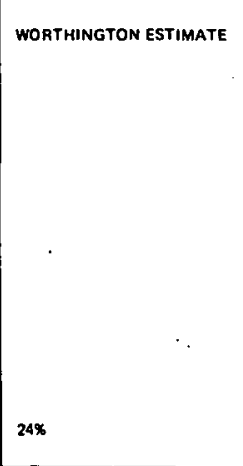 & $\begin{array}{l}15.4 \\
\\
0.32 \\
3.7\end{array}$ & ${ }^{248}$ & : & $\begin{array}{l} \\
\\
0.32 \\
1.06\end{array}$ & 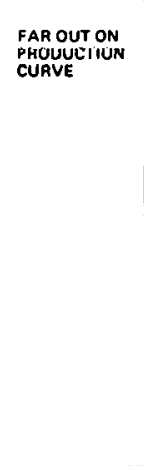 & N.A & NONE & 0.5 & $\begin{array}{l}2 \\
0 \\
12\end{array}$ & 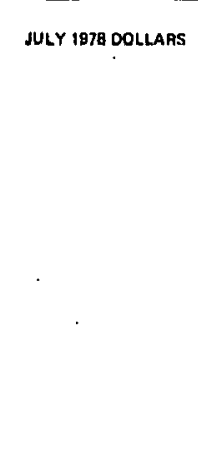 & $\begin{array}{l}0 \\
\\
0.32 \\
1.06\end{array}$ & 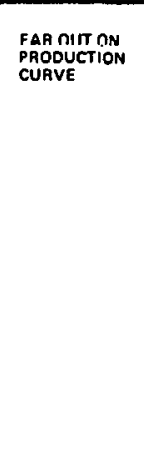 & Na. & wnwe & 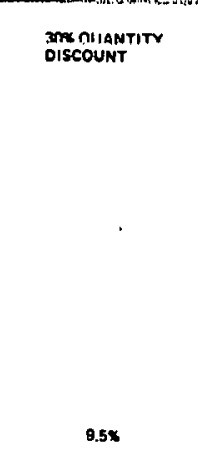 & : \\
\hline sub-rorat & & & 19.5 & - & 18.5 & & 0 & 12.2 & & & & & 29 & & 12.2 & & & & & $\infty$ \\
\hline 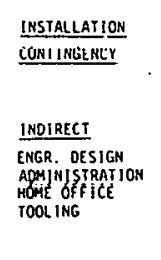 & 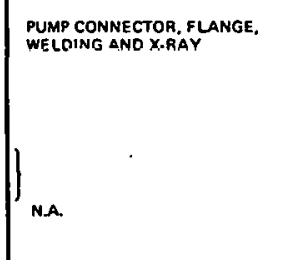 & & $\begin{array}{r}0.050 .190 / 10 \\
0 \\
0 \\
5.50 \\
0.70\end{array}$ & 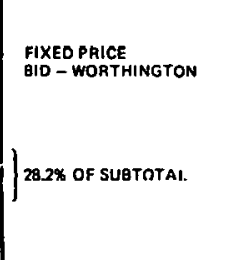 & $\begin{array}{l}0.19 \\
0 \\
000\end{array}$ & 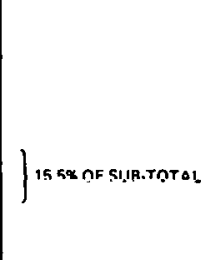 & 。 & 0.98 & $15 / 18$ & 80.3 & ${ }^{65 x}$ & $\begin{array}{l}\text { PRiced at Unit is } \\
\text { Joxur sub.ivital }\end{array}$ & ${ }^{42}$ & & aes & 5786 & 29.9 & $\cos x$ & $\begin{array}{l}\text { PRICED AT UNIT GA } \\
\text { PX OF SUa TOTAL }\end{array}$ & 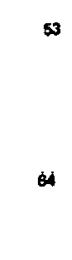 \\
\hline Total & & & 25.18 & & 22.11 & & 10 & 13.3 & & & & & 01.8 & & 13.3 & & & & & 4.18 \\
\hline
\end{tabular}



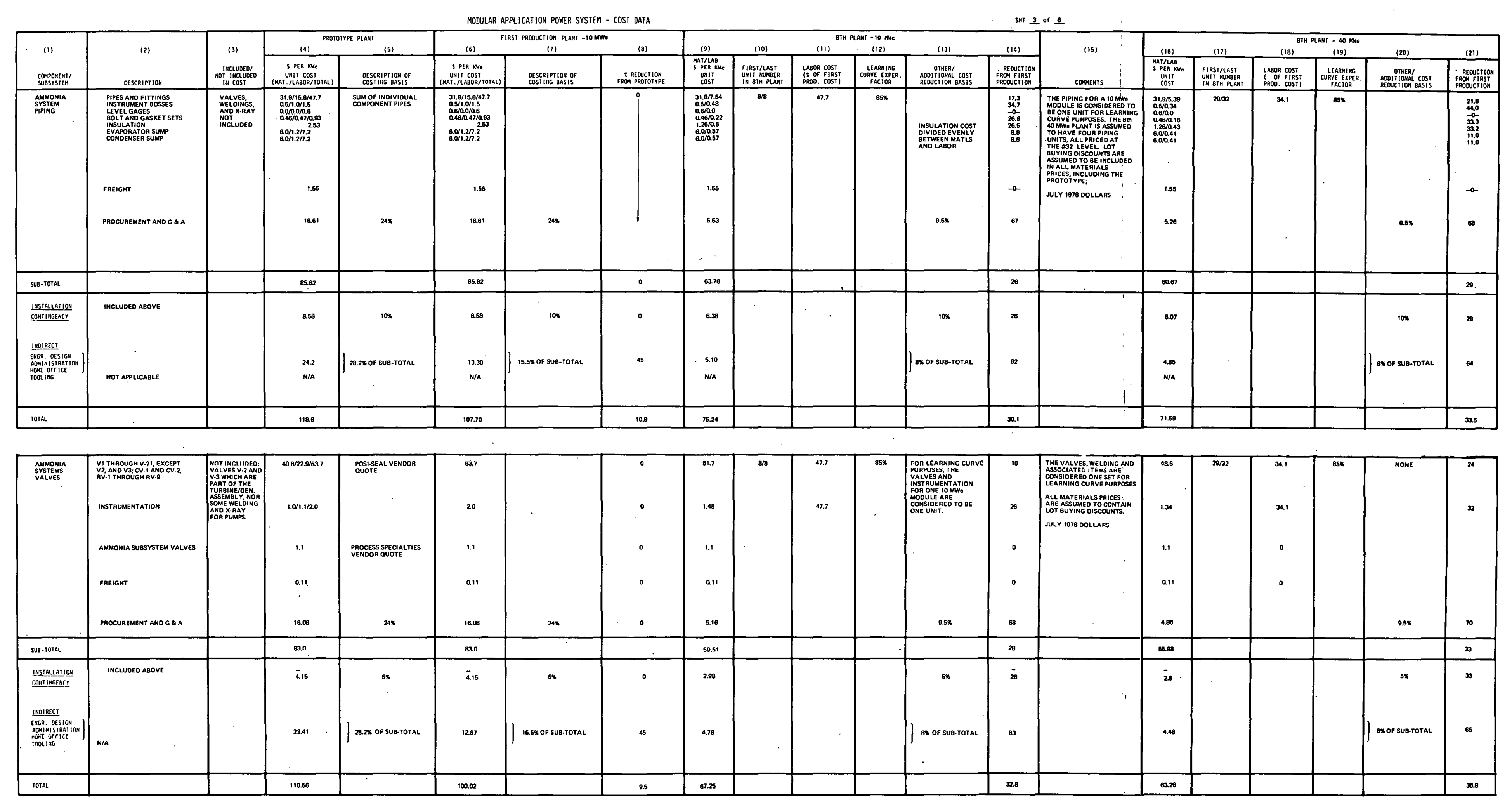

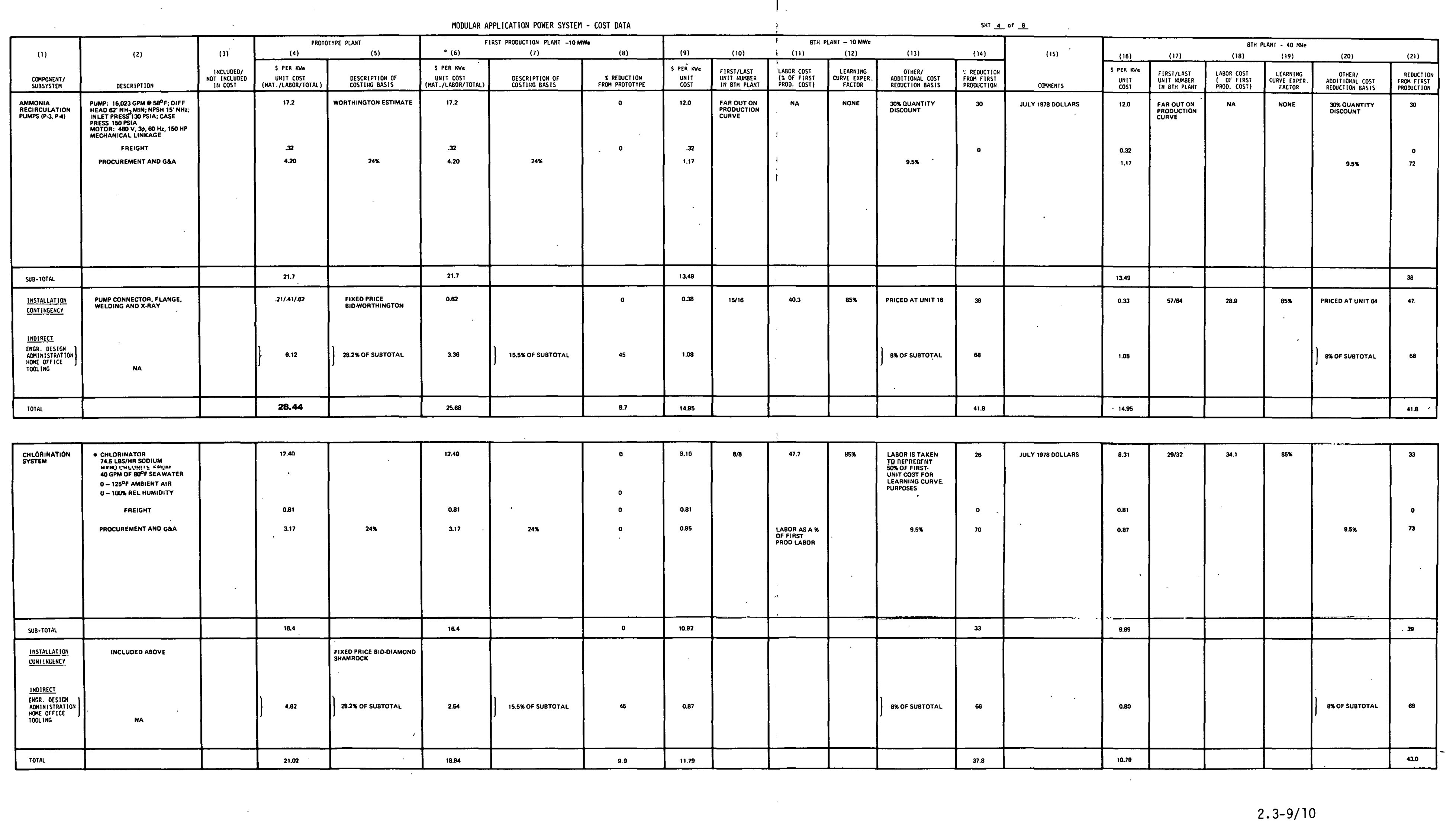

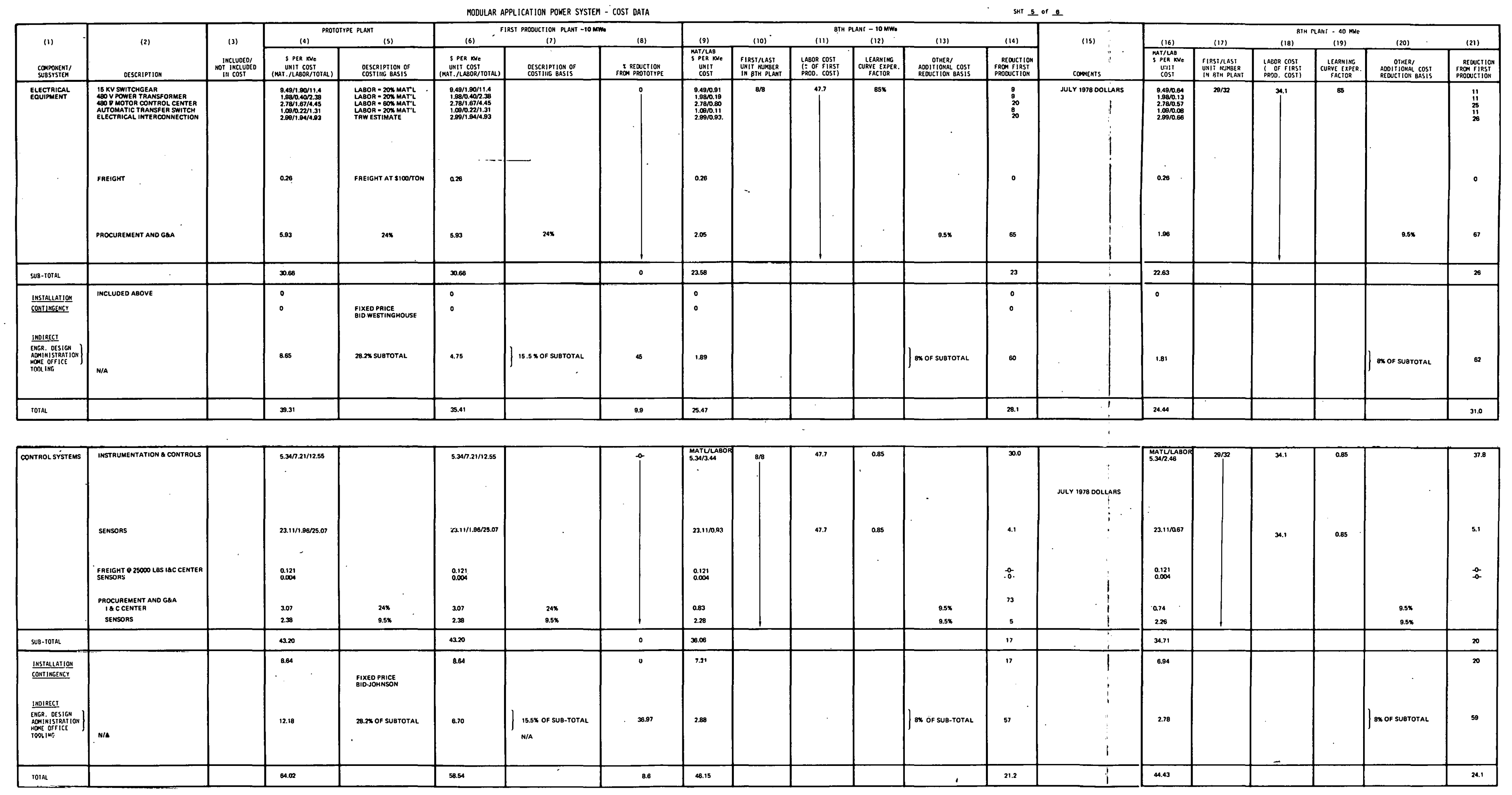

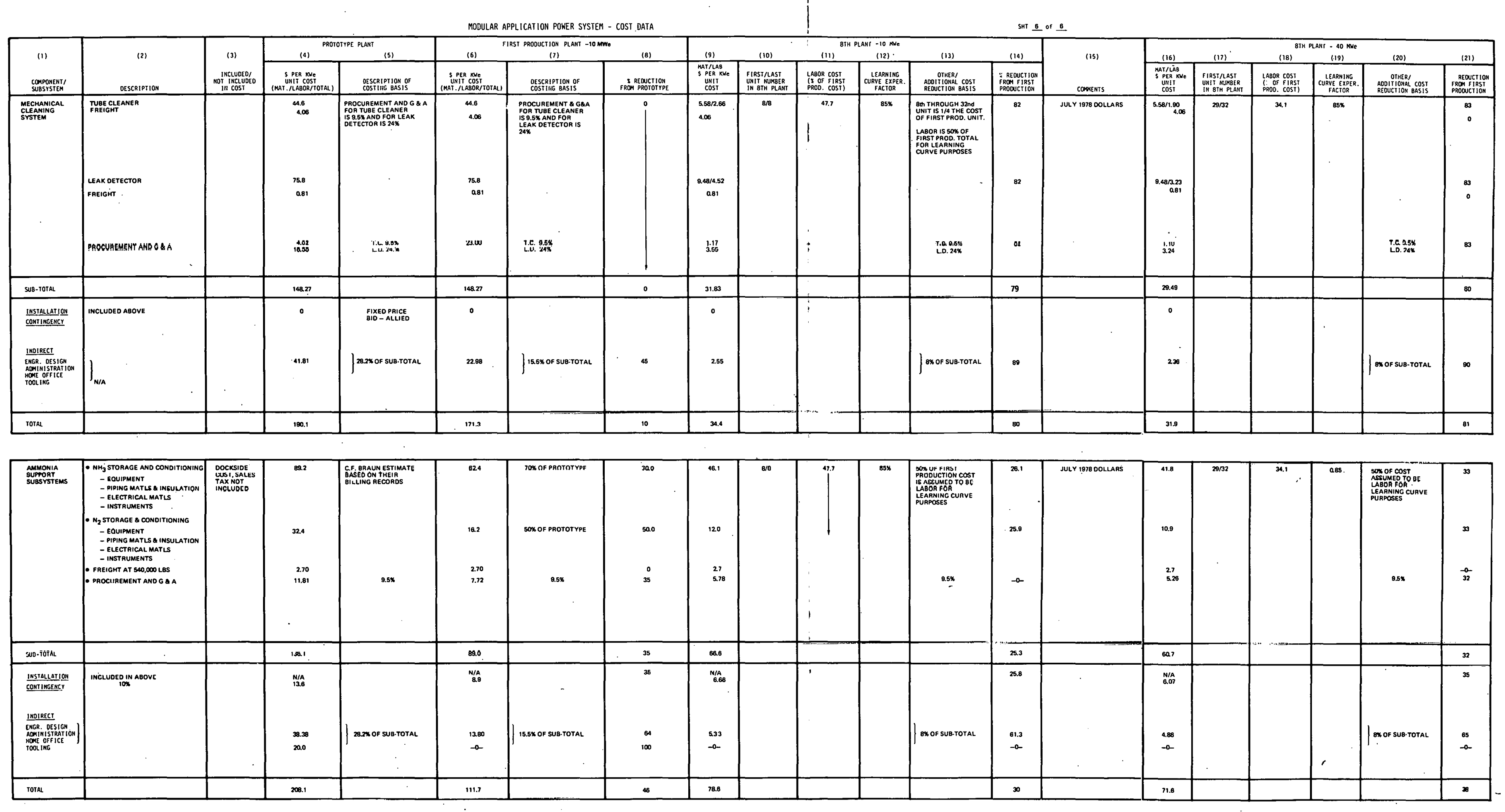


\subsection{MWe HEAT EXCHANGERS}

This power system development applies advanced, high performance heat transfer techniques in the design of both the evaporator and the condenser. A key project objective is to develop a low cost concept through the use of conventional shell and tube fabrication technology. TRW's selected heat exchanger design, based on thin, falling film heat transfer, has been evaluated and integrated with power system components into an efficient thermodynamic cycle as discussed in Section 2.1.

The heat exchangers constitute a major portion of the power module cost. Thus, the design effort has focused on performance considering:

- Producibility and cost

- Maintainability

- Fouling and corrosion.

The design utilizes theoretical and experimental data available for vertical tube, falling film heat transfer, principally test data and analysis by Carnegie-Mellon University (CMU), and Oak Ridge National Laboratory (ORNL). The projected performance of evaporator and condenser was substantiated by test data from CMU and Argonne National Laboratory (ANL).

The advantages of our design include:

- Vertical orientation

- Performance scale-up is simplified

- Provides an opportunity for a unique cleaning approach through the open head design

- Performance is relatively insensitive to platform motions

- Internal bundle configuration is relatively unconstrained

- Tube surface enhancements (Fluting)

- Ammonia side ' $h$ ' is significantly improved through falling film concept ( $h_{a v e}$ of the order $10,000 \mathrm{Btu} / \mathrm{hr}-\mathrm{ft}^{2}-{ }^{\circ} \mathrm{F}$ )

- Water side benefits are equal to the increased area ratio (i.e., enhanced area to equivalent smooth area)

- Performance-to-cost of enhanced-to-smooth tubes favors enhanced tubes. 
- Thermal/hydraulic performance

- Insensitive to seawater maldistributions

- Insensitive to ammonia maldistributions

- Moderately sensitive to seawater flow rate

- Directly proportional to inlet temperature difference

- Low sensitivity to platform roll, pitch, and heave.

- Long life and high corrosion resistance of titanium tubes in seawater.

\subsubsection{Design Requirements and Approach}

The system design optimization discussed in Section 2.1, provided a set of design requirements for the heat exchangers. The design parameters determined by the system optimization include, for both evaporator and condenser, the following specifications:

- Physical

- Tube effective length

- Tube diameter

- Tube enhancement ratio

- Number of tubes required.

- Functional (at nominal design conditions)

- Thermal duty

- Total flow rate of water

- Total evaporation/condensation rate of ammonia

- Nominal design temperatures of water and ammonia

- Recirculation rate of ammonia (evaporator only)

- Water side pressure drops

- Design fouling factor

- Availability allocation.

DOE defined requirements (see Section 1.3) include:

- Design life goals

- Handling

- Transportation

- Safety. 
Note that some of the physical and functional requirements are directly derived from the DOE requirements (e.g., design fouling factor).

The system design mode1, discussed in Section 2.1, incorporates accurate mathematical models describing functional performance of various candidate tube designs and cost algorithms. These models were developed as part of the initial heat exchanger design. The system level design optimization utilized these models to generate the specific design requirements pertaining to tube design and number of tubes required to provide the required thermal duty. The system optimization did not address the tube bundle design, removal of noncondensibles, metering of ammonia onto each tube, etc. The system model assumed that the shell side pressure drop in the evaporator was negligible and allowed for only a small shell side pressure drop in the condenser $\left(0.1^{\circ} \mathrm{F}\right.$ or less saturation temperature gradient from periphery to center of bundle).

The main design tasks which remained to complete the heat exchanger preliminary design were therefore:

- Rating check to verify the heat exchanger designs

- Thermal-hydraulic design addressing

- Shell side pressure drop/vapor distribution

- Uniform metering of ammonia to each of approximately 43,000 tubes (evaporator)

- Collection of noncondensables (condenser)

- Collection of condensate (condenser) and nonevaporated ammonia (evaporator).

- Physical and functional interface with the tube cleaning device

- Mechanical design which implements the thermal-hydrautic design requirements and meets applicable codes and standards.

These requirements must be satisfied to ensure that each of the 43,000 tubes behaves equally and optimally as was assumed in the design optimization program.

\subsubsection{Design Description}

The design of the 10 MWe evaporator and condenser are illustrated in Figures 2.4-1 and 2.4-2, while the major features and dimensions are shown in figures 2.4-3 and 2.4-4. The physical parameters are summarized in Tables 2.4-1 and 2.4-2. 


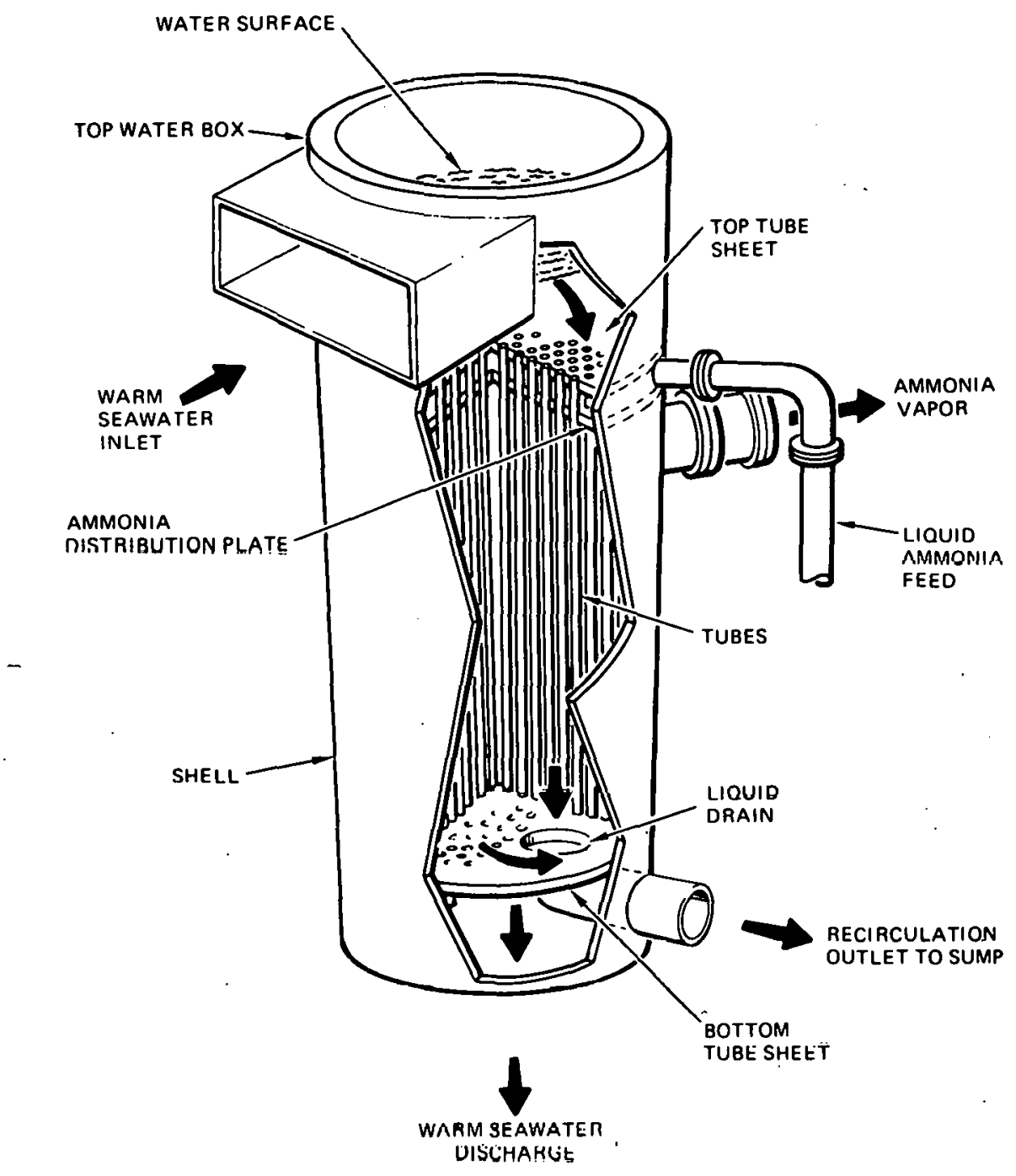

Figure 2.4-1. 10 MWe Evaporator Features

The heat exchangers incorporate fixed tubesheets and eccentric nonremovable tube bundles with the enhanced surface titanium tubes hydraulically expanded into carbon steel tubesheets with titanium cladding; the remainder of the units are of all carbon steel construction.

Protective, nonmetallic coatings will be applied to the water box. The tubesheets will be titanium clad to inhibit corrosion and to permit tube-totubesheet welding. The inlet water box is an open channel type header to permit in situ mechanical cleaning. The water enters via a rectangular inlet nozzle to improve water side distribution. Rod bundles, located at the vapor entrance in the condenser and at the liquid ammonia entrance in the evaporator distribution chamber, break and disperse the entering fluid and prevent impingement damage to the tubes. 


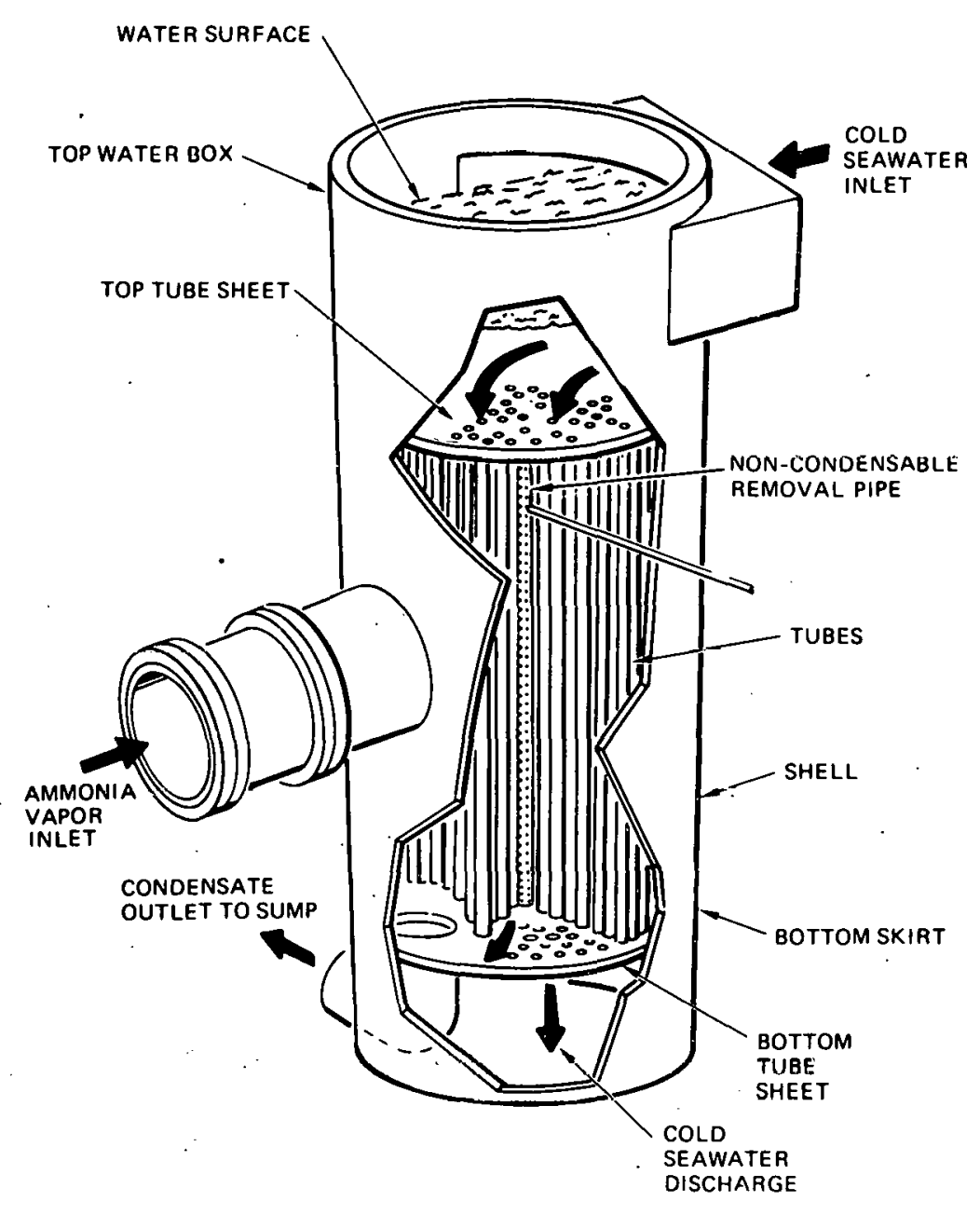

Figure 2.4-2. 10 MWe Condenser Features

The heat exchangers are immersed in seawater up to the level of the top tubesheet and are attached to the side of the floating platform by means of welded brackets. Design and construction includes the consideration of the requirements and limitations of transportation, barge loading for transportation. to the platform, raising vertically for attachment, inservice loading due to operation, and Sea State 9 accelerations.

As illustrated in Figures 2.4-1 and 2.4-2, the evaporator and condenser embody essentially identical bundies of vertical fluted tubes. The tubes are fluted to enhance heat transfer and offer significant performance/cost advantages. The tube bundle is constrained within the heat exchanger shell by two fixed tubesheets and by tube support baffle plates 
spaced at 4.5 feet intervals for the evaporator (4.8 feet for the condenser) between the fixed tubesheets. These tube support plates are designed to provide mechanical tube support without disrupting the falling film of ammonia on the tube exterior.

The design and performance projections of our heat exchanger design are predicated on the assumption that any one tube performs identically to any of the other 43,000 tubes in the bundle. While single vertical fluted tube performance data are available, unfortunately no similar comprehensive data on vertical bundles of significant size are available. However, this assumption regarding our heat exchanger design can be satisfied provided the following thermal hydraulic design considerations are met:

- The tube bundle shell side pressure drop is minimal. so that the evaporation/condensation pressures (and temperatures) are uniform throughout the tube bundle.

- The liquid ammonia is uniformly metered over each tube in the evaporator to ensure uniform and optimal heat transfer.

- The ammonia vapor velocities over the tubes are limited so that the falling film on the tube exterior is not adversely affected, e.g., sheared-off or otherwise altered in configuration.

- Noncondensibles are readily extracted from the condenser.

Each of the above considerations is embodied in the design of our heat exchangers as discussed in the following sections.

As shown in Figures 2.4-3 and 2.4-4, the tube bundles are eccentric to the heat exchanger shell. This approach affords a vapor space around the total height of the tube bundle and provides for vapor injection (condenser) or extraction (evaporator) without large local velocities over the entire length of the tubes, thus reducing tube side pressure gradients. The tube bundle itself features a triangular tube arrangement with a tube pitch of 1.25 inch. This tube arrangement limits the maximum vapor velocities in the bundle to 5 feet/second which is below design limit which would entrain or otherwise alter the falling film configuration. By these design features, minimum shell side pressure gradients and vapor velocities are assured. 


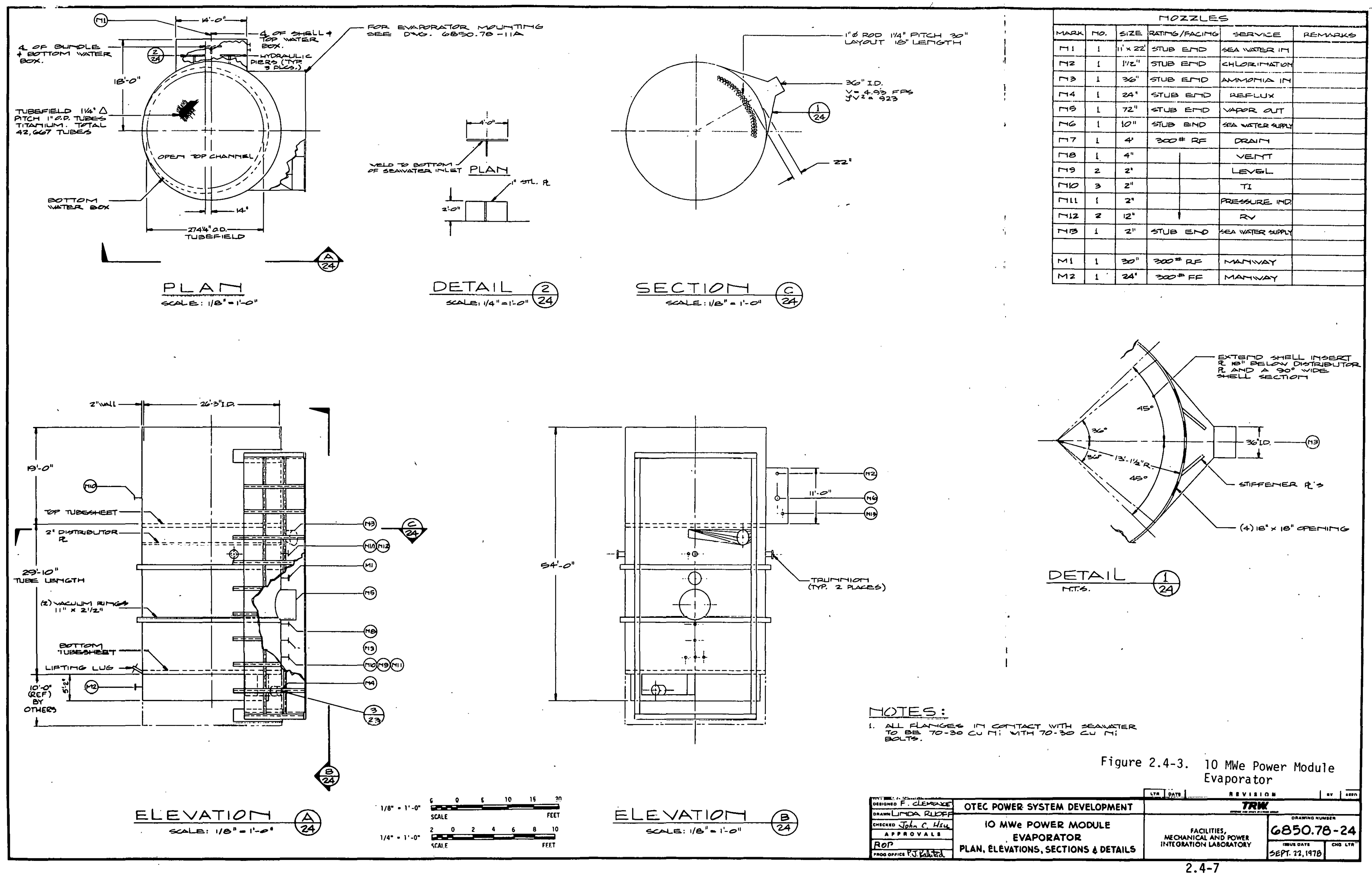



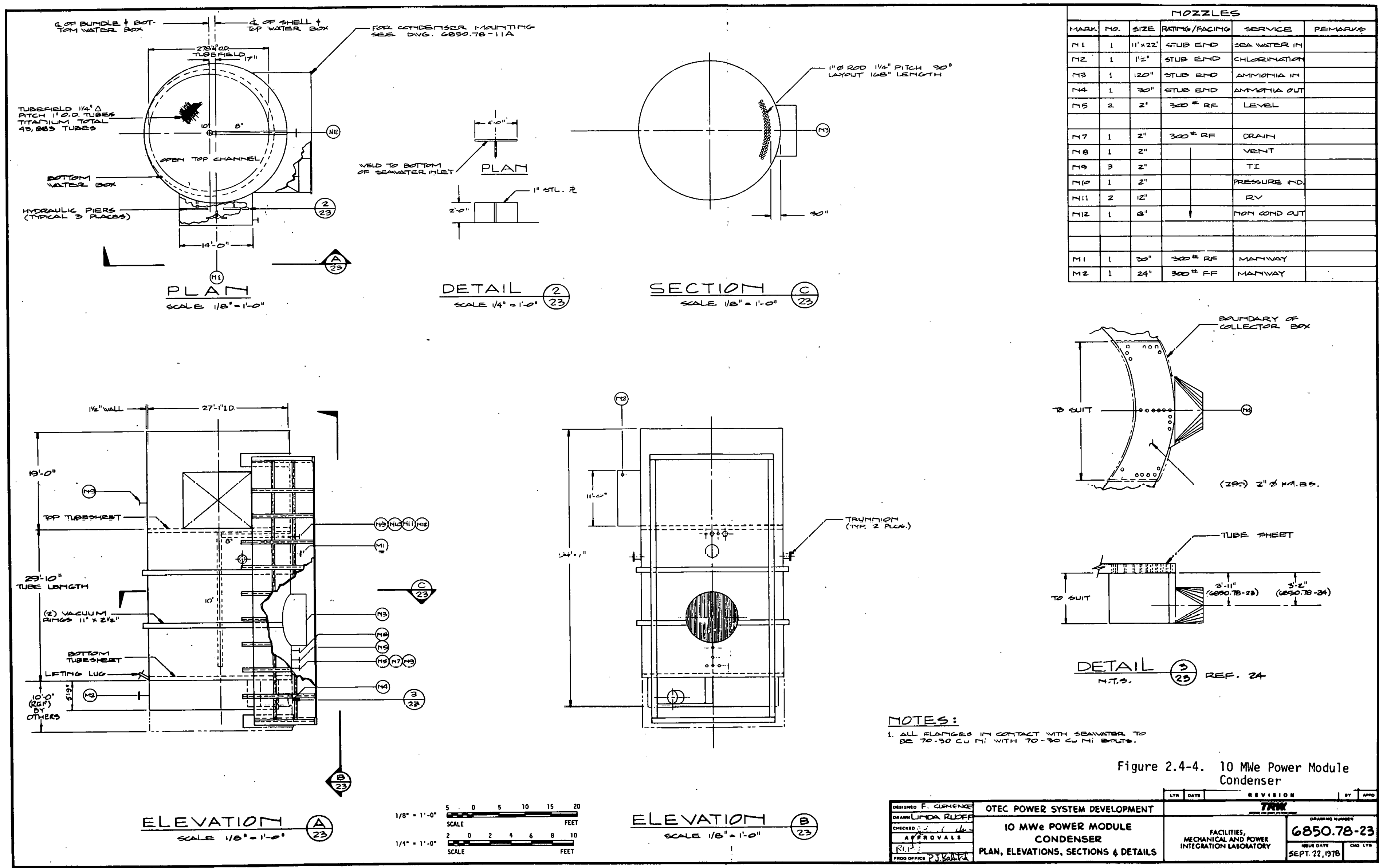

$$
\frac{\text { DETAIL }}{\text { N.T.S. }}
$$

MOTES:

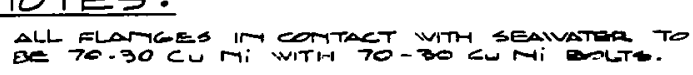

Figure 2.4-4. 10 Mwe Power Module

\begin{tabular}{|c|c|c|}
\hline 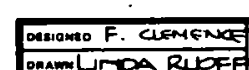 & OTEC POWER SYSTEM DEVELOPMEN & th \\
\hline 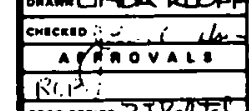 & 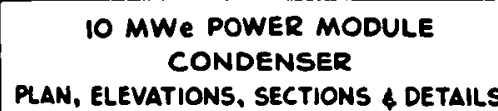 & 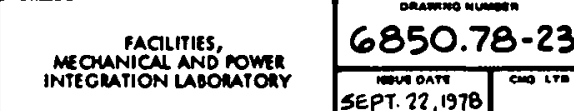 \\
\hline
\end{tabular}


Table 2.4-1. Physical Parameters for 10 MWe Evaporator

Overall Length

Maximum Weight (empty).

Total Number of Tubes

Tube $0 D$

Round Tube Wall Thickness

Tube Pitch

Tube Layout

Tube Sheet Diameter

Effective Tube Length

Actual Tube Length

Tube Sheet Thickness

Distribution Plate Thickness

Number of Tube Supports

Tube Support Thickness

Tube Support Spacing

Shell ID

Shell Wall Thickness

Tube Material

Tube Sheet Material

Shell Material

Baffle Material

Coating Materials

Cladding Material
$54 \mathrm{ft} .7$ in.

500 Short Tons

42,667

1 in. nominal -0.99 in. formed

$0.031 \mathrm{in}$.

1.25 in.

Triangular

$26 \mathrm{ft} .3 \mathrm{in}$.

$26.5 \mathrm{ft}$

$29 \mathrm{ft} .10 \mathrm{in}$.

$43 / 4$ in.

2 in.

5

$11 / 2$ in.

$4.5 \mathrm{ft}$.

$26 \mathrm{ft} .3 \mathrm{in}$.

2 in.

Titanium ASME SB338 GR2

SA516 GR60

SA516 GR60

SA516; SA283; SA285

NAPKO No. 5635 Coal Tar Epoxy or GACO N-200-1/N-11R Neoprene

Titanium Plate ASME SB265 GR2

The evaporator differs from the condenser by the liquid distribution plenum. This plenum is formed by the upper tubesheet and a metering plate situated 2 feet below. The purpose of this liquid distribution plenum is to ensure the uniform distribution and metering of liquid ammonia to each tube. This distribution plenum was subject to considerable study during the preliminary design phase and reflects a design which satisfies these requirements by incorporating

- A plenum with (acceptably) low pressure drops from the periphery to the center by a combination of liquid lanes and plenum height. 
Table 2.4-2. Physical Parameters for 10 MWe Condenser
Overall Length
$54 \mathrm{ft} .7$ in.
Maximum Weight (empty)
500 Short Tons
Total Number of Tubes
43,883
Tube OD
1 in. nominal $-0.99 \mathrm{in}$. formed
Round Tube Wall Thickness
0.026 in.
Tube Pitch
$1.25 \mathrm{in}$.
Tube Layout
Triangular
Tube Sheet Diameter
$27 \mathrm{ft} .1 \mathrm{in}$.
Effective Tube Length
$29 \mathrm{ft}$
Actual Tube Length
$29 \mathrm{ft} .10 \mathrm{in}$.
Tube Sheet Thickness
$43 / 4$ in.
Number of Tube Supports
5
Tube Support Thickness
$11 / 2$ in.
Tube Support Spacing
$4.8 \mathrm{ft}$.
Shell ID
$27 \mathrm{ft} .1 \mathrm{in}$.
Shell Wall Thickness
$11 / 2$ in.
Tube Material
Titanium, ASME SB 338 GR2
Tube Sheet Material
SA516, GR60
Shell Material
S^516, GR60
Baffle Material
SA516, SA283; SA285
Coating Materials
NAPKO No. 5635 Coal Tar
Epoxy or GACO N-200-1/N-11R Neoprene
Cladding Material
Titanium Plate ASME SB265 GR2

- Metering nozzle inserts with (flow controlling) pressure drops much larger than the pressure drop across the plenum.

(For further discussion, see Sections 2.4.3.12 and 2.4.4.5 and Appendix I.1).

Purging of noncondensibles from the condenser is provided for by incorporation of a noncondensible extraction tube situated vertically in the middle of the tube bundle. In the condenser it is anticipated that the noncondensibles will be swept toward the center of the tube bundle by the 
sweeping action of radially-inward flowing ammonia vapor. If noncondensibles are not removed, the center tubes will exhibit diminished performance. To circumvent this, the perforated noncondensible collection tube provides for the extraction of noncondensibles (along with some ammonia which can either be disposed of or processed to recover the ammonia).

\subsubsection{Thermal/Hydraulic Design and Performance}

This section is divided into four parts. The first part (Sections 2.4.3.1 and 2.4.3.2) deals with the enhancing method and its cost/performance effectiveness. The second part (Sections 2.4.3.3 through 2.04:3.7) provides heat transfer design and performance data. The third part (Sections 2.4.3.8 and 2.4.3.9) presents the results of the pressure drop analyses. The last part (Sections 2.4.3.10 through 2.4.3.14) discusses the design sensitivity to such factors as flow rates and pressure, velocity, and flow distributions. The last part also addresses some important design features (e.g., noncondensibles in the condenser, liquid and vapor lanes, etc.) affecting the thermal/hydraulic performance.

\subsubsection{Axial Flutes}

Axial flutes are effective in enhancing the water side heat transfer proportionally to the surface area enhanced to that of an equivalent smooth tube of the same cross sectional area. Flutes are small protrusions which extend beyond the outer limits of the smooth tube laminar and transition boundary layer into the region occupied by the turbulent core. Flutes, by definition, differ from fins in that flutes extend barely beyond the limits of the smooth tube transition 1ayer, whereas fins extend. deep into the turbulent core. Flutes maintain the heat transferred to. power consumed ratio at the highest 1 imit possible, without causing any flow separation.

The effectiveness of axial flutes can be established on a theoretical basis. The analogy between heat and momentum transfer does not consider the cancept of the vector nature of momentum and therefore the analogy is not universal. It breaks down when the momentum, or velocity, begins to exhibit its vectorial properties in a manner. which cannot be emulated by heat flow. The presence of separated flow always causes a departure from the analogy. Smooth tubes, since they do not exhibit abrupt changes of 
their geometric confines, adhere to the analogy and can be considered a standard for comparing thermal/hydraulic behavior as well as adherence to the analogy.

Flow systems which exhibit separated flow always have a greater pressure drop than equivalent systems which do not. Frequently, systems (e.g., fluids in tube bundles utilizing crossflow) which exhibit flow separation have a greater heat transfer rate than equivalent nonseparated flow systems. However, systems which depart from the analogy always exhibit a greater ratio of pressure drop to heat transfer,

Axial flutes do not cause a departure from the analogy. Their pressure drop to heat transfer ratio is equal to that for a smooth tube, and, as such, are at the limits of possible enhancement in systems where power conservation, as well as reduced surface is the ultimate goal. (Note, where reduced surface is the only goal and power considerations are unimportant departures from the analogy may be desirable.) Axially fluted tubes give the maximum possible heat transfer from a given power allotment but with a significantly reduced tube length, and thus, al so reduced heat exchanger surface area. The effect of axial flutes in achieving this goal has been demonstrated conclusively in the heat transfer laboratories of CMU. The analysis and results of experiments at CMU are included in Appendix I.1, where data points for fluted tubes are compared with equations for smooth tube behavior.

The overall heat transfer analysis shows that the seawater side thermal resistance is controlling (Section 2.4 .3 .8 ) so that it is very beneficial that axial flutes (area enhancement) be used on seawater side (internal).

The axial flutes are essential on the ammonia side (external), very high heat transfer coefficients (of evaporation and condensation) can be obtained. Further, in the evaporator, the flutes cause evaporation without bubble formation producing almost dry vapor, eliminating the need for a demister. This is further discussed in the following sections. 


\subsubsection{Tube Design Approach}

The tube selection was based on the following considerations:

Heat Transfer Considerations

For the evaporator the ammonia side heat transfer is insensitive to flute height range from 26 to $40 \mathrm{mils}$ and also relatively insensitive to shape. For the condenser the ammonia side heat transfer is more sensitive to flute size than flute shape.

Water side enhancement is desired since water side heat transfer dominates the overall heat transfer. The choice of semicircle flutes on the ammonia side is based on available experimental data (CMU).

\section{Structural Considerations}

The round tube thickness was derived based upon the ASME pressure vessel code requirement. Finite element analys is was utilized to derive the corrugating factor, which is the ratio of the buckling pressure of. the corrugated tube to that of an equivalent round tube of the same diameter and reference thickness. This corrugation factor was then applied to ASME code tube pressure design curves, see Appendix I.3.

\section{Producibility Considerations}

Current studies indicate that forming processes are economically feasible. The maximum area enhancement attainable is a function of initial material thickness, ductility, flute pitch, and amplitude. Also the number of flutes attainable for a given geometry decreases with increasing material thickness (see Section 2,4.6.3).

\subsubsection{Cost/Performance Effectiveness}

From the preceding section and Appendix I.1:

- Seawater side enhancement is desirable because water side almost totally controls the evaporator performance and significantly influences the condenser performance

- Amonia side enhancement significantly increases heat transfer performance

- Operatfunal range is within the limits of the teest data

- Performance is a function of enhanced-to-smooth tube area ratio. 
Figure 2.4-5 shows the superior performance of the flutes, while Figure 2.4-6 illustrates the cost/performance effectiveness of the fluted tubes.

The design tube profiles are shown in Figures 2.4-7 and 2.4-8 for evaporator and condenser, respectively. The overall profile is shown in Figure 2.4-9.

\subsubsection{Seawater Side Heat Transfer}

The seawater heat transfer coefficients were determined from equations developed from experimental data in the CMU thermal-hydraulic laboratories. These equations are based on the postulate that the seawater heat transfer coefficient for a fluted tube is greater than that of a smooth tube by the ratio of surface area of the fluted tube to that of an equivalent inside diameter smooth tube. Figure 2.4-10. shows the experimental and the calculated values for $J_{H}$, a nondimensional number directly proportional to the heat transfer coefficient. The calculated values are based on the smooth tube equation and the area ratio postulate (the area ratio being two in this illustration). It can be seen that the calculated values are confirmed by the experimental data. Thus, the area ratio postulate is established to be valid, or, if anything, slightly on the safe side.

The equations used for design purposes are described in Appendix I. 1.

\subsubsection{Ammonia Side Heat Transfer - Evaporation}

A problem, peculfar to OTEC, is the low temperature difference avallable in the heat exchangers. The low temperature difference makes boiling ammonia all but impossible since initial bubble formation, required for the boiling process, necessitates a minimum temperature difference which is greater, or at the limits of that avallable in the OTEC system. Vaporization is accomplished in the TRW design by an evaporation rather than a boiling process. Evaporation is achleved by heating extremely thin liquid films on the external surface of the tube. This liquid film then evaporates without requiring bubble formation. To create the necessary thin liquid films, flutes external to the tube are used. Ammonia liquid is allowed to flow down the exterior of the tube as a falling film. This liquid remains largely within the valley of the flutes; however, the surface drag upon this liquid causes periodic wave formations to wet the flutes and leave behind the thin liquid film. Extremely high heat transfer coefficients lave been obtained by this evaporation process. 


$$
2
$$




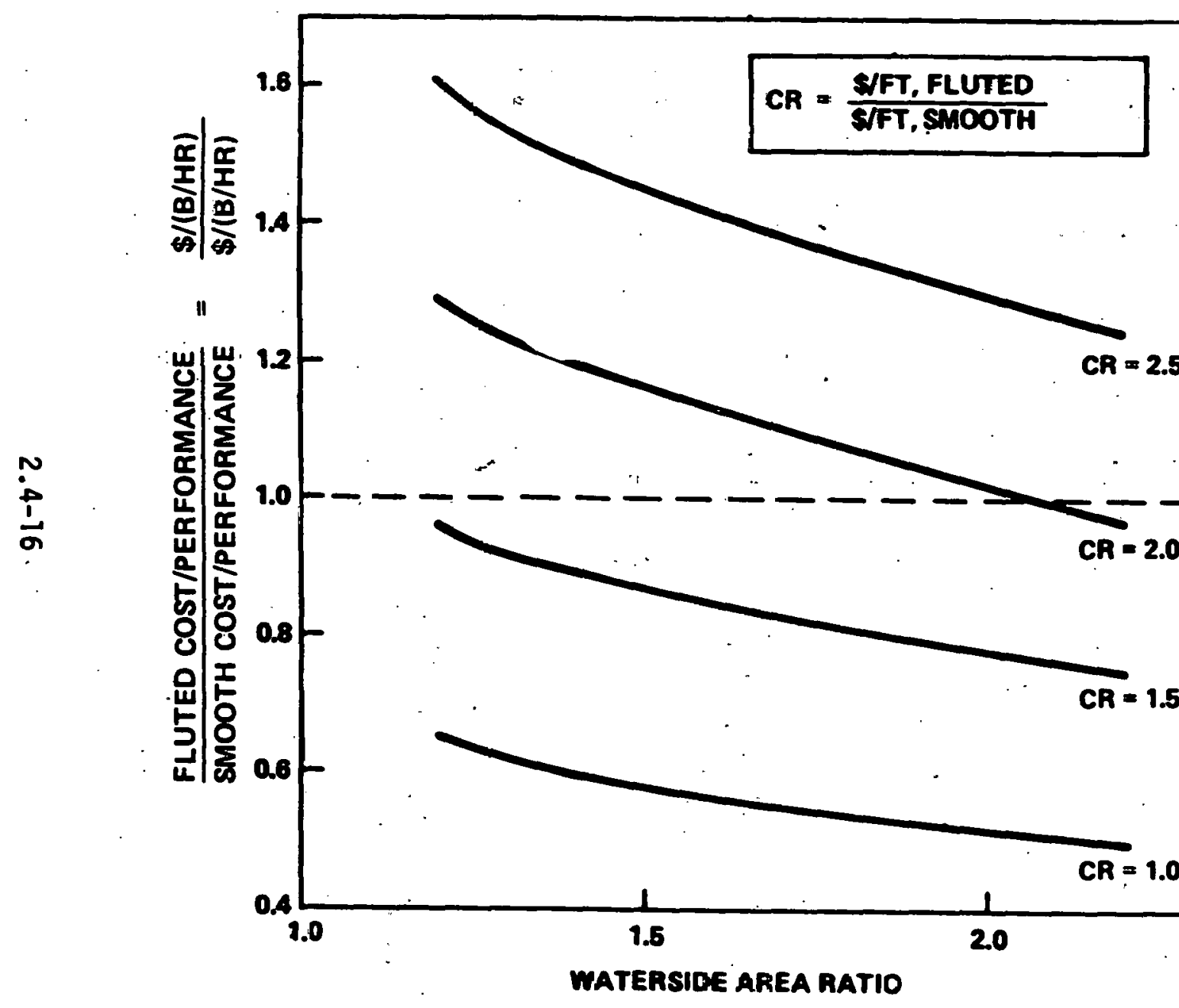

CONDITIONS:

- SEAWATER VELOCITY $=6$ FPS

- SMOOTH TUBE LENGTH = 25 FT

- IDENTICAL PUMPING POWERS

Figure 2.4-15. Tube Cost/Performance Effectiveness 


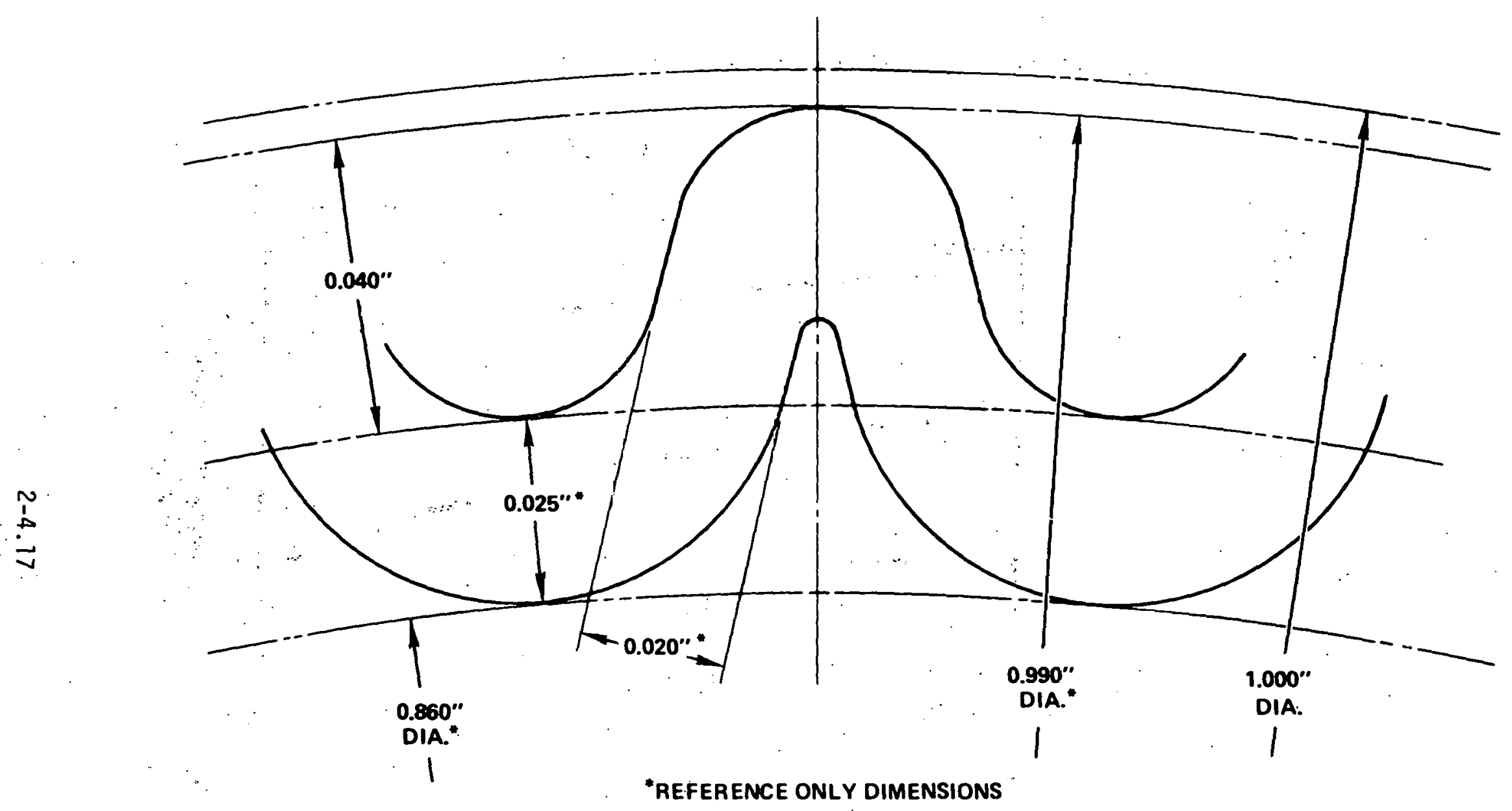

- 36 FLUTES

- CORRUGATED FROM 0.031" SMOOTH TUBE THICKNESS

- COMMERCIALLY PURE TITANIUM PER ASME SB 338 GR2 (OR EQUIVALENT)

Figure 2.4-7. Evaporator Tube 
$\stackrel{n}{i}$

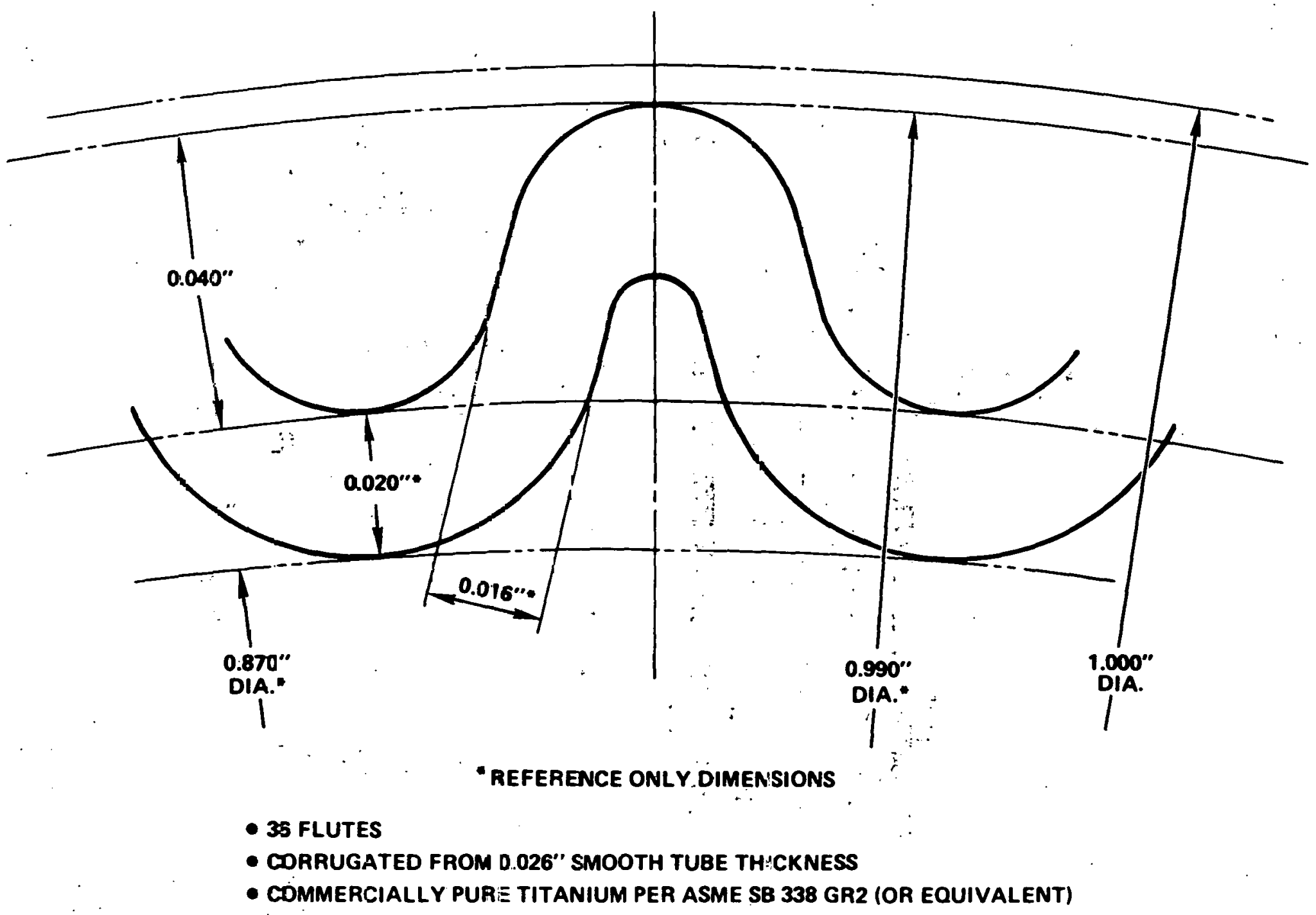

Figure 2.4-8. Condeinser Tube 


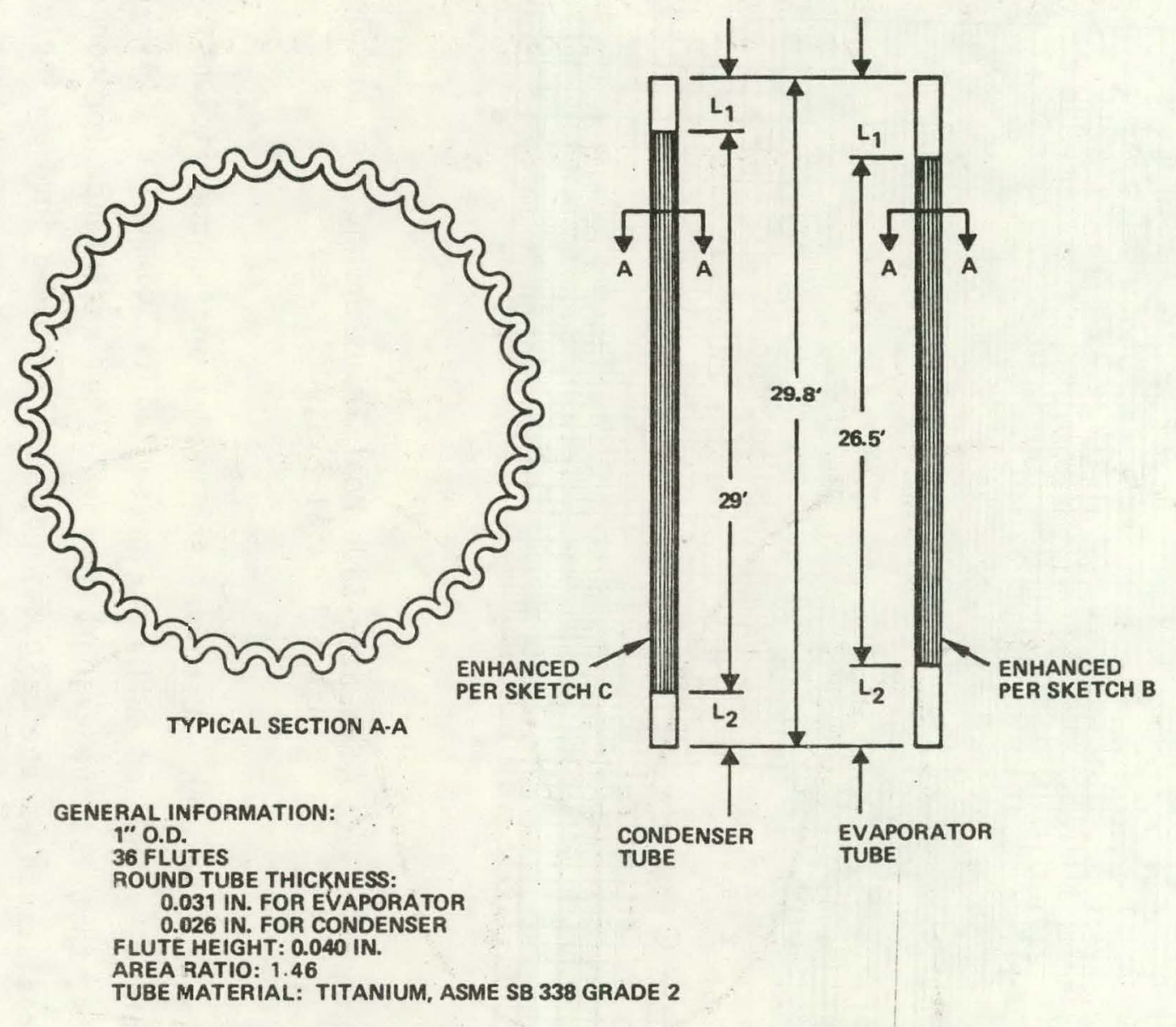

Figure 2.4-9. Tube Description 


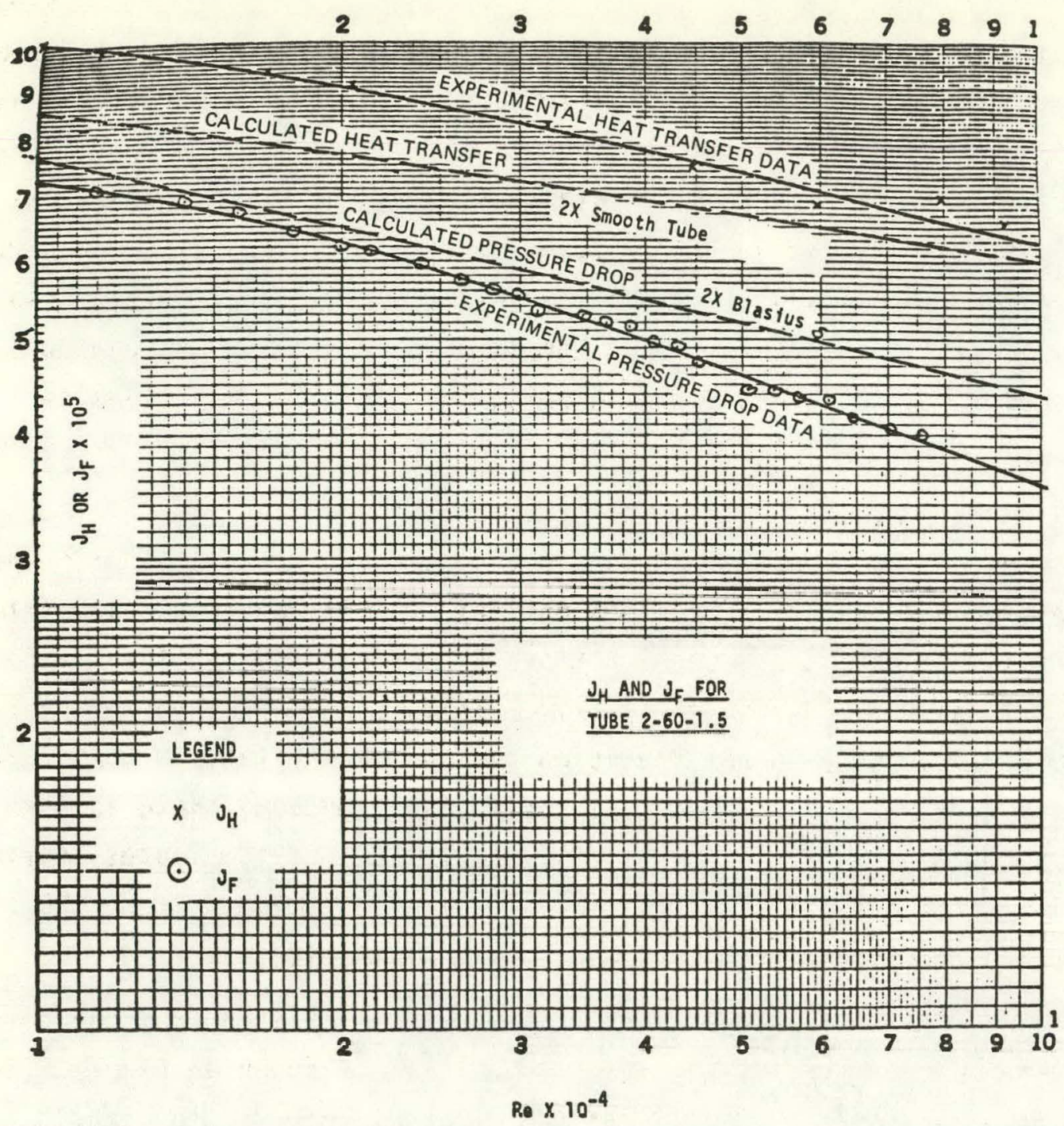

Figure 2.4-10. Seawater Side Heat Transfer and Pressure Drop (Internal Axial Fluted lubes)

Both the evaporation and condensing heat transfer coefficients, which were determined by $\mathrm{CMU}$ and $\mathrm{ORNL}$, are presented as "composite" heat transfer coefficients; that is, the evaporation and metal resistance (or condensing and metal resistance as the case may be) were combined into a single coefficient. In order to use these coefficients, the "composite" heat transfer coefficients had to be converted to pure evaporation (or condensing) coefficients by subtracting the metal resistance of the tested tube. The metal resistance of the design tube was then reinserted into the design calculations. 
Evaporation heat transfer coefficients were calculated from the composite heat transfer coefficients determined in the CMU thermal-hydraulic laboratories. Figure 2.4-11 shows a comparison of the smooth and fluted tube composite heat transfer coefficients for Freon 11. The basic heat transfer design equations were derived from these data and then converted to be applicable to ammonia. Since the initial tests, experiments have been run on evaporating ammonia and the ammonia equations have been well established. The procedure for developing the empirical equations is described in Appendix I.1.2.

\subsubsection{Ammonia Side Heat Transfer - Condensation}

The resistance to heat transfer in a condensing system, without the presence of noncondensibles, resides entirely within the condensate film. Reduction of the resistance to heat transfer, therefore, requires reduction of the thickness of the condensate film. This is accomplished in the TRW design by the use of external flutes on the condensing tubes. Condensate is formed, primarily on the crest of the flute. The condensate is then pulled by surface tension into the rill, or valley, of the flutes leaving the crest almost devoid of condensate. The lack of condensate on the crest of the flute results in high condensate film coefficients.

Condensing heat transfer coefficients were calculated from the composite heat transfer coefficients for the ORNL tube $E$ shown on Figure 2.4-12. (Note that heat transfer coefficient and flux are referred to actual enhanced surface area, while TRW uses equivalent smooth surface area as reference. )

The basic initial data were obtained experimentally at the heat transfer laboratories at Oak Ridge National Laboratory. The experimental data and the method of reducing that data are included in Appendix I.1.3.

\subsubsection{Tube Wall Heat Transfer}

The metal resistance is defined as the thermal thickness divided by the tube thermal conductivity. The thermal thickness is the wall thickness of a smooth tube which has the same wall resistance as the fluted tube. Little is available in the literature for determining the thermal resistance or the thermal thickness for tubes fluted hoth internally and externally. 


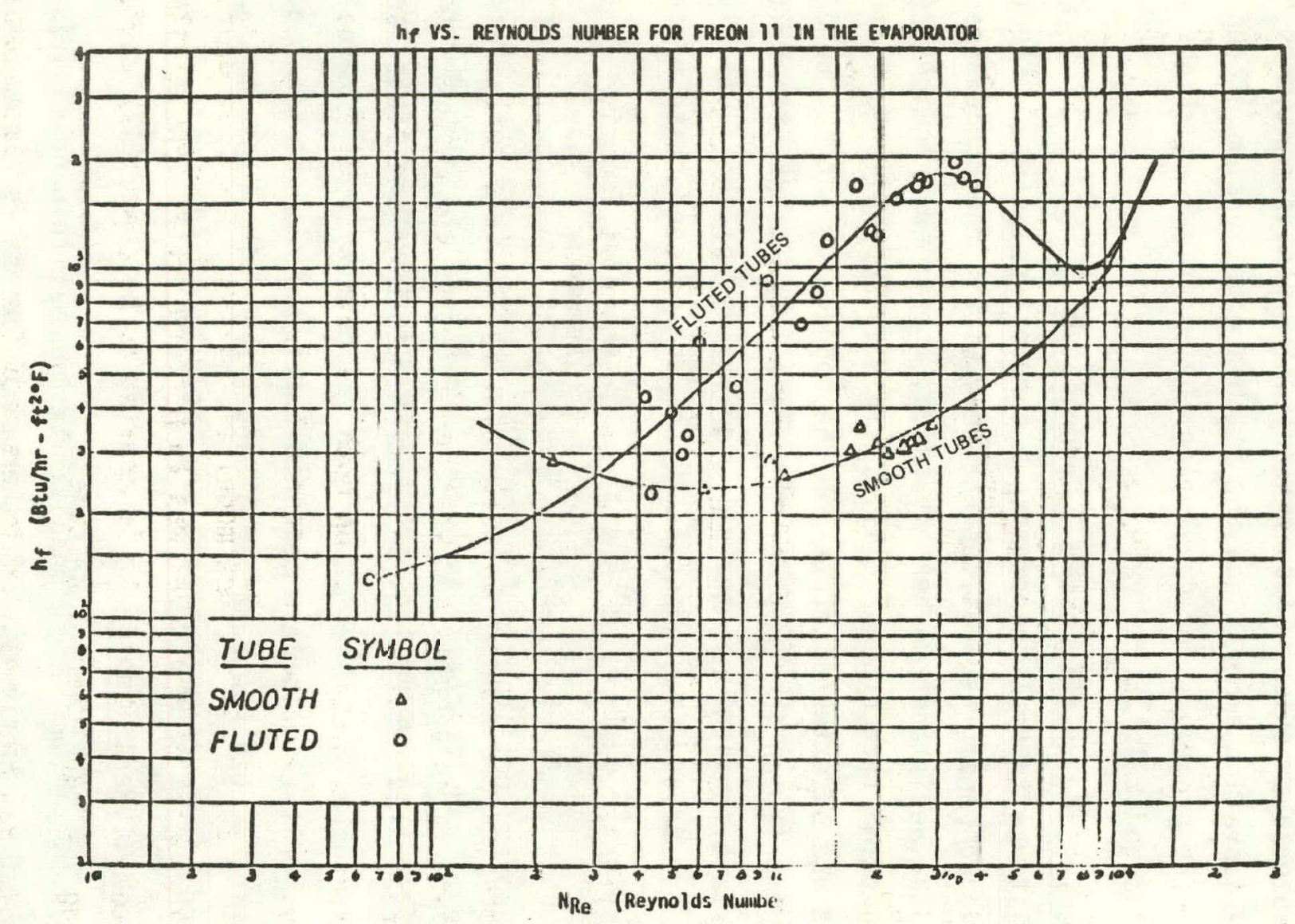

Figure 2.4-11. Evaporation Heat Transfer - Freon 11 (External Axial Fluted Tubes) 


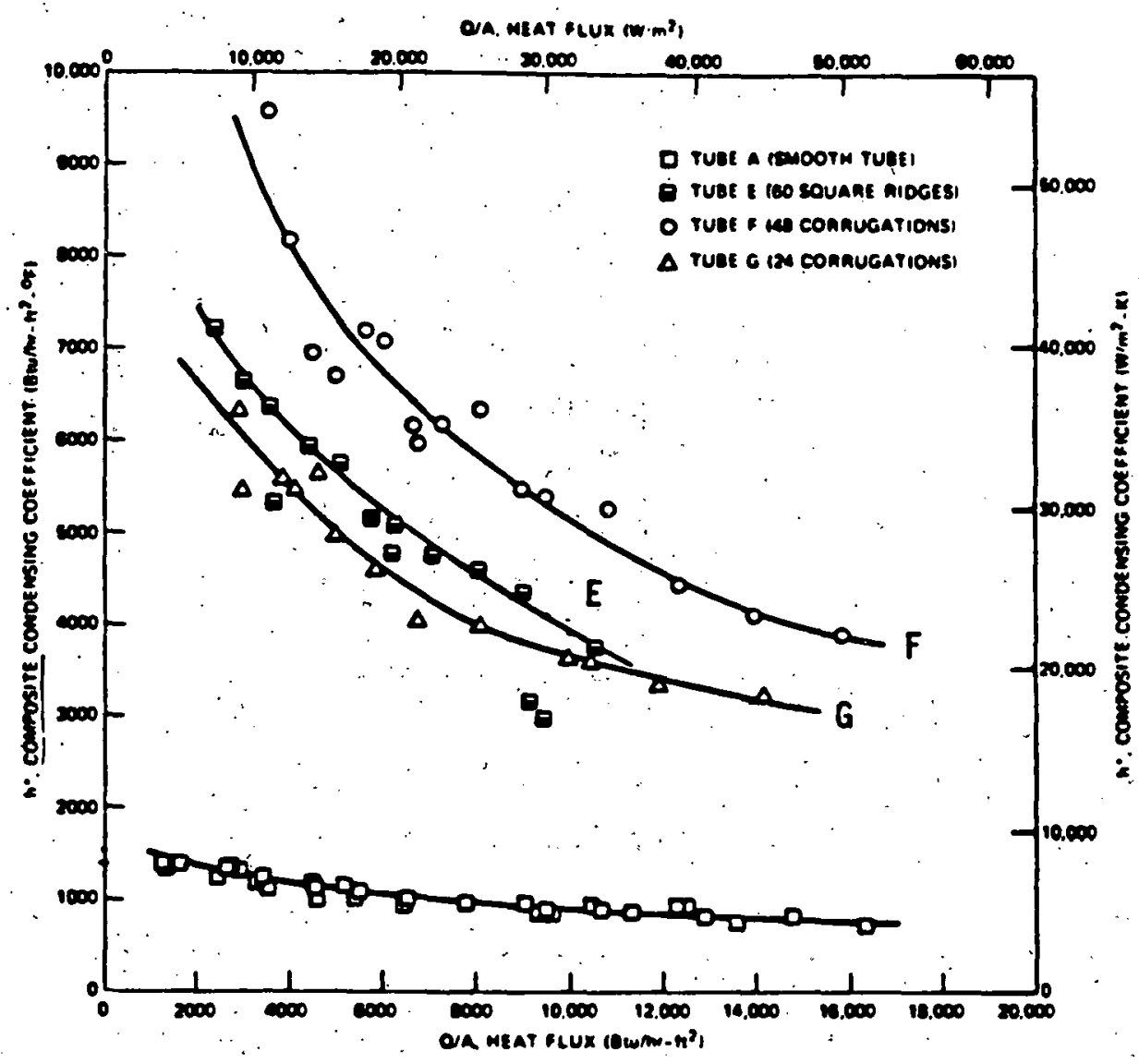

Figure 2.4-12. Composite Condensing Heat Transfer Coefficients for Ammonta

The graphical procedure originally used by TRW (and reflected in the system design) is considered somewhat conservative and includes the anticipated length of the path travelled by heat, width of the flute, and the point-to-point flux distribution on both the internal and external flutes. This procedure is described in Appendix. I.1.4.

Recently a finite difference. model of tube wall has been developed. While the primary purpose of the model was to perform design sensitivity studies of corrugated titanium tubes, it is proving to be especially useful in establishing the tube thermal thickness.

This model has been modified to the baseline PSD-I fluted tube configuration. Figure 2.4-13 illustrates the nodal network of a typical flute section (the model includes only half of the flute because of symmetry).

Preliminary resuits obtained to date indicate the following:

- The effective thermal thickness of the tube is approximately $28 \mathrm{mils}$ 


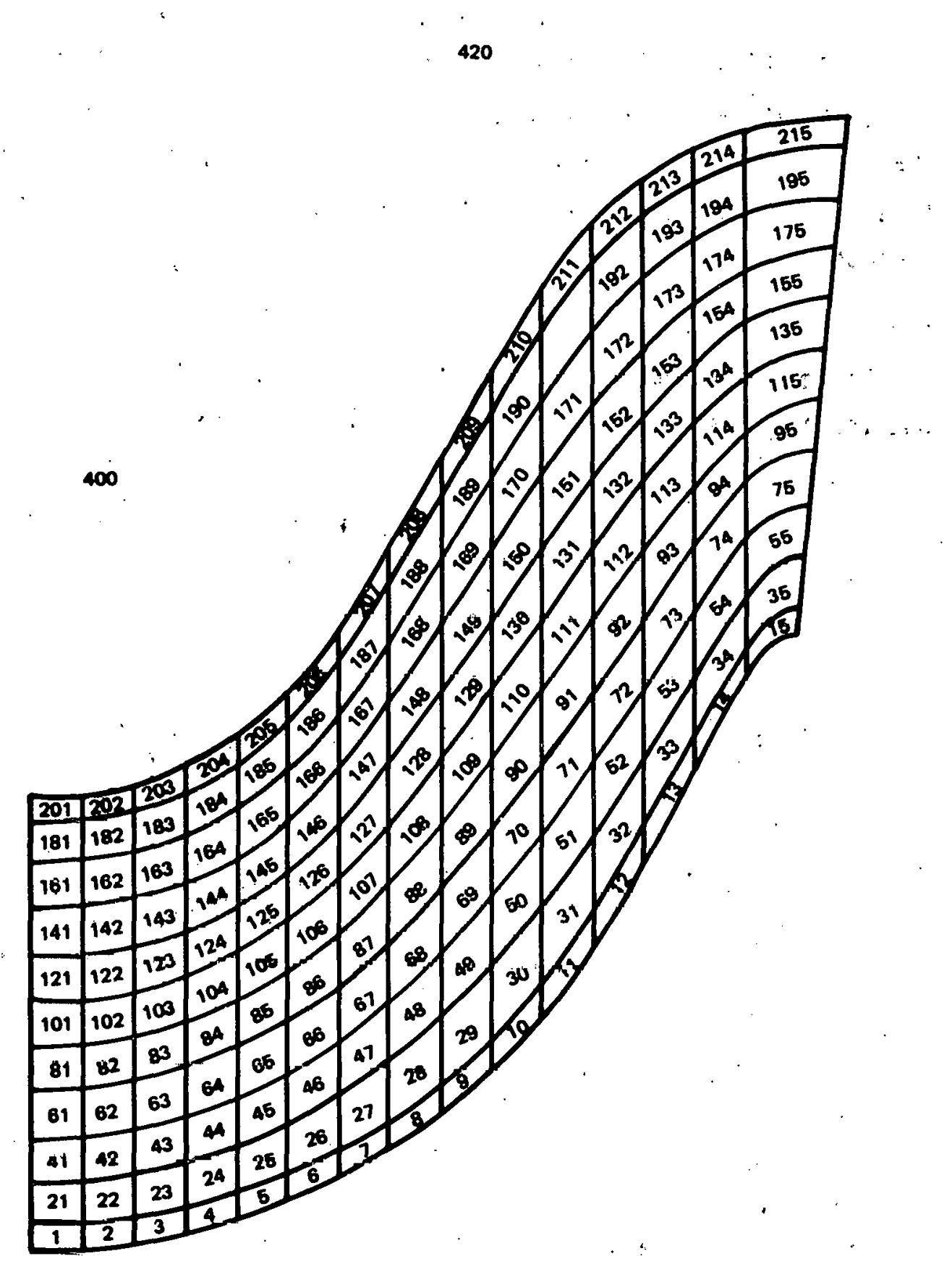

Figure 2.4-13. Finite Difference Model for Fluted Tube 2. 4-24 
- The effective thermal thickness is not very sensitive to the variation of the ammonia and seawater side convective heat transfer coefficient variations over the flutes.

- The effective thermal thickness is not sensitive to the magnitude of the average seawater side heat transfer coefficient.

While the results cited above are preliminary, they do indicate that the thermal'thickness predicted by the earlier method is indeed conservative and on the safe side. Thermal thickness evaluations are st 111 in process.

\subsubsection{Overal1 Heat Transfer and Design Sensitivity}

The overall heat transfer coefficient $\left(U_{0}\right)$, for clean condition (without fouling); is determined from the following expression:

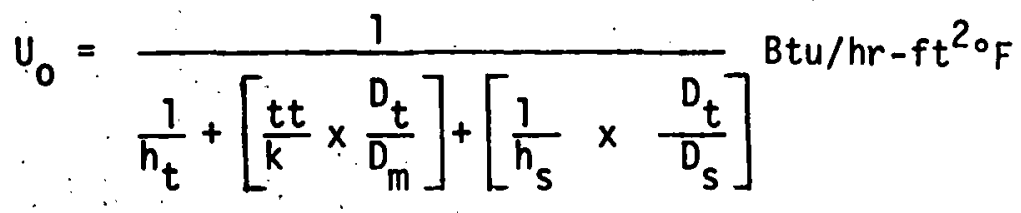

where

$$
\begin{aligned}
h_{t}, h_{s} & =\text { the tube side and shell side heat transfer } \\
& \text { coefficients, respectively, But } / \mathrm{hr}-\mathrm{ft} 2^{\circ} \mathrm{F} \\
& =\text { wall thermal thickness, } \mathrm{ft} \\
k & =\text { metal thermal conductivity, Btu/hr-ft }{ }^{\circ} \mathrm{F} \\
D_{t} & =\begin{array}{l}
\text { smooth tube equivalent diameter (diameter of a smooth } \\
\text { tube with same flow area as the fluted tube), } \mathrm{ft}
\end{array} \\
D_{m} & =\text { mean wall diameter of tube, ft } \\
D_{s} & =\text { shell side rill diameter of tube, } \mathrm{ft}
\end{aligned}
$$

The effect of fouling is to resist the flow of heat and hence to reduce the overall heat transfer coefficient as shown in Figure 2.4-14 and calculated by the equation

$$
\frac{1}{U}=\frac{1}{U_{0}}+F F
$$

where

$$
\begin{aligned}
F F & =\text { fouling factor } \\
& =0.0001 \mathrm{hr}-\mathrm{ft}^{2}-{ }^{0} \mathrm{~F} / \mathrm{Btu}, \text { design value }
\end{aligned}
$$




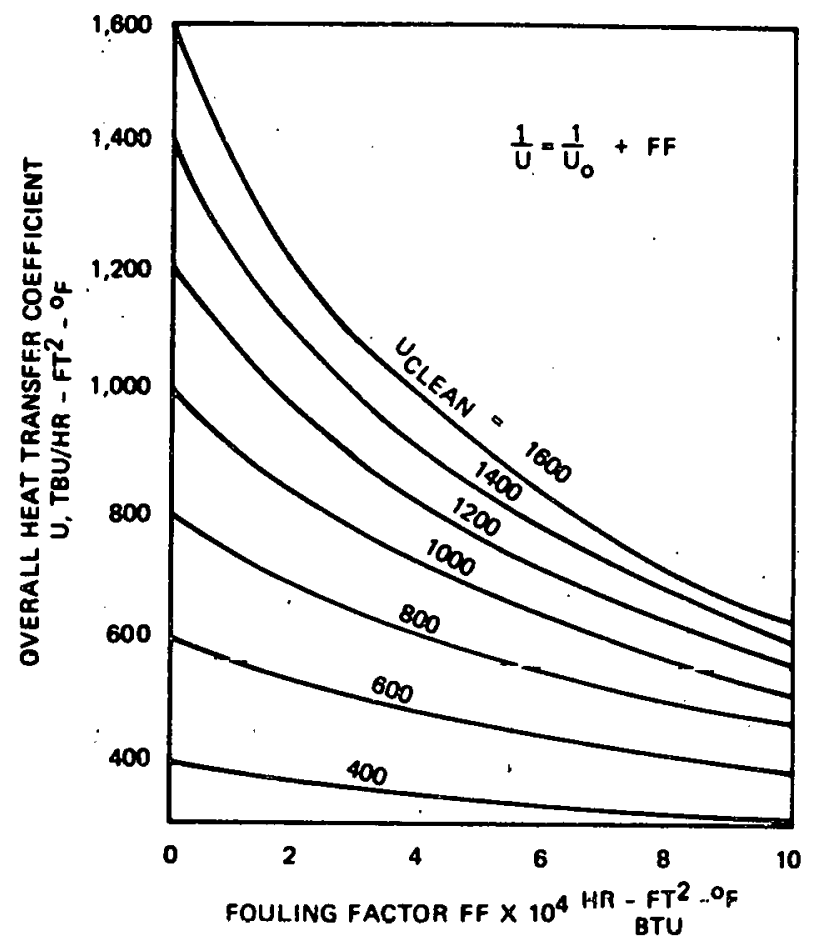

Figure 2.4-14.

Effect of Fouling on Overall

Heat Transfer Coefficient

Additional details of biofouling and its control are discussed in section 2.4.5 and 2.6.

The distributions of temperature, resulting from the heat transfer coefficients and the fouling factor, are shown in Figures 2.4-15 and 2.4-16 for the evaporator and the condenser, respectively.

Thermal resistance (reciprocal of the heat transfer coefftrient) components proportionately influence the overall thermal resistance (reciprocal of $U_{0}$ ) as shown in Table 2.4-3 for the clean heat exchangers: For a folled heat exchanger with a fouling factor (FF) of $0.0001 \mathrm{hr}-\mathrm{ft}^{2}-{ }^{0} \mathrm{~F} / \mathrm{Btu}$ the fouling resistance is about 8 percent of the total and hence the percentages should be multiplied by 0.92 .

The influence of the deviations of each of the component resistances is attenuated with respect. to the overall resistance, in proportion to the percentage values listed in Table 2.4-3. Deviations in the overall thermal resistance engender changes in the mean temperature difference which further attenuate the influence of the individual component resistances upon the heat exchanger performance (total heat transferred). 


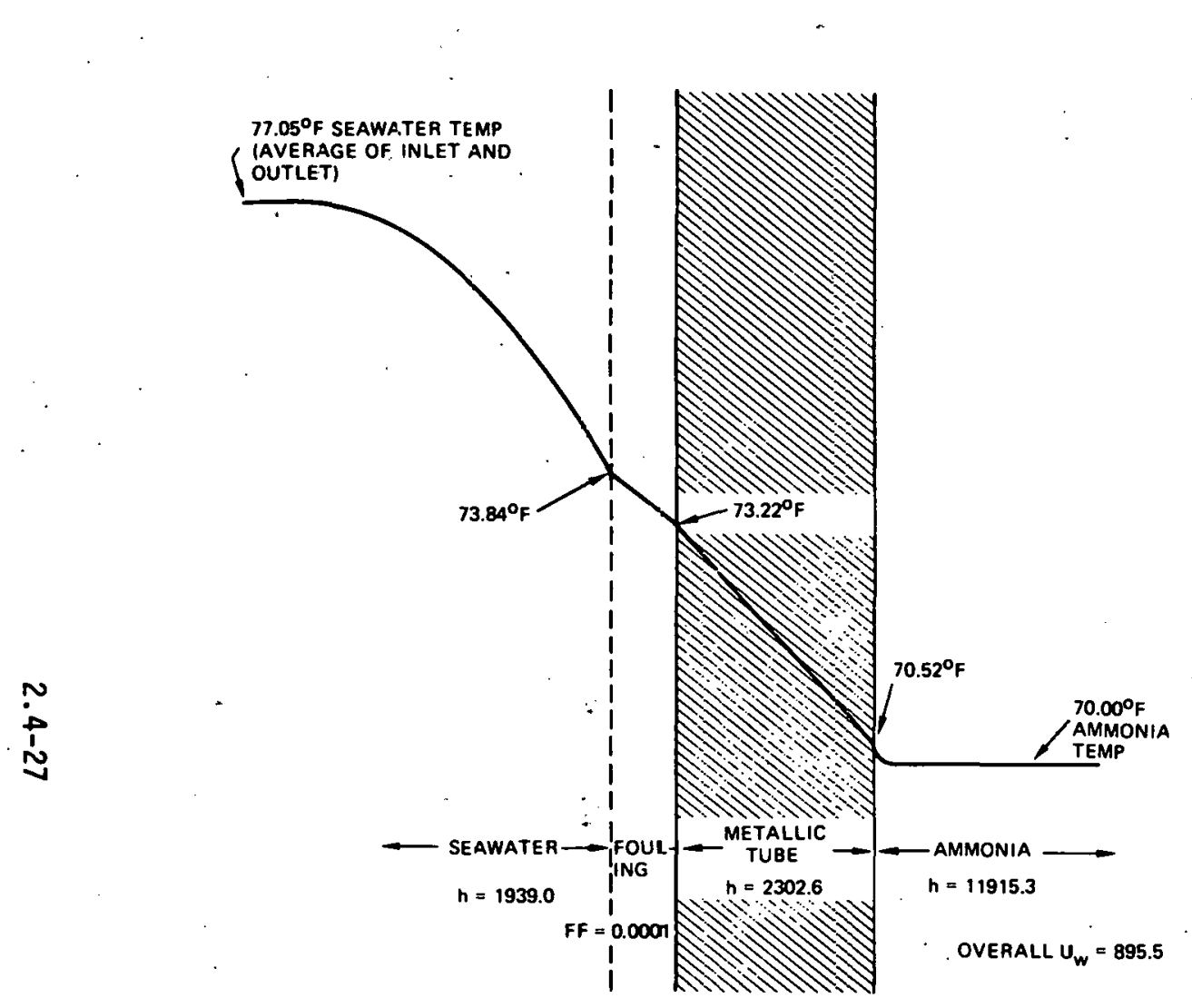

Figure 2.4-15. Temperiture Distribution in Evaporator

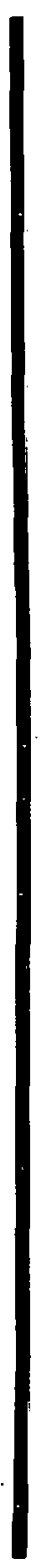

Figure 2.4-16. Temperature Distribution in Condenser 
Table 2.4-3. Thermal Resistance Distribution, (Clean Condition), Percent

\begin{tabular}{|l|c|c|}
\hline & Evaporator & Condenser \\
\hline Seawater, Convection & 50 & 63 \\
Metal Wal1, Conduction & 42 & 31 \\
$\begin{array}{c}\text { Ammonia, Condensation } \\
\text { or Evaporation }\end{array}$ & 8 & 6 \\
\cline { 2 - 3 } & 100 & 100 \\
\hline
\end{tabular}

Attenuating factors are 1isted in Table 2.4-4. Derivation of the attenuation factors is given in Appendfx I.1, Attachment 2." These attenuating factors are the proportionality factors, relating the heat transfer coefficlent deviation to the heat exchanger performance (thermal duty) deviation, both expressed in percentages. Since the heat exchanger performance directly affects plant efficiency, these attenuation factors provide a meaningful evaluation of the net effect of calculation error in the heat transfer coefficients.

Table 2.4-4. Attenuation Factors (Clean Condition)

\begin{tabular}{|l|c|c|}
\hline & Evaporator & Condenser \\
\hline Seawater, Convection & 0.30 & 0.36 \\
Metal Wall, Conduction & 0.25 & 0.17 \\
$\begin{array}{l}\text { Ammonia, Condensation } \\
\text { or Evaporation }\end{array}$ & 0.05 & 0.03 \\
\hline
\end{tabular}

As an 111 ustration, a 10 percent deviation of all the heat transfer coefficients in the evaporator (all in the same direction) would give a performance deviation of $(0.1 \times 0.30)+(0.1 \times 0.25)+(0.1 \times 0.05)=0.06$, or 6 percent. 


\subsubsection{Seawater Side Pressure Drop}

Essentially, all of the power expended in transferring heat in the heat exchangers occurs on the seawater side. The experimental values of $J_{F}$, a nondimensional number, directly proportional to the pressure drop was shown plotted in Figure 2.4-10. The calculated values of $J_{F}$, as determined for a smooth tube using the Blasius Equation and the area ratio postulate, which applies to friction, as well as heat transfer, are also shown. The calculated values and experimental data corroborate; consequently, the area ratio postulate is again affirmed to be valid and also slightiy on the safe side.

Additional details and results are in Section 2.1.8, while calculations are included in Appendix I.1.1.

\subsubsection{Ammonia Side Pressure Drops.}

The shell side pressure drop calculations are given in Appendix I.1.5, while the results are summarized in Figure 2.4-17 for the evaporator and the condenser.

The velocity of vapor in both the evaporator and the condenser tube bundle is less than 5 feet per second at all points. At this velocity, no significant liquid shear problems are expected. Bundle penetration pressure drops are $0.027 \mathrm{psi}$ and $0.031 \mathrm{psi}$ in the evaporator and condenser, respectively. At these pressure drop values, no difficulties are a: $: i-$ cipated with vapor distribution. Details of these calculations are $g^{i}$ " in Appendix I.1.5.

\subsubsection{Inlet Temperature Difference and Heat Transfer}

Total heat transferred in both the evaporator and condenser is determined by the following expression which is an alternate (for exchengers with one fluid isothermal) to the much used $q=$ UA(LMTD).

$$
q=(\Delta T)_{j} w c_{p}\left[1-\exp \left(-U A / w c_{p}\right)\right] B t u / h r
$$




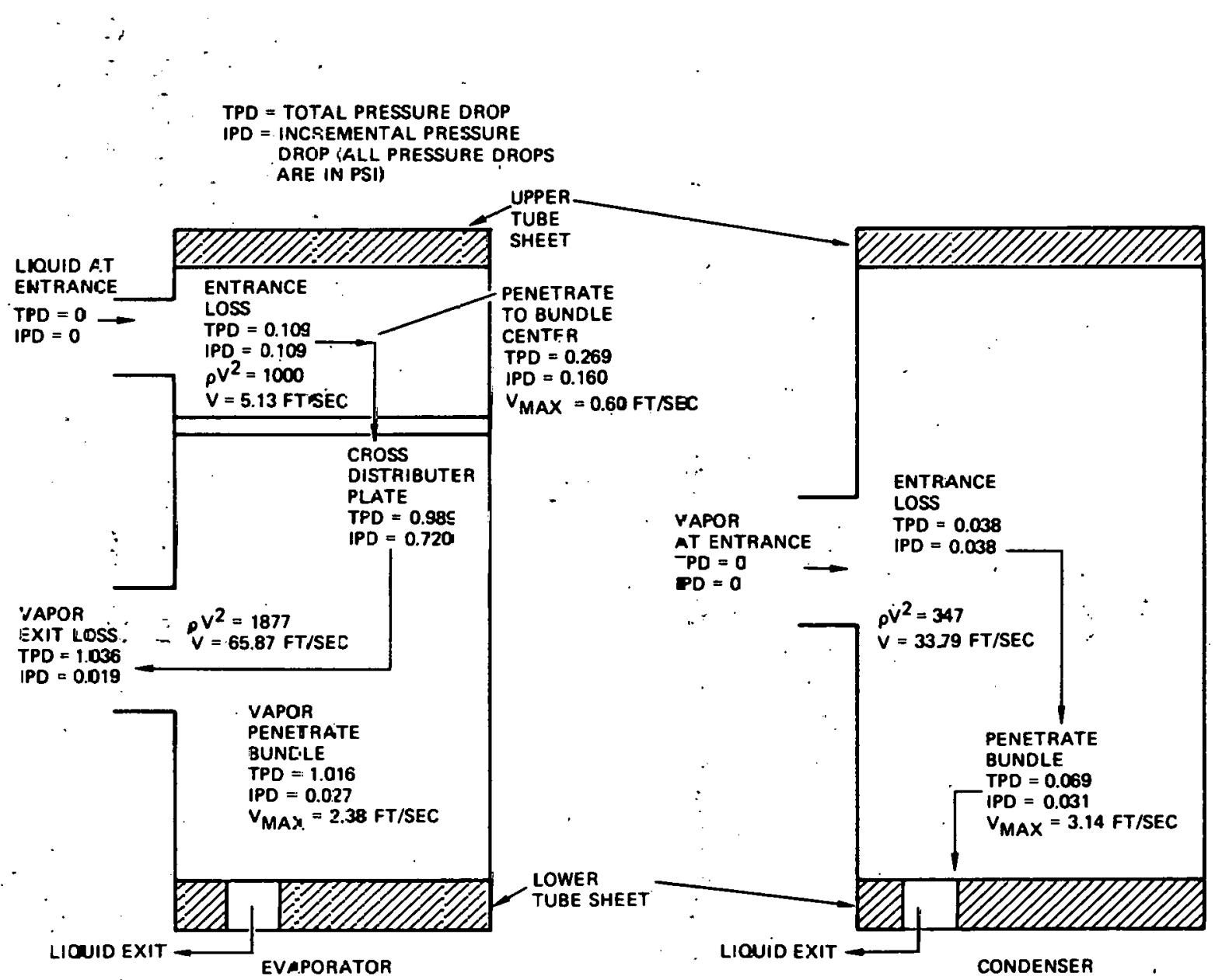

Figure 2.4-17. Pressure Distribution Evaporator and Condenser 
where,

$$
\begin{aligned}
U & =\text { overall heat transfer coefficient, Btu/hr- } \mathrm{ft}^{2}-{ }^{\circ} \mathrm{F} \\
A & =\text { surface, } \mathrm{ft}^{2} \\
W & =\text { flow rate, } 1 \mathrm{~b} / \mathrm{hr} \\
\mathrm{c}_{\mathrm{p}} & =\text { specific heat, Btu/lb- }{ }^{\circ} \mathrm{F} \\
(\Delta T)_{i} & =\text { inlet temperature difference, }{ }^{\circ} \mathrm{F}
\end{aligned}
$$

From which we obtain, keeping all yariables, except heat rate and inlet temperature difference, constant that:

$$
\frac{d q}{q}=\frac{d(\Delta T)_{i}}{(\Delta T)_{i}} \text { or } \frac{\Delta q}{q}=\frac{\Delta\left[(\Delta T)_{i}\right]}{(\Delta T)_{i}}
$$

that is percentage change in transfer rate equals percentage rate in inlet temperature difference.

\subsubsection{Liquid Ammonia Distribution in Evaporator}

Flow in the evaporator distribution plenum will be substantially uniform if the total pressure drop from periphery to the center of the plenum is less than about $1 / 4$ to $1 / 5$ of the orifice pressure drop. Pressure drops across the distributing plenum were determined using the Gunter Shaw Equation (see Appendix I.1, Attachment 9) integrated for flow and flow area change.

Pressure drops across the plenum were calculated for plenum depths of one, two, and three feet, without feed lanes and with radial feed lanes formed by removing one, three, or five rows of tubes. A row extends from the periphery to the bundle centerline. When feed lanes were considered, the bundle always had six such lanes and thus resemlbed, in cross section, a wheel with six spokes, as shown in Figure 2,4-18. 


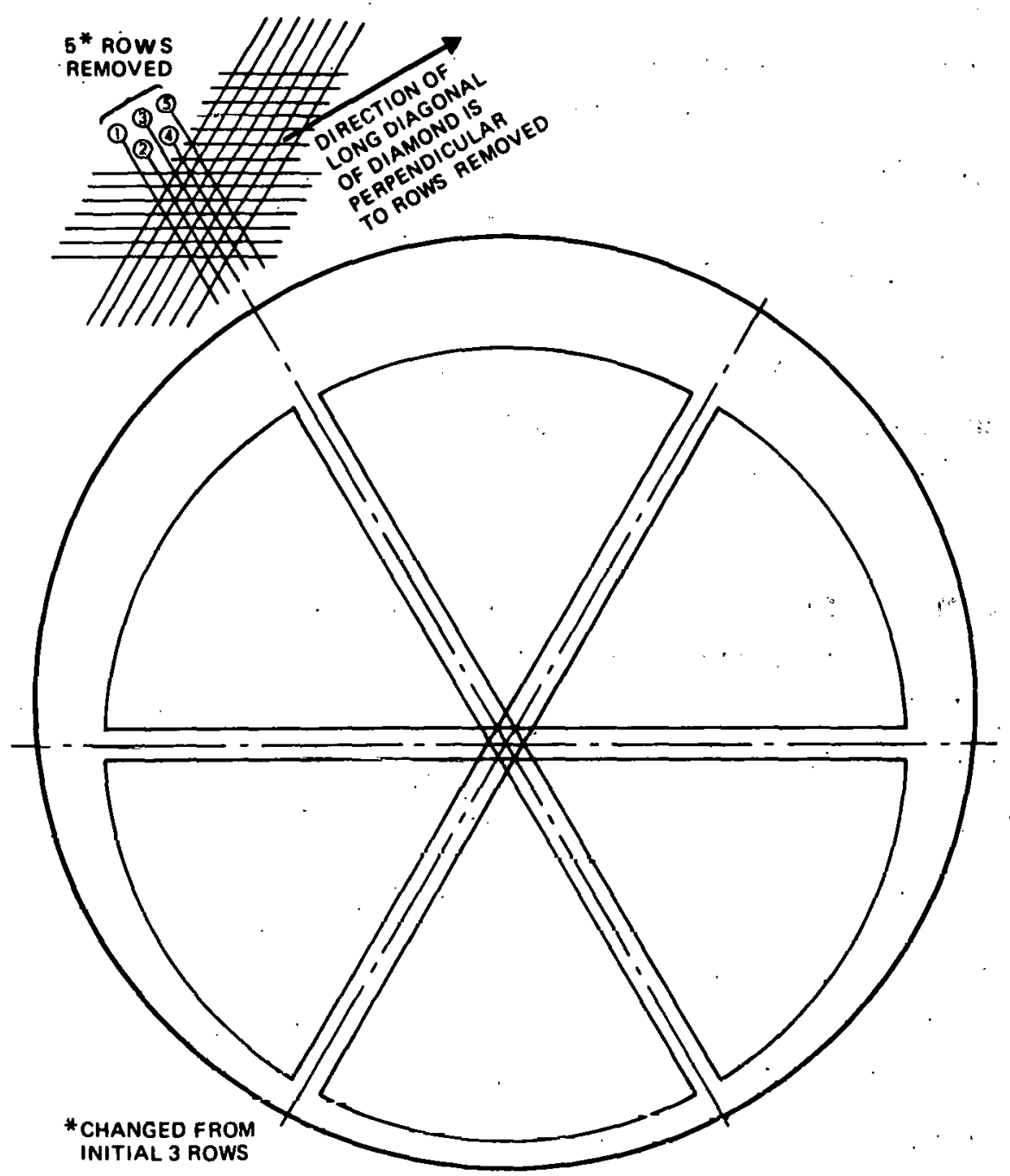

Figure 2.4-18. Access Lanes Evaporator.

A plenum 2 feet deep with six radial lanes each formed by removing three* tube rows was chosen. For this design the pressure drop is 0.16 psi. The orifice pressure drop, to ensure uniform distribution, was chosen as 4.5 times this value or 0.72 psi.

Recirculation ratio was chosen to give the optimum evaporation heat transfer coefficient. Under the most extreme conditions, a 20 percent deviation of the recirculation ratio from optimum conditions results in

ॠThe final design has five tube rows removed. 
only 10 percent deviation of the composite evaporation coefficient. This influence is further diminished by the low attenuation factor for the ammonia evaporation coefficient. The net result is that a 20 percent deviation in recirculation ratio will result in less than 1 percent deviation in heat rate.

\subsubsection{Noncondensibles in Condenser}

Since noncondensibles may significantly affect the condenser performance, special attention was paid in the design to remove the noncondensible gases efficiently.

A vertical pipe, with holes around its periphery and throughout its length, is placed at the center of the tube bundle. Since the vapor flow is radially inward, this design should be very effective. Removal of noncondensibles by purging during startup and normal operation is discussed in Sections 2.4.7.12 and 2.4.7.13, respectively.

\subsubsection{Effect of Seawater Flow Maldistributions}

Sensitivity to flow maldistribution is expected to be low. Flow. maldistribution causes a decrease in heat rate in part. of the heat exchanger and an increase in the remaining part. Since there is considerable cancellation between the increased and decreased heat transfer sections, the effect of flow maldistribution will be small.

\subsubsection{Materials and Corrosion Control}

\subsubsection{Materials Selection}

The selection of heat exchanger materials has been heavily influenced by cost and availability traded against the requirements for an economic 30-year life considering cost of maintenance/repair/replacement of key elements. Detail material evaluations were conducted during the conceptual design phase and were reported in the TRW Conceptual Design Report. A major decision was to use titanium over aluminum for the heat exchanger tube material. This choice was derived by the data available at the time of selection relating to the expected life of aluminum in seawater. The critical parameters were pitting corrosion and the effects of errosion (due to seawaler fluw and mechanical cleaning) of the water side flutes. 
The resulting analyses favored the selection of titanium as the low risk material and the one with the greatest cost benefits assuming an aluminum life of 15 years or less. Although subsequent information is increasingly favorable to the potential use of aluminum for the tubes, the data are inconclusive and titanium remains the near term, low risk preferred material. (Note: The basic design is not material dependent, thus if the economic use of aluminum can be qualified for OTEC use, it will be incorporated as the tube material.)

The materials selected for the various elements of the heat exchangers are listed in Table 2.4-5. These selections are consistent with present heat exchanger fabrication technology with the principal preliminary design activities concentrating on tube fabrication (discussed in Section 2.4.6) and the selection of cualings for stccl surfaces exposerl to seawater, steel corrosion allowances, the effects of immersion of the heat exchangers on material performance, tube-to-tubesheet joining methods, and ammonia metering devices. Changes since the conceptual design include the use of lower strength steel (Grade 60 rather than Grade 70) for pressure containing components to ensure that stress corrosion cracking due to ammonia will not occur. Further discussion as to materials is contained in Appendix D3.

Table 2.4-5. Heat Exchanger Materials

\begin{tabular}{|c|c|}
\hline Heat Exchanger & \\
\hline Shell & SA516 GR60 Steel \\
\hline Tubesheets & SA516 GR60; SA283 or SA285 GR B Stes1 \\
\hline Tubesheet $\mathrm{Cl}$ adding & SB254 GR1 or GR2 Titanium \\
\hline Tube & SB338 GR2 Titanium \\
\hline $\begin{array}{l}\text { Internal Structural } \\
\text { Members }\end{array}$ & SA51.6, SA283, SA285, ASTM A36 Steel \\
\hline Water Boxes & $\begin{array}{l}\text { SA516, SA283, SA285 Steel, Glass Fiber- } \\
\text { Reinforced Plastic }\end{array}$ \\
\hline $\begin{array}{l}\text { Water Box, Shell } \\
\text { or Pipe Coating. }\end{array}$ & $\begin{array}{l}\text { GACO N-200-1/N-11R Neoprene (or) NAPKO } \\
\text { No. } 5635 \text { Coal TAR Epoxy }\end{array}$ \\
\hline
\end{tabular}




\subsubsection{Coating Selection}

The water box and exterior surfaces of the heat exchanger will be covered with a protective coating. Corrosion data indicates that an uncoated steel tubesheet would require a corrosion allowance of 0.5 inches for this seawater immersion application if left unprotected for 30 years. The coating candidates are a zinc-rich inorganic primer overcoated with an epoxy-polyamide for heat exchanger exterior surfaces and a neoprene based elastomeric coating for the water box.

The neoprene coating has been successfully employed for 32 years in similar applications at the Portishead "A" Power Station in Bristol, England. There, tubeplates, water boxes, tube entries, etc., of the plants condensers, which are subjected to the combined effects of seawater coolant and estuary silt, are protected with this coating. The coating has shown no signs of degradation and the only maintenance has been recoating of areas damaged by maintenance workers. This material is preferred for coating, however, specific selection will occur during detail design. Information on this coating can be found in Appendix D2.

The marine coating system employing a zinc-rich inorganic primer overcoated with an epoxy-polyamide has a history of ocean service including successful 6-year service under rough-handling conditions on the 1 ift system pipes aboard the mining ship Glomar Explorer. This service is more severe than that expected for the OTEC heat exchangers. The manufacturer's data for this coating, Dimetcote 6 solvent-based inorganic zinc primer and Amercoat. 83/84 polyamide-cured epoxy top coat (Ameron Corrosion Control Division, Brea, California) is included in Appendix D2.

\subsubsection{Corrosion Allowance}

Corrosion allowances are provided on all steel surfaces exposed to seawater. No corrosion allowance is required for metal surfaces exposed to ammonia or for the titanium tubing. The excellent performance of titanium in seawater has been well documented and is summarized in the conceptual Design Report. 
ASME pressure vessel design convention calls for an 0.125 inch corroston allowance on steel vessels. However, since the present design requires immersion of the heat exchangers, increased protection is provided. If no protective coating is used, corrosion data indicates that an allowance of up to 0.500 inch is requtred (Appendix D.2). However, since the design incorporates protective coatings as described above, a conservative corrosion allowance of 0.125 inch is used for all coated steel surfaces exposed to seawater.

\subsubsection{Inmersion of Heat Exchangers}

The requtrement of immersing the heat exchangers in seawater during their 30-year 11 fe imposes severe limitations on the heat exchanger mounting system, corrosion protection system, and the types and design of electrical and fluid lines which are attached to the hull. Due to the large area of noble material (steel encased in concrete) in the hull and the relatively small area of the active material in the heat exchangers and support structure, the latter must be cathodically protected. It has been assumed that the hull designer will provide the cathodic protection system. As such, the heat exchanger contractor must provide corrosion protective systems which are compatible with the cathodic protection design and the hull designer must provide electrical isolation for all connections, mounting brackets, pipes, lines, cofferdams, etc., which attach to the hull from the heat exchangers. It is anticipated that passive cathodic protection using sacrificlal anodes will be used rather than the impressed current techniques. This is due both to economic considerations and the difficulty in designing impressed current systems compatible with coatings. A discussion of some of the design considerations is presented in Appendix D.3.

\subsubsection{Ammonia Metering System}

In order to prevent flooding or dry out of the evaporator tubes, the ammonia must be introduced to the tube surfaces in metered amounts. Several methods have been investigated to provide the metering orifices; viz, metallic or nonmetailic inserts in the metering plate, fluid paths formed as part of the tube, and slots broached into the holes in the metering plate. 
Tests are underway to evaluate thermoplastic and elastomeric inserts which would snap into the metering plate, see Figures 2.4-19 and 2.4-20. Advantages to such a system include low cost (the inserts can be injection molded of a polyolefin material), easy installation, and no special hole preparation. Tests have been performed with a fluid which simulates ammonia and good distribution around the tube was obtained (see Appendix D.3). A disadvantage is that the approach centers around the tolerances for the hole, tube, insert diameters, and grooves. The very small orifice area required for ammonia flow complicates the problem. Tolerance buildup may result in either a gap which leads to flooding of the tube, or an inter-. ference which makes tube installation very difficult.

The use of metal inserts (as shown in Figure 2.4-21) can alleviate the tolerance problem to some extent. That is, the tube would be inserted into the insert and then expanded to the insert inside diameter to give a close fit. However, metal inserts have a tendency to be "wet" by the ammonia and the metering/distribution grooves must be carefully designed.

Forming grooves into the tube would be convenient since no special hole preparation or auxiliary components are required. However, tolerances aga in become a problem and expanding a grooved tube against the metering plate would have to be developed. Hydraulic or rubber expansion methods, as described in Section 2.4.6 may be applicable for this expansion operation.

Broaching grooves in the metering holes is the most straight-forward since the round tube can be expanded against the hole to give a tight fit and accurate metering. The costs of broaching must be traded against the other candidate methods before a final selection is made.

Specific selection of the metering approach will occur during detailed design. 


\section{CONCEPT A}

\section{AMMONIA FLOW ORIFICE,}

EQUALLY SPACED ON CIRCUMFERENCE

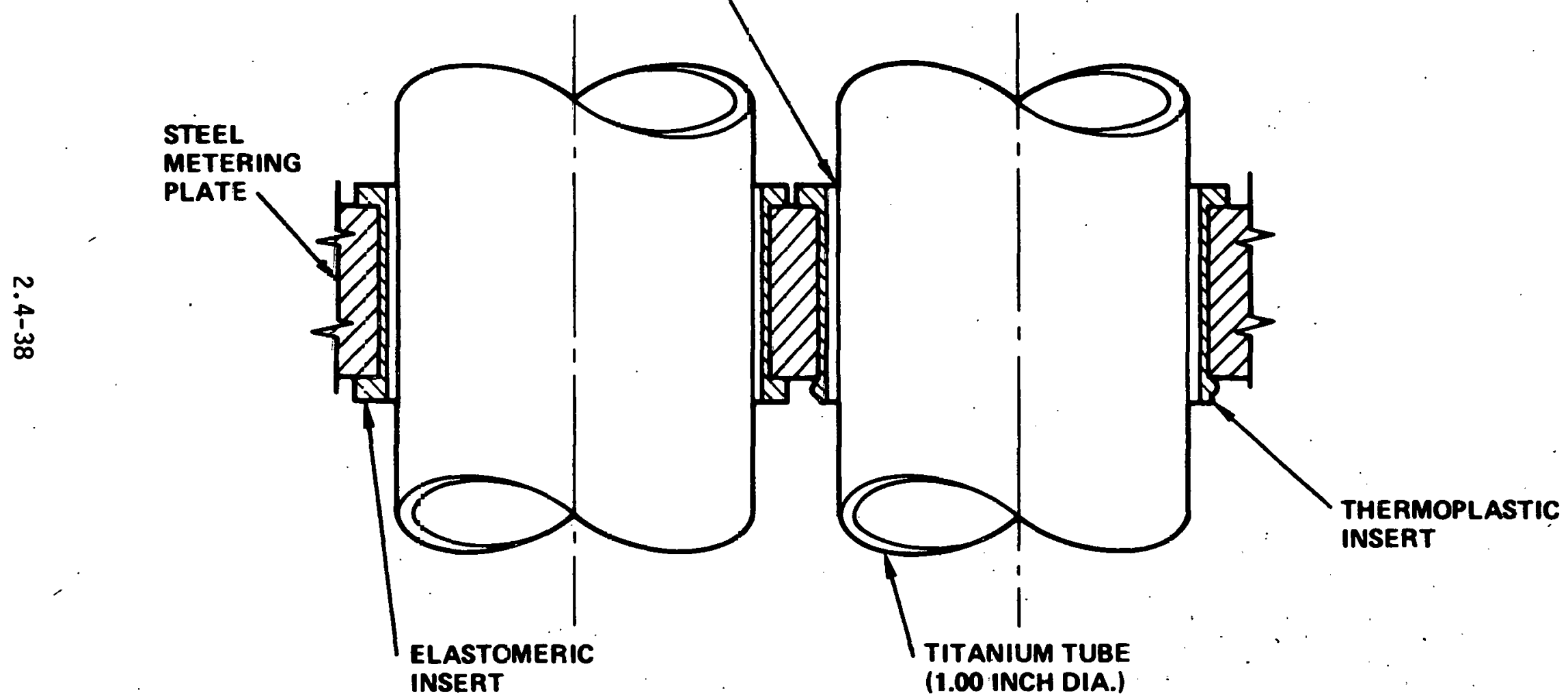

Figure 2.4-19. Ammonia Metering Insert 

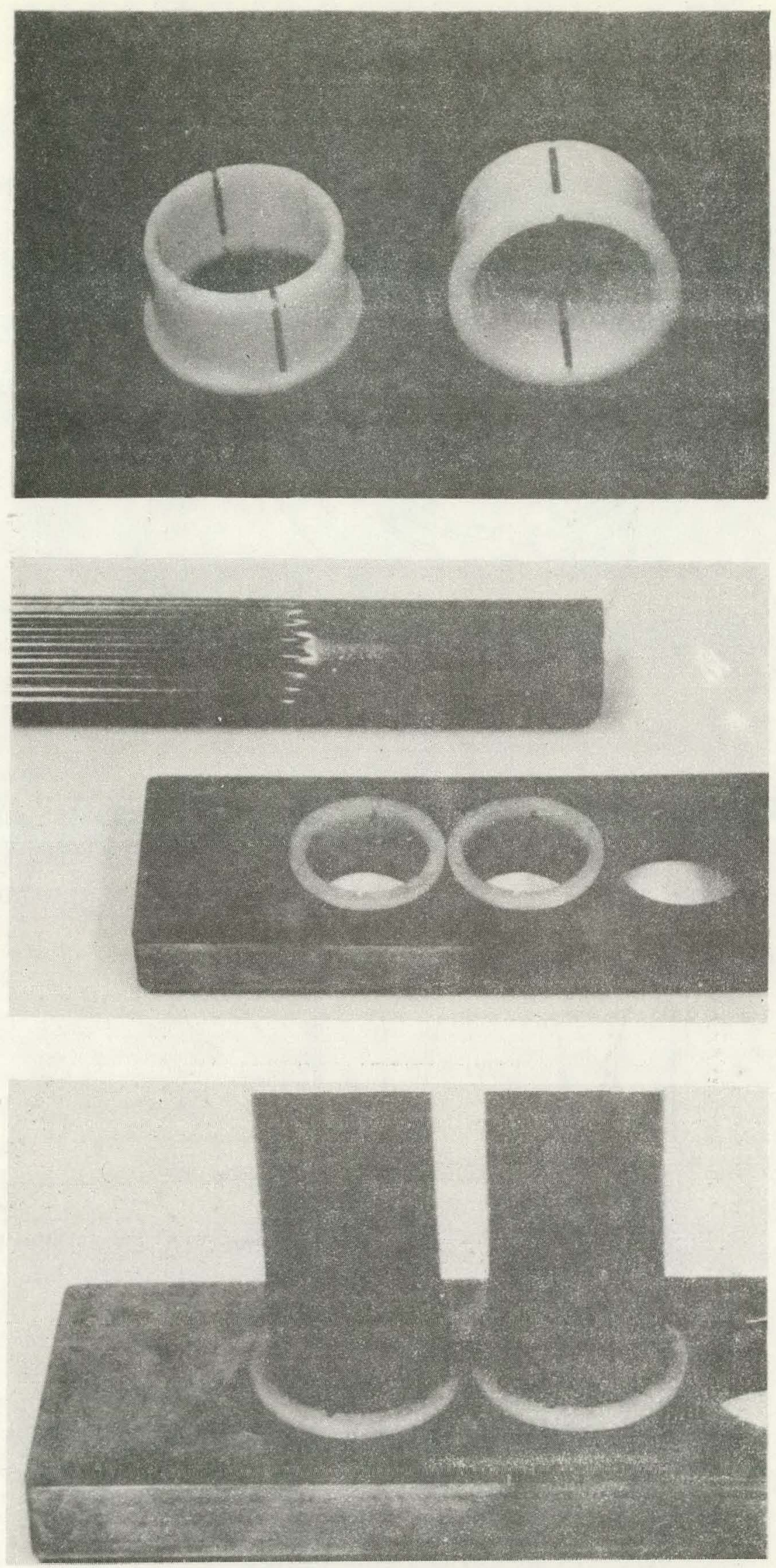

Figure 2.4-20. Polyethylene Inserts

2.4-39 

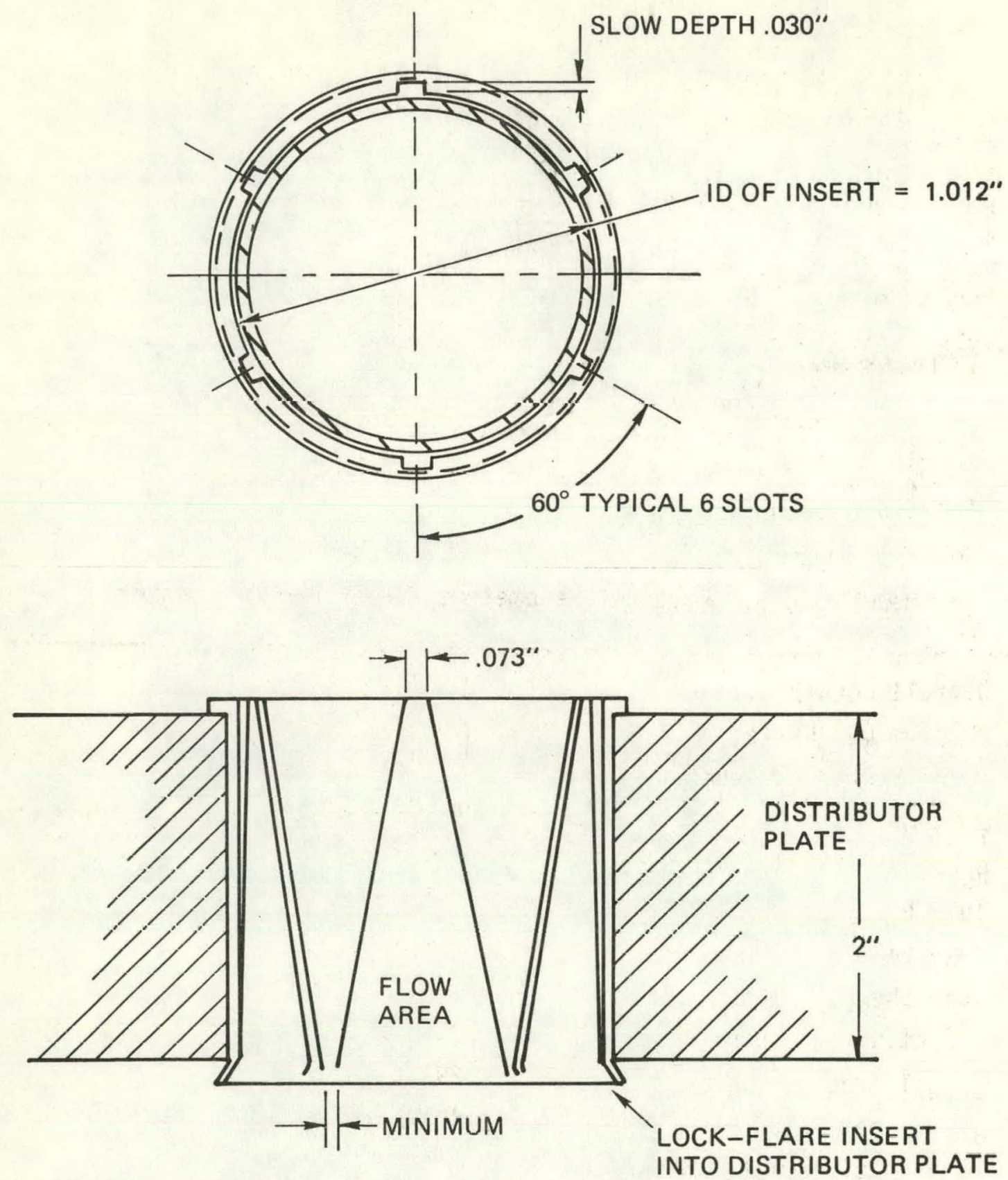

\section{MATERIAL - CARBON STEEL - \\ DIE FORMED TUBING OR \\ MOLDED POWDER METAL}

Figure 2.4-21. Evaporator Distribution Inserts 


\subsubsection{Biofouling and Cleaning Considerations}

A requirement of this power module development is to provide a blofouling control system which maintains the heat exchanger fouling resistance below $0.0005 \mathrm{Btu} / \mathrm{hr}-\mathrm{ft}^{2}-{ }^{\circ} \mathrm{F}$. Due to the effects on system performance costs., however, a design goal fouling factor of $0.0001 \mathrm{Btu} / \mathrm{hr}-\mathrm{ft}^{2}-{ }^{\circ} \mathrm{F}$ has been established.

During the conceptual design phase several conclusions were formulated (Note: the detail trade studies relating to effects and cost of biofouling and cleaning are contained in the:TRW Conceptual Design . Report SAN/1570-1). These include:

- The magnitude of fouling resistance is more significant for high performance heat exchangers than for conventional ones

- Periodic brushing combined with low dosage chlorination will result in near clean tubes

- It is cost effective to implement a brush type cleaning design.

Figure 2.4-14 illustrates the effects of fouling on the overall heat transfer coefficient for heat exchangers. Since a "low" performance heat exchanger would require more total surface area (thus, more cost) to produce the required energy exchange than a high performance one, an expenditure budget can be established for biofouling control based upon heat exchanger cost. This is illustrated by Figures 2.4-22 and 2.4-23.

Tests conducted by several researchers (noteably Carnegie-Mellon University and the University of Hawaii) ${ }^{\top}$ have shown that the biofouling film on a clean tube builds up slowly at first, taking up to 6 weeks to reach $0.0001 \mathrm{Btu} / \mathrm{hr}-\mathrm{ft}^{2}-{ }^{\circ} \mathrm{F}$ when water velocities are 6 feet/second (see Figure 2.4-24). Further, it has been reported ${ }^{2}$ that a minimal wiping action is required to remove this biofouling film and, when combined with low dosage chlorination $(0.05 \mathrm{mg} / \mathrm{l})$ countermeasures, a near clean tube can be maintatned. Therefore it is estimated that a cleaning cycle of approximately 1 week will maintain this fouling factor near the design goal fouling resistance. 


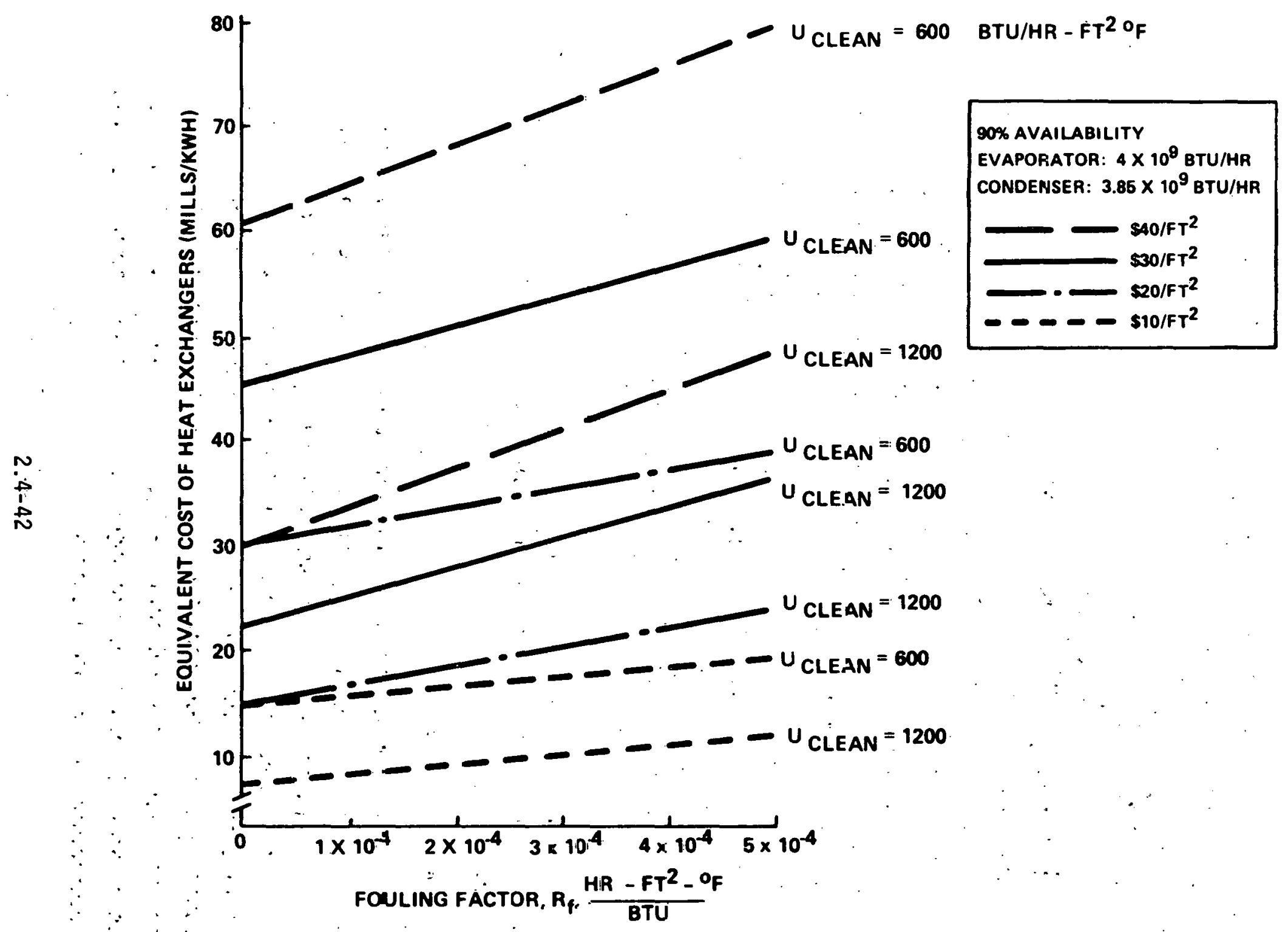

Figure 2.4-22. Annualized Cost of $0^{-} E C$ Heat Exchangers 


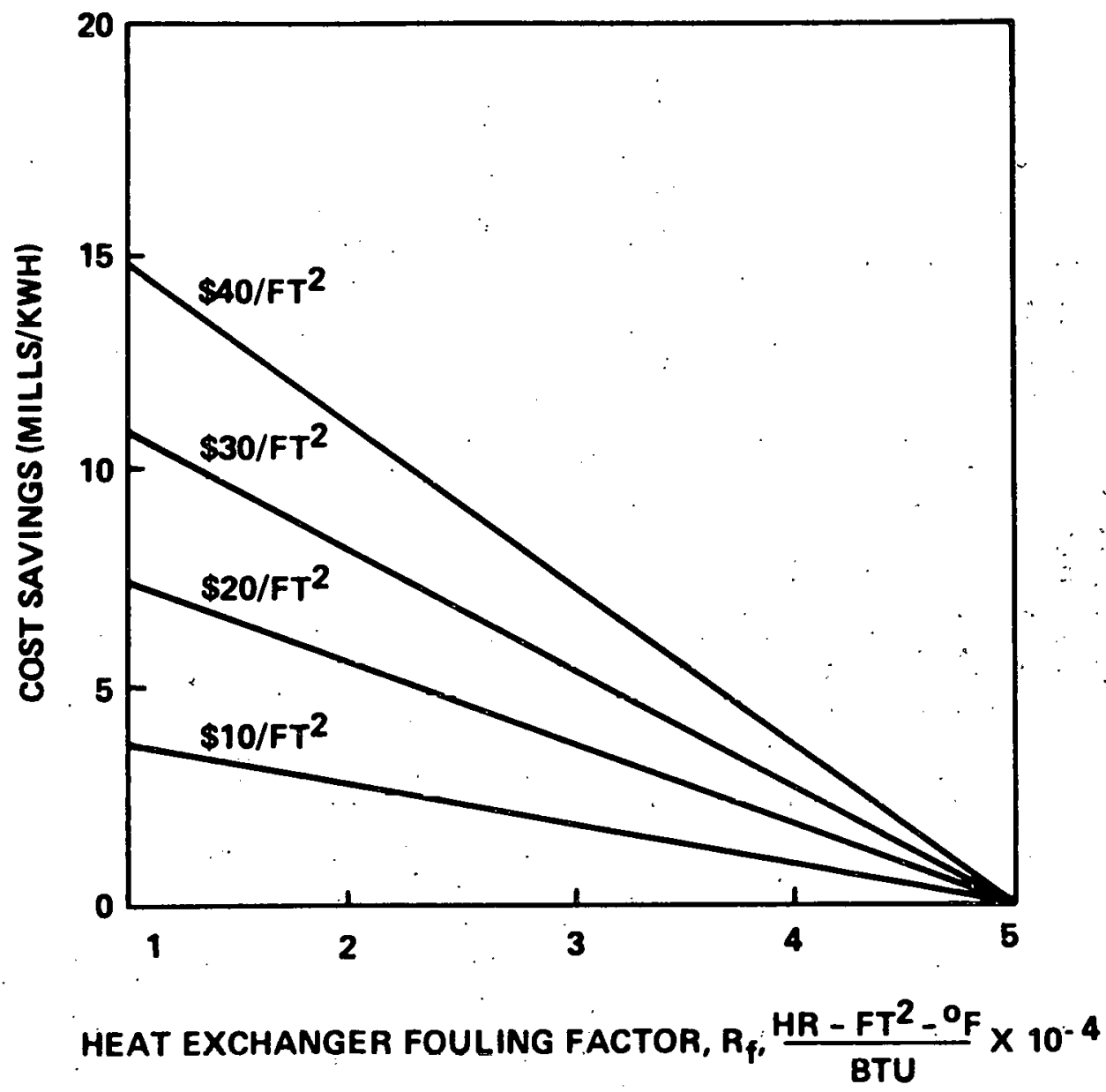

Figure 2.4-23. Heat Exchanger Cost

The details as to implementation of a cleaning capability combined with chlorination are discussed in Section 2.6.2. The basic concepts, however, are as follows:

\section{Cleaning Machine}

TRW's machine is similar to existing commercial brush-type scrubbers with improved efficiency and adapted to the vertical tube configuration. The machine attaches to the upper, open end of the exchanger and cleans a cluster of tubes by driving a scrubbing head down each tube by means of a multiple spindled, powered head. The powered head is moved from cluster to cluster and heat exchanger to heat exchanger by means of an overhead bridge crane and guide rails. The design duty cycle of the tube cleaner ( 12 hours per exchanger) can be modified to more or less as operational experience dictates. 


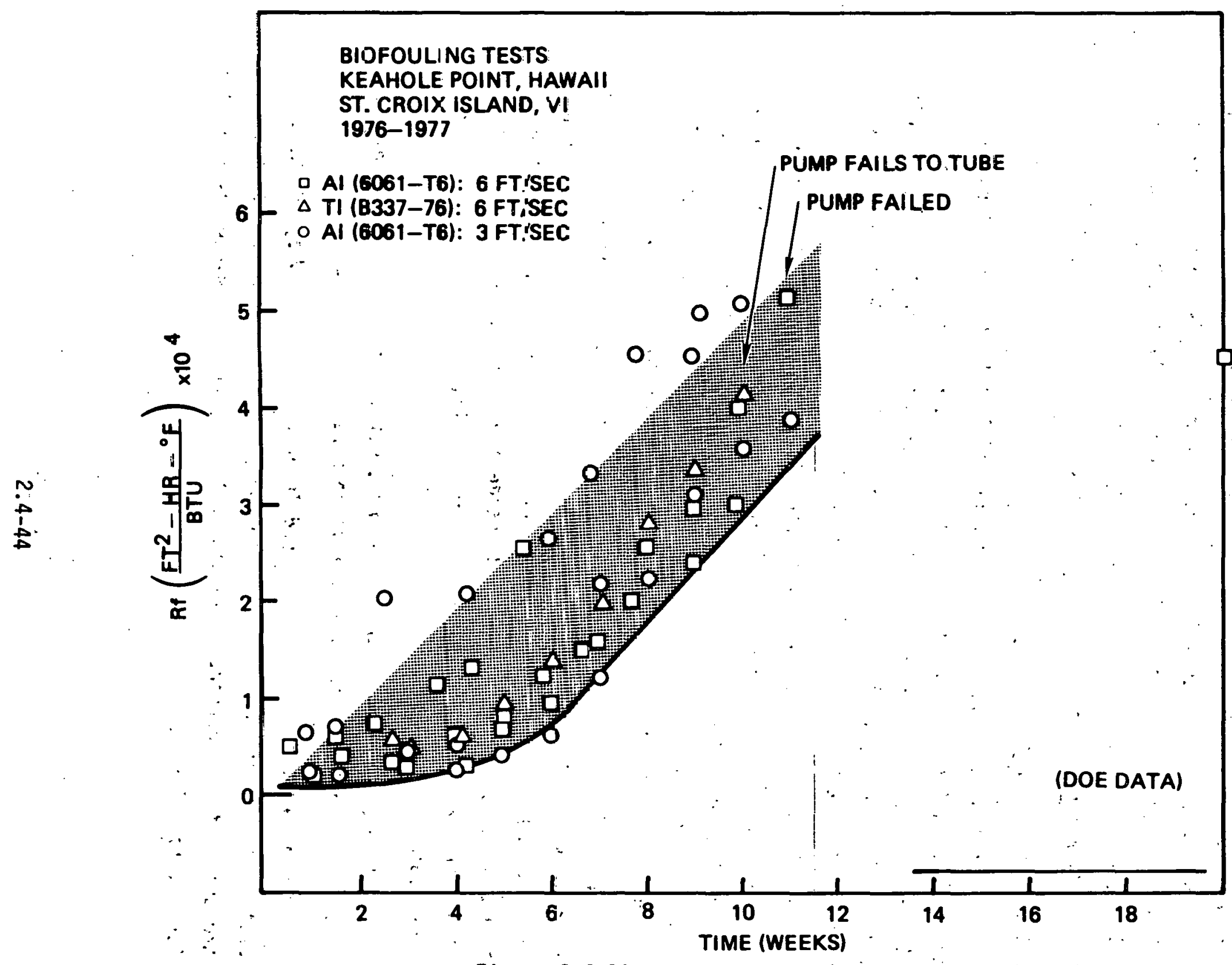

Figure c.4-24. Thermal Resistance Versus Time 


\section{Chlorinator}

In addition to the mechanical cleaning process, a low dose rate of chlorination (about $0.05 \mathrm{mg} / \mathrm{l}$ chlorine) will be continuously injected into the water supply. This added prevention is to decrease the buildup rate of biomass and to provide some protection (and less frequent maintenance times) for portions of the system not cleaned by the tube cleaner, (e.g., tubesheet, ducts, pumps).

\subsubsection{Mechanical Design and Producibility}

\subsubsection{Design Considerations}

The evaporator and condenser are designed to be fabricated using present technology. In both these heat exchangers the water box is open at the top to provide access to the tubes for tube cleaning and inspection/ repair. The tube cleaning equipment requires consideration of structural mounting to the water box.

In the evaporator even distribution of liquid ammonia flow to the tubes is essential. To accomplish this insert orifices are used. These inserts are installed between each tube and the distributor plate. No flow is permitted past the distributor plate except through these orffices. Proper insert design and assembiy will meet this flow requirement.

In operating the evaporator, ammonia liquid flows through each orifice and down each tube. The flow may be interrupted at the tube supports with some flowing liquid knocked off the tube. To prevent this, the design includes three small bosses formed inside the baffle hole. These "guides" will center and brace each tube while minimizing flow disturbances at the tube supports.

Liquid ammonia flows through an exit nozzle mounted offset from the tube bundle in the lower tubesheet in both heat exchangers.

The heat exchangers are designed in accordance with the ASME Code, Section VIII, Division $1^{3}$. Parts not covered by code, where applicable, are designed in accordance with Standards of Tubular Exchanger Manufacturers Association (TEMA R). 


\subsubsection{Design Details}

Tube Bundle Design

The tubes in the tube bundles are arranged eccentric with respect to the shell. The details of the tube bundle are shown in Figure 2.4-25. The tubefield is $1-1 / 4$ triangular. Periodically, this pattern is interrupted by a tube cleaning machine alignment stud or flow lanes as shown.

Tubesheet Design

The tubesheets require extensive design and analysis because of size, thickness, and fixed tubesheet considerations. Temperature differences. are of little consequence, (see Table 2.4-6) TRW will use C. F. Braun's fixed tubesheet analysis program to optimize the tubesheet design.

The large diameter tubesheets required will be built by welding together clad plates. Clad plate is not a short delivery item. The maximum width of plate presently available is 132 inches. Titanium clad plates will be cut into six pie-shaped pieces to form the tubesheet circle. Where these are jointed no tubes are installed because the titanium is not intimately joined to the carbon steel at the junction. In laying out the tubesheets, these joints will be located so they occupy the area needed for vapor or liquid lanes.

Explosive cladding of the pie shaped tubesheet sectors causes severe warping. Each piece wili have to be filattened - the eladder has this capability. Careful planning and execution of the welding of the sectors together will minimize further warpage. Considerable work is done on these plates in welding and straightening before any drilling can begin.

Tubesheet drilling is a time consuming effort. All indications are that drilling time wili govern delivery of the completed exchangers. Several drilling machines will be needed; each machine takes about 1 year to deliver. The number required will be established based on speed of drilling and overall exchanger schedule. 


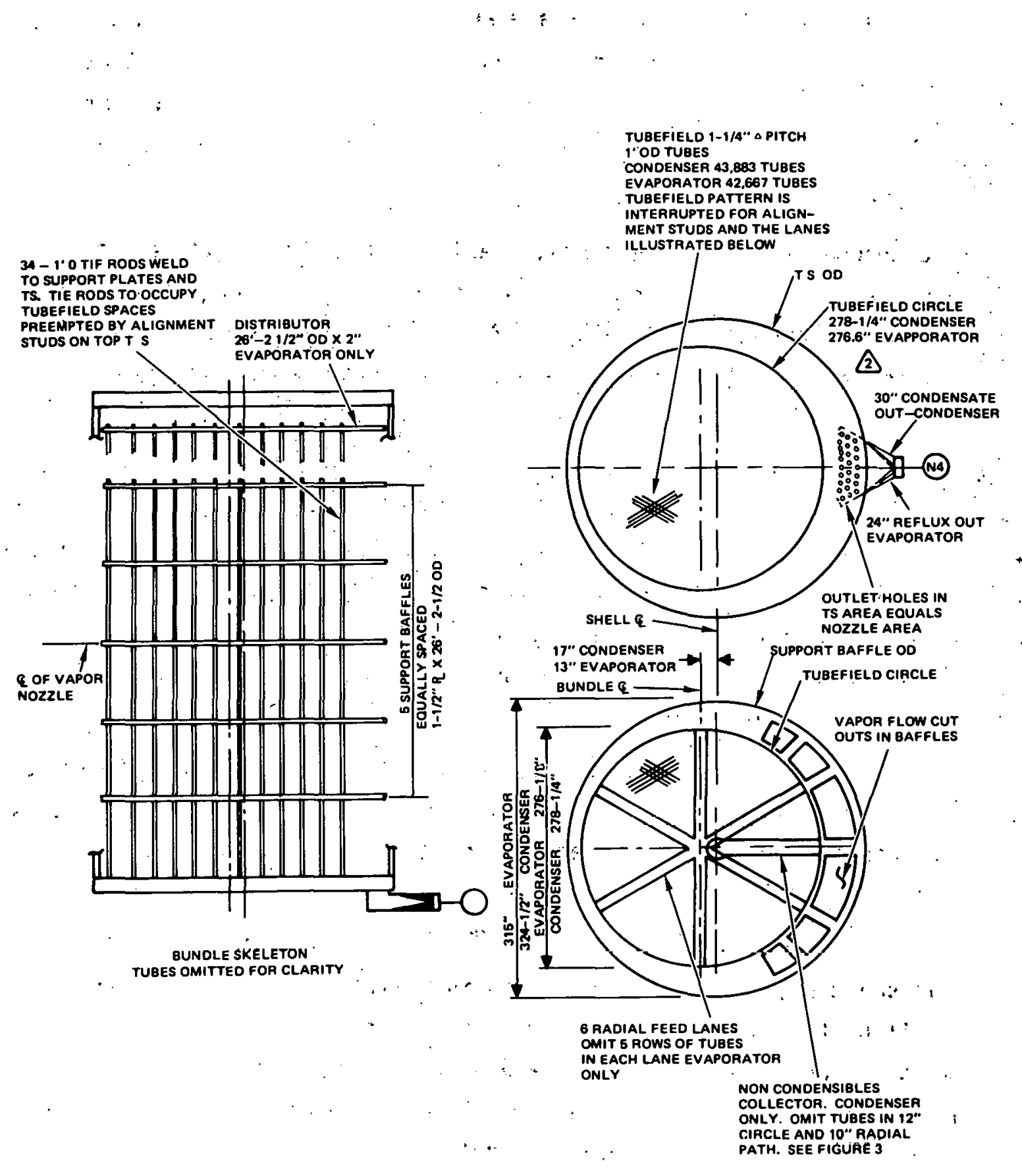

Figure 2.4-25, Tube Bundle Skeleton Detail 
Table 2.4-6. Tubesheet Temperatures

\begin{tabular}{|c|c|c|c|c|c|c|c|}
\hline & & & laporatc & & & ondens & \\
\hline Maximum tub & metal temp, & & 76.35 & & & 49.63 & \\
\hline Average she & fluid temp & & 70 & & & 50 & \\
\hline Average tub & fluid temp, & & 76.6 & & & 43.60 & \\
\hline Average tub & metal temp, & & 70.9 & & & 49.50 & \\
\hline Tubesheet & ckness & $4 \mathrm{in.}$ & 3 in. & $2 \mathrm{in.}$ & 4 in. & 3 in. & $2 \mathrm{in.}$. \\
\hline Hot end & (Shell side & 72.77 & 72.77 & 72.77 & 49.09 & 49.59 & 49.59 \\
\hline tubesheet & Tube Side & 80.00 & 80.00 & 80.00 & 46.20 & 46.20 & 46.20 \\
\hline temp, & Avg.Metal & 79.56 & 79.42 & 79.12 & 46.40 & 46.46 & 46.59 \\
\hline Cold end & Shell side & 70.61 & 70.61 & 70.61 & 49.67 & 49.67 & 49.67 \\
\hline tubesheet & Tube Side & 74.10 & 74.10 & 74.10 & 40.00 & 40.00 & 40.00 \\
\hline temp, & I Avg Metal & 73.93 & 73.87 & 73.75 & 40.58 & 40.77 & 41.15 \\
\hline
\end{tabular}

\section{Tube-to-Tubesheet Joints}

Thin wall tubes, especially titanium, are difficult to expand. It is proposed that hydraulic expansion be used with grooved tube-to-tubesheet construction. This technique has been successful in this country and to a greater degree in Europe and Japan. The technique is described by Wilson ${ }^{4}$. The only limitation is in extending the seal to the tubesheet face. This is overcome by following tube expansion with welding of the tubes to the cladding on the tubesheet face.

\section{Deffles}

Carbon steel plates are welded together to form baffles. Baffle drilling requirements differ from those of tubesheets, for these reasons:

a. Baffles are not clad and carbon steel is readily available

b. Baffles are stacked for drilling while tubesheets are not. Tubesheets require added work other than drilling, such as grooving. 
c. Baffle drilling may begin soon after fabrication approval. The time required to obtain clad material for tubesheets can be used as drilling time for the baffles.

The production scheduling problems remain to be worked out during procurement.

\section{Shell Openings}

Process nozzles (ammonia inlet and outlet) have welding stub ends. The smaller nozzles are 300-pound ANSI B-16.5 raised face flanges. The 300-pound ANSI rating is recommended for ammonia connections by the Coast Guard regulations, Part 98.25-40. Reinforcement for nozzle openings will be in accordance with the ASME Code; Section VIII, Division 1, Paragraph UG-37 ANG UA-7. The liquid ammonia inlet nozzle is a $36-$ inch round nozzle that will be transitioned to an 18 -inch by 60 -inch rectangle, to fit the 24-inch space between the tubesheet and the distributor plate. The cross sectional area of the 36 -inch pipe will be maintained. Nozzle reinforcement is in accordance with above cited code rules.

The 30-inch liquid ammonia recycle nozzle is connected to the bottom tubesheet. The nozzle is contained within the cofferdam.

\section{Distribution Plate for Evaporator}

A 2-inch thick distribution plate is used to uniformly distribute liquid ammonia to all tubes. It is 24 inches below the top tubesheet. Thirty-four tie rods support the distrfbutor plate and tube support baffles. Metering inserts at each tubehole control the pressure drop and the ammonia flowing to each tube. There will be tubesheet deflection. due to weight. This bow will be transmitted to the distributor plate. Calculations will establish the impact of bowing on the metering system. All hypothetical cases indicate that effects of deflection are negligible. If bowing is significant, adjustment can be made in the tie rods.

\section{Exchanger Support}

The exchangers will be submerged in operation. To connect the nozzles underwater during installation, a cofferdam is necessary. In essence, this is a flanged support and chamber about 34 feet long designed to keep seawater out. Gasketing this connection requires special fabrication effort. 
For this we propose an inflatable "0" ring gasket be used. This will be collapsed out of harm's way during installation and inflated when the exchangers are in position. Permanent bolting holding the exchangers in position will be installed inside the cofferdam. . Our recommendation is that the cofferdam be dry in service with bolting made of low alloy steel. If the cofferdam is flooded, flange faces and bolting must have corrosion protection adding to the fabrication requirements.

\section{Manways}

Access to the shell interior is required by the code. "A 30 -inch manway will be provided and mounted in the cofferdam area. If the cofferdam is flooded and a large corrosion allowance is required, the manway cost would increase substantially. If a man enters the exchanger through the manway, he will have access to its complete length because he can go up or down the shell through the openings in the tube supports. Openings will be designed for this, and flow purposes. A manway is also proposed in the skirt area for inspecting the lower tube to tubesheet joints or inspecting the lower tubesheet.

\section{Lifting Lugs}

The exchangers will be manufactured and shipped in the horizontal position. Provision must be made for lifting the units from the horizontal to vertical position and for lifting the units into position. The design and fabrication criteria of the lifting lugs will include for noninterference with the cofferdam and available:space for mounting. In addition, separate spreader bars will be required for handling. Because the units will not be shipped together, two spreader bars are needed.

\section{Design Alternatives}

During the detail design phase alternates will be considered. Three a)ternates are listed for consideration. After review the best design will be chosen.

a. The tubesheets have been considered as self supporting members. Weight may cause dishing of the tubehseets and troublesome bending stresses at the tuhesheet to shell joints. Figure 2.4-26 shows an eggcrate or truss structure that could support the bundle and reduce stresses and/or lead to a reduction in tubesheet thickness 
SUPPORT GRID FOR INSTALLATION BELOW THE BOTTOM TUBESHEET

TO COMPENSATE FOR TUBESHEET DISHING DUE TO BUNDLE WEIGHT
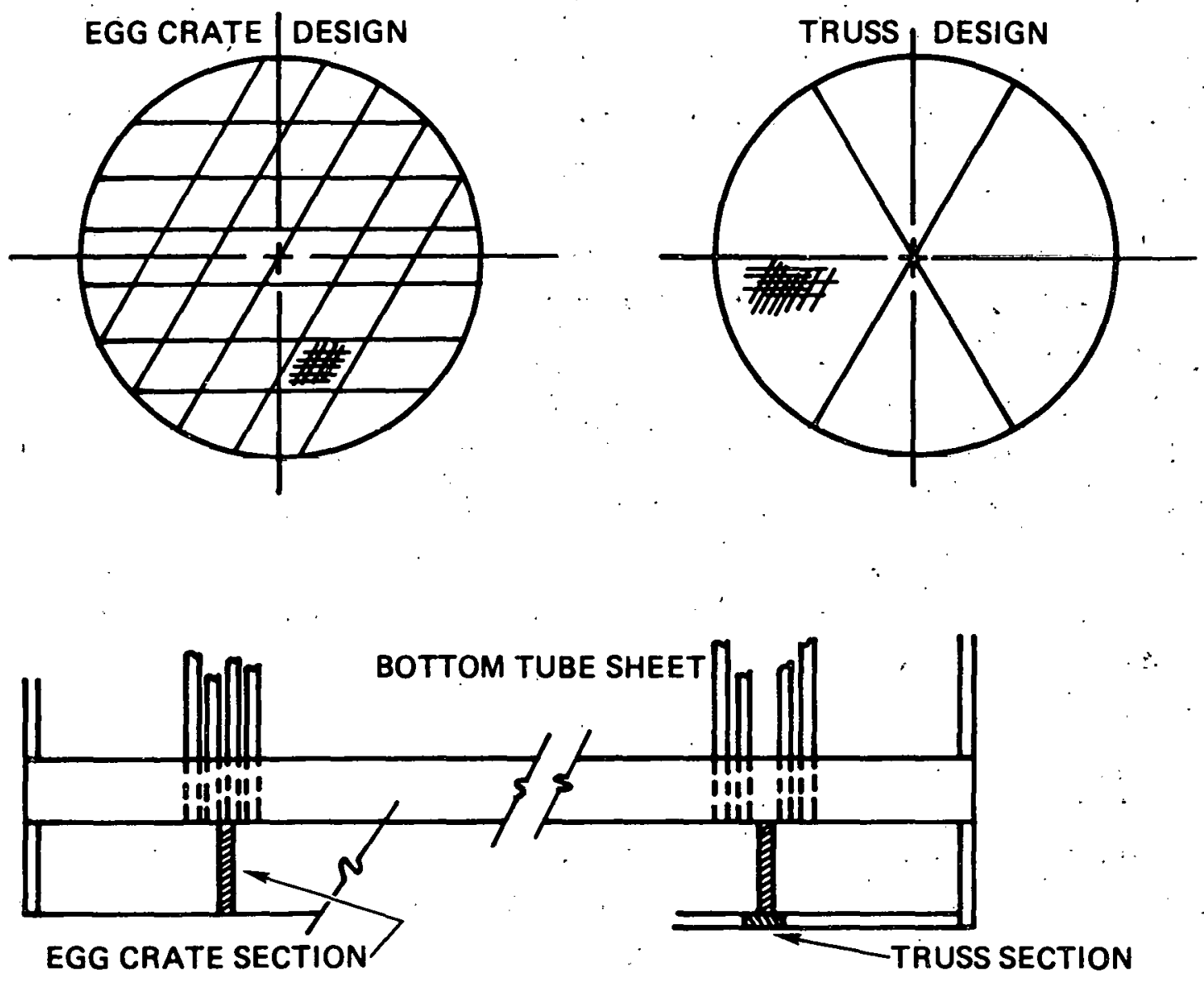

WITH BOTH THE EGG CRATE AND TRUSS CONCEPTS THE SUPPORT BARS FOLLOW THE TUBEFIELD LAYOUT. HOWEVER, THE TRUSS SECTION IS HEAVIER AND MAY REQUIRE MORE SPACE THROUGH THE TUBEFIELD

Figure 2.4-26. Tubesheet Support 


\section{b. Eccentric Bundle}

The current design is a tube bundle arranged eccentric to the shell. This allows space for fluid distribution within the shell. As an alternate design, a concentric tubefield design with a bustle around the shell at the inlet nozzle level would allow a straight (no transition) nozzle to be used. Ammonia would fill the bustle and enter the shell through a series of holes spaced around the shell. Uniformity of ammonia feed would be a benefictal side effect.

\section{c. Feed Lanes}

The present design has uniform width feed lanes in the evaporator. A feed lane as shown in Figure 2.4-27 with feed lane width decreasing toward the bundle center, will increase flow area at the feed lane periphery where the fiow is greatest, and decrease flow area at the center, where flow is least. We will investigate the optimum feed lane configuration during the detail design phase.

\subsubsection{Tube Producibility}

The objectives of the tube producibility study were to:

1) Establish the feasibility of producing enhanced tubing in commercially pure titanium (ASME SB-338, Grade 2 or ASME SB-265, Grade 2)

2) Develop approximate production costs for fabricating enhanced tubing by the candidate processes

3) To produce feasibility samples for verification of proress and possibly for structural and thermal tests.

In order to produce the degree of enhancement required; two basir. types of processes were evaluated; viz, those using one-piece tooling and those using two-piece tooling (male and female dies).

The processes using two-piece tooling were:

1) Roll forming. A process whereby the corrugation pattern is rolled into the flat strip material by a series of roliers. The corrugated strip is lhen passed through a second set of rolls which form the strip into a tubular cross section. The formed tube is then passed through a fusion welding machine and welded (Figure 2.4-28A).

2) Tube redrawing. A process that takes a tube of the same or slightly larger diameter than the final diameter and pulls it through a die to impart the contour into the tube (Figure 2.4-28B). 


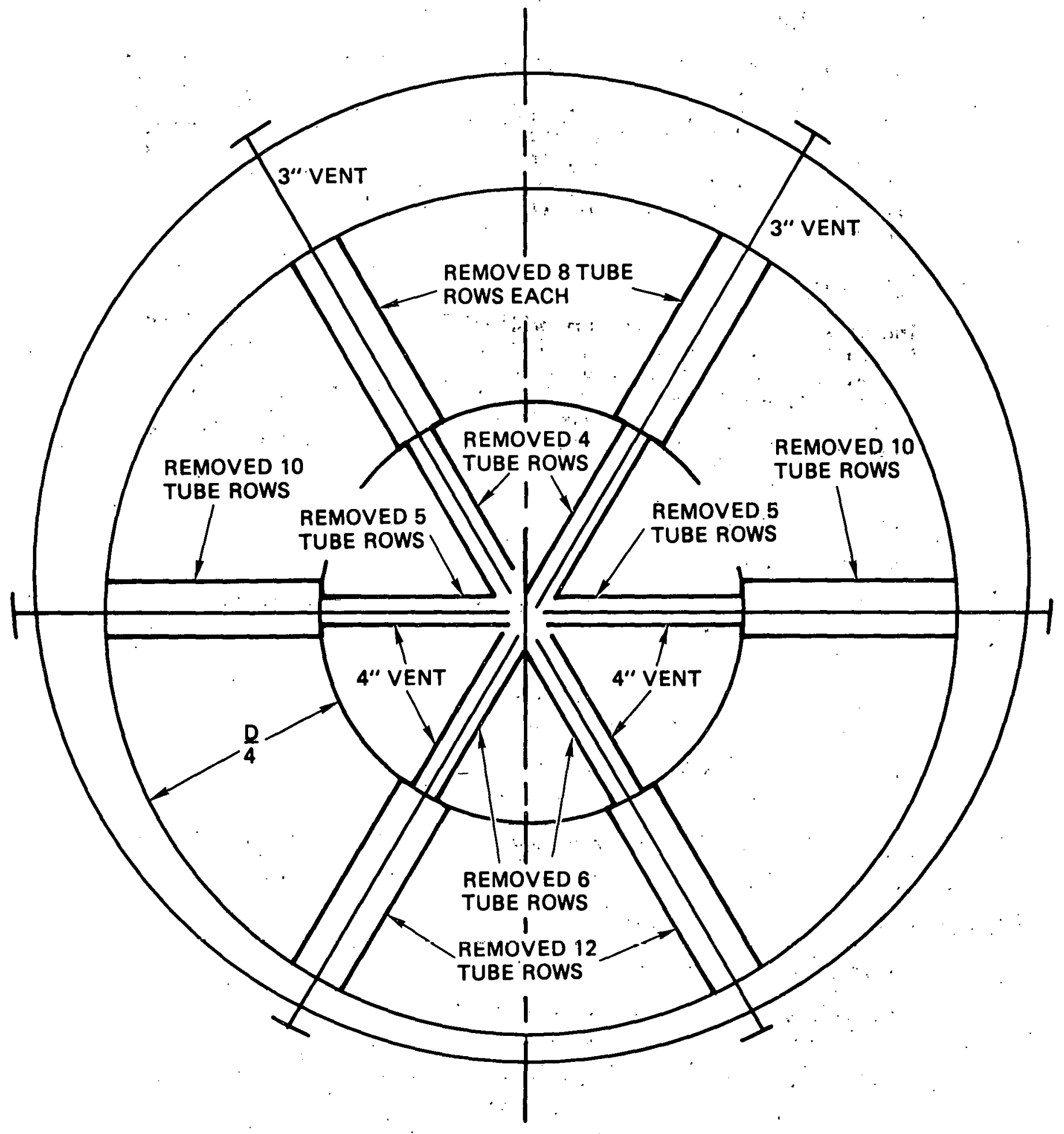

Figure 2.4-27. Evaporator Feedlanes 
A. ROLL-FORM

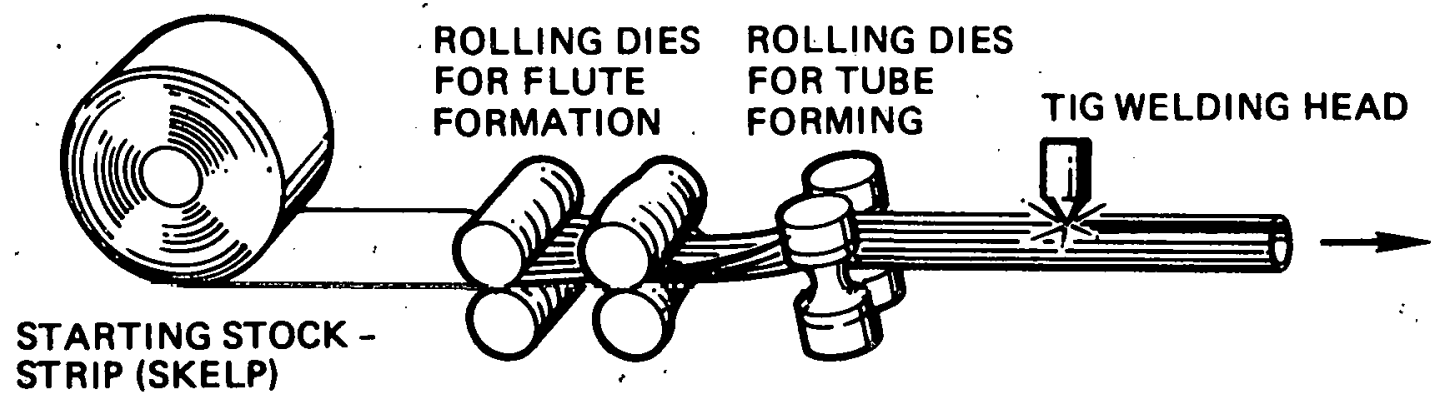

\section{B. REDRAW}

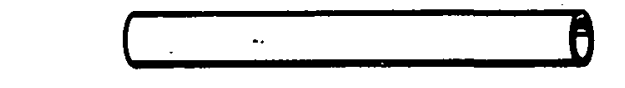

STARTING STOCK - ROUND TUBE

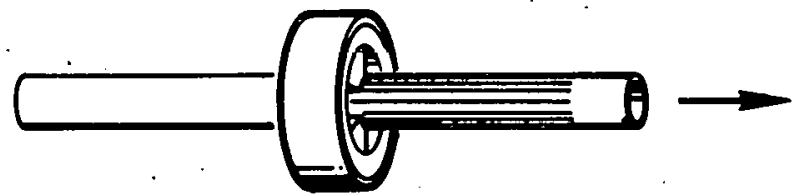

DRAWING DIE WITH RADIAL MOVEMENT

C. ROLL-UPSET

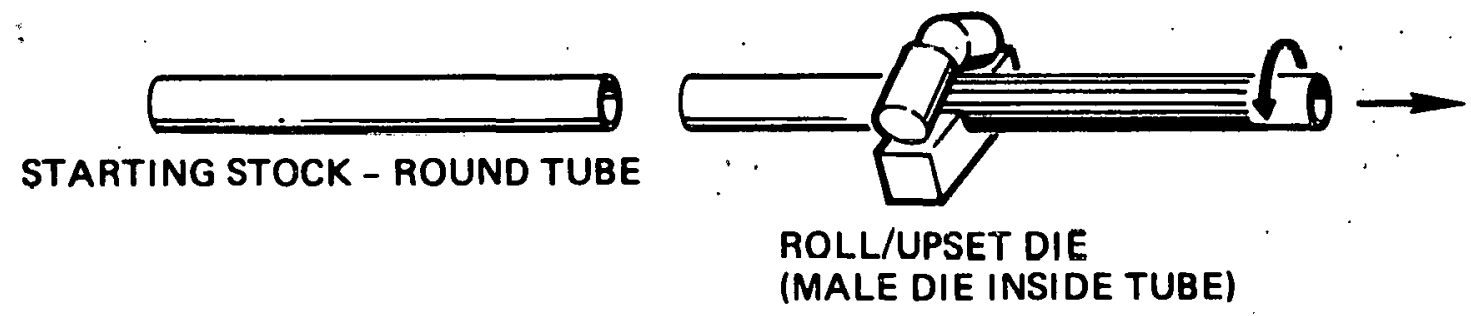

D. HOT FORM

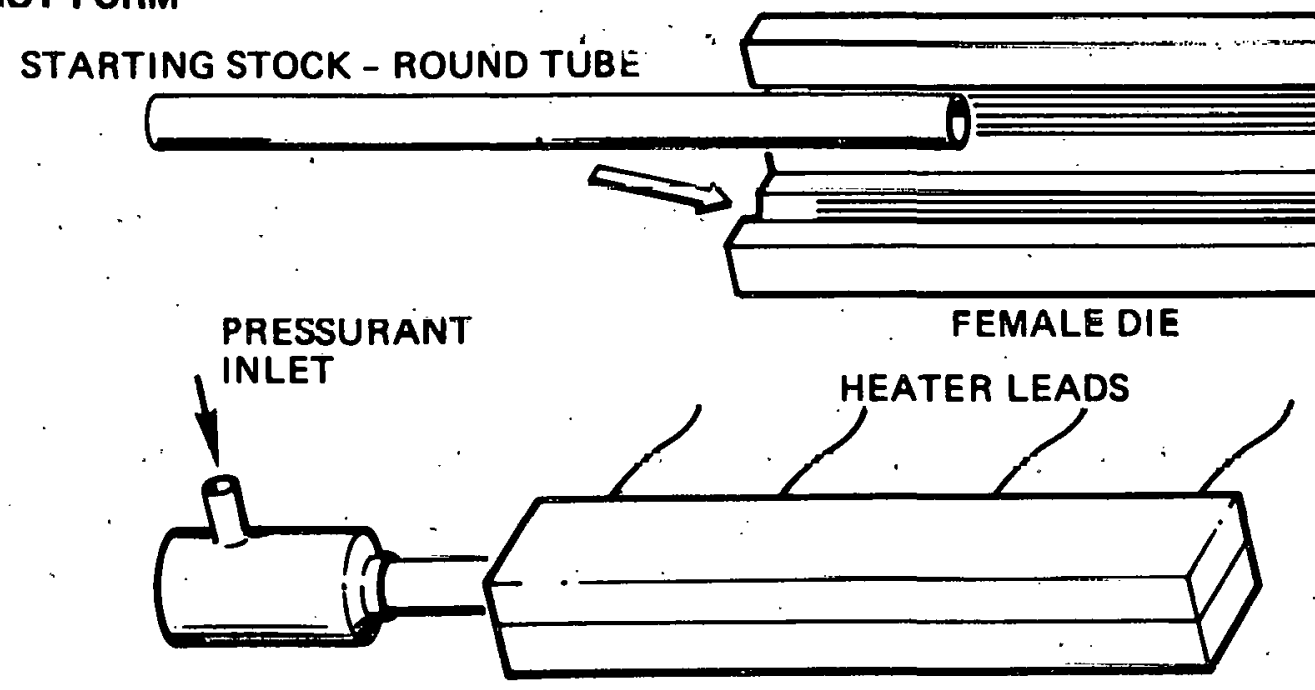

Figure 2.4-28. Tubular Area Enhancement Processes 
3) Roll Upsetting. A process that employs a stationary male die and rotating female dies. The rotating female die plastically upsets the tube material into the male die configuration by a combination of rolling and impacting action (Figure 2.4-28C).

The basic process using one piece tooling that was evaluated was high pressure hot forming (HPHF). The HPHF process for our preliminary evaluations consisted of a flat plate die with the corrugation contour machined into one surface. A piece of flat sheet was placed on the corrugated surface. The die was heated to the desired temperature and high pressure argon gas was applied. In the anticipated production method a round tube would be placed into a multisegmented female die with the corrugated contour machined into the surface, a tube will then be inserted in the die and the die heated to correct temperature. The tube will be pressurized with high pressure argon gas which will force the tube to conform to the die configuration (Figure 2.4-28D).

Future efforts regarding this process will consist of an attempt to form thirty-six corrugations into sheet stock, and rolling and welding the sheet stock and into a tubular configuration. Additional effort will be expended to increase the production rate of the process and thereby reduce cost.

\section{High Pressure Hot Forming}

The feasibility of the HPHF process has been established. Excellent conformance to the contoured tool was obtained. The process must be optimized so that cycle time can be reduced, grain growth controlled and the amount of thinning reduces the outcome of the optimization study will then form the basis to a realistic cost/producibility evaluation for this method.

\section{Tube Redraw}

TRW has been developing these methods to support the PSD-I programs. The results that have been achieved to date are promising. A modified drawing method appears feasible and the economics of such process are highly favorable. Further development work is in process. 


\section{Ro11-Upset}

One-inch nominal diameter tubes with twenty-two corrugations have been produced to date, in lengths up to 20-feet in both aluminum and titanium. The resultant cross sectional geometry is shown in Figure 2.4-29. General pictures of the enhanced tubing are shown in Figure 2.4-30.

Future efforts regarding the process will consist of improving the tooling materials and production rate increases.

\section{Rol1 Forming}

Thirty-one corrugations have been produced in flat sheet using this process. A cross secion of the contour produced is shown in Figure 2.4-31.

\subsubsection{Heat Exchanger Tube/Tubesheet Joining}

The joint between each of the thousands of titanium tubes and the heat exchanger tubesheet performs two critical functions:

- Structural retention of tubes under design loads and pressure

- Sealing of ammonia (pressure side) from seawater (water box side).

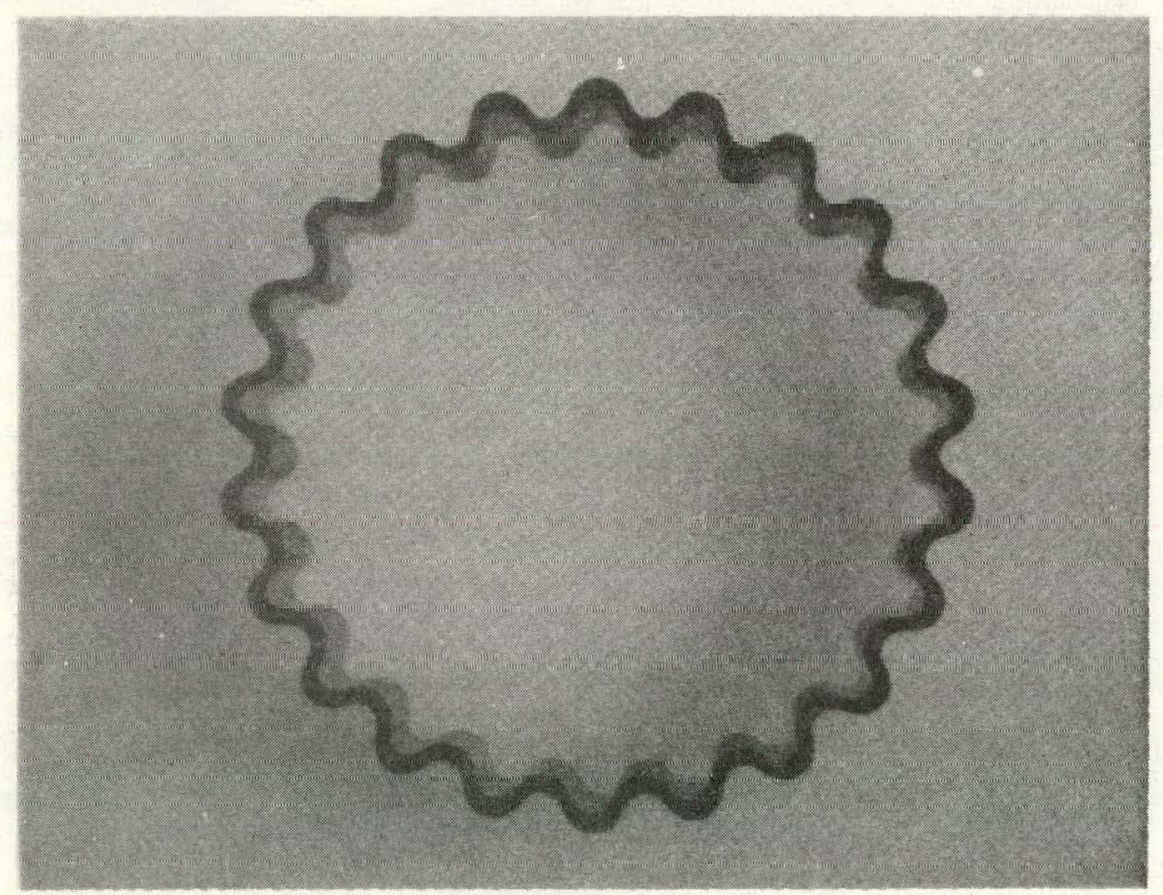

Figure 2.4-29. Sample Tube Made by The Rol1-Upset Process (22 Flutes On a 1-Inch 0.D. Titanium Tube) 


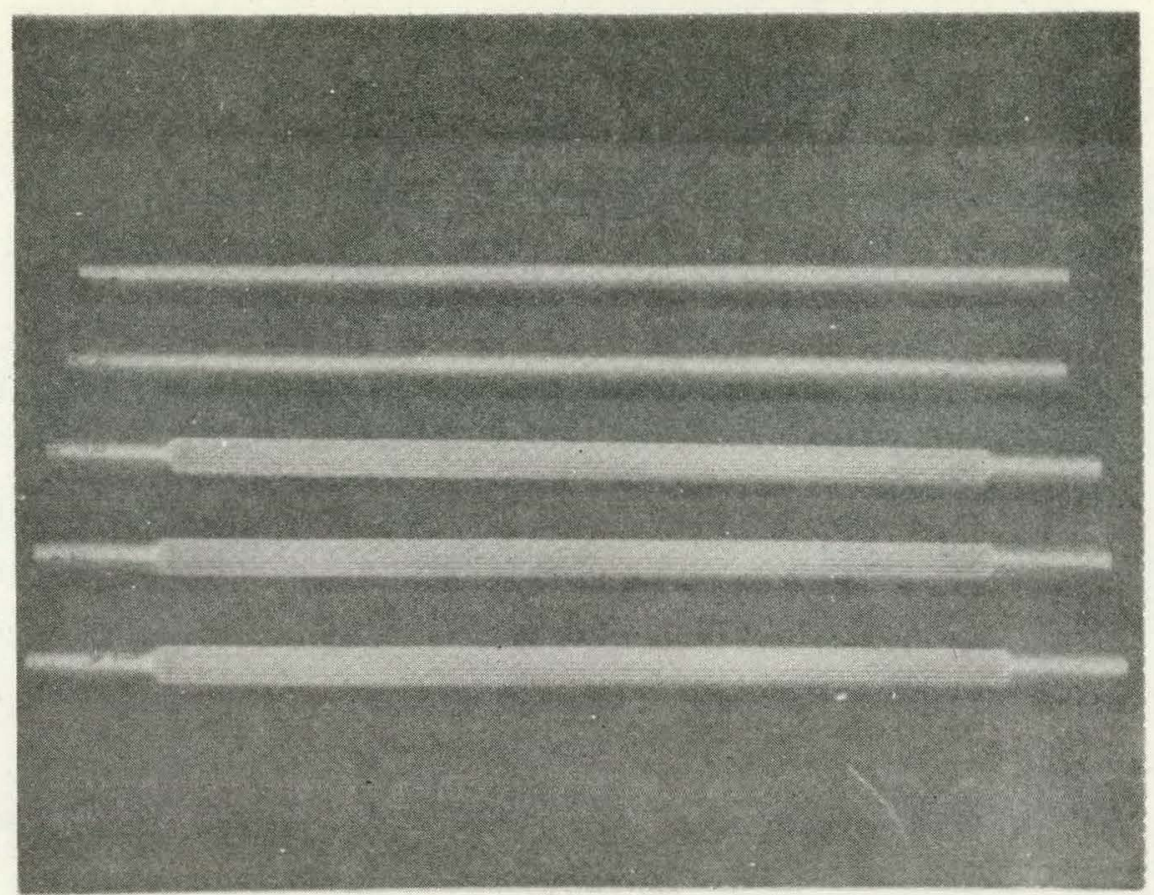

Figure 2.4-30 Sample Enhanced Area Tubes Made By the Roll-Upset Process, Starting With Round (1-Inch 0.D.) Titanium Tubes

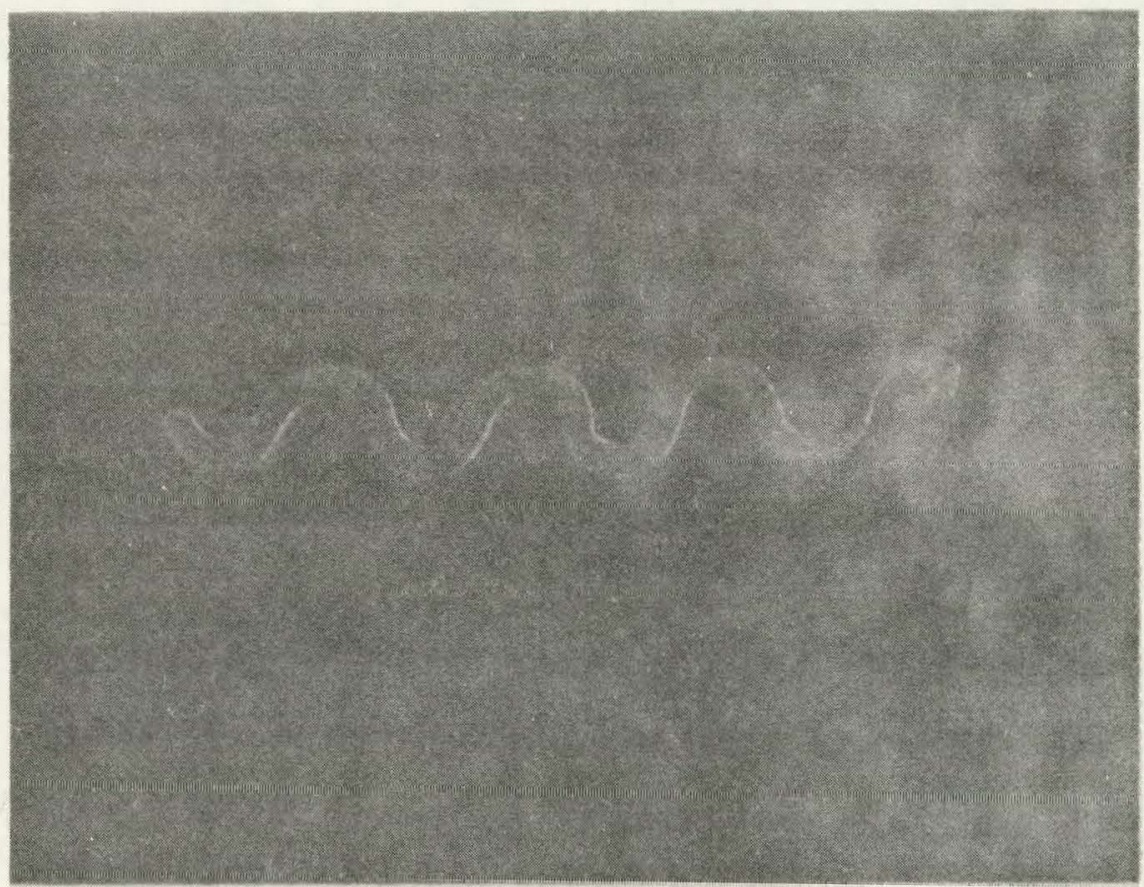

Figure 2.4-31. Sample Made by Roll-Forming Pilch of 0.100 Inch (Equivalent to 31 Flutes on a 1 -Inch 0.D. Tube) 
In the baseline design concept, the tubesheets are mild steel plates with a titanium cladding. The tube holes have twin grooves (TEMA geometry) machined into the tube plates. The titanium tubes are inserted into the tube holes to a level flush with the titanium-clad surface, the tubes are expanded into the tube holes at the TEMA-grooved section, and the tubes orbital-welded at the titanium-clad interface. This approach is highly reliable due to redundant sealing by the TEMA groove deformation and by the welding (see Figure 2.4-32, upper sketch). The method is, however, labor intensive and costly. The titanium cladding will be explosively bonded to the steel tubesheet to provide maximum reliability and tube joint integrity. Loose cladding can be used and is less costly. However, if leakage occurs seawater can be trapped in the cladding/tubesheet interface and galvanic corrosion can occur. In addition, the design would be complicated since the loose titanium cladding must be "trapped" at its edges using flanges and gaskets. In view of the 30-year life requirement, the explosively bonded approach was chosen for our baseline. The tubesheets for the 10 MWe heat exchanqers will be made of smaller segments and spliced by standard welding methods to form the full diameter.

- ROllinto gROOVED tubesheet, WELD TO TI CLADDING. HIGH RELIABILITY, AMMONIA LEAK DETECTION AT PERIPHERY OF CLAD INTERFACE, HIGH COST

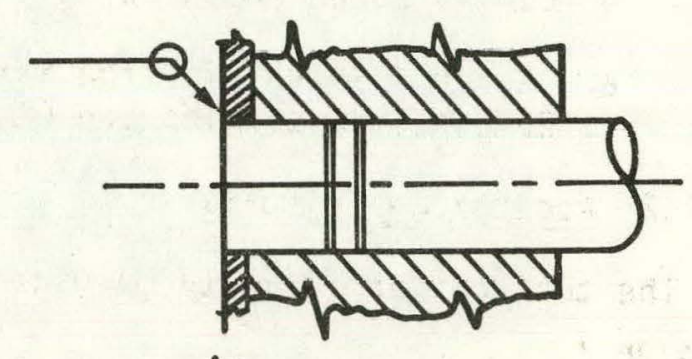

- Roll into grooved tubesheet, NONMETALLIC INSERT (GALVANIC ISOLATIONI AND COATING. TRW DEVELOPMENT. LOW COST, RELIABILITY TBD

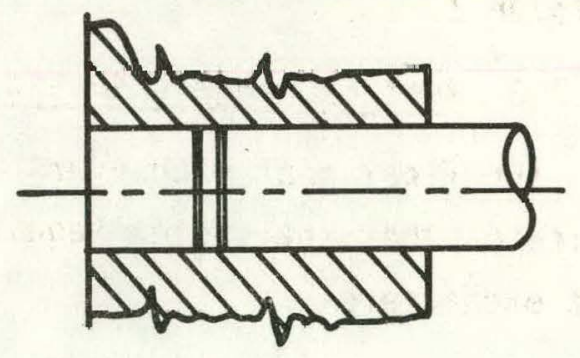

Figure 2.4-32. Tube-to-Tubesheet Joint 
Alternate approaches being evaluated for tube/tubesheet joining are aimed at lower cost, improvememt of retaining force, and greater sealing efficiency.: These methods are:

- Elastomeric (Neoprene) sleeve inserted into an additional groove in the base tubesheet surface at each tubesheet hole, coupled with Neoprene coating of the tubesheet surface with intimate joining of the Neoprene coating and.sleeve (this eliminates the need for titanium cladding and orbital welding see Figure 2.4-32, lower sketch).

- Hydraulic expansion (or rubber expansion) of titanium tubes into grooves for greater sealing efficiency. The rubber expansion method is licensed under a U.S. patent of HITACHI AMERICAN, LTD (see Appendix D.l for full details). This approach is recommended for the $200 \mathrm{kWe}$ test article as described in Section 2.5.7.3.

\subsubsection{Ad equacy of Design}

\subsubsection{Codes and Regulations}

The system is designed to meet the following codes and standards, as may be applicable.

- ASME Code Section VIII, Division I

- tema r

- CG-115 Marine Engineering Regulations

- CG-123 Rules and Regulations for Tank Vessels

- CG-174 A Manual for the Safe Handling of Flammable and Combustible Liquids and Other Products.

\subsubsection{Acceptance Criteria}

The test criteria/safety margins are based on ASME Section VIII, Division $\mathrm{I}$.

\subsubsection{Heat Exchangers Rating Check}

The final heat exchangers thermal/hydraulic performance analysis indicates that the system requirements will be satisfied by operational heat exchangers.

The analysis, included in Appendix I.1, Attachment 1.

- Determines the individual heat transfer coefficients on the tube, metal wall, and sheil side and the overall $U$ for the evaporator and for the condenser. 
- Checks calculated evaporation heat transfer coefficients and the condensation heat transfer coefficients against the experimental baseline data.

- Determines the tube side pressure drops for both the evaporator and condenser.

- Summarizes all heat transfer coefficients, tube velocities and heat rates calculated for the evaporator and condenser and compares the values with the optimization program computer results.

\subsubsection{Effects of Immersion}

The natural convection heat transfer coefficient for water, at $80^{\circ} \mathrm{F}$, surrounding the condenser shell at $50^{\circ} \mathrm{F}$, is $88\left(\mathrm{Btu} / \mathrm{hr}-\mathrm{ft}^{2}{ }^{\circ} \mathrm{F}\right)$. Considering wave action, this was estimated to be 100. Inclusion of the shell thickness and material results in an overall heat transfer coefficient (U) of 66 . For this value of $U$, it was calculated that the heat required to be removed by the condenser is increased by 0.33 percent. An additional 205 tubes are included in the condenser to accommodate this added heat load plus some contingency. It was determined that adding tubes was more cost effective than insulating the condenser. Additional analys is will be conducted during detail design to confirm. this.

Ambient seawater heating increases the evaporator efficiency. Therefore, no thermal protection has been included to counteract immersion effects upon the evaporator.

\subsubsection{Stress Analys is}

The preliminary calculations, included in Appendix I.2, establish basic structural requirements of the 10 MWe heat exchangers.

In this analysis:

- An equivalent smooth wall tube has been defined to reflect the stiffiness of the fluted tubes. This is necessary for inputting the tube data in fixed tubesheet analysis computen program.

- The tubesheet loadings due to exchanger immersion and due to intube pressure drop are calculated.

- The ASME Code thicknesses for internal and external pressures, and the required stiffening are calculated. 
- The fixed tubesheet computer program inputs and outputs are evaluated and calculated fatigue life due to cyclic service is presented.

The assumed design features of the pressure containment envelopes for shellside fluid in the 10 MWe evaporator and condenser are generally feasible. However, some considerations not included in the preliminary design will probably cause the final design to incorporate local shell reinforcement.

The evaporator and condenser tube geometries will depend to a large extent upon the method adopted to form the tubes. For example, seamless titanium tubing which is drawn through dies can be expected to have a smaller cross sectional area than corrugated titanium sheet metal which is subsequently rolled and welded. The design variables associated with tube wall geometry have an impact upon the ability of the tube bundle to resist axial and lateral loads, but the impact is not expected to be significant. The tubesheet design is only approximate. Final design will attempt to reduce tubesheet thickness.

In the preliminary design axial bending shell stresses are high in the region of the annular rings. In the final design, the designer will have the option either of reducing axial shell stresses to a level such that cyclic loading does not limit design life, or of imposing upon the final design sufficient constraints that the applicability of a fatigue analysis for the apparatus is assured throughout its life. The former option is recommended. A finite element analysis technique appears appropriate for the final design in order to accommodate local shell reinforcement and eccentric geometry as well as transverse loading on the system.

Structural support design for the heat exchangers does not currently appear to be exceptional. When the undefined loading conditions are resolved, the design task is expected to be straightforward. Shell reinforcement at supports will probably be required.

\subsubsection{Structural Dynamics and Vibrations}

Most heat exchangers are designed for and operate in a relatively benign stationary environment. Dynamic problems associated with stationar. heat exchangers are usualiy 11 mited to those of internal flow induced vibration and vibrations induced by external acoustic/vibration sources. 
OTEC heat exchangers must be capable of long term operation with these loads and additional unique loads due to the dynamics of the sea. Typical dynamic and vibration concerns are:

- Vibration and stability of tubes

- Acoustically induced vibration of tubes

- Dynamics of tube/baffle interaction

- Tube/baffle impact and vibration response

- Effect of tube vibrations on falling film fluid flow

- Effect of external vibration sources on the heat exchangers.

Evaluation of these conditions are a part of detail design and of the 200 kWe testing. Solution to any problems arising from the conditions will be implemented during the detail design phase.

The overwhelming number of tube vibrational problems encountered in past heat exchanger designs have resulted from high-velocities impinging upon and perpendicular to the tubes. Tube vibrational failures generally occur at the shell side inlet nozzle and, with lesser frequency, in the crossflow sections of baffled exchangers.

To prevent high impinging velocities, inlet nozzle velocities are maintained below the maximum levels permitted by the Tubular. Exchangers Manufacturer's Assoctation (TEMA). TEMA limits are stated in terms of maximum values of $\rho V^{2}$, where $\rho$ is the density. in pounds per cubic foot and $V$ the velocity in feet per second. TEMA permits a value of $\rho V^{2}=1500$ for entering subcooled 1 iquits and $a \rho v^{2}=500$ for entering wet vapors. The entering liquid to the evaporator will be subcooled. $\rho V^{2}$ in the evaporator liquid inlet pipe has a value of 1000 . This value is decreased before entering the evaporator by an inlet diffuser. The condenser vapor inlet nozzle has a $\rho V^{2}$ value of 347 . Both inlets, therefore, operate significantly below TEMA's upper limit. In addition, the tubing in front of both inlet nozzles is protected by a "rod baffle" consisting of solid rods which break and disperse the inlet flow. 
Vapor velocities within the tube bundle are below $5 \mathrm{ft} / \mathrm{sec}$; a velocity too low to cause any concern.

In addition to these dynamic and vibration problems, OTEC heat exchangers must operate immersed and attached to an ocean platform in Sea State 6 conditions and must withstand the effects of Sea State 9 conditions. For purposes of this design activity, it has been assumed that the sea induced loads and relative motions between the heat exchangers and platform result in a benign environment (i.e., there is no severe wave action against the heat exchangers and the mounting is infinitely. rigid). Modification of the design will occur following further identification of the interface requirements.

\subsubsection{Fluid Characteristics Under Sea Conditions}

The requirement to operate under Sea State 6 conditions translates to tilt angles of 4 degrees at the heat exchangers. Experiments at CMU have shown that, at these angles, the condensing and evaporating films are not affected. Thus, pitch and roll in Sea State 6 will not affect performance.

Little is known about the effects of heave. Heave should have the same effect as introducing a periodic " $g$ " load on the constant gravity attraction. This periodic attraction should induce a periodic movement in the liquid films which, in turn, will be manifested by wave motion on the top of the film (i.e., the part of the film furthest from the drag surface). This wave motion is expected to have no negative effects and may provide a beneficial influence upon the heat transfer rate.

\subsubsection{Effect of Tube Support Plates}

Within the condenser, disruption of the liquid film by support plates with intermediate liquid drain will be advantageous and, indeed, may significantly increase the condensing heat transfer rate. Little is known, however, about the effects of support plates on the evaporator heat transfer rates. It may be that specially designed support plates would redistribute and thin the film thus improving the heat transfer rate. 


\subsubsection{Vapor Generation in Evaporator Distribution Plenum}

The seawater temperature entering the evaporator distribution plenum is $10^{\circ} \mathrm{F}$ greater than the ammonia saturation temperature, therefore, some vaporization of ammonia in the distribution plenum may occur. Bubble formation and vaporization requires a minimum finite temperature difference; below this minimum temperature difference vaporization will not occur. Since vapor presence in the distribution plenum will tend to choke flow; it is undesirable. Preliminary cursory calculations indicated that vapor formation in the evaporator distribution plenum will not be a problem and the design has proceeded on this basis. More recent calculations, however, have indicated a possibility of vapor furmaliun. This will be evaluatcd further during detail design and $200 \mathrm{kWe}$ heat exchanger tests. Several design soluttons exist in the event this is identified as a problem.

\subsubsection{Seawater Pollution by Ammonia}

Leak detection methods, described in Section 2.6.4, will enable identification and repair of ammonia leaks into seawater. Further, ammonia monitors at seawater outlets of both heat exchangers will identify potential ammonia pollution of seawater. Makeup ammonia flow, ammonia pressures in heat exchangers sniffer probes, etc., will also provide indicators to enable shutdown of the system to prevent adverse contamination of seawater.

\subsubsection{Ammonia Contamination by Seawater}

The power mudule has been designed on the basis of no seawater leakage into the higher pressure ammonia. TRW is aware of reports that low pressure seawater has diffused into high pressure ammonia, however, an investigation of these reports has revealed no design criteria for this occurrence. TRW will follow the investigations and experiments now being planned for November 1978, in Freeport, Texas, to determine the magnitude of a problem of seawater leakage into the heat exchangers.

Seawater contamination of the ammonia wiil produce magnesium hydroxide and calcium carbonate precipitates within the ammonia. These precipitations will behave much the same as hardness behaves in water. Coating of evaporator heat exchanger tubing and collection of these precipitates in the evaporator sump can be expected. Water contamination of the ammonia in amounts of less than 0.1 percent will have no effect on system operation. 
Water concentrations greater than 0.1 percent will adversely affect turbine efficiency and may affect the evaporator heat transfer coefficients, although, in the latter case, little is known about how the evaporator heat transfer coefficients will be affected. The details of seawater contamination of ammonia is described further in the Appendix $\mathrm{H} 2$.

It is clear that the system cannot operate with large amounts of seawater contamination but seepage so small that it takes months to build up to measurable quantities can be tolerated. Provisions to purge ammonia, and thus keep nonvolatile contaminants low, are incorporated in an ammonia blow-down system in the evaporator."

\subsubsection{Initial Noncondensibles and Purging}

Initial purging of the power system is accomplished with the least amount of ammonia if the system is purged at atmospheric pressure. It has been calculated that the initial removal of noncondensibles will require about two purges with atmospheric ammonia to lower noncondensible concentration in purge effluent to about 10 percent and about three purges to lower it to less than 1 percent. Details of the initial purging is given in Appendix I.1.7.

\subsubsection{Operational Noncondensibles}

Since in-leakage is not expected, purging during operation should not be necessary. However, some noncondensibles may enter with replacement ammonia. Provisions for purging noncondensible during operation have been included in the design and sized to remove all possible "discoverable leaks." A "discoverable leak" is a leak of sufficient magnitude to ultimately display evidence of its presence within the system. Details of the calculations are given in the Appendix I.1.7.

\subsubsection{Demister}

In a boiling process bubbles are formed which rise to the liquid surface and burst forth expelling droplets. For the vertical tube falling film evaporator design, an evaporation process occurs in which vapor forms on the liquid surface. All available evidence on test runs of ammonia evaporation in installations similar to the TRW design indicate totally dry vapor will exil fruil tlie evapurdtur; thus no demlster is required. Vapor shear velocities are less than $5 \mathrm{ft} / \mathrm{sec}$ and will not remove or detach liquid droplets. If, however, tests should show that a demister is required sufficient space is available in the shell exit nozzle area for a demister pad. 


\subsubsection{References}

1. J.G. Fetkovich, G.N. Granneman, L.M. Mahalingam; D.L. Meir (CarnegieMellon University) and F.C. Munchmeyer (Univeristy of Hawaii), Degradation of Heat Transfer Rates due to Biofouling and Corrosion at Keahole Point, Hawai, 1977.

2. Private Communications, J.G. Fetkovich, Carnegie-Mellong University, October and November, 1977.

3. ASME Boiler and Pressure Vessle Code Section VIII, Division I, July 1977.

4. R.M. Wilson, Elastic-plastic Behavior of a Tube During Expansion; ASME Paper Number 78-PVP-112, 1978. 


\subsection{0 kWe HEAT EXCHANGER TEST ARTICLES}

Overail objectives of the heat exchanger test articles design are to achieve minimum cost, maximum simulation of thermal and hydraulic performance characteristics, to duplicate the essential mechanical design and fabrication features of the 10 MWe prototype unit, and to be compatible with the OTEC-1 platform.

\subsubsection{Cost Effectiveness of the 200 kWe Test Articles}

As described below, our test articles are essentially segments of the full size 10 MWe heat exchangers. They fully simulate the thermal hydraulic of the 10 MWe units and exactly duplicate the following characteristics/features of the full size units:

- Full length, diameter and configuration of tubes

- Tube-to-tubesheet joints

- Tubesheet

- Tube support baffles

- Metering orifice

- Materials

- Open top water box.

The size of the test article has been subject to considerable study. The selection of the $200 \mathrm{kWe}$ capacity represents a significant reduction from the initially targeted 1 MWe with large attendant cost savings. A test article with higher capacity will not yield significant additional data, while a smaller unit will seriously compromise simulation of the thermal hydraulic behavior of the full size units.

Because test articles are essentially segments of the full size units, they are representative of the full size units in every important physical and functional aspect and have the best potential of providing accurate and detailed cost data in terms of operational and fabrication costs of the ultimate larger production units. Our test articles will demonstrate:

- Thernal and hydraultc performance

- Materials and isolate corrosion effects 
- Effectiveness of biofouling and countermeasures

- Fabrication/assembly techniques.

The $200 \mathrm{kWe}$ test articles are tall vertical cylinders and require relatively small floor space. These characteristics may be a distinct advantage in terms of integration/installation in the OTEC-l platform. The reduced size of our test articles ensures full compatibility with the OTEC-1 cold and warm water and ammonia support systems.

\subsubsection{Design Ob.jectives}

Design objectives, specific to our vertical tube, falling film heat exchanger approach, are to:

- Verify the adequacy and design of liquid ammonia distribution across the evaporator distribution chamber to assure consistent thermal hydraulic performance

- Verify the adequacy of ammonia vapor distribution across the condenser tube bundle

- Verify that the generated ammonia vapor quality will be at or in excess of 99 percent out of the evaporator

- Confirm the effects of variable seawater conditions on generated vapor condition

- Confirm the effects of variable seawater conditions on seawater flow rate in each tube

- Verify the function and design of noncondensibles removal provisions during operation

- Verify the absence of tube vibrational problem

- Verify the ability to maintain fouling factor by brushing and chlorination.

In addition to the above, fabrication approaches and tube producibility will be confirmed during the manufacturing phases.

\subsubsection{Scaling Criteria and Implementation}

Characteristically, in our vertical tube, falling film heat. exchanger, any one tube behaves and performs as any other tube in the heat exchanger. This is, of course, predicated on certain design constraints and requirements already noted in Section 2.4.2. The design of a representative 
scaled test heat exchanger is therefore readily achieved by exploiting this characteristic and employing an appropriately sized portion of the full size tube bundle.

The primary scaling criterion for the test heat exchangers has been to maintain dimensions which are critical to the thermal/hydraulic performance of a 10 MWe heat exchanger. As such, TRW opted to employ full sized tubes (diameter and length) in the scaled test articles. Conversely, liberties have been taken as to the general configuration to obtain cost effective fabrication but one which verifies important manufacturing processes. The approach, therefore, was to design a representative section of the production unit; specifically, a triangular or pie shaped section. Since the $200 \mathrm{kWe}$ test article must transfer 1/50 as much heat as the production unit, this ratio was used to determine the number of tubes employed.

A wedge or pie shaped heat exchanger she 11 is not suitable for containing pressure and is difficult to fabricate, therefore, the wedge shaped tube bundle was installed in a cylindrical shell (Figure 2.5-1) with vapor barriers so that the wedge will be self-contained within this shell. For the wedge to represent the performance of the production unit the conditions at the boundary (vapor barriers) must simulate the boundary conditions of a similar wedge tube bundle section in the full size unit. The vapor barriers, however, represent a continuous drag to vapor flow, whereas the boundaries of a wedge within the full size unit are an interrupted surface (a row of tubes). The influence of the bounding surface is calculated to disappear in about two rows from the bounding surface. The performance of the wedge, with the continuous bounding surface, will then simulate the performance of a similar wedge within the full size unit provided the wedge is several rows wide.

At the apex of the wedge it is impossible to maintain the requirement that the wedge walls be separated by several rows. Figure 2.5-2, which gives normalized pressure drop versus radius for a 12-foot radius bundle, shows that approximately 98 percent of the total bundle pressure drop occurs in the peripheral 9 feet of the tube bundle and only 2 percent in the remaining 3 feet. Ninety-four percent of the heat transfer occurs in the peripheral' 9 feet of the tube bundle. Under these circumstances, and considering the large influence of the vapor barriers upon perforilance of the 


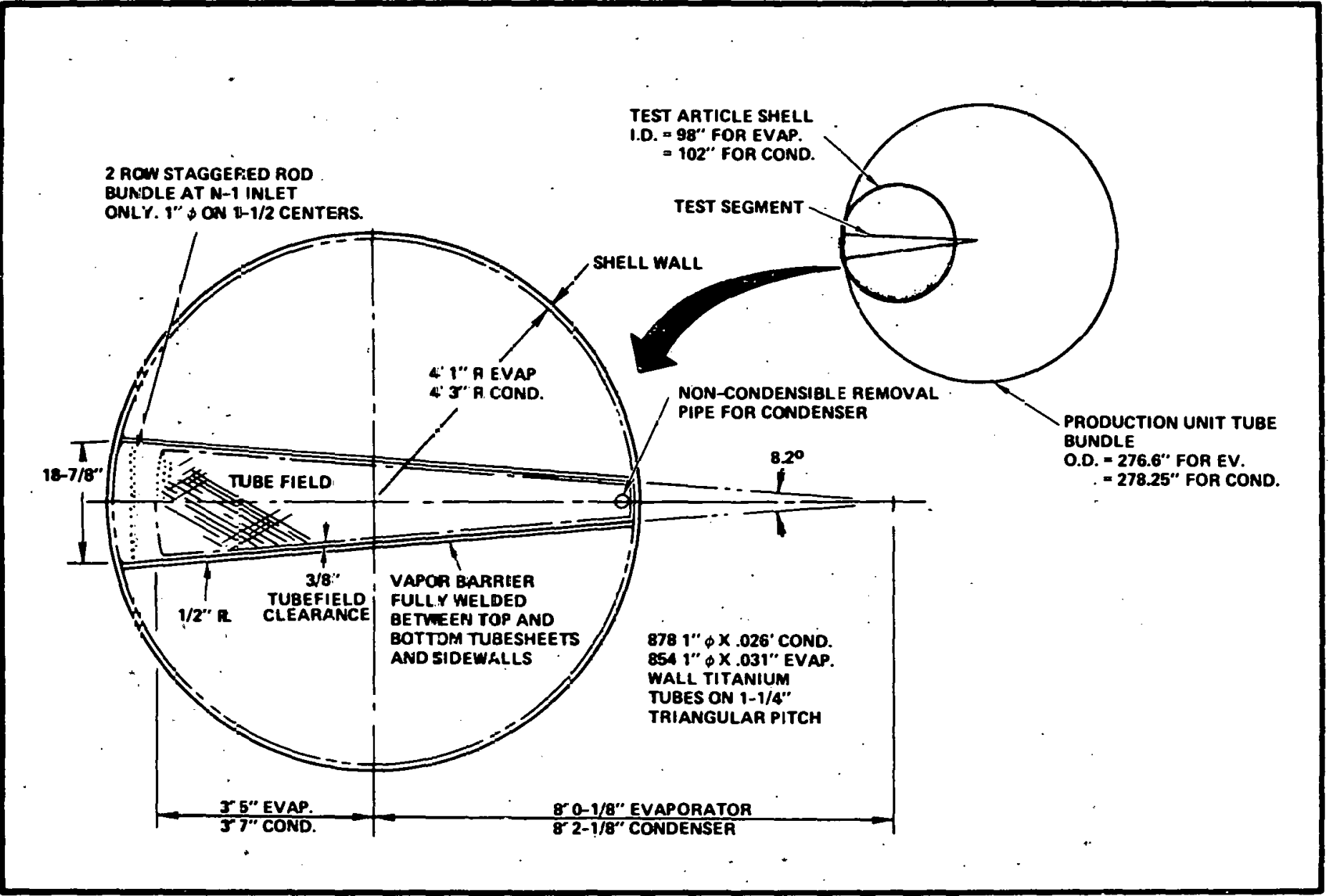

Figure 2.5-1. Relation of Test Segment to Total Tube Bundle 


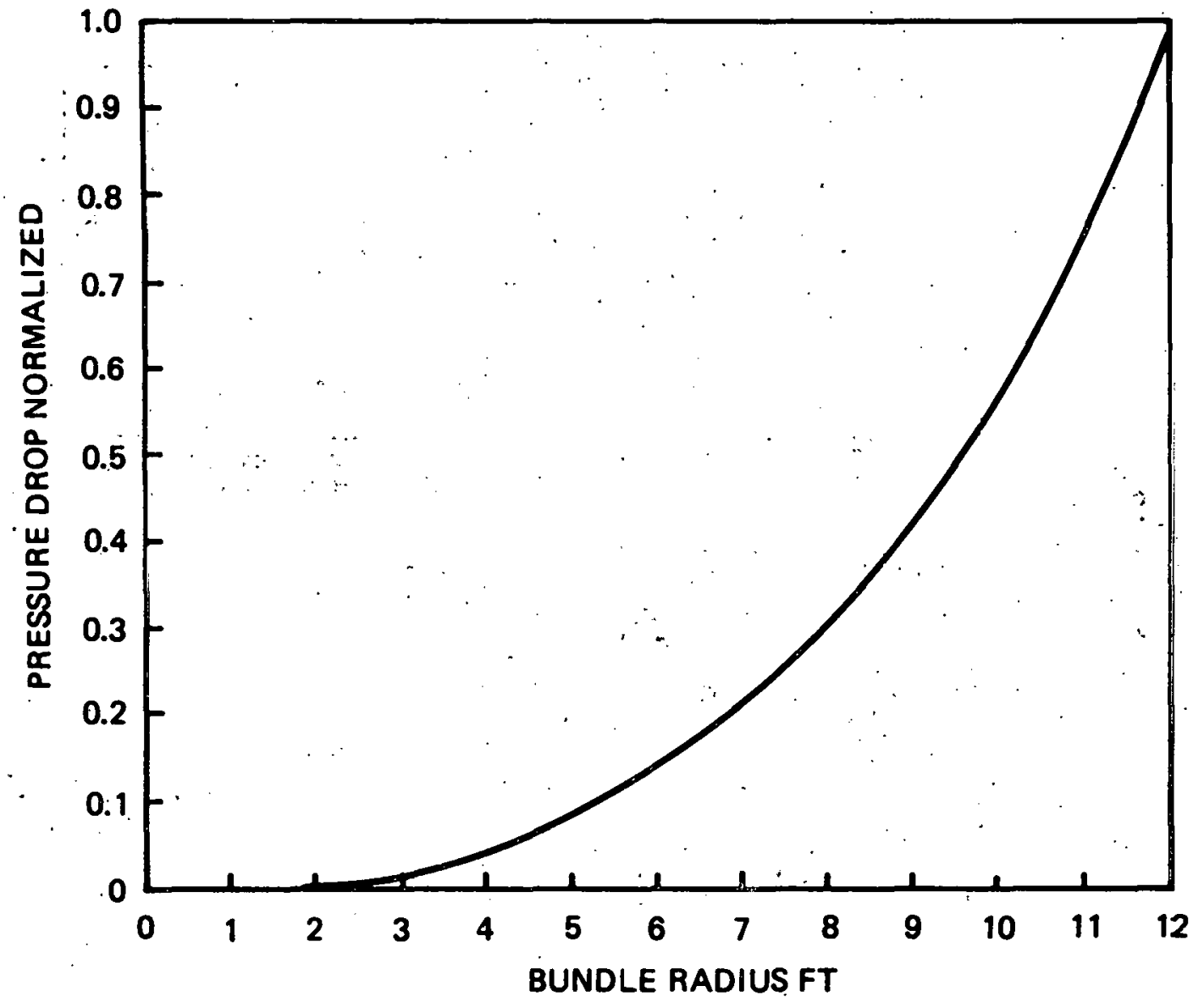

Figure 2.5-2. Normalized Pressure Drop Versus Radius 
section in the wedge apex, it is apparent that obtaining useful information from the test unit will not be compromised by truncating the wedge.

\subsubsection{Design Description}

The evaporator and condenser test articles are as shown in Figures 2.5-3 and 2.5-4, respectively. The seawater enters via a rectangular inlet nozzle. The inlet water box is an open channel-type header, as in the 10 MWe heat exchanger, to permit in situ mechanical defouling. The tube bundle is sector shape, which is a scale of 1/50 of a 10 MWe tube bundle. The major features and dimensions are shown in Figures 2.5-5 and 2.5-6. The design data are tabulated in Tables 2.5-1 and 2.5-2 while thermal data are shown in Tables 2.5-3 and 2.5-4.

\subsubsection{Instrumentation and Data Plans}

In order to accomplish the objectives for the test heat exchangers, listed in Section 2.5.2, the parameters to be measured, the ranges of measurement, the evaluations/interpretations of those measured data, and the supporting requirements are described in Table 2.5-5. The related instrumentation is listed in Tables 2.5-6 and 2.5-7.

\subsubsection{Interface Definitions}

\subsubsection{Space Requirements}

The test heat exchangers weight approximitely 35 tons each empty. Since the test articles have to be tested vertically, it does not require a large floor space to accommodate the units but a height clearance of approxinately 43 feet must be provided. The test articles are not designed to be submerged in the seawater.

Overall perspective of the test articles and supporting piping/ valves/pumps for an evaporator recirculation loop is shown in Figure 2.5-7. A list of equipment included for the test articles (exclusive of the instrumentation) is in Table 2.5-8. A process flow diagram is shown in Figure 2.5-8. Piping and instrumentation diagram for the evaporator test loop is shown in Figure 2.5-9 while the anticipated pressure profile is shown in Figure 2.5-10. 


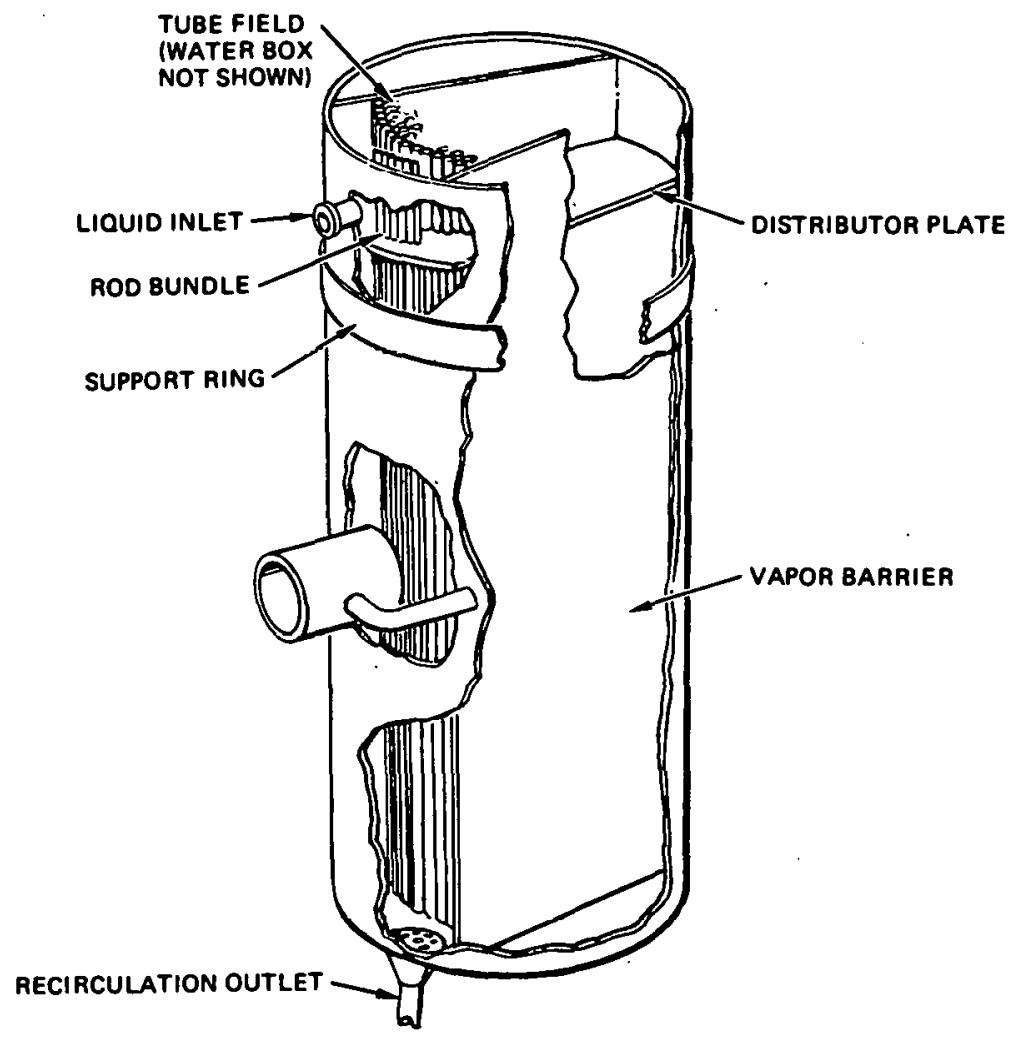

Figure 2.5-3. Evaporator Test Article

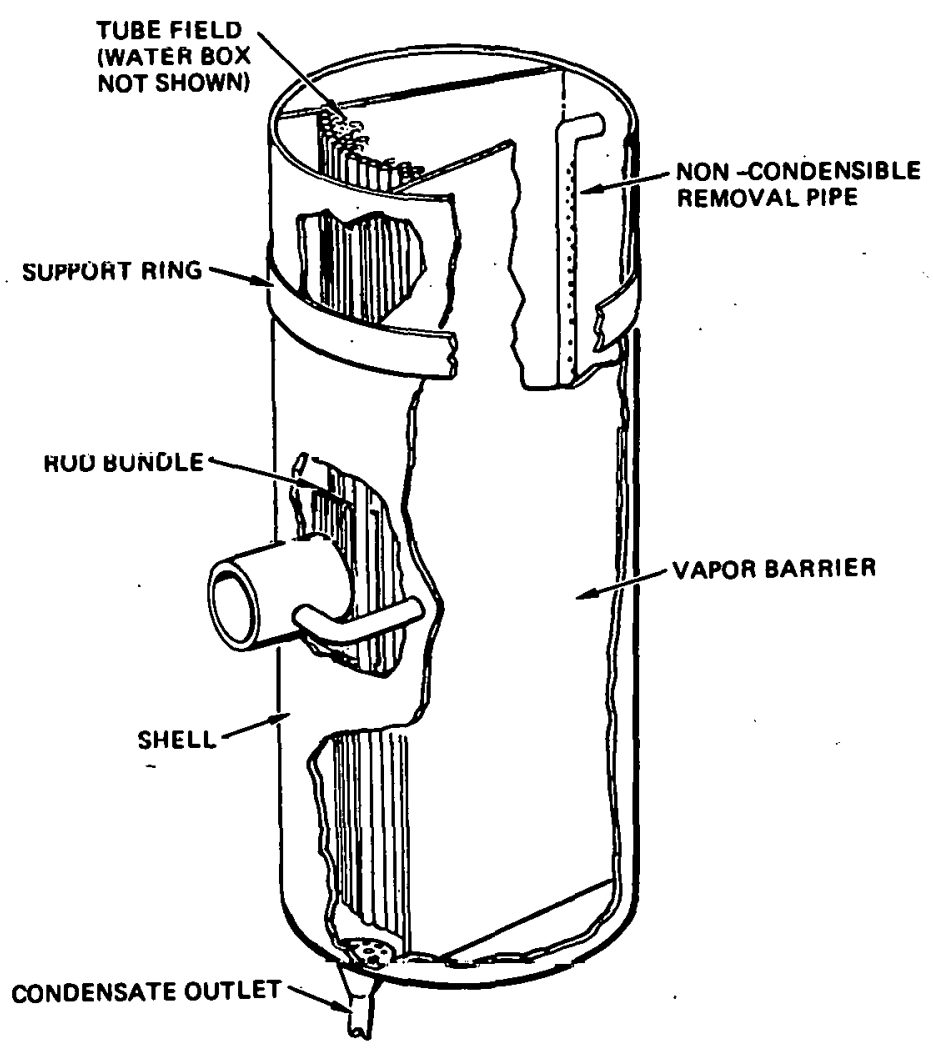

Figure 2.5-4. Condenser Test Article 


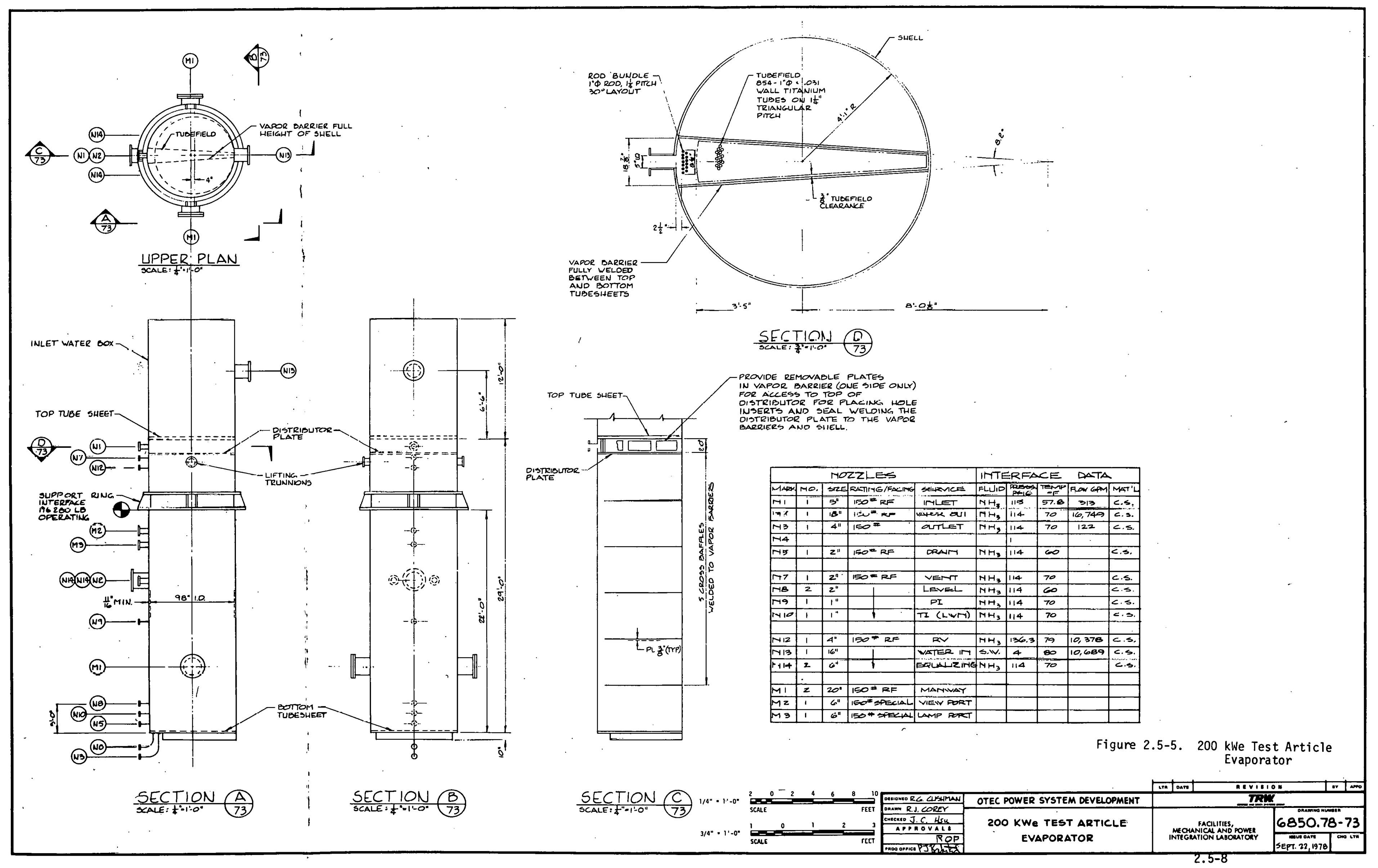




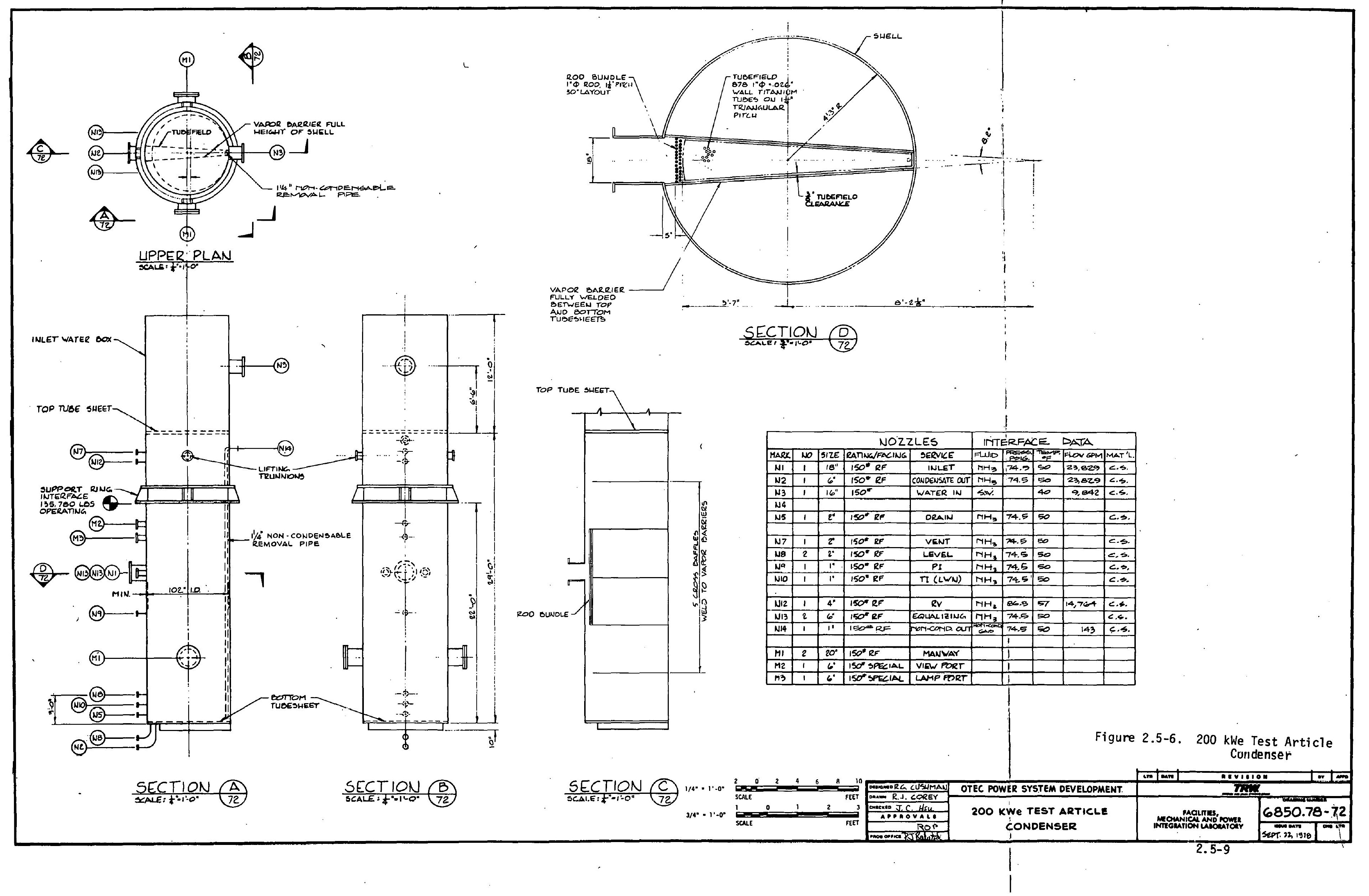


Table 2.5-1. Evaporator Design Data (200 kWe Nominal)

Number per module

Thermal rating

Water flow rate

Ammonia evaporation rate

Ammonia recirculation rate

Design pressure

Operating pressure

Overali length

Maximum Weight (empty)

Water enhancement factor

Ammonia enhancement factor*

Total number of tubes

Tube OD

Round Tube wall thickness

Tube pitch

Tube layout

Tube sheet diameter

Effective tube length

Áctual tube length

Tube sheet thickness

Number of tube supports

Tube support thickness

Tube support spacing

Shell ID

Shell wall thickness

Tube material

Tube sheet material

Shell material

Baffle material

Coating materials
1

$30.86 \mathrm{MBtu} / \mathrm{hr}$

$5,470,000 \mathrm{lb} / \mathrm{hr}$

$58,120 \mathrm{lb} / \mathrm{hr}$

95,330

151 psia

128.8. psia

$41 \mathrm{ft}$. - $10 \mathrm{in}$.

35 Short Tons

1.46

1.5

854

1 in. nominal -0.99 in. formed

0.031 in.

1.25 in.

Triangular

98 in.

$26.5 \mathrm{ft}$.

$29 \mathrm{ft} .10 \mathrm{in}$.

$4-3 / 4$ in.

5

$11 / 2$ in.

$4.5 \mathrm{ft}$.

98 in.

$11 / 16$ in.

Titanium, ASME SB338 GR2

SA516 GR60

SA516 GR60

SA516; SA283; SA285

NAPKO No. 5635 Coal Tar Epoxy

or GACO N-200-1/N-11R Neoprene

*Area ratios, fluid mechanic effect not included. 
Table 2.5-2. Concienser Design Data (200 kWe Nominal),

\begin{tabular}{|c|c|}
\hline Number per module & 1 \\
\hline Thermal rating & $29.9 \mathrm{MBtu} / \mathrm{hr}$ \\
\hline Water flow rate. & $5,052,000 \mathrm{lb} / \mathrm{hr}$ \\
\hline Ammonia flow rate & $58,104 \mathrm{lb} / \mathrm{hr}$ \\
\hline Design pressure & 101 psia \\
\hline Operating pressure & 89.2 psia \\
\hline Overall Jength & $41 \mathrm{ft} .-10 \mathrm{in.}$ \\
\hline Maximum weight (empty) & 35 Short Tons \\
\hline Water enhancement factor & 1.46 \\
\hline Ammonia enhancement factor* & 1.5 \\
\hline Total number of tubes & 878 \\
\hline Tube $O D$ & 1 in. nominal -0.99 in. formed \\
\hline Round tube wall thickness & 0.026 in. \\
\hline Tube pitch & $1.25 \mathrm{in.}$ \\
\hline Tube layout & Triangular \\
\hline Tube sheet diameter & 102 in. \\
\hline Effective tube length & $29 \mathrm{ft}$ \\
\hline Actual tube length & $29 \mathrm{ft} .10 \mathrm{in.}$ \\
\hline Tube sheet thickness & $4-3 / 4$ in. \\
\hline Number of tube supports & 5 \\
\hline Tube support thickness & $11 / 2 \mathrm{in.}$ \\
\hline Tube support spacing & $4.8 \mathrm{ft}$ \\
\hline Shell ID & 102 in. \\
\hline Shell wall thickness & $1 / 2 \mathrm{ill}$ \\
\hline Tube material & Titanium ASME SB338 GR2 \\
\hline Tube sheet material & SA516 GR60 \\
\hline Shell material & SA516 GR60 \\
\hline Baffle material & SA516; SA283; SA285 \\
\hline Coating materials & $\begin{array}{l}\text { NAPKO No. } 5635 \text { Coal Tar Epoxy } \\
\text { or GACO } \mathrm{N}-200-1 / \mathrm{N}-11 \mathrm{R} \text { Neoprene }\end{array}$ \\
\hline
\end{tabular}

*Area ratios, fluid mechanic effect not included. 
Table 2.5-3. Evaporator Thermal Data (200 kWe Nominal)

Water flow rate

Water flow per tube

Water velocity inside tube

Reynolds number inside tube

Prandtl number inside tube

Inlet water temperature

Outlet water temperature

Average water temperature

LMTD

Average tube wall surface temperature

Average shell wall surface temperature

hw (including enhancement) referred to $\mathrm{DW}^{*}$

$h$ fouling referred to $D w$

h wall referred to $D^{\star}$

$h$ ammonia referred to $D$

$U_{0}$ referred to Dw

Ammonia inlet temperature

Ammonia outlet temperature

Outlet vapor quality

Outlet maximum vapor velocity

Total pressure drop of water**

Total pressure drop of ammonia

For Vertical Evaporators

Feed rate per tube

Feed film Reynolds number

Exit film Reynolds number

Maximum distribution $\Delta p$
$5,470,000 \mathrm{lb} / \mathrm{hr}$

$1.78 \mathrm{lb} / \mathrm{sec}$

$6.61 \mathrm{ft} / \mathrm{sec}$

48,293

6.30

$800 \mathrm{~F}$

$74.10 \mathrm{~F}$

$77.10 \mathrm{~F}$

$6.62 \mathrm{~F}$

n, $720 \mathrm{~F}$

$\sim 70 \mathrm{~F}^{\circ}$

$1,939 \mathrm{Btu} / \mathrm{hr} \mathrm{ft}^{20 \mathrm{~F}}$

$10,000 \mathrm{Btu} / \mathrm{hr} \mathrm{ft}^{20 \mathrm{~F}}$

2,303 Btu/hr ft20F

$11,915 \mathrm{Btu} / \mathrm{hr} \mathrm{ft}^{20 \mathrm{~F}}$

$895.5 \mathrm{Btu} / \mathrm{hr} \mathrm{ft}^{20 \mathrm{~F}}$

$57.8 \mathrm{OF}$

$700 \mathrm{~F}$

$>99 \%$

$\lesssim 7.0 \mathrm{ft} / \mathrm{sec}$
$4.12 \mathrm{psi}$
1.04 psi

$111.7 \mathrm{lb} / \mathrm{hr}$

5,224

2,040

$<0.03$ psi

${ }^{*} \mathrm{Dw}$, water-side diameter corresponding to the cross section area of the water passage through the tube; 0 , the diameter of the external flutes (rill-to-rill diameter.)

**Tubeside pressure drop including entrance and exit losses. 
Table 2.5-4. Condenser Thermal Data (200 kWe Mominal)

Water flow rate

Water flow per tube

Water velocity inside tube

Reynolds number inside tube

Prandtl number inside tube

Inlet water temperature

Outlet water temperature

Average water temperature

LMTD

Average tube wall surface temperature

Average shell wall surface temperature

hw (including enhancement) referred to $D w^{*}$

$h$ fouling referred to $D w$

$h$ wall referred to $D^{*}$

$h$ ammonia referred to $D$

$U_{0}$ referred to $D w$

Ammonia inlet temperature

Ammonia outlet temperature

Inlet vapor quality

Inlet maximum vapor velocity.

Total pressure drop of water $\star \star$

Total pressure drop of ammonia

For Vertical Condensers

Feed rate per tube

Feed film Reynolds number

Exit film Reynolds number

Maximum distribution $\Delta p$
$5,052,000 \mathrm{It} / \mathrm{hr}$

$1.6 \mathrm{lb} / \mathrm{sec}$

$5.82 \mathrm{ft} / \mathrm{sec}$

26,019

10.91

$40^{\circ} \mathrm{F}$

$46.2^{\circ} \mathrm{F}$

$43.1^{\circ} \mathrm{F}$

$6.41^{\circ} \mathrm{F}$

$\sim 480 \mathrm{~F}$

$\sim 50^{\circ} \mathrm{F}$

$1350 \mathrm{Btu} / \mathrm{hr} \mathrm{ft}^{20_{\mathrm{F}}}$

$10,000 \mathrm{Btu} / \mathrm{hr} \mathrm{ft}^{20 \mathrm{~F}}$

$2,775 \mathrm{Btu} / \mathrm{hr} \mathrm{ft} 2 \mathrm{OF}$

$15,422 \mathrm{Btu} / \mathrm{hr} \mathrm{ft}^{20_{F}}$

$796 \mathrm{Btu} / \mathrm{hr} \mathrm{ft}^{20 \mathrm{~F}}$

$50^{\circ} \mathrm{F}$

$50^{\circ} \mathrm{F}$

$>96.5 \%$

$\leqslant 6.5 \mathrm{ft} / \mathrm{sec}$

$3.61 \mathrm{psi}$

$<0.07$ psi

$66.2 \mathrm{lb} / \mathrm{hr}$

0

2,751

$<0.04$ psi

${ }^{\star} \mathrm{Dw}$, water-side diameter corresponding to the cross section ared of the water passage through the tube; $D$, the diameter of the external flutes (rill-to-rill diameter).

**Tubeside pressure drop including entrance and extt losses. 
Table 2.5-5. Data Plans for Test Articles

\begin{tabular}{|c|c|c|c|c|}
\hline $\begin{array}{l}\text { Data } \\
\text { Required }\end{array}$ & $\begin{array}{c}\text { Parame ters } \\
\text { To Ee } \\
\text { Measured }\end{array}$ & $\begin{array}{l}\text { Operating } \\
\text { Ranges And } \\
\text { Accuracies } 3\end{array}$ & $\begin{array}{l}\text { Computations, } \\
\text { Interpretations, } \\
\text { Evaluations }\end{array}$ & $\begin{array}{l}\text { Support } 1,2 \\
\text { Requirements }\end{array}$ \\
\hline $\begin{array}{l}\text { Evaporator pressure } \\
\text { drop through Jistri- } \\
\text { butor orifice, pressure } \\
\text { drop through tube } \\
\text { bundle within distri- } \\
\text { bution chamber } \\
\text {. }\end{array}$ & $\begin{array}{l}\text { 1) Liquid } \mathrm{NH}_{3} \text { inlet } \\
\text { pressure } \\
\text { 2) Liquid } \mathrm{NH}_{3} \text { pressure in } \\
\text { distribution chamber } \\
\text { 3) } \mathrm{NH}_{3} \text { pressure below the } \\
\text { distribution plate }\end{array}$ & $\begin{array}{l}\text { 1) } 120+140 \\
\text { psia, } \pm 0.1 \% \\
\text { 2) } 120 \rightarrow 140 \\
\text { psia, } \pm 0.1 \% \\
\text { 3) } 120 \rightarrow 140 \\
\text { psia, } \pm 0.1 \%\end{array}$ & $\begin{array}{l}\text { Compare the pressure drop } \\
\text { in the distribution chamber } \\
\text { with that through the ori- } \\
\text { fice. The objective is met } \\
\text { if the } \Delta P \text { in the distribu- } \\
\text { tion chamber } \Delta \Delta \mathrm{P} \text { through } \\
\text { orifice. }\end{array}$ & \\
\hline $\begin{array}{l}\text { Condenser seawater } \\
\text { outlet temperature }\end{array}$ & $\begin{array}{l}\text { 1) Seawater outlet } \\
\text { temperature at } \\
\text { locations }\end{array}$ & 1) $\begin{array}{l}40 \rightarrow 50^{\circ} \mathrm{F} \\
\pm 1 \% \quad \pm 0.05^{\circ} \mathrm{F}\end{array}$ & $\begin{array}{l}\text { Compare the average temper- } \\
\text { atures and determine } \\
\text { uniformity }\end{array}$ & \\
\hline $\begin{array}{l}\mathrm{NH}_{3} \text { outlet vapor } \\
\text { quality. }\end{array}$ & $\begin{array}{l}\text { 1) } \mathrm{NH}_{3} \text { vapor outlet } \\
\text { pressure at calorimeter } \\
\text { 2) } \mathrm{NH}_{3} \text { vapor cutlet } \\
\text { temperature } \\
\text { 3) } \mathrm{NH}_{3} \text { throttling calori- } \\
\text { meter temperature } \\
\text { 4) } \mathrm{NH}_{3} \text { vapor and liquid } \\
\text { flows from sampling } \\
\text { line }\end{array}$ & 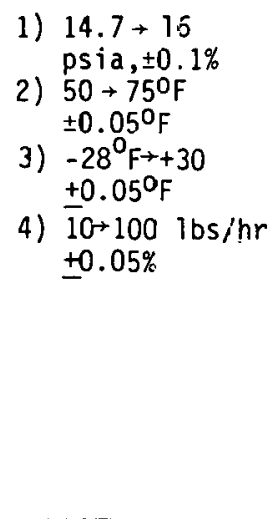 & $\begin{array}{l}\mathrm{NH}_{3} \text { vapor quality shall be } \\
\text { determined measuring the } \\
\text { temperature in a throttling } \\
\text { calorimeter, determining the } \\
\text { state enthalpy } h_{w} \text {, vaporiza- } \\
\text { tion enthclpy, } h_{\text {fg, and the }} \\
\text { corresponding fluld state } \\
\text { enthalpy, } h_{f} \text { and computing } \\
\text { the quality, } x \text { as follows } \\
\qquad x=\frac{h_{w}-h_{f}}{h_{f g}} \\
\text { When quality is below } 95 \% \\
\text { the separytor and flow } \\
\text { meters will be required to } \\
\text { determine quality. }\end{array}$ & $\begin{array}{l}\text { A throttling calorimeter shall } \\
\text { be provided and installed at } \\
\text { the } \mathrm{NH}_{3} \text { vapor outlet line } \\
\text { for evaporator test article, } \\
\text { also a gas-liquid separator } \\
\text { and flow meters shall be } \\
\text { provided at the evaporator } \\
\text { outlet in order to determine } \\
\text { vapor quality when it is } \\
\text { below } 95 \% \text { (These are to } \\
\text { be provided by the SIC.) }\end{array}$ \\
\hline
\end{tabular}

NDTES:

1. The test articles will be tested vertically.

2. The seawater flo' rate per tube shall be the same es that for 10 Mlle $(1.78 \mathrm{lb} / \mathrm{sec}$ for ejaporator and $1.61 \mathrm{~b} / \mathrm{sec}$ for condenser). The test articles are not designec to be submerged in the seawater.

3. Instrument accuracies are percent of actual reading.

4. Error analysis shows that $0 . C 5 \mathrm{~F}$ c ccuracy on temperature readings will result in approximately 4 percent error in computation of overall $U$ in the evaporator. 
Tat.1e 2.5-5. Data Plans for Test Articles (Continued)

\begin{tabular}{|c|c|c|c|c|}
\hline $\begin{array}{c}\text { Data } \\
\text { Required }\end{array}$ & $\begin{array}{l}\text { Parame }{ }^{2} \text { ers } \\
\text { To Be } \\
\text { Measured }\end{array}$ & $\begin{array}{l}\text { Operating } \\
\text { Ranges And } \\
\text { Accuracies }\end{array}$ & $\begin{array}{l}\text { Computations, } \\
\text { Interpretations, } \\
\text { Evaluations }\end{array}$ & $\begin{array}{l}\text { Support } \\
\text { Requirements }\end{array}$ \\
\hline $\begin{array}{l}\text { Overall heat transfer } \\
\text { coefficients, U irom } \\
\text { tube side to she l } \\
\text { side before and after } \\
\text { brushing and chlorina- } \\
\text { tion }\end{array}$ & $\begin{array}{l}\text { 1) Seawater inlet } \\
\text { temperature } \\
\text { 2) Seawater o.dtlet } \\
\text { temperature } \\
\text { 3) Seawater outlet flow } \\
\text { rate } \\
\text { 4) Liquid } \mathrm{NH}_{3} \text { inlet } \\
\text { temperature for } \\
\text { evaporator } \\
\text { 5) NH vapor cutlet } \\
\text { temperature from } \\
\text { evaporator } \\
\text { 6) Nill vapor temperature } \\
\text { in the sector for } \\
\text { condenser }\end{array}$ & $\begin{array}{l}\text { 1) For evaporator, } \\
70 \rightarrow 84^{\circ} \mathrm{F} \pm 0.050^{\circ} \\
\text { For condenser, } \\
40+50^{\circ} \mathrm{F} \pm 0.05^{\circ} \mathrm{F} \\
\text { 2) For evaporator, } \\
70 \rightarrow 80^{\circ} \mathrm{F}, \\
\pm 0.05^{\circ} \mathrm{F} \\
\text { For condenser, } \\
40 \rightarrow 50^{\circ} \mathrm{F} \text {, } \\
\quad+0.05^{\circ} \mathrm{F} \\
\text { 3) For evaporator, } \\
1.0 \rightarrow 2.0 \mathrm{~b} / \mathrm{bec} \\
\text { per tube, } \\
\pm 0.1 \% ; \mathrm{For} \text { conden- } \\
\text { ser, } 1.0 \rightarrow 2.0 \\
1 \mathrm{~b} / \mathrm{sec} \text { per tube, } \\
\pm 0.1 \% \\
\text { 4) } 50 \rightarrow 60^{\circ} \mathrm{F} \\
\pm 0.05^{\circ} \mathrm{F} \\
\text { 5) } 60 \rightarrow 75^{\circ} \mathrm{F}, \pm 0.05^{\circ} \mathrm{F} \\
\text { 6) } 40 \rightarrow 60^{\circ} \mathrm{F}, \pm 0.050^{\circ} \mathrm{F}\end{array}$ & $\begin{array}{l}\text { 1) } \Delta T_{\ell m}=\frac{\Delta T_{1}-\Delta T_{2}}{\ln \left(\Delta{ }_{1} / \Delta T_{2}\right)} \\
\text { where } \\
\Delta T_{1}, \text { temperature differ- } \\
\text { ence between tube side } \\
\text { and shell side at } \\
\text { entrance; } \Delta T_{2} \text { temperature } \\
\text { difference between tube } \\
\text { side and sinell side at } \\
\text { outlet. } \\
\text { 2) } Q=\text { wC. } \Delta T_{s} \\
\text { where } \\
W \text {, seawater flow rate per } \\
\text { tube } \\
\Delta T_{S} \text {, seawater temperature } \\
\text { difference between inlet } \\
\text { and outlet } \\
\text { 3) } U=Q / A \Delta T \text { Qm } \\
\text { where } \\
\text { A, heat transfer surface } \\
\text { area } \\
\text { 4) will be calculated } \\
\text { before and after brushing/ } \\
\text { chlorination }\end{array}$ & \\
\hline
\end{tabular}

NOTES:

2. The seawater flow rate per tube shall be the same as that for $10 \mathrm{MWe}(1.78 \mathrm{lb} / \mathrm{sec}$ for evaporator and $1.6 \mathrm{lb} / \mathrm{sec}$ for condenser $)$. The test articies are not designed to be submerged in the seawater.

3. In:strument accuracies are percent of actual reciding.

4. Er-or analysis shows that $0.050 \mathrm{~F}$ accuracy on temperature readings will result in approximately 4 percent error in computation of overall $U$ in the evaporator. 
Table 2.5-6. Evaporator Test Article Instrumentation List

\begin{tabular}{|c|c|c|c|c|c|}
\hline & Parameter & Type & $\begin{array}{l}\text { Operating } \\
\text { Range }\end{array}$ & Location & Quantity \\
\hline & Liquid $\mathrm{NH}_{3}$ inlet pressure & Transducer & $\begin{array}{l}123 \rightarrow 136.5 \\
\text { psia }\end{array}$ & $\begin{array}{l}\text { At the liquid } \mathrm{NH}_{3} \text { inlet } \\
\text { line }\end{array}$ & 2 \\
\hline & Liquid $\mathrm{NH}_{3}$ inlet temperature & RTD & $50-70^{\circ} \mathrm{F}$ & $\begin{array}{l}\text { At the liquid } \mathrm{NH}_{3} \text { inlet } \\
\text { line }\end{array}$ & 2 \\
\hline & $\begin{array}{l}\text { LiqLid } \mathrm{NH}_{3} \text { pressure in } \\
\text { distribution chamber }\end{array}$ & Transducer & $\begin{array}{l}122.9 \rightarrow 136.3 \\
\text { psia }\end{array}$ & $\begin{array}{l}\text { At the edge of } \\
\text { distribution chamber }\end{array}$ & 2 \\
\hline & $\begin{array}{l}\mathrm{NH}_{3} \text { pressure below the } \\
\text { dis=ribution plate }\end{array}$ & Transducer & $\begin{array}{l}122.2 \\
\text { psia }\end{array}-135.6$ & $\begin{array}{l}\text { At the edge of tube bundle } \\
\text { right below the plate }\end{array}$ & 2 \\
\hline & $\begin{array}{l}\mathrm{NH}_{3} \text { vapor out let pressure } \\
\text { after the throttling valve } \\
\text { to the calorimeter }\end{array}$ & iransduzer & $\begin{array}{l}14.7 \rightarrow 15.7 \\
\text { psia }\end{array}$ & $\begin{array}{l}\text { Measured at the throttling } \\
\text { valve outlet which is } \\
\text { installed at the vapor } \\
\text { outlet }\end{array}$ & 1 \\
\hline & $\begin{array}{l}\mathrm{NH}_{3} \text { vapor out let pressure } \\
\text { in calorimeter* }\end{array}$ & RTD & $(-28)$ to $(+30)^{\circ} \mathrm{F}$ & $\begin{array}{l}\text { Measured at the } \\
\text { throttling calorimeter }\end{array}$ & 1 \\
\hline & Seawater outlet flow rate & Flow meter & $\begin{array}{l}1.6-1.96 \\
\mathrm{ib} / \mathrm{sec} \text { per tube }\end{array}$ & $\begin{array}{l}\text { Below the lower tube } \\
\text { sheet }\end{array}$ & 8 \\
\hline & Seawater inlet temperature & RTD & $76-840 F$ & $\begin{array}{l}\text { Above the upper tube sheet } \\
\text { in the water box }\end{array}$ & 2 \\
\hline & Seawater outlet temperature & RTO & $70.7-77.5^{\circ} \mathrm{F}$ & $\begin{array}{l}\text { Below the lower tube sheet } \\
\text { in the bottom skirt }\end{array}$ & 2 \\
\hline & $\mathrm{NH}_{3}$ vapor outlet pressure & Transducer & $122.2 \rightarrow 135.6$ & $\begin{array}{l}\text { At the evaporator } \mathrm{NH}_{3} \text { vapor } \\
\text { outlet }\end{array}$ & 1 \\
\hline & $\mathrm{NH}_{3}$ vapor outlet temperature & RTD & $67 \rightarrow 73^{\circ} \mathrm{F}$ & $\begin{array}{l}\text { At the evaporator } \mathrm{NH}_{3} \\
\text { vapor outlet }\end{array}$ & 2 \\
\hline
\end{tabular}

*Calorimeter to be provided oy system integrating contractor (SIC) 
Table 2.5-7. Condenser Test Article Instrumentation List

\begin{tabular}{|c|c|c|c|c|}
\hline Parameter & Type & Range & Location & Quantity \\
\hline $\begin{array}{l}\text { Seawater outlet } \\
\text { temperature }\end{array}$ & RTD. & $45.6 \rightarrow 46.8^{\circ} \mathrm{F}$ & $\begin{array}{l}\text { At the center of } \\
10 \text { tubes cluster } \\
\text { below the lower } \\
\text { tube sheet }\end{array}$ & 88 \\
\hline $\begin{array}{l}\text { iloncondensible } \\
\text { quantity }\end{array}$ & $\begin{array}{l}\text { Noncondensible } \\
\text { analyzer * }\end{array}$ & $0 \rightarrow 1000 \mathrm{PPM}$ & $\begin{array}{l}\text { At the outlet of } \\
\text { noncondensible } \\
\text { evacuation pipe }\end{array}$ & 1 \\
\hline $\begin{array}{l}\text { Seawater inlet } \\
\text { temperature }\end{array}$ & RTD & $40^{\circ} \mathrm{F}$ & $\begin{array}{l}\text { Above the upper } \\
\text { tube sheet in } \\
\text { the water box }\end{array}$ & 2 \\
\hline $\begin{array}{l}\mathrm{NH}_{3} \\
\text { temperature } \\
\text { in the sector }\end{array}$ & RTD & $49-51^{\circ} \mathrm{F}$ & $\begin{array}{l}\text { At the edge of } \\
\text { sector }\end{array}$ & 2 \\
\hline $\begin{array}{l}\text { Seawater outlet } \\
\text { flow rate }\end{array}$ & Flow meter & $\begin{array}{l}1.44-1.76 \\
1 \mathrm{~b} / \mathrm{sec} \text { per } \\
\text { tube }\end{array}$ & $\begin{array}{l}\text { Below the lower } \\
\text { tubesheet }\end{array}$ & 8 \\
\hline
\end{tabular}

*Gas chromatograph to be provided by System Integration Contractor (SIC). 


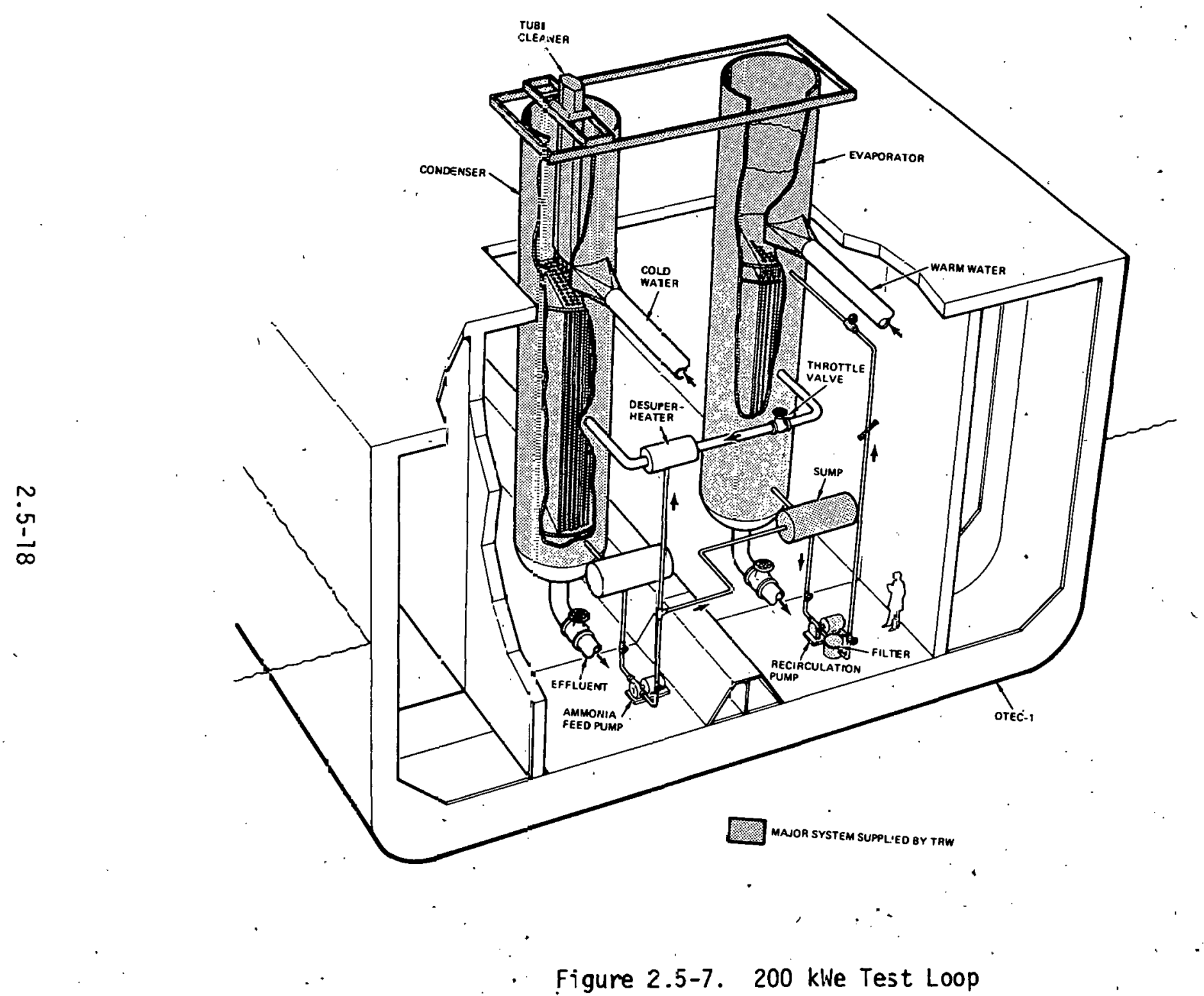


Table 2.5-8. Equipment Item List

200 kwe Test Articles

\begin{tabular}{|c|c|c|c|c|c|c|c|}
\hline $\begin{array}{l}\text { Item } \\
\text { No. }\end{array}$ & $\begin{array}{l}\text { Item } \\
\text { Function }\end{array}$ & $\begin{array}{l}\text { Size and Type } \\
\text { Connection }\end{array}$ & $\begin{array}{l}\text { Design } \\
\text { Pressure } \\
\text { (psig) } \\
\end{array}$ & $\begin{array}{l}\text { Type } \\
\text { Operator } \\
\end{array}$ & Service & $\begin{array}{l}\text { Weight } \\
\text { (Pounds) }\end{array}$ & Remarks \\
\hline$T-1$ & $\begin{array}{l}\text { Evaporator sump } \\
\text { Sump tank }\end{array}$ & $4 \mathrm{ft} 0$ in. ID $\times 10$ in. & 150 & $N A$ * & $\mathrm{NH}_{3}$ & 3,800 & \\
\hline$P-1$ & $\begin{array}{l}\mathrm{NH}_{3} \text { recirculation } \\
\text { puinp }\end{array}$ & $\mid \begin{array}{l}6 \text { in. 300\# RF suction } \\
4 \text { in. } 300 \# \text { RF discharge }\end{array}$ & $\begin{array}{l}150 \\
150\end{array}$ & $\begin{array}{l}\text { Electric } \\
\text { motor }\end{array}$ & $\mathrm{NH}_{3}$ & 205 & \\
\hline$F-1$ & $\begin{array}{l}\mathrm{NH}_{3} \text { full flow } \\
\text { filter unit }\end{array}$ & $\begin{array}{l}8 \text { in. } 300 \# \text { RF } \\
\text { inlet and outlet }\end{array}$ & 150 & NA & $\mathrm{NH}_{3}$ & 950 & \\
\hline$v-1$ & Pump shutoff & 6 in. $300 \#$ butterfly & 150 & Manual & $\mathrm{NH}_{3}$ & 40 & \\
\hline$v-2$ & Pump shutoff & 6 in. $300 \#$ butterfiy & 150 & Manual & $\mathrm{NH}_{3}$ & 40 & \\
\hline$V-3$ & $\begin{array}{l}\text { Flow control } \\
\text { modulating }\end{array}$ & 6 in. $300 \#$ butterfly & 150 & $\begin{array}{l}\text { Pneu- } \\
\text { matic }\end{array}$ & $\mathrm{NH}_{3}$ & 75 & \\
\hline RV -1 & $\begin{array}{l}T-1 \text { pressure } \\
\text { relief }\end{array}$ & 4 in. $300 \#$ & 150 & NA & $\mathrm{NH}_{3}$ & 28 & \\
\hline$R V-2$ & Line relief & 2 in. $300 \#$ & 150 & NA & $\mathrm{NH}_{3}$ & 20 & \\
\hline \multirow[t]{4}{*}{$R V-3$} & Line relief & 2 in. $300 \#$ & 150 & NA & $\mathrm{NH}_{3}$ & 20 & \\
\hline & Condenser & 102 in. $x 41 \mathrm{ft}$ & 86 & & $\mathrm{NH}_{3}$ seawater & 70,000 & \\
\hline & Evaporator & 98 in. $\times 41 \mathrm{ft} .10$ in. & 136 & & $\mathrm{NH}_{3}$ seawater & 70,000 & \\
\hline & Tube cleaner & $32 \times 32 \times 8 \mathrm{ft}$ & - & Manual & - & & Section 2.6.3.4 \\
\hline
\end{tabular}

*Not applicable 


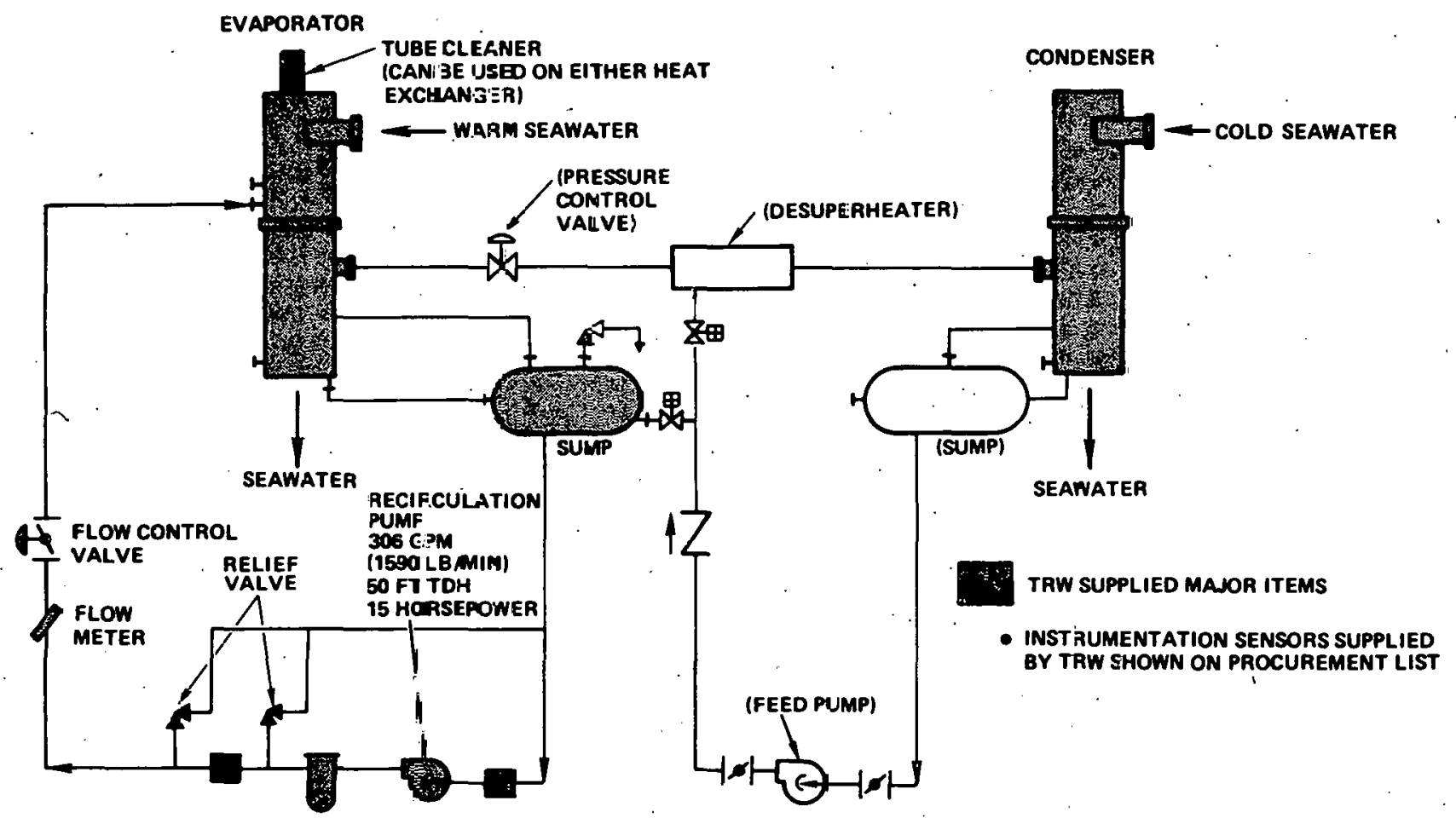

Figure 2.5-8. 290 kike Process Flow Diagram (Nominal Condition) 


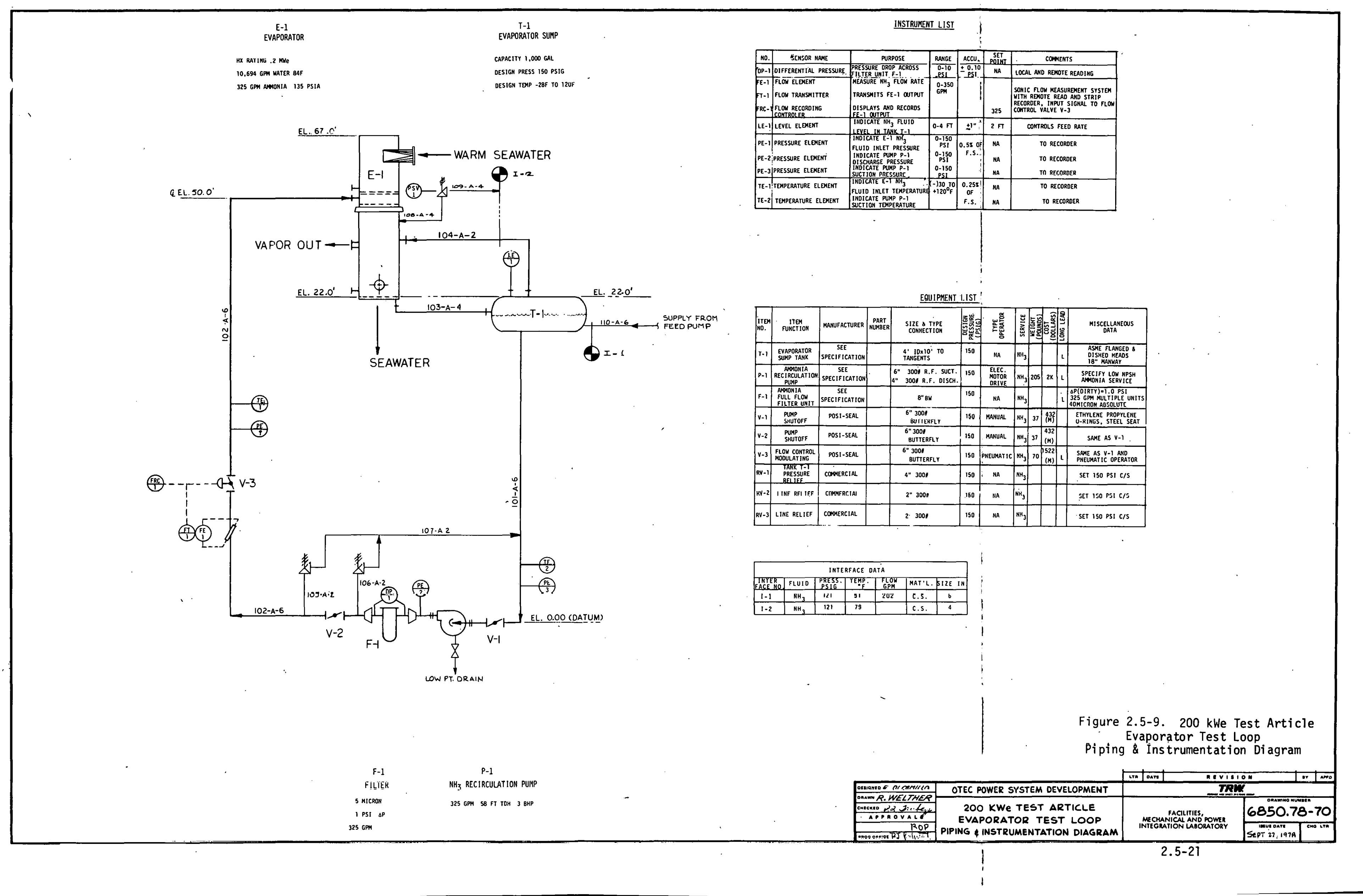


PRESSURE PROFILE

LOCATION

1. SUMP PRESSURE (T-1)

2. PUMP SUCTION PRESSURE

3. PUMP DISCHARGE

4. FILTER $(F-1)$

5. CONTROL VALVE

6. EVAPORATOR INLET

7. EVAPORATOR MEAN

8. EVAPORATOR OUTLET

\section{PRESSURE}

128.8 PSIA

134.7 PSIA

150.2 PSIA

148.5 PSI

143.5 PSIA

129.8 PSIA

129.3 PSIA

128.8 PSIA

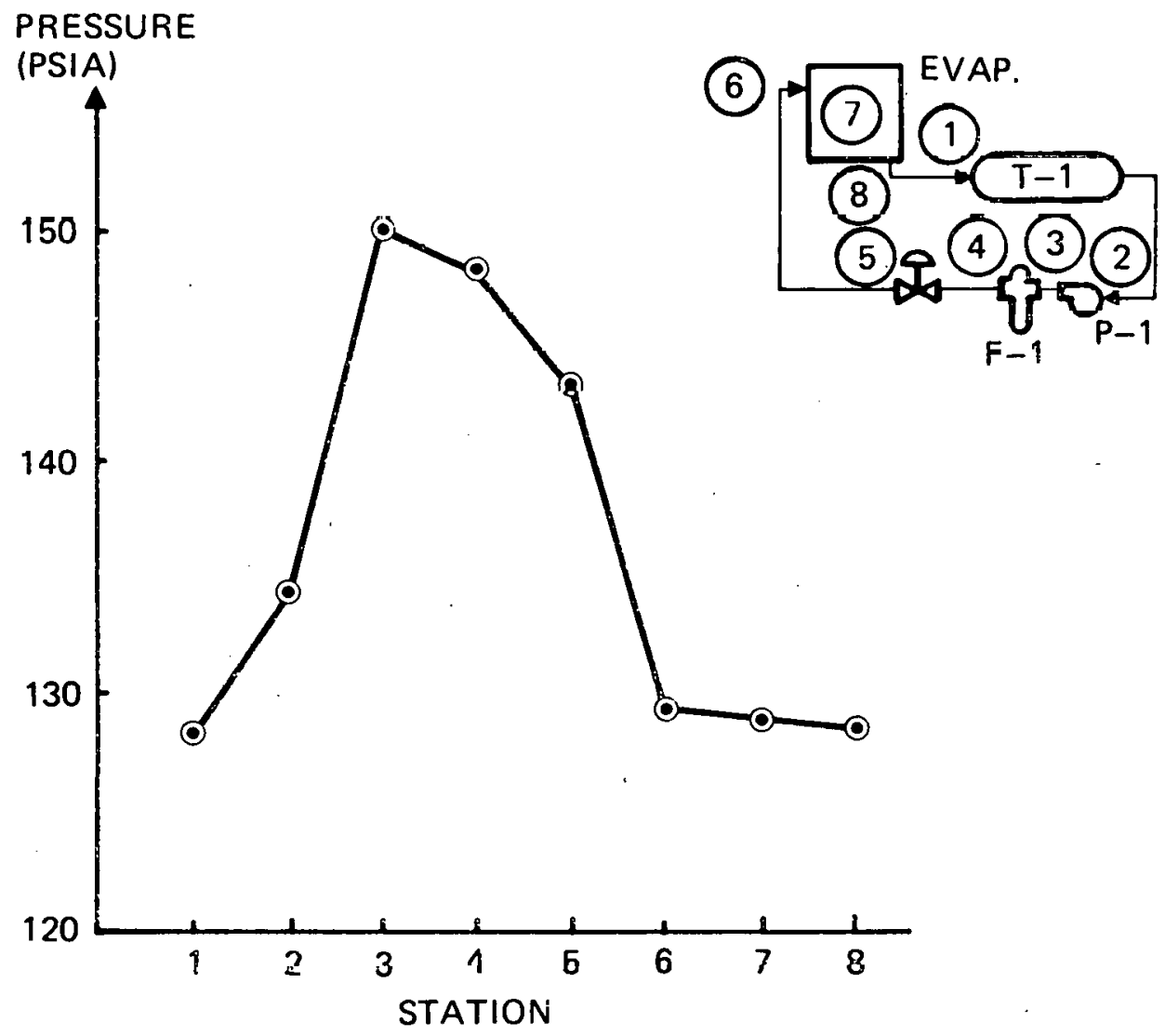

Figure 2.5-10. Evaporator Recirculation Loop Pressure Profile 


\subsubsection{Hajor Physical Interfaces}

The major physical interfaces between test articles and the OTEC/test loop are:

- Seawater inlet nozzles for evaporator and condenser

- Liquid ammonia inlet nozzle for evaporator and vapor ammonia inlet nozzle for condenser

- Vapor ammonia outlet nozzle for evaporator and liquid ammonia outlet nozzle for condenser

- Support ring for evaporators and condensers connected to supporting structures.

Major support considerations are:

- The seawater flow rate in each tube must be the same as that for 10 Mwe heat exchangers. Therefore, the tubesheet should be leveled to the seawater level. If this is not feasible, a butterfly valve is required downstream of the lower tubesheet to control seawater flow rate.

- A throttling valve must be provided and installed in the ammonia vapor outlet.

- If detection of ammonia leakage into seawater is desired, leak sampling, piping is required to sample seawater effluent for ammonia concentration analysis.

- Test sampling piping for the noncondensible analysis is required at the outlet of the noncondensible vent pipe. 


\subsubsection{Mechanical Design and Producibility}

Since design approach is the same as 10 Me heat exchangers, only the design features which are different are presented in the following sections.

\subsubsection{Tubefield}

The tube layout is identical to that of the $10 \mathrm{MWe}$ 's, except that it is confined within a sector (wedge) shape, as shown in Figure 2.5-1.

\subsubsection{Fixed Tubesheet Design}

Elongation of the shell will occur due to pressure only since there is very little temperature difference between the tubes and the shell. The only force considered on the tubes is the pulling action: from longitudinal expansion. The vapor barriers, which weld completely between the tubesheets, provide complete staying action of the tubesheets and are only partially stressed. Since this restraint is dominant, any detailed stress analys is of the tubesheets will be reserved for the final design phase.

\subsubsection{Tube-to-Tubesheet Joints}

The titanium tubes will be hydraulically expanded into the titanium clad tubesheets. The tubes will be seal welded to the tubesheet cladding following expansion. The hydraul ic expansion process. is a relatively new procedure but has proven to be an improvement over mechanical expanders for the harder materials such as titanium and, in particular, the thinner walled tubes. Tube welding of the very thin gages specified is not a common practice. However perfection of thin gage welding should be only a matter of practice and control utilizing standard equipment.

\subsubsection{Shell Openings}

All shell openings in both the evaporator and the condenser will be reinforced in accordance with the ASME code. Both heat exchangers have bottom nutlets penetrating the bottom tubesheet. The bottom outlets do not require additional reinforcement since they are self-reinforced by the excess thickness of the tubesheet. Each heat exchanger will have one manway access in each vapor space. The location is for convenience of fabrication and will be determined in the detail design. The manways satisfy inspection opening requirements of the ASME code. 


\subsubsection{Vapor Barriers}

The tube field on each test heat exchanger is limited to a triangular section bounded on the side by vapor barriers. These barriers are solid plate welded both to the tubesheet and to the shell wall. The full penetration welding at the tubesheet acts as tubesheet stays. The vapor barriers require a pressure equalizing connection to accommodate pressure differentials across them.

The tube support baffles are stitch welded to the vapor barrier. This fixes the baffles and provides stiffening for the vapor barrier plates. Analysis of the vapor barrier during the detail design phase may indicate additional stiffener requirements.

The evaporator distributor plate is seal welded to the vapor barrier. To accomplish this, one plate will be provided with removable access panels above the distributor.

\subsubsection{Vessel Support}

The heat exchangers weigh only 35 tons (dry) each. As such they present no support problems. Each unit will be supported on a gusseted double ring attached to the shell near the top tubesheet. The vessels will be side stayed at a lower location on the shell to el iminate the moments on the supports induced by the motion of the barge.

\subsubsection{Lifting Lugs}

Both the evaporator and condenser require some lifting lugs to permit up-ending the exchanger from its horizontal shipping position to place it vertical in its mounting. Since the water boxes on the top of each unit are thin, open-end cylinders, they are not of sufficient strength for lifting lugs. The recommended lifting attachment for both items consists of two short trunnions attached to the vessel shell just below the top tubesheet. The lift is accomplished by the use of a spreader bar and slings around the trunnions long enough to allow the vessel to swing vertically upright under the spreader bar. The spreader bar and slings are common rigging equipment and are not speciffed with this design. 


\subsubsection{Stress Analysis}

Calculations for the 200 kWe exchangers are less rigorous than those for the 10 MWe exchanger due to the less severe environment and to the more straightforward construction. The circumferential and longitudinal stresses have been found, 12,586 psi and 6,284 psi, respectively. There is no temperature expansion stress on the tubes since the temperature difference between the tubes and the shell is only $2^{\circ} \mathrm{F}$. The elongation stress in the tubes was calculated to be 3,924 psi. The details of the calculation can be referred to in Appendix I.2.

\subsubsection{Sliructural Dynamics}

The test heat exchangers will be installed un OTEC-1 occan platform and will have to be designed to maintain structural integrity under the worst case loading conditions caused by Sea State. 9 at their respective locations on the ocean platform. A dynamic analysis is required to determine the dynamic loads at the platform/heat exchanger interiace poinls. It is assumed that the System Integration Contractor will perform this analysis and will provide the interface loads for the heat exhanger test articles. 


\subsection{BIOFOULING CONTROL, AMMONIA LEAK DETECTION, AND LEAK REPAIR}

\subsubsection{Approaches and Objectives}

The biofouling control and ammonia leak detection/repair subsystem consists of four separate elements, i.e., chlorinator, tube cleaner, ammonia leak detector, and leak repair. The.need for biofouling control to maintain optimum system performance was discussed in the heat exchanger section (Section 2.4.5) of this report. The design goal fouling factor of 0.0001 $\mathrm{hr} \mathrm{ft}^{2}-{ }^{\circ} \mathrm{F} / \mathrm{Btu}$ will be achieved by a combination of continuous chlorine injection and periodic tube cleaning as described in Sections 2.6.2 and 2.6.3. The performance simulations described in Section 2.2.4 show the relationship between power output degradation and fouling factor changes. Tradeoff studies will be performed in Phase II to establish optimum power output versus cleaning frequency and chlorine content. The levels assumed below for preliminary sizing of these subsystems will be adjusted accordingly.

Based on an estimated tube cleaner subsystem cost of about $\$ 600,000$, the resulting cost per kllowatt hour of about 1 to 2 mils makes this subsystem extremely cost effective. Parasitic power losses for tube cleaner operation (estimated at less than 10 horsepower) are negligible.

Although the probability of ammonia leakage into the seawater has been minimized by the tube and the tube-to-tubesheet design approaches discussed in Section 2.4, practical experience shows that leaks may develop unpredictably. For this reason, this subsystem includes techniques for locating and stopping ammonia leaks while the exchangers are in service. These techniques are discussed in Sections 2.6.4 and 2.6.5.

\subsubsection{Chlorination Subsystem}

The function of the chlorine is to deter micro-organisms from adhering to heat exchanger surfaces and to inhibit the growth of micro-organisms. Continuous low chlorination $(0.02$ to $0.05 \mathrm{ppm})$ well below acceptable seawater contamination levels, and has proven an effective deterrent for mussels in coastal and estuarine installations. A chlorination dose of $0.05 \mathrm{ppm}$ was selected for this application. 
The chlorinator will consist of two separate units, a power supply and a chlorine generator. The power supply takes $480 \mathrm{VAC}, 3$ phase $60 \mathrm{~Hz}$ power and converts it to $D C$ power as required by the chlorine generator.

The chlorine generator electrolyzes a seawater stream producing sodium hypochlorite ( $\mathrm{NaOCl}$ ) which remains in solution. The chlorine generator unit housing contains a seawater pump, electrolytic cells, a chlorine concentration sensor which regulates the power input, a means of disposing safely of the hydrogen generated in the electrolytic process, and the required piping and valves.

A chlorine dose of $0.05 \mathrm{mg} / 1$ (equivalent to $0.05 \mathrm{ppm}$ ) was selected for both the warm and the cold water stream. The seawater flow rates are:

$273,500,000 \mathrm{lb} / \mathrm{hr}$ to the evaporator $253,800,000 \mathrm{lb} / \mathrm{hr}$ to the condenser $527,300,000 \mathrm{lb} / \mathrm{hr}$ total seawater flow

At $0.05 \mathrm{ppm}, 26.3 \mathrm{lb} / \mathrm{hr}$ of chlorine must be generated.

A commercially distributed chlorinator capable of supplying $30 \mathrm{lb} / \mathrm{hr}$ equivalent chlorine has been selected. For its operation, a unit of this size requires from 40 to $120 \mathrm{gpm}$ of seawater. If this water is at about $80^{\circ} \mathrm{F}$, the power consumed in generating chlorine ranges up to $2.5 \mathrm{~kW} \mathrm{hr} / \mathrm{lb}$ of chlorine. Figure 2.6-1 is a block diagram showing the main elements of the chlorinator assembly.

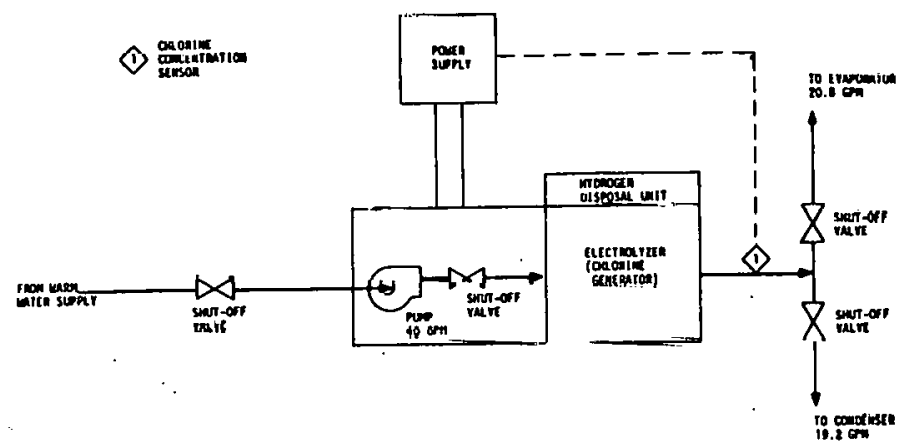

Figure 2.6-1. Chlorinator Block Diagram 


\subsubsection{Tube Cleaner Subsystem}

The tube cleaner subsystem removes contamination from the inner surfaces of the evaporator and condenser tubes. Experience with commercial seawater exchangers indicates that the specified fouling factor can be maintained by brushing each tube approximately once per week with relatively light bristle pressure (approximately 5 pounds drag force). To clean two exchangers in 1 week, allowing time for maintenance/repair or increased duty cycle and to minimize the positioning problems, a multiple brush ( 95 brushes) head is used. With the anticipated stroke times, a single exchanger can be cleaned in a 12-hour shift, leaving a large time margin for other activities.

The tube cleaner can perform the cleaning function white the heat exchangers are operating without noticeably reducing the number of active tubes. Only those tubes being cleaned are out-of-service during their cleaning cycle. The cleaning device cleans the entire inner surface of each tube and will not mar, scratch, or degrade the inner surface of the tubes, the tubesheets, or the tube-to-tubesheet joints. It consists of three major components:

1. A cleaning head with multiple cleaning devices (brushes)

2. A positioner which moves the cleaning head for progressively cleaning selected groups of tubes

3. A controller/recorder to command the positioner to its various positions and to operate the head through its cleaning cycle.

\subsubsection{Description}

A prospective drawing of the tube cleaner is shown in Figure 2.6-2. A positioner sits on a square bed called the $X-Y$ positioner frame. This frame rests on top of the heat exchanger water box/tube cleaner support structure. The positioner moves the cleaning head in the $X, Y$ and $Z$ directions by means of air motors through a rack and pinion drive.

The tube cleaner head is a 32-foot long cylinder with a hexagonal cross section. The entire head moves vertically (Z-direction) with a 16-foot stroke, along the vee ways shown in View "B" of Figure 2.6-3. The vertical drive consists of two racks. mounted longitudinally on the head with the pinion driven by the Z-drive fluid motor shown in Section A-A and view "B". 


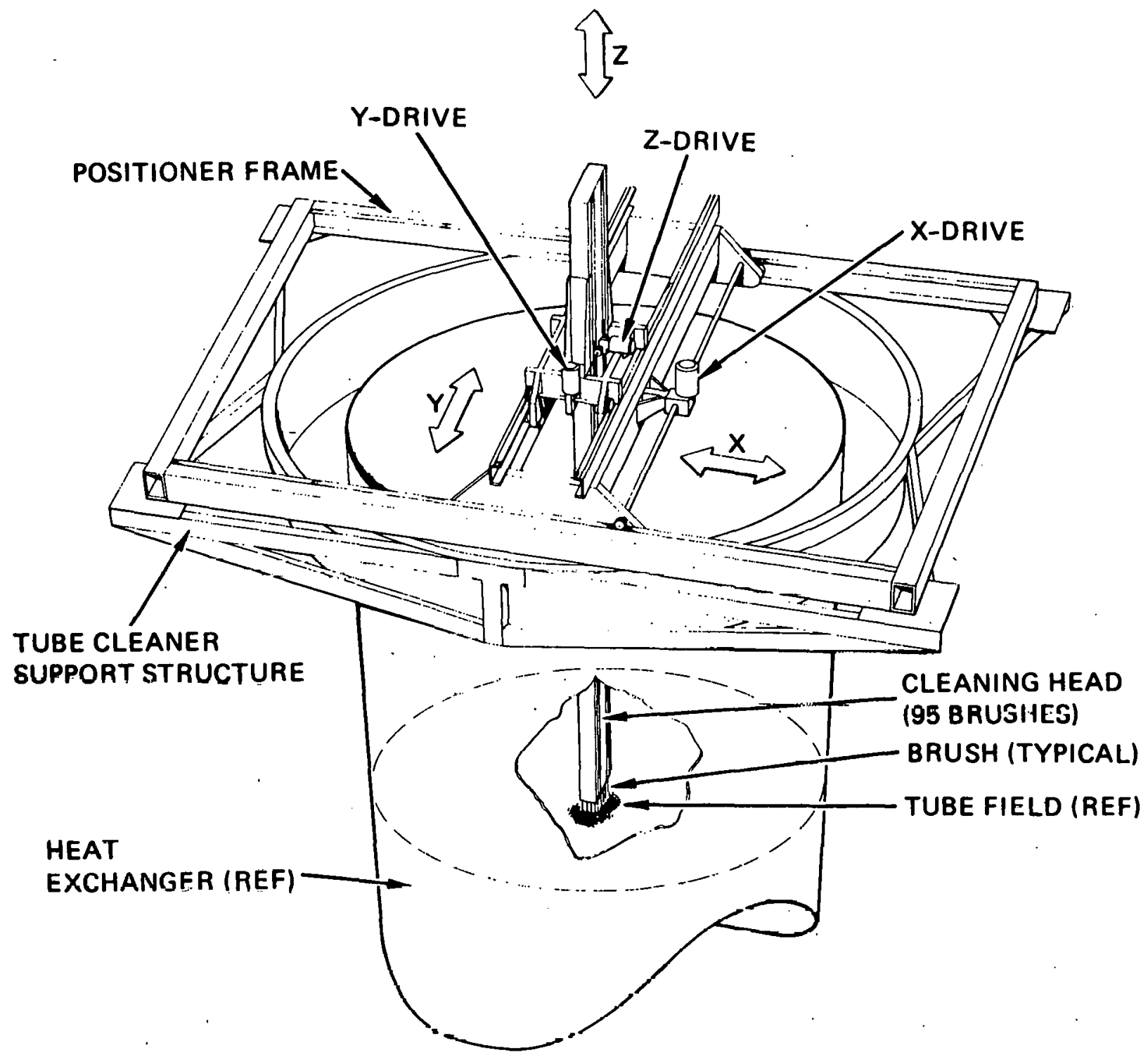

Figure 2.6-2. 10 MWe Heat Exchanger Tube Cleaner

The controller/recorder is located away from the heat exchanger. The relationship between the controller and the positioner and the head is shown schematically in Figure 2.6-4. The control and feedback signals are carried through conduits and power is supplied to the positioner and to the head liriough a compressed air manifold. 


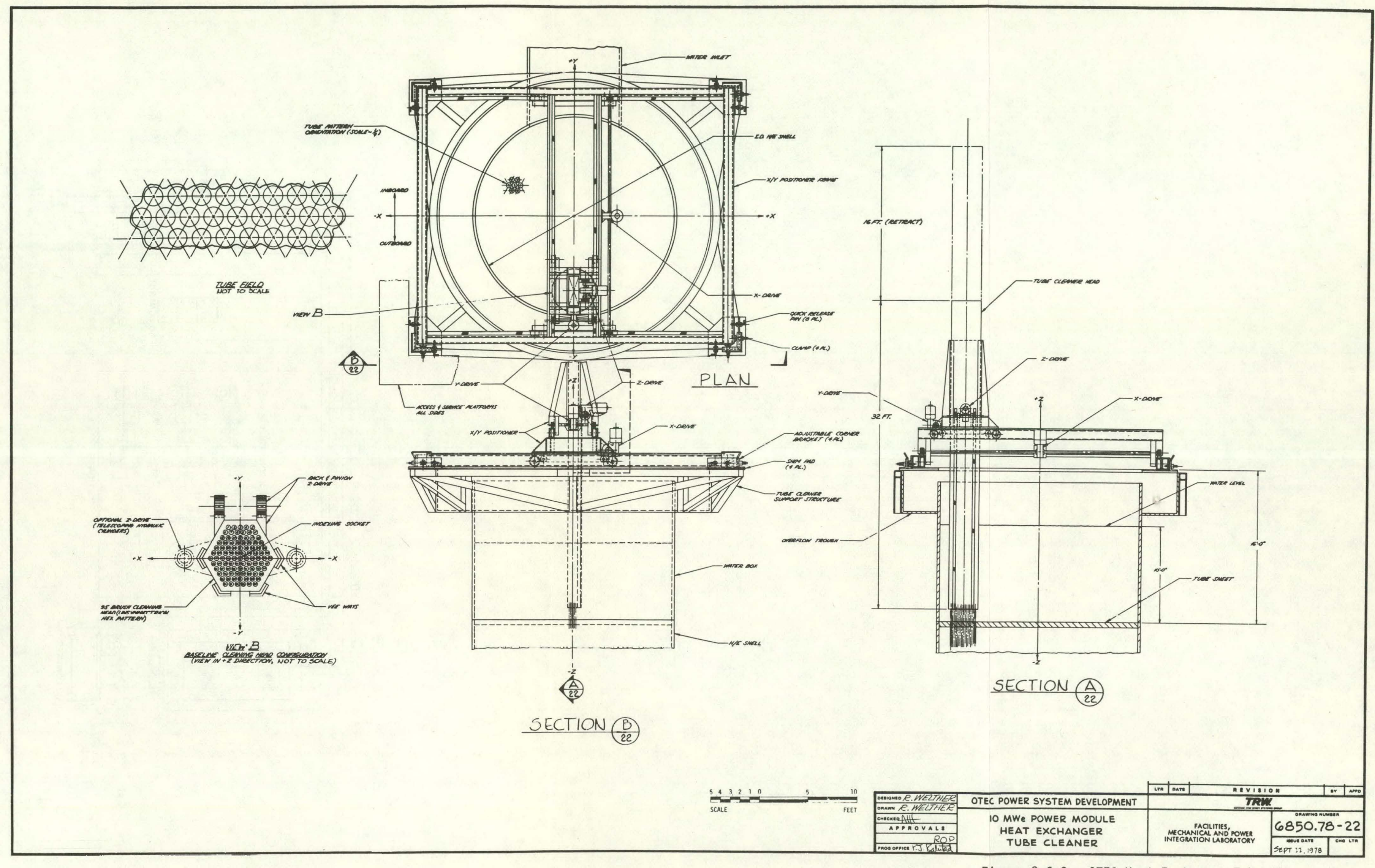

Figure 2.6-3. OTEC Heat Exchanger Tube ICleaner 2.6-5 
CONTROL SIGNALS CONDUIT

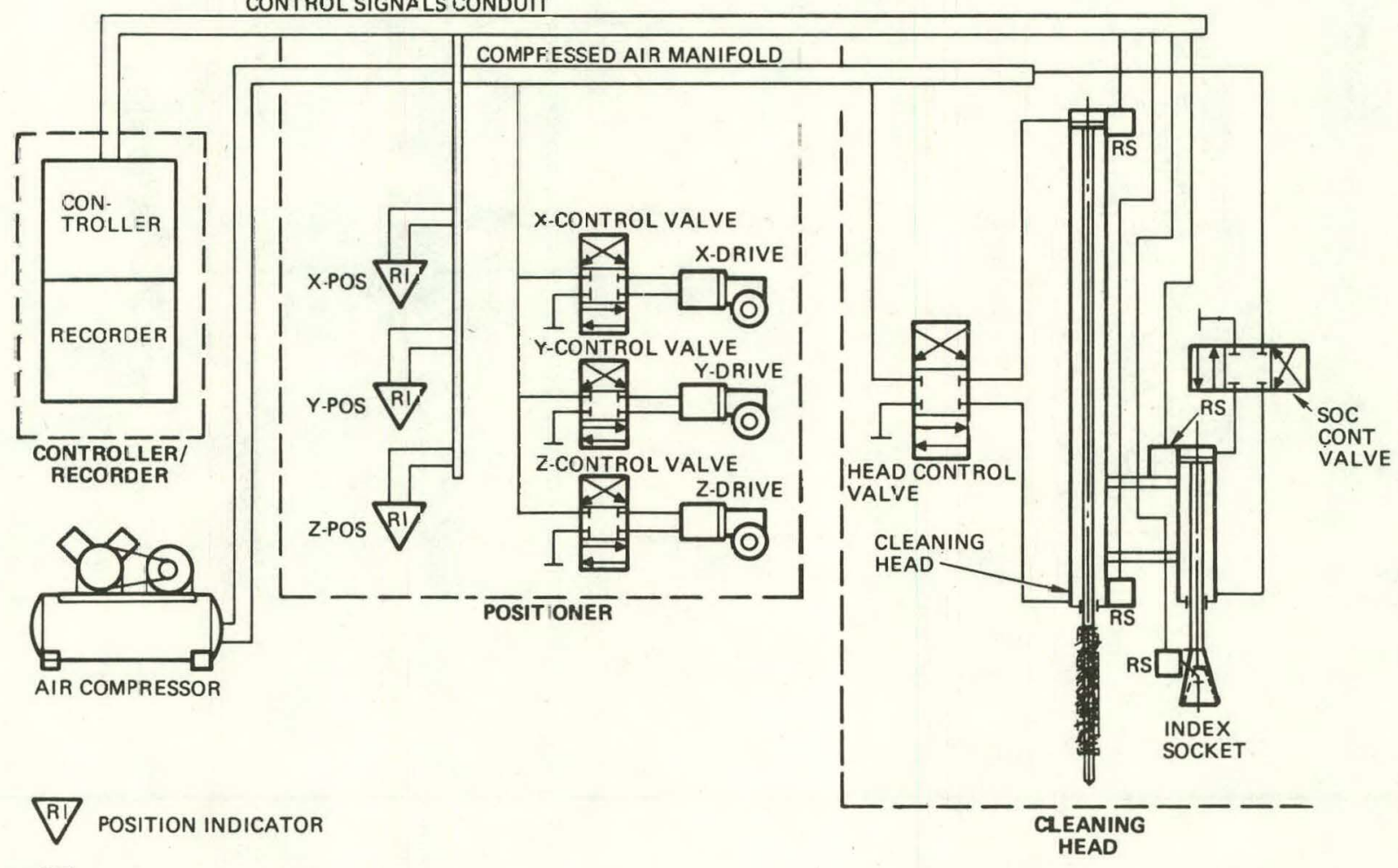

=S $\square$ REMOTE SWITCH

Figure 2.6-4. Schematic Showing Relationship Betweer Contro.ller, Positioner and Head 
The functional flow diagram for the tube cleaner subsystem is shown in Figure 2.6-5. The sequence of events for the tube cleaning operation is:

a. Startup operations. The entire tube cleaner subsystem is moved from its stowed position by manual operation of a shipboard crane. It is positioned atop the heat exchanger to a start point. This initial position is indicated as the number 1 position in. Figure 2.6-6. The entire tube field of the heat exchanger is divided into 494 head positions. Each position is in the shape of a hexagon corresponding to the cleaner head cross section.

b. Alignment Sequence. The positioner is locked and the cleaning head is lowered to its operational position just above the tubesheet. It is aligned to its cleaning position by means of an actuator engaging a guide pin-located on the tubesheet. The heat exchanger has a guide pin for each of the 494 head positions. When the guide pin is engaged, a feedback signal is sent to the controller to proceed to the next step:

c. Down Stroke Cleaning Sequence. . The cleaner head contains 95 brushes. These brushes are commanded downward into 95 tubes. As the brushes move down the tubes they perform the cleaning through linear brushing along the flutes of the tubes.

d. Upstroke Cleaning Sequence. The brushes are moved up the tube and perform the upstroke cleaning process. The cleaner head is then disengaged from the guide pin only after the upstroke sensors sense completion of all upstrokes.

e. Repositioning Sequence. The guide pin receptacle is disengaged and the-head is moved to the next cleaning position.

f. Repeat Sequence. The entire process ( $b$ through $e$ ) is repeated 493 times for each heat exchanger. The anticipated timeline for these operations is shown in Table 2.6-1.

\subsubsection{Operation}

The positioner consists of a bridge crane type structure with precision $X-Y$ position control supported on a framework which interfaces with the heat exchanger at four support pads. The pads on the heat exchanger are equipped with adjustable bearing plates to accommodate initial alignment so that subsequent placements of the tube cleaner on a heat exchanger will require engagement/locking only.

The cleaning head employs individual double action pistons to drive the brushes. The plstons are flutd driven from a common manifold source at low pressure. This permits brushes to "dead head" against the tubesheet 


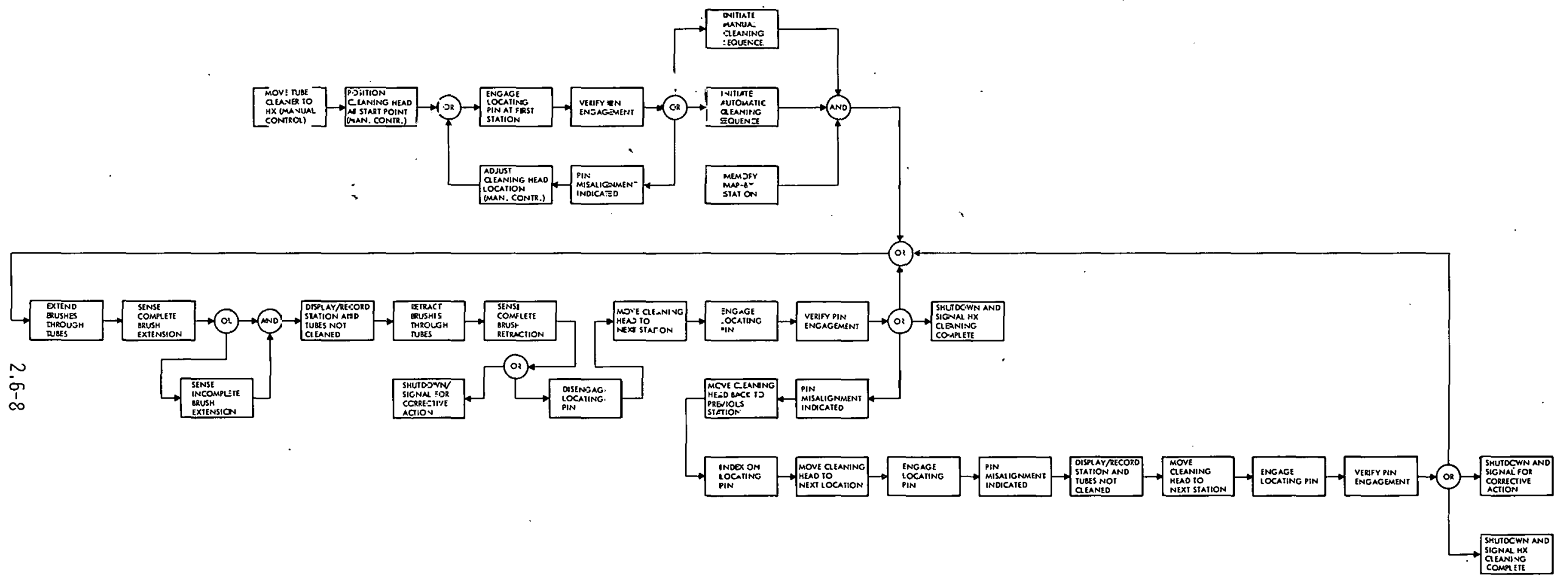

Figure 2.6-5. PSD-1 Biofouling Control Subsystem Tube Cleaner Functional Flow 
$n$
$\dot{o}$
$b$

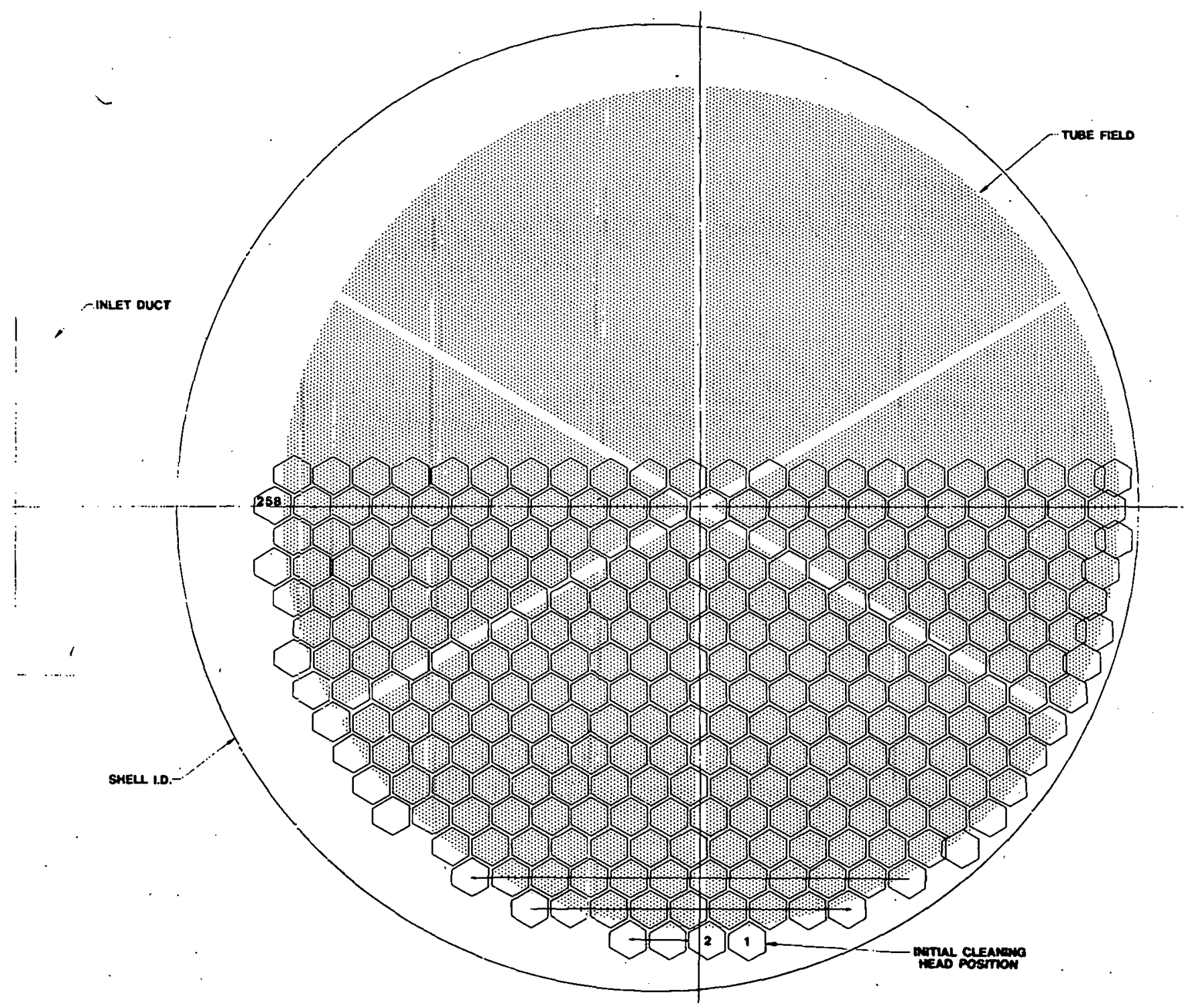

Figure 2.6-6. OTEC 10 MWe Evaporator Cleaning Sequence 
Table 2.6-1. Tube Cleaner Timeline

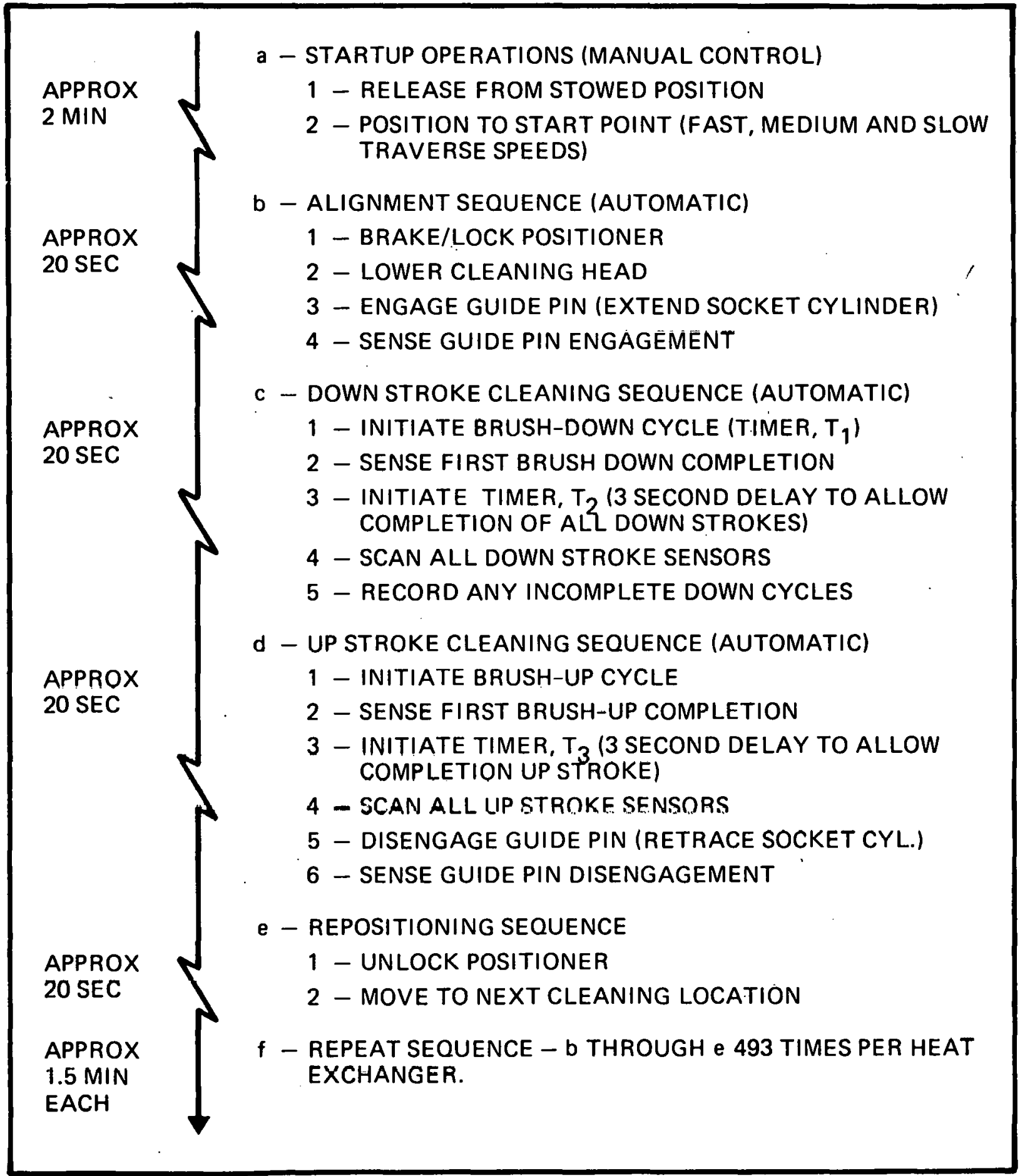


where there are no tubes. The head is equipped with a $Z$ (vertical) drive to permit raising the brushes for inspection and/or replacement. Normally, the $Z$ drive is not actuated during a cleaning cycle. Engagement with the guide pin is accomplished with the small center mounted actuator.

Brush configuration is important for our application. Bristle length is tailored to the flute configuration with the rill bristles stiffer than the crest bristles since rill fouling is considered much more likely than crest fouling. The brush is mounted in a floating socket with some radial clearance to permit the brush to center in the tube and clock itself with the tube flutes. A net fit brush with many $\vec{n} y l o n$ bristles (approximately 16 to 24 inches long) has more effective cleaning action than longer bristles which tend to fold back or "follow" along the tube wall. Net fit brushes also have.less drag force, reducing energy consumption and reducing bristle and tube wear.

Nonrotating brushes are more compatible with fluted tubes. A rotating concept. (three smaller diameter brushes mounted on an eccentric bell crank) has been conceptualized, but rotation from a cleaning point of view is considered unnecessary. Rotation would al so complicate the brush drive mechanism and increase cost of the unit. More aggressive cleaning devices, such as reamers, scrapers, rotating gears, etc., are not necessary for titanium tubes.

The loads to the guide pin are to be determined at a later time sincethe anticipated sea states cannot be reduced to acceleration/jerk rates until a ship, barge, or platform is selected. Water mass movement in the upper water box, due to vessel pitch/roll and flow impingement from the inlet nozzle, are additional loads that the submerged portion of the cleaning head will see. This combined loads environment will be established early in Phase II.

The positioner requires precision positioning control and off-theshelf encoders, in conjunction with fluid motor drives, and was found to provide the required accuracy. The programmed positions, especially near the sea water nozzle inlet, may require biasing if the steady state inlet flow results in deflection of the cleaning head, sufficient to cause misalignment. This can be accommodated in the controller computer program. 
The controller/recorder block diagram is shown in Figure 2.6-7. The major components consist of a computer/controller, signal conditioning/ interface, display/recorder and a remote control. The computer/controller is programmable to permit blanking out brush stroke indicator readings in each position where there are no tubes (see Figure 2.6-6 for areas where there are no tubes). Except for these "tube" positions, the noncompletion of any downstroke will be recorded (displayed or printed out) for subsequent corrective action. If tubes must be plugged for leakage control, a new disk mask will be made to negate the recording of incomplete downstroking of plugged tubes. The controller/recorder will also indicate the inability of the tube cleaner to execute cleaning any group of 95 tubes and identify their location in the matrix.

\subsubsection{0ther Tube Cleaner Approaches}

The initial screening of concepts identified during the industrial survey eliminated the three following concepts for the reasons noted:

a. Random sponge rubber balls (Amertap, Inc). Flow is not reversible in the heat exchanger and capture and return of the balls from the lower water box would require sophisticated mechanisms in a hostile environment. In addition, the fluted tube configuration does not appear compatible with the balls which may have difficulty scouring the rills.

b. Caged short brushes (American MAN). Brushes are dedicated to each tube with cages at both ends to trap the brushes in a position which does not restrict the flow field. Flow reversal is required to move the brushes back. through the tubes. Since reversed flow. is not feasible in the TRW heat exchangers, this concept cannot be used unless flow can be reversed locally. Assurance of full travel would require further design concept development. In addition, potential cage contamination is an unknown factor for this application.

c. High velocity water jet cleaners. This has questionable cleaning ability for expected fouling without extensive testing.

\subsubsection{Alternate Hydraulic Approach}

During the design studies a hydraulic tube cleaner was configured which utilized the working media to drive the brushes. This concept would eliminatc the long (approximately 30 feet) piston rods required for the selected approach resulting in a low profile unit which is essentially submerged in the upper water box. A positioner, similar to the selected approach is required. The design calculations developed to size the system are summarized in Appendix G.

$$
2.6-12
$$




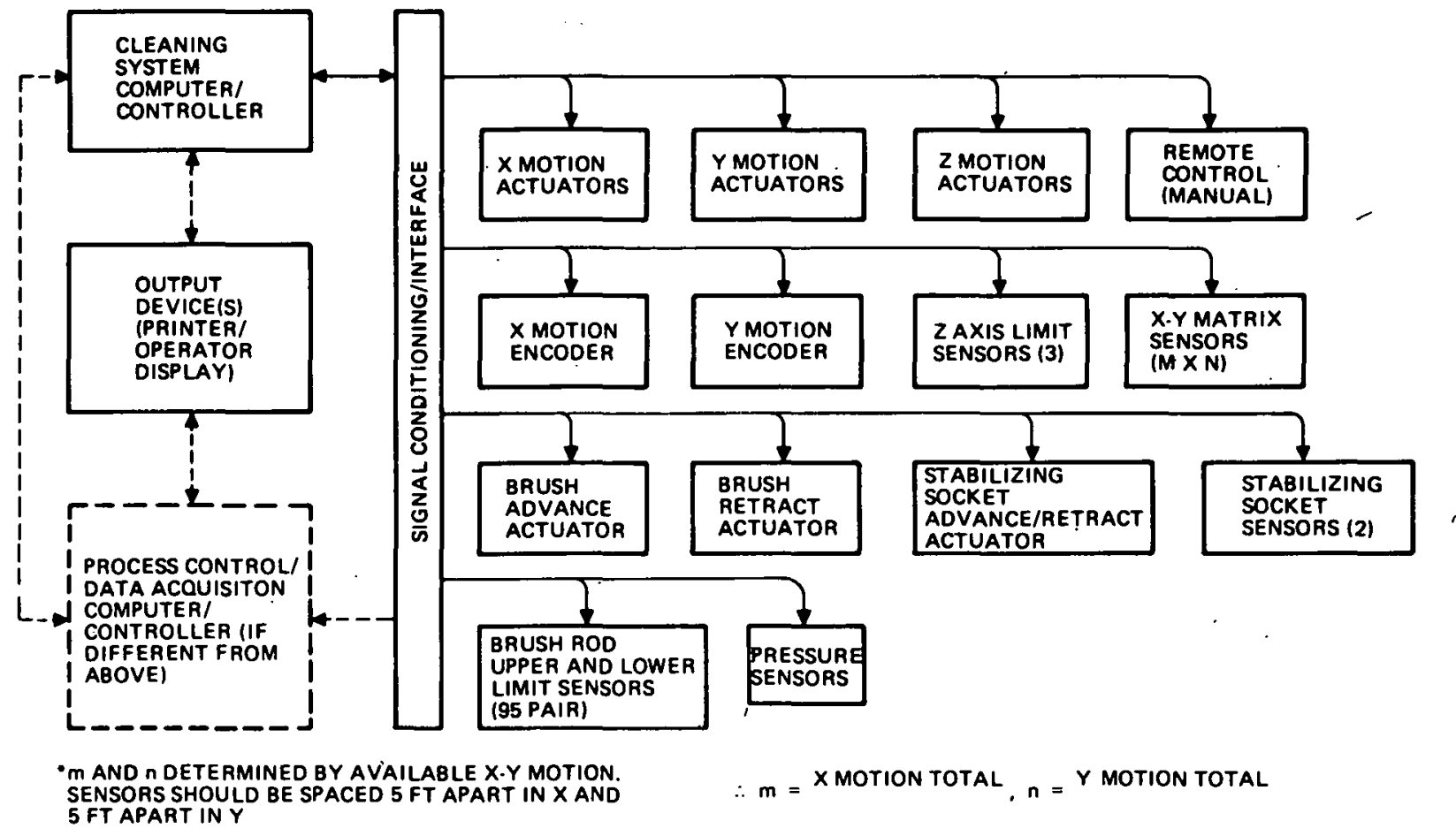

Figure 2.6-7. Controller/Recorder Block Diagram

A pump delivers inlet seawater to a header positioned over a group of 95 tubes as shown in Figure 2.6-8. Sufficient head is developed by the pump to drive the brushes down the tubes. Then, through valving, the pump produces reduced head in the cluster of tubes, causing the flow to reverse and draw the brushes back into the header. The header is repositioned by the programmed positioner to the next group of 100 tubes and the process repeated.

The submerged and primed pump is started with bypass valve $D$ open (low pressure recircillation) as shown in the schematic of Figure 2.6.9. The sequence is initiated by closing $D$ and opening valve $A$ simultaneously. When $A$ is open, flow is from the pump (inlet seawater) through one port of valve $A$ to the pump back through the other port of $A$, into the header/HX tubes. When all brushes are down (stops on lower tubesheet) relief valve $C$ will open, signaling completion of the downstroke. Valve $A$ is then closed and valve $B$ opened to reverse the flow through the pump and return the brushes to the header. The upeniny of relfef valve $C$ signals the completion of the return of the brushes. Valve $D$ is opened to reduce pump sad and powcr consumption while repositioning the header for the nex $L$ group of tubes. 

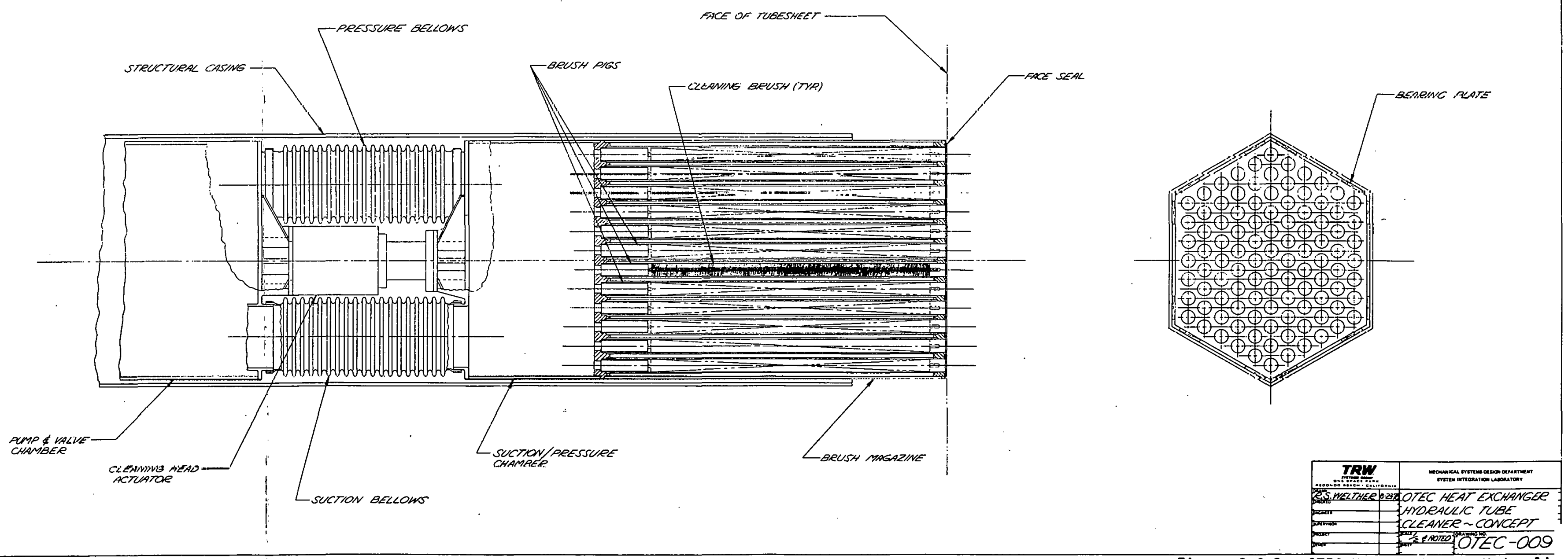
Figure 2.6-8. OTEC Heat Exchanger Hydraul ic Tube cleaner - Concept 


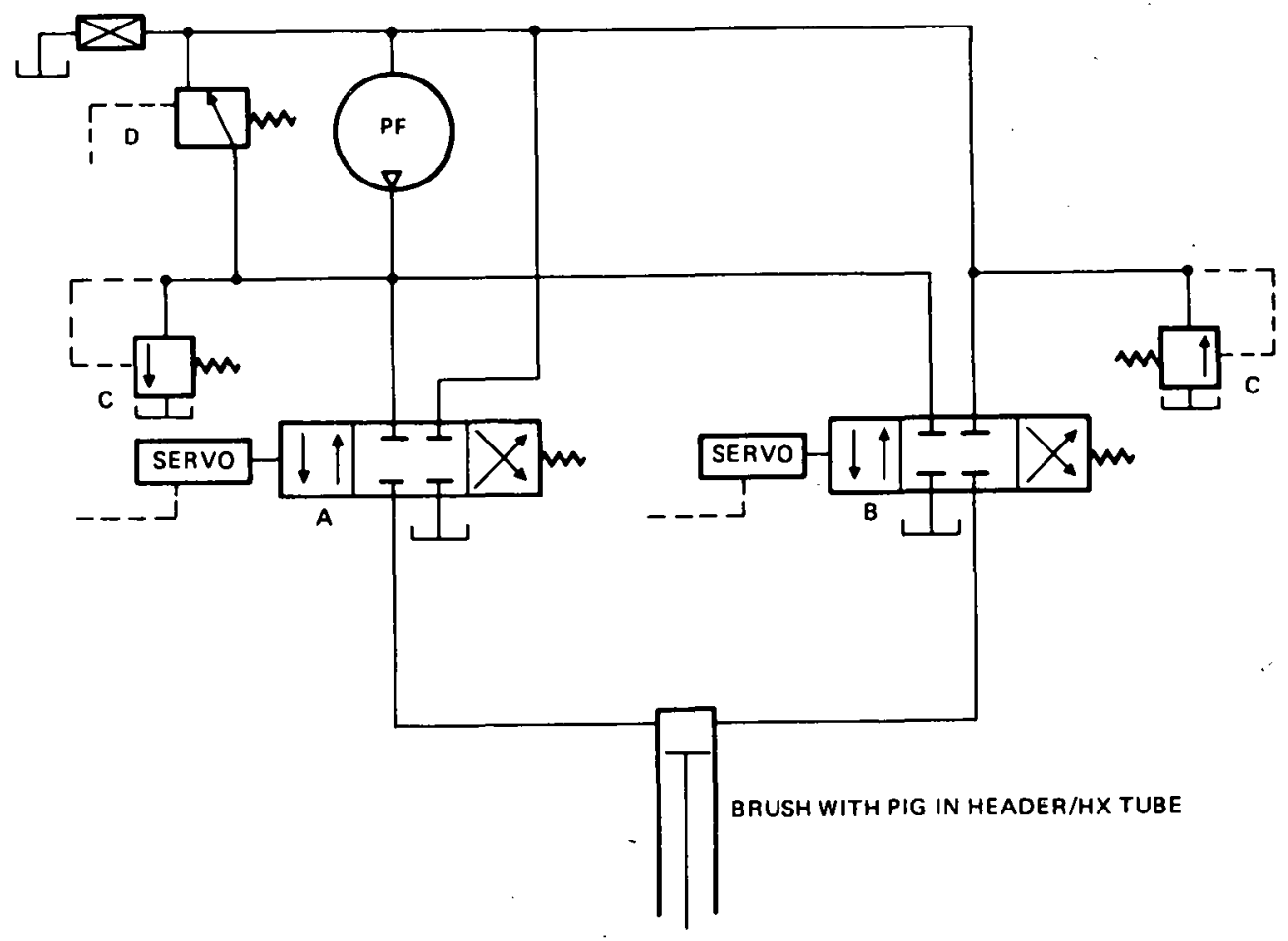

Figure 2.6-9. Schematic of Submerged and Primed Pump

The hydraulic concept is predicated on using low drag (approximately 5 pounds force) brushes; a value as yet unsubstantiated for this application. Verification of complete stroking is complicated by the fact that there is no physical (rod) attachment to the pig/brush. A sensor in the pig/brush assembly or at the bottom tubesheet would be required to indicate completion of the downstroke. Several solutions to this problem are conceptualized in Appendix $G$ and offer potential for further use.

TRW is of the opinion that experience is required to gather statistical data on brush drag force before committing to a concept that has limited brush retraction force capability.

One of the self imposed design requirements for the hydraulic tube cleaner concept was positive indication that the brushes had fully completed the downstroke before retrieval. This requirement may very well disappear as experience is gained with the selected concept, particularly if we find that downstroking is so reliable that sensing is not required. Alternately, 
the hydraulic concepi could be designed to overpower the downstroke by increasing the pump pressure at or near the completion of the downstroke to insure complete downstroking during normal operation. There is a potential failure mode, however, that must be accommodated. It is a condition in which the entire plant may be shutdown for some time (say several weeks) and excessive biofouling occurs in the tubes. This could conceivably require high brush forces to break loose large depositions or even larger crustacean attachment, particularly in the fluted length of the tubes. Although submersion tests, such as those done by Project RIFT, show no biofouling of titanium structures, tubes, and especially fluted tubes, may provide the physical mechanism to promote crustacean attachment.

For these reasons, full stroke indicators for the hydraulic concept were investigated based on llie fulluwing requirements.

a. The indicator must get reset in the header before initiating the downstroke

b. The indicator must not be capable of getting tripped during the downstroke

c. The indicator must "cock" at the completion of the downstroke

d. The indicator must not get tripped during the upstroke

e. The indicator must permit sensing of full downstroke before initiating the next downstroke.

rree pig/brushes were assumed. The ușe of a fnllower string or cable added significant complexity in cable retrieval/stowage mechanisms for 95 individual cables and was discarded. The sensing device to indicate full stroke must either be positioned at the lower tubesheet (requiring numerous devices if dedicated to single tubes) or communicate in some way with the $\mathrm{pig} / \mathrm{brush}$.

Several mechanical concepts were investigated that depended on contact with the brush stops on the lower tubesheet to "set" in a way that could be monitored when the brush returned to the cleaning head. These concepts are not presented here since they falled to meet one or more of the above requirements. In most cases they failed requirement (b). Candidate solutions are presented in Appendix $G$. 


\subsubsection{200 kWe Tube Cleaner}

The $200 \mathrm{kWe}$ tube cleaner is primarily intended to evaluate tube cleaning concepts. A conceptual drawing is shown in Figure 2.6-10. It differs from the 10 MWe design in the following ways:

- The $200 \mathrm{kWe}$ tube cleaner has no controller/recorder; only manual control is utilized

- Mechanical drives (lead screws) rather than compressed air motors are used for positioning

- The cleaning head contains 7 brushes rather than 95

- There are 132 cleaning head positions rather than 494

- The cleaning head is pentagonal in shape rather than hexagonal.

\subsubsection{Ammonia Leak Detection}

\subsubsection{Requirements}

The ammonia leak detection system must detect leakage of ammonia into ambient air, by way of pumps, valves, fittings, etc., and leakage into seawater within heat exchangers, by way of heat exchanger tubes, tubesheet to-tube joints and shell-to-tubesheet joints. The detectors shall be capable of sensing $0.1 \mathrm{ppm}$ of ammonia in the lower water box for bulk detection, $1.0 \mathrm{ppm}$ level of ammonia concentration in the composite (cluster of 95 tubes) and $1.0 \mathrm{ppm}$ in individual tubes. Appendix $\mathrm{H}$ details our efforts leading to the ammonia leak detector segment design.

Leakage of ammonia gas into ambient air will be detected with an infrared analyzer calibrated for a full-scale range of 0 to $300 \mathrm{ppm}$ ammonia in air. Fourteen sampling locations will be strategically selected to provide ammonia concentrations to a central panel, and alarm when leakage occurs. This is a conventional method of ammonia leakage detection.

The concentration of ammonia is seawater samples will be measured using a Technicon Autoanalyzer Monitor IV system. This is an integral monitoring unit incorporating a plototube calorimeter capable of detecting $0.01 \mathrm{ppm}$ ammonia. Each heat exchanger has a unit sampling water effluent in the lower water box. 
Prel iminary leak rates of $50 \mathrm{lb} / \mathrm{hr}$ for the evaporator and $40 \mathrm{hb} / \mathrm{hr}$ for the condenser have been established. Leaks in the heat exchanger to the seavater must be detected at a sensitivity level less than $0.10 \mathrm{ppm}$ ammonia: Each heat exchanger contains approximately 43,000 fluted tubes with a nominal In of: 0.85 inch. The evaporator and condenser have one-biofoul ing control subsystem tube cleaner which cleans 95 tubes simultanenusly with three dimensional position controls. The cleaning head indexes to each group of 95 tubes every 2 minutes until the lot has been cleaned by transversing brushes in and out of each tube.

\subsubsection{Modes of Operation}

The ammonia leak detection sampling system is described hy three modes of operation: 1) bulk outlet sampling, 2) composite tube sampling, and 3) individual tube sampling.

The bulk outlet sampling mode consists of aspirating tubes lcoated in the outlet stream of each quadrant of the heat exchanger \pm ube bundle. Samples are withdrawn from each tube by pumping into a mixing reservoir at atmospheric pressure. The reservoir provides a continuous flow sample to an auto-analyzer monitoring continuously. When the bulk sample exceeds a recorded $0.10 \mathrm{ppm}$ level, an audio/visual alarm is initiated. The general leak location of the particular quadrant can be determined by samplinq the quadrant sampling tubes individually by sequencing the air operated valves. Figure 2.6-11 shows the bulk outlet sampling mode.

After the bulk outlet sampling mode identifies that a hulk leak exists two methods of identification of leaking tubes are availahle. If the leak is major (tube rupture or equivalent) the system will be shutdown for visual leak identification as described in Section 2.6.5.3 if the leak is minor, permitting system operation while identifying and repairing the leak, the composite sampling mode of leak detection may be entoloyed.

This concept consists of directing a modified biofouling tube cleaner to the indicated quadrant and commencing a composite sampling of a group of 95 heat exchanger tubes. sample seawater is taken from each tube. The modified biofouling tube cleaner will be designed with hollow tubes to allow sample seawater flow from heat exchanger tubes through the biofouling tube cleaner to storage reservoir. Transporting the sample fluid is accomplished by differential pressure from the heat exchanger outlet to a reduced 

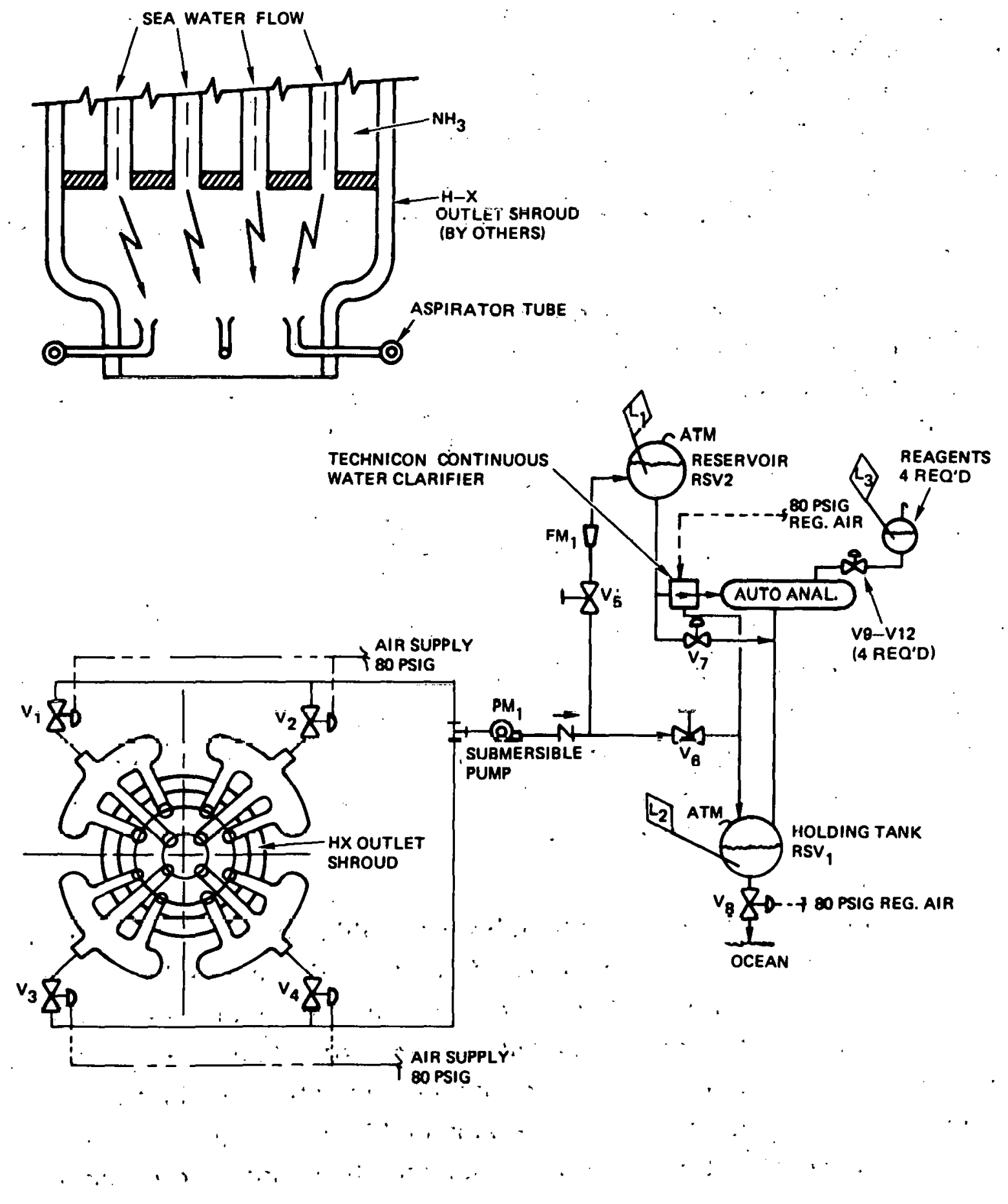

Figure 2.6-11. Bulk Outlet Sampling - Schematic 
pressure (-2 psia) reservoir as shown schematically in figure 2.6-1?. Two reservoirs are provided since the chemical diagnostic auto-analyzer has a lag time of 3 to 7 minutes and the cleaning cycle is 2 minutes. The first reservoir contains 95 individual containers which are filled with a sample from each tube. These samples are sized to contain $50 \mathrm{ml}$ of seawater. A composite sample from ? to 95 tubes may be obtained by the overflow from the $50 \mathrm{ml}$ container which is collected at the hottom of the reservoir. A. labeled sample is drawn at atmospheric pressure from a preprogrammed composite size for analysis. The cleaning head progresses to the next group of 95 tubes with only a composite sample stored in a second reservoir. If the first sample does not indicate a composite leak; then all effluents will be discharged.

In the event of the first composite reservoir sample indicates ammonia concentration above $0.10 \mathrm{ppm}$, then samples are taken from each of 95 tubes sequentially from samples previously stored and labeled within the first reservoir. Figure 2.6-13 illustrates the individual tube sampling mode schematically. The unique feature of this mode is the transportation of seawater samples by a single pump (vacuum) and the label and storage of these samples separating both a composite and individual sample. A degree of complexity is required for the valving of 95 samples. If there is no leak indication from the original bulk sample, then all samples are discarded for readiness of subsequent groups. During the analyzing time of 3 to 7 minutes, the other composite samples are collected and distributed to the auto-analyzer after 2 minutes. If either of the composite reservoirs indicate excessive ammonia, then the individual tube reservoirs.wil repeat. the process for that indicate group.

\subsubsection{Implementation}

A cursory study was made to establish a feasible rethod of obtaining a seawater sample representative of a leak from the shell-to-tubesheet, tubeto-tubesheet and an individual heat exchanger tube. The shell-to-tuhesheet leak can probably be detected by the bulk system sample test. The tube-totubesheet interface and heat exchanger tube"leak is determined by the camposite and individual tube sample testing of 95 tube groups. The existing tube eleaning subsysteminachinery is ulilized lu minlmize costs due to cost considerations. 


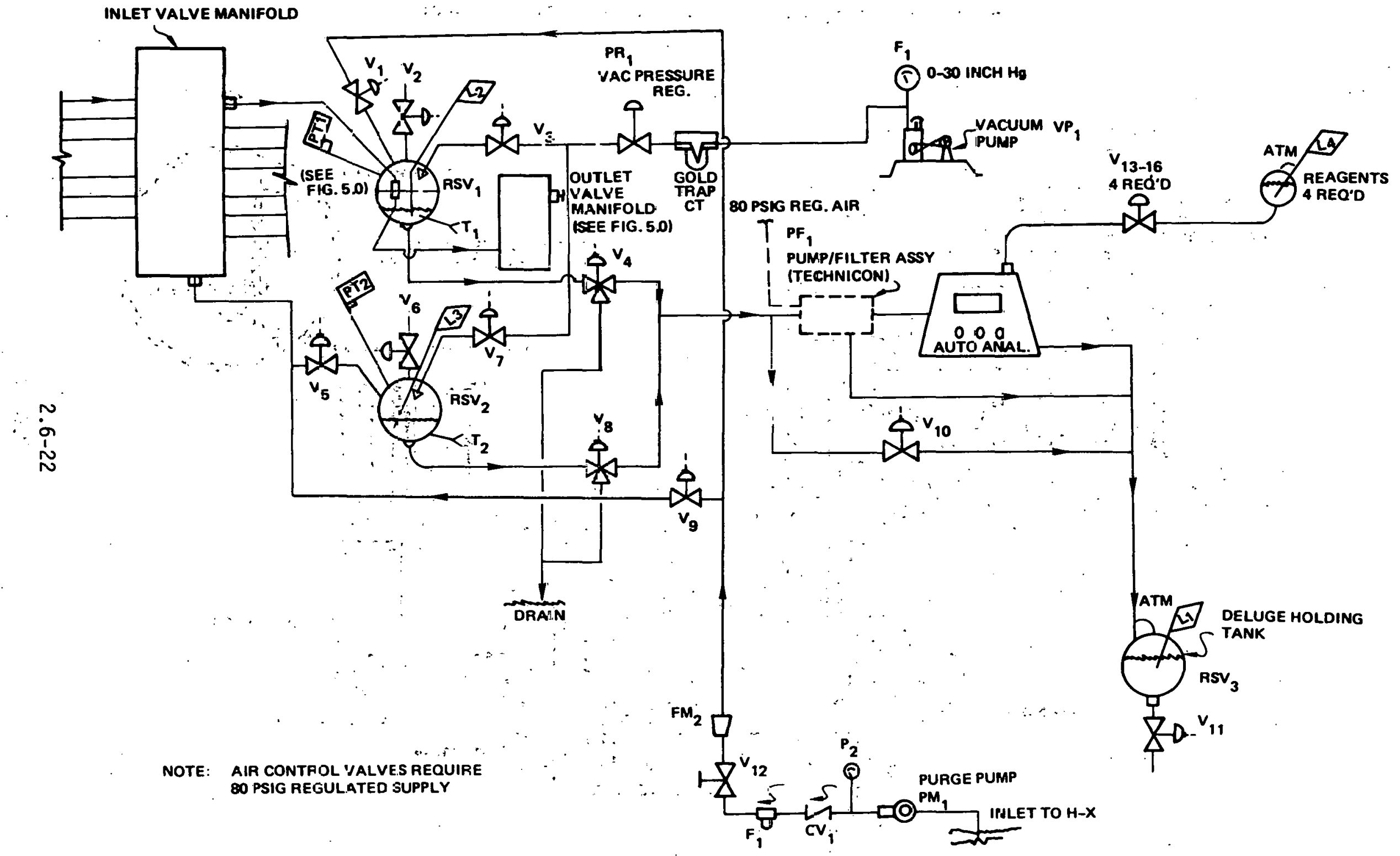

Figure 2.6-12. Composite Sampling Mode - Schematic (One Tube Sample Shown) 


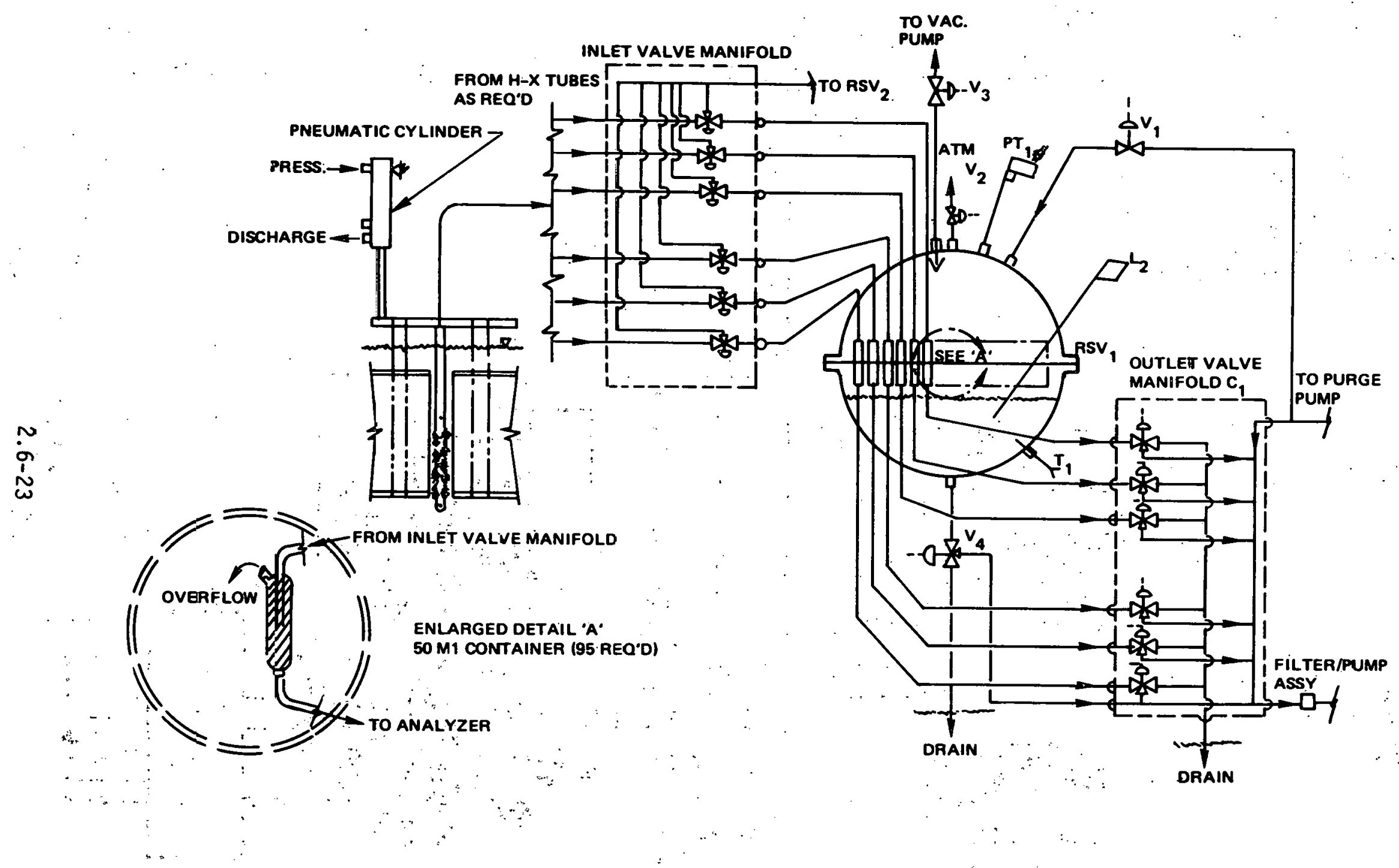

Figure 2.6-13. Individual Sampling Mode - Schematic 
Modifications to the existing design are necessary and may also require some development effort. The modification identified at this time requires a hollow (tube fabrication) brush rod for fluid passage to the sample storage reservoir. Also, an interchangeable or modified brush head assembly will be required. This brush head will require a check valve, centering brushes and multihole entry ports. The concept of the reservoir location and brush assembly is shown by the sketch illustrated in Figure 2.6-14.

A preliminary sizing for the hollow brush diameter and sample flow was. conducted. Several avaliable tube sizes were analyzed and are tabulated below.
$\frac{0 D}{1 / 2} \frac{\text { WALL }}{0.019} \quad \frac{\text { ID }}{0.402}$
$\mathrm{A}_{0}-\mathrm{Ft} \mathrm{t}^{2}$
$\underline{\mathrm{D}_{H^{-F t}}}$
$3 / 8 \quad 0.065$
$8.814 \times 10^{-4}$
0.0335
$1 / 4$
0.245
$3.274 \times 10^{-4}$
0.0204
0.028
0.194
$2.053 \times 10^{-4}$
0.0162

The study has revealed areas requiring design development as discussed below. The solution to the stated areas of concern may be solved either analytically, empirically, or both.

The chief concern of the bulk sampling mode is the number, size, and location of this sampling tubes within the flow stream of the heat exchanger outlet. The objective is to minimize the number of sample tubes of a given size which can detect ammonia concentration less than $0.10 \mathrm{ppm}$ and to ascertain quadrant location. Analys is and a small scale is proposed for determining the sampling method and detail of the system.

Additional system studfes are required for the feasibility of combining the composite sampling system with the biofouling control subsystem. Design development is required for the following modifications:

- Locating two reservoirs with an inlet and outlet valve manifold on a moving platform above the cleaning head

- Modifying the brush rod for flow passage to reservoirs

- Development or modifying the existing brush head with a check valve, brush, and entry ports 

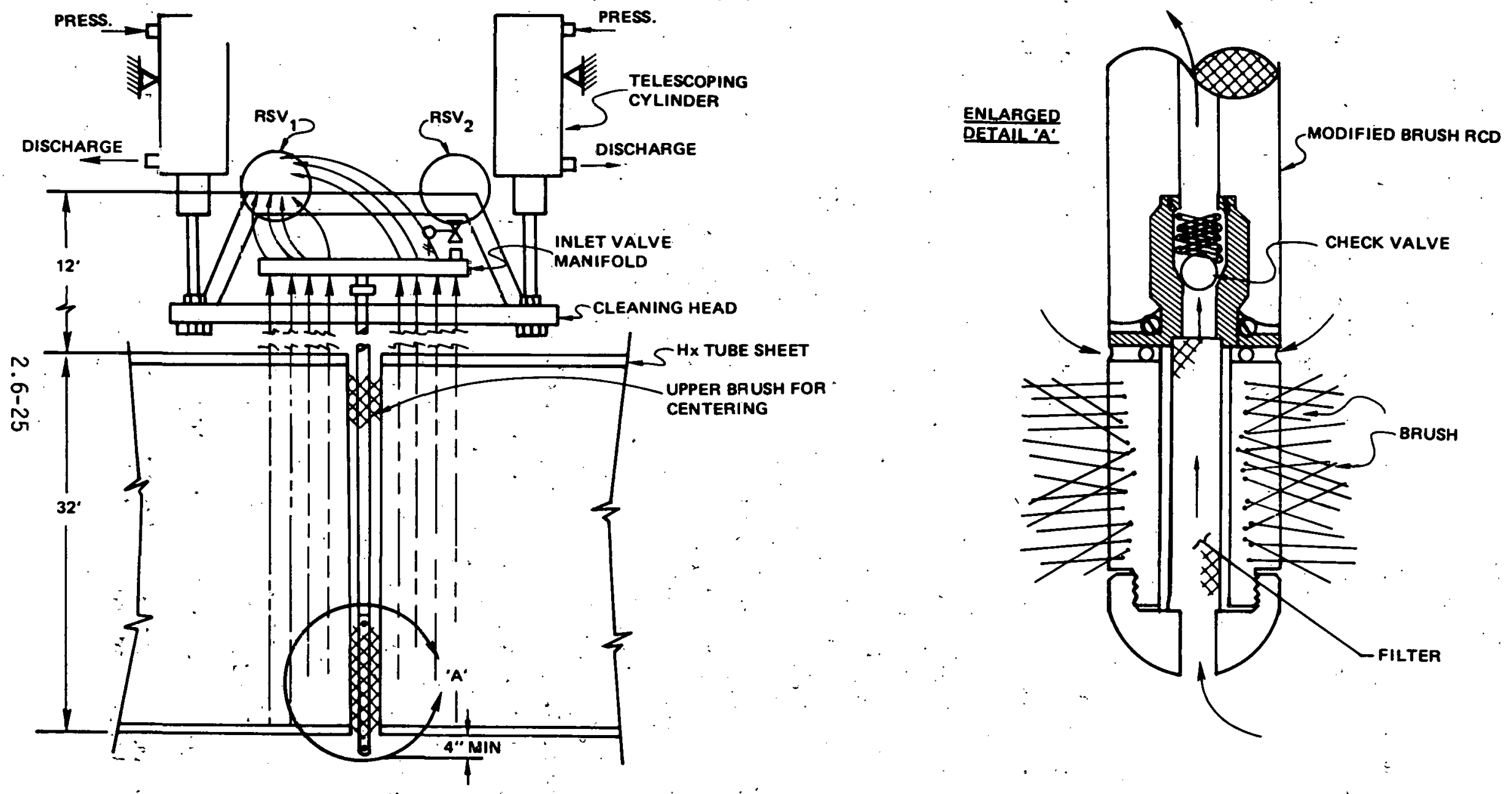

Figure 2.6-14:- Reservoir Location and Brush Assembly 
- Modify the brush actuators from 95 individual brush cylinders to two large brush head cylinders.

Additional effort is required for studying alternative concepts and detall analysis of the vacuum transport concept.

Hardware design and development is required for the multiplex valve/ manifold and associated programmable microprocessor required for individual tube sampling. This valving shall have 95 inlet ports and 95 outlet ports for parallel thruput for one function. Another function is to bypass 95 inlet flows. into a common manifold with a single outlet. In addition, each 95 inlet flows may be sequenced by any predetermined combination. The valve must have a low pressure drop (less than 0.20 psi at $0.25 \mathrm{gpm}$ ) and must seal an internal vacuum. Inese functions are shown schillalically by Figure 2.6-13.

The tentative selection for the analytical instrument is a "Technicon Monitor IV." This instrument may require repackaging into an hermatic enclosure with temperature control for a continuous salt environment and to preclude electrical ignition of concentrated ammonia atmosphere. Suitable instrumentation and controls will be provided for automatic operation. Air operated valves are suggested or explosion proof electric devices.

\subsubsection{Ammonia to Seawater Leak Repair}

The possibility of ammonia leakage to the seawater has been minimized by designing the tubes with adequate margins and using redundant seals at the t.uhe-t.n-tubesheet joints (welding plus rolling) as described in Section 2.4. However, leaks may develop due to unpredictable causes and require repair to maintain predicted system performance levels and prevent seawater contamination.

Heat exchanqer tubes or tube-to-tubesheet joints which are found to be defective will be sealed from the seawater circuits. Sealing will be accomplished by the use of a specially designed sealing plug. A concept for such a plug is illustrated in Figure 2,6-15. Its operation is illustrated in Figure 2.6-16. Seal plugs will be installed in tubes which exhibit an ammonia leakage rate above a certain minimum value as determined by the ammonia leak detectors, Section 2.6.4. Plugs will be installed manually as shown in Figure 2.6-15 when the heat exchanger is shutdown for scheduled maintenance or during operation by the use of special tools operated above water level. 
$N$
0
1
$N$

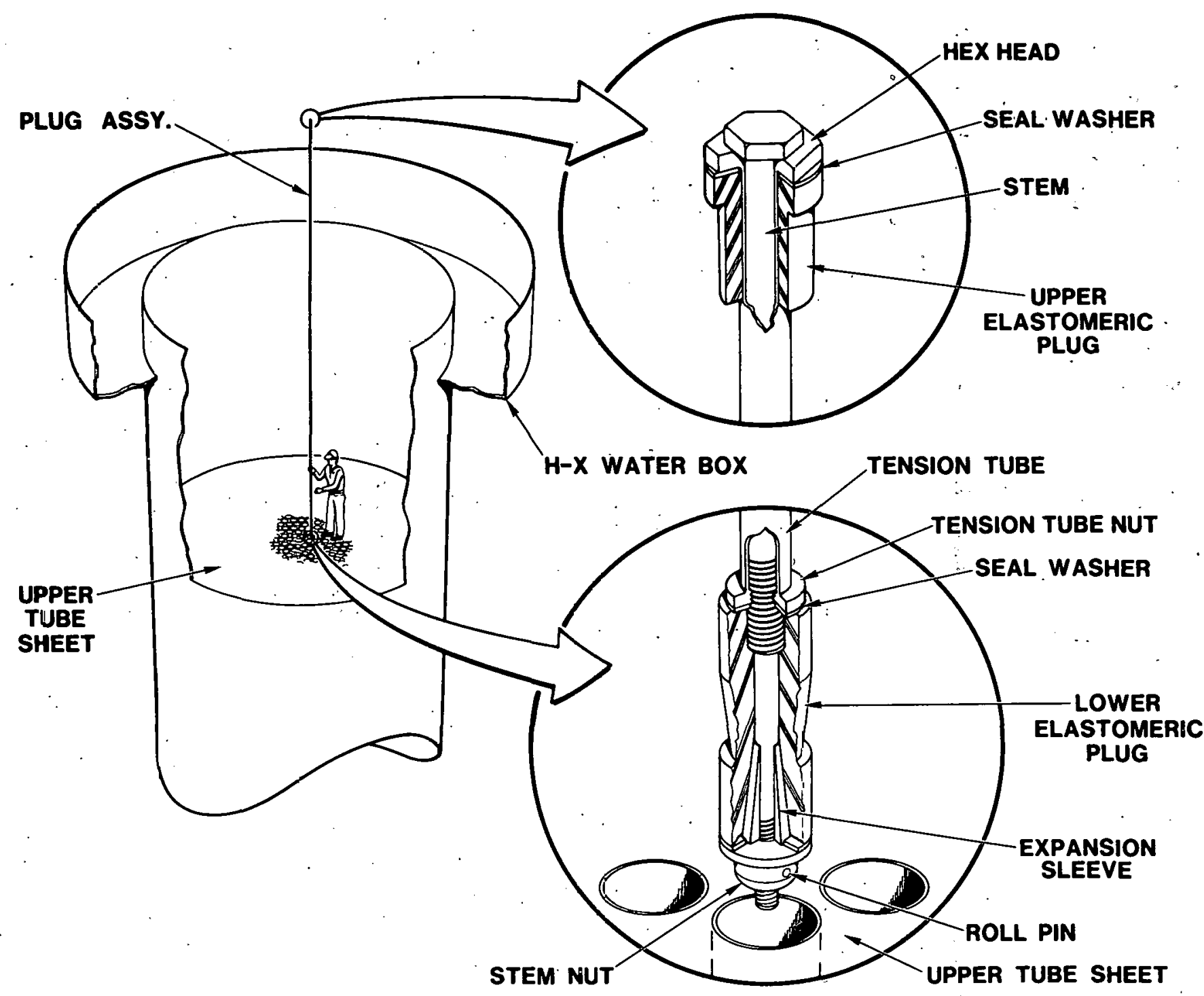

Figure 2.6-15. Heat Exchanger Tube Sealing Plug Concept 


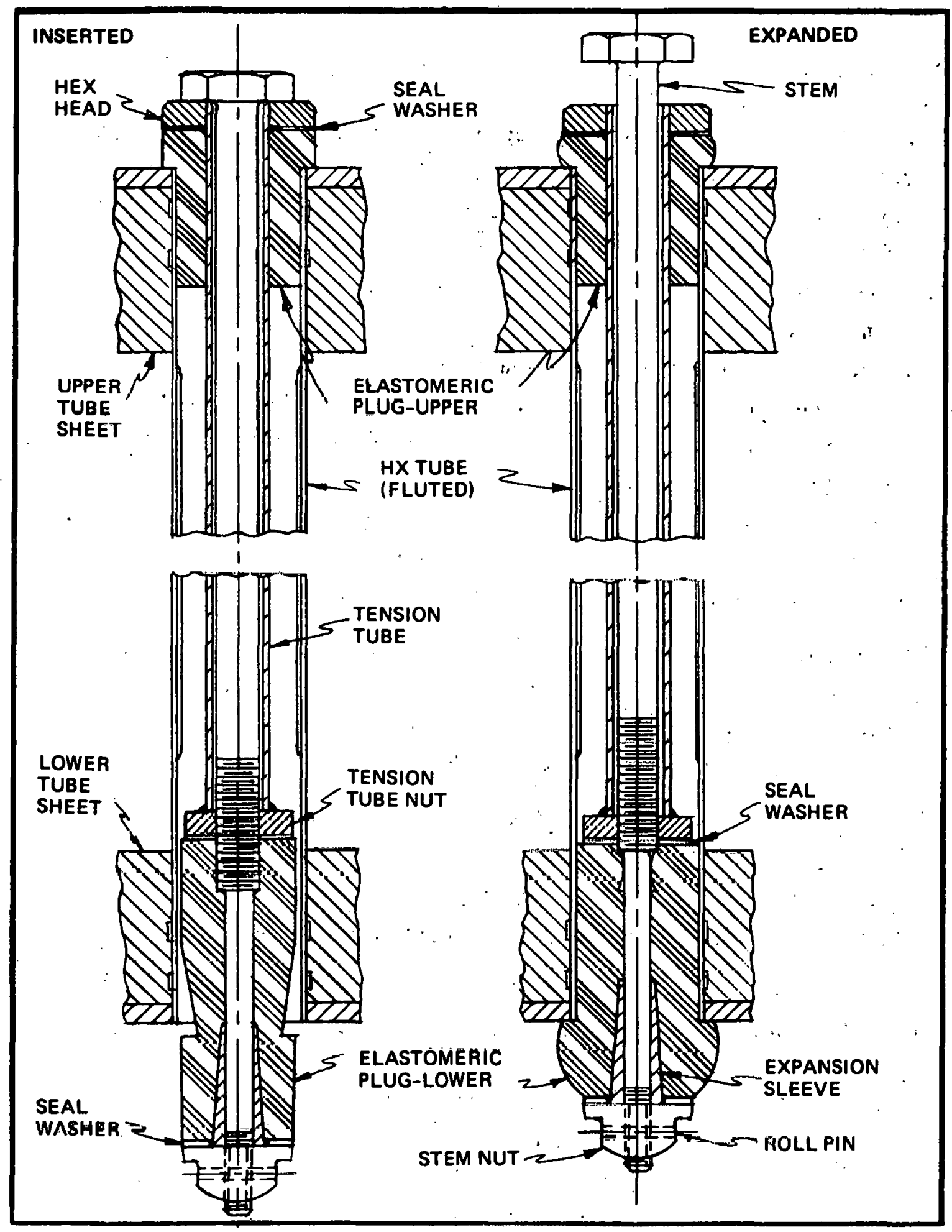

Figure 2.6-16. Heat Exchanger Tube Sealing Plug Concept-Operation 
Installation of the sealing plug assembly is a simple operation which requires the use of only two wrenches as follows: when a leaking tube has been identified an unexpanded plug is manually inserted from the top tubesheet. The plug is allowed to drop down until it rests on the upper seal shoulder. Then the large hex (welded to the tension tube) is held stationary with one wrench while the small hex. (stem head) is turned out counter-clockwise (see figure 2.6-16). This action compresses the specially designed lower elastomeric seal causing it to increase in diameter and expand out over the tube and tube-to-tubesheet joint as shown in Figure 2.6-16. This effectively seals the tube and lower tube-to-tubesheet joint and provides an anchor for pulling down the upper seal. After the lower seal has been completely expanded and set, the small hex is held stationary and the large hex turned down (clockwise) compressing the upper elastomer a predetermined amount to effectively seal the upper end of the tube and tube-to-tubesheet joint. The upper end has been designed to be compatible with the tube cleaner head and brushes.

The materials of construction for the plug will be determined during a development and test phase and will be selected to provide leak tight sealing for a maximum perind of time. Neoprene is the prime candidate seal material because of its excellent resistance to seawater.

\subsubsection{Identification of Leaking Tubes}

Two methods of leak detection are available. The first method utilizes composite and individual sampling leak detection for minor leaks during system operation, as described in Section 2.6.4.2.

The second method will be utilized for major leaks. The general procedure will consist of system shutdown and isolation of the problem condenser or evaporator by closure of valves $v-1, v-2, v-3, v-4$, or $V-5$ (see figure 2.1-4). The problem heat exchanger will then be purged and pressurized with nitrogen gas to operating pressure (12a psia for the evaporator, an psia for the condenser). Because of the unique open top water hox configuration, relatively simple visual techiniques will be used to identify leaking tubes. With the water pumps off, the tubes will be 
naturally filled with water to a fev inches above the tube sheet. Leaking tubes can then be identified by nitrogen bubbles rising in the water. A man standing on the tube sheet can readily identify and plug defective tube as shown in Figure 2.6-15.

In the event that the leak is at the hottom tube to tube sheet joint migrating bubbles may come up adjacent tubes requiring trial and error selective plugging identification of the defective tube. Since the tuhe sealing plug weighs less than 15. pounds for easy handling and is designed for installation in 20 minutes or less this selective plugging identification should be accomplished in less than one hour with two trained maintenance persumiel.

It is observed that the system could be shut down, 14 leaking tubes identified and plugged and the system returned to operations in approximately one day or, one tube in 12 hours, using the visual technique, as indicated in the maintenance time lines of Table 2.13-5. The on-line composite/individual tube sampling technique can take as long as 27 hours, maximum, to identify and repair a leaking tube at an estimated additional equipment cost of approximately $\$ 1, n n n, n n n$. Based on these ohservations it. is recommended that an economic analysis be conducted early in detailed design to determine the most cost effective approach. 


\subsection{ROTATING MACHINERY}

This section describes the turbine generator and the ammonia pumps, and the performance requirements and interfaces of the seawater pumps.

\subsubsection{Turbine Generator}

\subsubsection{Introduction and Summary}

The preliminary design efforts for the turbine: generator concentrated on the turbine. No turbine (or expander) using ammonia as the motive fluid is known to exist whereas the generator will be an off-the-shelf design. The main objectives of the preliminary turbine design work are listed below.

- Select the optimum type of turbine - axial flow or radial inflow

- Select the optimum flow path - single or double flow

- Select the optimum number of stages - single or multiple

- Evaluate critical areas to a depth which provides technical and economic credibility

- Arrive at a cost estimate for detail design, development, and fabrication.

The bulk of the preliminary design work was done by the Elliott Company, a Division of Carrier Corporation, under subcontract with TRW. Elliott is a leading manufacturer of turbomachinery for the power and process industries. Their products include centrifugal and axial compressors, steam turbines, power turbines, and expanders. Elliott's report is included as Appendix F.2. In addition, Professor L.L. Ambs of the IIniveristy of Massachusetts was engaged as a consultant. Professor Ambs is the author and coauthor of various papers and reports on turbine designs for OTEC power recovery. The conclusions of the preliminary design work are listed below (see Appendix F.1):

- Althuugh an ammonta turbine has not been built, its design is well within the state of the art and fabrication can be done with existing shop techniques and facilities.

- The optimum design for 10 MWe net power recovery is a four-stage axial dnuble flow turbine running at $1800 \mathrm{rpm}$ connected to a four-pole synchronous generator. 
- Variable nozzles for the first expander stage are justified for off-design conditions, for matching the expander to particular site conditions, and for high frequency control (see Section 2.2.2).

- Blade stress and frequencies are mechanicaliy safe.

- Critical speeds are safely away from the operating speed.

- Stress corrosion cracking investigations should be authorized at the earliest possible date to insure that material selections and certain design features are suitable before further turbine design work is done.

\subsubsection{Requirements}

\section{Turbine Generntonr Rnquirement}

The turbine generator requirements for a 10 MWe deliverable power module are summarized in Tahle ?.7-1.

Table 2.7-1.. Requirements

Output, 14.0 MWe* (gross) at $60 \mathrm{~Hz}$ (synchronoü speed)

Nominal input, $807.2 \mathrm{lb} / \mathrm{sec}$ saturated ammonia vapor at $70^{\circ} \mathrm{F}$, $50^{\circ} \mathrm{F}$ outlet state.

Turbine flange to flange efficiency greater than 85 percent

Generator efficiency greater than 97 percent

Provision for power peaking control during input variation

Use of existing technology

30-year life

Base load duty cycle

* Based upon the assumed efficiencies of 85 percent for the turbine and 97 percent for the generator and parasitic loads.

\section{Design Point Criteria}

The system design simulations of the 10 MWe plant produced a set of thermodynamic flow conditions for the turbine (see section 2.1). The flow conditions used for the preliminary design are given in Table 2.7-2. 
Table 2.7-2. Design Point Criteria

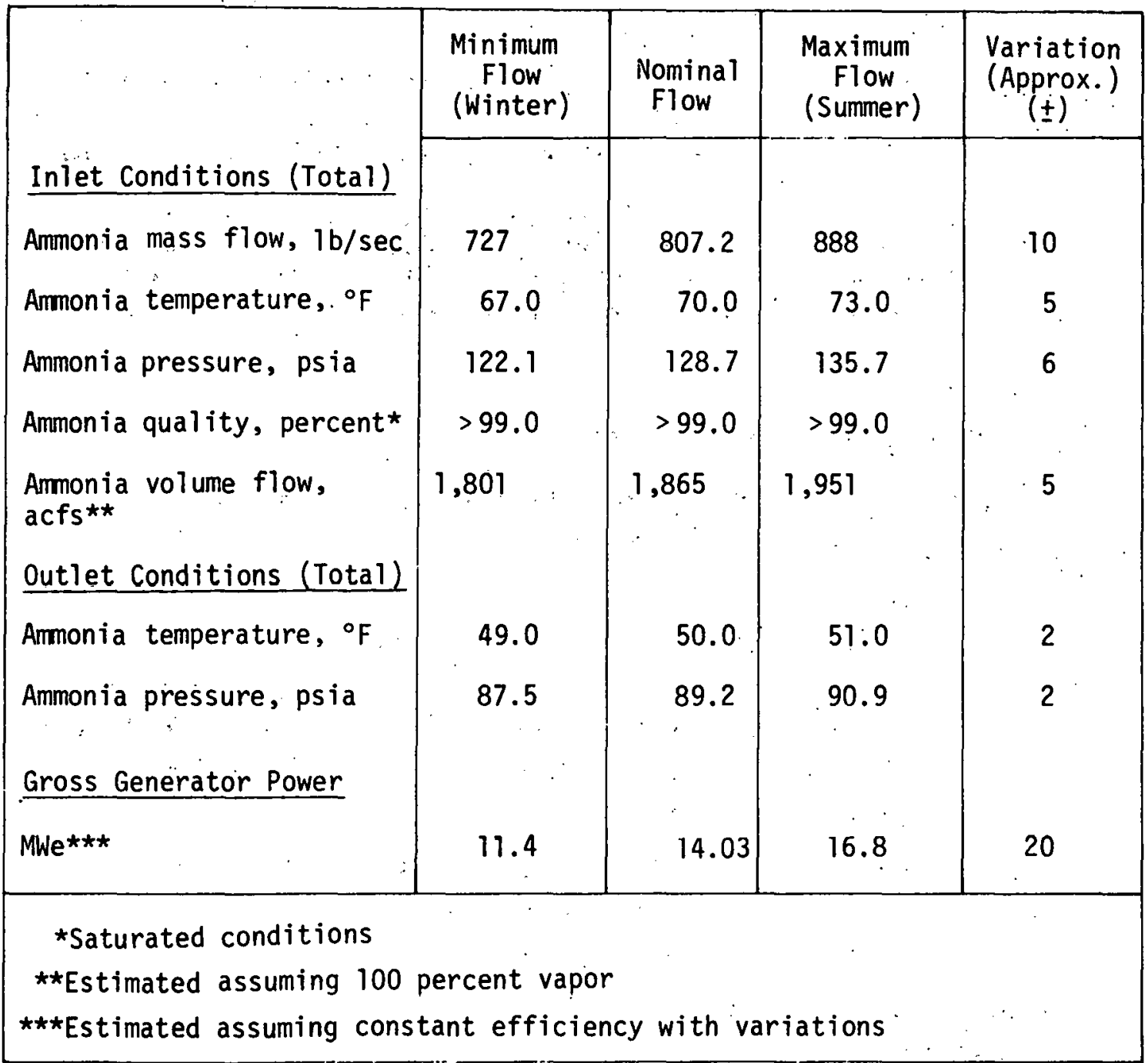

\subsubsection{Technical know-how}

Turbines using ammonia as the motive fluid have not yet been built since there has been no demand for such a turbine. However, the design parameters are well understood and the existing technology and mechanical design details from the power generation and chemical process industries are applicable. The size of the turbine for a 10 Mwe net power station is within the limits that can be handled with the extsting machine tools and shop facilities by a number of machinery manufacturers. Our study indicates that a very efficient ( 89,6 percent) turbine can bc built. 
The closest design with operational experience is for hot gas expanders used to recover power in fluid catalyst cracking plants. Ammonia compressors, also have seen service in large sizes. Tables 2.7-3 and 2.7-4 list a few of the existing expanders and compressors that approach the sizes required and that incorporate technology applicable to an ammonia turbine for the OTEC power module.

\subsubsection{Turbine Optimization and Design}

\section{Efficiency}

The importance of efficiency was discussed in Section 2.1.8. "Because of tradeoffs within the system, an increase in turbine generator efficiency reduces the size of other expensive equipment such as evaporators, condensers, and seawater pumps. As a result, the plant cost decreases by about $\$ 17 / \mathrm{kW}$ for each percent increase of turbine efficiency. Various options were analyzed in order to achieve a turbine generator set with maximum efficiency.

Off design behavior is also an important consideration for the turbine generator when combined with the need for a maximum turbine generator efficiency. Because the plant and turbine generator are optimized at the nominal site conditions, off design site conditions could produce 'flow limiting conditions in a turbine with flxed flow nuzlles. Fluw clioking would occur at the maximum flow conditions of "summer" operation. At the minimum flow conditions of "winter" operation, the pressure in the evaporator would drop below that which would be possible resulting in a lower value of pressure and energy available to the expander. Variable inlet stator vanes provide a cost effective solution to off design conditions.

\section{Aerodynamic Design}

The aerodynamic design of turbines can be divided into three phases. In the first phase, overall design point criteria are set. In the second phase, the design point criteria are used to establish the bastc turbille geometry, including number of stages, blade sizes, and blade angles. Finally, in phase three the blade shapes which will achieve Phase II requirements are dctermined. The resulting turbine efficiency is affected by all three phases. $\because$ 
Table 2.7-3. Hot Gaș Expanders

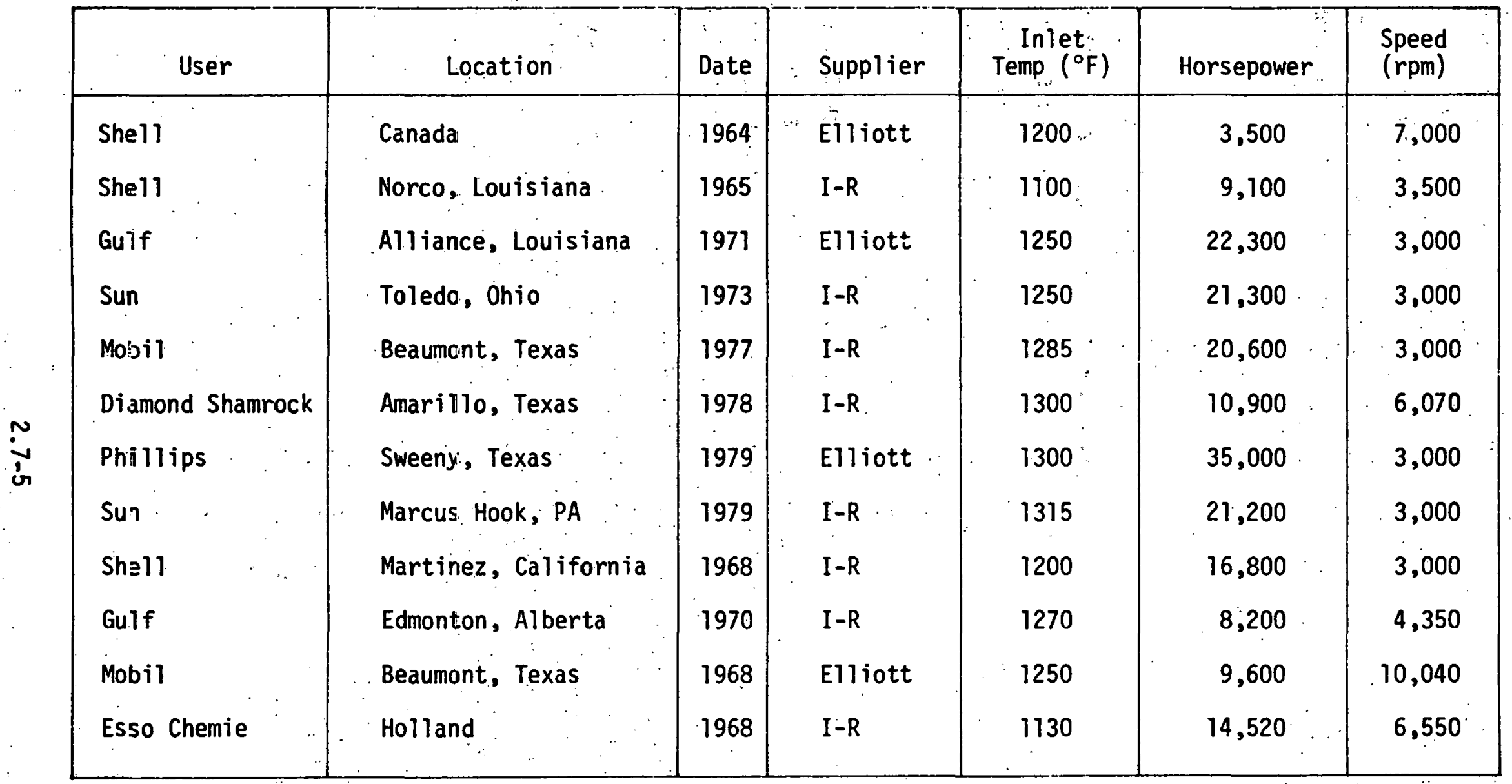


Táble 2.7-4. Centrifugal Ammonia Compressors

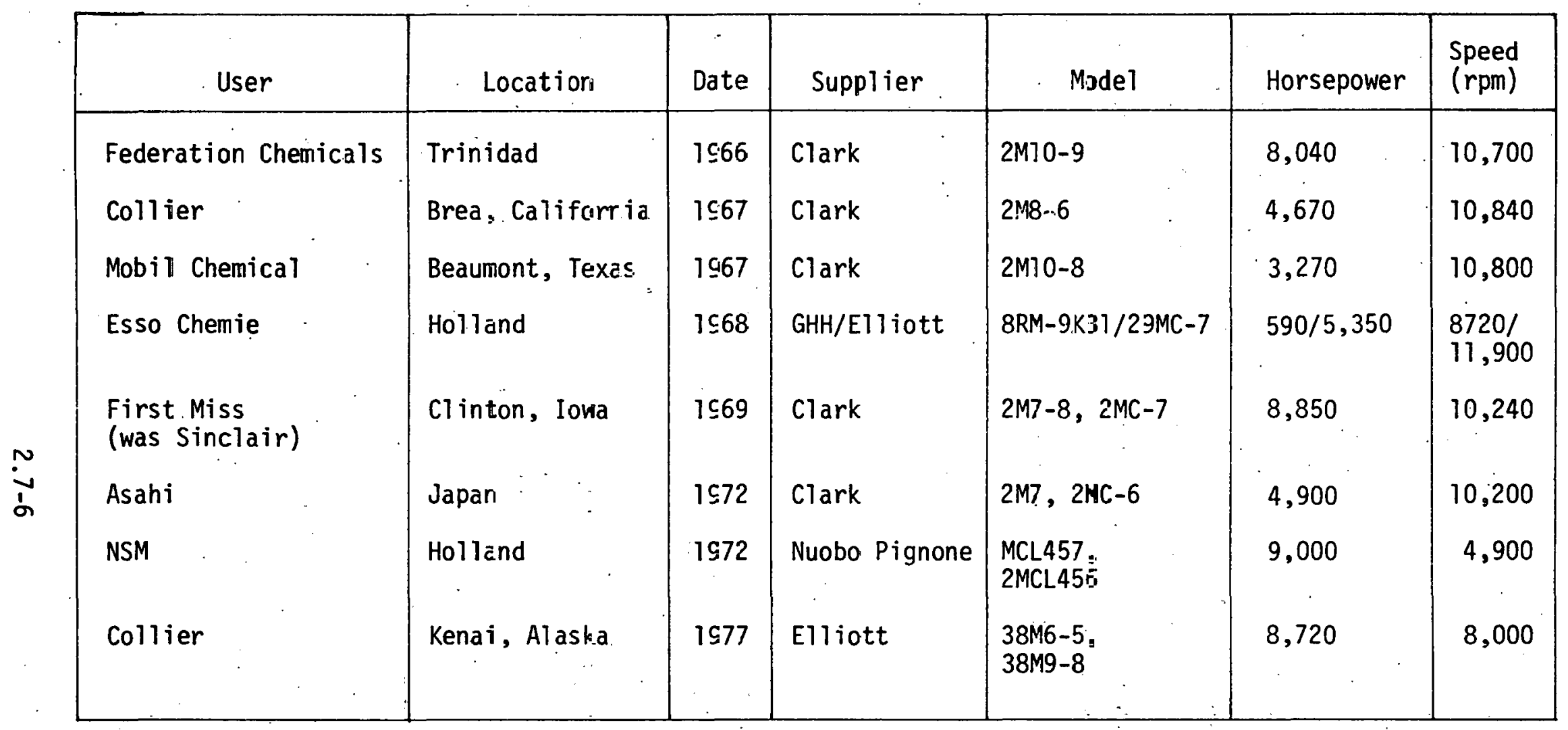


Similitude plays an important role in attaining high efficiency and assists the designer in the design process. A number of dimensionless parameters, such as turbine velocity ratio, flow coefficient, specific speed, specific diameter, Reynolds number, and Mach number are used. Simili. tude consideration indicates that only four of the parameters are needed to completely describe the characteristics of a compressible flow turbomachine ${ }^{l}$. Correlations of performance by the use of the selected parameters shows that there are certain ranges of the parameters which will yield machine performance with high efficiency. The preliminary design of the current project focused on these regions of high efficiency.

A computer program was used to identify promising candidate axial flow expanders. These computer runs are included in Appendix F.1. Table 2.7-5 summarizes some of the results.

Table 2.7-5. 14 MWe Axial Flow Turbine Configurations

\begin{tabular}{|l|c|c|c|c|}
\hline & $\begin{array}{c}\text { Power Output } \\
\text { Per Stage } \\
\text { (MWe) }\end{array}$ & $\begin{array}{c}\text { Flow } \\
\text { Per Stage }\end{array}$ & $\begin{array}{c}\text { Efficiency } \\
\text { Total To } \\
\text { Static }\end{array}$ & $\begin{array}{c}\text { Speed } \\
\text { (rpm) }\end{array}$ \\
\cline { 2 - 5 } Single Stage Single Flow & 14 & Full & 90.2 & 3600 \\
Single Stage Double Flow & 7 & Half & 90.4 & 3600 \\
Two Stage Single Flow & 7 & Full & 90.5 & 1800 \\
Two Stage Double Flow & 3.5 & Half & 89.2 & 3600 \\
Three Stage Single Flow & 4.67 & Full & 90.0 & 1800 \\
Three Stage Double Flow & 2.33 & Half & 90.5 & 1800 \\
Four Stage Single Flow & 3.5 & Full & 87.4 & 1800 \\
Four Stage Double Flow & 1.75 & Half & 90.5 & 1800 \\
Five Stage Single Flow & 2.8 & Full & 90.2 & 1200 \\
Five Stage Double Flow & 1.4 & Half & 90.3 & 1800 \\
\hline Note: The major characteristics of these designs are included in the \\
\hline
\end{tabular}




\section{State of the Art Technology}

Having identified promising candidate expanders, a detailed design study was made to select and evaluate the optimum turbine possible with state of the art technology (this study, made by Elliott Company, Division : of Carrier Corporation, is included as Appendix F2). The results of the design study showed that a four-stage axial double flow machine with exhaust diffuser will yield the highest cost effective efficiency.

In performing the detailed design study comparisons, geometry was constrained to be within existing manufacturing technology, and conventional blade shapes were used. It should be pointed out that a design tradeoff exists in the expander comparison. As the number of stages is reduced, the axial flow velocity through the turbine increases in order to maintain high efficiency. As the axial flow velocity leaving the turbine increases, the importance of a high diffuser pressure recovery also increases. Approximately 10 percent of the available head to the turbine leaves as kinetic energy in the exhaust of a single stage machine. A high diffuser pressure recovery will allow this energy to be recovered but may be difficult within present layout constraints. The net result is that even though somewhat greater disc losses arise by multistaging, the diffuser is not as critical and the overall flow efficiency is higher for a four-stage turbine than for single or double-stage turbine. The following paragraphs summarize key results (for details see Appendix F.2).

\section{Radial Inflow}

State of the art technology limits the maximum wheel diameter of radial inflow turbines to 52 inches. For the nominal operating conditions, a synchronous speed of $3600 \mathrm{rpm}$ gives the best range of velocity ratios for the wheel diameters studied. Mass flows of one-half or greater than the required flow rate result in designs where the exducer outside diameter approaches or exceeds the wheel tip diameter which is an impractical design. This leaves the only practical design for high efficiency radial inflow turbines as a four-flow design.

Figure 2.7-1 shows the comparison between four-flow radial inflow turbines of various wheel diameters. A normalized efficiency of 1.00 on the efficiency scale is the peak efficiency of a four-stage double flow 31 -inch 


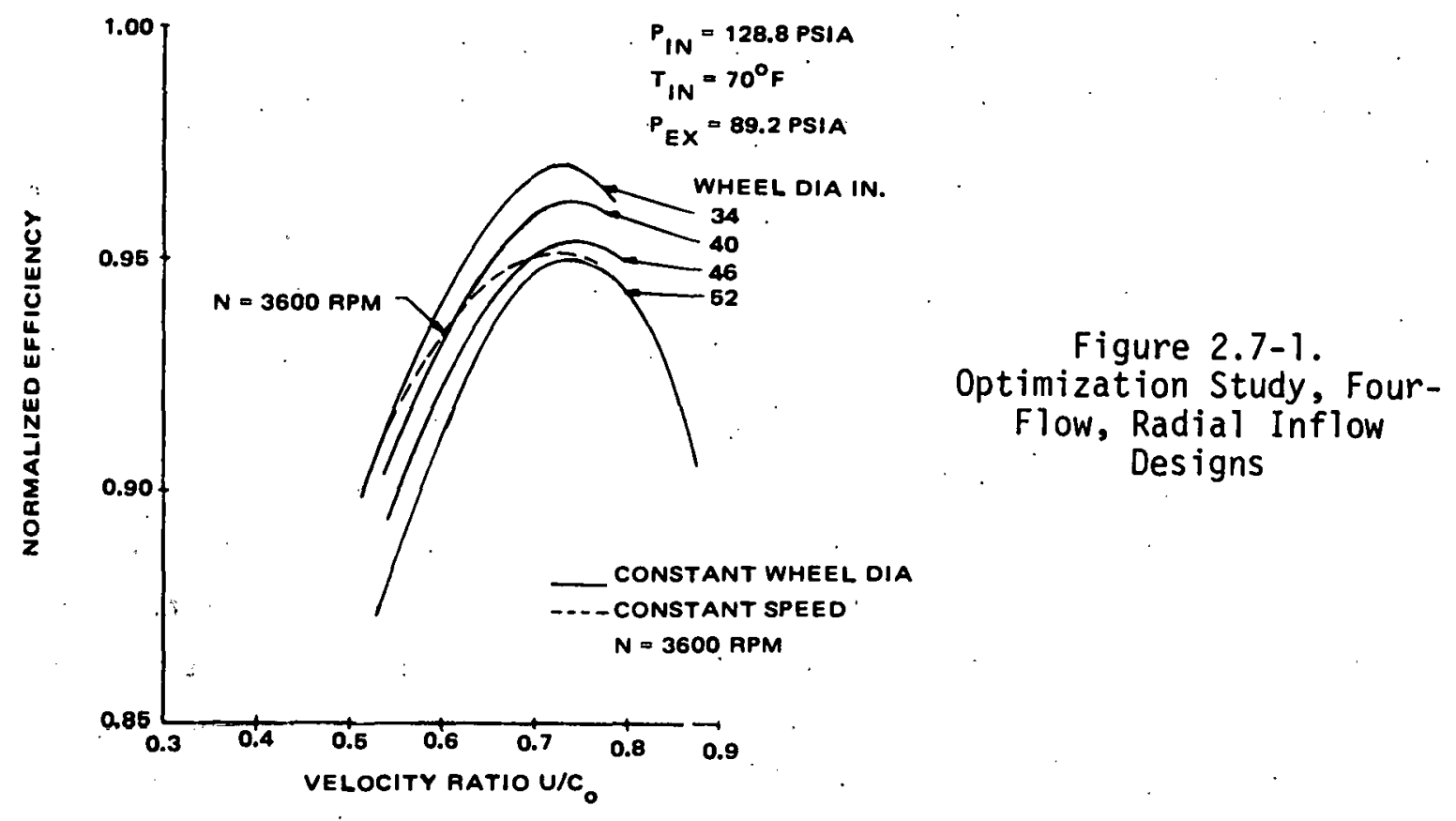

base diameter axial turbine - the final optimum selection. A 46-inch radial inflow turbine has the maximum efficiency at synchronous speed. Its efficiency is 95 percent of the optimum axial turbine. Slightly higher efficiencies are possible at nonsynchronous speeds, but a gear would have to be used and the gain would be offset by the gear losses.

\section{Single Stage Single Flow}

Figure 2.7-2 shows the efficiencies obtainable with a single stage single flow axial turbine. Again, 1.00 on the efficiency scale is the best efficiency obtainable with a four-stage double-flow turbine. Curves are shown for different diffuser recovery factors. A recovery factor of 0.7 is the best possible. At that value, the diameter of the diffuser exit is the same as the 126-inch diameter condenser inlet. The peak efficiency of a single-stage single-flow turbine is a little less than 98 percert of the optimum turbine selection. The diffuser at a recovery factor of 0.7 is over 40 feet long. Even if the space could be made available, the probability of obtaining a pressure recovery factor of 0.7 is considered small. 


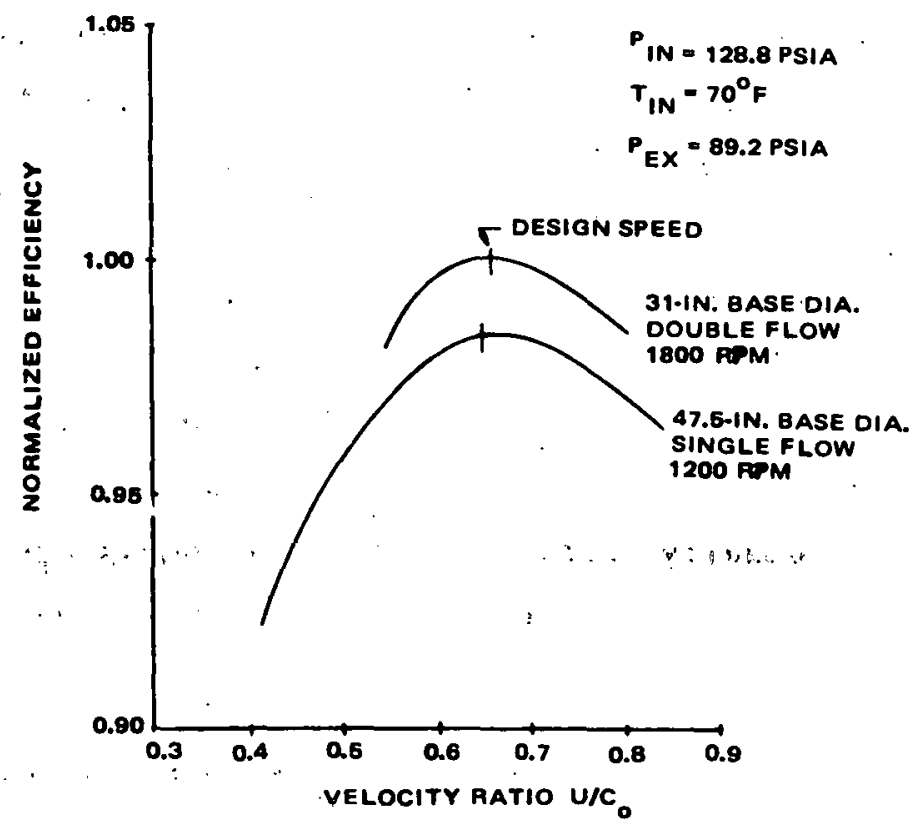

Figure 2.7-3, $\dot{a}:$ Optimization Study, FourStage, 10 MWe Net Designs Real Blades

Four-Stage Single and Double-Flow

Figure 2.7-3 compares a four-stage single-flow axial turbine with a four-stage double-flow axial turbine. The single-flow turbine is 1.6 percentage points less efficient for several reasons. The thrust bearing produces a large loss. The synchronous speed must be reduced from $1800 \mathrm{rpm}$ to $1200 \mathrm{rpm}$. At the lower speed, the base diameter must be increased and the blade $L / D$ ratios must be decreased in order to peak the velocity ratio. These changes also contribute to the lower efficiency of a four-stage single-flow turbine compared to a four-stage double-flow turbine.

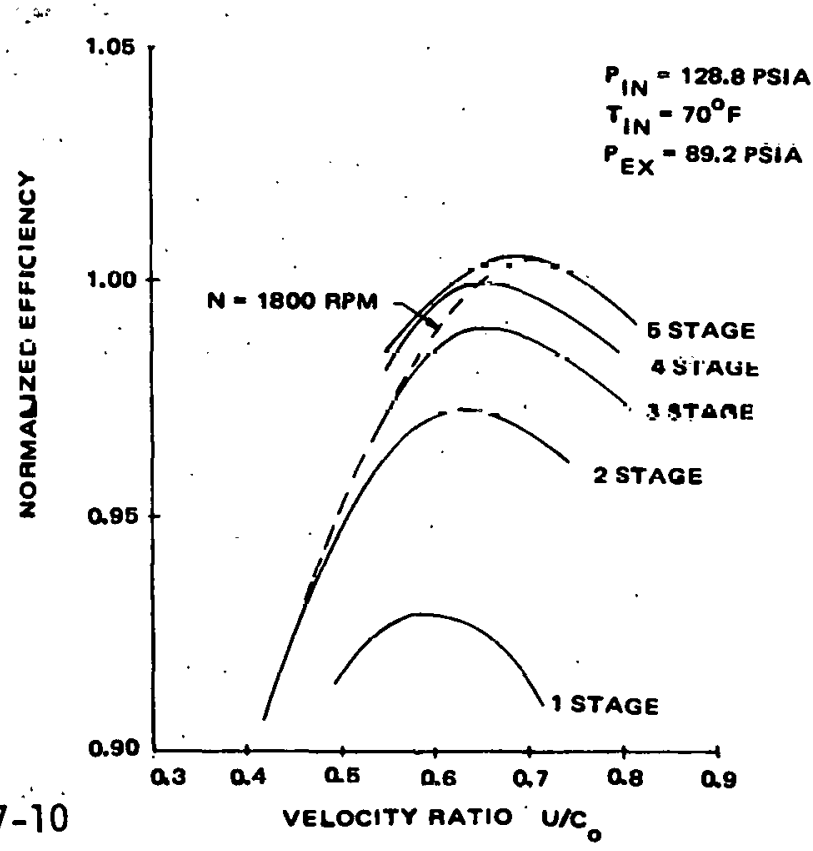

Optimication Study, DoubleFlow Designs, Real Blàdes Base Diameter $=31 \mathrm{in}$. 


\section{Number of Stages}

Figure 2.7-4 shows how the efficiency of a double-flow axial turbine can be improved by increasing the number of stages. The peak is with five stages but the improvement in efficiency from four stages to five stages is small and is not cost effective. "Any greater number of stages would also not be cost effective.

Figure 2.7-4 is based upon the use of real blades. The study in the appendix by Elliott al so compares the efficiencies obtainable with idealized blades to find the optimum theoretical design possible. The conclusion is the same - a four-stage design is optimum. The efficiency of a five-stage turbine with idealized blades is actually less than that of a four-stage design because the blade $L / D$ ratio is limited to state of the art technology.

\section{Variable Stator Vanes}

The use of variable stator vanes is considered the best approach for control of power peaking with an axial flow turbine. The reasons are given below.

- Large volume flows can be handled

- Low pressure drop

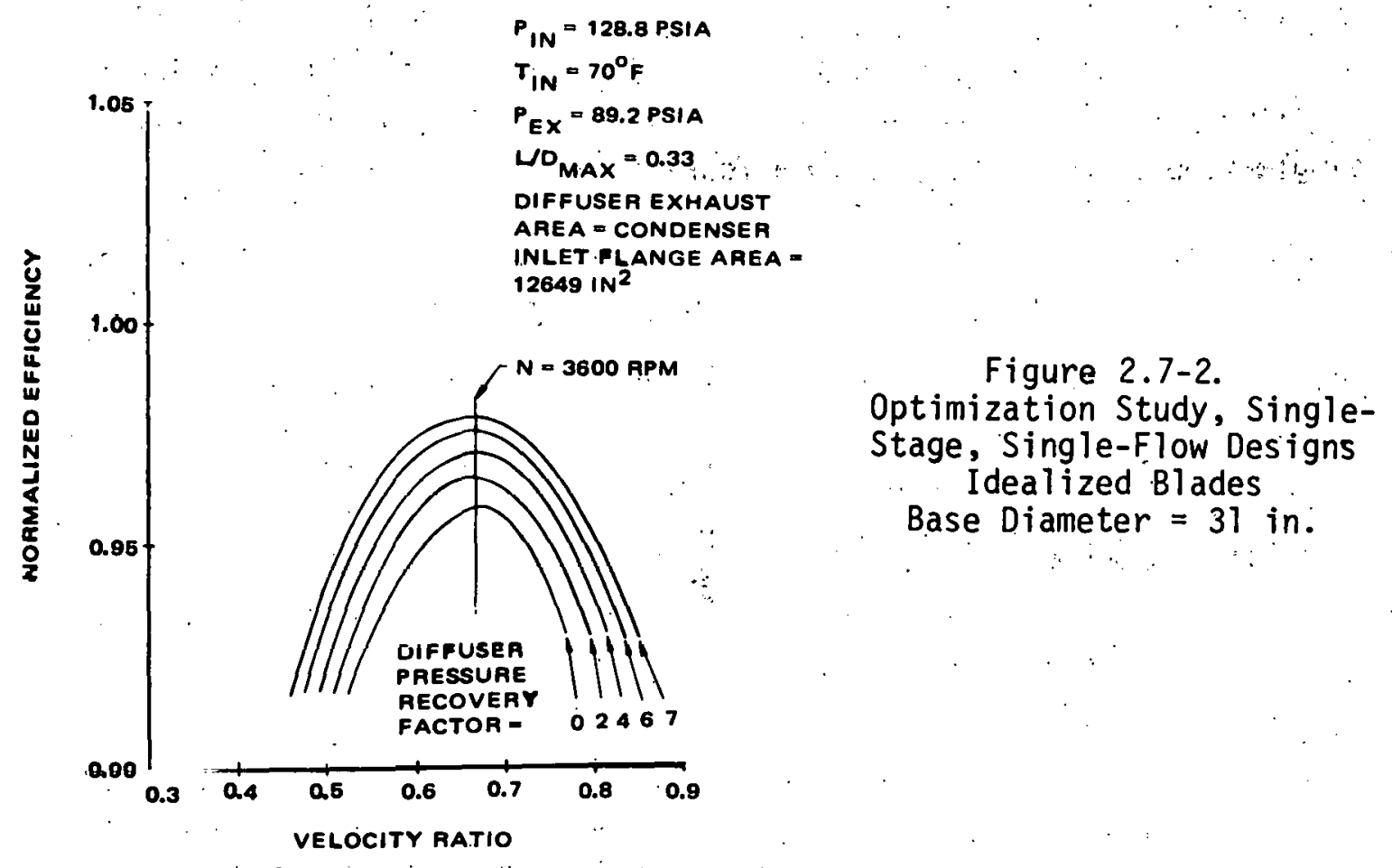


- No flow is bypassed around the turbine

- The system can adjust to off design conditions (changing sea state conditions or different site locations).

Variable nozzles have not been used for axial flow steam turbines because steam conditions are usually considerably different from the ammonia conditions that will be used for OTEC. Steam pressures and temperatures are usually much higher and steam volume flows are usually much less. Historically, axial flow steam turbines have been built with fixed nozzles. Single or multiple valves with conventional seats and plugs have been used for control. Some pressure drop through the valves is tolerable with the usual range of steam conditions and the volume flows allow the use of reasonably sized valves. The use of variable stator vanes in steam turbines would have created serious deformation problems at the steam pressures and temperatures usualiy employed.

Variable stators have for decades been used very successfully throughout the process industry on axial flow compressors. A typical control linkage is shown on Figure 2.7-5. This type of control has given a high level of reliability with a minimum of maintenance. The use of the variable vanes in the control system is described in Sections 2.2.2 and 2.9.3.

Variable stator vanes at the inlet to the first stage of the OTEC axial flow turbine provide a means of accommodating the flow variations from minimum to maximum conditions while maintaining high efficiency. The use of variable stator vanes increases the net power by $150 \mathrm{~kW}$ at the minimum operating point and by $252 \mathrm{~kW}$ at the maximum operating point. Assuming a 360 degree sine wave over a year from minimum to maximum flow conditions, the average yearly increase is $128 \mathrm{~kW}$. At $\$ 1000$ per kilowatt, the saving is $\$ 128,000$. The total cost of variable stator vanes is roughly $\$ 55,000$. The use of variable stator vanes saves money over the life of the turbine in addition to providing better control.

Only one set of variable stator vanes is required at the inlet to the first stage of each flow path. Efficiency is almost constant over the entire range of operating conditions with just one set of variable vanes for each flow path. 


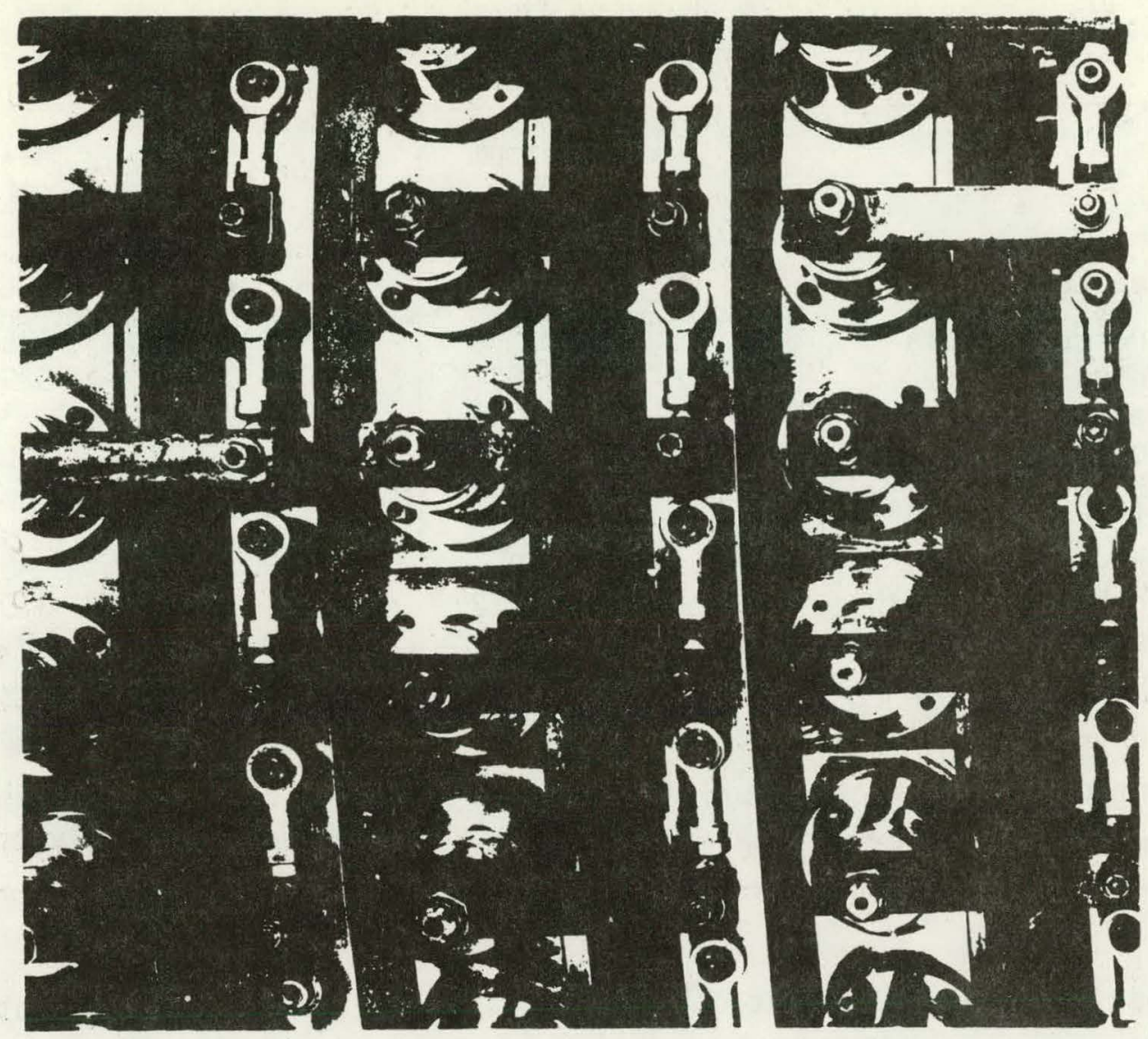

Figure 2.7-5. Variable Stator Control Linkage

\section{Thermodynamic Operating Conditions}

As concluded by Elliott the optimum turbine design is a four-stage double-flow axial turbine with variable inlet stator vanes. The thermodynamic operating conditions for this turbine selection are given in Table 2.7-6.

Performance maps are given in Appendix F.2 to predict power output over a wide range of operating conditions. These maps take into consideration mass flow, inlet pressure, exhaust pressure, váriable stator vane angle, and generator efficiency.

\section{Layout and Arrangement}

A crosscut of the optimized turbine is shown in Figure 2.7-6 and the string arrangement of the turbine generator set is shown on Figure 2.7-7. A barrel construclion is used for the turbine to avoid any leakage problem with a long horizontal joint. 
Table 2.7-6. Thermodynamic Operating Conditions

\begin{tabular}{|c|c|c|c|}
\hline & $\begin{array}{c}\text { Minimum } \\
\text { Flow } \\
\text { (Winter) }\end{array}$ & $\begin{array}{c}\text { Nominal } \\
\text { Flow }\end{array}$ & $\begin{array}{c}\text { Maximum } \\
\text { Flow } \\
\text { (Summer) }\end{array}$ \\
\cline { 2 - 4 } Inlet Conditions (Tota1) & & & \\
Pressure, psia & 122.1 & 128.7 & 135.7 \\
Enthalpy, Btu/1b & 628.54 & 629.04 & 629.56 \\
Temperature, OF & 67.0 & 70.0 & 73.0 \\
Quality, percent & 0.9999 & 0.9999 & 0.9999 \\
Outlet Conditions (Tota1) & & & \\
Pressure, psia & 87.5 & 89.2 & 90.9 \\
Enthalpy, Btu/1b & 612.372 & 611.233 & 610.203 \\
Temperature, OF & 49.0 & 50.0 & 51.0 \\
Quality, percent & 0.9761 & 0.9735 & 0.9711 \\
Expander Mass Flow, 1b/sec & 727 & 807.2 & 888 \\
Isentropic Heat Drop, Btu/1b & 18.069 & 19.874 & 21.637 \\
Total to Static Efficiency,\% & 89.48 & 89.60 & 89.46 \\
\hline
\end{tabular}

Looking at the crosscut, the major parts of the turbine are noted, outer barrel, inner casing, end walls, and rotor assembly. Flow enters from the top center and is distributed circumferentially before it turns axially to feed both sets of blading of the double flow design. After passing through the four stages the ammonia is efficiently diffused to exhaust pressure. The two exhaust flows are joined before exiting through the common exhaust flange on the bottom vertical centerline. The stages are located between the journal bearings. The shaft end mechanical seals are inboard of the journal bearing. The thrust bearing, and speed control devices are outboard at the journal bearing on the nondrive end.

The major parts contained by the inner casing are the variable stator vanes for each direction flow, three diaphragm assemblies for cach direction of flow, and a diaphragm seal for each diaphragm. The variable stator vane linkages are indicated. One control rod penetration of the outer barrel is required for the ring of variable stator vanes serving each flow direction. The rods penetrating the outer casing are sealed by bushings and 0 -rings to prevent ammonia leakage to the atmosphere. 


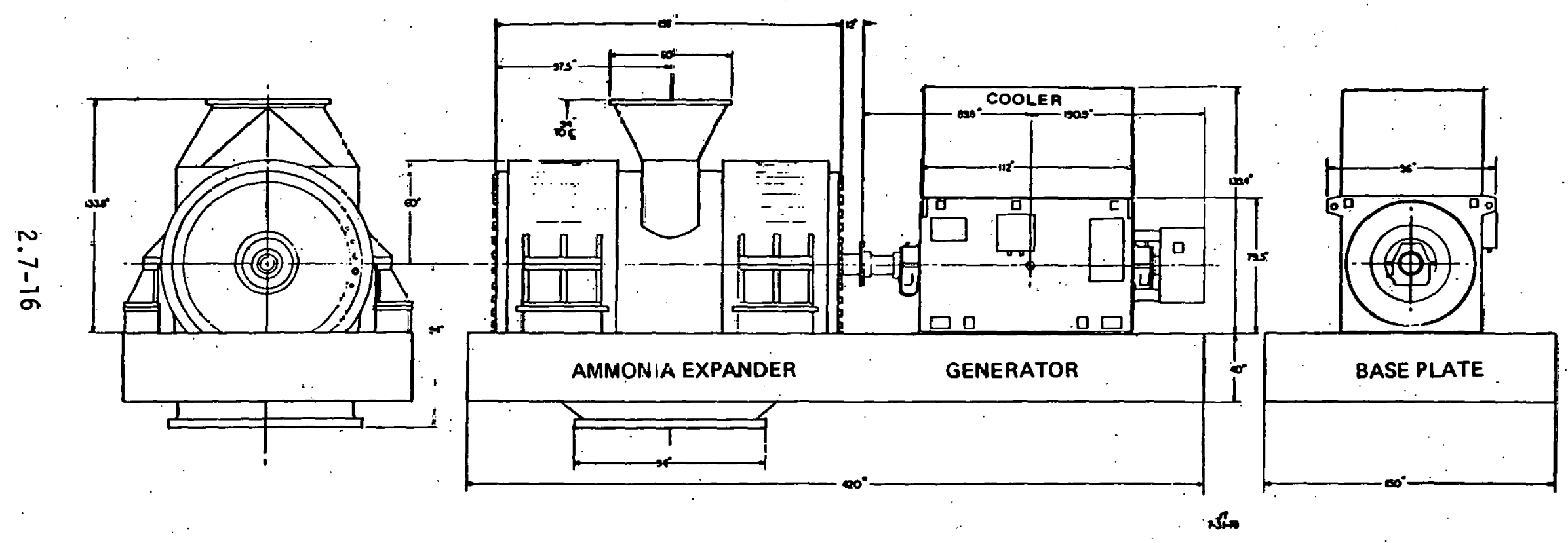

Figure 2.7-7. Turbine Generator/String Arrangement 
The string arrangement on Figure 2.7-7 shows the pertinent dimensions. Roughly another 17 feet clear space is required to pull the rotor from the turbine barrel and another 13 feet of clear space at the other end is required to pull the generator rotor. A laydown area 38 feet wide by 24 feet long is required for work on the turbine rotor. This same area could be used for the generator rotor. If a separate laydown area is deemed necessary for the generator rotor, it can be 20 feet by 20 feet.

Scalability

The optimized turbine generator set developed in the preliminary design study can be scaled upwards. One way of increasing the power output of the train is simply to double the capacity of the generator, double end it, and put duplicate turbines at each end of the generator. The controls for such a train become more complicated.

Another approach is to scale the optimized turbine designed for $1800 \mathrm{rpm}$ to other synchronous speeds, $1200 \mathrm{rpm}$ and $900 \mathrm{rpm}$. This is done by holding the velocity ratio $\left(U / C_{0}\right.$, mean blade speed divided by isentropic velocity) constant, holding the blade $L / D$ ratio constant, and varying the base diameter. The base diameter increases by the inverse ratio of the synchronous speeds (1800/1200, for example). The capacity and the gross power output increase by the square of this ratio. Once again, scaled duplicate turbines could be coupled to a double-ended generator to double the capacity of the train.

By accepting a nonsynchronous speed turbine, the optimized turbine can be scaled to any desired gross power output. Again the velocity ratio and the blade $L / D$ ratio are held constant. The original base diameter times the square root of the power ratio gives the new base diameter. The original base diameter times the square root of the power ratio gives the new base diameter. The original speed divided by the square root of the power ratio gives the new speed. A gear will have to be used to drive the generator at synchronous speed. This will reduce the power at the generator coupling by about 2 percent. Gears have other disadvantages by increasing the size of the oil facilities and they are a frequent source of maintenance problems. 
Table 2.7-7 shows various scaled arrangements of the optimized 15 MWe maintenance problems.

Table 2.7-7. Scaled Turbines

\begin{tabular}{|c|c|c|c|l|}
\hline $\begin{array}{c}\text { Gross Output } \\
\text { (MWe) }\end{array}$ & $\begin{array}{c}\text { Speed } \\
\text { (rpm) }\end{array}$ & $\begin{array}{c}\text { Base Diameter } \\
\text { (inches) }\end{array}$ & $\begin{array}{c}\text { Relative } \\
\text { Throughput }\end{array}$ & Remarks \\
\hline 15 & 1800 & 31.0 & 1.0 & Base design \\
30 & 1800 & 31.0 & 2.0 & Two 15 MWe turbines \\
33.75 & 1200 & 46.5 & 2.25 & \\
60 & 900 & 62.0 & 4.0 & Two 33.75 MWe turbines \\
67.5 & 1200 & 46.5 & 4.5 & Two 60 MWe turbines \\
120 & 900 & 62.0 & 8.0 & Gear required \\
25 & 1394 & 40.0 & 1.67 & Gear required \\
75 & 805 & 69.3 & 5.0 & \\
\hline
\end{tabular}

All of the turbine sizes shown on the table are believed to be within the state of the art manufacturability. But for turbine units above 15 MWe gross output, there may only be selected manufacturers with the required machine tools and shop capabilities.

\subsubsection{Generator}

\section{Design}

The generator proposed in Elliott's study is a Brown Boveri 4-pole synchronous generator, totally enclosed, water-to-air cooled, rated at $18,000 \mathrm{~kW}$. It is a standard model. The efficiency is 97.03 percent at the normal design point operating conditions of $15,040 \mathrm{~kW}$.

Some improvement in efficiency could be achieved with a hydrogen cooled generator, perhaps 0.2 to 0.5 percentage points. But the utility industry has in general not found hydrogen cooling economical below about 35 MWe. For this reason, hydrogen cooled generators are generally not available below this capacity. 
The design power factor of the generator will depend upon the grid to which the generator is connected. A generator power factor of 0.85 is generally considered adequate for utility installations; but this must be verified for the grid that is to be served before firm design conditions are given to the generator supplier.

\subsubsection{Control and Instrumentation}

\section{Normal Control}

A schematic of the control system is shown in Figure 2.7-8. In normal operation, two modes of control are foreseen. One mode is a base loaded operation where it is desired to maximize the power output at all times for the available energy that can be extracted from the prevailing seawater temperatures. The other mode is a nonbase loaded operation for a captive user with a variable demand. The variable inlet stator vanes are an essential part of the control system for both modes of control.

For the base loaded operation, synchronous speed is maintained by the power grid to which the generator is connected. When the generator moves from synchronous speed, the grid supplies real power to return the generator to synchronism: A load controller senses the generator power output. The controller moves the variable stator vanes a predetermined amount at preset time intervals in one direction. If the power output increases, movement in the same direction continues. The amount of movement at each time interval decreases as the position of the variable stator vanes approach a predetermined set point. If the power output decreases, the controller reverses llie direction of the varlable stator vane movement.

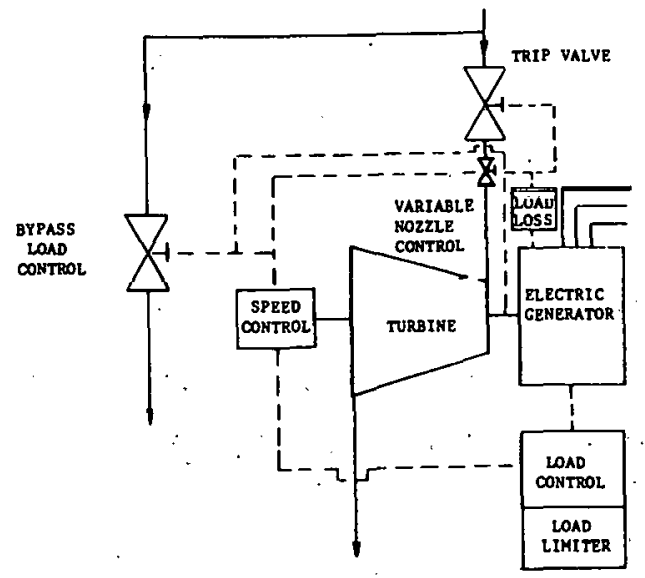

Figure. 2.7-8. Proposed Control Schematic 
This continual hunting maximizes the power output for any seawater conditions. A load limit override protects the generator from any stator vane movement that. would exceed the rated capacity of the generator. The controller dead band, proportional band, and reset must be adjusted and tuned at the site to match the response of the system.

For the nonbase loaded operation; the generator produces the power required by the load. If the generator load decreases, the speed will tend to increase. The speed control will quickly move to close the variable stator vanes to return the speed to $1800 \mathrm{rpm}$. If the load increases, the speed will tend to drop and the variable stator vanes will quickly open to return the speed to $1800 \mathrm{rpm}$. The load limiter control will override any speed control input to the variable stator vanes that would exceed the capacity of the generator.

The control scheme has been reviewed with Woodward Governor Company. It is considered practical although there are no known applications of this kind. Sections 2.2.2 and 2.9.3 discuss the turbine control scheme, as it is embedded in the actual instrumentation and control.

\section{Startup}

It is assumed the power loop is charged with dry ammonia and that the ammonia feed and the ammonia recirculation pumps are in operation on automatic control. The turbine trip valve is closed, the turbine bypass valve is open, and the turbine variable stator vanes are at their minimum position. The turbine generator oil system is placed in operation. Then the warm and cold seawater pumps are activated.

The turbine bypass valve is slowly throttled to increase the pressure in the evaporator to its normal operating pressure. Next, the turbine trip vaive is opened to admit a nominal amount of vapor. When the breakaway torque is reached, the turbine generator will come up to some idling speed. The variable stator vanes are opened and the bypass valve is further throttled until approximate synchronous speed is reached. The variable stator vanes are used to synchronize the generator.

After synchrorization, the load on the generator is gradually applied by slowly closing the bypass valve and opening the variable stator vanes. After the bypass valve is completely closed, a bumpless transfer is made to automatic control for normal operation....

$$
2.7-20
$$




\section{Planned Shutdown}

A planned shutdown is essentialiy the reverse of startup. The load on the generator is gradually reduced by slowly opening the turbine bypass valve. When the generator output is just above the parasitic load of the sea station, about 4 MWe, the turbine is manually tripped. The automatic trip actions are described under Emergency Shutdown. When the turbine is tripped, the complete loss of power output from the generator will shutdown the warm and cold seawater pumps. Without heat input to the evaporator, its pressure will decay:

\section{Emergency Shutdown}

A number of emergency conditions will automatically trip out the turbine. These are listed below:

- Loss of generator load

- Overspeed

- Low lube oil pressure

- Low seal oil pressure

- Axial displacement of turbine

- Axial displacement of generator.

- Excessive turbine vibration

- Excessive generator vibration.

Loss of generator load is the most serious because this would lead to a rapid increase in speed. Load loss will immediately initiate three simul. taneous trip actions. These are closing the turbine trip valve, opening the turbine bypass valve, and moving the variable stator vanes to their minimum position.

If the turbine should reach overspeed, redundancy trips are provided:

a. A speed signal from the electronic speed counter

b. A mechanical, overspeed trip on the turbine shaft.

The mechanical trip is a spring opposed pin that is thrown outward by excessive speed unt1l it hits a.striker plate. Movement of the striker plate causes a: loss of oil pressure that initiates the trip. The overspeed 
set points are $1854 \mathrm{rpm}$ ( 3 percent) for the electronic speed counter and $1980 \mathrm{rpm}$ (10 percent) for the mechanical overspeed trip. In addition, a manual trip is provided. Each of these trip devices will initiate all three trip actions described for loss of generator power.

The three redundant trip actions will also be initiated by any of the other emergency conditions - low lube or seal oil pressure, excessive axial displacement of the turbine or generator, or excessive vibration of the turbine or generator. All of these trips will be provided with a prealarm to warn the operator of pending trouble.

All alarm and trip conditions will show on an annunciator panel. This will have a first-out feature that cledrly identifies the first emergency condition that initiated any trip.

\section{Control Valves}

Two main control valves are closely associated with the turbine - the trip valve and the bypass valve. The trip valve is 60 inches in diameter and must close in about 0.5 seconds. A swing through type butterfly will be used for the trip valve. It will be located as close as possible to the turbine inlet flange.

The bypass valve will he 30 inches in diameter. It must seat tightly so that all available ammonia flow passes through the turbine. The important characteristic of this valve is that it can fully open at the time of an emergency tripout in about 1 second or less.

\section{Instrumentation}

The turbine, the generator, and the oil system will be provided with instrumentation to continuously monitor the performance of the mechanical components and indicate malfunctions. The monitoring instruments are listed in Table 2.7-8.

In addition to the monitoring type of instrumentation; liermodynamic data around the turbine will be collected. This includes the following data:

- Inlet pressure.

- Outlet pressure 
Table 2.7-8. Monitoring Instruments

\begin{tabular}{|c|c|c|}
\hline$\therefore \quad$ Turbine & & $\begin{array}{l}\text { Speed } \\
\text { Vibration } \\
\text { Axial Position } \\
\text { Bearing Metal Temperature } \\
\text { Bearing Drain Oil Temperature } \\
\text { Seal Drain 0i1 Temperature }\end{array}$ \\
\hline$\therefore$ Generator & & $\begin{array}{l}\text { Stator Temperature } \\
\text { Vibration } \\
\text { Axial Position } \\
\text { Bearing Metal Temperature } \\
\text { Bearing Drain 0il Temperature } \\
\text { Cooling Air Temperature } \\
\text { Cooling Water Temperature } \\
\text { Cooling Water Leak Detection. } \\
\text { Power Output }\end{array}$ \\
\hline Oil Console & & $\begin{array}{l}\text { 0il. Reservoir Level } \\
\text { 0il Temperatures at Various Points } \\
\text { 0il Pressures at Various Points } \\
\text { Seal 0il Differential pressure } \\
\text { 0il Cooler \& Filter Differential Pressure }\end{array}$ \\
\hline
\end{tabular}

- Interstage pressures

- Ammonia flow (liquid flow from the condenser).

The inlet ammonia quality and the ammonia composition will also be required. for complete thermodynamic evaluations. This data could be based upon samples taken as required or possibly analyzed continuously.

A11 instrument outputs will be fed to a computer for readout as desired. Iri a number of cases, local instruments will be provided for backup and for aids while visually inspecting the unit.

\subsubsection{Mechanical Design}

\section{Stress Corrosion}

Contaminated dry liquid ammonia can cause stress corrosion cracking of steel. Oxygen is considered to be the main contaninant that causes the problem and high strength steels have been found more susceptible than low strength steels. Water is considered an inhibitor to stress corrosion cracking by contaminated ammonia. The 1975 DOT regulations require 
0.2 weight percent water in all ammonia transported in high strength steel tanks. If the water content is less, stress relieved low strength steels must be used.

Surveys show stress cracking corrosion by ammonia occurs mainly in storage and transportation vessels that are subject to air (oxygen) contamination. Refrigerated ammonia storage tanks do not have the problem: One suggested answer is that the oxygen is removed and vented off as noncondensibles by the holding refrigeration facilities. Ammonia production plants do not have any particular problem. It is believed the oxygen content of as-made ammonia is in the order of $0.0001 \mathrm{ppm}$. This is way less than can be detected analytically. Ammonia refrigeration compressors have no known failure problems, but the ammonla passing linuugh the comprcssor is in the superheated vapor state.

In the ammonia turbine, some liquid ammonia will be present. The possibility exists for oxygen contamination during the several transferring operations that will be required before the ammonia is in the pialfurin storage vessels - activating idle loading lines, for example. Therefore, the possibility of oxygen contamination is quite real. Using sufficient water to inhibit stress cracking corrosion would reduce the cycle efficiency an intolerable amount. The ammonia purification column should remove some oxygen with the noncondensibles vented from its condenser, but this may not be adequate. One report suggests that ammonia: with 1 ppm by weight of water should have less than $2 \mathrm{ppm}$ by weight of oxygen and that the vessel should be inspected once every 2 years. For less frequency inspection, the oxygen content should be a tenth of this (see Section 2.8.2.2, ammonta conditioning subsystem).

Because past stress corrosion cracking problems have been mainly confined to storage and transportation vessels, essentialiy all work has been done on steels used for vessel fabrication. The steels that wuld be used for the stressed parts of an ammonia turbine (shaft, wheels, biades, shrouds, and the like) have not been investigated. Stress corrosion cracking susceptibility will determine suitable materials and could affect certain design features. For example, if dampening-shrouds must be replaced with zigzag lashing pins, it could reduce the turbine performance by 
1.4 percent. Discs that are shrunk on or that are integral with the shaft is another design feature that cannot be decided at this time. It is imperative that possible materials for the ammonia turbine be investigated for stress corrosion cracking susceptibility before further turbine design work is done.

\section{Materials}

A table showing the material selections for the main components is included in Appendix F.2. The main feature is that normal steam turbine steels are used for the rotating parts but in an annealed condition. This. is to reduce their yield strength and hopefully avoid stress corrosion cracking problems. Fortunately, the operating stresses are low enough in the ammonia turbine to permit this.

The pressure containing parts, i.e., outer casing barrel and endwalls, are low strength materials selected for resistance to stress corrosion cracking. The materials selected for the pressure containing parts are also suitable against low temperature embrittlement. This protection is needed should the system temperature drop to $-28^{\circ} \mathrm{F}$ if it is vented to atmospheric pressure.

\section{Radial Bearings}

The choice is between tilting pad type or cylindrical type. The tilting pad type is more expensive and is normally. used for high speed applications to avoid possible oil whip vibration problems. For the $1800 \mathrm{rpm}$ rotor speed selected, the cylindrical type is recommended. They will be spherically seated in the bearing housings to facilitate alignment of the bearings to the shaft. The size selected will take into consideration the loading, sea state conditions, and critical speeds.

\section{Thrust Bearing}

Aside from any aerodynamic aspects, a double flow turbine, compressor, or pump has an advantage over a single flow design in that the thrust load is inherently balanced.: For the 10 MWe net turbine generator, a double flow turbine design results in a significant thrust bearing size reduction. Thrust bearing frict lon losses are therefore conslderably reduced. 
A modest size double acting Kingsbury thrust bearing (55.1 square inches) is considered adequate to accommodate the generator thrust loading due to any magnetic misalignment of the generator and the thrust. due to manufacturing tolerances on either side of the double flow unit. A typical Kingsbury type thrust bearing with its tilting shoes is shown in Figure 2.7-9. The thrust collar is removable from the shaft for ease of maintenance but does not require removal to change the seal for the thrust bearing size required on a 10 MWe net turbine generator.

\section{Seals}

The turbine shaft end seal selection is important since ammonia losses and contamination of the confined hull of the platform must be avoided. This applies to the shutdown condition with the turbine under pressure as well as to the normal operating conditions. The available seal types include labyrinth seals and dry carbon ring seals. Both the labyrinth and carbon ring seals allow some leakage in the operating condition and even more in the shutdown condition. Bushing and face seals require the use of a sealing oil and are frequently used in compressor applications to avoid leakage of the process gas to the atmosphere.

The bushing type seal requires more seal oil flow and has a considerably greater flow of oil towards the pressurized gas side of the seal which must be drained and separated from the entrained gas. Although bushing seals are in use with shutdown pistons to seal in the shutdown condition without a flow of seal oil, this is not a common feature with this type of seal.

The seal design selected for the turbine is the contact type face seal with shutdown features. A typical seal of this type is shown in Figure 2.7-10. This type of seal has a proven record of performance in process gas compressor installations. The seal oil flow past the contact face towards the pressurized gas into the contaminated seal oil drain compartment of the seal is in the order of 10 gallons per day. During idle periods, shutdown pistons automatically lock the face seal ring. This permits the seal oil flow to be shutdown with no ammonia leakage even though the turbine is still pressurized. 


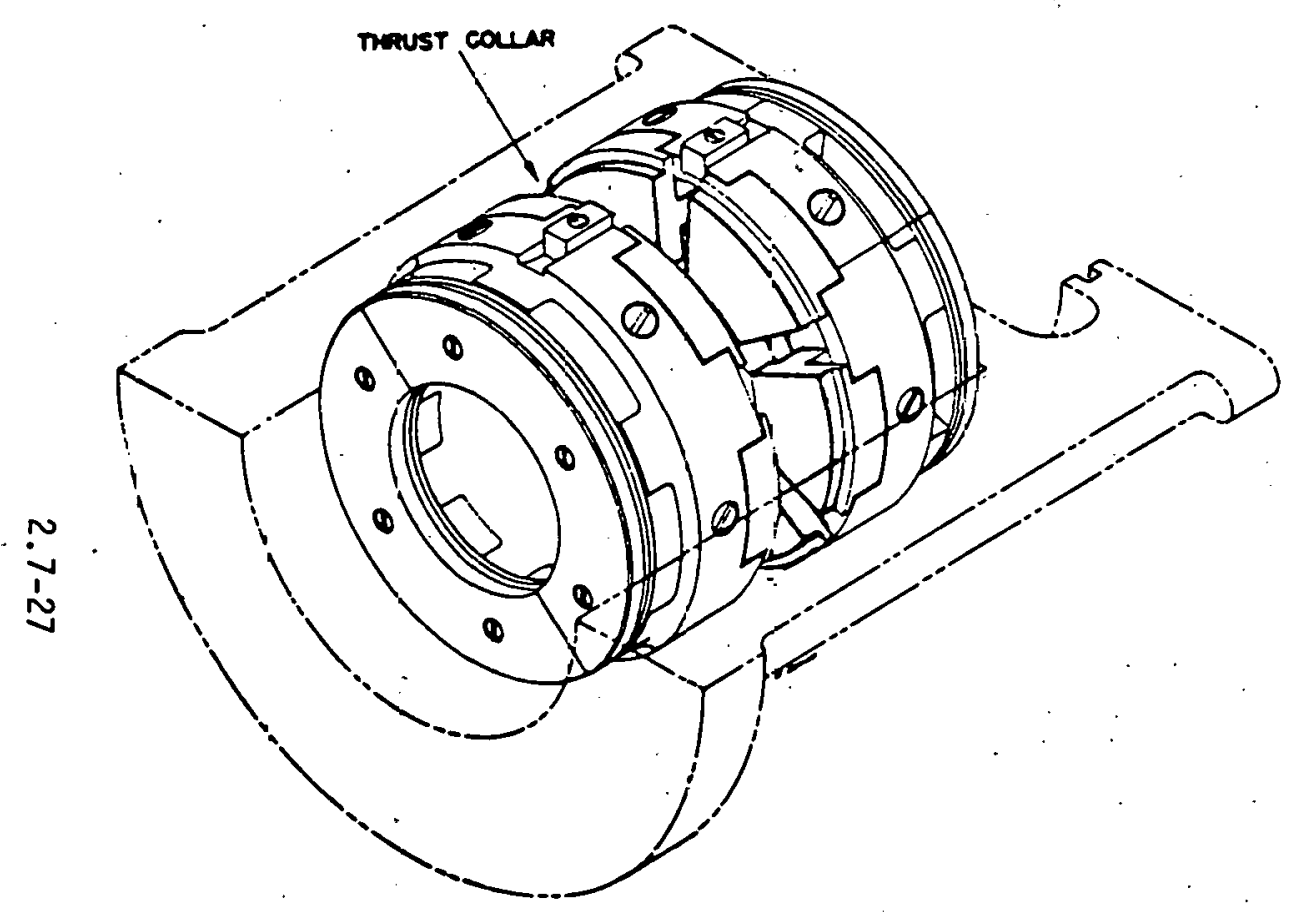

Solf-Equalizing. Tilting Pad Typo, Thrust Booring

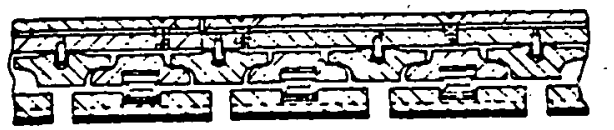

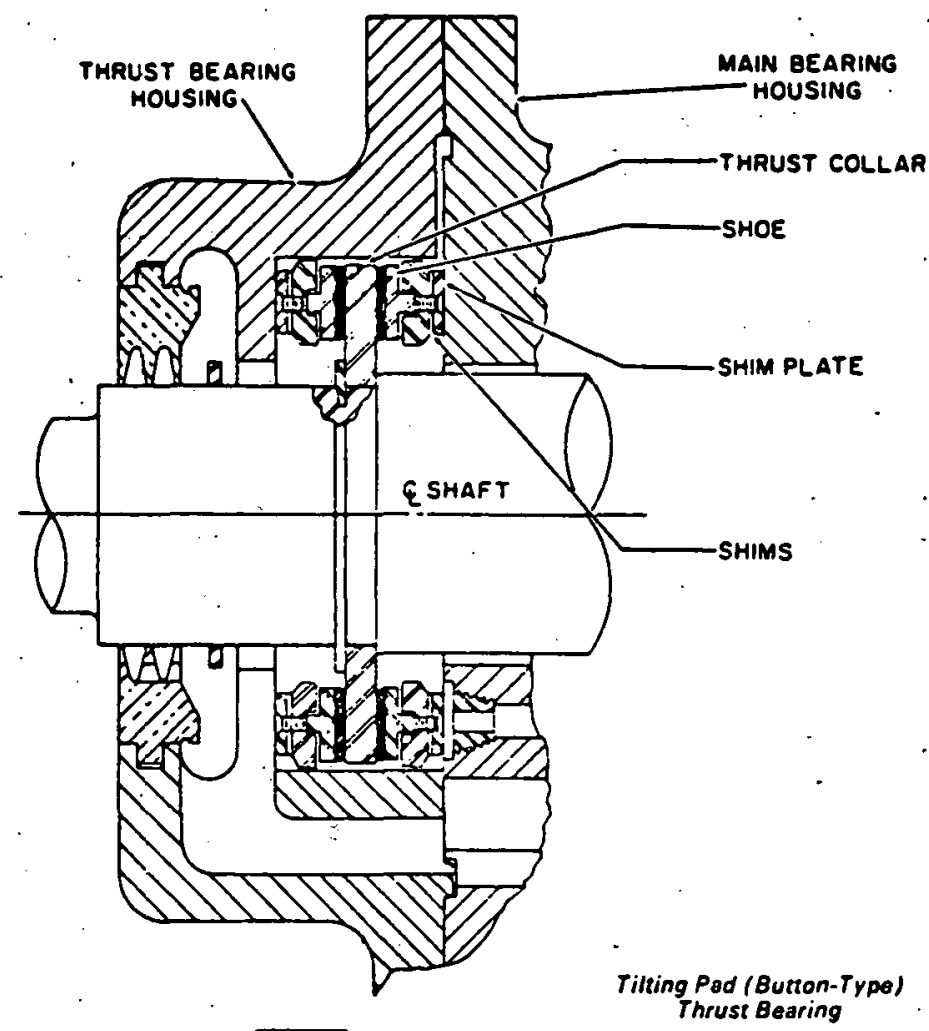

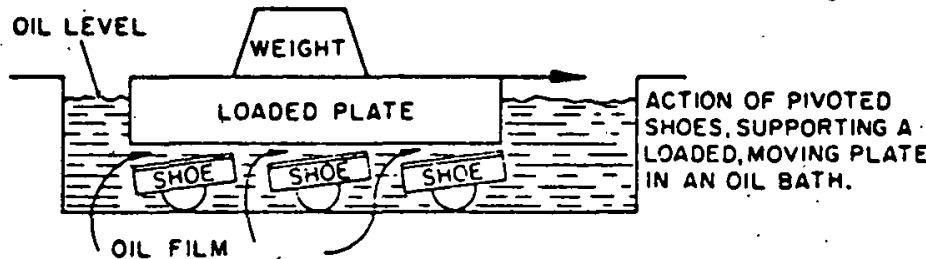

Figure 2.7-9. Thrust Bearing (Typical) 


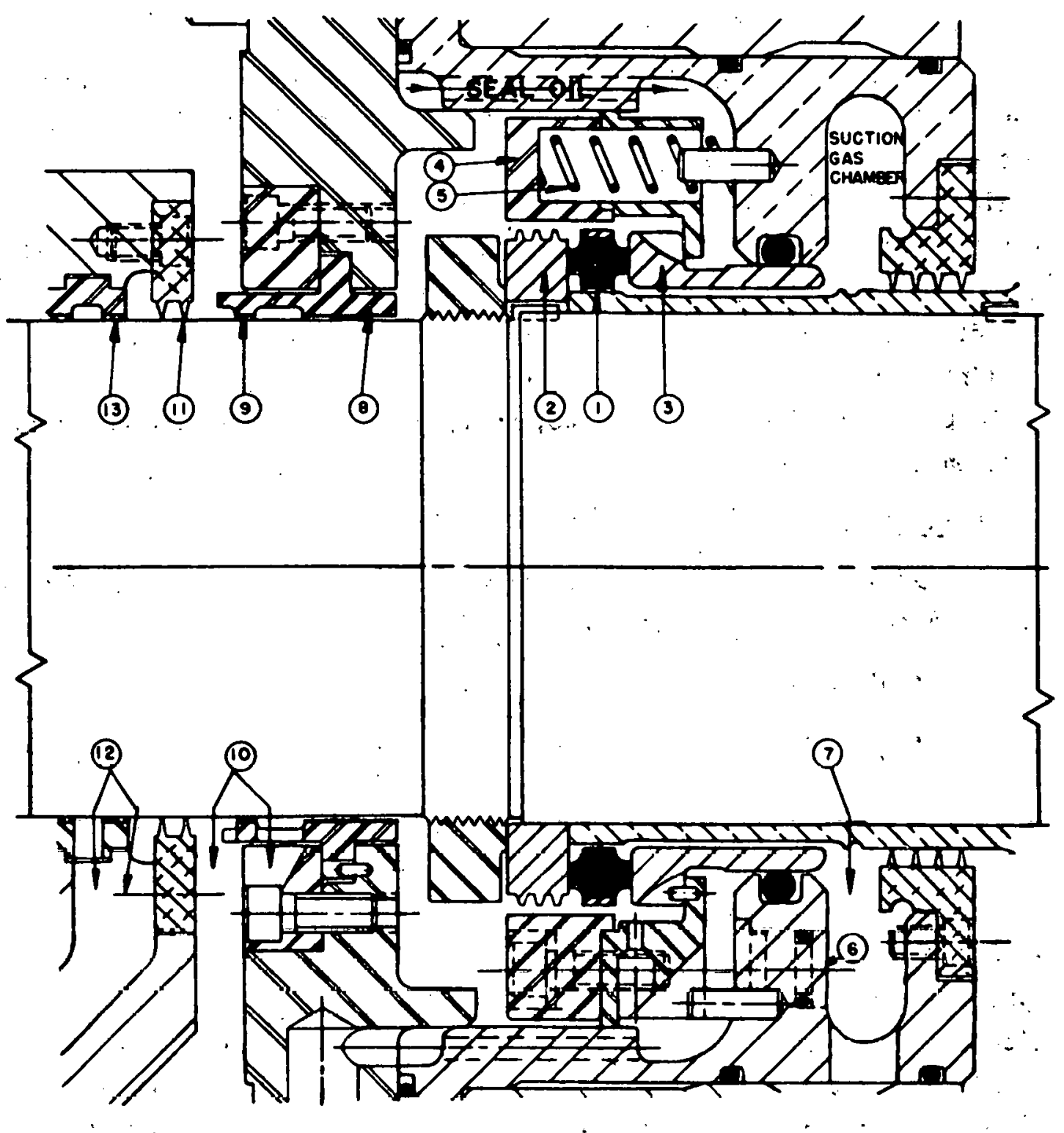

1. ROT $\triangle T$ TING, CARBON RING

2. ROTATING SEAL RING

3. STATIONARY SLEEVE

4. SPRING RETAINER

5. SPRING

6. SHUTDOWN SEAL PISTON

7. GAS AND CONTAMINATED OIL DRAIN
8. FLOATING BABBITT.FACED STEEL RING

9. SEAL WIPER RING

10. SEAL OIL DRAIN LINE

11. SECONDARY WIPER RING LABYRINTH

12. BEARING UIL URAIN LINE:

13. BEARING WIPER RING

Figure 2.7-10. Face Seal with Shutdown Features 


\section{Coupling}

Three types of couplings were considered: solid, gear, and diaphragm. A solid type would be lowest cost but would require precise alignment. This requirement would be quite a problem after any field maintenance that required removing a coupling hub. A gear type coupling has the disadvantage that it requires lubrication oil which increases the size of the auxiliary oil equipment. It also requires that a separate 2-micron filter be provided. In addition, coupling lockup sometimes becomes a problem with gear type couplings. For only a slight additional cost, a dry diaphragm type coupling can be provided. This type of coupling is now widely accepted and is the recommended coupling.

\section{Critical Speeds}

The proposed four-stage double flow axial turbine will have a flexible shaft. A flexible shaft design has the following advantages:

- More space for the inlet channel and exhaust diffuser

- Better maintenance accessibility to the seals and bearings

- Reduces the sizes of the bearings and seals for less oil flow. and power loss.

The first critical speed is approximately $1300 \mathrm{rpm}$ or 28 percent below the operating speed of $1800 \mathrm{rpm}$. The second critical speed is approximately $2700 \mathrm{rpm}$ or 50 percent above the operating speed. It is quite common to operate turbine driven generators and compressors between the first and second critical speeds. While the desired spread between critical speeds and operating speeds is well defined by standards for mechanical drive turbines, this is not the case for turbines driving constant speed generators. Some turbine generator clients set the limit to: 20 percent below and 20 percent above the operating speed. The selected turbine easily meets these conditions. No problems are anticipated with a flexible shaft turbine. 


\section{Blade Stresses}

The rotating element is the critical item in any piece of rotating equipment. When the rotating element of a turbine fails, it is usually the blades or shrouds that fail. A Goodman diagram is included in the Elliott report for the fourth and most critical stage to show that the combination of alternating and steady state blade stresses are well below the failure line. Barring any stress corrosion cracking problems, blade failure problems are not likely.

Another blade design criterion is to design blades so that their natural frequency exceeds low multiples of the operating speed and does not coincide with the nozzle passing frequency. The fundamental naturai frequencies of the blades range from 8 to 11 times the operating speed or from 240 to 330 cycles per second. The passing frequency, speed times number of stator vanes, is 1140 cycles per second. No blade vibration problems are anticipated.

\section{Moisture Erosion}

Some moisture may be entrained from the evaporator and enter the turbine. Within the turbine, about 2 weight percent moisture will be condensed ahead of the fourth and last stage. This compares with 8 to 10 weight percent moisture frequently encountered in the exiraust end of steam turbines. No moisture erosion problems are expected with the ammonia turbine for the following reasons:

- Low moisture leve 1

- Low velocities encountered in the design

- An apparent hardness of an ammonia droplet that is about one-half that of steam

- A stable droplet size of about one-third that of steam

- An erosion coefficient that is only 0.003 comparned to about 30 for a typical steam turbine.*

\footnotetext{
*The erosion coefficient is a function of stator to rotor blade clearance, stator blade trailing edge thickness, moisture content, blade tip speed, and absolute pressure. Based upon steam turbine experience, the threshold of significant erosion is a coefficient of 8 .
} 
Consequent7y, no special erosion protection measures are considered necessary. These might have been such things as stellite strips on the leading edges of the rotating blades and stationary moisture collectors.

\section{0il System}

An oil system is required for lubrication, for control, and for the turbine, shaft-end seals. A schematic of the oil system is included in the Elliott report. The oil system is in accordance with API Standard 614 "Lubrication, Shaft Sealing, and Control $0 i 1$ Systems for Special Purpose. Applications" with only a few minor exceptions. This type of an oil system is standard and is almost universally used in the process industry. A few special features are worth pointing out.

All instrumentation for tripping out the turbine because of some.0il system failure are redundant. Three separate instruments are used for each trip caused by an emergency condition. At least two out of the three instruments must signal the trip condition before a trip can occur. This prevents one malfunctioning instrument from inadvertently tripping the turbine. Each trip condition is provided with a prealarm instrument. The prealarm may give an operator time to correct some problem before the situation reaches trip conditions.

$A$ main and a standby $A C$ motor driven oil pump are provided. In addition, a $D C$ motor driven oil pump is provided for backup of the bearing oil supply for emergency coastdown. This pump protects the turbine generator bearings if there should be a failure of the sea station power system that serves the $A C$ motors.

A small amount of seal oil flows past the contact faces of the turbine shaft and seals. This is swept out of the contaminated seal oil drain compartments of the seals with ammonia from the process side of the turbine. The oil and ammonia are separated in drainers (one for each seal) and the ammonia is vented into the vent gas collection system. Any ammonia dissolved in the oil leaving the drainers is driven off in an electrically heated degassing tank before the oil is returned to the oil reservoir. The total amount of ammonia vented from the seal oil system into the vent gas collection system is about 525 pounds per hour. This is a significant amount but it is recovered. Of the two $200 \mathrm{cfm}, 5 \mathrm{I}$ horsepower compressors serving the vent gas collection system, one is essentially dedicated to recovering the vented ammonia from the turbine seal o1l system. 


\subsubsection{Ammonia Feed and Recirculation Pumps}

\subsubsection{Introduction and Conclusions}

Liquid ammonia pumps are required to

- Pump ammonia condensate from the condenser sump to the evaporator sump

- Pump liquid ammonia from the evaporator sump tank to the evaporator liquid plenum.

The pump and pump drive selections are as follows:

\section{Condensate Feed}

Two (2) 100 percent flow pumps; one serving as a standby. Pumps are horizontally split, single-stage, double suctlon pumps with AC adjustable frequency variable speed drives rated at 400 horsepower.

\section{Evaporator Recirculation}

Two (2) 100 percent flow pumps; one serving as a standby. Pumps are horizontally split, single-stage, double suction pumps with fixed speed induction motor drives rated at 200 horsepower.

The overall analysis and the pump and pump drive selection involved the following steps:

- Define pump requirements

- Obtain representative vendor pump data

- Define pump drive requirements

- Obtain vendor data or pump drivers

- Investigate cost data and compare capital and operating costs for various types of pump and drive combinations

- Select optimum pump/drive combination for the condensate feed pump and the recirculation pump.

The details of this analysis are contained in Appendix L. 


\subsubsection{Requirements}

The flow and head requirements of the ammonia feed and recirculation pumps are shown in Table 2.7-9. The minimum, nominal and maximum flow rates correspond to expected. seasonal variations in the cold and warm water temperatures as defined in Section 2.1.2. The effect of these temperature variations is to perturb the liquid ammonia fiow to maximize the power module net power output at off design conditions.

Table 2.7-9. Evaporation and Condenser Pump Operating Requirements

\begin{tabular}{|c|c|c|c|c|c|c|c|c|}
\hline \multirow[b]{3}{*}{. } & \multicolumn{4}{|c|}{ Evaporator } & \multicolumn{4}{|c|}{ Condenser } \\
\hline & \multicolumn{2}{|c|}{ Flow } & \multicolumn{2}{|c|}{ System P } & \multicolumn{2}{|c|}{ Flow. } & \multicolumn{2}{|c|}{ System P } \\
\hline & gpm & $1 \mathrm{bs} / \mathrm{sec}$ & $\mathrm{ft}$ & ps $i$ & gpm & $1 \mathrm{bs} / \mathrm{sec}$ & $\mathrm{ft}$ & psi \\
\hline Maximum & 16,210 & 1393 & 58 & 15.5 & 10,280 & 893.4 & 175 & 47.4 \\
\hline Nominal & 15,390 & 1324 & 57. & 15.2 & 9,291 & 807.2 & 154 & 41.8 \\
\hline Minimum & 14,590 & 1257. & 55 & 14.8 & 8,303 & 721.5 & 135 & 36.6 \\
\hline
\end{tabular}

Pumps, pump drives and controls were selected to satisfy the following requirements:

- Meet system head and flow requirements shown in Table 2.7-9.

- Meet overall system availability requirement of 0.90 .

- Minimize the elevation difference between ammonia pump floor level and condensate and evaporator sumps by selection of pumps with minimum NPSH requirements.

- Minimize space requirements for pumps, drivers and controls to minimize cost penalties due to excess platform space requirements. 


\subsubsection{Pump Arrangements}

The pump configurations shown in Figure 2.7-11 were investigated to provide a comprehensive range of cost and performance data for the tradeoff analysis:

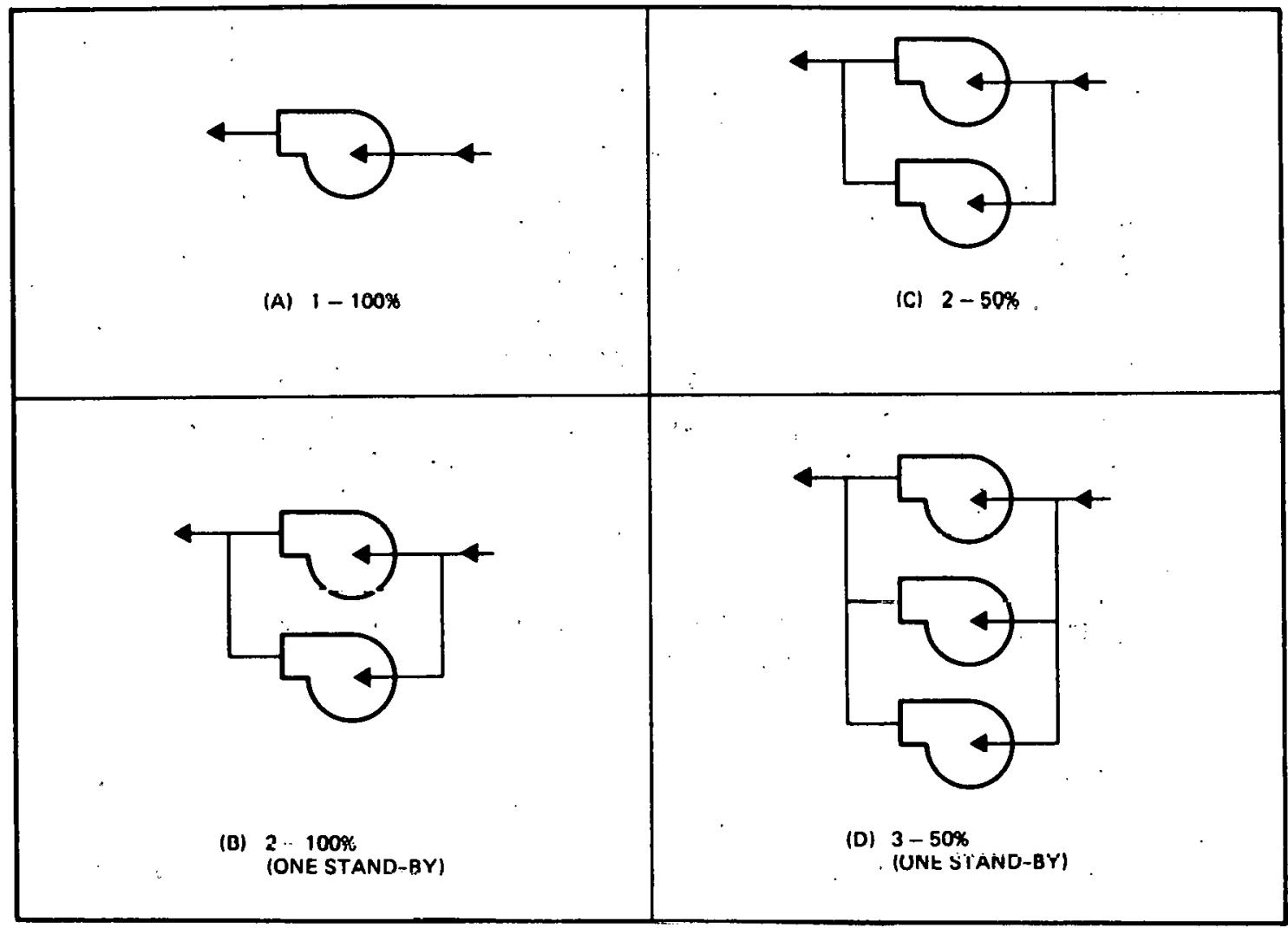

Figure 2.7-11. Pump Configuration

The significant flow and head parameters that the pump must satisfy are shown in Table 2.7-9. Additionally, the net pump suction head requirement (NPSHR) was set at 15 feet to minimize the draft of the PSD-I platform. This is a fairily severe requiremerit, but was satisfied by pump configurations rer.nmmended by vendors who supplied pump data. A typical head-flow curve for these pumps is shown in Figure 2.7-12, supplied by Ingersoll-Rand. These pumps are horizontally split, single-stage, double suction pumps with double mechanical seals which are required for liquid ammonia service. Double mechanical seals are used to minimize leakage of ammonia. A section drawing and outline drawing of a candidate design are shown in Figures 2.7-13 and 2.7-14 for the evaporator recirculation pump (for the selected 100 percent pump option) courtesy of Ingersol1-Rand. 


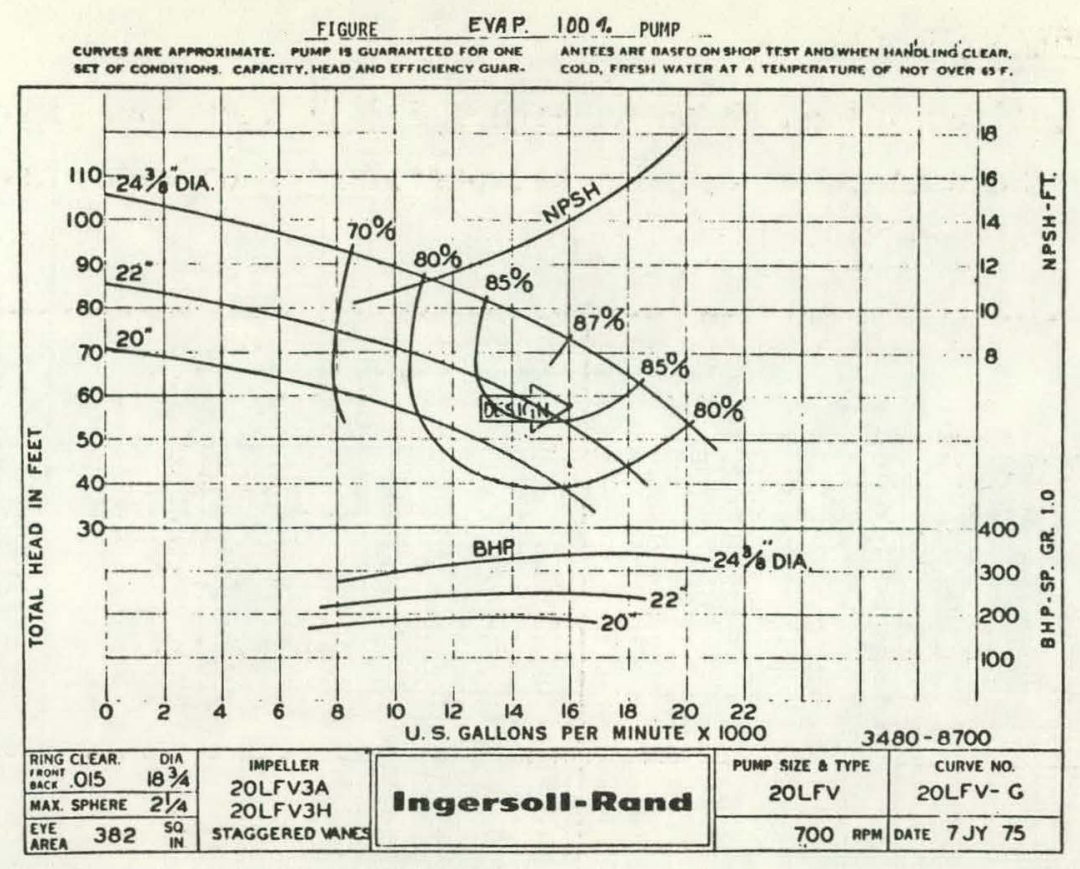

Figure 2.7-12. Evaporator Pump Head-Flow Curve (Typical)
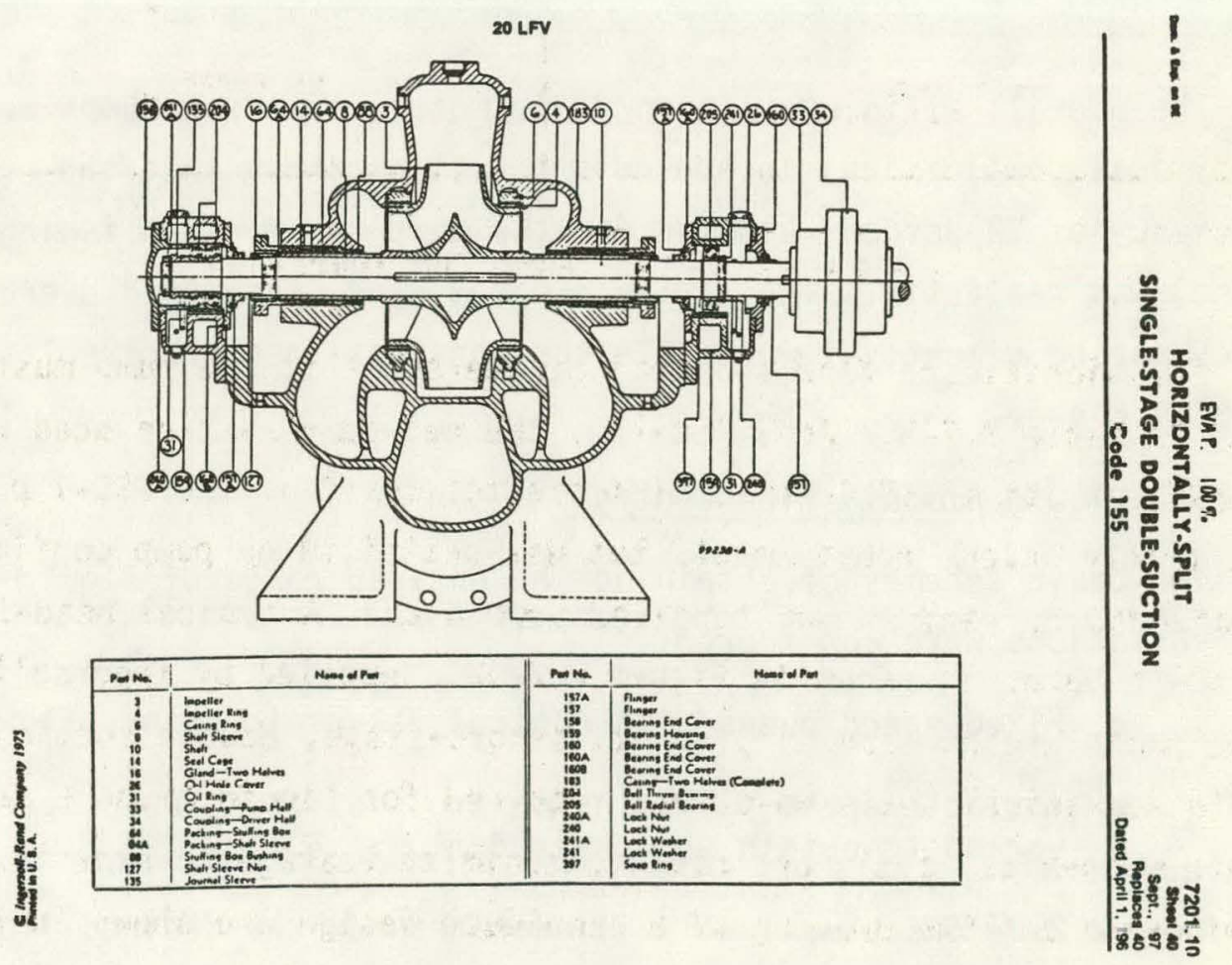

Figure 2.7-13. Evaporator Recirculation Pump Section 


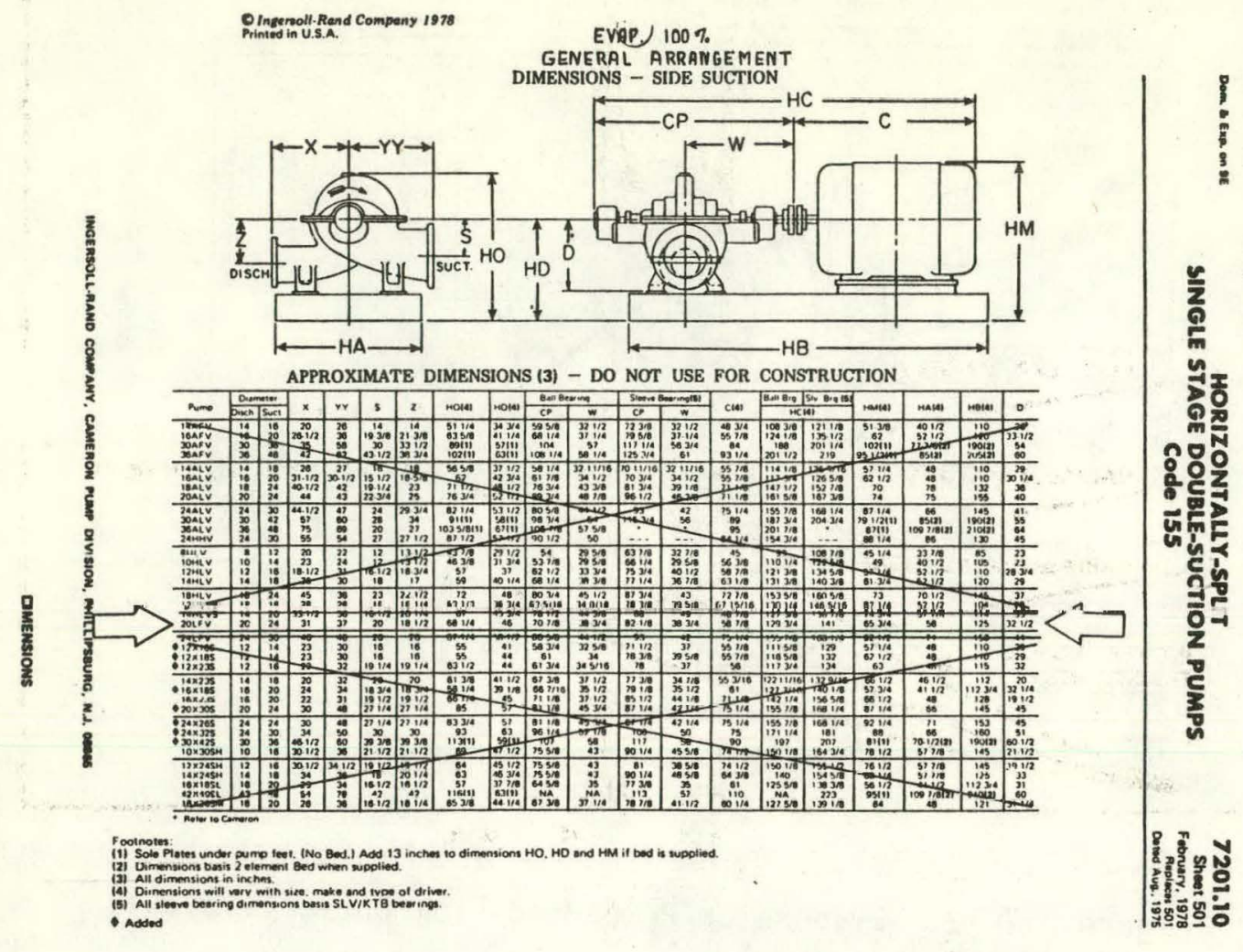

Figure 2.7-14. Recirculation Pump Outline Drawing

The overall efficiency (pump/drive/motor) of these pumps are evaluated for typical combinations in Appendix L. It is shown that the overall efficiency of 72 percent assumed for the purpose of establishing a power budget, was realistic. The variable speed condensate feed overall efficiency may be slightly lower while the constant speed recirculation pump slightly higher.

\subsubsection{Liquid Ammonia Flow Control}

Two basic schemes of obtaining the desired range of liquid ammonia flow variations were considered:

- Fixed speed pumps with control valves to change flow

- Variable speed pumps (no control valves). Pump speed is varied to obtain the desired flow.

Figure 2.7-15 schematically illustrates how the desired liquid ammonia flow rate is obtained using either fixed speed pumps or variable speed pumps. 


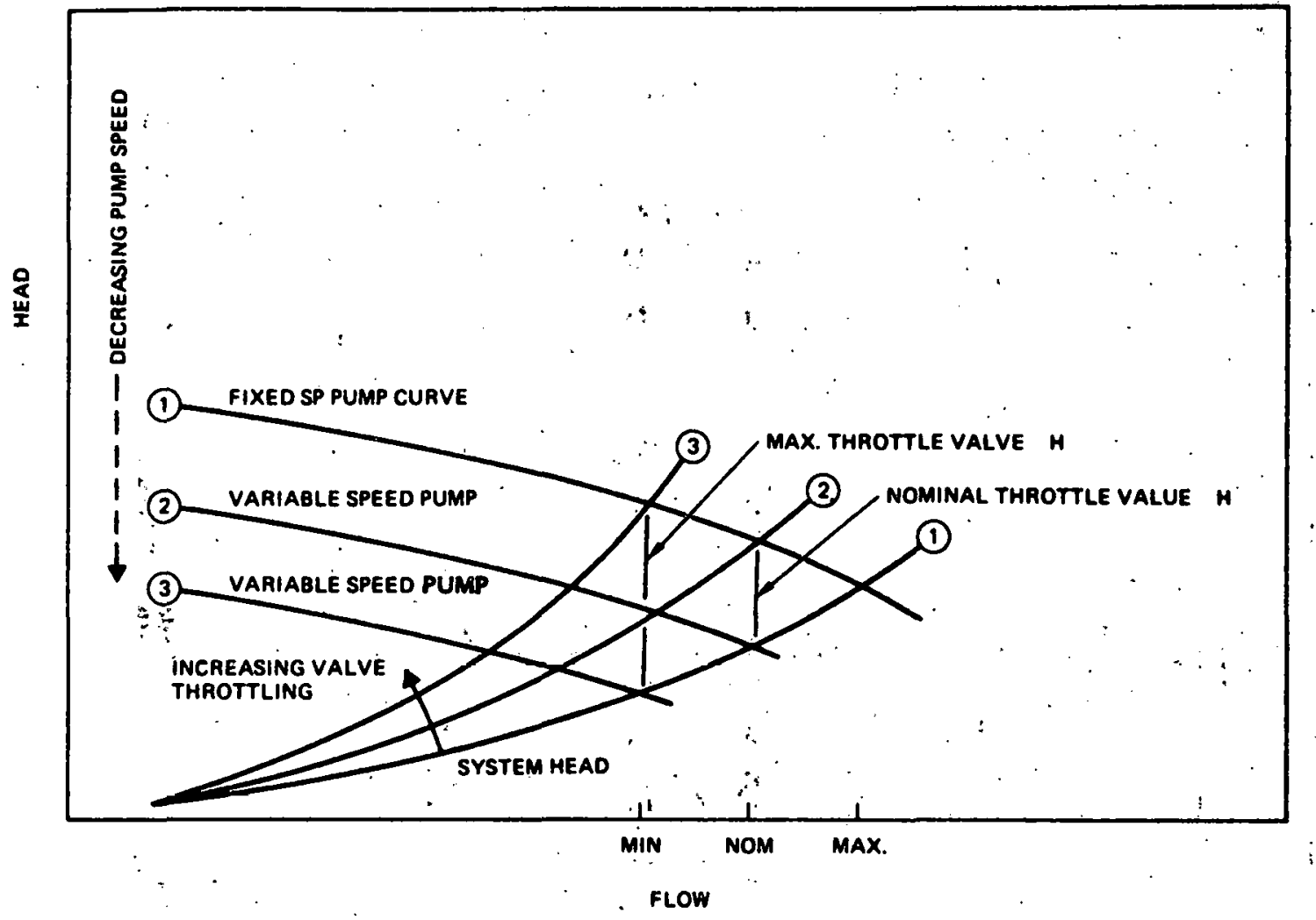

Figure 2.7-15. Fixed and Variable Speed Pump Head-Flow Characteristics and System Head-Flow Curve

\section{. Fixed Speed}

When operating the pump at a fixed speed, the pump will develop a unique head flow curve. The intersection of the pump head flow curve with the sysitem head flow curve will result in a unique flow operating point for the system.

To change the flow, it is necessary to change the control valve position which in effect causes a consequent change in the system head curve. The new system head curve, corresponding to the new valve position, intersects the pump head curve at a different point resulting in a new and different operating point. Closing the control valve creates a steeper system head curve which intersects the pump curve at a higher head, lower flow point. Conversely, opening the control valve creates a flatter system head curve which intersects the fixed speed pump curve at a lower head, higher flow point. 


\section{Variable Speed}

Similar flow changes can be obtained by varying pump speed. Figure 2.7-15 depicts three pump head curves, each one corresponding to a different pump speed.

As pump speed is reduced from its maximum value, the pump head curve will decrease and will intersect the system head curve at lower values of head and flow.

\subsubsection{Fixed and Variable Speed Driver Characteristics}

The pump drives must be adequately sized to provide required pump horsepower under all load operating conditions. The drive should have high reliability. and high electrical and mechanical efficiency.

The initial capital cost of the drives and their operating efficiency are the characteristics used in the tradeoff analysis to obtain the most cost-effective pump assembly. The fixed speed and variable speed drives considered are shown in Table 2.7-10.

Performance data for these motors and drives were obtained from several vendors as discussed in Appendix $L$.

Table 2.7-11 gives the efficiency for the various fixed and variable speed drives as a function of rated speed for two power ranges: 400 to 500 horsepower and 100 to 200 horsepower, representative of the two power ranges.

Table 2.7-10. Fixed and Variable Speed Drivers

\begin{tabular}{|l|l|l|}
\hline \multicolumn{1}{|c|}{ Fixed Speed } & \multicolumn{1}{|c|}{ Variable Speed } & Symbol \\
\hline & Wound Rotor Motor-Liquid Rheostat & WRM \\
& Wound Rotor Motor-Energy Recovery & WRM/ER \\
Squirrel Cage Induction & Adjustable Frequency & AF \\
& Dotor & DC \\
& Direct Current & HYD \\
\hline
\end{tabular}


Table 2.7-11. Fixed and Variable Speed Overall Drive Effictency (High HP/LOW HP) (Motor, Controls, Trans formers, etc.)

\begin{tabular}{|c|c|c|c|c|c|c|}
\hline \multirow{3}{*}{$\begin{array}{l}\text { Percent } \\
\text { Rated } \\
\text { Speed }\end{array}$} & $\begin{array}{l}\text { Fixed } \\
\text { Speed }\end{array}$ & \multicolumn{5}{|c|}{ Variable Speed } \\
\hline & \multirow[b]{2}{*}{$\begin{array}{l}\text { Induction } \\
\text { Motor }\end{array}$} & \multicolumn{2}{|c|}{ Wound Rotor Motor } & \multirow[b]{2}{*}{$\begin{array}{l}\text { Adjustable } \\
\text { Frequency }\end{array}$} & \multirow[b]{2}{*}{$D C$} & \multirow[b]{2}{*}{ Hydraulic } \\
\hline & & $\begin{array}{l}\text { Liquid } \\
\text { Rheostát }\end{array}$ & $\begin{array}{c}\text { Energy } \\
\text { Recovery }\end{array}$ & & & \\
\hline 100 & $0.92 / 0.91$ & $0.89 / 0.88$ & $0.89 / 0.88$ & $0.89 / 0.87$ & $0.90 / 0.87$ & $0.87 / 0.85$ \\
\hline 90 & $\therefore-$ & $0.79 / 0.78$ & $0.88 / 0.87$ & $0.87 / 0.85$ & $0.89 / 0.87$ & $0.79 / 0.76$ \\
\hline 80 & - & $0.69 / 0.68$ & $0.87 / 0.86$ & $0.86 / 0.84$ & $0.87 / 0.85$ & $0.69 / 0.67$ \\
\hline
\end{tabular}

\subsubsection{Performance/Cost Tradeoff Analysis}

The main consideration was the performance/cost tradeoff between the fixed speed and variable speed drives. The significant characteristics are tabulated in Table 2.7-12.

Table 2.7-12. Fixed and Variable Speed Pump/Drive Tradeoff Considerations.

\begin{tabular}{|l|l|}
\hline \multicolumn{1}{|c|}{ Fixed Speed } & \multicolumn{1}{c|}{ Variable Speed } \\
\hline Lower Capital Cost & Higher Capital Cost \\
Least Complex & More Complex \\
Minimum Motor Control Hardware & More Motor Controls \\
Minimum Volume/Floor Space & Greater Volume/Floor Space \\
Highest Efficiency at Maximum & $\begin{array}{l}\text { High Efficiencies Even at Reduced } \\
\text { Speed and Flow } \\
\text { Requires Large Control Valves }\end{array}$ \\
Harsh Startup Loads & No Control Valves Required \\
& Smooth Startup/Shutdown \\
\hline
\end{tabular}


The detailed tradeoff studies are presented in Appendix $L$. The conclusions based on comparing present value cost, including a cost credit for life cycle operating power cost are: $\therefore$

- For the evaporator recirculation pump, the fixed speed drive gives the minimum life cycle pump capital and. operating cost.

- For the condensate feed pump; a variable speed drive gives the lowest life cycle costs.

\subsubsection{Availability Considerations}

The final tradeoff consideration was single pumps 'versus multiple pumps to provide redundancy and thereby increase power module availability. Availability/operability is analyzed and discussed in considerable detail in Section 2.13, where it is concluded that the 30-year availability without standby (redundant) pumps would be 0.886 versus 0.906 with redundant pumps. Therefore, it is concluded that redundant ammonia pumps are required to meet the availability requirement of 0.90 . Even if this requirement was relaxed, a simple cost analys is shows that at $40 \mathrm{mills} / \mathrm{kW} / \mathrm{hr}$ the annual cost savings resulting from a' 2 percent availability increase results in an annual cost savings of about $\$ 70,000$. At 10 percent interest and 30-year life this is equivalent to a present value cost savings of about $\$ 660,000$. The additional cost of redundant pumps is less than this by a factor of about five as discussed in Appendix $L$.

Conclusion

Redundant ammonia pumps are cost effective and required to meet the system availability requirements of 0.90 .

\subsubsection{Technology Status}

These ammonia pumps are off-the-shelf designs and no difficulties are anticipated. Double mechanical seals will be used töminimize leakage. 


\subsubsection{Seawater Pumps}

\subsubsection{Scope}

The power required to drive the seawater pumps represents the largest parasitic demand on the power module electrical output. Performance optimization of these pumps is therefore important. Furthermore, operability (see definition Section 2.13) is a major consideration since pump shutdown implies power module shutdown unless redundancy is provided.

According to DOE technical direction, the seawater pumps will be government furnished. In the preliminary design phase these pumps were therefore only addressed to

- $\therefore$ Define performance requirements

- Power required

- Efficiency

- Head

- Flow rate

- Identify and quantify design requirements necessary to define

- Input power characteristics

$\therefore$ Configuration

- Interface with heat exchangers

- Startup characteristics

- Maintenance Concept

- Availability and startup reliability.

The head and flow rates at design conditions derived by system optimization together with the assumed efficiencies and power requirements are summarized in Table 2.7-13. 
Table 2.7-13. Seawater Pump Requirements to Meet Nominal System Performance

\begin{tabular}{|c|c|c|c|c|c|c|}
\hline \multirow[t]{2}{*}{ 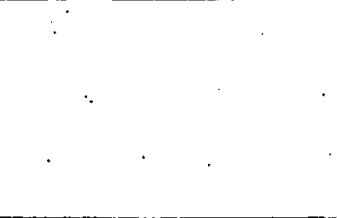 } & \multirow{2}{*}{$\begin{array}{l}\text { Head } \\
(\mathrm{Ft})\end{array}$} & \multirow{2}{*}{$\begin{array}{l}\text { Flow } \\
(\mathrm{gpm})\end{array}$} & \multicolumn{2}{|c|}{$\begin{array}{c}\text { Assumed } \\
\text { Efficiency } \\
\text { (percent) }\end{array}$} & \multirow{2}{*}{$\begin{array}{l}\text { Power } \\
\text { Requirement } \\
\text { (MWe) }\end{array}$} & \multirow{2}{*}{$\begin{array}{l}\text { Shaft Power } \\
\text { Requirement } \\
\text { (HP) }\end{array}$} \\
\hline & & & Pump & Drive & & \\
\hline Cold Water Pump & 15 & 494,300 & 87 & 92.4 & 1.78 & 2210 \\
\hline Warm Water Pump & 10.6 & 534,700 & 87 & 92.4 & 1.35 & 1680 \\
\hline
\end{tabular}

The seawater pumps subsystem must interface with the inlet connections on the evaporator and condenser. These interface locations as shown on the interface drawings, each measure 11 feet in height and 14 feet in width. It is planned that the connection will be accomplished by welding to the carbon steel duct intake on the evaporator and condenser. Conceptually the seawater pump subsystem and physical interface with the heat exchangers are shown in Figure 2.7-16. The pump is submerged in the seawater supply troughs as indicated in the arrangement drawings. The setting depth will be sufficient to eliminate cavitation problems.

\subsubsection{Configuration}

The pump configuration that TRW has assumed for the purpose of design layouts is an axial propeller type impeller with completely enclosed AC drive and planetary reduction gear. Figure 2.7-17 is included to illustrate a typical configuration and major characteristics of this type of pump. A possible supplier is TRW Pleuger Unterwasserpumpen $\mathrm{GmbH}$ which provided this information. Typical pump curves and power requirements for two of the configurations shown in Figure 2.7-17 are given in Figures 2.7-18, 2.7-19, 2.7-20, and 2.7-21. This information is given only to illustrate that suitable pump designs are available and that high efficiency can be achieved at the head-flow combinations required.

\subsubsection{Power Characteristics}

The input power characteristics for the seawater pumps is planned to be 4160 volts, $3 \emptyset, 60$ hertz AC power at a minimum power factor of 0.80 . 


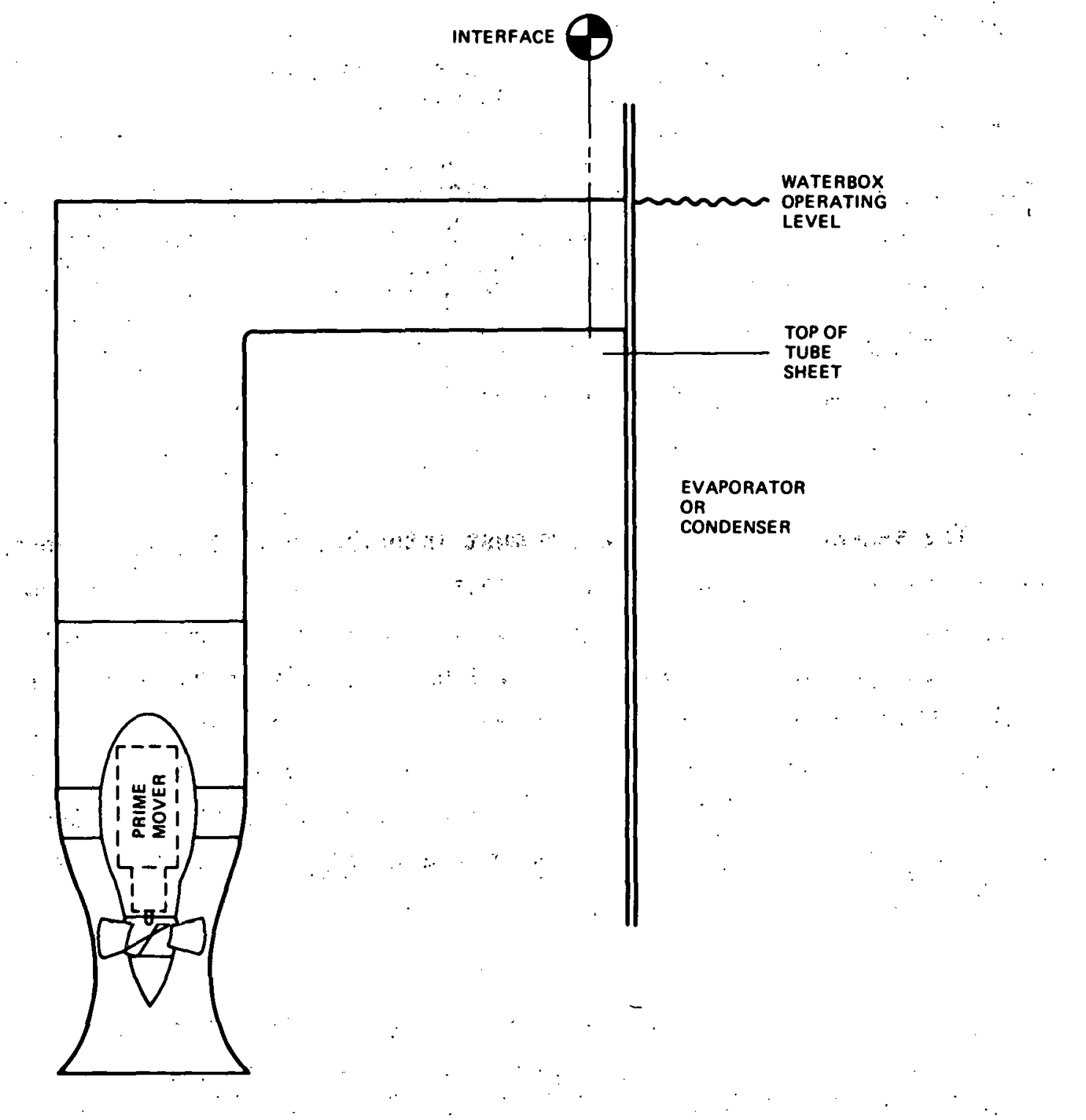

Figure 2.7-16. Seawater Pump Concept

The pumps must be started and operated prior to power module operation. The power required to operate is included in the startup power budget (see Section 2.2.5.8). Inrush current is addressed in Section 2.10.2.5.

\subsubsection{Operability}

The type of pump indicated here has been designed and used successfully for dynamic positioning of oil drilling platforms. Maintenance and repair can be accomplished in our conceptual arrangement by pulling the complete drive and impeller assembly. 


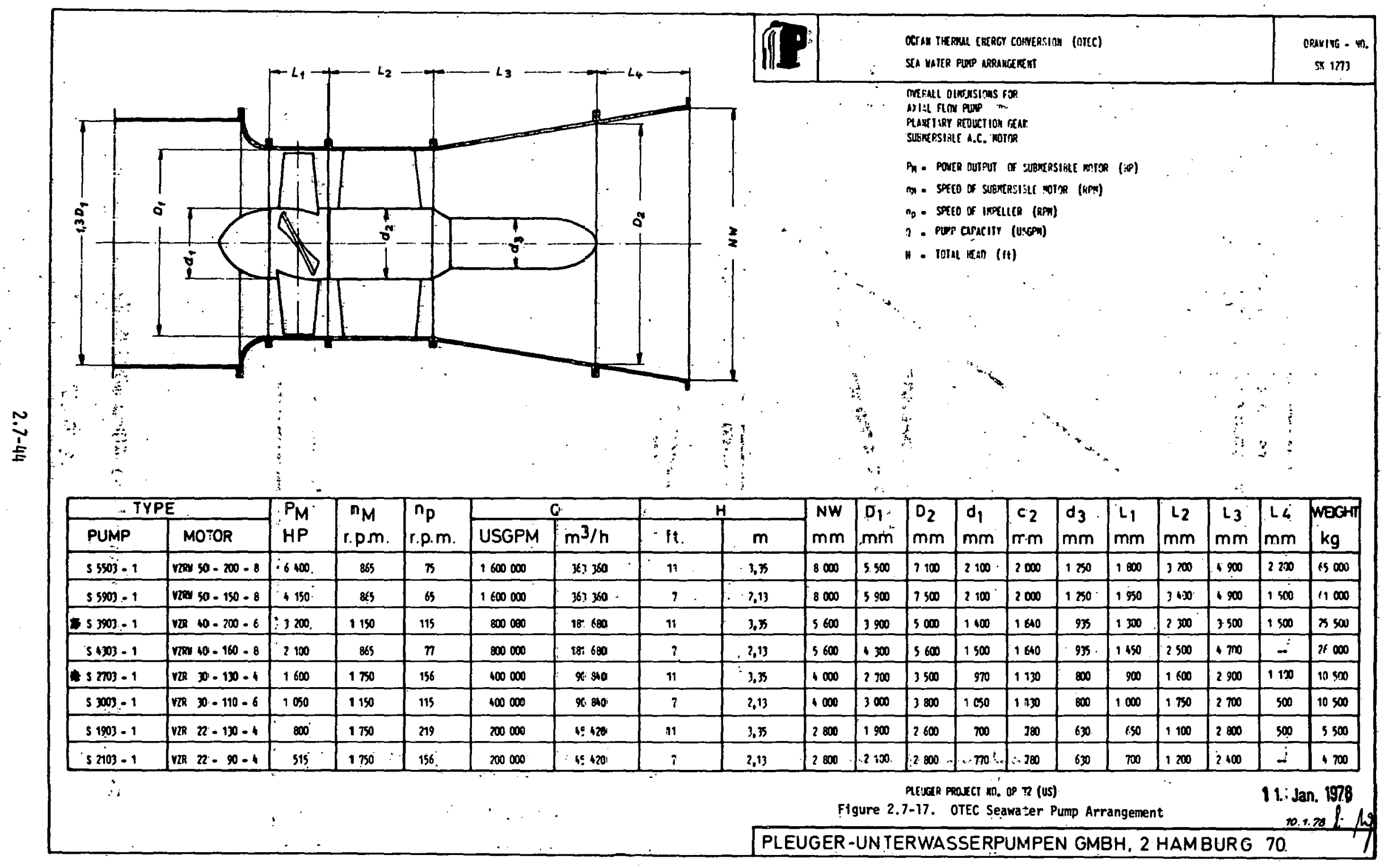




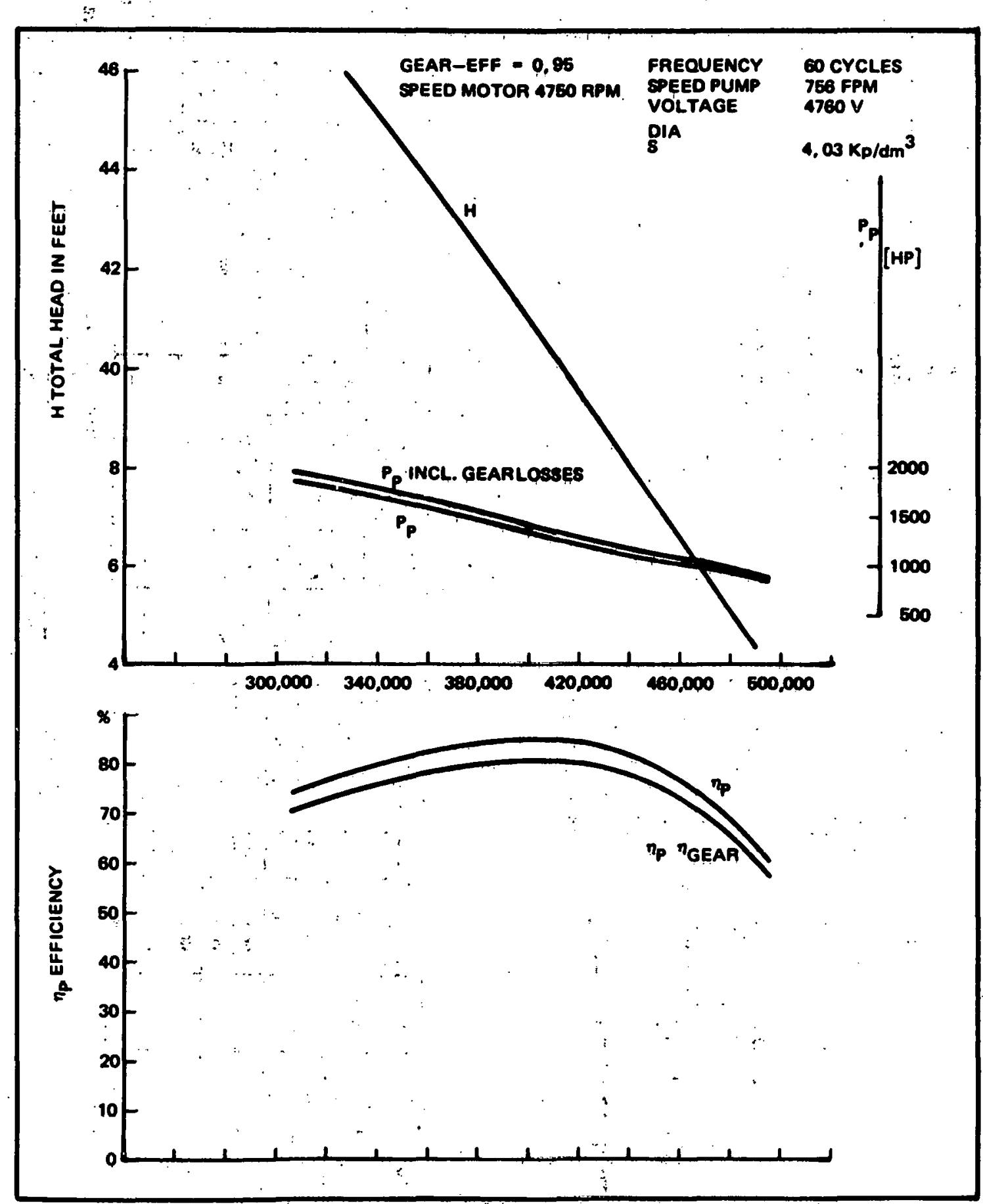

Figure 2.7-18. Pleuger Pump 400,000 GPM Head-Flow Curve 


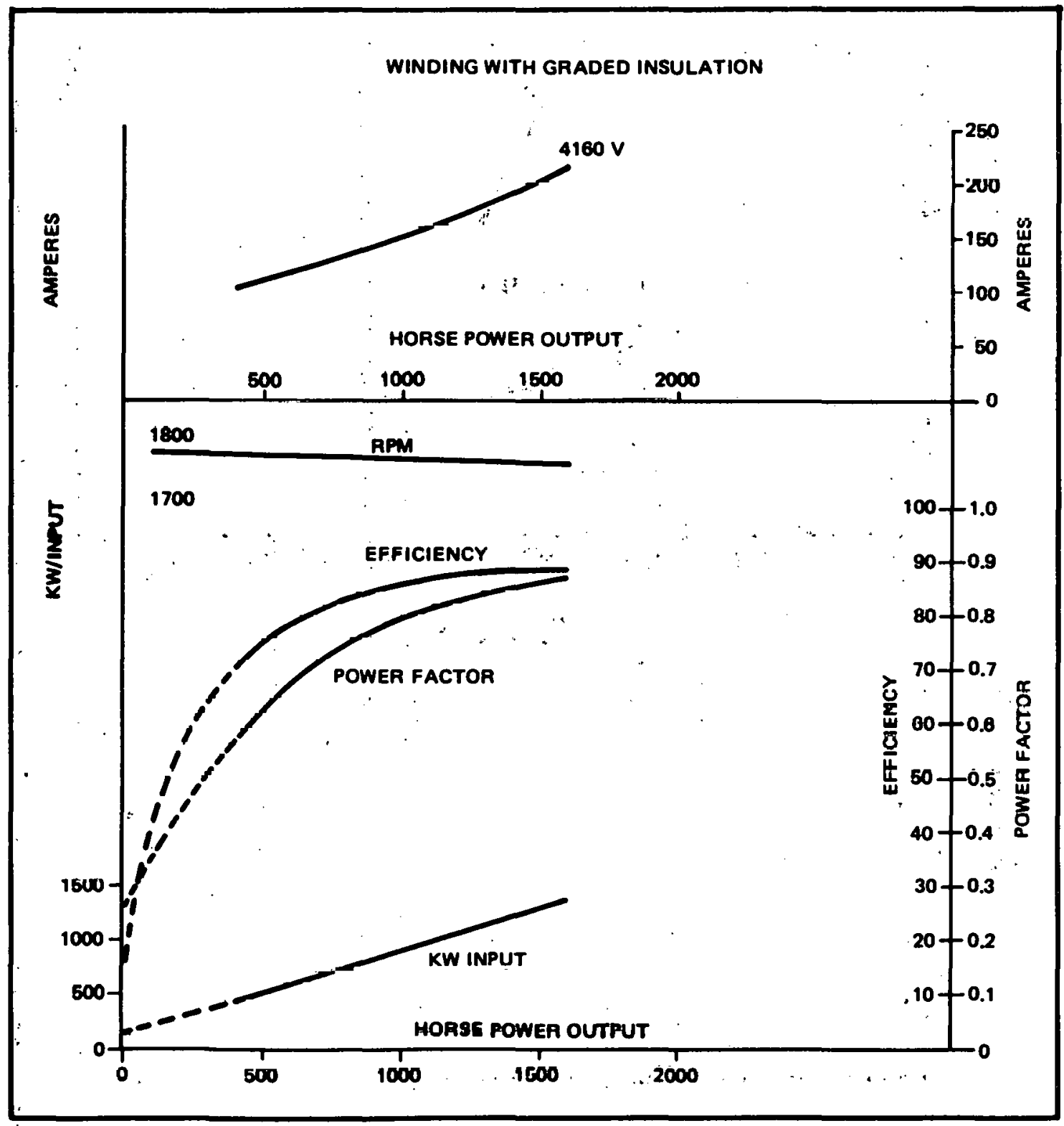

Figure 2:7-19. Pleuger Pump 400,000 GPM Power Requirements $2.7-46$ 


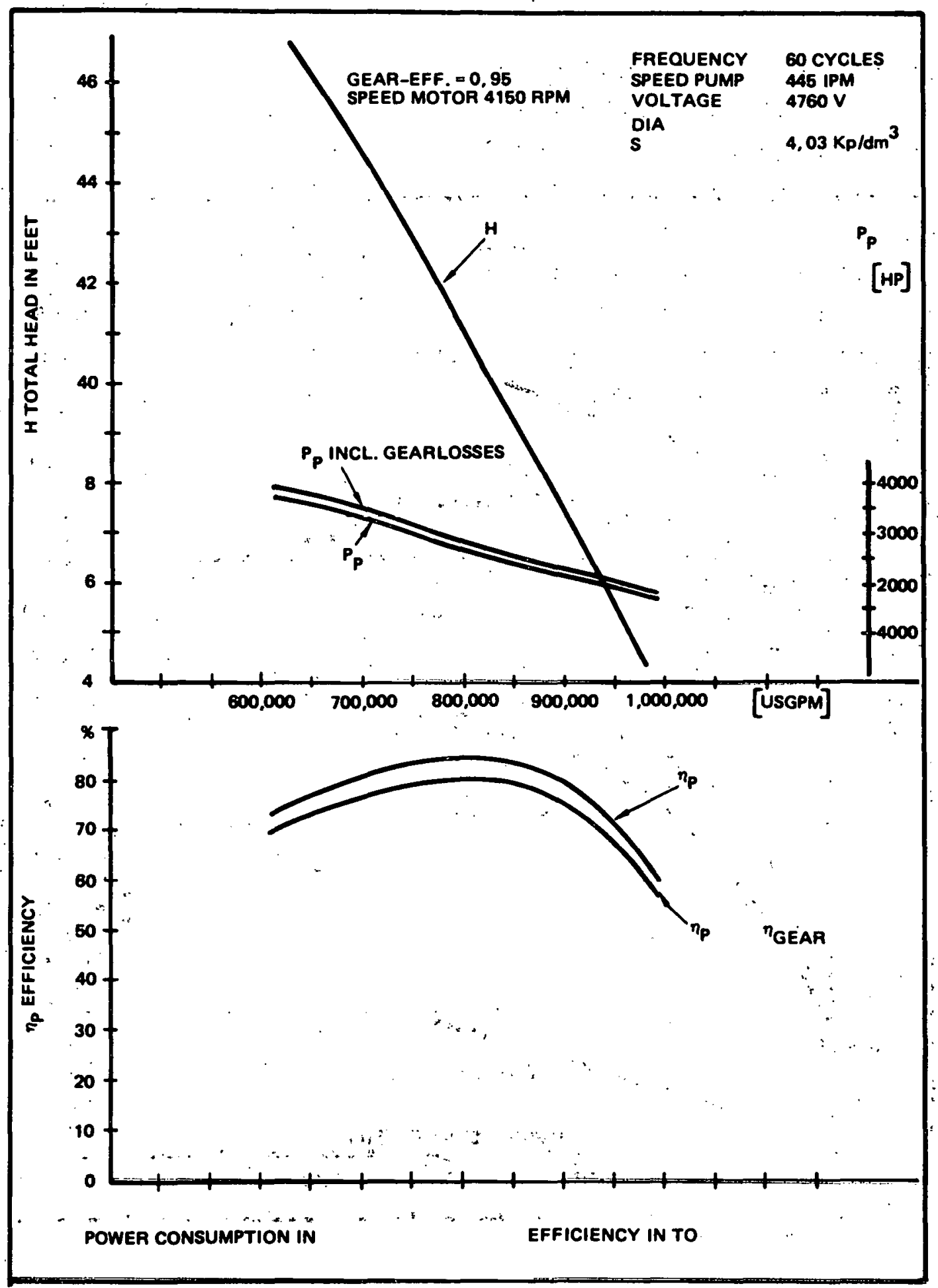

Figure 2.7-20. Pleuger Pump 800,000 GPM Head-Flow Curve

$$
2.7,47
$$




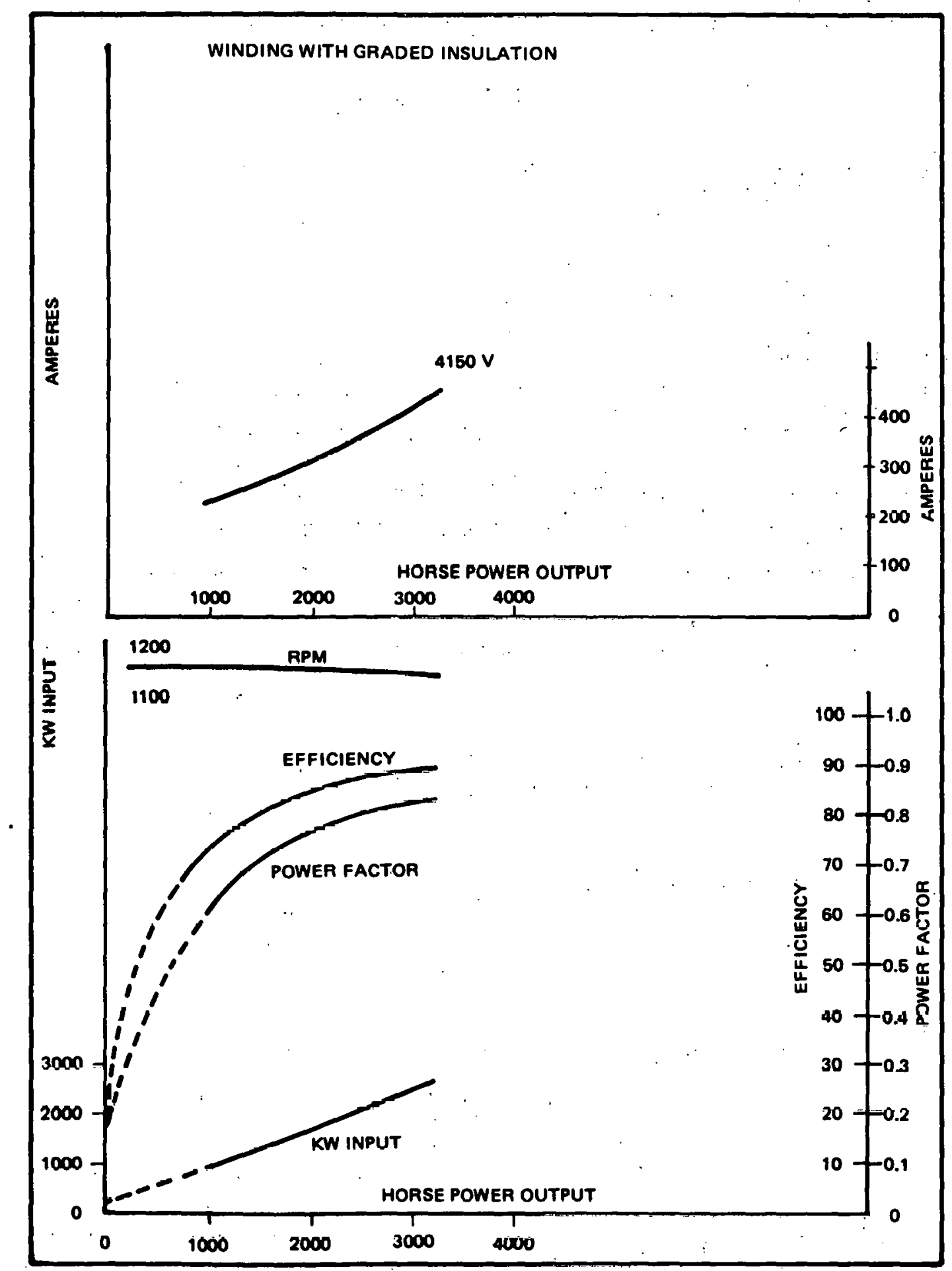

Figure 2.7-21. Pleuger Pump 800,000 GPM Power Requirements $2.7-48$ 
pump assembly up and out through the pump casing. In the avallability and startup reliability allocation, the seawater pumps were allocated at the following mean-time-to-repair (MTTR) and mean-time-between-faflures:

$$
\begin{aligned}
& \text { MTT'R }=80 \text { hours } \\
& \text { MTBF }=720 \text { days }
\end{aligned}
$$

The MTTR includes repair time and module startup time. See Section 2.13 for the basis for these estimates. 


\subsubsection{References}

1. O.E. Balje, A Study of Design Criteria and Matching of Turbomachines, Part A, ASME Journal of Engineering for Power, January 1962. 


\subsection{SUPPORT SUBSYSTEM}

\subsubsection{Subsystem Requirements}

Start up, operation and shutdown of the ammonia power loop requires storage, supply, conditioning and recovery of the ammonia energy transfer medium. This is done in the ammonia support system. The system is designed to store the entire ammonia power loop inventory indefinitely and to purify contaminated ammonia in a column. Ammonia leaks are recovered and reclaimed in a vent piping network. The power loop makeup and initial charging is from wet ammonia storage and subsequent post maintenance rechanging is from dry ammonia storage. Figure 2.8-1 presents a simplified version of the equipment involved in storing, purification and recovery of ammonia. It includes three storage tanks and associated pumps, a purification column system and an ammonia vent gas compression system. The system is further detailed in Section 2.8.2. Prior to startup or when removing ammonia for performing maintenance work on the ammonia power loop, it will be necessary to purge the loop with gaseous nitrogen to prevent any occurrence of flammable oxygen-ammonia mixtures. To provide the nitrogen for this purpose, a liquid nitrogen storage and vaporization facility are included. A simplified sketch of the nitrogen system is presented in Figure 2.8-2. This system includes a liquid nitrogen shipping tank with pump, an onboard nitrogen storage tank system and vaporizer. A detailed description is given in Section 2.8.3 and Section 2.2.5 describes the relationship among these procedures.

\subsubsection{Ammonia Storage, Conditioning, and Recovery Subsystem}

The preliminary design of the ammonia support subsystem has followed the conceptual design. Equipment sizes have been adjusted to meet the requirements of the 10 MWe power unit. The system as presented by the P\&ID shown in Figure 2.8-3 and the plan and elevation drawing Figure 2.8-4 can be divided into ammonia storage and transfer facilities, an ammonia purification system and an ammonia vent and recovery system. A complete discussion of the design of this subsystem is contained in Appendix M. 


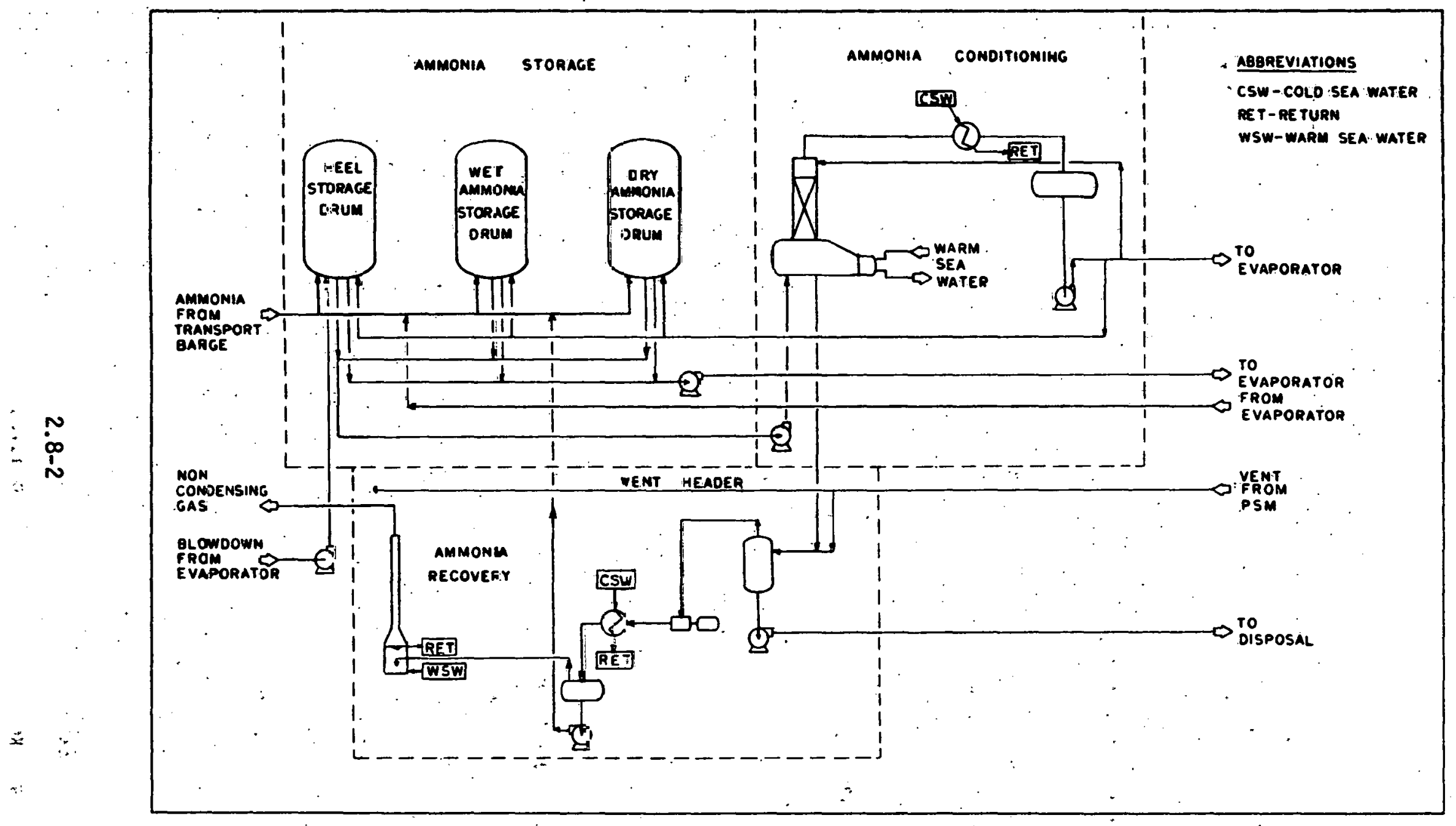

Figure 2.8-1. Ammonia Support System Schematic 


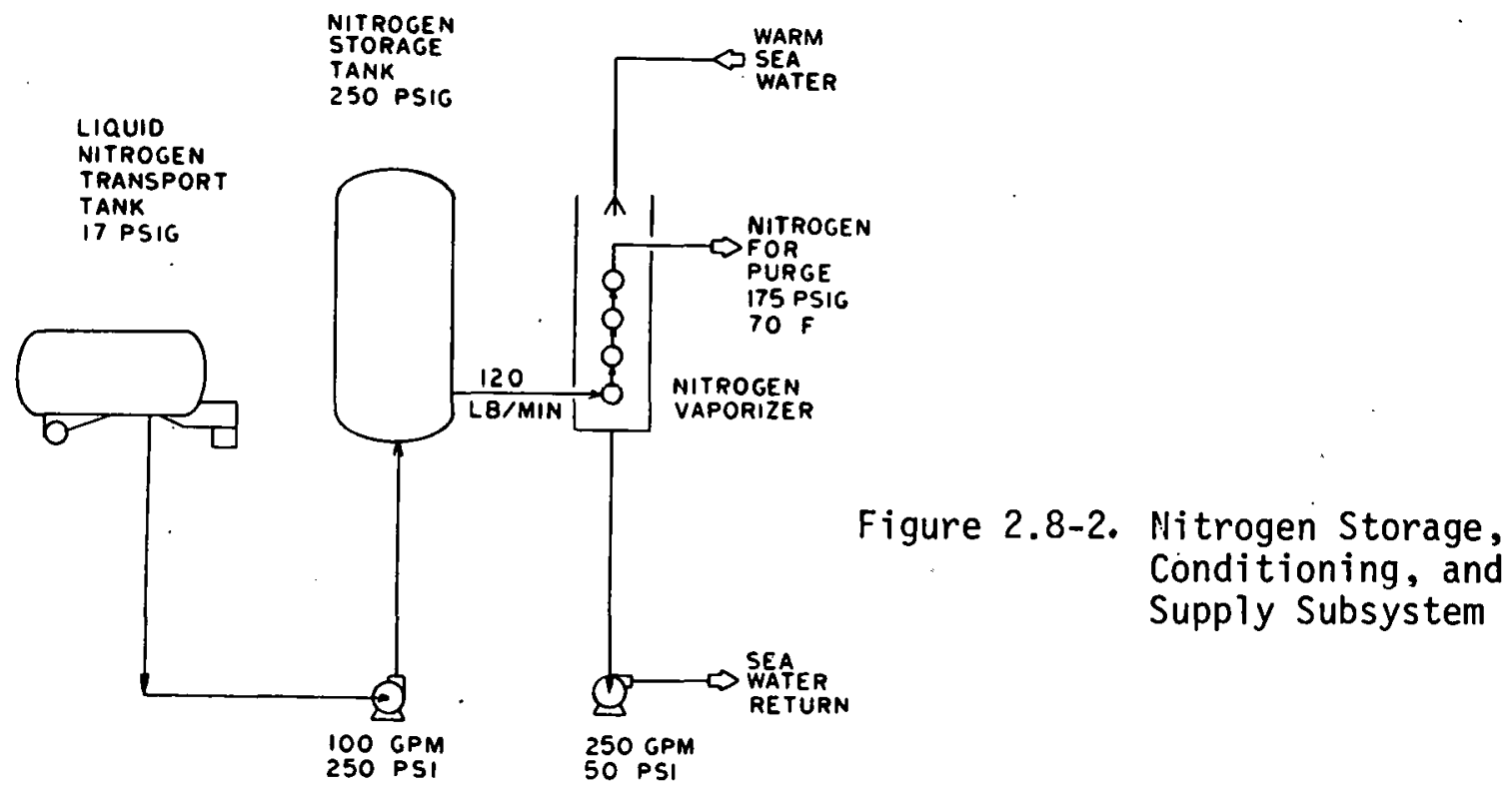

\subsubsection{Ammonia Storage System}

The ammonia storage system includes

D-100 Ammonia Heel Storage Drum

D-101 Wet Ammonia Storage Drum

D-102 Dry Ammonia Storage Drum

P-100 Blowdown Pump

P-101 Ammonia Transfer Pump

Each of the three carbon steel drums is sized to have 29,000 gallons of available capacity in a vesse $14 \mathrm{ft} .-0$ in. diameter by $25 \mathrm{ft} .-0$ in. long w1th 2 to 1 SE heads. The design pressure of 250 psig satisfies the code of Federal Regulations (CFR) Section 46 and the OSHA requirements. The drums are provided with a local level indication and board mounted level and pressure recorders and high level and pressure alarms, again as per CFR-46.

Two of the drums are designated as ammonia storage drums and one drum is intended for heel storage. For this description, ammonia heel is defined as the ammonia liquid blowdown from the power loop evaporator.

Code requirements limit the filling of the drums to 82 percent of the total volume. The available capacity of each drum is 29,000 gallons or 147,200 lbs of 99.5 percent ammonia at $70^{\circ} \mathrm{F}$. Total capacity of three drums is 442,000 pounds of 99.5 percent ammonia with 0.5 percent water. 


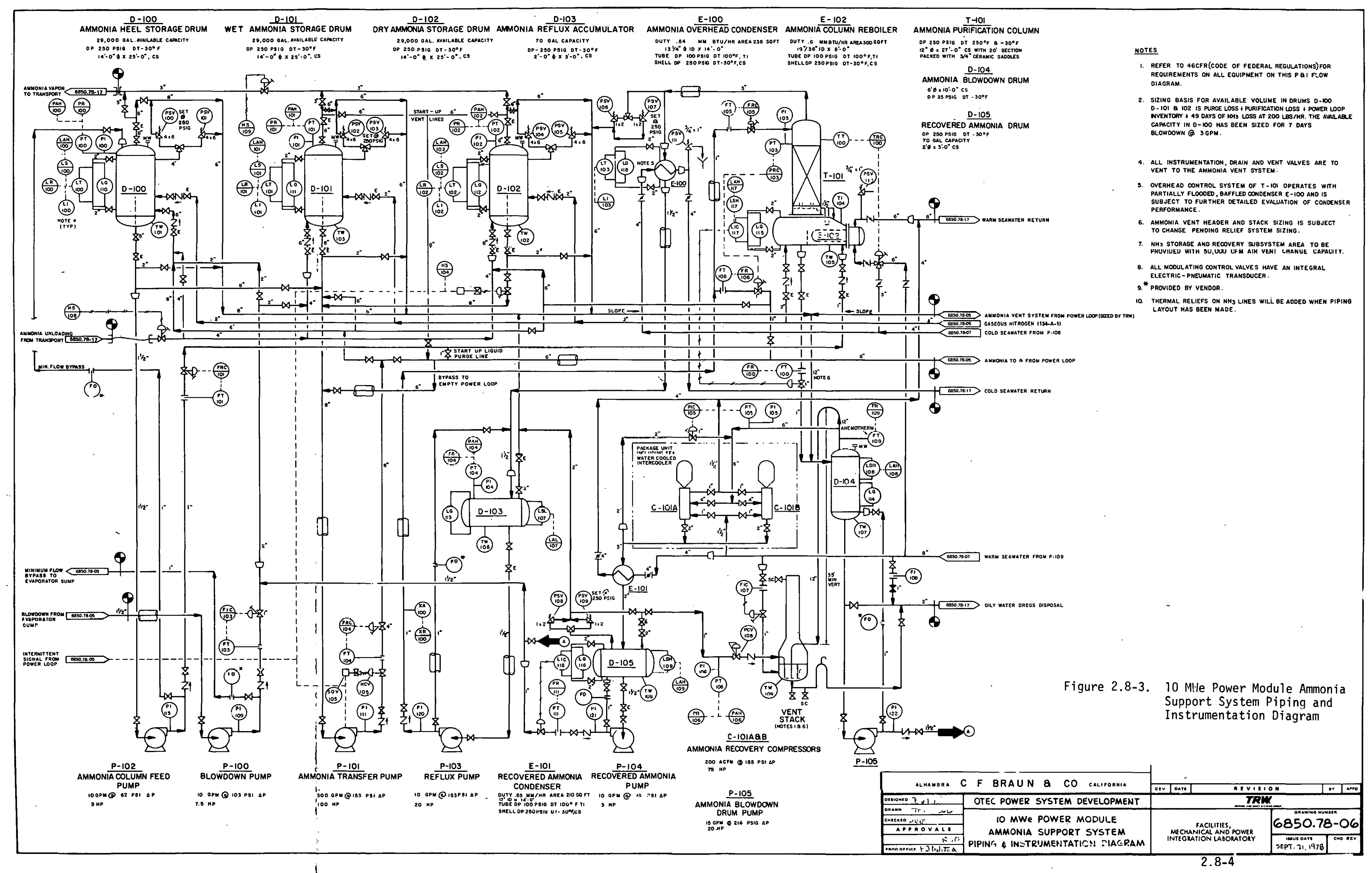




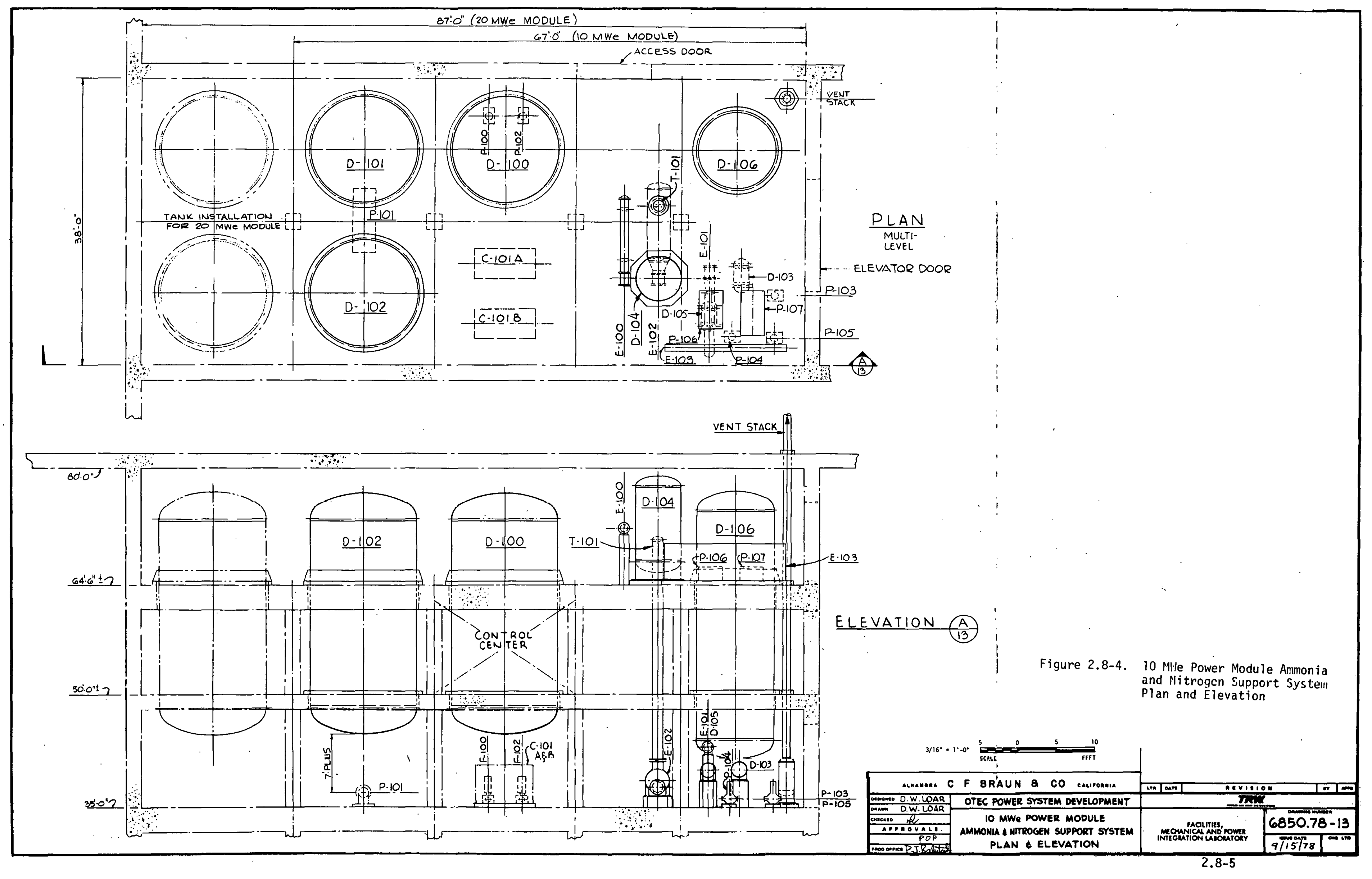


Initially the three ammonia storage drums will be filled with 442,000 pounds of 99.5 percent ammonia from a transport vessel. About 7,000 pounds of 99.5 percent ammonia will be used to purge nitrogen from the power loop. This leaves 435,000 pounds of 99.5 percent ammonia in the three storage tanks or 432,800 pounds of 100 percent ammonia and 2,200 pounds of water. In the ammoria purification process 3 pounds of ammonia are lost for every 1 pound of water removed. Therefore, 6,600 pounds of ammonia are lost in the purification process. Of the 426,000 pounds of 100 percent ammonia left, 191,000 pounds are used in the power loop charge. This leaves 235,000 pounds of 100 percent ammonia in storage after the system is charged, and the purification process completed.

Based on assumed power loop system ammonia losses of 200 pounds per hour, the remaining ammonia in storage will sustain 49 days of continuous operation, adequate for a platform location in a remote area. The ammonia loss rate will affect the size of the required storage and reprocessing facilities. Ammonia losses can be divided into continuous and intermittent losses.

Examples of continuous losses would be the glands of pumps and valves, the turbine seal system, and the evaporator and condenser tube or tubesheet losses. The magnitude of the continuous loss from these items will vary. Leakproof design of all equipment containing ammonia and operational and preventive maintenance procedures will reduce the continuous losses. This implies early recognition of potential leakage spots and design means to overcome these.

Examples of activities leading to intermittent ammonia losses would be manual opening of vent and drain or instrument valves, relfef valve activation, startup and shutdown, equipment venting and ammonia loading operations.

Actual experience will be needed to determine a more accurate basis for the design estimate of $200 \mathrm{lbs} / \mathrm{hr}$ for the overall continuous loss rate. At a value of $\$ 150$ per ton, ammonia losscs and the costs associated with the capital and operating costs of the ammonia recovery equipment are factors in the economic viability of the power module as further described in Section 2.8.2.3. 
Ammonia makeup and blowdown quantities will depend on the overall leakage and ammonia contamination rate from the power loop. The blowdown pump has been sized at $3 \mathrm{gpm}$ and will require a minimum flow bypass. Again, actual experience will determine the blowdown rate from the evaporator and whether a low continuous rate or intermittent blowdown at a high rate is preferable. The type and quantity of contaminants, their buildup rate and effect on overall system performance will dictate the optimum removal method. The heel tank will store 7 days of continuous blowdown at $3 \mathrm{gpm}$ and allow ample time for repairs or turnaround of the ammonia purification system and its associated equipment.

The storage system also includes ammonia transfer pump P-101. This pump is sized for $500 \mathrm{gpm}$ to either fill or unload the power loop in about 85 minutes. The pump rate can be controlled with a control valve. The discharge and suction lines of the pump are provided with automatic on/off type valves to allow ammonia supply for the power loop after the manual block valves have been set as required. The pump and valves are activated intermittently by the level in the condenser sump.

The inlet and outlet lines of each drum are provided with excess flow valves and the inlet line with a check valve. The dual rellef valves in each drum are sized to handle the fire load and any overfill from the shipping supply vessel. Board mounted control allows remote shutoff of the valves in the fill and vent lines to and from the drums. It is assumed that the drums will be filled with a pump or loading compressor associated with the ammonia supply container on the transport vessel

\subsubsection{Ammonia Conditioning System}

The purpose of this system is to remove oil, contaminants, solids such as iron and magnesium hydroxide, and water from the circulating ammonia: in the power loop.

The overall power module efficiency is decreased by roughly 2 percent for every percent of water in the ammonia evaporator. Maintenance of a low water level in the power loop ammonia is therefore essential for optimum power recovery. The initial power loop charge of 99.5 percent ammonia can be dewatered in the evaporator at startup to essential dryness. The remaining high-water ammonia heel can be removed from the evaporator sump to the ammonia heel storage drum $D-100$.

$$
\text { 2.8-7 }
$$


The carbon steel ammonia conditioning system includes a 12-inch diameter by 27-foot purification column T-101. This column has a 20-foot section packed with 3/4-inch ceramic saddles. Vapor is generated by a horizontal, ammonia column reboiler E-102. This reboiler is heated by a mixture of warm and cold seawater at a controlled rate to maintain the top temperature of the column. The overhead is condensed in ammonia overhead condenser E-100 and flows from there to reflux accumulator D-103. E-100 is cooled with cold, $40^{\circ} \mathrm{F}$ seawater. Reflux and feed are on manual control. The system pressure is maintained by varying the product rate which in turn changes the level in the overhead condenser. Further study will be requircd to ovaluate the sensitivity of the overhead pressure control as a function of level fluctuations in the flooded condenser and in turn column stability and water and ammonia separation. Another control system that has been considered would involve the use of an inert gas such as nitrogen to maintain the system pressure. In that case it would not be necessary to operate with a flooded condenser. However, the inert gas would dissolve to a certain extent in the liquid ammonia product and contribute to an additional vent requirement from the power loop condenser.

The bottom product of the column is removed on level control from the reboiler section. It. will consist of vily dregs, water, ammonia, higher boiling contaminants and some solids. The mixture is flashed in blowdown drum D-104. Flashed anmonia is recovered and the residue removed by gravity flow to a rentral disposal system, which is part of the support vessel.

Details on the column design calculations are given in Appendix $M$. The column is designed for 1000 pounds of ammonia product per hour.

\subsubsection{Ammonia Vent and Recovery System}

As indicated under Section 2.8.2.1, the recovery of ammonia is an essential part of the economic viability of the OTEC module.

The energy consumption to produce ammonia is about $40 \times 10^{6} \mathrm{Btu}$ per ton. A loss of $200 \mathrm{lbs} / \mathrm{hr}$ represents about $1200 \mathrm{~kW}$ or 12 percent of the net power output of the unit, from ais overall energy economic point of view. 
Alternately, at a prel iminary estimated delivered cost of 30 mils per kWh for the 10 MWe module, and an ammonia cost of $\$ 150$ per ton, an hourly loss rate of 200 pounds represents 5 percent of the module output.

Obviously then, there is a significant economic incentive to recover the ammonia and to reduce continuous and frequently occurring ammonia leaks. With reduced leakage, the size of the equipment in the recovery system can be reduced and crew safety can be improved. Leakproof design should be part of the early design requirements of all equipment. Ammonia from leaking tubes in the evaporator and condenser will dissolve in seawater. The pungent odor of ammonia will provide adequate detection of atmospheric leaks. However, there will be a number of equipment items such as relief valves, compressors, pump and valve glands that will be connected to the vent system. Leakage detection from these items will require special techniques. It might be desirable to instrument the vent systems to facilitate leakage detection and localization.

All vent and relief headers and lines will discharge to the ammonia knockout drum D-104. The purpose of this drum is to remove any liquid carry over. Large quantities of liquid ammonia separated in D-104 will not vaporize and can be returned to the heel drum on manual control with ammonia blowdown drum pump P-105. Vapor flow is detected with a wide range anemotherm after the knockout drum. The "normal" vapor flow is recovered with the ammonia compressors $C-101 \mathrm{~A}$ and $\mathrm{B}$. Vapor flow in excess of the compressor capacity, bypasses to the bottom of the vent stack. The ammonia compressor is redundant because of the rapid payout from recovered ammonia in case one compressor is down. Each compressor will be equipped with suction valve unloaders and a bypass to contrul the suction pressure slightly above atmospheric pressure. Compressed ammonia will be condensed in recovered ammonia condenser E-101 and will flow from there to recovered ammonia drum D-105. Recovered ammonia pump P-104 removes the liquid ammonia to the heel drum D-100 for preprocessing. A local pressure controller maintains the discharge pressure of the compressor at $200 \mathrm{psig}$, for ammonia condensation. 
Noncondensables and some ammonia are vented to the vent stack. Here, a significant part of the ammonia will dissolve in the seawater, which is continuously added to the bottom of the vent stack. As per CFR-46 regulations any excess vapor will discharge through a stack 10 feet above the highest occupied structure on the support vessel. Ti-metal, as well as plastics, will be considered in the detailed design for equipment and piping items in contact with seawater.

\subsubsection{Electric Power Requirements During Startup and Shutdown}

Part of the ammonia storage and conditioning systems will have to be operational prior to startup and after shutdown. The ammonia transfer pump will be required. The recovery compressor system should also be operational. The ammonia purification system would probably not have to be operational during startup or shutdown. The nitrogen system will be activitated during startup and shutdown. Adequate electric power, about $300 \mathrm{hp}$, to operate these systems should be available, apart from the power generated in the power loop, possibly from an on-board diesel generator system. Section 2.2.5 discusses the startup power budget in detail.

\subsubsection{Instrumentation and Interlocks for the Nitrogen and Ammonia Support Systellis}

To the extent that CFR-46 regulations permit, it is planned to have most of the instrumenlation associated with the twn systems on a local board. Remote set point control from the main control ruouil (see section 2.9.4) will be provided on the ammonia blowdown and supply for the power loop and on critical variables such as feed and reflux rate which affect the control of the purification system.

For personnel protection in the below-deck-located ammonia and nitrogen support systems area, a protection interlock and shutdown system will be incorporated thal can be activated. from the central control facility. 


\subsubsection{Nitrogen Support Subsystem}

\subsubsection{Purging}

Initially, air must be purged from the system with nitrogen to avoid a flammable mixture when ammonia is introduced. Then the nitrogen can be purged with ammonia vapor to free the system of noncondensibles before charging the system with liquid ammonia. When maintenance requires opening any part of the system containing ammonia, that part of the system must first be isolated, vented to atmospheric pressure, and purged with nitrogen. If personnel are to enter the system, the nitrogen will have to be displaced with air. This can be done with portable blowers.

If a system is purged by adding a purge gas, allowing the system pressure to rise, then venting down to the original pressure, the concentration of the original gas at the end of any number of cycles can be calculated as described in Section 2.8.3.3.

\subsubsection{Flammability Limits}

One of the main objectives of purging is to avoid flammable mixtures. Figure 2.8-5 is a plot showing the range of flammable mixtures for the system of ammonia, nitrogen, and oxygen. This plot is based upon four data points found after a literature search. Only straight-line boundaries could be drawn through the four points. It is assumed the data points apply for ambient pressure and temperature. Higher pressures do not significantly increase the flammable range. Higher temperatures, however, do. But for the OTEC concept, the temperature will be close to ambient or lower. The plot is therefore sufficiently accurate to serve as a guide for the amount of purging required to avoid flammable mixtures.

The dashed construction lines on the plot show safe purging limits. The dashed line at 14 percent oxygen is the minimum oxygen content to support combustion. Once the oxygen in the system is diluted below 14 percent by purging with nitrogen, it is safe to introduce ammonia. The dashed line from 50-50 nitrogen and ammonia to 21 percent oxygen in nitrogen shows that once ammonia is diluted to 50 percent by purging with nitroyen, air can be safely introduced into the system. The American Gas Association (AGA) recommends dilution down to $1 / 5$ of the safe 1 imit. This is a rather 
FLAMMABILITY LIMITS

FOR THE

AMMONIA, NITROGEN, OXYGEN SYSTEM

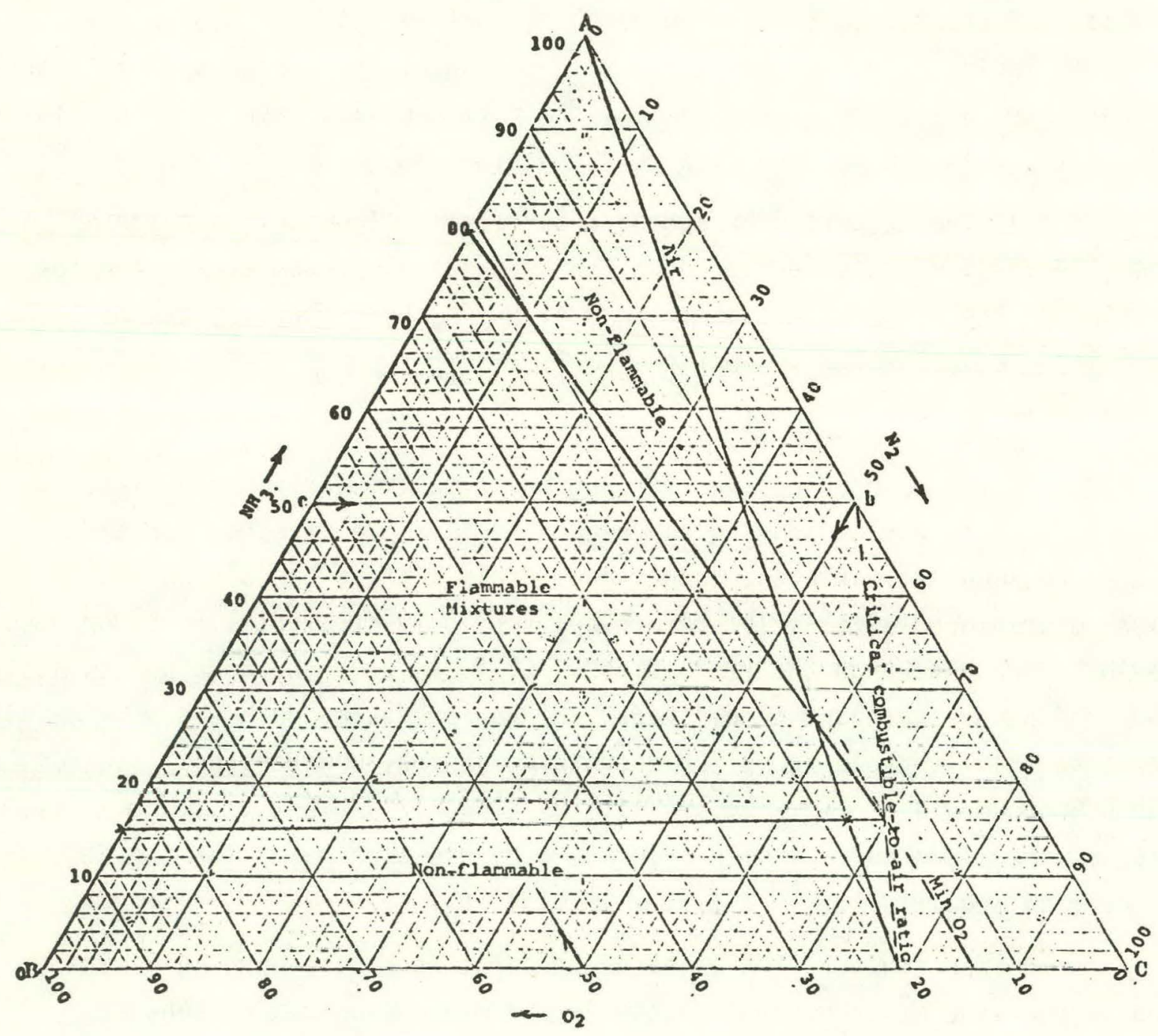

Plotted data points taken from the United States Department of the Interior, Bureau of Mines, Bulletin 279, 1938 Edition.

Figure 2.8-5. Ammonia Support Subsystems 
conservative approach. Nevertheless, this guide can be followed without an excessive use of nitrogen.

\subsubsection{Nitrogen Purging Requirements}

Nitrogen purging requirements were calculated using $1 / 5$ of the safe limit as recommended by $A G A$ and using a formula for dilution when perfect mixing is assumed. When purging with nitrogen to remove air, the oxygen content can be reduced to $1 / 5$ of 14 percent with three volume changes in three cycles using equal system volumes of nitrogen each cycle. When purging with nitrogen to remove ammonia, the ammonia content can be reduced to $1 / 5$ of 50 percent with three volume changes in six cycles using an amount of nitrogen equal to $1 / 2$ of the system volume each cycle. Using this approach, it takes three volume changes to purge either air or ammonia to safe limits. The volume of a 10 MWe power unit is about 31,000 cubic feet. It therefore takes about 93,000 standard cubic feet of nitrogen to either purge air or to purge ammonia. If it is assumed that each power system startup shutdown cycle requires a complete purge, the consumption of nitrogen is about 186,00 standard cubic feet, or about 13,750 pounds of nitrogen.

\subsubsection{Purging Nitrogen with Ammonia}

To displace the nitrogen in the power loop with ammonia, it is assumed that five volume changes will be adequate. The required ammonia vapor is drawn from the vapor space of the ammonia storage vessels or supplied as liquid with the ammonia column feed pump $P-102$. It is introduced at the high points and nitrogen is purged from the low points. The ammonia vapor drawn from the vapor space of the ammnnia storage vessels is essentiaily water free. About 7,200 pounds of ammonia are required for five volume changes of the 31,000 cubic foot power loop.

\subsubsection{Noncondensibles}

Initially, some nitrogen will be left in the systeln after purging with ammonia vapor. Once the unit is started, this nitrogen and any remaining air wtll be swept into the condenser. The most likely location for the inerts to accumulate will be near the bottom of the condensers and above the liquid level in the pump suction drum. Once the inerts are 
purged to a tolerable level, there should be no further introduction of inerts into the system.

When purging nitrogen and inerts from the system, there will be ammonia losses. No attempt is made to recover these losses. To do so would require a water scrubbing column, heat exchanger to remove the heat of solution and to cool the stripped scrubbing water, and a water circulation pump. The normal design of such a scrubber has 25 weight-percent ammonia in the water leaving the scrubber. A stripper to strip the ammonia out of this water would require electrically heated reboilers. An alternative might be to use refrigeration to condense the ammonia out of the purge gas. In any event, recovering ammonia from purge gas requires additional equipment and adds parasitic loads. If the purge gas is very dilute, recovery appears uneconomical.

\subsubsection{Nitrogen Package Unit Equipment}

Figure 2.8-6 shows the piping and instrumentation diagram (P\&ID) for the subsystem.

\section{Nitrogen Storage}

Industrial practice for nitrogen storage in the capacity range required for the UTEC concepl is to use pressurized cryogenic storage. For the preliminary design a storage pressure of 225 psig was selected. Pressure control is by a simple pressure regulator. At a storage pressure of 225 psig the vaporization loss due to heat in leakage amounts to about $1 / 4$ of 1 percent per day of the nitrogen in storage.

\section{Nitrogen Storage Vessel}

For the preliminary design, one 11,000 gallon nitrogen storage tank was selected. This vessel will provide about 1,024,000 standard cubic feet of nitrogen. This is enough nitrogen for purging for five complete power sys lem shutdown startup rycles.

The nitrogen storage vessel selected is a standard size modified to meet shipboard requirements. It is a vertical vessel mounted on three legs, 122 inches outside diameter by 32-feet 7 -inches high. The empty weight is 47,000 pounds and the filled weight is 120,000 pounds. Design conditions are $250 \mathrm{psig}$ and $-320^{\circ} \mathrm{F}$. The vessel is of double wall construction with an inner shell of stainless steel and an outer shell of carbon 


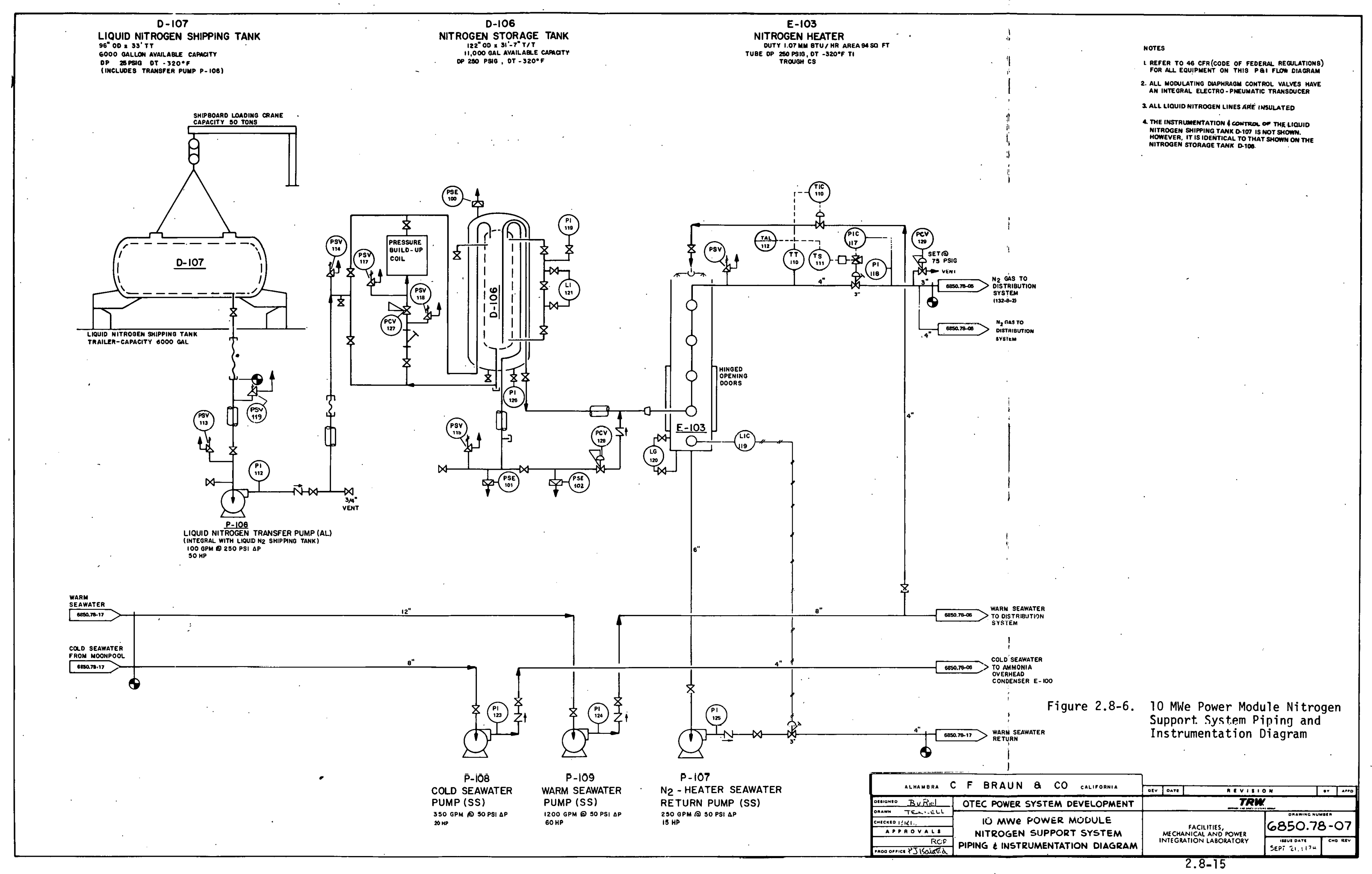


steel. The annular space between the shells is evacuated to a pressure of 50 microns of mercury and filled with Perlite.

The nitrogen storage vessel is not excessively large. However, this vessel will provide the nitrogen requirement with considerable contingency. Vessels of this size have been supplied for use on LNG supertankers. Smaller standard size vessels are available and a 13,000 gallon size is also standard. Any larger size would be a special design.

The nitrogen storage vessel will be purchased complete with all pressure controls, level indication instruments, and all required safety valves and rupture discs. Autorefrigeration will cause some reduction in storage pressure as liquid nitrogen is withdrawn from the vessel. A heater is also provided to overcome this effect and thus allow rapid removal of liquid nitrogen from the storage vessel.

\section{Nitrogen Shipments}

Liquid nitrogen is transported in special tanks mounted on a truck trailer. The largest transport tanks in use have a working capacity of 8,000 gallons. Transport regulations limit the pressure in the tank to $17 \mathrm{psig.} \mathrm{It} \mathrm{is} \mathrm{planned} \mathrm{to} \mathrm{ship} \mathrm{the} \mathrm{truck} \mathrm{trailer} \mathrm{to} \mathrm{the} \mathrm{platform,} 1 \mathrm{ift}$ the trailer onto the platform, and pump the liquid nitrogen to the onboard nitrogen storage vessels. This is considerably safer than trying to use a flexible hose designed for a temperature of $-320^{\circ} \mathrm{F}$ between the barqe and the plattform.

\section{Nitrogen Transport Tank}

The liquid nitrogen transport tank is of double wall construction with an inner shell of stainless steel and an outer shell of carbon steel. The annular space between the shells is evacuated to a pressure of 50 microns of mercury and filled with Perlite. The empty weight of an 8,000 gallon tank is 38,000 pounds and the filled weight is 91,000 pounds. Design conditions are $25 \mathrm{psig}$ and $-320^{\circ} \mathrm{F}$. This vessel will be purchased complete with.all required instrumentation and safety devices. A heater is also included to overcome the autorefrigeration effect when liquid ammonia is rapidly removed from the tank. This tank is a standard design modified to meet shipboard requirements. A $100 \mathrm{gpm}$ pump will be mounted on the transport tank. This pump will pump out the 8,000 .gallons of nitrogen in less than $1-1 / 2$ hours. 


\section{Nitrogen Vaporization}

When nitrogen is required for purging, the 225 psig storage pressure is adequate to supply the demand. The heater supplied with the storage vessel will overcome the autorefrigeration effect when liquid nitrogen is removed from the vessel. The liquid nitrogen from storage, however, must be vaporized and heated before it can be used for purging.

\section{Nitrogen Heater}

A nitrogen heater design developed by C. F. Braun has been used for the preliminary design. It will require further detailed design by suppliers. Vaporizers of this type have been used in liquid natural gas service. The heater design requirement is to vaporize 7,200 pounds of nitrogen per hour and heat the nitrogen to $60^{\circ} \mathrm{F}$. In the preliminary design this is accomplished by spraying warm seawater over a 4-inch by 192-inch titanium pipe coil contained in an epoxy lined carbon steel box. The box has access doors in the lower part for de-icing the lower coils. The exchanger is rated at about $10^{6} \mathrm{Btu} / \mathrm{hr}$ and the design is based on seawater entering at $80^{\circ} \mathrm{F}$. 'Testing or further calculations will be required to determine whether water freeze up could occur on the outside. The dry weight of the vaporizer is estimated at 3,500 pounds and the operating weight is estimated at 4,300 pounds. The overall dimensions are about 2-1/2 feet by 5 feet by 20 feet.

The nitrogen heater is provided with a shutdown feature, should the temperature of the nitrogen vapor to the distribution header system drop below $40^{\circ} \mathrm{F}$. This is to protect the carbon steel nitrogen steel distribution network.

\subsubsection{Preliminary Design}

The preliminary design package for the nitrogen support subsystem is part of Appendix $M$ and consists of the following:

- Process and Instrumentation Flow Diagram:

This flow diagram Figure 2.8-6 shows the nitrogen storage vessel, the nitrogen transport and the nitrogen vaporizer including all interconnecting piping and required instrumentation. Therei is aiso a description of the equipment on the flow sheet and indication of flow routing to other systems. Line sizes, control valve sizes, and relief valve settings are also indicated. 
- Equipment Data Sheets

The equipment data sheets include all of the design criteria for the nitrogen storage vessel, the nitrogen transport tank and the nitrogen vaporizer. Outline sketches are included with the data sheet for the nitrogen vaporizer. The equipment data sheets were developed to the extent that cost estimates could be made.

- Motor data and instruments are listed on appropriate motor and instrument 1 ists. 


\subsection{INSTRUMENTATION AND CONTROL}

\subsubsection{Instrumentation and Control System Design}

The instrumentation and control system performs the functions defined in Sections 2.2 .1 and 2.2 .2 by providing:

- Efficient operation of the plant

- Trips, to protect against damage and to assure the safety of the operators

- Data collection and alarms for real-time display to the operators

- Data collection for evaluation of plant performance

- Flexibility to permit experimentation with 'process variables or procedures and collect data about the experiments.

This section describes the implementation of the selected system that meets all requirements (a second design is described in Appendix $K$ ). The equipment chosen to implement the instrumentation and control design is:

- Sensors and actuators

- Control center including displays and operator controls

- Local control panels with their own displays, controls, and one-variable analog computers

- Plant computer and peripherals

- Instrument wiring.

Figure 2.9-1 is a block diagram of the system discussed in the remainder of Section 2.9. The preliminary specifications that were developed for the procurement of this equipment are in the specification package.

\section{9 .2 Sensors}

Appendix $K$ lists the instrumentation points chosen for the PSD-I plant, as summarized in Table 2.9-1. In accordance with the redundancy requirements of Section 2.2.1, 110 points are redundant out of 277 identified points. In addition, a 50 percent allowance is added for uncertainty (EPRI Report NP- $254^{\top}$, suggests 30 percent spares for a conventional plant during the design phases. Therefore, 50 percent uncertainty for a first 


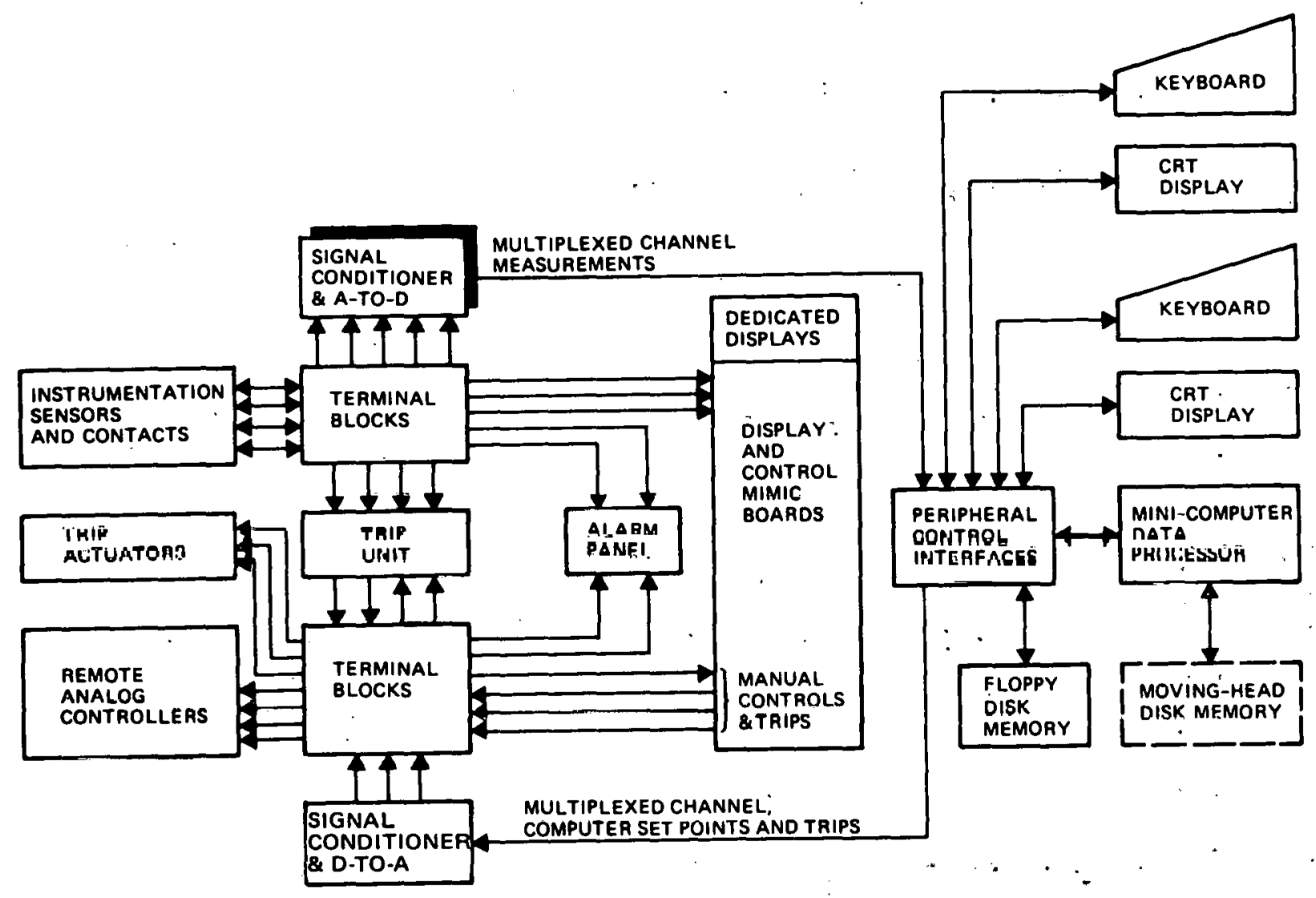

Figure 2.9-1. OTEC Instrumentation and Control System Block Diagram

OTEC plant is reasonable). The point counts of Table 2.9-1 serve ds the basis for the layout of console and wall spare, and for software estimates.

Conventional industrial instrumentation concepts are utilized to minimize risks and cost. Sensor accuracy is specified in the Sensor Lists of Appendix K. As many sensors of each type as possible are used to reduce costs and ease maintenance support problems. Table 2.9-2 shows the functions of the sensors and typical manufacturers of each.

The sensors chosen were based upon tradeoffs between various types, Resistance strain gauge pressure sensors were picked over piezo resistance gauges due to the fact that the latter needs a damping element at higher ranges which introduces the possibility of added error. RTD temperature elements are more accurate, more easily calibrated, and have faster response than thermocouples. 
Table 2.9-1. Summary of Point Count: Sensors

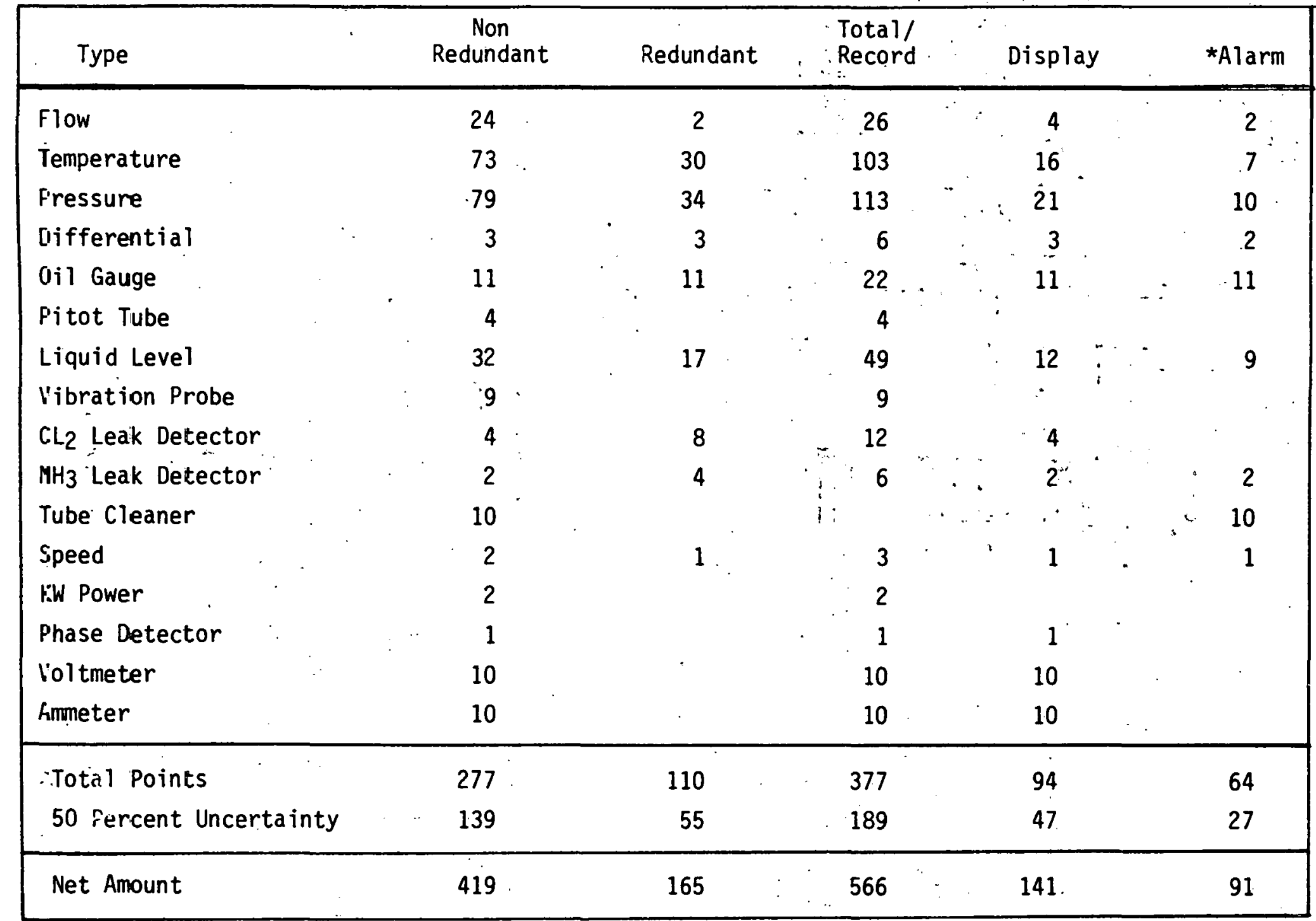

tAlarms are both wired and computer-displayed. 
Table 2.9-2. Typical Sensors for PSD-I

\begin{tabular}{|l|l|l|}
\hline \multicolumn{1}{|c|}{ Function } & \multicolumn{1}{|c|}{ Sensor Type } & Typical Manufacturer \\
\hline Pressure & Resistance Strain Gauge & Taylor \\
Differential Pressure & Resistance Strain Gauge & Taylor \\
Liquid Level $(\Delta P)$ & Resistance Strain Gauge & Taylor \\
Temperature & RTD . Taylor \\
Flow & Parity Turbine & Brookstaser \\
\hline
\end{tabular}

The baseline uses switch-type sensors fur drivilly dlarms. During Phase III, continuous sensors plus level settings will be compared to switch sensors. The continuous sensors can be tested in-place, as state variables vary normally, at the expense of added computer software. On the other hand, the switch sensors must be removed periodically for testing but do not need remote level settings or comparison software. A comparison of the higher initial costs of the continuous sensor with the higher maintenance cost of the switch sensor will be made during Phase III.

A11 transmitters will produce a 4 to $20 \mathrm{~mA}$ output signal. Where practical, the transmitter sensor elements are mounted near each other. All transducers will be excited at 24 VDC. All instrumentation within the OTEC PSD-I plant will be explosion-proof, conforming with Class I, Group D, as described in Article 500 of the National Electrical Cude.

\subsubsection{Control}

The actuators are shown in the ammonia power cycle drawing (Figure 2.1-4) and on the ammonia treatment plant drawing (Figure 2.8-3). Many of the actuators are manually controlled from the treatment-piant's local control board or from switches at the actuators themselves. The ten actuators ( 6 for the ammonia cycle and 4 for lie lreatiment plant) shown on Table 2.9-3 require automatic control. The baseline design uses fieldmounted analog controllers to control the actuators. All of these set-points can be set remotely from the main control room. Two of them also can be set by the plant computer in the automatic mode, as shown in Table 2.9-3. 
Table 2.9-3. Actuators for the Ammonia System

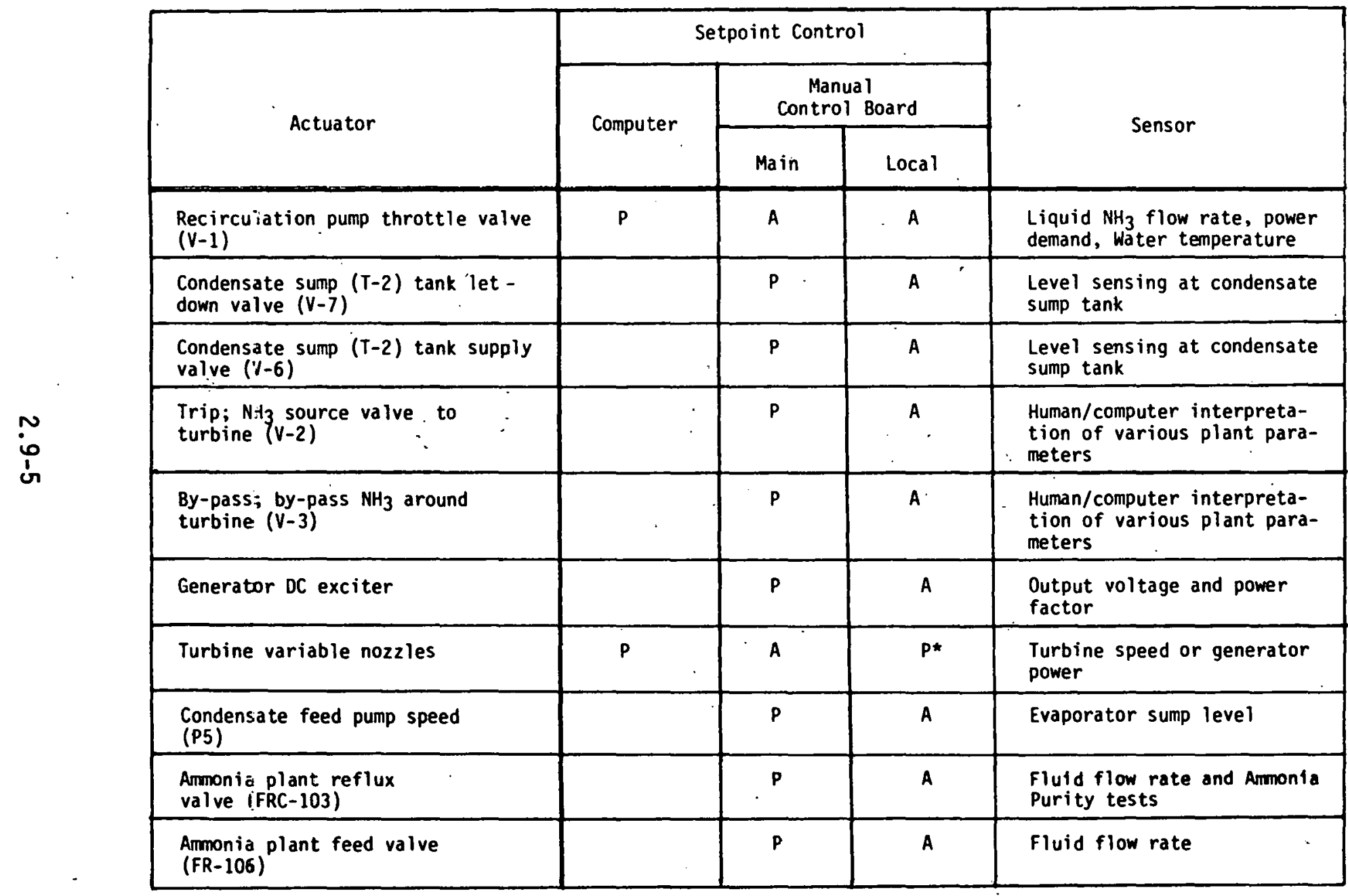
$P=$ Primary
Al ternate
$p^{*}=$ Startup only 
The remote actuators are operated from switches on the mimic board in the control room. Direct-reading lights and computer-driven digital displays on the mimic board and console confirm that operator actions have been executed.

Appendix $K$ discusses an alternative direct-digital control design in which all instrumentation feeds a large plant computer that computes the ten actuator commands. Because plant operation would so strongly depend on the operation of the computer and its associated peripherals, dual redundancy was chosen for the alternative design. Though the alternative design was rejected, a variant that allows more operator interaction may be reexamined during Phase III.

As required by Section 2.2.2, the plant computer drives the set-points for the ammonia recirculation pump throttle and for the variable turbine nozzles during steady-state operation. It drives the throttle valve as a function of desired power output and inlet water temperatures. When the plant is connected to an infinite grid, the plant computer drives the nozzles in a hunting mode, searching for the maximum net output power. When the plant is starting-up, the computer establishes the set-point for the recirculation pump throttle but the variable nozzles are controlled by an analog computer, whose input is turbine speed and whose frequency response requirements are far higher than those of the plant computer. In the island option, the digital computer controls the recirculation pump throttle but the nozzles are controlled by the same local analog controller using speed inputs. Software requirements for the control loops are estimated to be 50 words of data storage, 200 words of program, and 400 computer operations per iteration.

\subsubsection{Control Center}

A plan view of the control center is shown in Figure 2.9-2. The three operators operate the entire power station from the center including the ammonia loop and treatment plant and the government-furnished hydraulics.

The control center contains wall displays, a console, some electronic equipment, and a desk for the assistant operator as required by Section 2.2.1. 

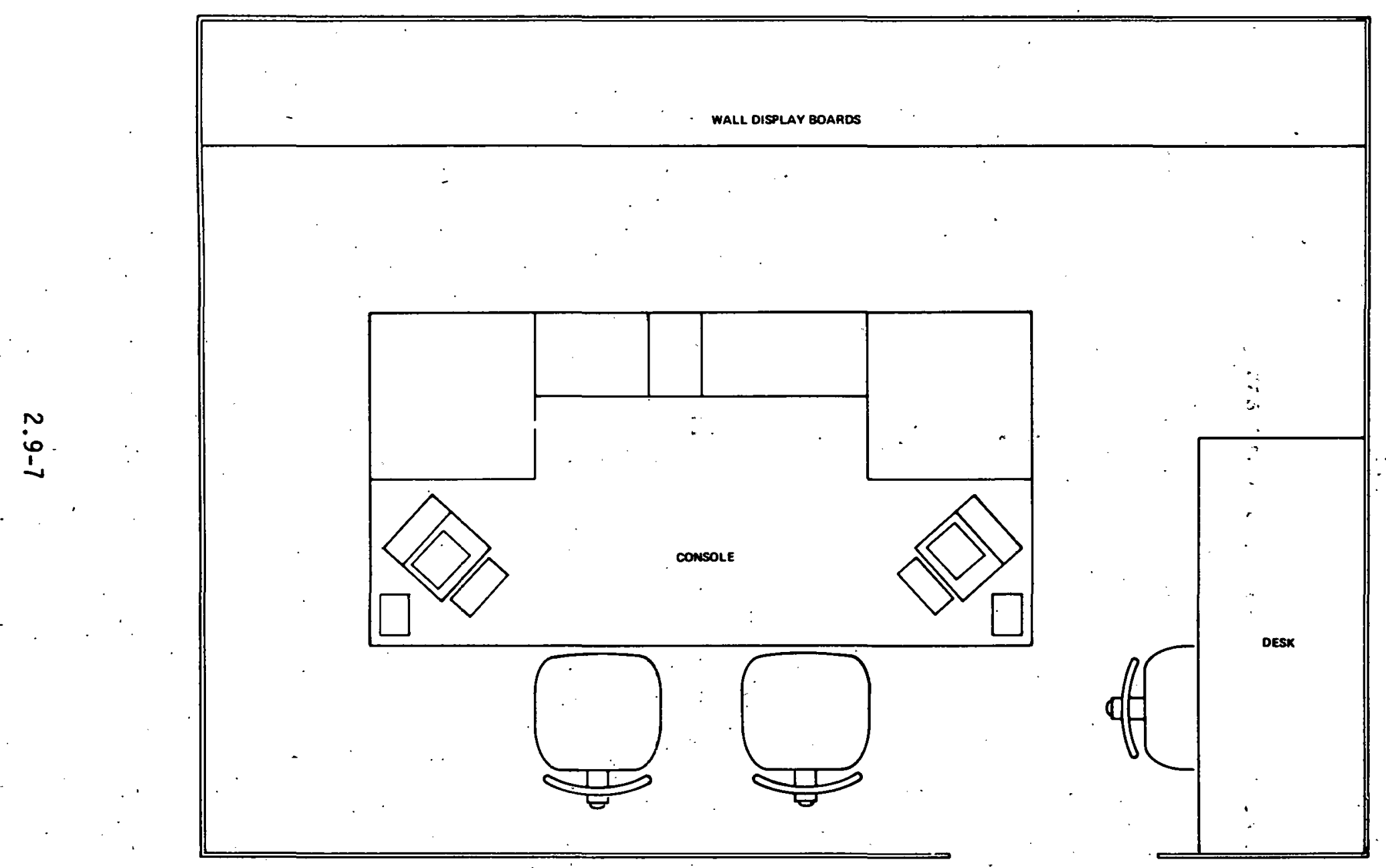

Figure 2.9-2. Floor Plan of Control Room 
Table 2.9-4 shows the allocations for wall-display space and for console space. Two wall-mounted mimic boards will be furnished, one for the PSD-I electrical system and one for the ammonia power cycle and top-level treatment plant (the detailed treatment plant is mimicked on a local control board in the hull of the ship). Status lights on the mimic boards in the control room are driven directly from field contacts while hand-switches drive valves and circuit breakers. Eighteen computer-driven digital displays on the board convey added information (voltages, currents, net and gross power, flow rates, pressures, temperatures). The electrical mimic board reproduces the power buses shown in Figures 2.10-1 and 2.10-3. It includes plant auxiliary loads, emergency power, and interfaces to the ship's power and to the power mains. The ammonia mimic board displays the status of all valves and motors and permits remote manual set-point control of the actuators listed in Table 2.9-3. The mimic board shows the status of all valves.

The wal1-mounted turbine-generator pariel has manual controls for the lube system, seals, variable nozzles, and exciter. It also has an automanual switch for disengaging the speed control loop after synchronization on an infinite grid.

Figure 2.9-1 shows how the interfaces from the fleid sensurs and ar.tuators are wired to the control room.. Section 2.9.7 describes the wiring practices in more detail. The rellabilily of critical measurements is assured by duplication of sensors and alarm Indicatur's for thosc critical parameters.

The DOE is expected to furnish sulie yet undefined ship's interface equipment and hydraulic interface equipment. For the purpose of sizing the console and wall space requirements, the assumptions of Table 2:9-4 were. made, leading to a requirement for $1.25 \mathrm{ft}^{2}$ of console space and $31 \mathrm{ft} 2$ of wall space. TRW would like the DOE-furnished ship's electric power displays (included in the these totals) to be adjacent to the PSD-I electric power display.

The requirements for PSD-I alarms are discussed in Section 2.2.3. Table 2.9-1 shows that 91 alarms are necessary. For purposes of sizing the control center, these alarm indicators are grouped above each subsystem panel on the wall, Fig. 2.9-3. An audible annunciator will sound each time 2.9-8 
Table 2.9-4. Control Center Display Space

\begin{tabular}{|c|c|c|c|}
\hline \multirow{2}{*}{ Display Category } & \multirow[b]{2}{*}{ How Displayed } & \multicolumn{2}{|c|}{ Area Required } \\
\hline & & Console & Wall \\
\hline \multirow[t]{2}{*}{ ELECTRICAL } & $\begin{array}{l}\text { Mimic board } \\
03 \times 3 \mathrm{ft}\end{array}$ & & $9 \mathrm{ft}^{2}$ \\
\hline & $\begin{array}{l}\text { Output meters (gross } \\
\text { and net power, voltage, } \\
\text { power factor). }\end{array}$ & $1 \mathrm{ft}^{2}$ & \\
\hline $\begin{array}{l}\text { AMMONIA RECIRCULATION } \\
\text { LOOP }\end{array}$ & $\begin{array}{l}\text { Mimic board: } \\
3 \times 4 \mathrm{ft}=12 \mathrm{ft}^{2} \\
\text { including } 16 \text { computer } \\
\text { driven displays }\end{array}$ & & $12 \mathrm{ft}^{2}$ \\
\hline TURBINE/GENERATOR & $\begin{array}{l}10 \text { displays } \\
10 \text { controls }\end{array}$ & . & $3 \mathrm{ft}^{2}$ \\
\hline \multirow[t]{5}{*}{ SHIP INTERFACES* } & 4 TV monitors & & $12 \mathrm{ft}^{2}$ \\
\hline & $\begin{array}{l}2 \text { Intercoms } \\
\text { a } 8^{\prime \prime} \times 10^{\prime \prime}=80 \text { in }^{2}\end{array}$ & $1.25 \mathrm{ft}^{2}$ & \\
\hline & $\begin{array}{l}\text { Air quality panel and } \\
\text { wave motion alarm }\end{array}$ & & $2 \cdot \mathrm{ft}^{2}$ \\
\hline & $\begin{array}{l}\text { Electrical power (mimic) } \\
\text { CB status, power } \\
\text { generation and con- } \\
\text { sumption }\end{array}$ & & $9 \mathrm{ft}^{2}$ \\
\hline & $\begin{array}{l}\text { HYDRAULIC PANEL } \\
2 \text { CRT, } 16 \text { alarms, } \\
10 \text { meters }\end{array}$ & & $8 \mathrm{ft}^{2}$ \\
\hline ALARMS (WIRED) & 91 at $4 \times 4$ inches & & $11 \mathrm{ft}^{2}$ \\
\hline TRIP INDICATORS & $\begin{array}{l}3 \text { at } 4 \times 6 \text { inches }= \\
24 \text { in }^{2}\end{array}$ & 0.75 & \\
\hline $\begin{array}{l}\text { DEDICATED DISPLAYS } \\
\text { (not on mimics) }\end{array}$ & 20 & $1.5 \mathrm{ft}^{2}$ & \\
\hline $\begin{array}{l}\text { COMPUTER CONTROL/ } \\
\text { DISPLAY PANEL }\end{array}$ & $\begin{array}{l}2 \text { CRTS plus } 2 \text { for } \\
\text { panel }\end{array}$ & $11 \mathrm{ft}^{2}$ & \\
\hline TOTAL & & $15.5 \mathrm{ft}^{2}$ & $66 \mathrm{ft}^{2}$ \\
\hline
\end{tabular}

* These assumptions are only preliminary pending definition of details by DOE or its contractor. 
an alarm is detected. The visual alarm indicators will remain illuminated until the trouble has been cleared; the audible tone can be cancelled by the operators.

The alarms are actuated by out-of-limit conditions detected as follows:

a. High and low limit contact on actuators, sensors, detectors and switches

b. Computer-recognized limits compared to previously-recorded upper and lower limit levels stored in computer memory.

The alarm panel occupies approximately $11 \mathrm{ft}^{2}$ of wall space. The trip initiation panel has three guarded trip buttons, three indicators, and an annunciate-cancel button. It uccupies $3 / 4 \mathrm{ft}^{2}$ of console space.

Two CRTs with keyboards are instailed on the console for calling-up detailed status and dlagnostic data. Twenty computer-driven dediraled displays are included on the console for key outputs (gross and net power generated, output voltage and power factors, 16 amomia loop displays such as condenser and evaporator temperature). For planning purposes, 20 more are included on the wall boards.

The total wall space is about $66 \mathrm{ft}^{2}$ and the total console space is $15.5 \mathrm{ft}^{2}$. Figure 2.9-3 shows an artist's rendering of the appearance of the control room. During Phase III, the operator work tasks will be analyzed to determine if three operators are satisfactory. If more operators are needed, the possibility of further automation or increasing the size of the control room to accommodate additional people will be evaluated.

\subsubsection{Diagnostic Instrumentation}

The points identified in Appendix $K$ and summarized in Table 2.9-1 are for both operational instrumentation and diagnostic instrumentation of the first power module. It is expected that 20 percent of the instrumentation will be removed in the second power module but that 5 percent will be added as a result of experience. When going to the third module, another 5 percent may be removed as more design issues are resolved. Therefore, the instrumentation system is designed so one entire input signal-conditioning unit services the diagnostic instrumentation and can be removed in the second power module, Fig. 2.2-2. Section 2.9.6 describes the signal conditioning units. 


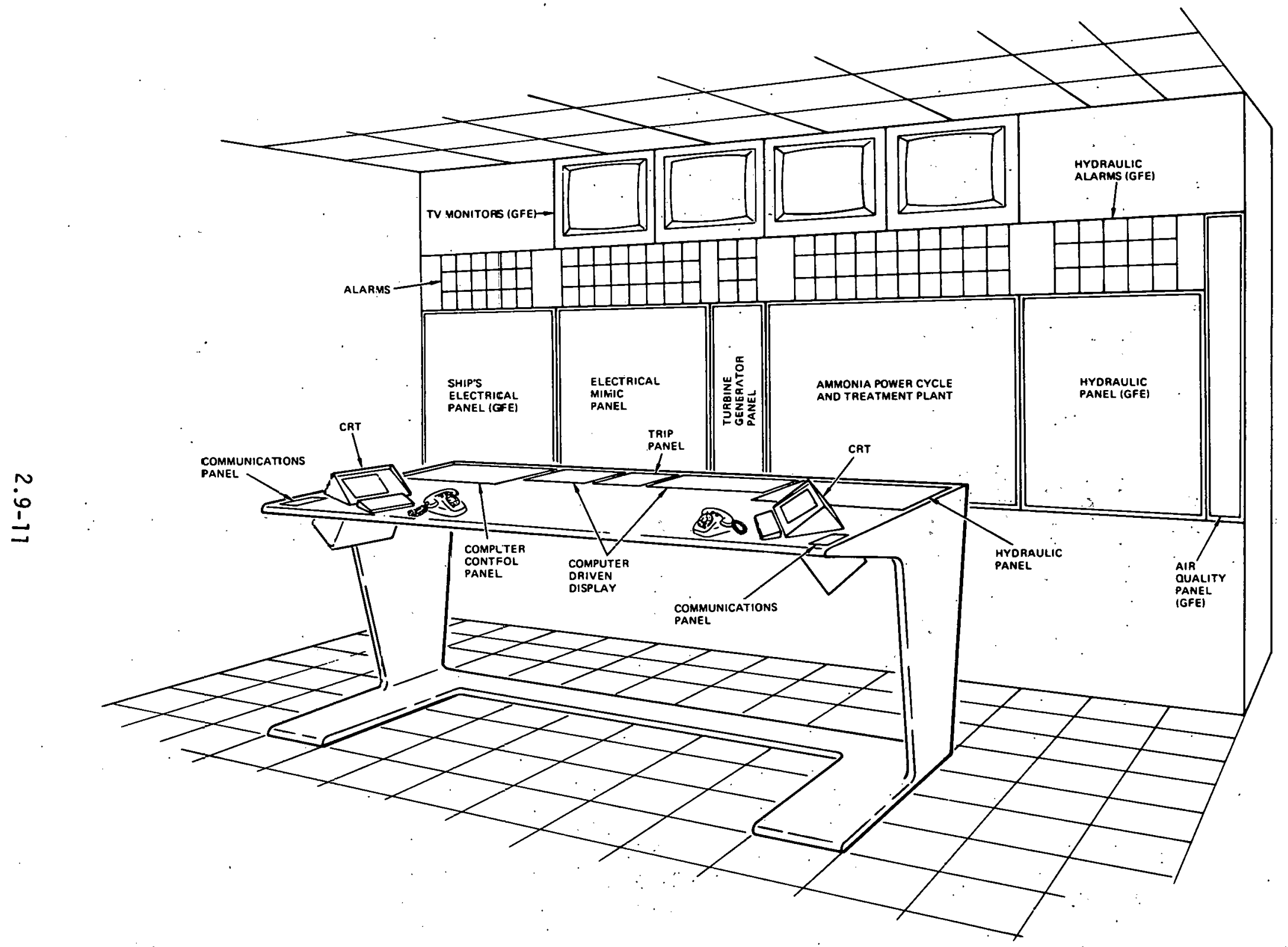

Figure 2.9-3. Control Room Wall and Console Displays 
When a recording is made of the latest values as required by Section 2.2.1.3, all plant data, operational and diagnostic, are scanned once each second and stored. After each trip, one set of data are also recorded. Historical data that are still resident in core can be called on the CRT in tabular form under seven categories of "system" and "subsystem." Section 2.9.6 shows the software budget for recording and display formats.

TRW identified a steady-state model (Section 2.2.4) and four dynamic models (Section 2.2.6) required to predict plant performance. In addition, many subsystems have detailed performance calculations. One of the principal functions of PSD-I is to validate these models. Therefore, all measurements needed to validate the models and calculations were in the Measurement List of Appendix K.

The data required to assess normal. plant performance, to determine the cause of abnormal performance and trips, to validate the models, and to evaluate the results of experiments are called "diagnostics." Some diagnostic data are computed in the plant digital computer; most are reduced at an on-shore DOE central processing facility. The mix is presently: unknown between the two kinds of calculations desired by DOE. Therefore, some estimates have been made of the amount of diagnostic software that should be resident in the plant computer. We took the heat exchanger diagnostics, Section 2.5.4, as representative of the subsystems.

Calculations are needed for such parameters as orifice pressure drop, ammonia quality, and local heat exchange coefficients. To do these calculations in the plant computer would require approximately 500 storage registers and 300 words of program. Assuming that the other six systems and subsystems are cqually complex, a total of 3500 words of data storage and 2100 words of program storage is needed.

\subsubsection{Plant Computer}

Table 2.9-5 shows the functions performed by the plant computer, as required by Section 2.2.1.6. Each function has been sized in terms of memory and in terms of the number of computer operations to be executed.

The off-the-shelf MAX II/III executive was chosen to meet software functional requirements with the assumption that software development would be performed on a scientific computer. The MAX II/III requires $14 \mathrm{~K}$ words of 
Table 2.9-5. Software Budget for Plant Computer

\begin{tabular}{|c|c|c|c|}
\hline Software Function & $\begin{array}{l}\text { Words } \\
\text { Memory }\end{array}$ & $\begin{array}{l}\text { Executions } \\
\text { Per Second }\end{array}$ & $\begin{array}{l}\text { Equivalent Add- } \\
\text { Operations Per } \\
\text { Second }\end{array}$ \\
\hline Executive & 14,000 & 1 & 80,000 \\
\hline Self-Test & 500 & 1 & 500 \\
\hline $\begin{array}{l}\text { Keyboard } \\
\text { CRT }\end{array}$ & 1,000 & 1 & 1,000 \\
\hline Analog/Discrete I/0 & 1,500 & 1 & 3,000 \\
\hline Recorder Format & 1,000 & & \\
\hline Cartridge Disk Drive & 1,000 & & . \\
\hline CRT Formats & 11,000 & & 6,000 \\
\hline Alarms & 250 & 1 & 500 \\
\hline Control Law & 250 & 1 & 400 \\
\hline Diagnostics & 5,600 & 1 & 3,000 \\
\hline Subtotal & 36,100 & & $94 ; 400$ \\
\hline Pad for uncertainty & 25,000 & & 94,400 \\
\hline TOTAL & 61,100 & & 188,800 \\
\hline
\end{tabular}

main memory. Though it contains more functions than are needed for the PSD-I job, it is less expensive than developing a new executive. Self-test software is estimated at 500 words, while $1 \mathrm{~K}$ words are allocated for keyboard and CRT drivers. Drivers for input-output to the signal conditioners are sized at 1500 words for 550 inputs. Historical data are recorded on a replaceable cartridge. 1000 words are needed to drive the cartridge and 1000 words to format the data. CRT format generation assumes that 6 CRT formats are generated for each subsystem, for a total of 42 formats, of which 18 are different. Allowing 600 words of code per format requires a total allocation of $11 \mathrm{~K}$ words for CRT formatting. The CRT unit has internal 
refresh capability so it need only be driven once per second as data are rescanned. The timing estimate assumes 2 CRT formats are being generated at all times. Alarm and trip computations are sized for 90 alarms requiring 100 fixed limits, 100 storage registers, and 50 words of program. Control function requirements discussed in Section 2.8.3 are 250 words. System diagnostic requirements are estimated in Section 2.9.3 to be 800 words per system and subsystem for a total of 5600 words.

Total known software requirements are 36,000 words. At this early stage, a large pad is prudent so a 64,000 word requirement is imposed on the computer. If an on-board high-order language interpreter is desired, if graphic formats are needed, if diagnostic software grows sharply, and if real-time review of historical data is needed beyond 10 seconds, a disc would be needed for virtual memory.

Some of the software may be written in high order language and compiled on a scientific computer. Those programs would require 300 percent more memory and execution time. A resident interpreter may or may not be desired to simplify software changes by the plant operator (DOE may prefer to prepare and verify new programs at a shore-based facility). A resident interpreter would add approximately 40,000 words to the program and would require virtual memory, stored on supplementary discs.

Based on this analysis of computer functions, a Modcomp II was chosen as the baseline computer. It 15 a standard production model 16-bit digital processor with a proven record of reliable performance in difficult industrial applications. Computer operation is managed by a real-time operating system residing in core. The program is modular and therefore flexible and adaptable to changing requirements of OTEC plant operation and data prücessing.

The basic executive software program includes codes that control the multi-programming environment, perform task check-pointing, power fallure recovery, and handle system traps. The file control services enable the user to perform data recording and other functions. required for file control such as open, close, wait, and delete.

The monitor console routine (MCR) is the terminal interface between the user and the real-time operating system. MCR includes: initialization 
commands, status, messages, task controi commands, and system maintenance commands. The MCR organization permits users to add commands to meet special application needs. The real-time operating system provides a dedicated, execute-only environment for monitoring and controlling many real-time processes concurrently.

Program development and system generation takes place in another (host) computer. This means that all of the plant computers! resources are devoted to supervising real-time applications.

The main memory is a random-access memory (RAM) of 128 kilobytes $(64,000$ words $)$. If added memory is needed, as noted above, we plan to add 5 million words of virtual memory on disc:

A cartridge is provided to facilitate data recording for permanent archive storage: Each cartridge can accommodate data for several days of operations. It can be conveniently filed for future reference, for on-shore data reduction, and for off-line simulation studies.

Three signal conditioners (Figure 2.9-1) provide the input and output ports needed from the instrumentation sensors to the computer and from the computer to the control actuators and switches.

Figure 2.9-1 shows an operational input signal conditioner that handles approximately 425 signals, a diagnostic input signal conditioner that handles approximately 150 signals, and an output signal conditioner that handles approximately 50 continuous signals and 90 discretes, all operational. Each signal conditioner consists of multiplexers, sample-hold circuits, analog-to-digital converters or digital-to-analog converters, a power supply, and electromagnetic interference filters. One shelf unit of the signal conditioner can accommodate 256 analog inputs or 64 analog outputs, or any combination. The signal conditioner can be expanded to a maximum of 2048 differential inputs or 4096 single-ended inputs. This capacity provides more than adequate flexibility for future expansion.

\subsubsection{Instrumentation Wiring}

Figure 2.9-1 shows the wiring plan. Individual field wires are brought into the cable-spreading room, above the control room, where they conner.t. to terminal blocks. The terminal blocks are wired downward to the control 
room with cable bundles of approximately \#18 wire. Wiring from the control room to the computer room below is also with \#18 wires, many of which are shielded. Cabling to the console in the control room is run beneath the floor, not to obstruct the operators' view of the wall boards.

The average horizontal length of wiring from the field to the terminal blocks is 60 feet. Adding 30 percent for vertical runs, the average length is 90 feet.

For estimating purposes, 220 points are assumed to require two wires and 350 points are required to require four wires. As a result, there are 1800 wires from the control room to the field and there are 3600 terminations to be connected. A circumferential cable tray runs around the machinery room (in addition to cable trays for power wiring) 12 feet above the-floor. Tray length was estimated at 550 feet with dual trays at the entrance to the cable-spreading room. The trays are filled to 50 percent capacity allowing for growth. To minimize wire length and tray length and to help protect against fire, half of the wire goes around the tray in one sense and the other half in the other sense. Drops to transducers and actuators from the trays are in conduit. Estimates are based on. 400 conduits, each 12 feet long, for a total of 4800 feet of conduit. These wire, tray, conduit, and-termination calculations were used to estimate instrumentation wire costs. 


\subsubsection{References}

1. EPRI Report NP-254, "Study of Remote Multiplexing for Power Plant Applications," Volume 3, September 1977. 


\subsection{ELECTRICAL SUBSYSTEM}

\subsubsection{Requirements}

The electrical subsystem design requirements are defined as follows:

- Deliver 10 MWe net power to an external base load.

- During startup, energize auxiliary loads from an external startup power source.

- Provide for synchronized coupling of the turbine-generator to the electrical distribution subsystem and provide for the controlled transfer of electrical load to the turbine-generator.

- Provide for the synchronized coupling of external load to the electrical subsystem and provide for the controlled assumption of its full load.

- The energized of critical loads from ships power when both the turbine-generator and the startup power source are down.

- Assure maximum flexibility for the operation and testing of the OTEC system and its constituent subsystems.

- Assure maximum safety of operation for personnel and equipment.

- Assure parametric similarity to the larger, integrated multimodule (40 MWe) OTEC system.

- Perform all above in a cost effective manner.

\subsubsection{Design Approach}

\subsubsection{Primary Power Distribution and Control}

To satisfy the design requirements sumarized in Section 2.10.1, a $13.8 \mathrm{kV}$ split bus system is utilized for the distribution and control of primary power (see Figure 2.10-1). The distribution and control of primary power are handled by the $15 \mathrm{kV}$ rated switchgear, its power circuit breakers and its control and instrumentation devices shown on Figures 2.10-1 and 2.10-2.

The major components of the electrical subsystem are:

1. The system load. Base line is an infinite grid.

2. The turbine-generator 


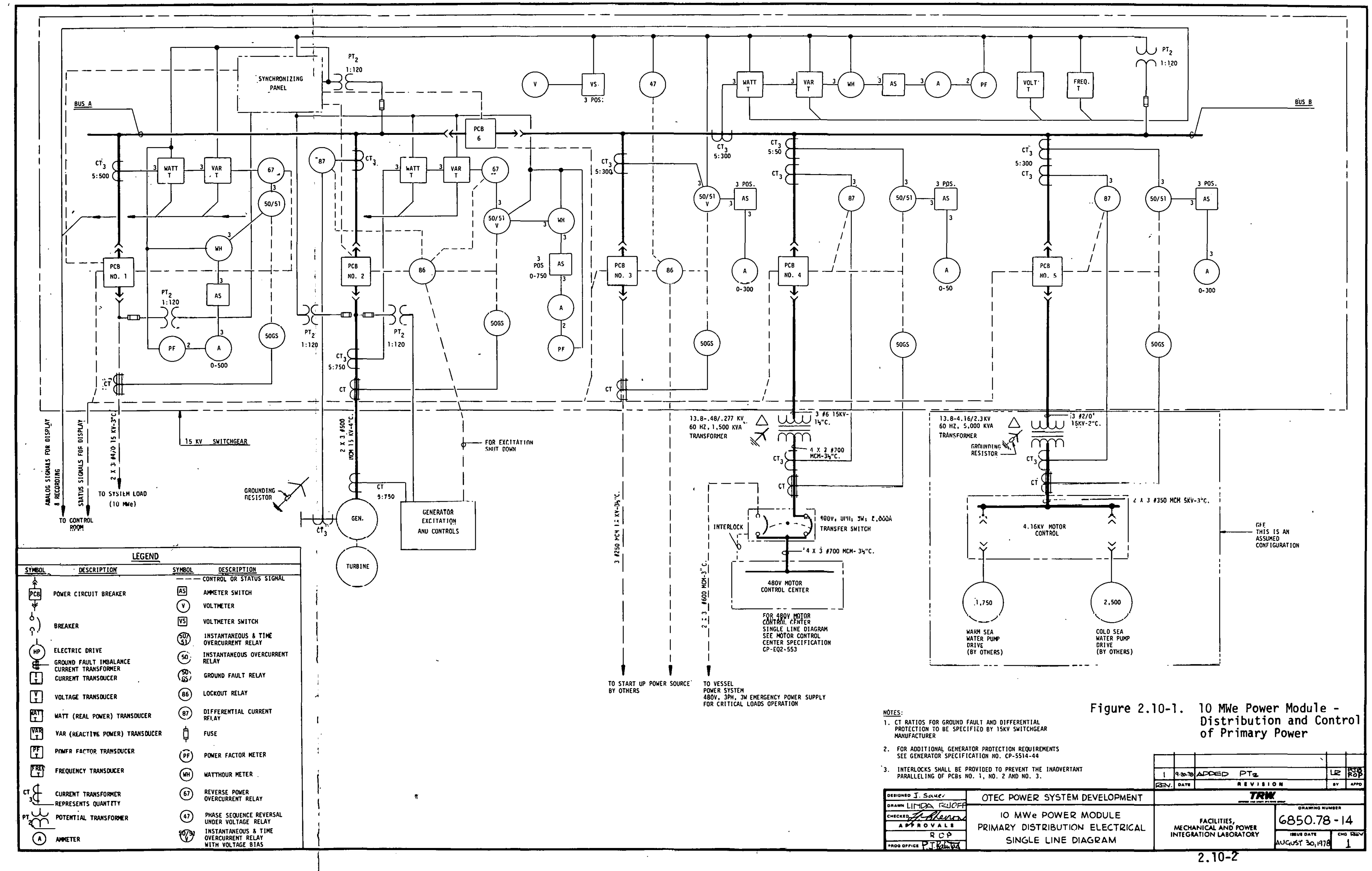


3. The startup power source. Startup power is drawn from a startup power source which in the base line, is the infinite grid itself.

4. The $480 \mathrm{~V}$ subsystem including auxiliary and critical loads (see Figure 2.10-3) and the interface to the ships electric power system.

5. The seawater pump drives.

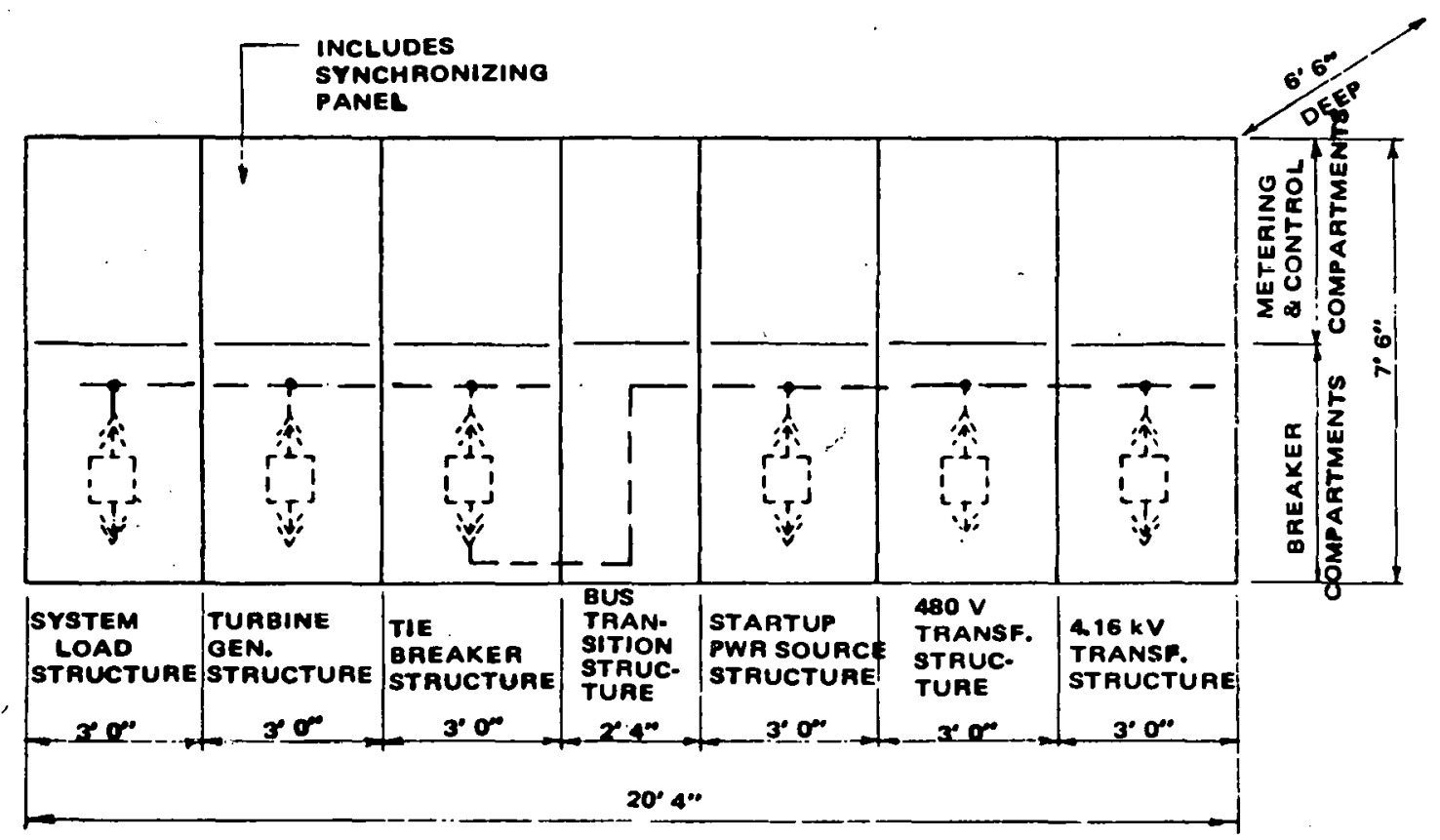

Figure 2,10-2. $15 \mathrm{kV}$ Switchgear General Arrangement

Scale: $3 / 8^{\prime \prime}=12^{\prime \prime}$

Dimensions are Approximate

Components 1 and 2 are supported by Bus $A$. Components 3, 4, and 5 are supported by Bus B. Buses A and B can be operated independently to permit OTEC power system testing or can be tied together by the tie power circuit breaker for normal OTEC system operation.

The primary distribution system is equipped with standard practice protective relaying to assure safety of operation to personnel and equipment. The protective relaying is shown in Figure 2.10-1. All power circuit breakers are tied to instantaneous, time overcurrent and ground fault current protection schemes. Power circuit breakers No. 4 and No, 5 are also included in differential protection schemes to provide additional transformer and associated feeder protection. Power circuit breaker No. 3 is tied to a phase sequence reversal and under voltage protection scheme to assure correct phase rotation and phase matching of the startup power 


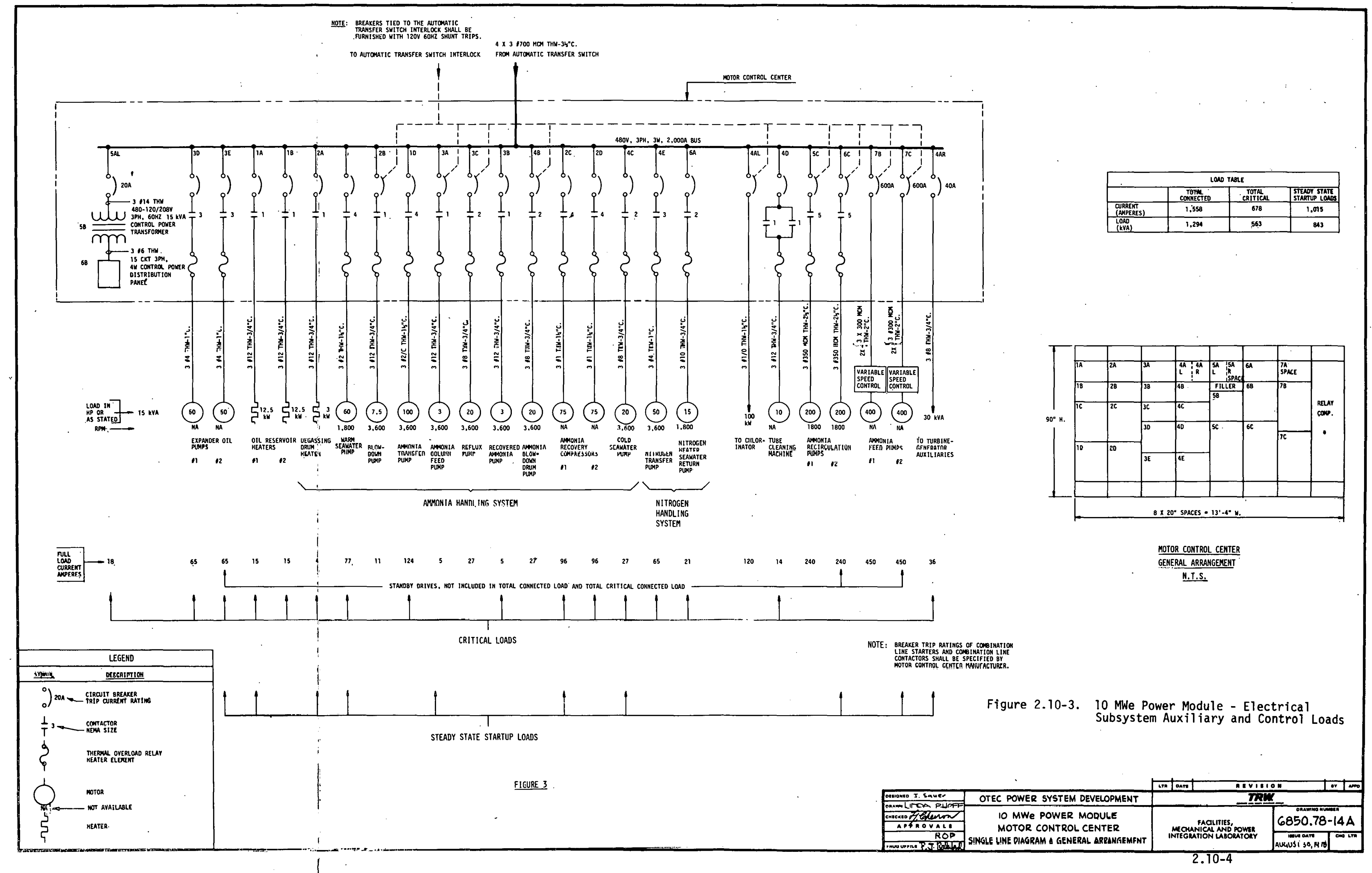


source and the electrical subsystem and to provide system under-voltage protection. Where the possibility of reverse current flow exists, reverse power overcurrent protection is provided. Power circuit breakers No. 1 and No. 2 are tied to reverse power protection schemes. The trip times and current characteristics of the various protection schemes will be coordinated to assure selective tripping and closest isolation to fault. This coordination will also be provided with the protective schemes of external electrical subsystems such as the system load, the startup power source, and the seawater pumps electrical subsystem. The power circuit breakers will also be interlocked to prevent undesirable configuration of power flow, such as the connection of two nonsynchronized power sources.

The primary distribution system is also equipped with a full complement of metering and instrumentation. The metering is used for routine operation. The instrumentation is tied to a data acquisition system and is used for system performance assessment and system status indication. Both metering and instrumentation are shown on Figure 2.10-1.

All $13.8 \mathrm{kV}$ branch circuits are supplied with current metering. The system load and generator branch circuits are also supplied with power factor, watt (real power), var (reactive power) and watthour (time integral of real power) metering.

For remote display and recording in the control room, transducers are supplied to generate electrical parametric analog signals and power circuit breaker auxiliary contacts are supplied to provide breaker status information. The transducers and the auxiliary. contacts are part of the $15.0 \mathrm{kV}$ switchgear. The display and recording of information these devices supply is part of the instrumentation and control subsystem (Section 2.9). The transducers provide system voltage and frequency information, and also provide watt and var. information for each of the $13.8 \mathrm{kV}$ system load, generator and startup power source branch circuits and the auxiliary loads $13.8 \mathrm{kV}$ bus.

The design of the electrical subsystem permits the following modes of operation:

a. Operation and test of auxiliary loads from the startup power source. 
b. Operation and test of auxiliary loads from the startup power source, while the turbine-generator independently drives the grid.

c. Transfer to $480 \mathrm{~V}$ shipboard power for the operation of critical loads when the OTEC system, the power grid, and the startup power source are down.

d. Normal operation of the OTEC system with the turbine-generator energizing the system load, the auxiliary loads and the critical loads.

Synchronization and power transfer are handled by the synchronizing panel, its associated potential transformers (PTs) and respective power circuit breakers.

During startup, power circuit breaker Nos. 3, 4, 5, and 6 are closed an power circuit breaker Nos. 1 and 2 are open. This permits energization of the auxiliary loads by the startup power source while the turbine-generator and the system load are kept isolated. The synchronizing panel monitors Bus B (startup power source and auxiliary loads) and the turbine-generator voltages, frequencies and the phase sequences. When the voltages are equal and in phase and when the frequencies are stabilized, then power circuit breaker No. 2 is closed. This ties the turbine-generator to the electrical subsystem. By loading the turbines as described in Section 2.2.5, circuit breaker No. 3 is opened and the auxiliary luads are transferred from the startup power source to the turbine-generator. The auxiliary power source is not removed. 10 couple the syste.m load to Bus A (turbine-generator) the synchronizing panel monitors the system load and Bus A voltages, frequencics and the phase sequences. (Circuit breaker No. 1 is closed when the system load and Bus $A$ voltages are equal and are in phase. This ties the system load to the electrical subsystem.

The tie-power circuit breaker No. 6 can also be part. of a synchronizing scheme. This breaker and the synchronizing panel can be used to tie two power sources when the turbine-generator energizes the system load and the startup power source independently energizes the auxiliary loads. During this condition, power circuit breakers No. 1 through 5 are closed and No. 6 is open. In this case, the synchronizing panel monitors the voltages, frequencies and phase sequences of Bus $A$ (system load and turbine-generator) and Bus B (startup power source and auxiliary loads). Power circuit 
breaker No. 6 is closed when the voltages are equal and are in phase. This ties Buses $A$ and $B$ together. By the appropriate control of the excitation and throttling of the turbine-generator and startup power source, the auxiliary loads can be transferred from the startup power source to the turbine-generator with the turbine-generator also energizing the system load. Power circuit breaker No. 3 is open after the load transfer is completed, removing the startup power source and resuming normal system operation.

\subsubsection{2 $480 \mathrm{~V}$ System}

Figure 2.10-3 shows the single line diagram and the general arrangement of the $480 \mathrm{~V}$ motor control center. Figure 2.10-3 al so shows:

a. Motor full load current data based on motor horsepowers and Table No. 430-150 of the National Electrical Code

b. Other full load current data based on kVA or kW ratings

c. The total full load current and total apparent power (kVA)

d. The critical loads full load current and apparent power (kVA).

The critical loads need to be operated when both the startup power source and the turbine-generator are down. Some of these loads are part. of the ammonia handling and nitrogen handiing systems, the generator auxiliaries, the tube cleaning machine and control and instrumentation circuits. When the turbine-generator and the startup power source are both down, the automatic transfer switch transfers to the vessels' $480 \mathrm{~V}$ power system to energize the critical loads. When this transfer occurs, an interlock from the transfer switch trips all the breakers that feed nonessential loads. This permits the sizing of the critical power source and its feeder for the critical loads only, rather than sizing for the full connected load of the motor control center. The automatic transfer switch and its interlock to the nonessential breakers are shown in Figures 2.10-1 and $2 \cdot 10-3$.

Based on the data shown on Figure 2.10-2, a 1,500 kVA dry type power transformer was selected to feed the $480 \mathrm{~V}$ motor control center. A drytype enclosed self-ventilated transformer was selected rather than silicon 
fluid filled because its characteristics make it more suitable for marine conditions:
a. Lighter - requires less platform seawater displacement
b. No insulating fluid sloshing
c. Minor maintenance and cost advantages.

\subsubsection{Seawater Pumps System}

This system is government furnished. However for the design of the electrical subsystem, some assumptions were made regarding the seawater pumps electrical system. It was assumed that the seawater pumps would be driven by squirrel cage inducliun motors. Based on the brake horsepower requirements of these drives, a 1,750 HP motor size was assumed for the warm water pump and à 2,500 HP mulur size was assumed for the cold water pump.

The voltage level of $4.16 \mathrm{kV}$ was assuilled based on rigure 2.5 of the IEEE, Handbook No. 141, "Electrical Power Distribution for Industrial Plants." Figure 2.5 in Reference 1 shows $460 \mathrm{~V}, 2,300 \mathrm{~V}$, and $4,160 \mathrm{~V}$ cost curves for induction motors, control and appropriate system cost as a function of motor horsepower. From the full load current of the seawater pump motors their apparent power (kVA) loading was calculated: From this it was assumed that a 5,000 kVA $4.16 \mathrm{kV}$ transformer would supply power to the seawater pump motors.

As discussed in Section 2.2.5.8, TRW will analyze the use of variable speed pumps to reduce startup power, after the details of the grid are better defined in Phase III.

\subsubsection{Generator Short Circuit Power Capacity and System Voltage Selection}

The calculated approximate, short circuit duty for a 40 MWe net output OTEC station is 407 MVA. The short circuit interrupting rating of the switchgear must be above the 407 MVA short circuit duty. $15.0 \mathrm{kV}$ class switchgear is available with a nominal 500 or 750 MVA interrupting capacity. Therefore, $15.0 \mathrm{kV}$ class switchgear was selected for the implementation of the power distribution scheme for an integrated 40 MWe net output OTEC station. $13.8 \mathrm{kV}$ is the highest standard distribution voltage this 
switchgear is rated for. The use of this standard voltage level will assure the lowest feeder costs as opposed to the use of a lower standard voltage level. Therefore $13.8 \mathrm{kV}$ primary distribution voltage selection was presumed for an integrated 40 MWe net output OTEC station. To make the 10 MWe module representative of modules used in future integrated OTEC stations, $13.8 \mathrm{kV}$ primary distribution voltage was selected.

\subsubsection{Startup Inrush Current}

For the OTEC power module to produce power, its auxiliary loads must be started and operated from a startup power source. The major auxiliary loads are:
a. Cold seawater pump motor, 2,500 HP (assumed)
b. Warm seawater pump motor, $1.750 \mathrm{HP}$ (assumed)
c. Ammonia feed pump motor, $400 \mathrm{HP}$
d. Ammonia recirculation pump motor, $200 \mathrm{HP}$.

This section addresses inrush current. Section 2.2.5.8 addresses steady state loads during startup. In the baseline design, where PSD-I is connected to a grid, the startup power source is the grid itself; providing power through a transformer and switchgear. If PSD-I is an isolated plant, the startup source could be a nearby OTEC plant, a startup barge, or the ship's own generators using the low-power startup scheme described in Section 2.2.5.8. For the sizing of the startup power source and the cabling to it, the inrush current of the seawater pumps was considered. The baseline pumps are driven by induction motors employing autotransformer-type reduced voltage starting to reduce the inrush from approximately 6 times to 2.3 times of normal running kVA. The startup power suurce must be sized to satisfy the starting inrush of the motors and to keep the voltage drop caused by the inrush to a tolerable magnitude. The 6 to 2.3 ratio reduction in inrush, due to the use of reduced voltage starters, permits a proportional reduction $[(2.3 / 6.0)]$ in the size of the startup power source. It is recommended that the startup power source and cabling sized to limit the inrush caused voltage drop to a maximum of 10 percent. Larger than 10 percent voltage drop may cause relays or contactors to drop out; motors to slnw dnwn, stall or fail to accelerate; or intcrfere with the proper operation of voltage sensitive devices. 
Table 2.10-1 shows Option D as the recommended choice for the OTEC power module starting.

Table 2.10-1. Startup Power Options

\begin{tabular}{|c|c|c|c|c|}
\hline OPTIONS & $\begin{array}{c}\text { MAXIMUM \% } \\
\text { VOLTAGE DROP }\end{array}$ & $\begin{array}{l}\text { REDUCED } \\
\text { VOLTAGE } \\
\text { STARTING }\end{array}$ & $\begin{array}{c}\text { ACROSS } \\
\text { THE LINE } \\
\text { STARTING }\end{array}$ & $\begin{array}{c}\text { STARTUP } \\
\text { INRUSH POWER } \\
\text { IN MVA }\end{array}$ \\
\hline A & 15 & NO & YES & 19.0 \\
B & 15 & YES & NO & 7.5 \\
C & 10 & NO & YES & 30.0 \\
D & 10 & YES & NO & 11.5 \\
\hline
\end{tabular}

\subsubsection{Power Wiring and Conduiting}

The power wiring and conduiting in Figures 2.10-1 and 2.10-3 were based on the following:

- Calculated full load currents or National Electrical Code Motor Currents Table No. 430-150

- National Electrical Code, Article No. 430, for motor feeders

- Safety factor of 1.25

- National Electrical Code, Table No. 310-16,750 $\mathrm{C}$ raled insulation, for $600 \mathrm{~V}$ rated ( $480 \mathrm{~V}$ service) feeders

- National Electrical and Code, Table No. 310-43, for $15 \mathrm{kV}$ and $5 \mathrm{kV}$ rated (13.8 kV and $4.16 \mathrm{kV}$ service) feeders

- National Electrical Code, Table No. 3A, for conduit sizing. 


\subsubsection{Electrical Equipment Room}

The electrical equipment room plan and elevation views are shown on Figure 2.10-4. Figure 2.10-4 shows these views and the electrical equipment arrangement for both a 10 MWe module and 20 MWe configuration. The equipment arrangement and the sizing of the electrical equipment room were based on the following design considerations:

a. Keep interequipment power feeders as short as practicable

b. Provide space around equipment necessary for maintenance (e.g., removal of draw-out devices from switchgear or motor control center)

- c. Comply with National Electrical Code, Article No. 450, for power transformer installation requirements.

The openings required for conduiting and wiring access to other areas of the facility are shown on interface drawing 6850.78-17. 

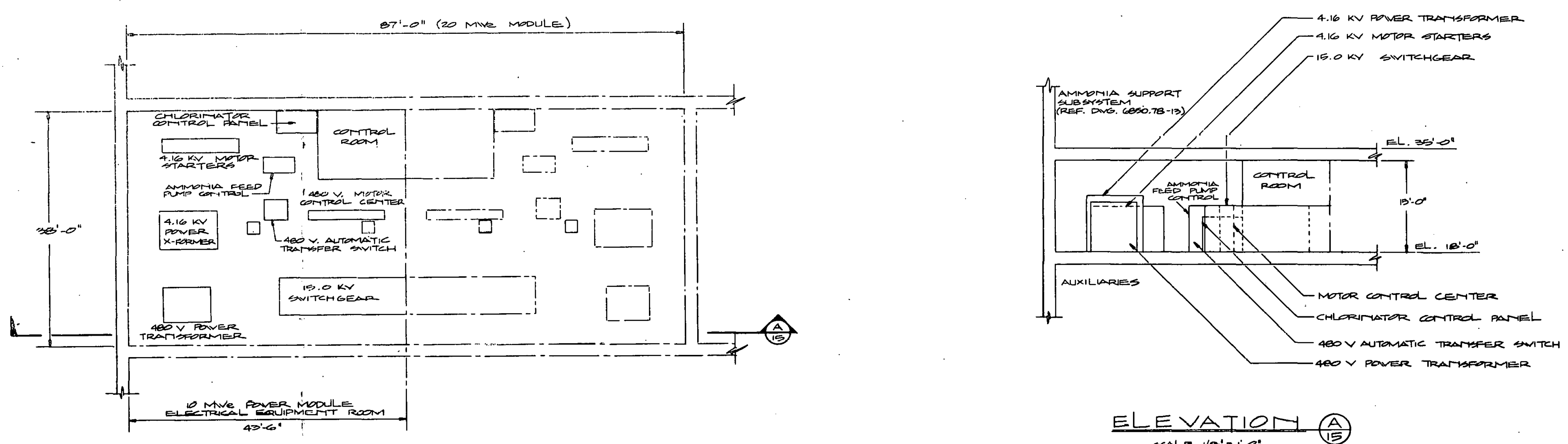

$\frac{\text { ELEVATIONy }}{\text { (15) }}$

PLAPH

' seate-Ve's'-o'

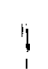
Figure 2.10-4, 10 Me Power Module - Electrical Equipment
Room Plan and Elevation

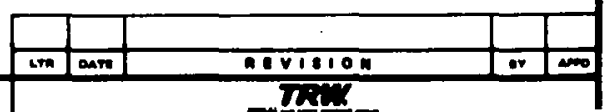

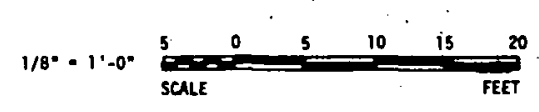

\begin{tabular}{|c|c|c|c|}
\hline entamo r. Sancen & OTEC POWER SYSTEM DEVELOPMENT & \multicolumn{2}{|c|}{ Fen } \\
\hline 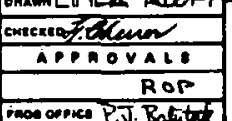 & $\begin{array}{l}10 \text { MWe POWER MODULE } \\
\text { ELECTRICAL EQUIIPMENT ROOM } \\
\text { PLAN \& ELEVATION }\end{array}$ & 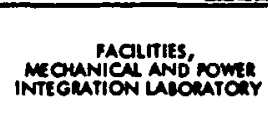 & 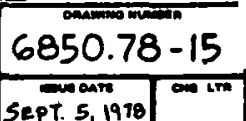 \\
\hline
\end{tabular}


2.10.3 References

1. IEEE Handbook No. 141, "Electrical Lower Distribution for Industrial Plants," 1969. 


\subsection{INSTALLATION APPROACH}

\subsubsection{Introduction}

The power system components can be organized into the following subsystems.

- Evaporator Heat Exchanger Subsystêm

- Condenser Heat Exchanger Subsystem

- Turbine-Generator Subsystem.

- Power Loop Subsystem

- Electrical Power and Controls Subsystem

- Biofouling and Ammonia Leak Detection Subsystem

- Ammonia Storage Conditioning and Supply Subsystem

- Inert Gas Storage Conditioning and Supply Subsystem.

The final manufacturing and installation plans will depend on the equipment and material suppliers and the platform hull contractor resources and capabilities. Close coordination will be required between the power system contractor and the platform hull contractor for selection of the power system equipment suppliers.

Manufacturing of the majority of equipment within the subsystems are well established. Most components of the subsystem are of standard manufacture. Their manufacture and installation can be accomplished by established techniques.

The only components which offer unique fabrication problems are the heat exchangers. These problems are discussed in Section 2.4. Design and manufacturing of the turbine is discussed in Section 2.7.1. The majority of components will be subassembled within the supplier's facilities prior to shipment to the platform hull contractor assembly and outfitting dock. This will require that certain subcontractors ship their components to others for modular buildup and inspection. The remainder of the major subsystem components can be shipped directly to the portside assembly dock for a sequential installation aboard the platform hull.

The majority of power module component installation should be completed within the shipyard environment of the assembiy dock. The use of component 
subassembly modular buildup will minimize construction schedule time at the assembly dock. The interrelationships between unions and construction trades (steam fitters, boilermakers, pipe fitters, iron workers, electricians, etc.) required for construction installation of the power module must be considered. The extraordinary large cost incurred where construction and installation is performed at sea should be minimized to develop the most cost effective construction-installation procedures.

A step-by-step breakdown of the power module construction-installation requirements must be determined before a schedule can be developed. OTEC planners must know the time required for each operation, the lead time required for material and equipment procurement, the time required for fabrication and delivery of" subassemblies, and special tests required (and the time needed to make them), before the final planning can be performed.

After the installation process has been broken down into all of its activities, it can be listed or plotted in such a way that all sequential relationships are shown. The plot will show the time required for the construction and power module installation and checkout. This analysis will pinpoint the operations whose completion will be responsible for establishing the proper sequence of work operations, determining the status of work in progress. This type of planning will begin during the final design and contract award stages. A typical breakdown for heat exchanger installation is shown on the PERT chart, Figure 2.11-1. The majority of these activities are routine and similar to those encountered by the construction industry.

The final procedures used for power system component subassembly and installation into the platform hull will require coordination with the OTEC platform hull contractor. All power module subassembly fabrication sizes will have to be tailored to suit the construction equipment capabilities of the platform hull contractor. All schedules for the power module equipment will require coordination with stages of platform hull construction to insure an efficient cost effective assembly of the power module. Close communications for the designs and equipment layout will be required between the power module contractor and the platform huli contractor.

The power module installation into the platform hull will require assembly at an outfitting dock and at sea. Procedures will have to be developed for both sites. The equipment locations and piping system layout have been arranged such that assembly would not exceed the capabilities 


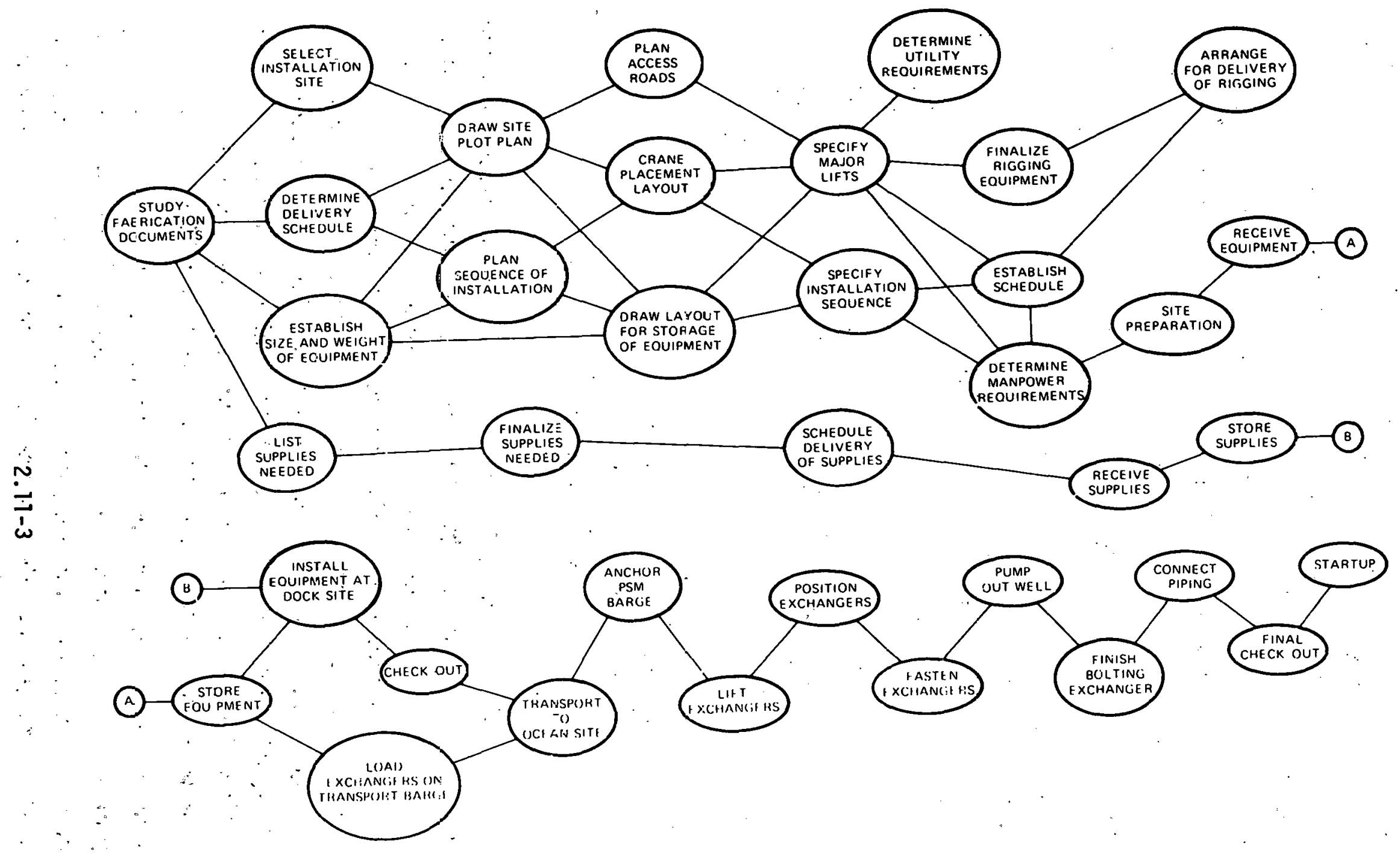

Figure 2.11-1. Pert Chart for Manufacturing and Installation of 10 MWe Power System Module 
of potential platform hull contractors surveyed by TRW. The OTEC platform hull construction and installation processes study funded by the government will examine and evaluate this subject in greater detail. The information from this study will be helpful for selection of the final installation and construction procedures.

\subsubsection{Assembly at the Outfitting Dock}

The on-board power module installation could be performed within the shipyard graving aock where the platform hull is constructed, or at an outfitting dock located near the shipyard. The latter approach would minimize the high cost of using an established shipyard (or one built specially for OTEC requirements). This method could prove more schedule-effectivity for multiple plant construction required for full scale development of an OTEC Park. This approach was used for the concrete LPG storage barge built for the Atlantic Richfield Company. A temporary floating outfitting dock, composed of two cargo barges pinned together end-to-end, was installed and utilized during the outfitting phase of the LPG barge construction.

The portside outfitting assembly dock location, construction equipment available, transportation facilities, utilities and available storage space acreage will have an important impact upon the final fabrication and installation methods. These factors are a part of normal construction planning and should not present any special problems.

Transportation of power module equipment to the outfitting dock is a major concern. The dock should be accessible by navigable waterways, roadways and railroads. Large pieces of equipment (e.g., the turbine-generator) should be able to be transported to the site without excessive expense. The size and weight of the equipment or subassembly will determine the optimum method of transportation.

The waterway should have the depths required for the outfitted platform during transportation to the deployment site. All of the inboard items of equipment can be installed within the platform hull at the outfitting dock. All material and equipment delivered to the site will be controlled by an inventory control system. "This will document dates of deliveries, condition and storage location within the site to result in an efficient construction-installation operation. 
The power module equipment layout has been arranged such that the installation sequence is not critical. Normal installation trade practices can be followed to minimize costs.

The installation sequence is illustrated in Figure 2.11-2. Lower deck equipment and piping is installed first. The electrical equipment, ammonia and nitrogen subsystems will be installed next. The turbine generator will then be installed. With all major inboard equipment installed, the remaining piping, instrumentation, equipment and piping testing, inspection and checkout can then be completed. There are no special problems pertaining to inspection that would impact the construction schedule. The above deck remainder of the platform hull would then be completed. This type of assembly should present no special problems for the platform hull contractor.

Placement of the lifting cranes at the outfitting dock will require detailed construction planning well in advance of the actual installation. The cranes must be stationed to accommodate the various lifts. Weight; height, and rotation angle of the lift must be properly planned. Special designs of the dock may be required to support the heavy concentrated loads imposed by the crane during lifts. Some of the heavier lifts can be handled by floating crane barges or derricks. Cranes of suitable size and capacity are readily available. Lifts may require more than one crane as illustrated in Figure 2.11-3.

The platform will be towed to the deployment site after outfitting and checkout of the installed portions of the power module. All pipe connections passing through the platrorm hull will be sealed. The tow operam tions would be routine, with no unusual problem expected. Position keeping of the platform, connection of the power cables:and coldwater pipe will be determined by the ship systems contractor. The OTEC commercial piant studies $1,2,3$ discuss this area in greater detail.

\subsubsection{Installation at Sea}

The heat exchangers and warm water pumps will most likely be installed at a water depth greater than the outfitting dock or after the platform hull position keeping system is completed. The outfitted 40 MWe platform draft prior to heat exchanger and pump installation is 35 to 40 feet, and the 


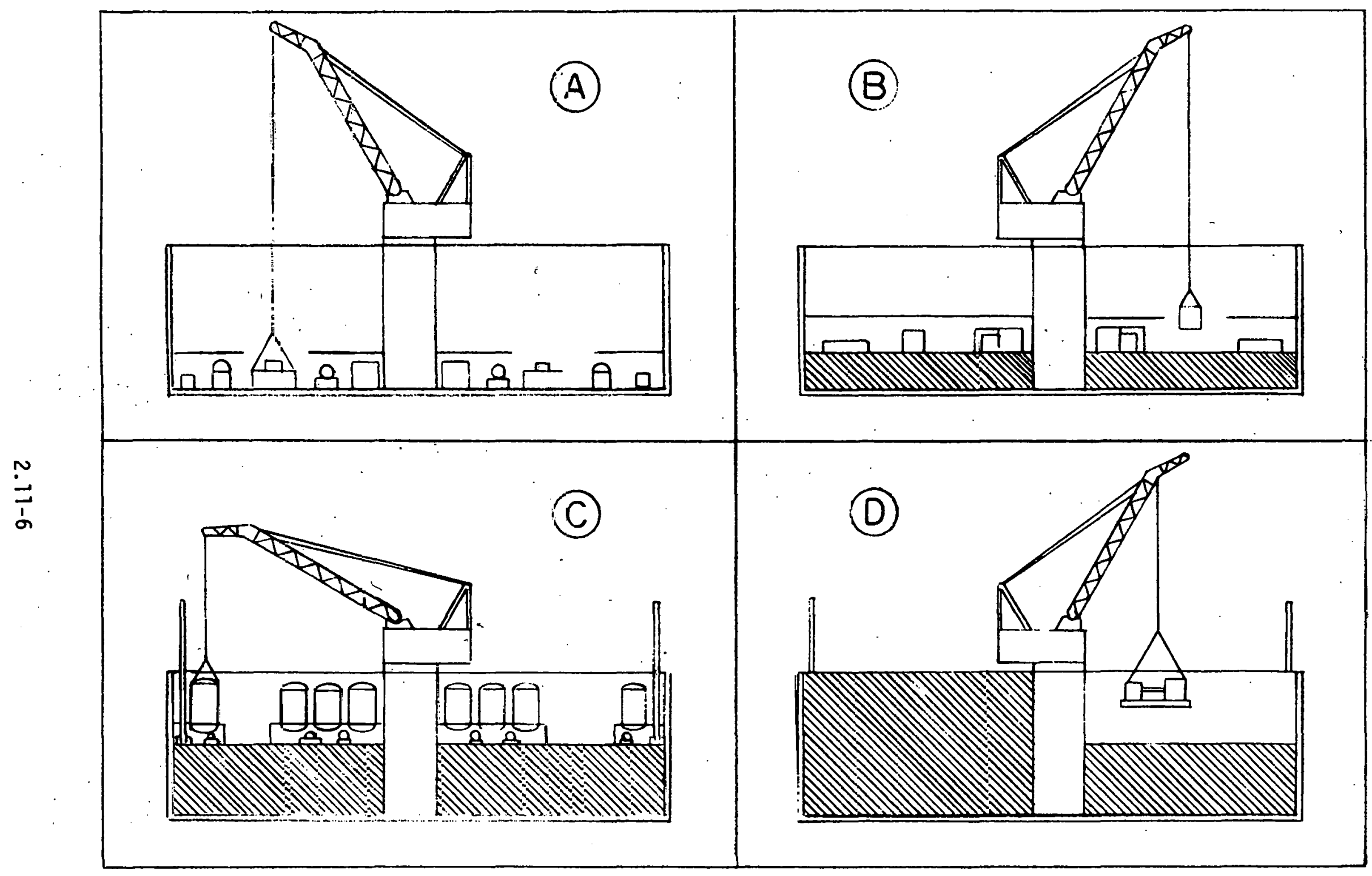

Figure 2.11-2. Installation of Equipment Within the PSM-1 Barge 
A 290-ton $\mathrm{C}_{3}$ splitter for an ethylene-propylene plant is lifted by two 210-foot-long gin poles and tailed into position with a 165-ton crane.

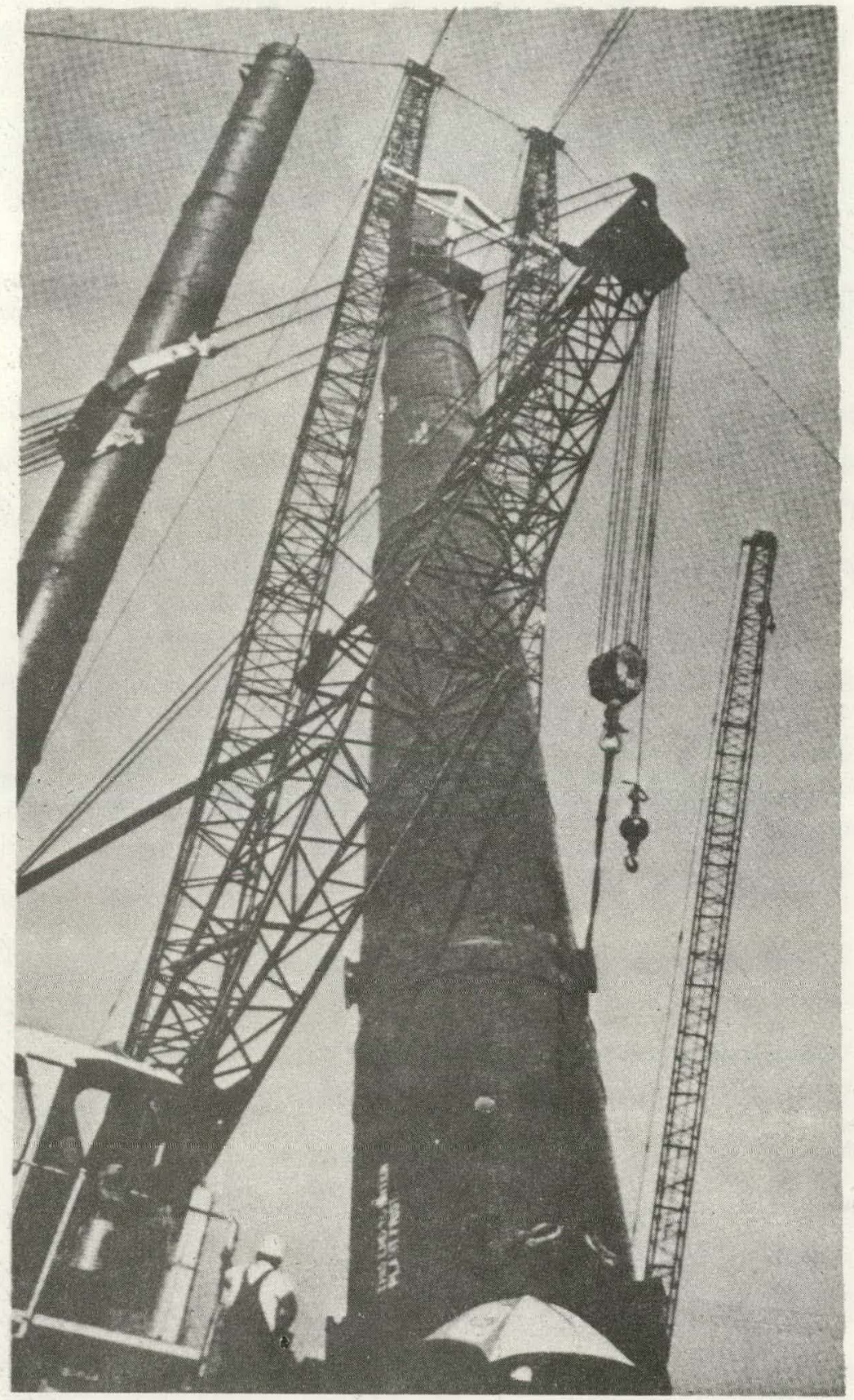

Figure 2.11-3. A Major Lift. 
35 and 40 feet) and the waterway depths of potential U.S. construction contractors would dictate that this method of installation is required.

The heat exchangers will most likely require road or railway transportation to a seaport waterway from the manufacturer's plant. Procedure for this type of transportation has been developed for petroleum and chemical process plant construction. A typical example of this method of transportation is shown in Figure 2.11-4. Vessels 80 feet long weighing approximately 800 tons have been transported by this method.

The exchangers can then be transported by barges to the attachment locatiun, as shown in Figure 2.11-5. Our designed pipe connections on the heat exchanger dn not extend beyond the cofferdam support saddles and the exchanger supports were designed with the strength requirements for the environmental loads that could occur during transportation installation and operations of the OTEC power module.

Transportation in a vertical position was considered. Vertical transportation could minimize the heat exchangers structural reinforcement. This approach was not effective since special exchanger support equipment and handling techniques would have to be developed. These costs more than offset the savings in structural reinforcement.

During transportation all heat exchanger piping nozzles will require protection to prevent seawater inclusion. Blanking flanges will he attached to all nozzles. The larger size nozzles (120 inch diameter or more) will require storage of the blanking flanges within the cofferdams after the heat exchanger has been attached to the platform hull. Close tolerances between the hull stub-outs and the exchanger nozzles piping connections must be maintained to minimize the possible fit-up problems for the large size nozzle connections.

The movemenl of the heat exchangers from the transport barge to final attachments with the platform hull is a major operation, since the evaporator and condenser each weigh about 500 tons. However, this lift operation would not be extraordinary by industrial dry land standards. 


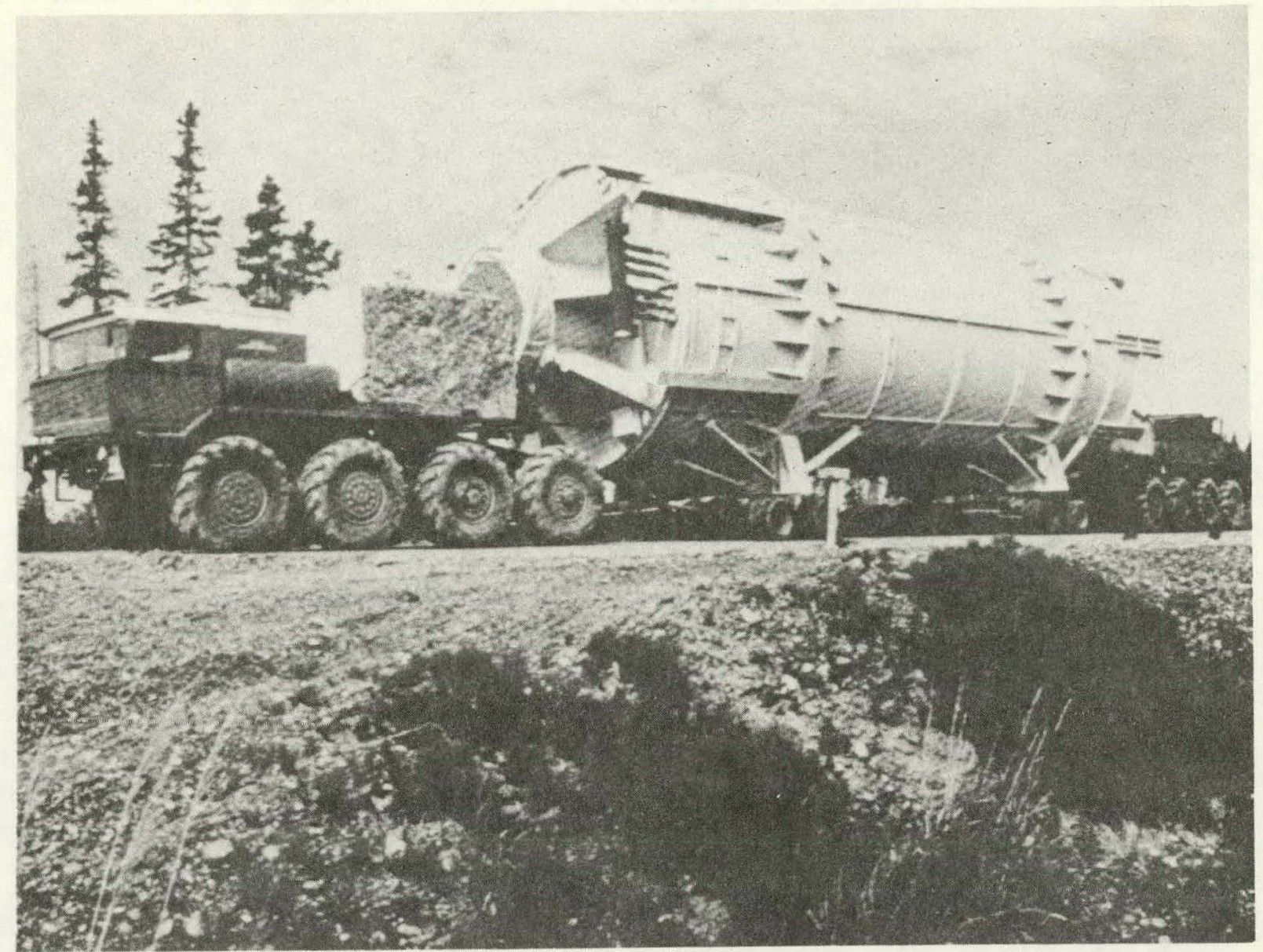

Figure 2.11-4. Moving a Large Vessel Overland for a Short Distance

This lift operation will require detail planning between the power and ship systems contractors to insure that operation will not damage the exchangers. Subscale model tests of attachments in shallow water should be performed to develop the final procedures prior to attempting the operations at the deployment site. Adequate safety and handling procedures can be developed from the test.

Lifting lugs wi11 be provided on both heat exchangers. Two trunnions will be located at right angles to the ammonia piping and opposite each other. They will be slightly above the center of gravity of the heat exchangers. A third lifting lug will bo located near the bottom and oriented 90 degrees from the first two swivel lugs. The lifting lugs and attachments are shown in Figure 2.11-6. 


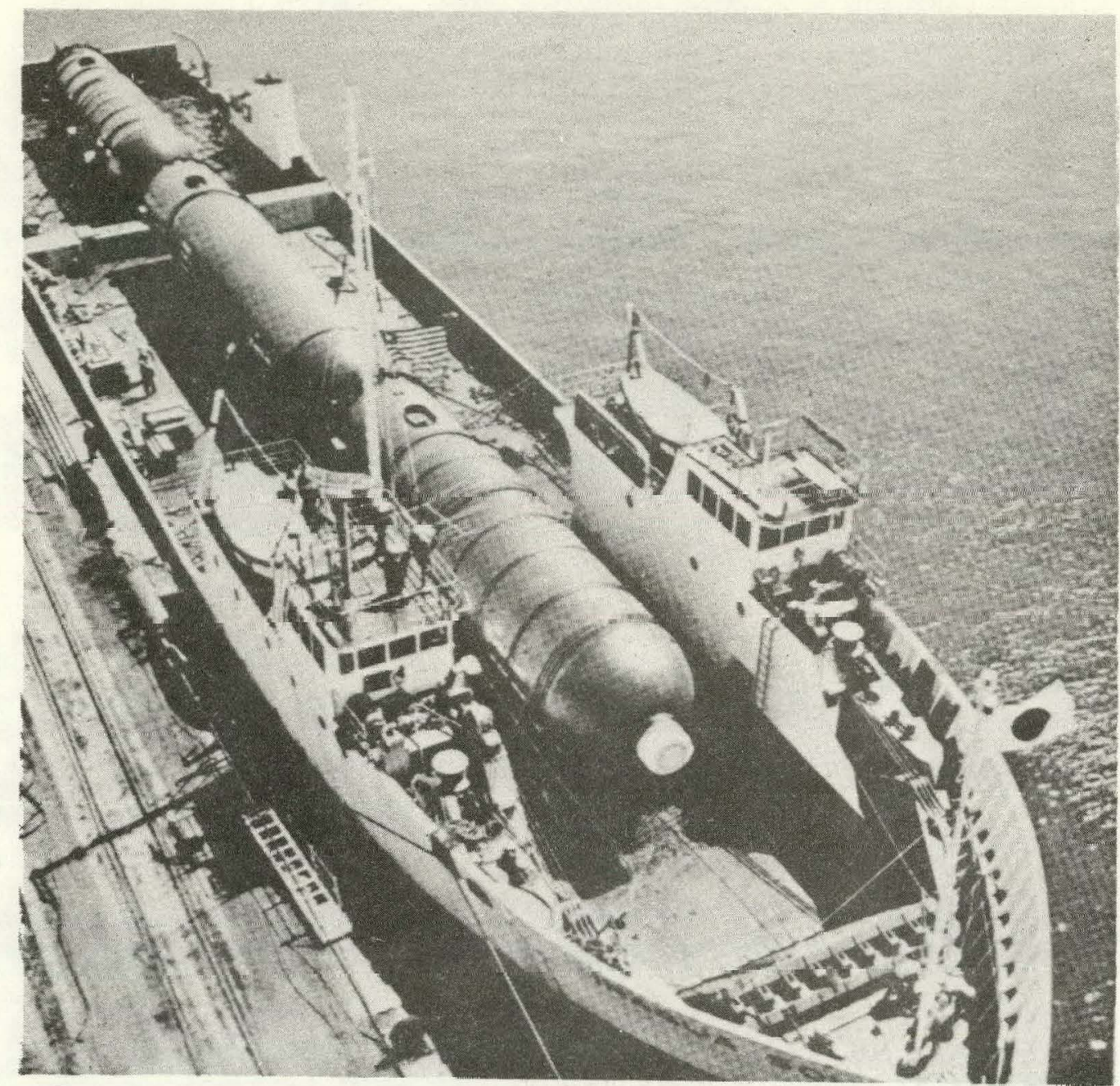

Rediturs weighing 4'¿', 436, and 570 tons are loaded upun an oceangoing vessel in Japan fur' shinfritent tu Delawal'e.

Figure 2.11-5. Large Cylindrical Vessels Loaded on a Transport Ship

A lifting harness can be fabricated as shown in Figure 2.11-7. The main hook of the lifting crane will attach to the harness which is fastened to the trunnions. The jib boom of the crane will attach to the bottom lug.

The movement of the heat. exchangers can be completed by one of the following methods. All options require the positioning to be performed during calm seas.

- Option I. Launch the exchangers from the transport barge into the seawater and float it into position. A 150-ton crane mounted on the platform hull would be required to guide the exchangers to their final position. 
- Option II. Use a separate crane barge with 600-ton capability to lift each heat exchanger to the final position.

- Option III. Permanently install a 600-ton crane on the platform hull. Using the crane, lift each exchanger from the transport barge to the final position.

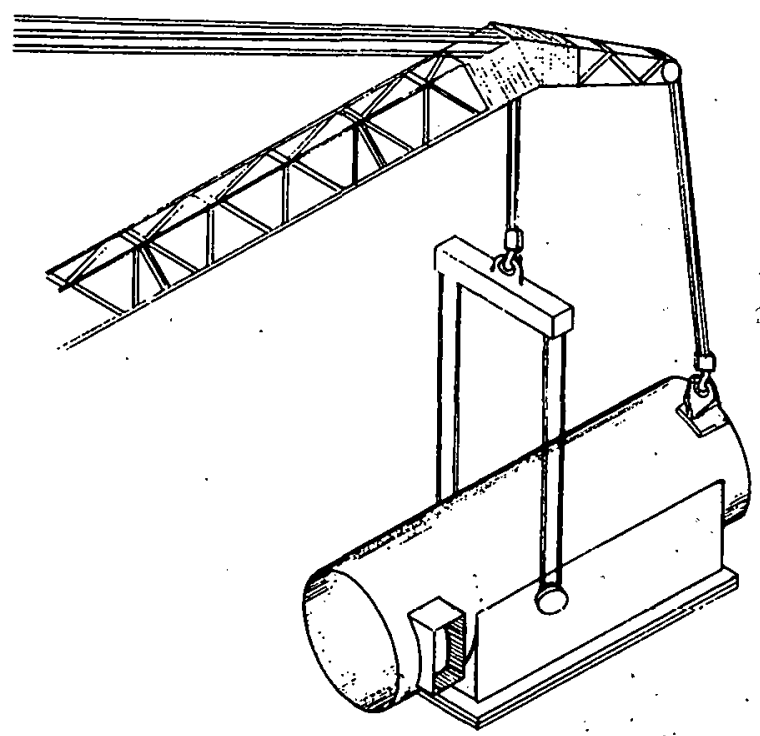

Figure 2.11-6. Lifting an Exchanger from the Transport Barge

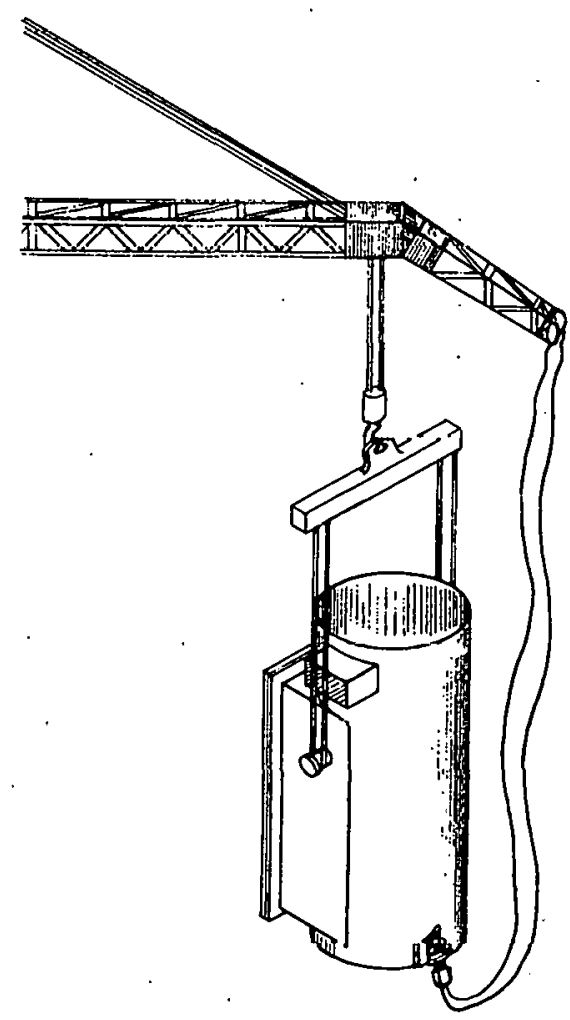

Figure 2.11-7. Rotating an Exchanger to the Vertical Orientation by Loosening the Jib Crane 


\subsubsection{Option I}

Option I will require special handling procedures to minimize the shock impact loading upon the heat exchangers immersion. The shock loading could loosen or rupture tubes from the tube sheet. The shock loading could be minimized by launching of the heat exchangers by controlled flooding of the transport barge. Once the deck of the transport barge dips under water, stability is lost and the transport barge will usually list heavily. The exchanger will then slide sidewise into the seawater. This type of launching can be performed to initiate the exchanger list in the desired direction. Side launching would place very heavy stresses on the transport barge edge and, if not properly designed, can cause buckling or failure of the transport barge side.

The limited available platform crane capacity of Option I would require use of a crane barge during maintenance of the power module. This is also a requirement for Option II (the 150-ton crane can lift the turbine and the generator unit and thus perform needed maintenance).

\subsubsection{Option II}

The availability of a floating construction crane barge is an important consideration. The downtime of the plant during maintenance and the exchanger installation time could be increased if the crane barges lease schedule was not compatible with OTEC operations. Availability of a crane barge for multiple operations may prove a cost effective option. This will also reduce the cost of the platform hull deck. and support structure, since the deck will not be required to support the heavy concentrated loads imposed by the crane crawlers.

Floating crane barges of up to 3000-ton crane capacities and built to U.S. Coast Guard requirements are availabie. The majority of these crane barges have been fabricated for North Sea operations. The transportation of the exchangers to the deployment site could be performied aboard the crane barges.

The semisubmersible crane vessel Heerema (built by Mitsui shipbuilding) has a 8000-ton deck load capacity and crane capatities of 3000 and 2000 tons. Accommodations for 350 persons are provided. Stationkeeping is provided by a conventional twelve-point system. For OTEC purposes a crane barge similar 
to the SUN 800 vessel could be purchased or leased. Its crane lift capacity is 800 tons at a height of 210 feet. This crane vessel is available from the Sun Shipbuilding and Drydock Company of Chester, Pennsylvania.

The floating crane would lift each exchanger from the transport barge and position it alongside the platform hu11. The 150-ton crane on the platform would assist this operation. This operational approach would minimize the shock loading due to launching, simplify orientation of the exchangers and allow the exchangers to be under complete control at all times.

\subsubsection{Option III}

Option III has the advantage that the crane would be available at all times for maintenance. The final selection of a crane will require additional study by the platform hull systems contractor. A few possible crane arrangements are:

- Stationary mounted revolving crane, long reach available

- Crawler mounted crane with ballast counterweight, moderate reach

- Traveling guy derrick crane, short reach

- Moveable stiffleg derrick crane, moderate reach

The final selection of the lift operations for installation of the exchangers and maintenance of the OTEC power module will be made during the final design stages. The rigors of marine service and environment must be given foremost attention for the final crane selection and placement. Close coordination will be required between the power system and platform hull systems contractors for selection of the most cost effective option.

\subsubsection{Heat Exchanger Attachment}

After an exchanger has been lifted clear of the transport barge and hangs over the sea, it will be rotated into a vertical position. The crane's jib hook will be left unattached allowing the exchanger to rotate from a horizontal to a vertical orientation. The placement of the trunnions a few inches offset from the center of gravity will allow the exchaingers lo hang vertically when the jib crane is slacked off. Four capstan winches will assist in final alignment as shown in Figure 2.11-8. Additional control cables will be used as required.

\section{$2.11-13$}


The exchanger saddle and cofferdam flanges will be mounted to an attachment bracket on the side of the platform hull. Conceptual details for the attachment bracket are shown in Figure 2.1-12.

Guide appurtenances will assist the alignment, so that as the capstan winches draw the exchangers to the platform hull, the support and attachment brackets will mate together. An inflatable "0" ring rubber gasket will, be used to provide a watertight seal in the cofferdam. The gasket can be collapsed and set into a groove (out of harms way) in the hull attachment bracket to provide a flat surface during docking. Hydraulic clamps can be used for a temporary restraint of the exchanger to the

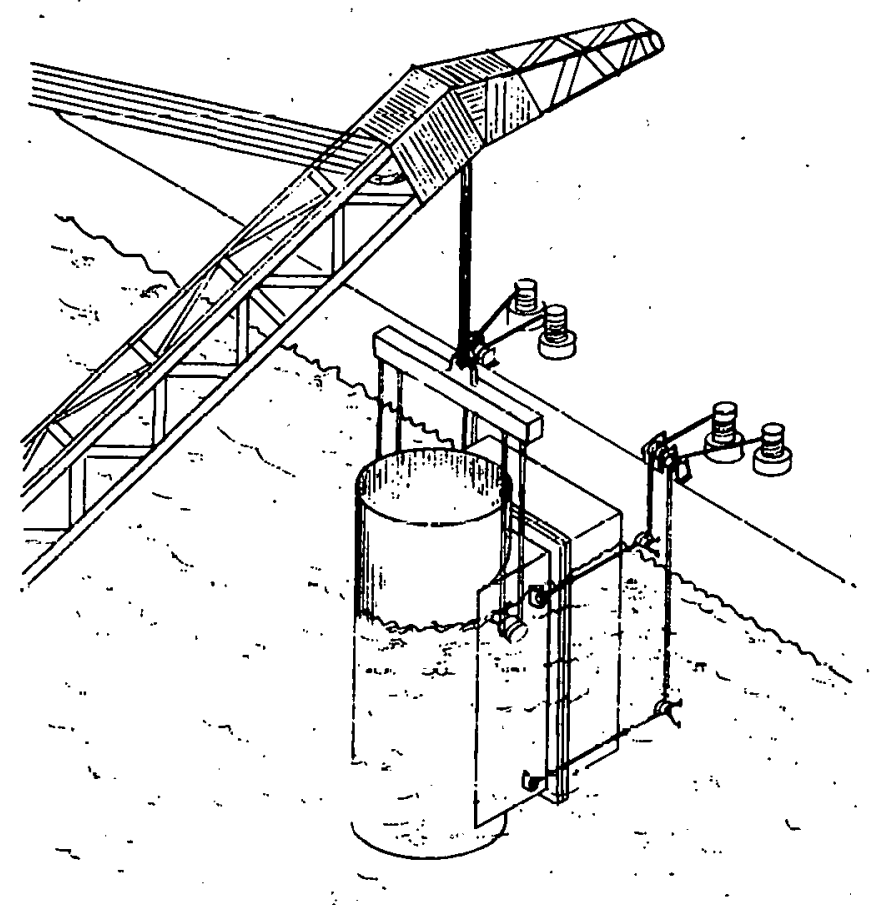

Figure 2.11-8. Final Positioning of an Exchanger to the Side of the PSM-1 Barge

platform hul1. The gasket can then be inflated with air from the platform hull via a permanent airline connection. The cofferdam can then be pumped dry. Access manholes and ladder will be installed to permit workmen to climb into the cofferdam space for final piping and instrumentation installation and checkout.

After the exchariger has been completely bolted to the platform hull workmen can complete the piping and instrumentation installation and final checkout. All pipe welding will require radiographic testing. Care must be maintained that seawater and debris will not enter into the exchanger. 
Minor repairs will be done by the permanent crew while the system remains in operation. Such minor tasks will typically involve instrument adjustment, seal repair and/or replacement, and piping repair. Major repairs can be performed at sea. This may necessitate shutting down a module for a period, depending upon the complexity of the task. Adequate facilities for storing ammonia during shutdown have been provided. Tasks requiring shutdown include repair or replacement of the expander-generator and repair of heat exchangers.

The installation of the tube cleaning machine is an essential part of the installation of the 10 MWe heat exchanger, as described in Section 2.6.3. Provision for cleaning the tubes and having the cleaning machine operational, including the period of assembly of the remainder of the PSD-I system, must be provided. After the exchangers are installed, a set of rails for handling the tube cleaner is added. The tube cleaning machine is mounted on these rails. During operation, the machine locks into an alignment stub (built into the heat exchangers) allowing cleaning of 95 tubes at one time. Each bank of 95 tubes is cleaned as a group before cleaning is done on the next bank or until all tubes have been cleaned.

Final checkouts will be made in accordance with engineering specifications and procedures prepared during the final design phases. These procedures will include identification of appropriate power and other utilities needed to perform the checkout functions.

The OTEC power module has to be designed for the maximum maintainability at its sea station. Disconnecting the cold water pipe, electrical cables and position keeping system would be a major operation. All components should be maintained at sea. Each item of equipment should be either repairable at sea, or replaceable. An inventory of spare parts must be kept aboard the platform to enable the operating crew to carry out all of the routine maintenance tasks. 


\subsubsection{References}

1. "OTEC, Platform Configuration and Integration," Final Report by Gibbs and Cox, Inc., Executive Summary, Volumes I, II, III, June 1978.

2. "OTEC, Platform Configuration and Integration," Final Report by Lockheed, Missiles and Space Company, Volumes 0 (Executive Summary), 1,2, and 3, Apri1 1978.

3. "OTEC, Platform Configuration and Integration," by M. Rosenblatt and Son, Inc., Executive Summary, Volumes I, II, and III. 


\subsection{NET ENERGY AND RESOURCE ANALYSIS}

Net energy analysis is a particular kind of cost-benefit analysis for energy producing projects which compares the amount of energy used to operate a plant with the amount of energy the plant is expected to produce. The present analysis for a 10 Mhe OTEC power module is only partial since the whole system that produces power comprises a ship, cold water pipe, mooring, shore cable, and other subsystems besides the power modules. This analysis estimates the energy represented in the components of one power module: that is, the evaporator, the condenser, the turbine, the generator. the ammonia sumps, storage tanks, pumps, valves, pipe runs, control systems, and switchgear. In addition, estimates are given for the energy of fabrication and assembly of the power module, and operation and maintenance. The present analysis provides one input for a net energy analysis of the entire power plant.

The methods used here are similar to that of Perry, et al. ${ }^{1}$ They are based on weights of materials and parts rather than costs since weight estimates are more reliable at this stage of design development. In Table 2.12-1, the components of one power module are listed, in as much detail as is applicable, with the estimated weight for each. Energy coefficients, in Btu/ton, have been estimated for many classes of industrial products in previous publications (Perry, et al; Reister ${ }^{2}$ ). These are listed in Table 2.12-1 (taken from Perry, et al except as noted) for the categories most nearly appropriate to the power module components. Multiplying each weight by its energy coefficient and summing the products gives the energy "embodied" in the power module components, excluding the energy of shipboard assembly.

The energy coefficients are derived from an input-output analysis that traces the multiple flows of energy from primary sources (coal and crude petroleum, hydro-electric and nuclear) throughout the whole national economy. The rationale of this analysis is set out by Bullard, et al. ${ }^{3}$ That publication also provides a basic table of energy coefficients, in Btu/doliar, for industrial products. These are in Btu/dollar. because of the nature of the economic statistics available for the input-output analysis. Reister has converted some of them to coefficients in Btu/ton, 


\section{THIS PAGE WAS INTENTIONALLY LEFT BLANK}


Table 2.12-1. Energy Content of 10 MWe Power Module Components

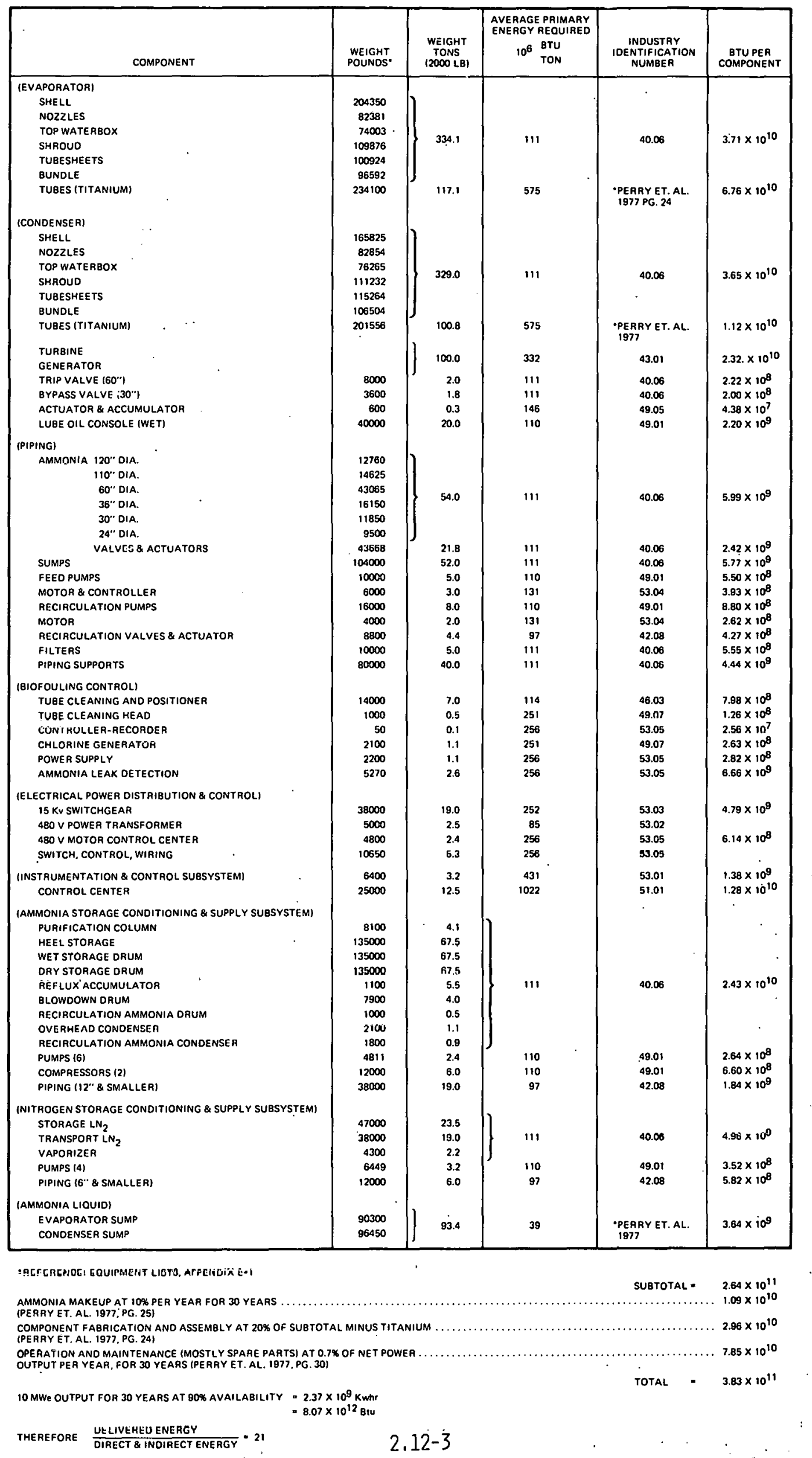


THIS PAGE ,

\section{WAS INTENTIONALLY \\ LEFT BLANK}


using data on the weights and values of industrial shipments. The definitions and conventions that apply to the coefficients in Table 2.12-1 are set out in Perry, et $\mathbf{l}^{1}$, with references to Reister and Bullard et al.

\section{Conclusion}

From Table 2.12-1, the estimated direct and indirect energy needed to produce and operate one power module is $3.83 \times 10^{11} \mathrm{Btu}$. The power output of one module, at 90 percent availability, for 30 years is $8.07 \times 10^{12}$ Btu. The output is about 21 times the energy needed to make and operate the module. Thus, there is a positive return on the energy investment.

As previously stated, the analysis does not encompass the entire.system. Some components, such as the ship system, do not produce energy. Thus, the net energy return ratio for the full system will be lower than the ratio for a power module alone. Typical OTEC power module ratios given in the literature are around 7 or 8 . Thus, it appears that an OTEC system composed of these power modules will give a net positive energy return, and be competitive with other OTEC designs. 


\section{THIS PAGE WAS INTENTIONALLY \\ LEFT BLANK}




\subsubsection{References}

1. A.M. Perry, et al, Net Energy Analysis of an Ocean Thermal Energy Conversion (OTEC) System, Oak Ridge Associated Universities research memorandum ORAU/IEA(M)-77-1, February 1977.

2. D.B. Reister, The Energy Embodied in Goods, Oak Ridge Associated Universities research memorandum ORAU/IEA(M)-77-6, February 1977.

3. C.W. Bullard, et al, Net Energy Analysis: Handbook for Combining Process and Input-Output Analysis., Energy Research Group, CAC Document 214, University of Illinois, Urbania, October 1976. 


\subsection{OPERABILITY, MAINTAINABILITY AND SAFETY}

\subsubsection{Availability Analysis}

\subsubsection{Plant Availability and Reliability}

The utility industry is in the process of creating industry-wide definitions of reliability and availability through an Edison Electric Institute committee. Meantime, those terms are defined as follows, according to EEI and Federal Energy Administration reports (Refs. 2 and 3 ).

The calendar elapsed time $\left(\mathrm{T}_{C}\right)$ at a power plant is subdivided as follows :

a. "on"-time $=$ service time $=T_{S}$. Includes full power and part-power service time.

b. outage time $=T_{0}$

1. scheduled $=T_{O D}$

2. forced outage $=$ unscheduled outage $=T_{\text {OF }}$

3. start-up time, TOS, when plant is being started or restarted and is not connected to the grid.

The energy delivered during the service time is:

$$
E=\int_{0}^{T_{S}} p(t) d t
$$

where $p(t)$ is the instantaneous net power output at the time, $t$. The average output power, $\mathrm{P}_{\mathrm{a}}$ is $\mathrm{Pa}=E / T_{S}$. Over a period of time, which the availability analysis takes to be a year:

$$
\begin{aligned}
& \text { Reliability }=R=\frac{\text { Service Time }}{\text { Service + Forced Outage Time }}=\frac{T_{S}}{T_{S}+T_{0 F}} \\
& \text { Availability }=A=\frac{\text { Service Time }}{\text { Elapsed Time }}=\frac{T_{S}}{T_{C}}
\end{aligned}
$$

Nulice that "rellabllity" is the probability that the plant will deliver any power at all when it is not down for scheduled maintenance. "Availability" is the probability that the plant delivers any power at all; it 
penalizes the plant for scheduled outages and forced outages alike. The availability analysis computes availability, averaged over yearly periods. In order to allow for plant operation at part-power, "equivalent reliability" and "equivalent availability" are defined, based on power-weighted operating time. During Phase II, only the raw availability was computed.

During the elapsed time $T_{C}, N_{S}$ attempts are made to start the plant. $N_{S S}$ of them are successful on the first try whereas $N_{S}$ are unsuccessful. The following start-up parameters are introduced:

$$
\begin{aligned}
\text { Startup Failure Ratio } & =\frac{\text { Number of Failures to Start }}{\text { Number of Attempts to Start }}=\frac{\mathrm{N}_{\text {SU }}}{N_{S}} \\
& = \\
\text { Mean Time to Start } & =\frac{\text { Startup Time }}{\text { Number of Starts }}=\frac{T_{O S}}{N_{S}}
\end{aligned}
$$

The startup failure ratio, also called the start-up reliability, is calculated in the simulation of Section 2.13.1.4.

\subsubsection{Equipment Failure and Repair Rates}

The failure-modes-and-effects-analys is (Section 2.13.2) identifies certain equipment as contributing to plant outages. This section shows how OTECSOS models the failure rates of those pieces of equipment and their repair times.

a. Wearout Failures

Table 2.13-1 shows the equipment that is assumed to wear out, due to such causes as bearing wear, contact wear and ronrnsion. Pending an item-by-item analysis in Phase III, an overall average wearout time of 240 days was chosen with a normal distribution whose standard deviation is 20 days, Figure P.2-4 (Appendix P), based on the frequency of failures of the 14 items tabulated in Appendix P. 1 .

After each wearout failure, unless there is a redundant. backup, the plant is assumed to shut down for a repair time proportional to the random failure MTTR. 
Table 2.13-1. Wearout Failures

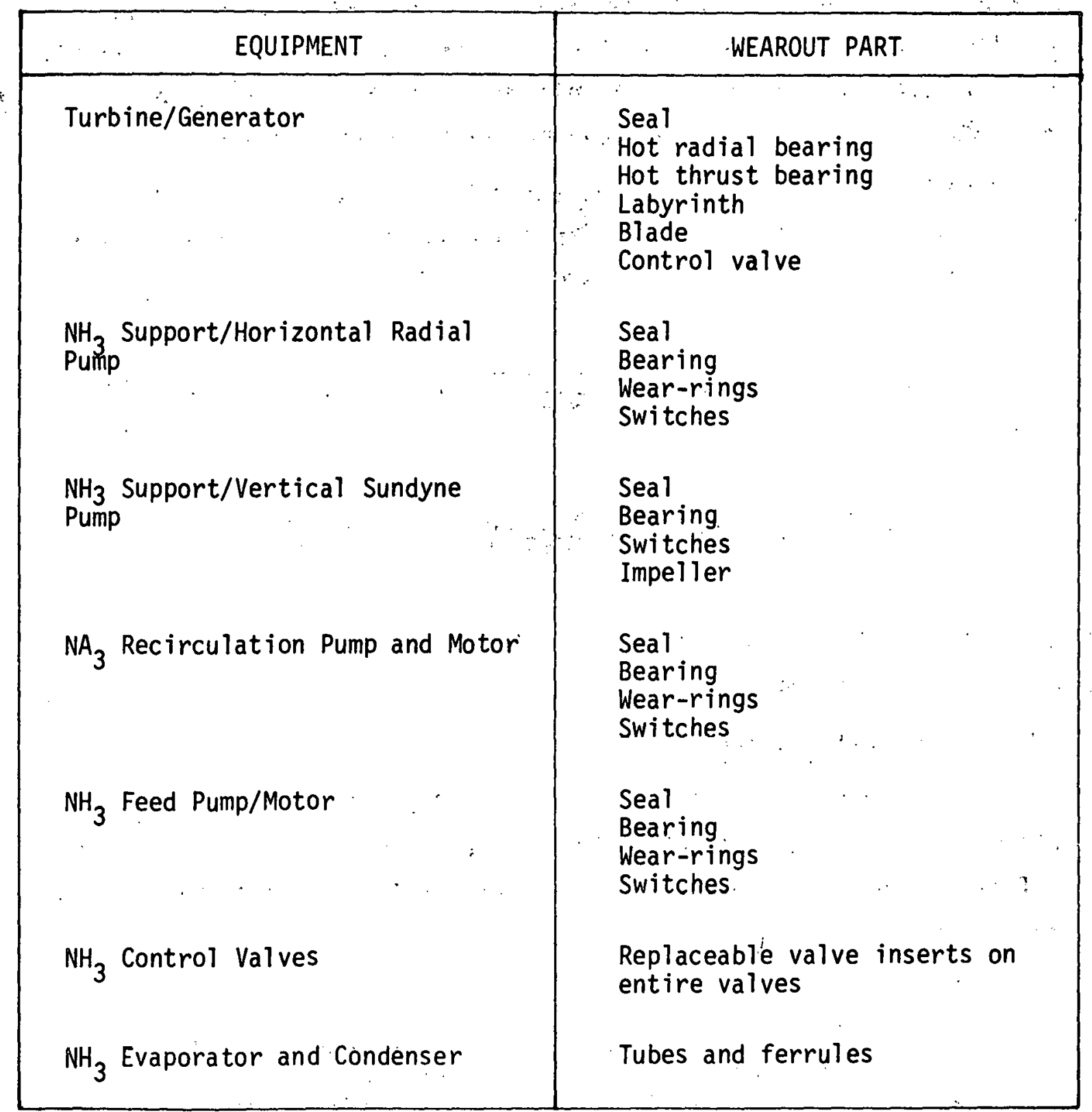


b. Scheduled Maintenance

It is assumed that the OTEC power cycle and treatment plant are shut down every 200 days (180-day shut down was also tested) for scheduled maintenance. A detailed list of items to be replaced will be prepared during Phase III; candidates are those shown in Table 2.13-1. The plant is out of service for 8 days for scheduled maintenance after which, for analytic reasons, the plant is assumed restored to as-new condition.

\section{c. Random Failures}

All equipment that does not exhibit wearout is assumed to fail at random, with an exponentially-distributed probability of failure. The mean-times-between-fallures (MTBF) are shown in Table 2.13-2 and the mean-times-to-repair (MTTR) are shown in Table 2.13-3 for each component. The MTTRs include a basic repair time plus 10-15 hours for purging and recharging, where applicable. As the exact time for purge and recharge become known (see Section 2.2.5) in Phase III, the MTTRs will be adjusted.

Sources of random failure and maintenance data were obtained from the manufacturers and users of electric power equipment and compiled on survey sheets shown in Appendix P.1. Additional data were compiled on component part failure data in FARADA and from the RADC Non-Electronic Reliability Notebook, EDRI steam power plant studies, C.F. Braun experience and TRW data (references 4-16). The mean-time-between-failures (MTBF) shown in Table 2.13-2 are best combined estimates. Further data have been requested from hardware vendors and will be integrated during Phase III. Instrumentation and control equipment was summarized together with sysleil auxiliaries. for this preliminary design analysis.

The repair times are times are log-normally distributed with the MTBFs shown on Table 2.13-3. Maintenance data are based on experience in power plant applications or similar environments. The mean-timcs-torepair (MTTR) include the time necessary: to isolate the fault (from the monitored dala); to locate dufective parts or foiled equipment; to access the equipment for repair or replacement(s); to perform the repair or effect the replacement(s); to checkout the corrective maintenance, and to prepare the system for startup. MTTRs do not include extended logistics delay (to order parts). Further maintenance/repair data have been requested from hardware vendors and will be included during Phase III. 
Table 2.13-2. Mean-Time-Between-Failures (MTBF) Estimates for 10 MWe Equipment

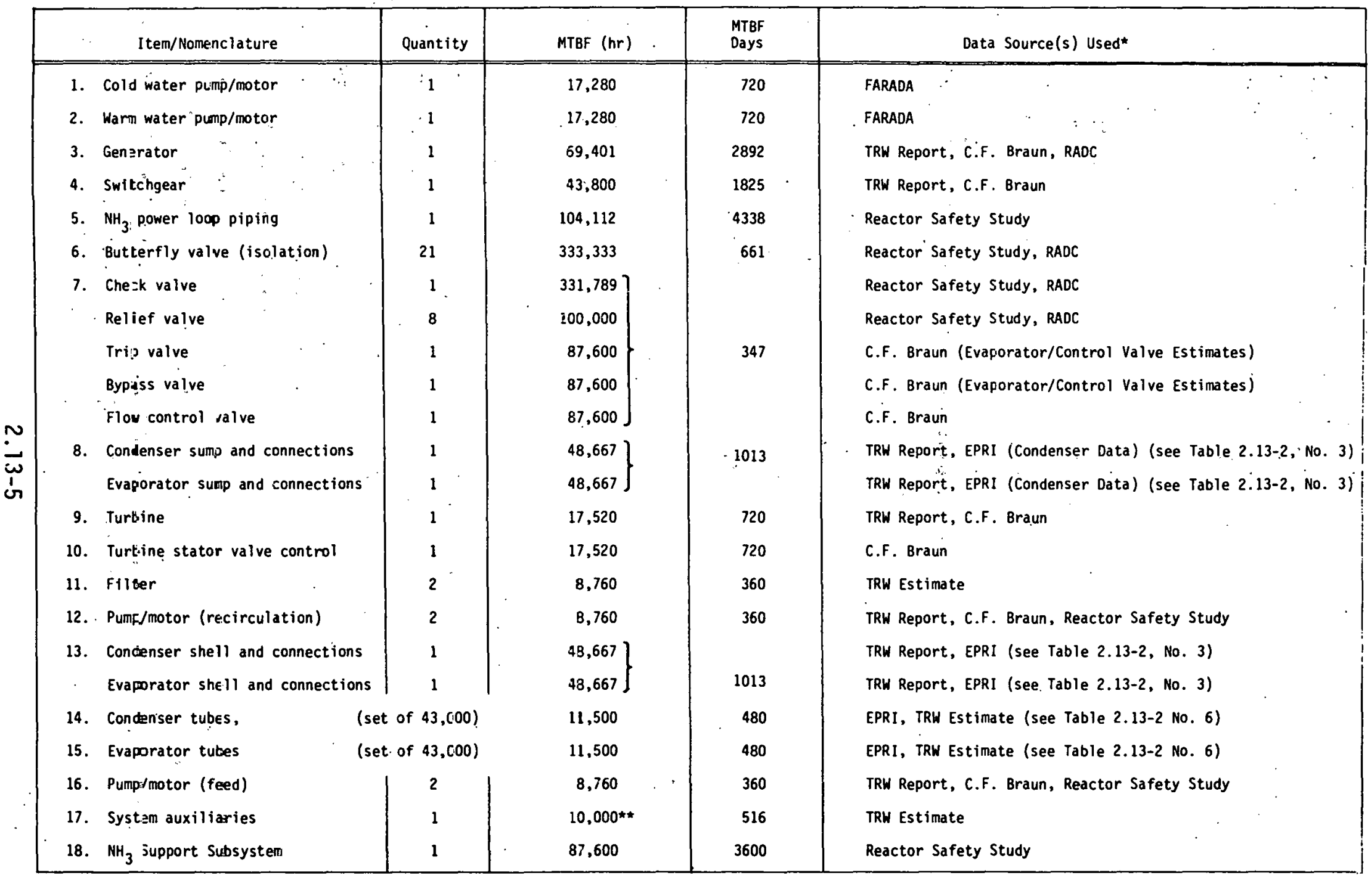

* See Table 2.13-2 for data source(s) used, and Appendix 0.

* Include: Instrumentation and control components. 
Table 2.13-3. Mean-Time-To-Repair (MTTR) Estimates for 10 MWe Equipment

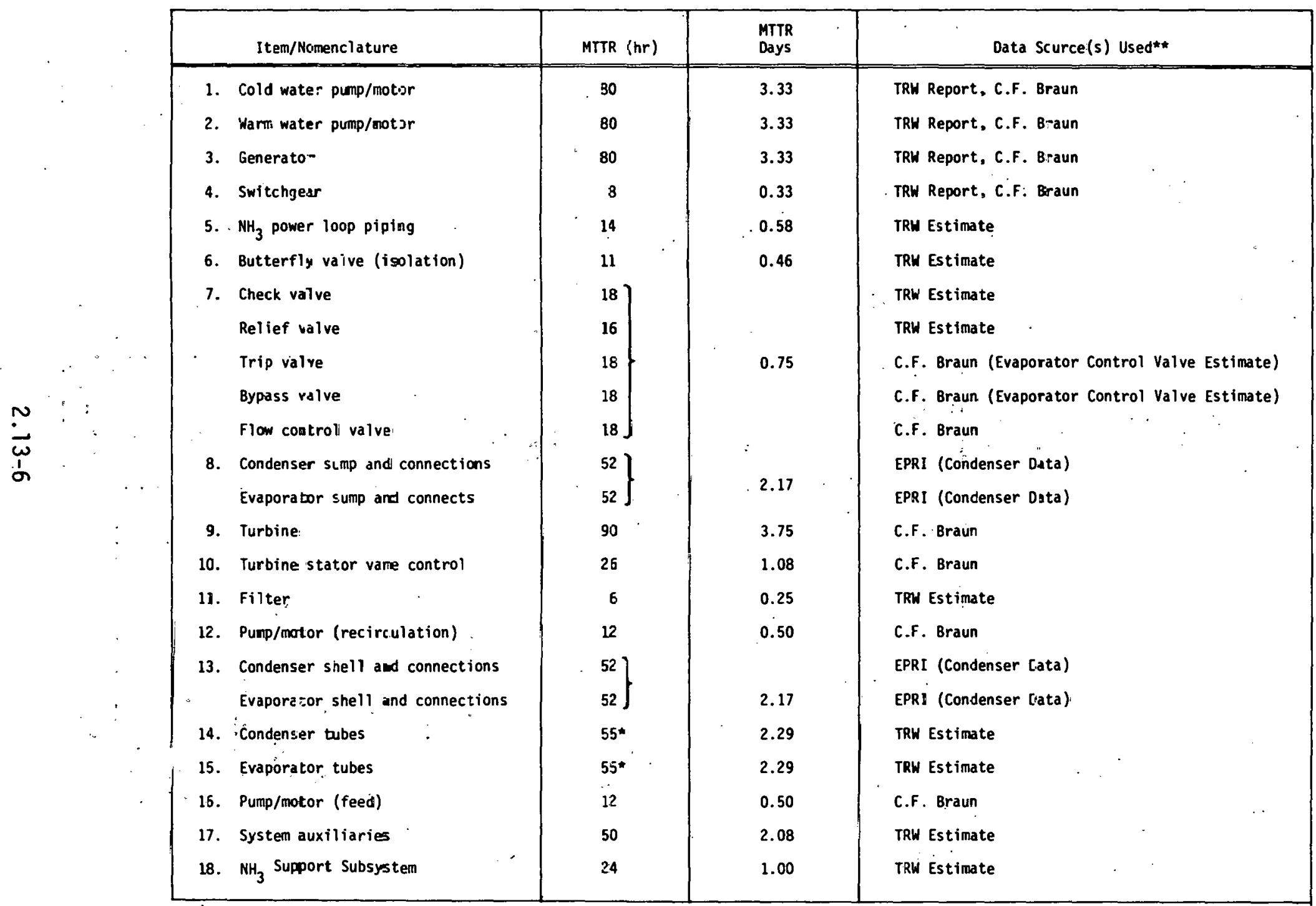

* Based upor plugging an estimated 81 tubes. See Table 2.13-5, Tube Repair Action Time (Hours).

** See Table 2.13-2 for data source(s) used 
Heat exchanger tube failures and repair are especially important in this analysis. Table 2.13-4 shows the time to repair tubes in the condenser and evaporator. The timeline sequence for the corrective maintenance (repair) action is accomplished in five steps: shutdown, $\mathrm{N}_{2}$ purge, tube repair (which includes identifying and plugging leaks), $\mathrm{NH}_{3}$ fill, and startup. Times to perform each task are shown for various numbers of tube failures: The values used in the simulation was for 81 tubes to fail after 6570 hours (about 280 days) of operation, requiring 55 maintenance hours.

\subsubsection{Availability Analysis}

This analysis is a simulation of the availability of the 10 MWe power module for a 30-year period using a TRW-developed computer program called OTECSOS. The program is a Monte Carlo analys is, which is far more accurate than the conventional calculation of the uptime ratio = MTBF/ $(M T B F+M T T R)$, because the latter does not allow for:

a. build up of a service queue when several parts wear out within a short time of each other.

b. scheduled outages for preventive maintenance.

Table 2.13-4. Tube Repair Time (hr)

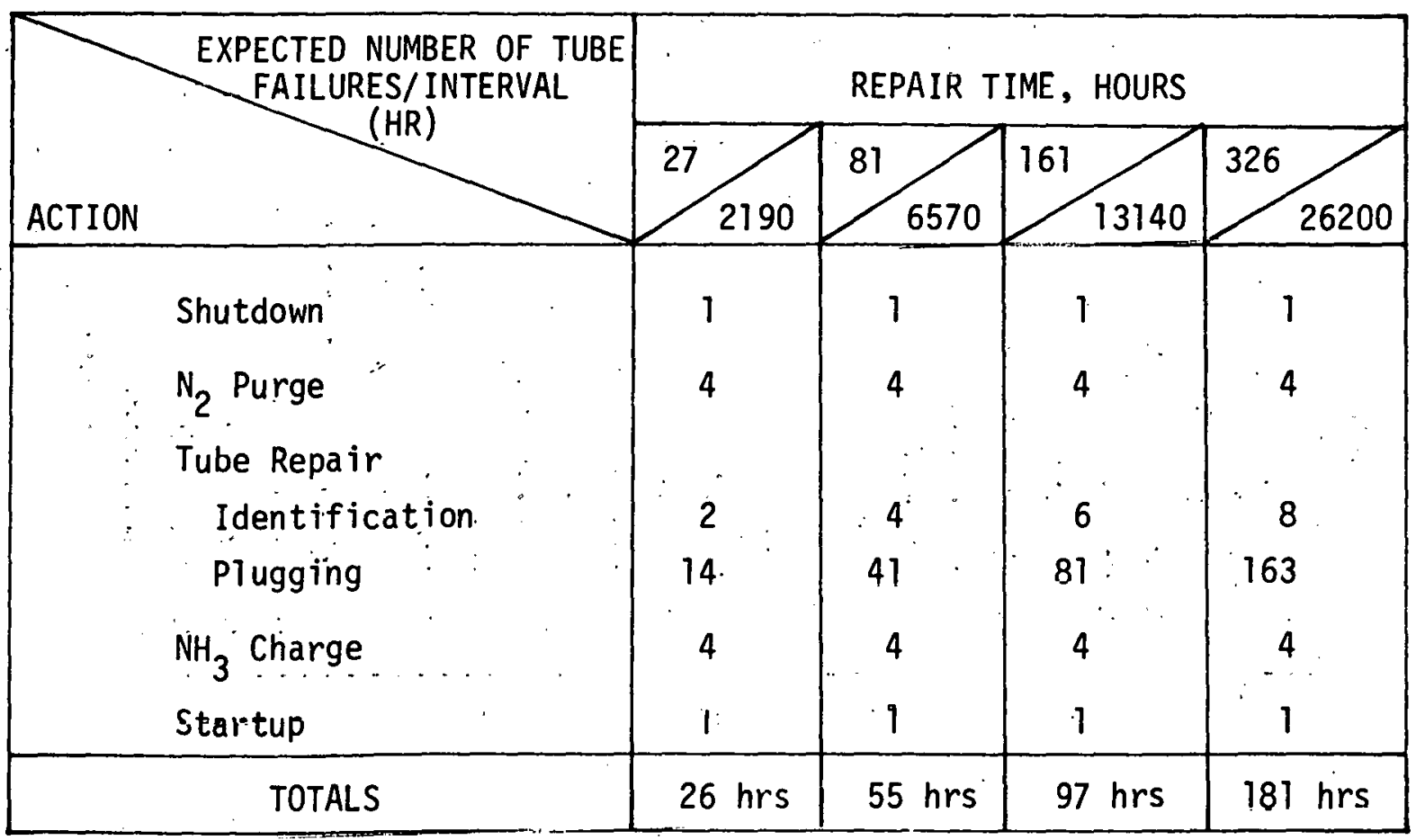


OTECSOS models the wearout and random failures described in Section 2.13.1.2. Using random-number generators, OTECSOS predicts the unscheduled failures that occur over thousands of 1 ifetimes of the simulated plant; taking twelve trials per day for 30 years. Scheduled and unscheduled failures can cause plant outages. Other random-number generators predict the repair time as the failures leave the repair queue. The statistics of plant outages are collected in the computer memory and are analyzed. Figure 2.13-1 shows the flow diagram of the program and Appendix P.2 describes its operation in detail. Figure 2.13-2 shows the reliability model of the power cycle. As a first approximation, treatment plant failures cannot cause power outages because the power cycle can operate for at least a day without the treatment plant. Thus, Figure 2.13-2 shows the power cycle components whose failure disables the plant. Single-point-failure components are drawn in series; dually redundant components are drawn in parallel.

The results of the analysis are tabulated in Table 2.13-5. The average availability is 0.906 for 30 years. Due to statistical variability, the annual average ranges from 0.88 to 0.93 . 13 to 22 unscheduled outages are expected each year, causing unscheduled downtime of 13 to 30 days annually. The breakdown of outages between random and wearout failures is shown. Note that the minimum number of random failures plus the minimum number of wearout failures, do not equal the total number of unscheduled outages because both minimal do not occur simultaneously, on the same random trial. Startup reliability ranges from 0.97 to 0.99 . The availability and startup reliability predictions for the baseline design meet the DOE goals.

The following sensitivities of availability, downtime, and number of outages were investigated (see Appendix P.2.6);

1. Redundancy of ammonia pumps is discussed in Section 2.13.1.5.

2. Doubling of the repair times of key components reduced the mean availability from 0.906 to 0.886 . 


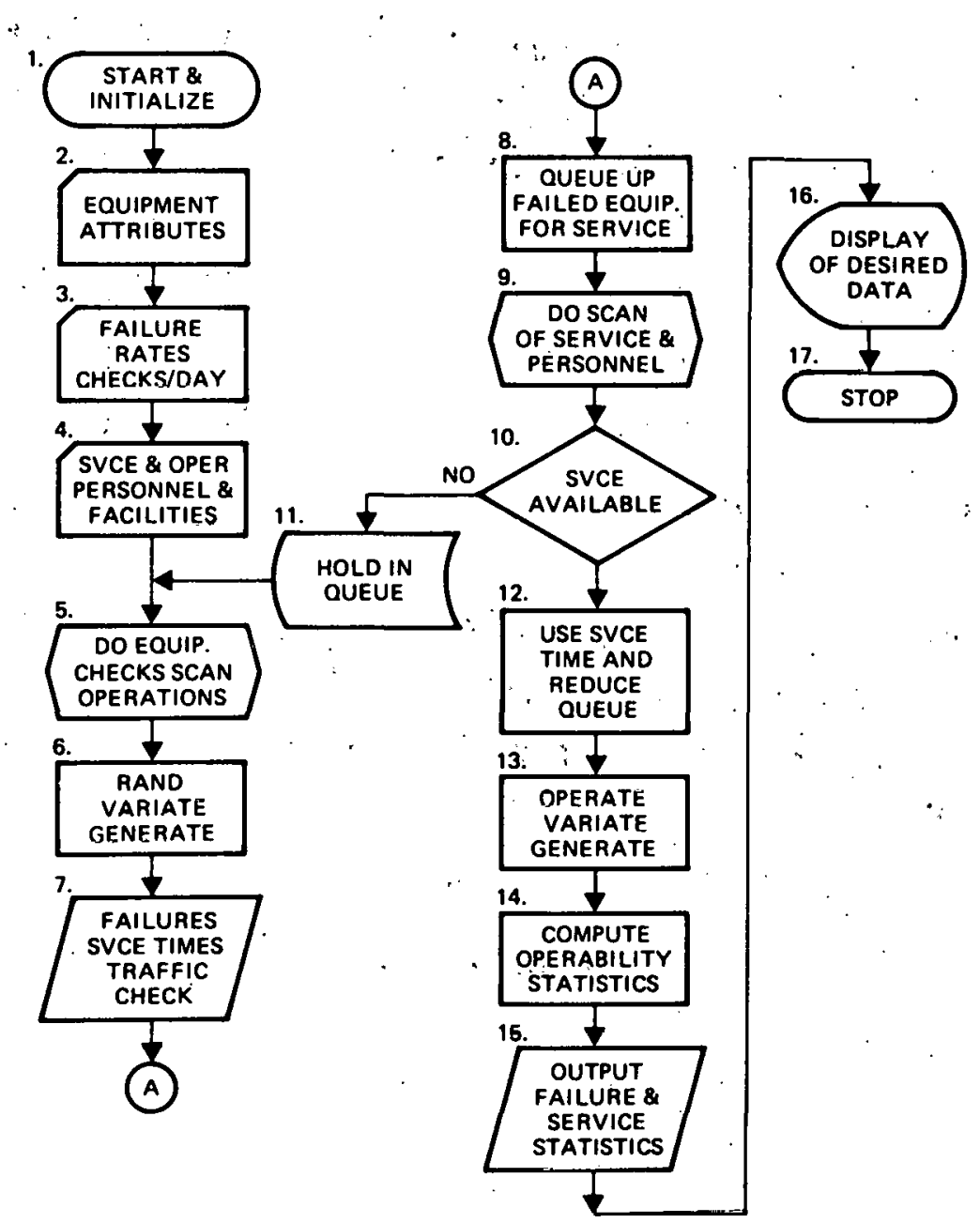

Figure 2.13-1. Flow Diagranll OTECSOS Program 


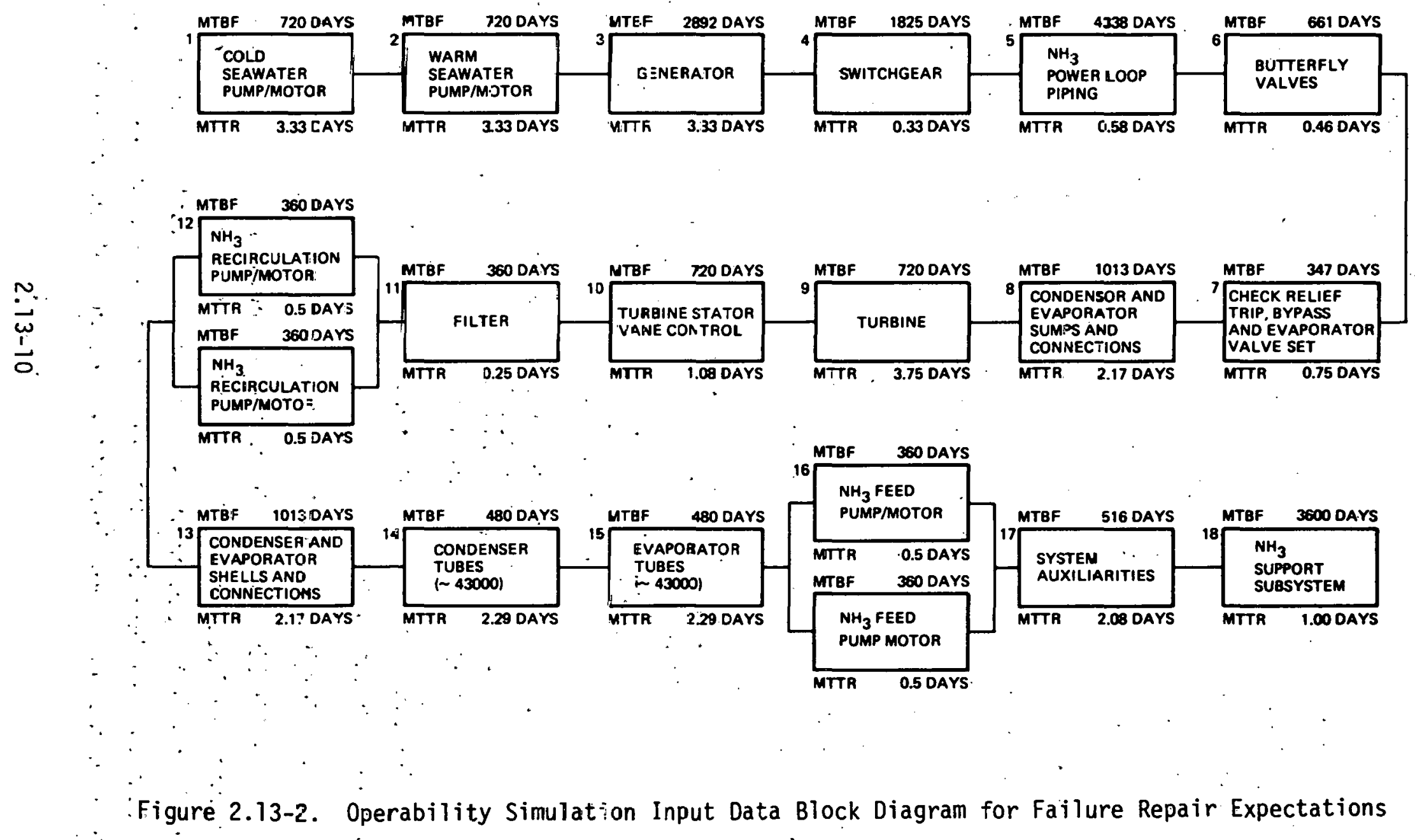


Table 2.13-5. Results of Availability Simulation

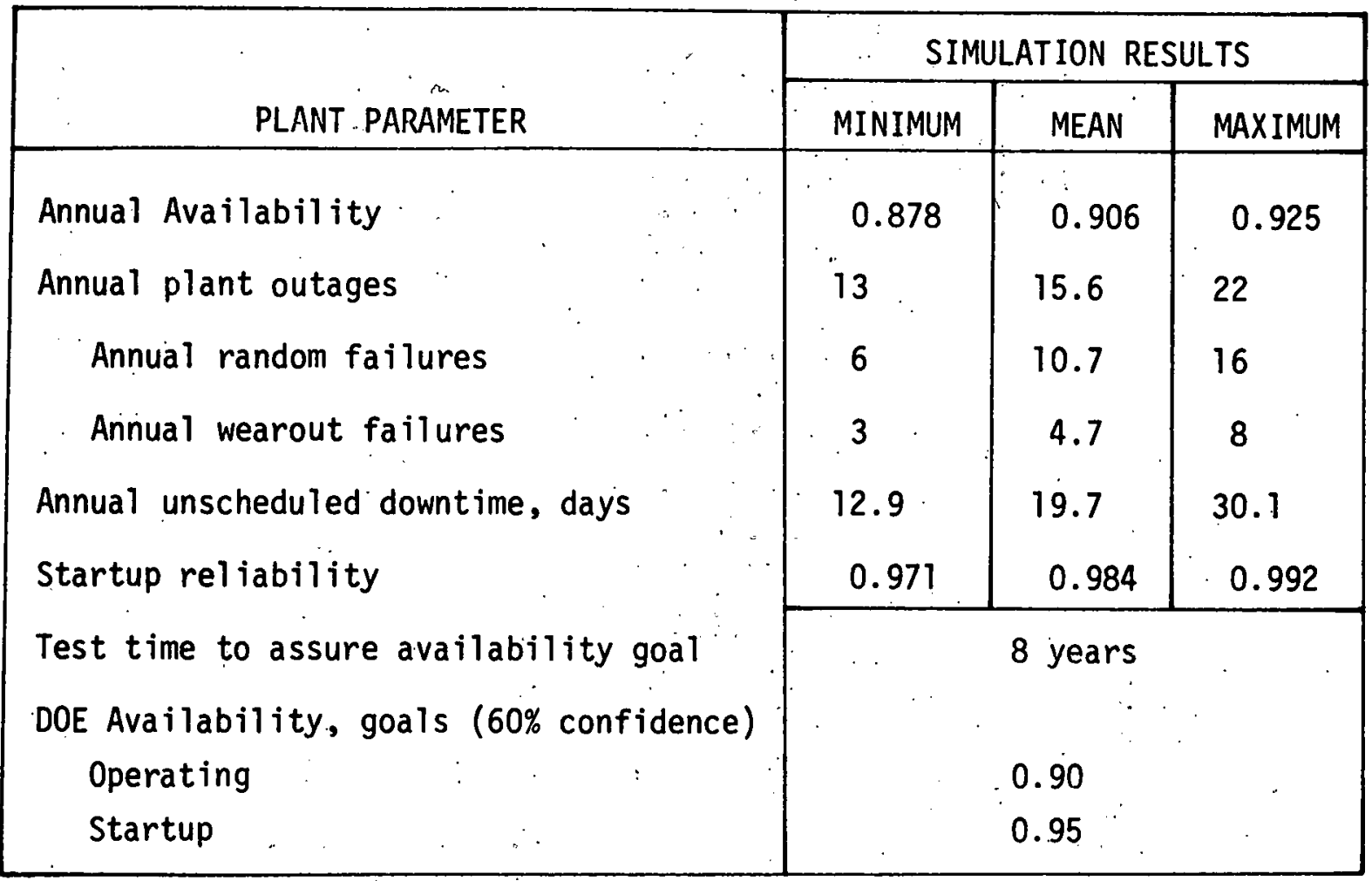

3. Reduction of the preventive maintenance interval from 200 days to. 180 days decreased unscheduled downtime by 5 days in 30 years (19.7-days per year to $19.5+$ days per year) at the cost of 48 extra days of unscheduled downtime ( 6 extra scheduled outages of 8 days each), an obviously poor strategy.

4. Reduction in MTBF of the seawater pumps from two years to one year resulted in an average availability of 0.898 . Thus the cost benefit of less reliable pumps should be analyzed in Phase III.

The availability analysis results are useful for design, operations, and maintenance planning.

\subsubsection{Startup Reliability}

The OTECSOS was used to estimate startup reliability, using the definition of Section 2.73.1.1. When maintenance on a failed component is complete and the component is checked-out by itself, a plant startup is attempted. Fallure to stàrt can occur because a new failure occurred, because the repair was improperly done and not discovered during checkout, 
or because the repaired component was incorrectly connected in the system. These probabilities were difficult to compute in Phase II so an approximation was made, that startup failures historically resulted in unusually long MTTR. Thus, in the analysis, failure to start occurs when the randomly selected repair time exceeds 3-1/2 standard deviations. Based on that assumption, the startup reliability is shown in Table 2.13-1 and in Table P-l of Appendix P. Start-up reliability meets the DOE. goals.

In Phase III, a more accurate model of startup will be used, that models the component and system failure rates during the startup interval.

\subsubsection{Pump Redundancy}

The availability of the power !nilute was calculated with and without redundant ammonia recirculation and feed pumps. The MTBF and MTTR of the pumps are shown in Table 2.13-2 and Table 2.13-3. In the redundant configuration, the MTBF of random failures in the operating and standby pumps are assumed to be identical in this Phase $I 1$ analysis. Wearout failures are charged only to the operating pump. It was assumed to take 15 minutes to detect and switch from a failed operating pump to the standby pump. A failure of the standby pump while the first pump is being repaired causes a plant outage until one of the pumps is repaired.

The results are shown in Table 2.13-6. The redundant pump configuration gives a higher availability, fewer jutages and-1ess downtime on the average than does the non-redundant pump configuration. The redundant pump configuration exhibits less statistical dispersion of failures because of the larger population from which failures are drawn. Startup reliability is not significantly affected. The redundant configuration was chosen as the basel ine because:

1. It met the DOE availability goals and the non-redundant configuration did not:

2. The added 7.4 days per year of downtime caused a loss of revenue of $\$ 88,800$ per year at $\$ 0.05 / \mathrm{kw}-\mathrm{hr}$ which has a preserit value of $\$ 442,200$ over 30 years at 20 percent. This is considerably more than the $\$ 250,000$ cost of the two redundant pumps, showing that the redundant pumps pay for themselves. 
Table 3.12-6. Redundancy in Ammonia Recirculation and Feed Pumps

\begin{tabular}{|l|c|c|}
\hline \multirow{2}{*}{ Annual availability } & & \multicolumn{2}{|c|}{ AVAILABILITY $\cdots$} \\
\cline { 2 - 3 } Minimum & REDUNDANT PUMPS & NON-REDUNDANT PUMPS \\
\cline { 2 - 3 } Mean & 0.877 & 0.820 \\
Maximum & 0.906 & 0.886 \\
Annual plant outages & 0.925 & 0.946 \\
Minimum & & \\
Mean & 13.0 & 9.0 \\
Maximum & 15.6 & 16.8 \\
Annual unscheduled downtime & 22.0 & 23.0 \\
Minimum & 12.9 days & 5.5 days \\
Mean & 19.7 & 27.1 \\
Maximum & 30.1 & 51.0 \\
Mean startup rel iability & 0.984 & 0.980 \\
\hline
\end{tabular}

\subsubsection{Failure Modes and Effects Analysis}

The purpose of the failure modes and effects analys is (FMEA) is to identify those equipment failures that can cause safety hazards, reduce power output, or cause a plant outage. The probability of plant outage is computed in Section 2.13.1, using the results of the FMEA and using the failure rates of the components. The effect of failures on safety is discussed in Section 2.13.4. The subtle effects of failures on power reductions, as compared to power outages, will be analyzed in Phase III.

The results of the Phase II FMEA are shown in Table 2.13-7.

The key failure modes are identified and the detection methods are noted for each failure effect. 
Table 2.13-7. Analysis of 10 MWe Failure Mode and Effects

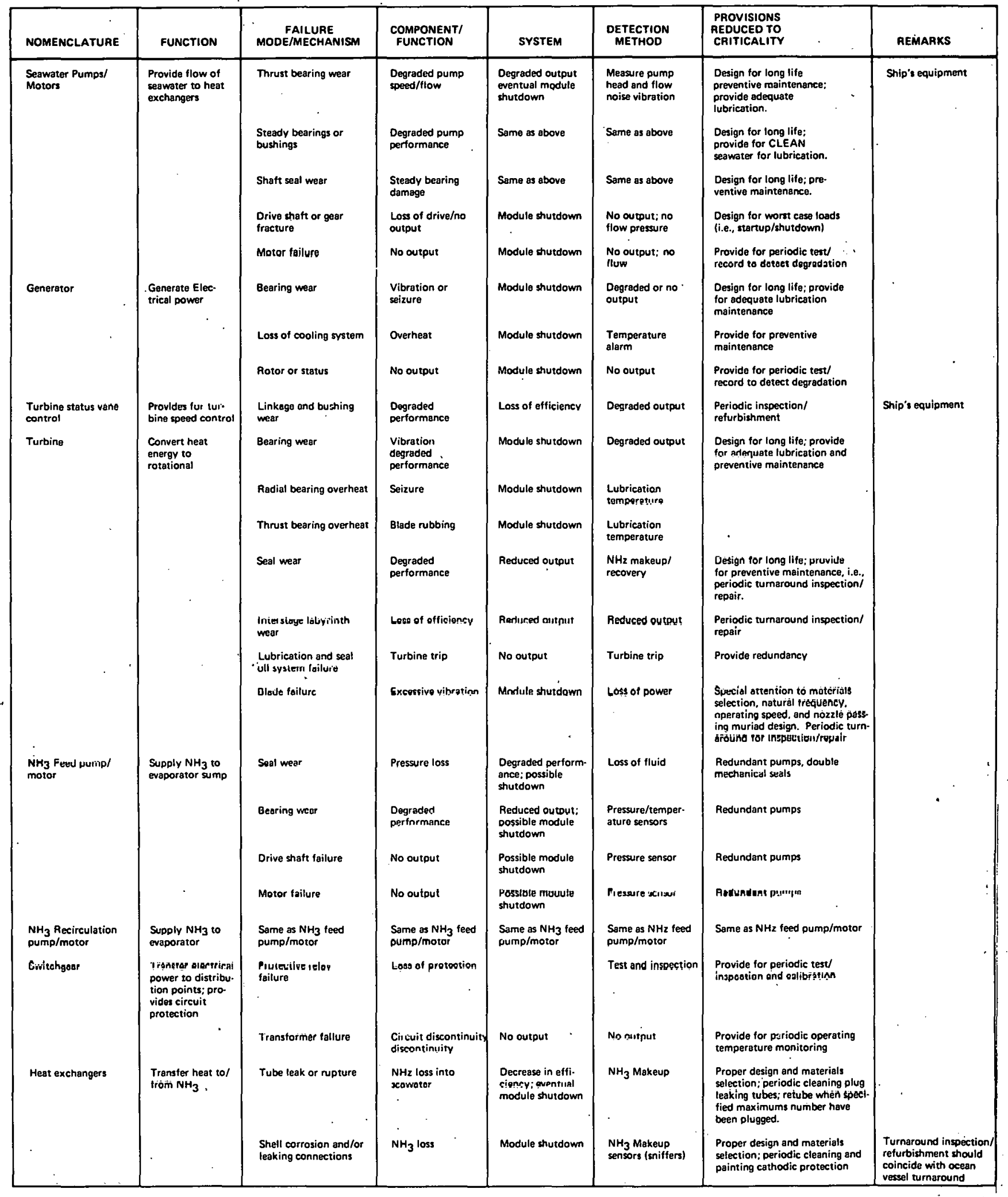


Table 2.13-7. Analysis of 10 MWe Failure Mode and Effects (Con't)

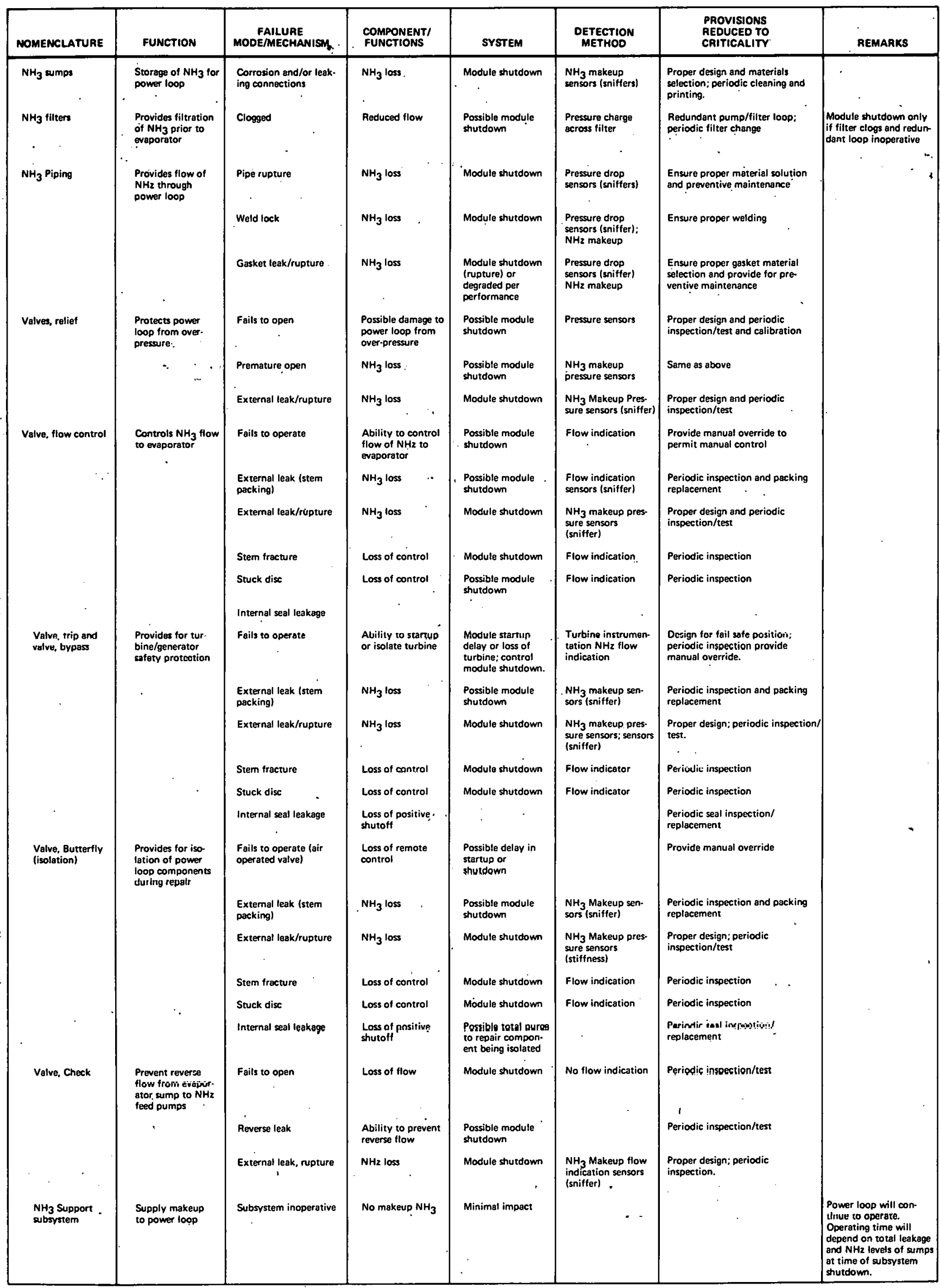


The failure modes identified in this table are those that are (in most cases) likely to cause degradation and eventually require module shutdown for repair. A notable exception is failure of the air-operated valve controller for the butterfly isolation valves because manual override will be incorporated, delay in startup will be minimal.

This FMEA includes the instrumentation and control component switch and the auxiliary equipment, as noted in Tables 2.13-2 and 2.13-3. The design of Section 2.9 includes enough redundancy that plant operation can continue after loss of electronic component.

The methods of detecting each failure in Table 2.13-7 are included in the diagnostic sensors and dragnostic software descrlbed in Section 2.9.

\subsubsection{Operability/Maintenance Plan}

The basic operability plan is summarized in Table 2.13-8. Operability of the 10 MWe module is predicated on the need to perform daily inspections and reviews of monitored data to detect any signs or trends of anomalous behavior. It is further assured by the periodic maintenance of equipment that is subject to wear or other known environmental deterioration rates with respect to time. A preliminary maintenance concept to implement the desired system operability is described in the paragraphs below. This concept cover's both system and critical component asperts of preventive and corrective maintenance, as well as overhaul and spares support. An extensive electronics instrumentation system monitors the plant and computes diagnostic data (Sections 2.2.1.3 and 2.9).

\subsubsection{System Maintenance Concept}

Two levels of maintenance are required to support the PSD-I power module; on-board and manufacturer overhaul. To minimize equipment downtime, maintenance on-board the vessel w11l be supported by a round-the-clock maintenance crew. PSD-I power module equipment design supports the level of maintenance with provisions for isolation of malfunctions to the faulty component (turbine, generator, heat cxchanger, pump) which are repairable by experienced personnel. Diagnostic computer software and equipment manuals isolate the fault to a replaceable component part (e.g., seals, 


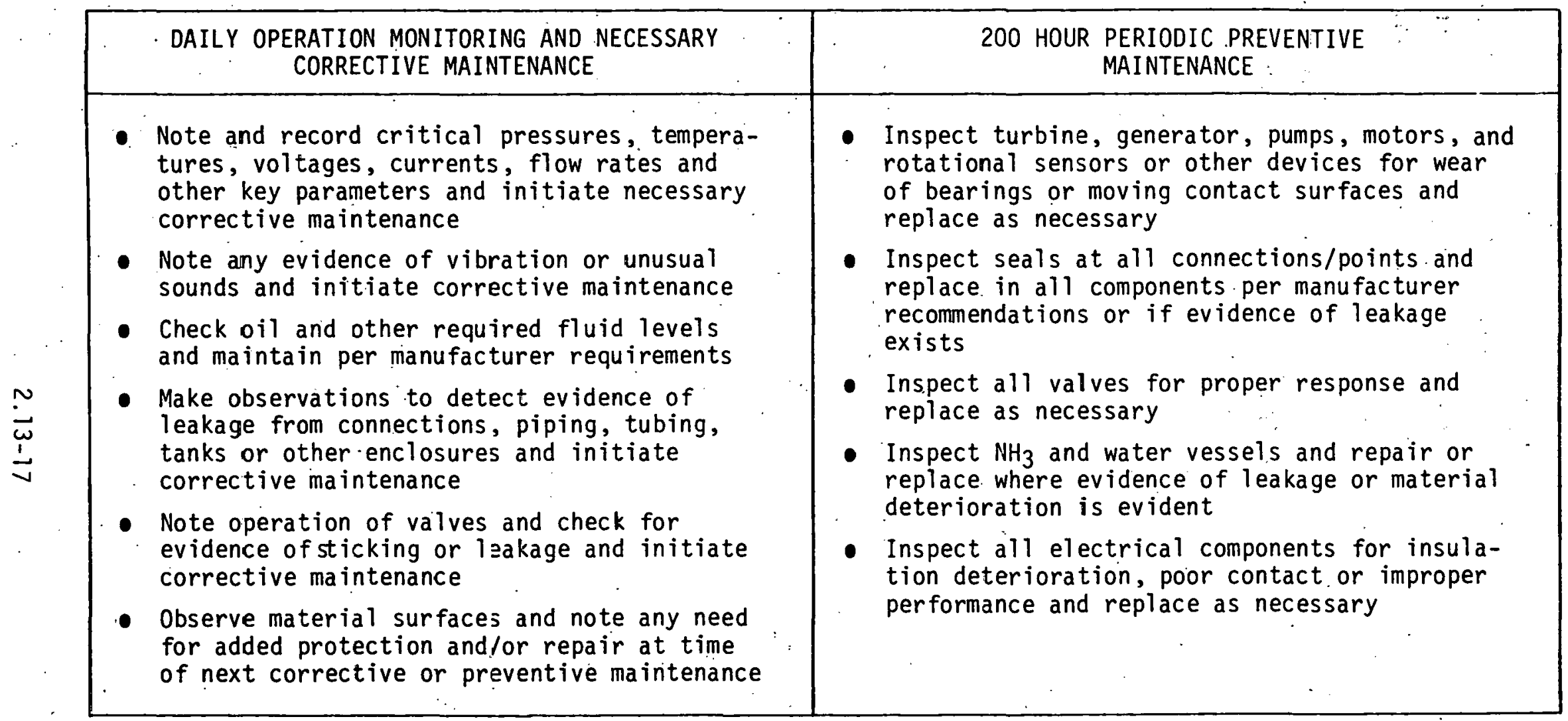


bearings, connectors, switches, etc.). Repair on-board will include welding of metal surfaces and limited machining of bearing surfaces.

A minimum of one complete set of spare items is required on-board the vessel at the time of installation. More exact numbers of individual requirements will be determined along with requirements for manufacturer support during Phase III when the logistics pipeline is defined and the logistics delays are understood. Spares will be obtainable. directly from the manufacturer. In addition, each manufacturer will be required to maintain "inspection and repair as necessary" (IRAN) at the facility or other established location to provide overhaul support of the equipment during the initial startup. The system contractor will provide turnaround overhaul pipeline via replacements from its spares stock.

Manufacturers recommendations will be followed to protect the equipment during shipment from the factory/overhaul facility to the vessel, during the erection procedure, while awaiting actual operation after assembly and during extended storage. Protection of this equipment can be complex; : requiring humidity and temperature controls or other variables that must be considered individually. Manufacturer's service engineers will be consulted in determining the frequency of maintenarice monitoring necessary and for laying out a plan of surveillance to achieve the required protection.

Based on the initial operability analysis, an estimated 10-person maintenance crew (Tahle 2.13-9) is required to maintain the 10 MWe power module on a 24-hour-per-day basis. A crew schedule of 12 hours on and 12 hours off shifts for two foremen/engineers with three 8-hour shifts for mechanics may be used. The crew will perform all routine preventive maintenance activitles, as well as normal corrective maintenance. Additionally, the crew will prepare for major nonroutine repairs (to be accomplished by shore-based maintenance specialists) and will assist the shorebased team.

During preventive maintenance shutdowns, all equipment will be inspected and repaired as necessary. 
Table 2.13-9. Maintenance Personnel Requirements

\begin{tabular}{|l|c|}
\hline \multicolumn{1}{|c|}{ TYPE } & NUMBER \\
\hline Mechanic/Pipefitter & 2 \\
Mechanic/Welder & 2 \\
$\therefore$ Roving Operator (oiler) & 1 \\
Millwright & 2 \\
Electrician/Instrumentation Engineer & 3 \\
\hline
\end{tabular}

\subsubsection{Equipment Maintenance Concept}

\section{Turbine}

The maintenance concept for the turbine is to perform preventive and corrective maintenance on-board the.platform and equipment overhaul maintenance at the manufacturer's facility. Corrective maintenance consists of fault isolation and replacement of bearings, seals, labyrinths, and maintenance of lube and seal oil system, etc. A complete inventory of spare radial bearings, thrust bearings, couplings, coupling hubs and seals, interstage labyrinths, interstage diaphrams, oil pump bearings and seals will be maintained on-board. Following replacement of a failed item of equipment, a new part will be ordered from the manufacturer.

The turbine fault isolation will include data from constant monitoring of vibration, bearing temperature, oil temperature, and turbine efficiency.

A general inspection and on-board overhaul will be accomplished during the preventive maintenance period. It is anticipated that the on-board overhaul interval will be 4 years and the overall time out of service will be 140 hours. Overhaul of the turbine rotor or stator will be performed by the manufacturer if inspection reveals it to be necessary.

Preventive maintenance requirements will be refined during detailed design and identified in the-individual equipment manuals. 


\section{Generator}

The maintenance concept for the generator is to perform preventive and corrective maintenance on-board the ocean vessel and equipment overhaul maintenance at the manufacturer's facility. Corrective maintenance consists of fault isolation and replacement of bearings, field windings and maintenance of cooling and lubrication systems, in addition to replacement of other worn component parts.

The generator fault isolation incorporates monitoring of bearing temperature, oil temperature, vibration, and winding temperature by instrumentation and alarms. The field windings will be tested and results recorded periodicaliy in order to detect insulation degradation.

Preventive maintenance requirements will be refined during detailed design and identified in the individual equipment manuals.

\section{$\mathrm{NH}_{3}$ Feed and Recirculation Pumps/Motors}

The maintenance concept for the pumps is to perform preventive and corrective maintenance on-board the platform and equipment overhaul maintenance at the manufacturer's facility. Corrective maintenance consists of fault isolation and replacement of bearings, seals, etc. A complete inventory of spare seals or packing, sleeves, wear rings, and bearings will be maintained on the platform. Following replacement of a failed item of equipment, a new part will be ordered from the manufacturer.

Preventive maintenance will include review of data from a dally inspection and bearing oil level check as well as the periodic test of the redundant pumps/motors. Additional requirements will be refined during detailed design and identified in the individual equipment manuals.

\section{Heat Exchangers}

Shel1. The maintenance concept for the heat exchangers is to perform corrective maintenance on-board the platform and equipment overhaul maintenance at the manufacturer's facility. In addition to corrective maintenance, the shells will be periodically inspected and the sea-water protective coating re-applied. Preventive maintenance of the shell will be accoimplished in conjunction with platform maintenance during any scheduled 
shutdowns. Requirements will be refined during detailed design and identified in the individual equipment manual.

Tubes. The maintenance concept for the heat exchanger tubes is to clean the tubes continuously (see Section 2.6.3, Tube Cleaning Machine) and inject chlorine into the sea water continuously (see Section 2.6.2, Chiorination) to reduce the fouling.

Corrective maintenance consists of identifying and plugging leaking tubes when the leak rate exceeds an acceptable limit, as described in Section 2.6.5.

A general. inspection will be accomplished during scheduled shutdown regardless of performance. Any discrepancies noted will be corrected. Preventive maintenance consists of tube cleaning and chlorination as will be described in the maintenance manual.

Flow Control Valve, Trip and Bypass Valves, and Butterfly (Isolation) Valves. The maintenance concept for the valves is to perform corrective maintenance on-board and equipment overhaul maintenance at the manufacturer's facility. Corrective maintenance consists of fault isolation and replacement of packing, seal rings, or actuator components. A complete inventory of spare packing, seais, and actuator components will. be maintained on-board. Following replacement of a failed item of equipment, a replacement unit will be ordered from the manufacturer.

Preventive maintenance of these valves consists of a daily inspection for leaks in the packing and for open/close status. Excessive leakage will be cause for module shutdown. for replarement. A complete inspection/ refurbishment will be accomplished on a IRAN basis during scheduled shutdown. Additional requirements will be refined during detailed design and identified in the individual equipment manuals.

Rel ief Valves. The maintenance concept for the relief valves is to perform preventive and corrective ma intenance on-board and equipment overhaul maintenance at the manufacturer's factlity. Corrective maintenánce will be limited to removing and replacing defective relief valves, e.g., valves, exhibiting premature openings or failure to actualce wher tested. Following replacement of a failed valve, a replacement will be ordered from 
the manufacturer. A general inspection and periodic calibration testing will be accomplished during the preventive maintenance shutdown. Discrepant valves will be identified by testing and be replaced at that time.

$\mathrm{NH}_{3}$ Piping and Sumps

The maintenance concept for the $\mathrm{NH}_{3}$ piping and sumps is to perform preventive and corrective maintenance on-board. Equipment overhaul maintenance is not anticipated. Corrective maintenance consists of locating and repairing gasket leaks, etc. A complete inventory of spare gaskets will be maintained on-board.

Preventive maintenance consists of perindir. inspection, cleaning and applying protective coatings minimize the adverse effects of the environment. Requirements will be combined during the detailed design phase.

\section{Switchgear}

The maintenance concept for the switchgear is to perform corrective and preventive maintenance on-board and equipment overhaul maintenance at the manufacturer's facility. Corrective maintenance includes replacement of faulty circuit breakers, relays, transducers, transformers, and fuses. A complete inventory of spares (prel iminary list in Table 2.13-10) will be maintained on the platform. Following replacement of a failed item of equipment, a replacement will be ordered from the manufacturer.

Preventive maintenance consists of:

1. Annual testing/calibration of $15 \mathrm{kV}$ switchgear and testing of all power circuit breaker tripping mechanism, during plant shutdown.

2. Annual exercising of automatic transfer switch and annual testing/calibration of transfer switch voltage sensing relays.

\subsubsection{Safety Issues}

\subsubsection{Introduction}

TRW will be conducting system safety analyses and studies during Phase III to ensure that all identified potential hazards are evaluated, assessed, and acted upon. The method for implementing those safety analyses is described in the following paragraphs. 
Table 2.13-10: Preliminary Spare Parts List for Switchgear

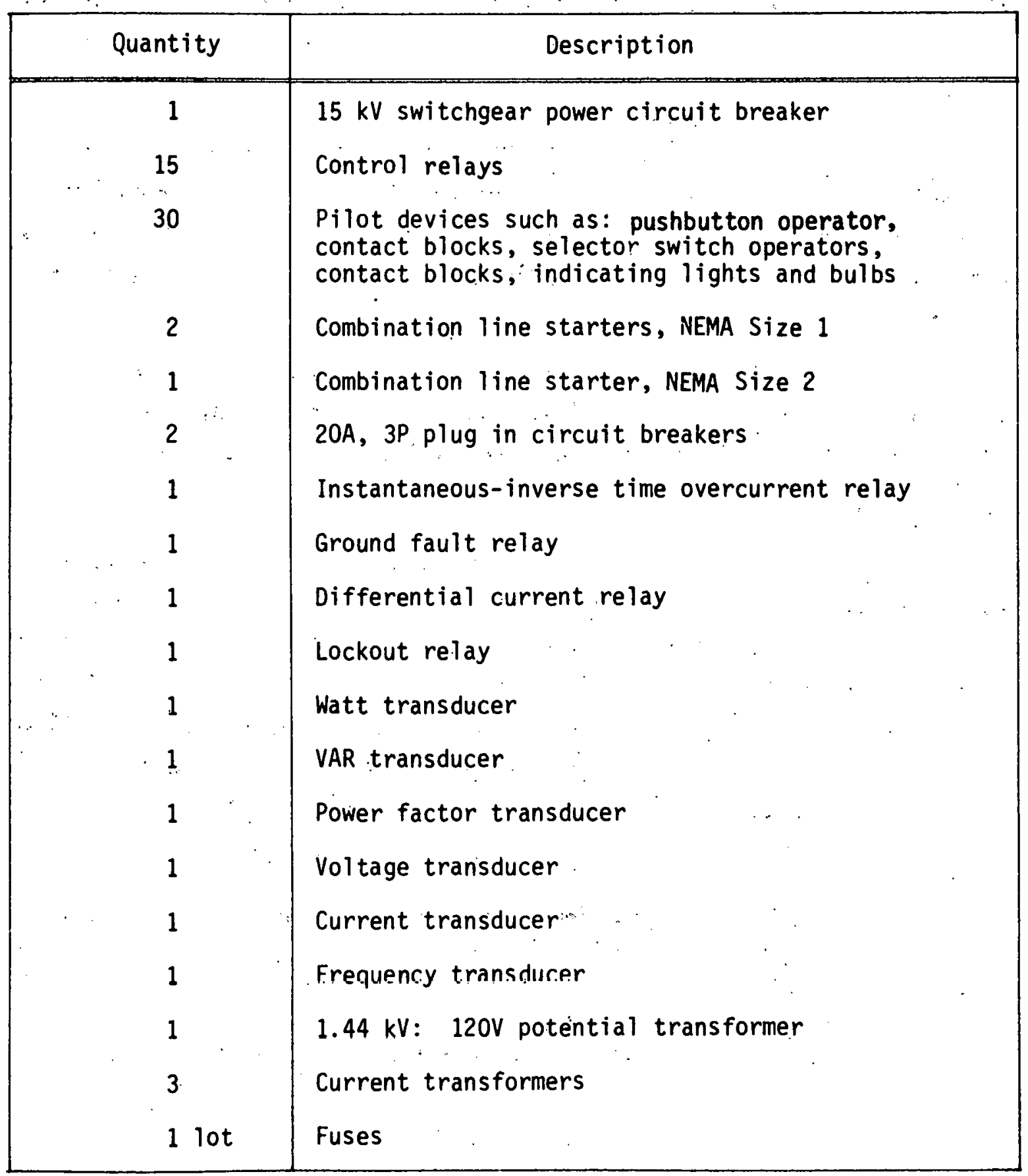


The most significant hazards arise from ammonia. Fire, rotating machinery and electrical shock pose safety issues deemed less severe. The basic resolution of safety issues is by means of design to reduce hazards. Attention to operational procedures and thorough training of personnel will further reduce risk. A safety engineer will participate in all design reviews.

\subsubsection{Ammonia Hazards}

A study of the hazards of amionia was conducted and the safety ramifications of that analysis will be utilized in the design, development, fabrication, checkout, and delivery of del iverable hardware.

a. Anmonia Combustion

Ammonia-air mixtures can be a fire or explosion hazard when exposed to heat or flame. The flammability limits of ammonia-air mixtures at various temperatures and pressures are given in Table 2.13-11.

The flammability limits are increased by increasing either the temperature or pressure. The risk of accidental ignition is low because the auto-ignition temperature in the air is $1204^{\circ} \mathrm{F}$; hence, spontaneous combustion is not a hazard.

Table 2.13-11. Flanmability Limits of Ammonia-Air Mixtures

\begin{tabular}{|c|c|c|c|}
\hline \multirow{2}{*}{$\begin{array}{c}\text { TEMPERATURE } \\
\left({ }^{\circ} \mathrm{F}\right)\end{array}$} & \multirow{2}{*}{$\begin{array}{c}\text { PRESSURE } \\
\text { (PSI) }\end{array}$} & \multicolumn{2}{|c|}{ AMMONIA (VOLUME \&) } \\
\hline & & LOWER LIMIT & UPPER LIMIT \\
\hline 75 & 15 & 15.3 & 25.7 \\
\hline 75 & 100 & 15.0 & 29.0 \\
\hline $300^{\circ}$ & 100 & .13 .5 & 31.0 \\
\hline
\end{tabular}

\section{b. Ammonia Explosion}

The results of laboratory tests to determine the explosion pressures of ammonia-air mixtures in an enclosed stainless steel test vessel are given in Table 2.13-12.' The explosion pressure ratio is defined as the ratio of the absolute explosion pressure to the absolute initial pressures. The magnitude of the explosion pressure ratio 
Table 2.13-12. Explosion Pressure of Ammonia-Air Mixture

\begin{tabular}{|c|c|}
\hline $\begin{array}{c}\text { AMMONIA } \\
\text { (VOLUME \%) }\end{array}$ & $\begin{array}{c}\text { MAXIMUM EXPLOSION } \\
\text { PRESSURE RATIO }\end{array}$ \\
\hline 15 and 31 & 1 \\
16.5 and 28 & 3 \\
18.5 and 27 & 4 \\
19.5 and 26 & 5 \\
22.5 and 24 & 6 \\
\hline
\end{tabular}

for ammonia-air mixture is approximately $3 / 4$ of that found for common hydrocarbon fuels under similar conditions.

It should be pointed out that flammable concentrations of ammonia and air rarely occur at atmospheric pressures and even when they do, the mixture is difficult to ignite and burns with little vigor. The risk of accidental fire or explosion is low, because ammonia is not highly combustible. Industry can and routinely does handle materials such as propane, gasoline, and methane that have a much higher explosion hazard. Metal compatibility is discussed in paragraph $\mathrm{g}$.

c. Physiological Effects

Ammonia vapor can be very irritating. The gas is colorless and has a distinct, pungent odor. Ammonia's affinity for, and high solubility in water, causes it to irritate moist skin surfaces and mucous membranes of the eyes, nose, throat, and lungs. Because of its irritating effects and sharp, pungent odor at low concentrations that are not dangerous, one would not voluntarily remain in concentrations that are hazardous. This serves as a built-in warning and safety feature.

Direct contact of liquid ammonia with the eyes or skin can cause severe burns. Liquid ammonia vaporizes rapidly when exposed to the atmosphere and will absorb heat from anything it contacts. When it touches the skin it can freeze the tissue and cause "freeze burns" that are similar to regular burns. 
Ammonia is detectable by odor in concentrations of less than five parts per million (PPM) in air. A concentration of 20 PPM is easily detectable and 100 PPM has a moderately strong odor and is an irritant to the nose.

The use of ammonia requires the OTEC plant be designed to Chemical Safety Data Sheet Sd-8 of the Manufacturing Chemists' Association Inc., and the Compressed Gas Association (CGA) Pamphlet G-2 (Reference 20).

d. Ammonia Spills

The most probable causes of release of ammonia to the environment are spills, leaks, and containment-vessel fallures. The seals and glands are designed with an ammonia recovery system that passes the leaked vapor to the treatment plant. Nevertheless, if a leak or spill should occur, most of the plant is located on the open decks of a surface ship subjected to natural ventilation. Safety below decks is addressed in paragraph $f$.

Spills of up to 160 tons of ammonia have been reported at land-based plants. The amount of ammonia initially converted to vapor ranges from 0.2 percent to 25 percent for refrigerated and pressurized storage respectively. Since ammonia is lighter than air (the relative density of vapor compared to dry air at $32^{\circ} \mathrm{F}$ and one atmosphere is 0.597 ), most of the ammonia vapor from an outdoor spill will rise above ground level unless a strong temperature inversion is present that can trap dilutc vapor and keep it from rising.

There have been a few reportcd incidents involving ammonia spll1s on water. An analytical and experimental study of spills of liquid ammonia on water was carried out to determine the effects of a possible leak from ships or barges. The results of this study reported that in large surface spills of up to 3,000 tons, about 60 percent of the ammonia would be absorbed in the water (in slower, smaller spills up to 82 percent could be absorbed). The remaining 40 percent would be liberated as vapor. For underwater releases at depths greater than ten times the leak diameter, all the ammonia would be absorbed in the water.

e. Handling

Should a leak or spill occur, it will be quite obvious. The sharp, irritating odor of ammonia is a safety feature that provides a warning and allows people without safety equipment to get out of the area before toxic concentrations can build up. Adequate personal safety equipment should be provided and be readily accessible around ammonia 
installations and used in the area of a leak or spill. These include PVC suits, gloves, goggles, chemical respirators, and self-contained breathing apparatus.

Eye protection should always be used when handling ammonia and safety showers should be conveniently located. Rescue equipment should be stored" in an accessible location but away from potentially hazardous areas.

By diluting a leak with water, the hazards of high concentrations of ammonia vapor can be reduced to allow corrective action. In some instances, however, the use of water should be undertaken with caution. When liquid ammonia is stored at temperatures colder than the available water supply, sprays should not be directed on the container walls since this would heat the ammonia and increase the vapor pressure. Cooling an enclosed vessel or adding water to a full tank of ammonia vapor produces a vacuum either by condensing the vapor or absorbing it in the water. This may cause the tank to collapse, so one should be cautious with the use of water under these circumstances.

\section{f. Protection of Enclosed. Spaces}

The use of ammonia in enclosed spaces requires special considerations. To protect the crew against toxic vapors and to prevent flammable mixtures of ammonia and air to build up, adequate ventilation must be provided. Ignition sources must be el iminated where flammable mixtures may be present. Pressure relief valves must discharge to a safe location outside the enclosure, floor drainage must be provided, and electrical equipment must be vapor tight. Exits to safe areas must be identified and clearly marked. Canister masks must be widely distributed. Should escape routes be blocked, vapor-proof rooms could be strategically located in case of a leak or accident. The same safety precautions for outdoor use, such as sprinkler systemis, protective clothing, and respiratory protection should also be provided.

Coast Guard Regulation 98-25-75 requires one complete air change every 3 minutes below decks following an accident to allow operating and maintenance personnel to work around the equipment. The air changes will also prevent the formation of explosive mixtures of ammonia vapor with air.

A prominent space has been reserved in the control room for an air quality panel and alarms, to be driven from a ship-wide leak detection systcm, Section 2.9.4. As part of the ship's interface, TRW requests that rarelyvisited compartments and enclosed spaces be monitored and 
connected to the system. Thus, if a leak is detector or if an operator must otherwise visit a compartment in which an ammonia leak is known to exist, he can wear the proper equipment in advance of his visit.

Prominent space is also reserved in the control room for 4 television monitors, to be connected to the ship's CCTV system, Section 2.9.4. The operators will be able to monitor enclosed spaces, while personnel are in them, to determine whether the people appear to be in danger.

The instrumentation and controls provide safety protection in the form of alarms in the control room, easilyoperated "trip" switches that trip the plant in three sections, and automatic trips that activate, based on measurements and on computer calculations, Sections 2.2.3 and 2.9.4. Two channels of trip sensing and actuation are provided for redundancy, to ensure the safety of the crew. Remote operation of the activator from the control room provides some added. safety protection in that it reduces the number of personnel required in the hold.

g. Materials Compatibility

Most common metals are not affected by anhydrous ammonia. However, when mixed with a little water or water vapor, liquid or gaseous ammonia will rapidly attack copper, sllver, zinc, and copper alloys such as brass and bronze. These metals should not be used in connection with the storage or handiing of ammonia.

Ammonia reacts with mercury to form an explosive compound and is therefore a hazard. Instruments containing mercury will not be used in ammonia services.

Carbon steel, stainless steel, and iron are suitable for use with anhydrous ammonia liquid and vapor. Carbon steel is the most commonly used material for ammonia systems, including storage, piping, and various processes. Ammonia plants have operated for well over 10 years without any sign of internal corrosion of low carbon steel components. There is a long history of refrigeration plants, some up to 50 years old, that have gone without corrosion problems.

The use of carbon steel with ammonia at temperatures up to $300^{\circ} \mathrm{F}$ is common practice. Carbon steel bullets have been designed to store pressurized ammonia at temperatures of around $300^{\circ} \mathrm{F}$. In process applications, ammonia temperatures of 250 to $300^{\circ} \mathrm{F}$ and pressure of 250 to $300 \mathrm{psi}$ have been handled using carbon steel. Compression and absorption refrigeration cycles operate up to a temperature of $300^{\circ} \mathrm{F}$ and a pressure of 200 psi with carbon steel 
equipment. Internal corrosion has not been a problem in these applications. In the OTEC plant, ammonia temperatures are not expected to exceed $120^{\circ} \mathrm{F}$.

At temperatures above about $840^{\circ} \mathrm{F}$ ammonia begins to dissociate, liberating free hydrogen and nitrogen. This can cause material problems in carbon steel from either hydrogen embrittlement or nitriding. No such temperatures are contemplated in the OTEC plant.

No cryogenic storage of ammonia is planned in the OTEC plant. If it were, brittle fracture and condensation of ammonia-water vapor on the outside of tanks would be potential problems.

In order to reduce the possibility of stress corrosion, air and other contaminants should be kept out of the system and materials should be stress relieved to eliminate residual stresses. Vessels should also be inspected periodically. The OTEC plant is designed for nitrogen purge prior to charging.

\section{h. Storage and Shipping}

Anhydrous ammonia can be stored either in atmospheric pressure vessels (refrigerated) or pressurized vessels (at ambient temperature). The OTEC plant will store ammonia in pressurized tanks which experience has shown are cheaper in sizes under 5000 tons capacity.

The Interstate Commerce Commission requires that all anhydrous ammonia transported by interstate pipeline must contain a minimum of 0.2 percent water by weight as a corrosion inhibitor.

Experience with shipping anhydrous ammonia has shown that transporting it to power plants can be routinely handled either by truck, train; or barge, following established U.S. Department of Transportation and U.S. Coast Guard rules and regulations.

\section{i. Training Program}

A training program is essential for all employees handling ammonia or present on OTEC platform. Operators and maintenance men must wear coveralls and goggles whenever operating or working on ammonia valves and ammonia-containing equipment. All employees and supervisors must be familiar with the location of all turret nozzles, fire hydrants, safety showers, eyewash fountains, ammonia canister masks, fresh air packs, and emergency oxygen supplies. The plant should also have a minimum of two protective suits complet.e with masks which have their own 
air or oxygen supply. The suits should be located in the control room, accessible to all employees at all times. Supervisors should be trained in the use of suits, and a man wearing protective equipment should be backed up by a safety man who is also dressed in protective equipment.

j. Conclusions

We conclude from our review that the hazards from ammonia, though they exist, are easily controllable with currently available technology. There appears to be no unreasonable risk to operating personnel or to the OTEC power module:

Since the power plant is isolated from immediate help in the unlikely event of a significant ammonia release, a failure mode and effect analysis should continue throughout the design, construction, and operational: phases of the project. Particular attention will be given to guidelines for design engineers; review of all system and component designs by a safety engineer, instrumentation and detection of leaks, quality control of manufactured hardware, life support systems, and preparation of emergency plans.

\subsubsection{Fire Protection}

The power module is designed to avoid ignition sources and to prevent fires from spreading. In addition, TRW requests the platform designer to supply a ship-wide fire protection system for ammonia fires, 0il fires; and electrical fires. Ammonia fires are discussed in Section 2.13.4.2.

Potential sources for ofl fires are turbine lubricatiun oil, turbine control system oil, and high-pressure hydraulic control system oil." The flash point of these oils is about $400^{\circ} \mathrm{F}$ and the ignition temperature is $700^{\circ} \mathrm{F}$. Extinguishing methods should include dry chemical foam and aqueous film fọrming fnam (AFFF) systems.

To avoid electrical fires and explosion hazards, the electrical system will be designed in accordance with Class I, Group $D$ environment, and in accordance with National Electrical Code Article 501. All instrumentation wiring is explosion-proof. The cable-spreading room is divided into two compartments where the redundant wiring is separated.' In addition, hand $\mathrm{CO}_{2}$ systems and halon systems will be provided in critical areas. Where the potential for electrical fires exist. 


\subsubsection{Rotating Machinery}

There are three main safety considerations for the rotating machinery. One is the prevention from overspeed, second is the prevention of leaks, and the third is personnel protection from exposed rotating parts.

The only item subject to overspeed is the turbine-generator set. All other rotating machinery is $A C$-motor driven and is limited to the synchronous speed of the motor field. Three redundant overspeed trips with three redundant trip actions will be provided for the turbine-generator. They are detected as follows:

- Loss of generator load

- A speed signal from the electronic speed counter sea at $1854 \mathrm{rpm}$ ( 3 percent above normal. speed)

- A mechanical overspeed device on the turbine shaft set at $1980 \mathrm{rpm}$ (10 percent above normal speed).

The three redundant trip actions are:

- Close the trip valve at the turbine inlet

- Open the bypass around the turbine to direct all flow from the evaporator to the condenser

- Move the variable stator vanes of the turbine to their minimum position.

The probability of ammonia leakage from the casings of rotating machinery is reduced by avoiding the use of axial joints. The turbine will utilize barrel construction. The end wall joints of barrel constructed turbines and the back wall joints or radially split centrifugal pumps are considerable easier to seal.

Another source of leakage for rotating machinery is the shaft endseals. Mechanical seals of the type frequently used for centrifugal compressors will be used for the ammonia turbine. This type of seal is described in Section 2.7.1. Leakage of ammonia to the atmosphere is avoided with this type of seal.

Fonr centrifugal pumps that are not hermetically sealed, tandem mechanical seals will be used in ammonia services. Both the inboard and outboard seals seal in the same direction. Methanol, from a small surge pot 
provided for each pump, floods the cavity between the tandem seals to provide lubrication of the outboard seal faces. Methanol (or a synthetic lube oil) is used so as to provide lubrication at the low temperature resulting from liquid ammonia flashing across the inboard seal faces. A vent line with a restriction orifice is connected to the top of the surge pot. A. pressure switch on the surge pot signal.s a large flow of ammonia vapor indicating failure of the inboard seal. A level switch on the surge pot signals loss of methanol by leakage or failure of the outboard seal. The vent line from the surge pot is routed to an atmospheric vent. Exposed rotating parts, such as couplings, will have guards in accordance with OSHA requirements, Paragraphs 1910.211 through 1910.222.

\subsubsection{Electrical Shock Protection}

The generator, switchgear, and wiring design includes considerations for electric shock protection of operating and maintenance personnel. A11 accessible connections to the high voltage switchgear will be protected by double interlock barriers or guards (above $500 \mathrm{~V}$ ) which will automatically remove power when the area is entered. Warnings will also be provided to note the interlocks and the presence of all voltages (above $30 \mathrm{~V}$ ) will be appropriately indicated. All capacitors above $70 \mathrm{~V}$ will have automatic discharge when exposed for service. Grounding will be provided throughout to minimize the possibility of voltage potentials across insulated electrical conductors or from inadvertent contact with electric current sources by personnel. Al1 connectors will provide keying that precludes mismatched electric cable connections. It is assumed that adequate lightning protection will be provided by the ship system and power distribution system for adequate safety of personnel and equipment. 


\subsubsection{References}

1. Calabro, S.R., Rel iability Principles and Practices, McGraw Hill 1962, P. 134.

2. "Report on Equipment Availability for the Ten Year Period 1967-1976," EEI Equipment Availability Task Force, - December 1977.

3. "A Report on Improving the Producibility of Electric Power Plants," FEA, March 1975.

4. "Ocean Thermal Energy Conversion - An Engineering Evaluation "and Test Program," TRW Report: Contract No. NSFC958, Volume 3, June 1975.

5. "An Assessment of Accident Risks in U.S. Commercial Nuclear Plants, Reactor Safety Study: Appendices III and IV." Wash - 1400 pp 204-248, October 1975.

6. "Availability of Fossil-Fired Steam Power Plants." EPRI Special Report, FP-422-SR, June 1977.

7. "Nonelectronic Reliability Notebook." RADC: AD/A-005657, (Rel iability Analysis Data Control), January 1975.

8. Technical Interchange Meetings with TRW, C.F. Braun \& Co., 1977 through 1978.

9. "Steam. Plánt Surface Condenser Leakage Study." EPRI Report No. NP 481, March 1977.

10. FARADA. "Failure Rate Data Handbook." FARADA - GIDEP, Government - Industry Data Exchange Program, 1965 through 1975.

11. Load Study Committee 1974 - 1985 Forecast, Detroit Edison Co., January 1974.

12. Long Range Area Load Study 1973 - 1993, Detroil Edison Co., October 1974.

13. "Electrical Generating Plant Availability." Federal Power Commission, May 1975.

14. Michigan Public Service Commission Hearings, Case U-4100. Statements by W.G. Meese, R.W. Hartwell and J.R. Hamann, Detroit Edison Co. Public Information Department, September 1974.

15. Barker, Kovacic and Nelson, "Actions Necessary to Improve Producibility of Nuclear and CoalmFired Electric Generating Stations." FEA, Office of Energy Conversion, August 7975.

16. Stelzer, I.M., "Electricity Prices for the Next Decade.". National Economic Research Association, November 1974. 
17. OSHA Paragraph 1910.111, "Storage and Handling of Anhydrous Ammonia."

18. F.A. Patty, Industrial Hygiene and Toxicology, VolumeII, Interscience Publishers, 1963.

19. American Conference of Governmental Industrial Hygienists, Threshold Limit Values - 1977.

20. "Anhydrous Armonia, Booklet G-2." Compressed Gas Association, New York, 1977.

21. ANSI K61.1 "Standard Safety Requirements for the Storage and Handling of Anydrous Ammonia."

22. "Ammonia Plant Safety Symposium." American Institute of Chemical Engineers, 1956. 
3. 40 MWe COMMERCIAL POWER SYSTEM (CONCEPTUAL DESIGN)

The conceptual design of the 40 MWe commercial size power system described in this section is responsive to the following DOE design guidance requirements as discussed in Section 1.

a) Develop the conceptual design of a 40 to 50 Mwe closed-cycle ammonia power system module for a floating OTEC demonstration plant.

b) Explore a modular approach to the heat exchanger design for the 40 to 50 MWe commercial size power system.

c) The commercial power heat exchangers are to be immersed in seawater. The depth of water at the top of the heat exchangers will be 0 to 20 feet.

d) Investigate the compatibility of the power system with other than the reference platform; i.e., surface platform/ship.

e) The modular application power system module size is to be 10 MWe for the proof-of-concept pilot plant.

\subsection{DESIGN APPROACH}

A modular approach to heat exchanger design was explored by reexamination of module size evaluations reported in the Conceptual Design Report. As reported, cost savings accruing to design improvements, manufacturing methods, and the availability of a dedicated on-site facility will apply to heat exchangers of any size, and tend to maintain the cost per kWe constant out to larger sizes, but will, of course, involve large capital facilities investment which will certainly be justified for large scale production. It is questioned that such risk capital will be available for building the commercial size power system (demonstration plant) and, in fact, a design which requires this involvement for the trial could be an impediment to its implementation.

Consequently, because there are no known compelling forces to go to larger modules, it is TRW's recommendation that the power module be approximately 10 MWe, compatible with the application power system module, and that the commercial power system include four or five 10 MWe modules. There are no penalties seen in this approach and the advantage is the orderly generation of the building blocks for a logical progression from the modular application power system module to the commercial power plant 
(demonstration plant) with a minimum of redesign and capital expenditure. 10 MWe heat exchangers can be manufactured, transported, and installed using existing facilities. Certain advantages of startup auxiliary power, shutdown, load shedding, system control, and plant availability also result with the use of smaller modules as described in the Conceptual Design Report. This design approach offers advantages in that the major components of the full size power module (heat exchangers, turbine, and pumps) will serve in both the modular application power system module (pilot plant) and in the commercial power system (demonstration plant).

The compatibility of the selected 10 MWe application power system module with vertical heat exchangers was investigated with respect to the al ternate hull concepts being evaluated by DOE in separate studies.

These concepts may convenientiy be divided into two categories and are shown in Figures 3.1-1 and 3.1-2:
A. Surface interacting
B. Surface decoupled.

The candidate hulls belonging to Category $A$ include the ship or barge (reference hull) the disk shaped barge, and the spherical or tuned sphere. The Category $B$ hulls include the semisubmersible, the spar buoy, and the submersible.

The compatibility of TRW's heat exchanger design with these hull concepts can easily be evaluated considering key heat exchanger characteristics described in Sections 2.4 and 2.6 versus constraints dictated by the hull concepts. Key heat exchanger characteristics include:

1. Shell-and-tube design with vertical tubes, water on the tube-side, ammonia on the shell side.

2. Falling film ammonia heat transfer mode, heat transfer enhancement (Flutes) on both aminonia side and water side.

3. Open top design (open water box). Water flows through the tubes by maintaining a head of water (free surface) relative to the seawater level. The upper tube sheet is at or near the seawater level.

4. On-line tube cleaning by vertical, multiple spindle, rod brushes interfacing at the top of the heat exchangers.

5. On-line leaking tube identification and plugging capability. 


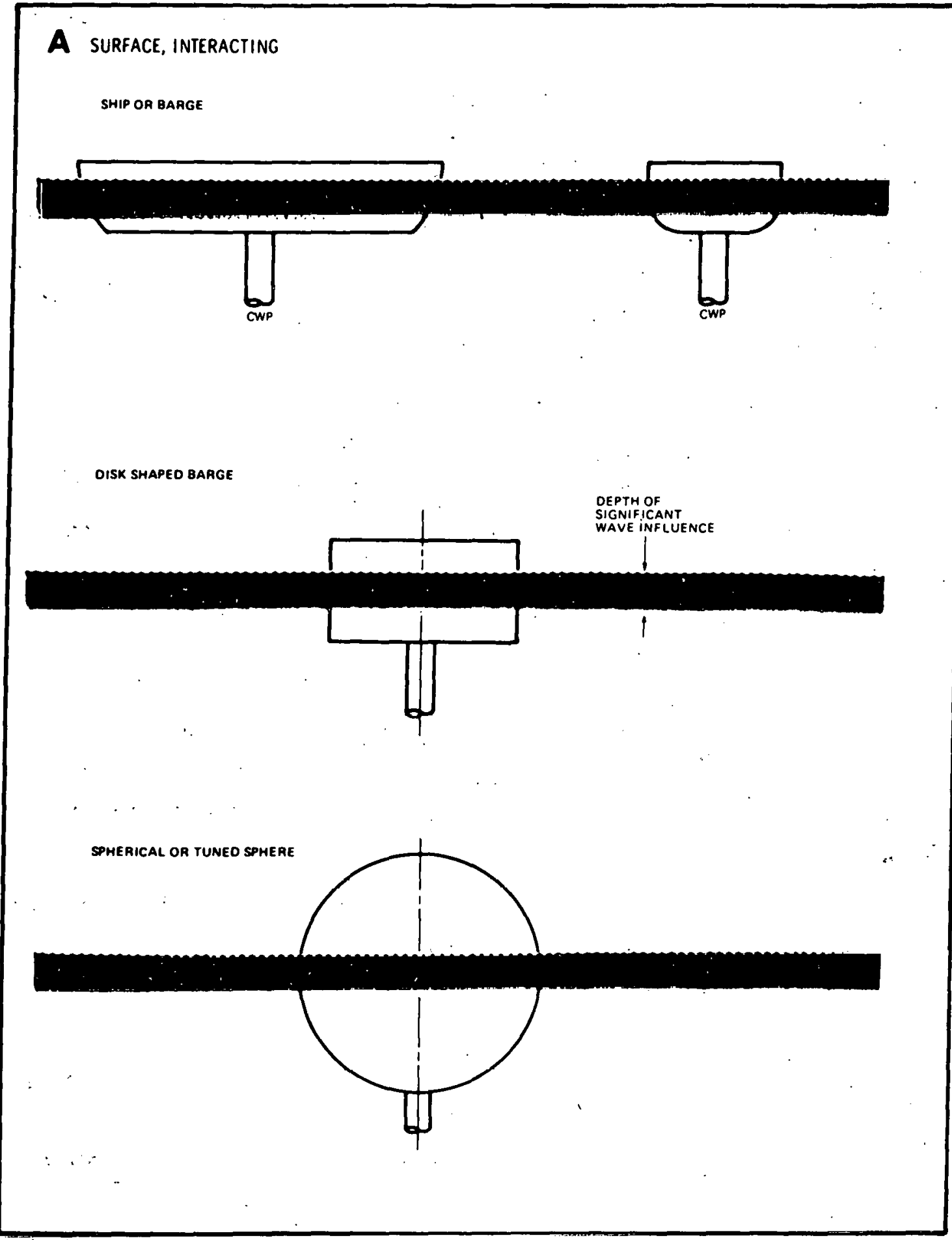

$\because \cdot$

. Figure 3.1-1. Surface Interacting Hull

$\because \ddots \quad \therefore \quad, \quad \ldots \cdot 3-3$ 


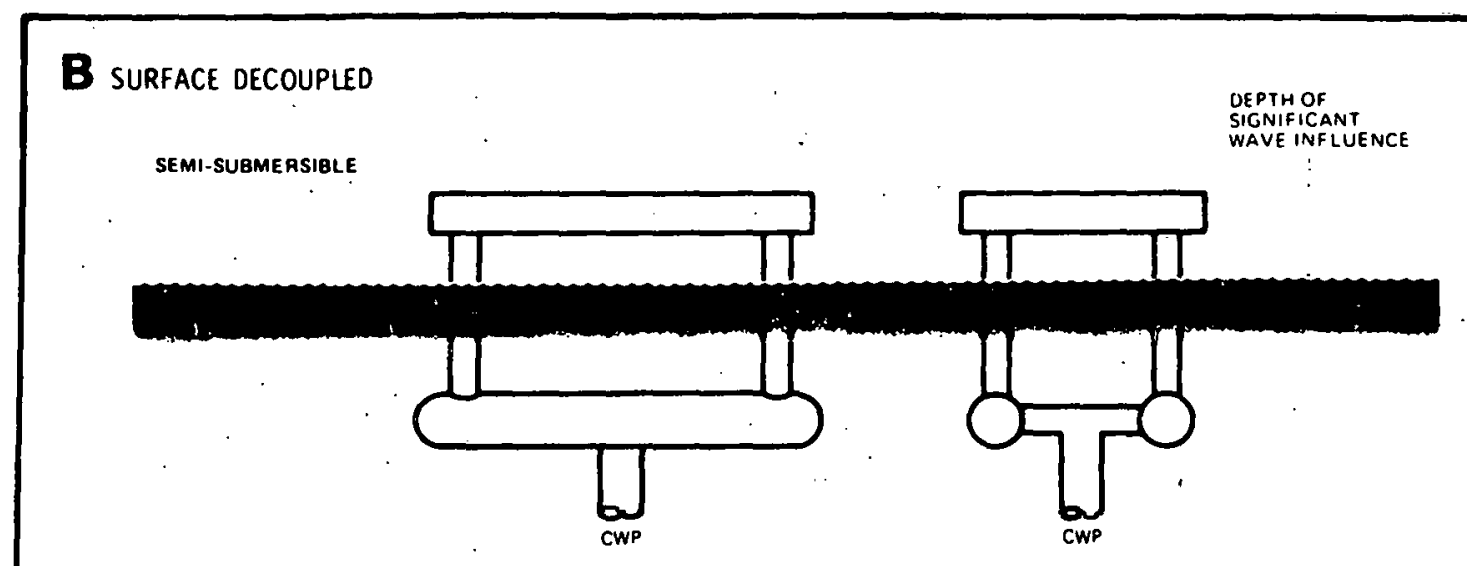

SPAR BUOY

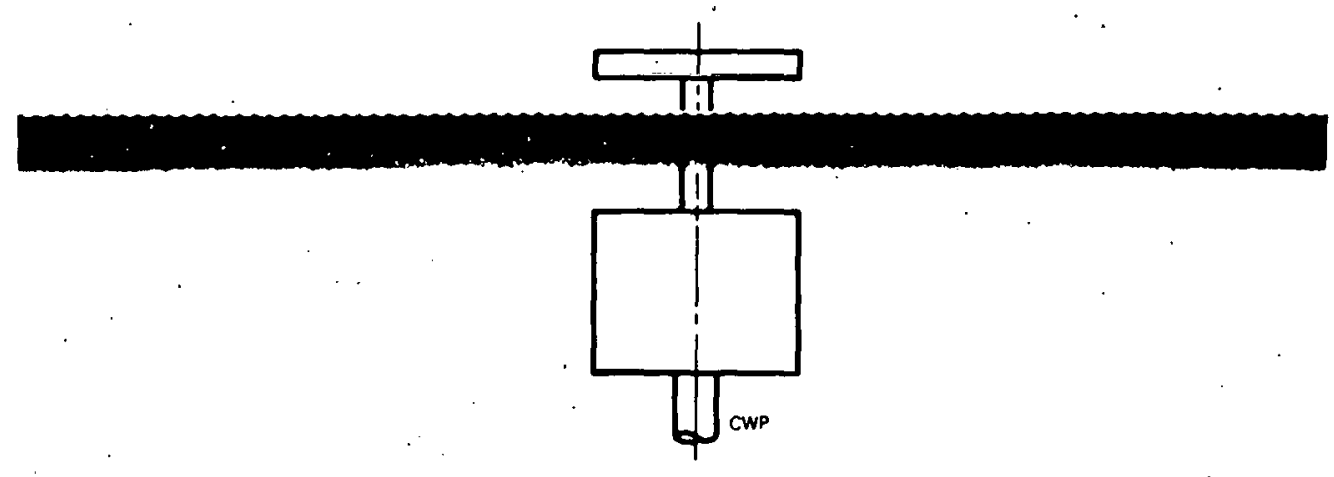

SUBMERSIBLE (PROLATE SHOWN)

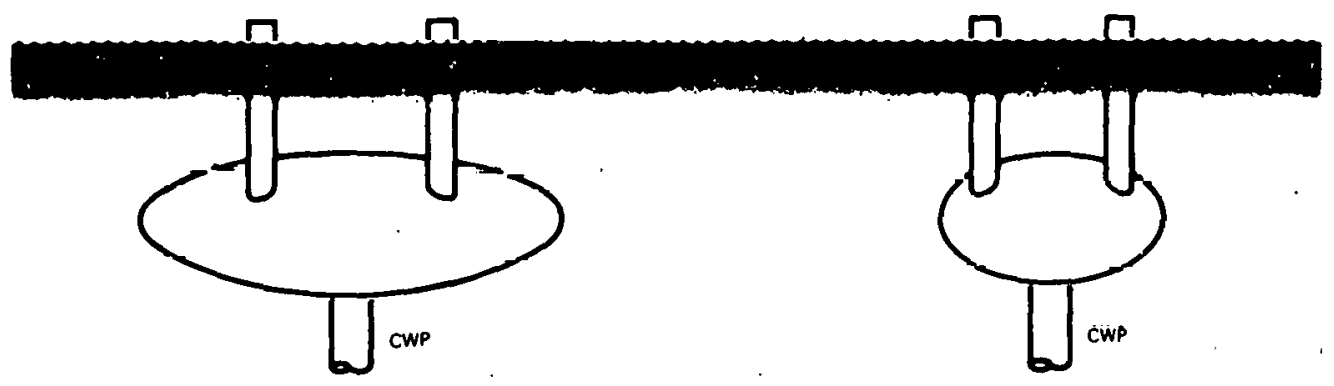

Figure 3.1-2. Surface Decoupled Hulls 
The surface decoupled hull forms are not compatible with the open top design (item 3 ). A closed top is required at a water depth of up to 20 feet to satisfy hull submergency requirements with the DOE design guidance depth constraint. This would then obviate the unique cost-effective "on-line" tube cleaning, leaking tube identification or leaking tube plugging characteristics (I tems 4 and 5) of TRW's heat exchangers design.

The heat exchanger design characteristics are compatible with all the surface interacting hull forms; the heat exchangers may be located interna? to the hull or external, immersed in seawater as directed by DOE. We have chosen to immerse the heat exchangers with the top tube sheet at seawater level to minimize the draft and cost of the surface ship or barge platform based on the following design rationale. Both heat exchangers require gravity drain of liquid ammonia to sump fed recirculation and feed pumps located within the ship or barge hull. The net positive suction head (NPSH) requirements of the pumps therefore establish the hull bottom equipment leve1.: As described in Section 2.7.2 ammonia piping Tayouts and pump selections were made to minimize NPSH requirements. Other benefits obtained include minimizing the tube cleaner extension requirements and providing dry access to the top of the tube sheet for plugging maintenance operations during plant shutdown at sea.

The commercial power system plant size was selected at 40 MWe based on ship/barge configuration studies that indicated the optimized minimum plan area to unit output power configuration with four 10 MWe application power system modules as shown in Figure 3.1-3 and described in the following section.

\subsection{GENERAL ARRANGEMENT DRAWING}

The general arrangement of a 40 MWe commercial size power system utilizing four of the 10 MWe modular application power system module is shown in Figure 3.1-3 as configured in a reference surface platform/ship hull. The configuration incorporates immersed heat exchangers attached on the periphery of a hull section containing the power plant and support system. This approach obtains a hull plan area reduction of approximately 19 percent per unit kWe as compared to the hull plan proposed in the conceptual design with Internal heat exchangers. In addition, we have reduced the hull draft approximately 16 percent by judicious design of ammonia sumps and selection of ammonfa punips with low NPSH. 
The general arrangement is structured around a central moon pool containing four power module dedicated cold water pumps, furnished by the ship systems contractor. The operating water dynamic effects of the moon pool are discussed in Section 2.2.5. Four 10 MWe modular application power. sys tem modules are configured around the moon pool. Two of the modules will be exactly as shown in Section 2.1.4 and two modules will be constructed of identical parts in a mirror image configuration as shown in Figure 3.1-3.

Ammonia support subsystems and electrical equipment and control rooms, dedicated to two power'modules, 20 Mwe total, are located in centrally located equipment areas shown in Figurc 3.1-3 and described in Sections $2.8,2.9$ and 2.10 .

The lower deck level of the centrally located support areas is dedicated to ship service auxiliaries for the power modules including air conditioning, ventilation, and seawater support systems: The elevator and vertical stairwells include pipe and duct chases, as shown in Figure 3.1-3, to carry these services from level to level and compartment to compartment. In addition a 20 foot by 30 foot area is required, on the auxiliary level, for electronic repair and parts storage instrument shop and instrumentation and control equipment including the central plant digital computer, recorders, and ship interface adapters.

\subsection{PERFORMANCE AND COST ESTIMATES}

The 40 MWe commercial size power system will obtain electrical power performance characteristics as indicated in Table 3.3-1. Other power system performance characteristics are described as applicable to 10 MWe module characteristics in Section 2.1 .

The estimated rinst.s of first and eight production 40 MWe commercial power systems are displayed in Table 3.3-2. Cost approach and assumptions are described in Section 2.3.

\subsection{CRITICAL INTERFACES}

The critical interfaces of a typical modular application power system module drid support system are shown in the four interface drawings of Section 2.1.5. Interfaces shown include containment dimension and hull penetrations. The estimated moon pool dimensions are shown in Figure 3.1-3 with suggested buoyancy tank consideration. 

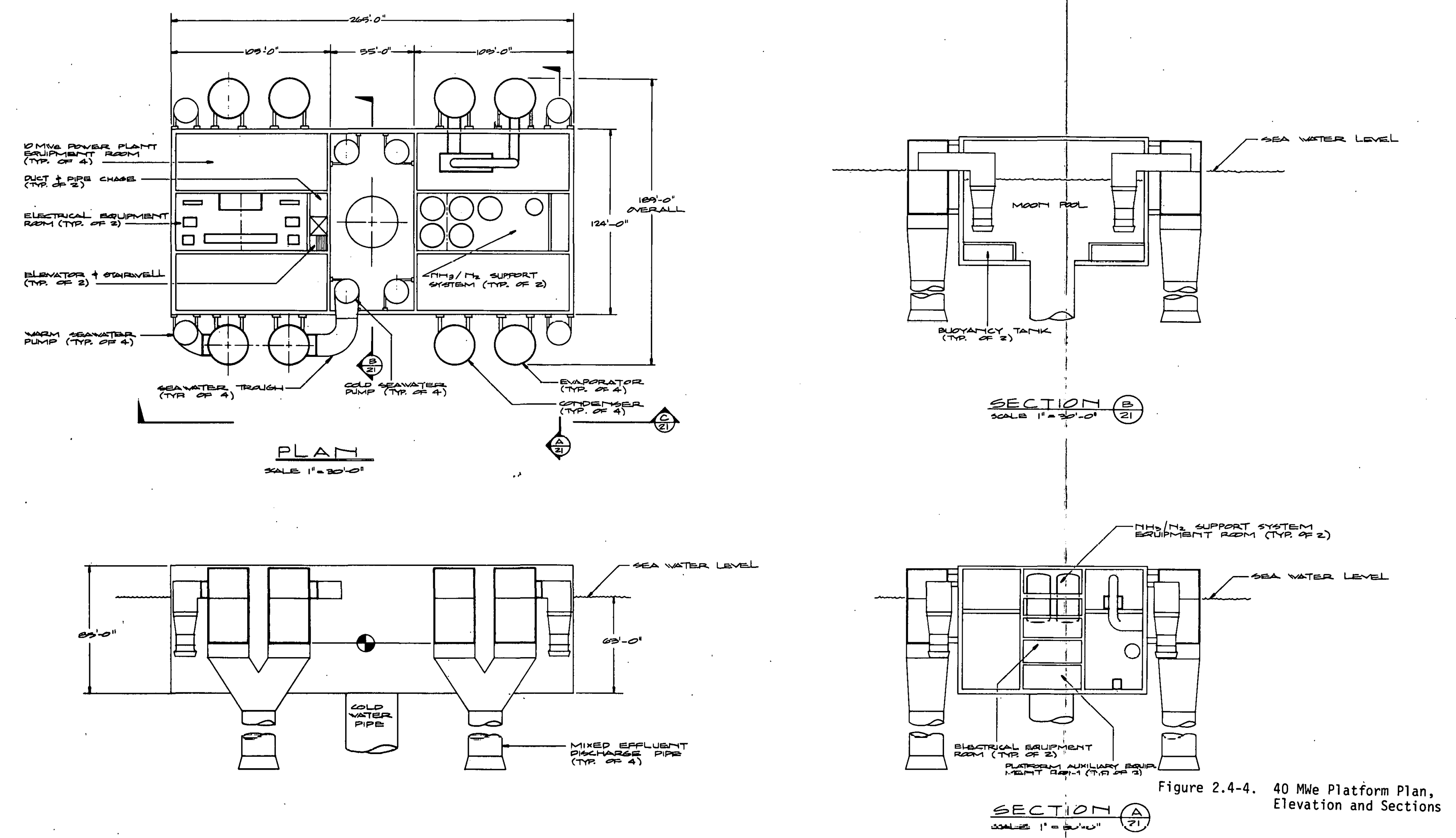

ELEVATION (C)
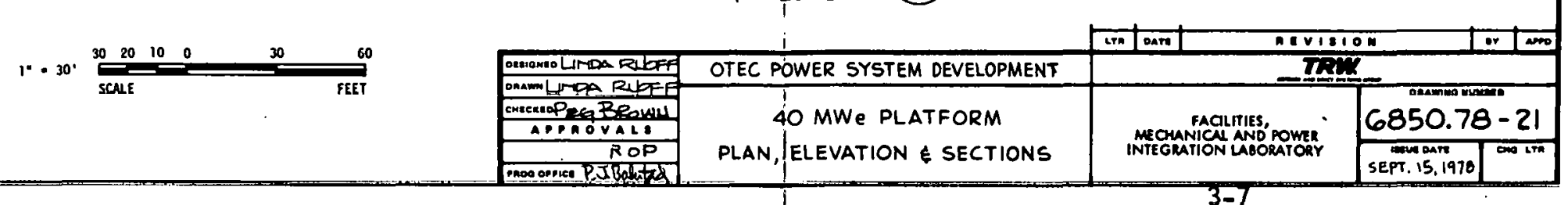
Table 3.3-1. Commercial Size Power System (40 MWe)

\begin{tabular}{|lc|}
\hline Gross Power & 56.12 MWe \\
Net Power & 40.00 MWe \\
Gross Power/Net Power & 1.40 \\
Warm Water Pumping Power & 5.40 MWe \\
Cold Water Pumping Power & 7.12 MWe \\
Ammonia Feed Pumping Power & 0.96 MWe \\
Ammonia Recirculation Pumping Power & 0.56 MWe \\
Chlorination Power & 0.20 MWe \\
Mechanical Cleaning Power & 0.04 MWe \\
Controls, Miscellaneous & 1.84 MWe \\
\hline
\end{tabular}

The estimated weight of power plant and support equipments for a 40 MWe platform, excluding ship systems is as follows:

\section{Item Weight (1b)}

Power modules (excluding heat exchangers) $\quad 3,400,800$

Ammonia/nitrogen support $\quad 1,663,600$

Electrical/control equipment $\quad 359,200$

Subtotal $\quad 5,423,600$

Heat Exchangers (negative buoyancy)
Condenser (operating)
$2,304,000$
Evaporator (operating)
$2,408,000$
Total power plant operating displacement
$10,135,600$
$(4,5: 5$ long tons $)$ 
Table 3.3-2. 40 MWe Power Plant Cost Breakdown Summary (July 1978 Installed Costs New Orleans, La)

\begin{tabular}{|l|c|c|}
\hline \multicolumn{1}{|c|}{ Item } & First Production \\
$\$ /$ kWe & $\begin{array}{c}\text { 8th Plant } \\
\text { \$/kWe }\end{array}$ \\
\hline Evaporator & 565 & 505 \\
Condenser & 546 & 483 \\
Turbine/Generator & 168 & 153 \\
Ammonia Feed Pumps & 13 & 13 \\
Ammonia Recirculation Pumps & 15 & 15 \\
Ammonia System Piping & 75 & 72 \\
Amronia System Valves & 67 & 63 \\
Control Systems & 46 & 44 \\
Chlorination Systems & 12 & 11 \\
Cleaning System/Leak Detector & 34 & 32 \\
Ammonia Support Systems & 79 & 72 \\
Electrical Equipment & 25 & 24 \\
\hline TOTALS & 1645 & 1487 \\
\hline
\end{tabular}

